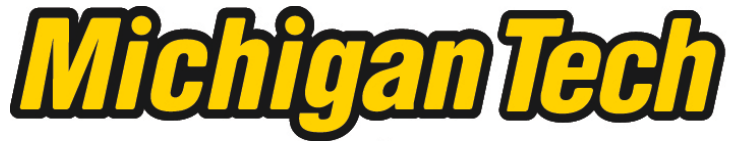 \\ Michigan Technological University Create the Future Digital Commons @ Michigan Tech
}

2013

\section{An Investigation of Waste Glass-Based Geopolymers Supplemented with Alumina}

Mary U. Christiansen

Michigan Technological University

Follow this and additional works at: https://digitalcommons.mtu.edu/etds

Part of the Civil Engineering Commons, Materials Science and Engineering Commons, and the Sustainability Commons

Copyright 2013 Mary U. Christiansen

\section{Recommended Citation}

Christiansen, Mary U., "An Investigation of Waste Glass-Based Geopolymers Supplemented with Alumina", Dissertation, Michigan Technological University, 2013.

https://doi.org/10.37099/mtu.dc.etds/588

Follow this and additional works at: https://digitalcommons.mtu.edu/etds

Part of the Civil Engineering Commons, Materials Science and Engineering Commons, and the Sustainability Commons 


\title{
AN INVESTIGATION OF WASTE GLASS-BASED GEOPOLYMERS SUPPLEMENTED WITH ALUMINA
}

\author{
By \\ Mary U. Christiansen
}

\begin{abstract}
A DISSERTATION
Submitted in partial fulfillment of the requirements for the degree of DOCTOR OF PHILOSOPHY

In Civil Engineering
\end{abstract}

MICHIGAN TECHNOLOGICAL UNIVERSITY

2013

(C) 2013 Mary U. Christiansen 

This dissertation has been approved in partial fulfillment of the requirements for the Degree of DOCTOR OF PHILOSOPHY in Civil Engineering.

Department of Civil and Environmental Engineering

Dissertation Advisor: Dr. Lawrence Sutter

Committee Member: Dr. Theresa Ahlborn

Committee Member: $\quad$ Dr. George Dewey

Committee Member: $\quad$ Dr. Aaron Sakulich

Department Chair: $\quad$ Dr. David Hand 

To my family and friends. 



\section{Table of Contents}

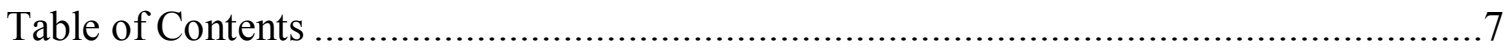

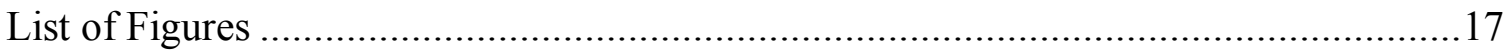

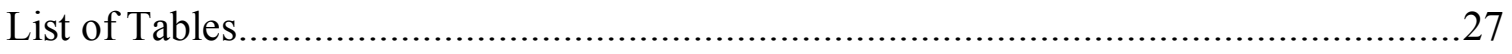

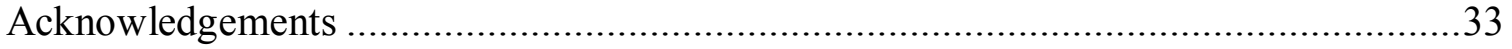

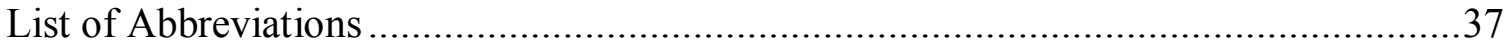

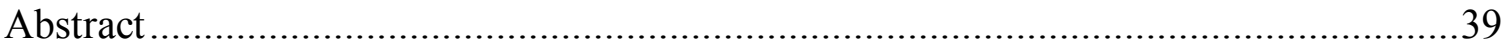

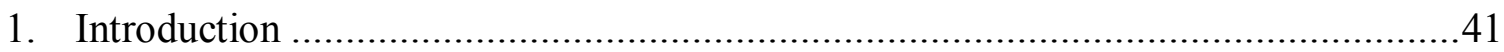

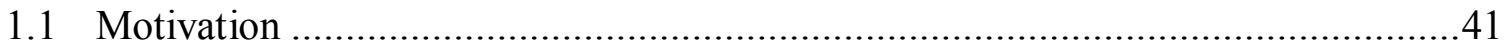

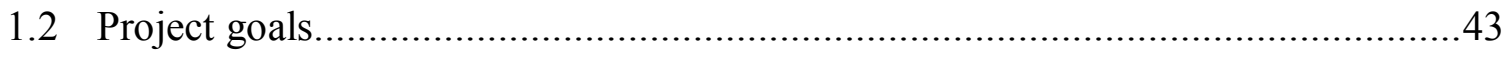

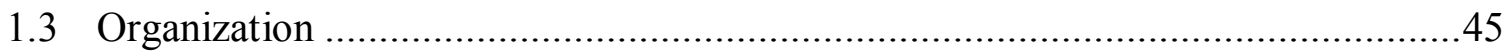

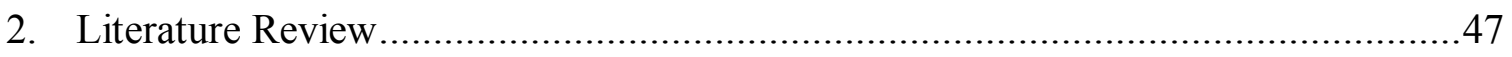

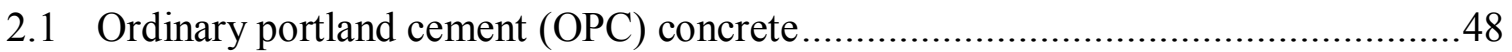

2.1.1 Production of ordinary portland cement ..........................................................49

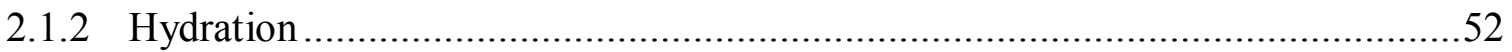

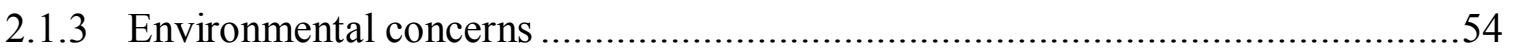

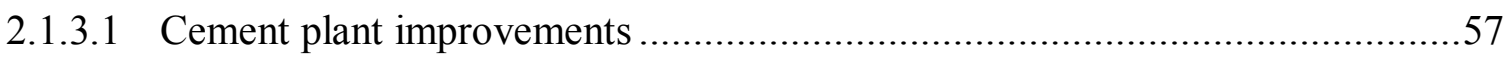

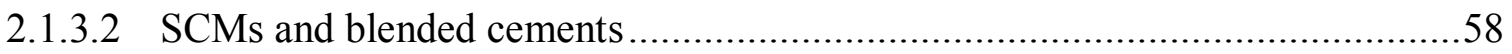

2.1.3.3 Alternative cement systems ………………...........................................59

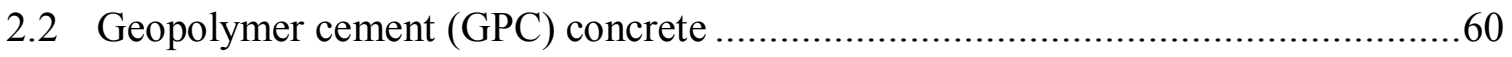

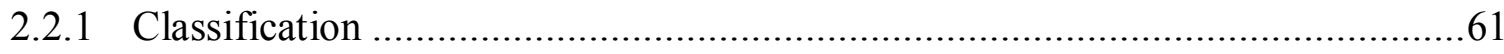

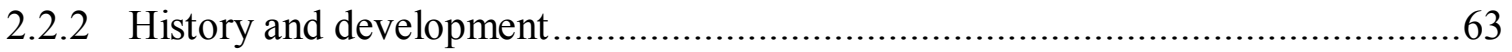

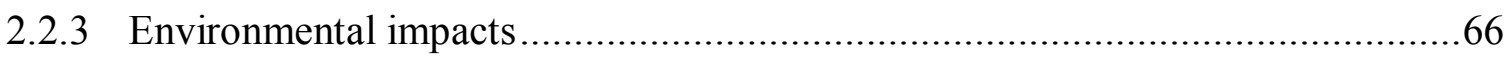




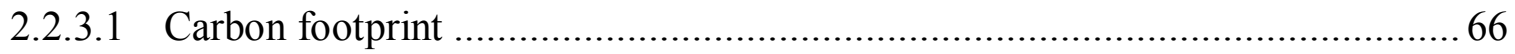

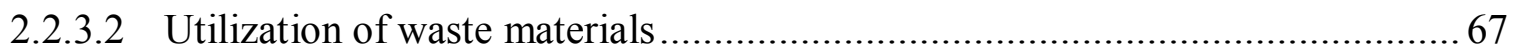

2.2 .4 Performance

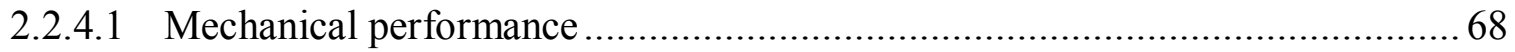

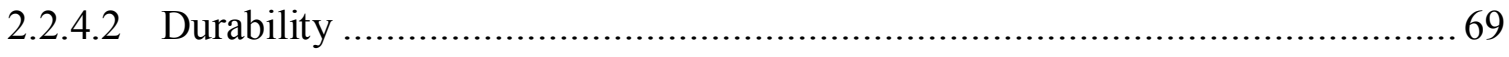

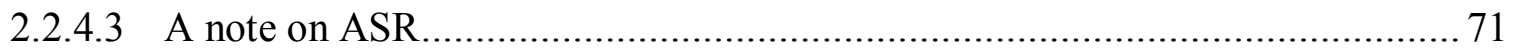

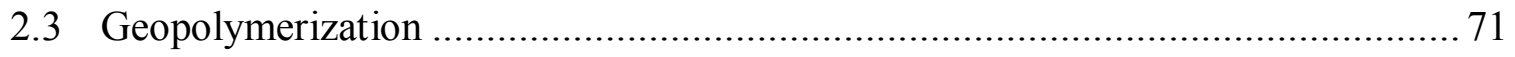

2.3.1 Silica chemistry and polymerization.............................................................. 72

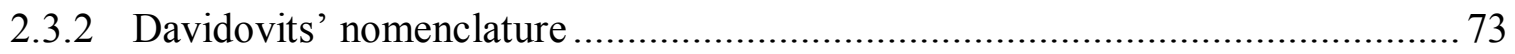

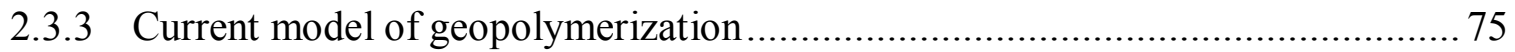

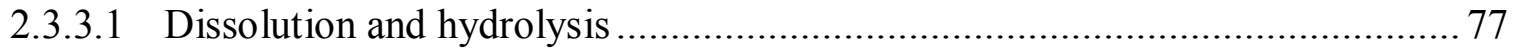

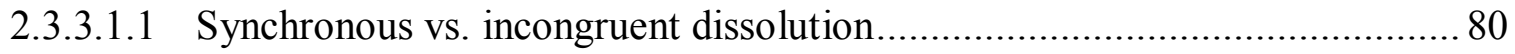

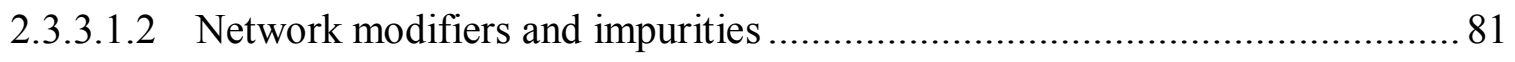

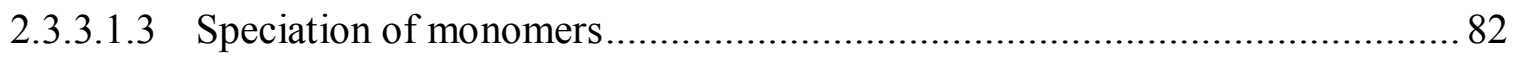

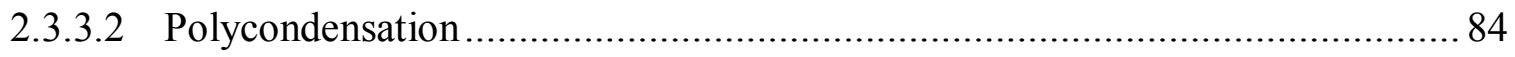

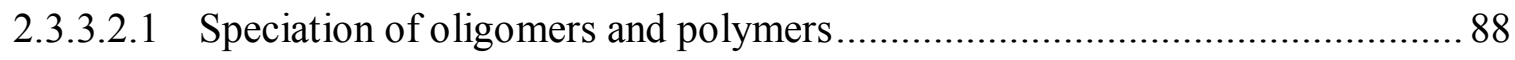

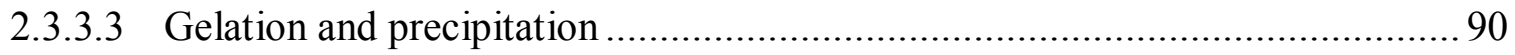

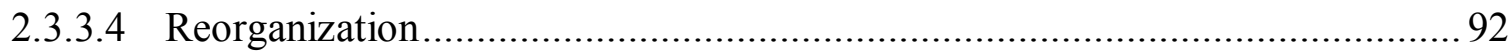

2.3.3.4.1 Magic-angle spinning nuclear magnetic resonance (MAS-NMR) spectroscopy 93

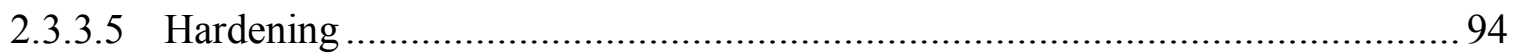

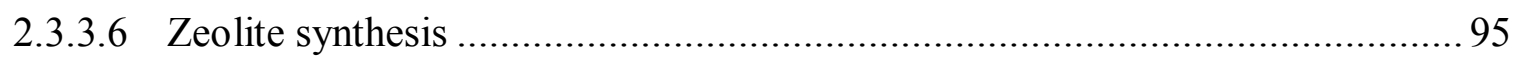

2.3.3.6.1 Are geopolymers amorphous zeolites? ………........................................ 98

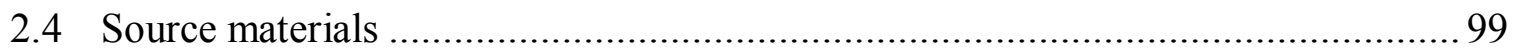




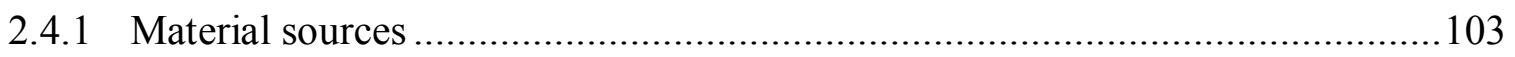

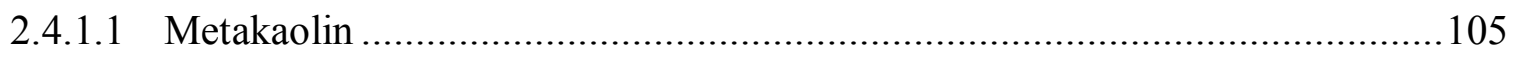

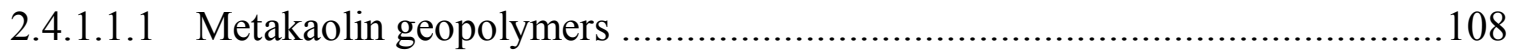

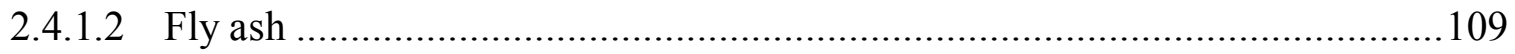

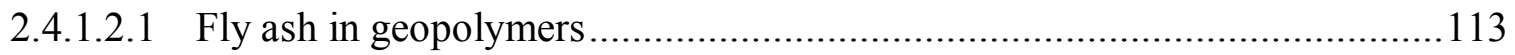

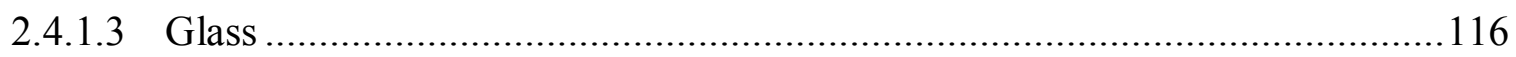

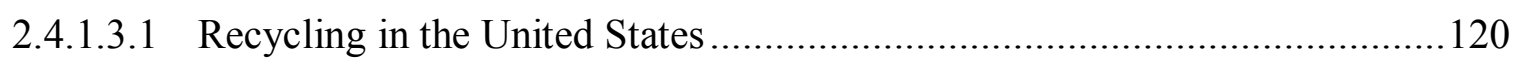

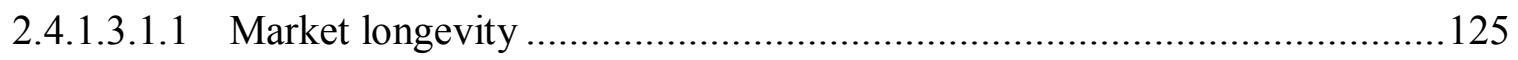

2.4.1.3.2 Glass in geopolymers ………..........................................................126

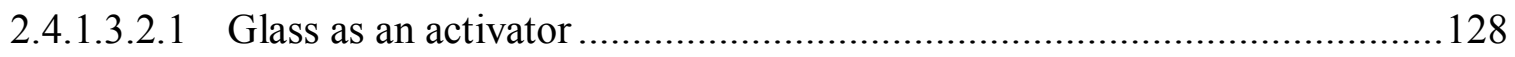

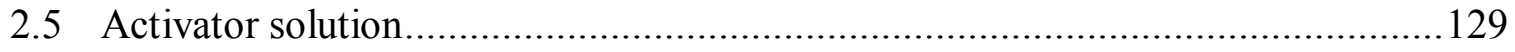

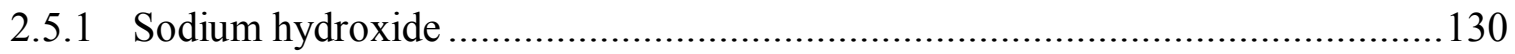

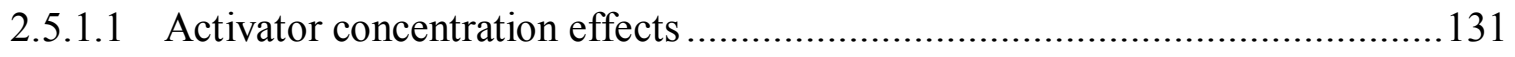

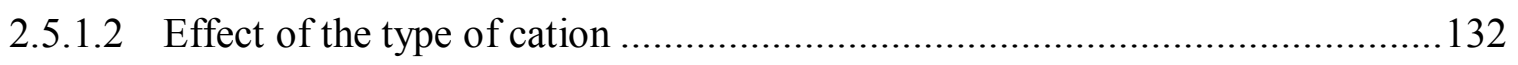

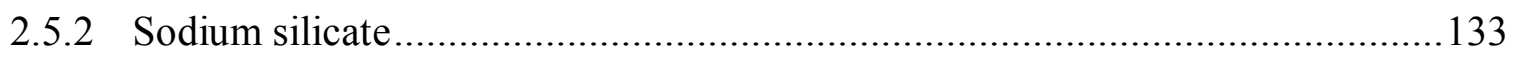

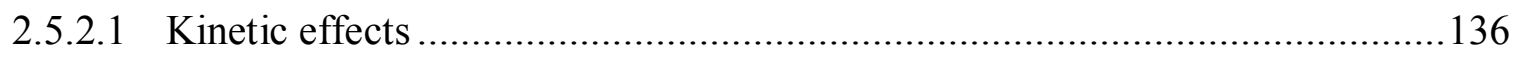

2.5.2.2 Effects on reaction product phases........................................................138

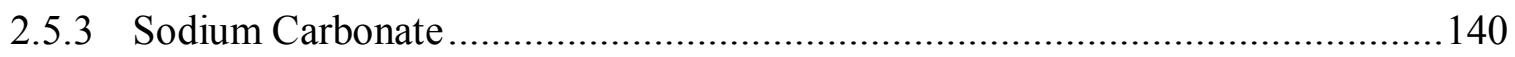

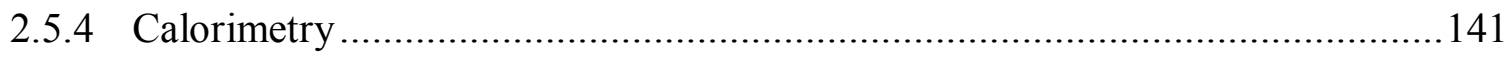

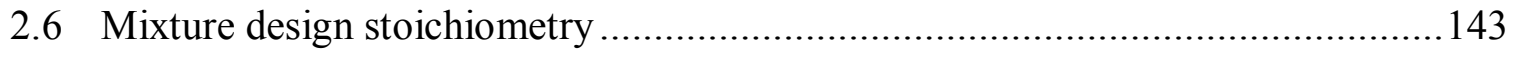

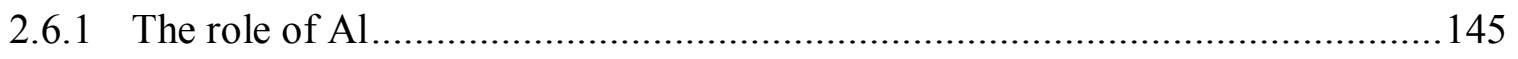

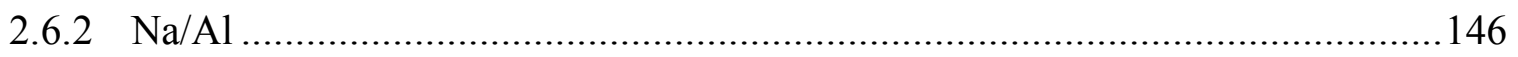

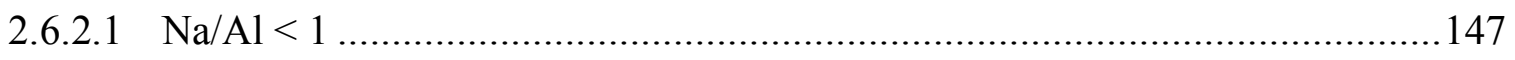

2.6.2.2 $\mathrm{Na} / \mathrm{Al}>1$ 


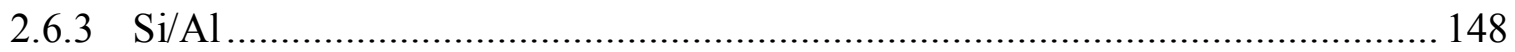

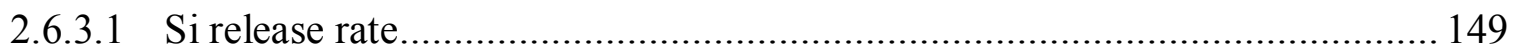

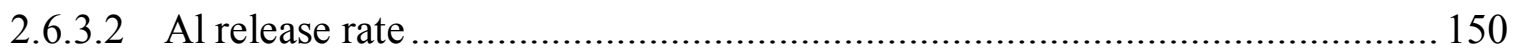

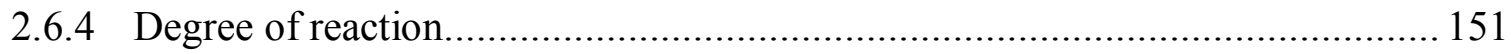

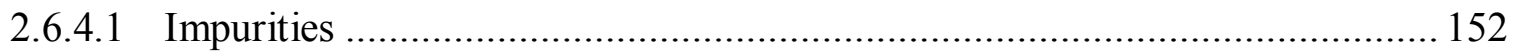

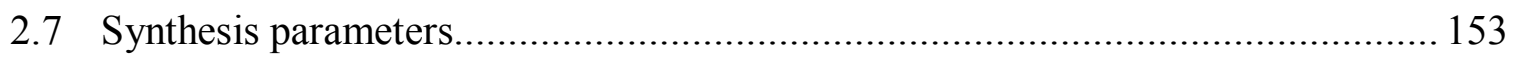

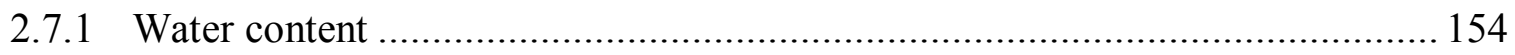

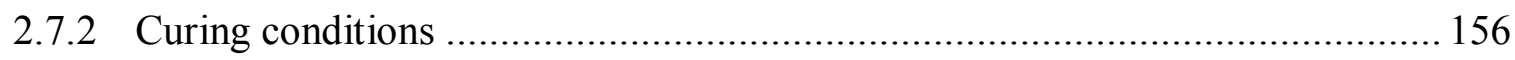

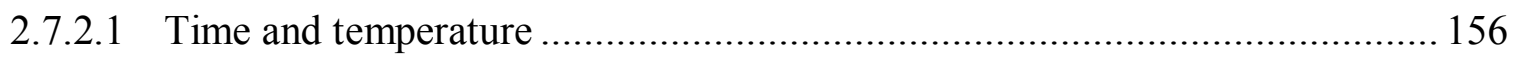

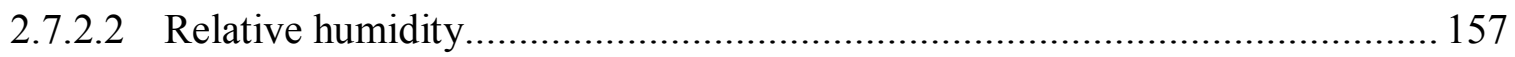

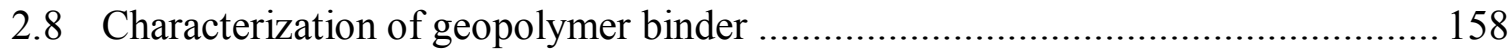

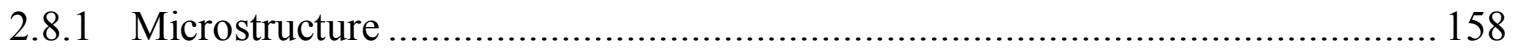

2.8.1.1 Effect of Si availability on microstructure ……….................................... 159

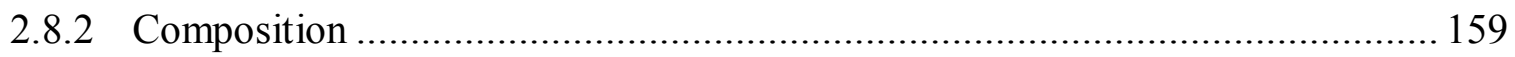

2.8.3 Relationship to mechanical properties ........................................................ 160

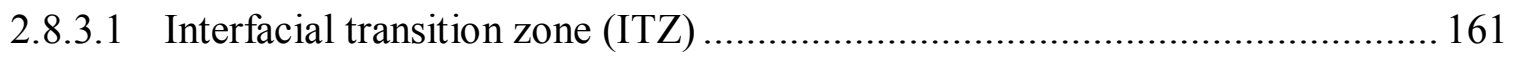

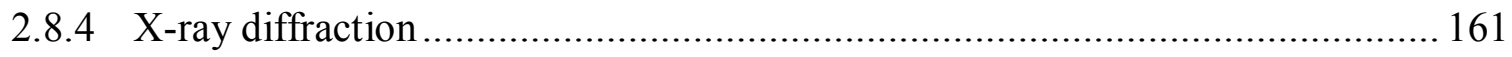

2.8.4.1 Zeolites found in geopolymers ………….............................................. 162

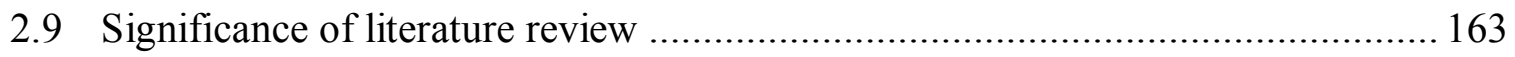

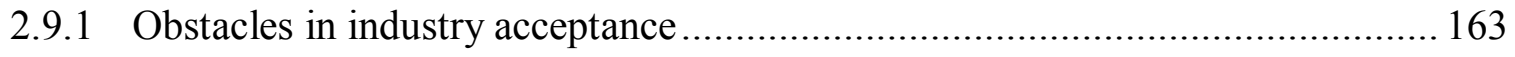

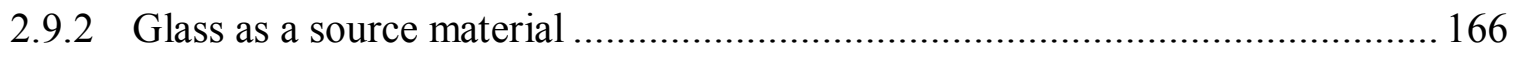

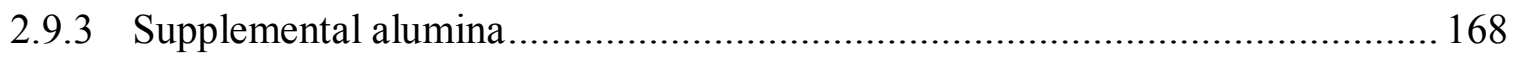

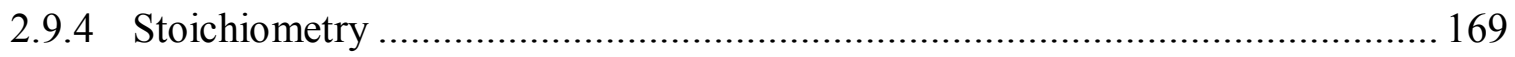

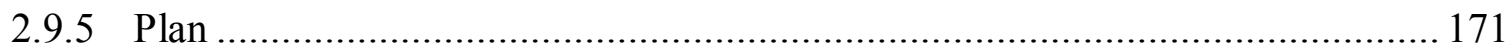




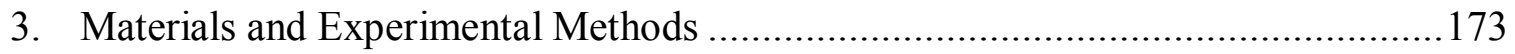

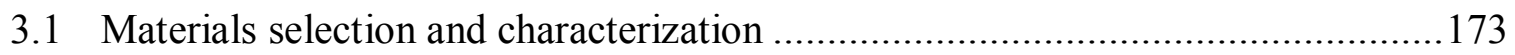

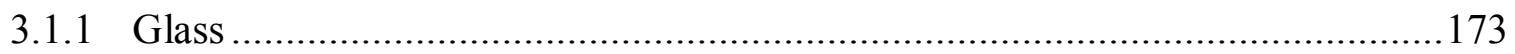

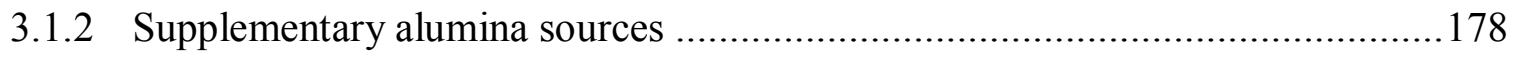

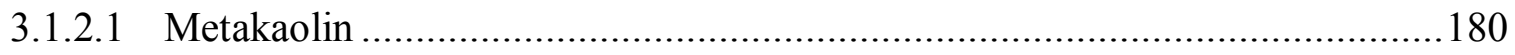

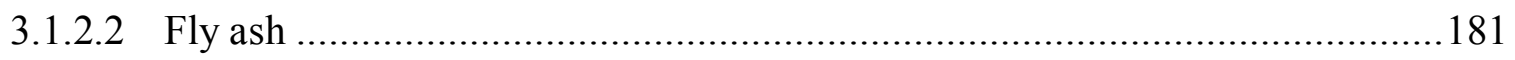

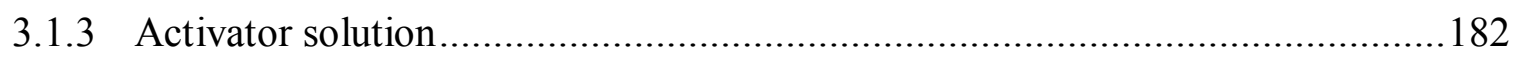

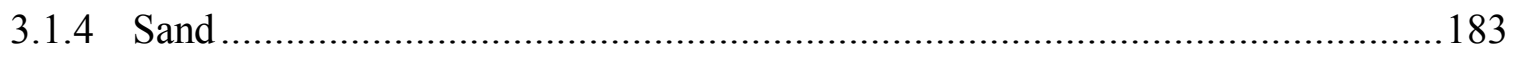

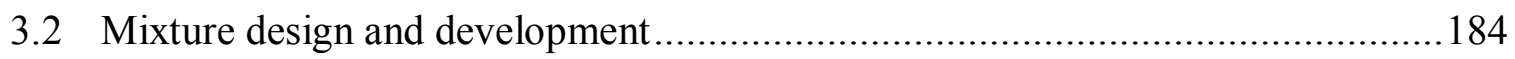

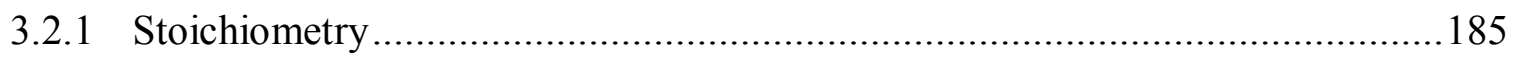

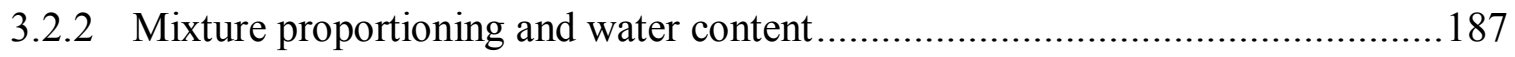

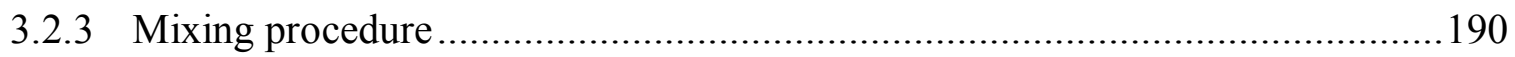

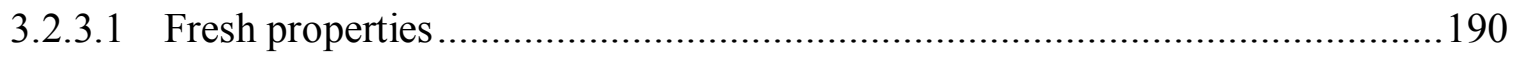

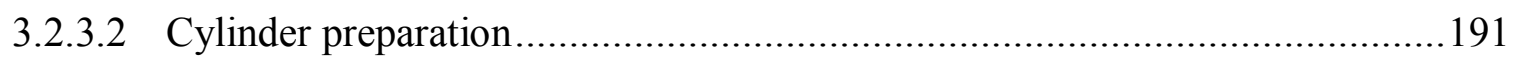

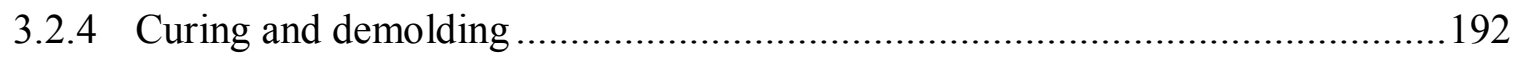

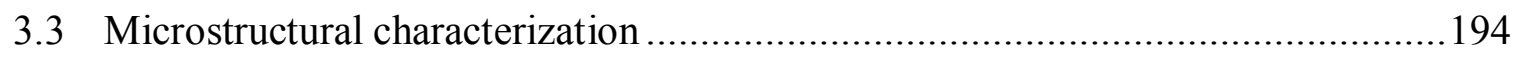

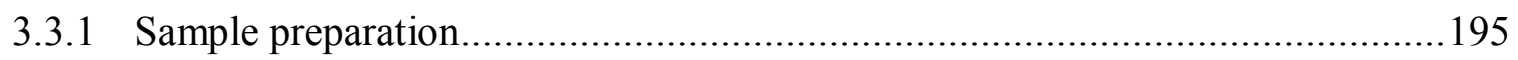

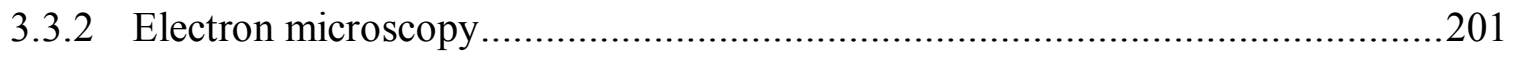

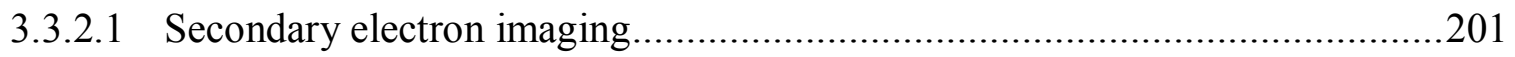

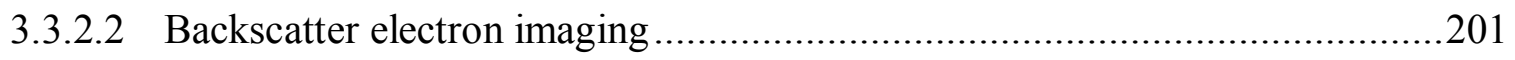

3.3.2.3 Energy dispersive X-ray spectroscopy ………….....................................202

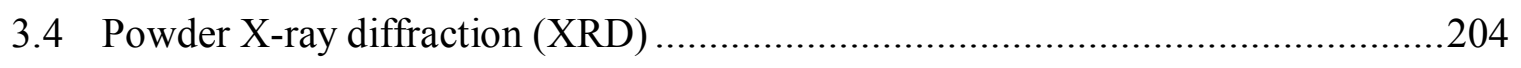

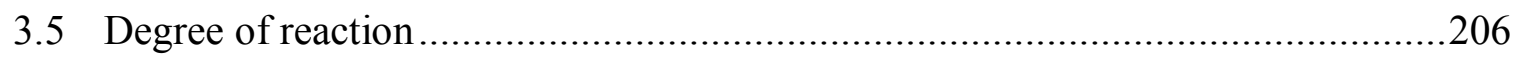

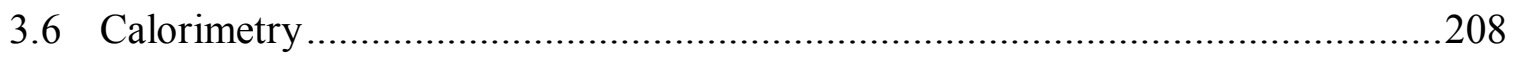




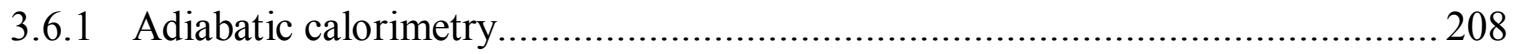

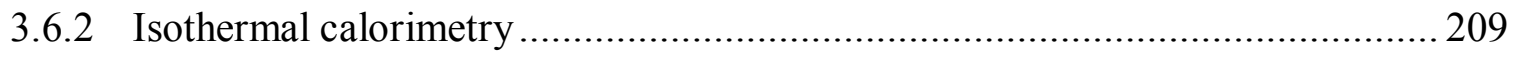

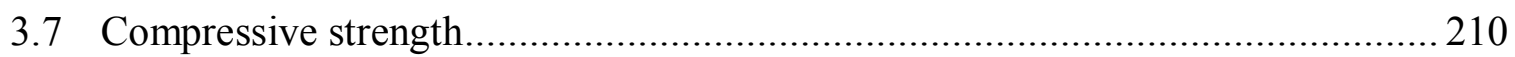

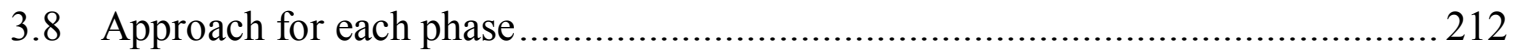

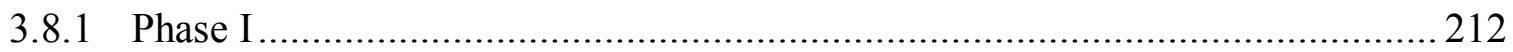

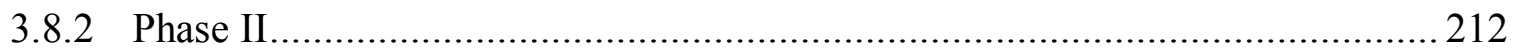

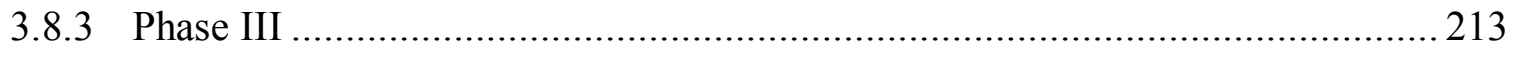

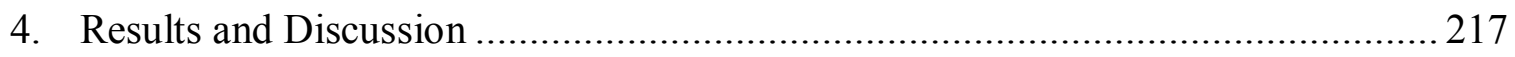

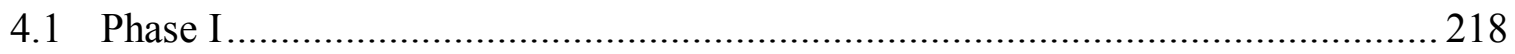

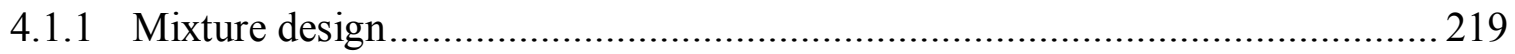

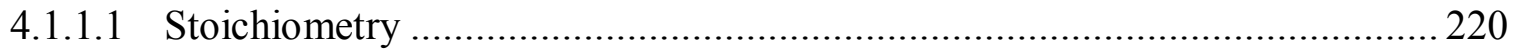

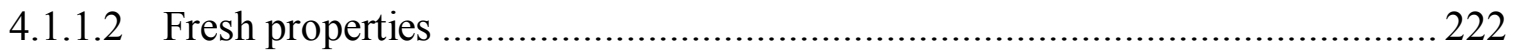

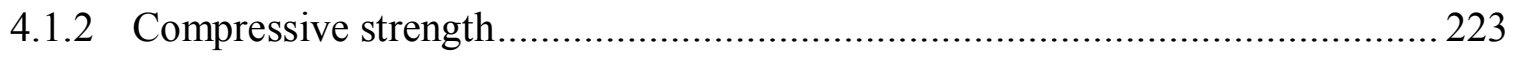

4.1.2.1 Early age strength through 28 days.........................................................223

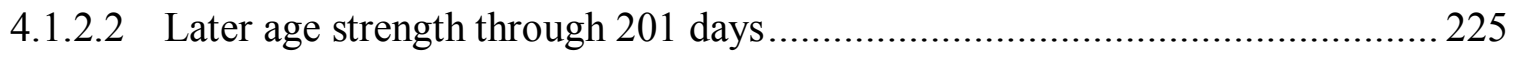

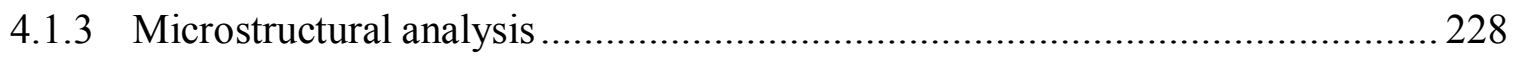

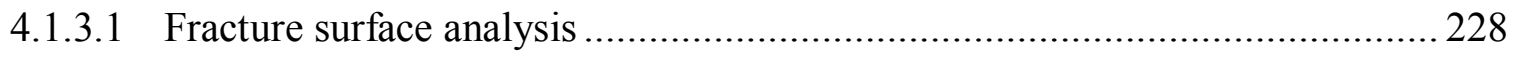

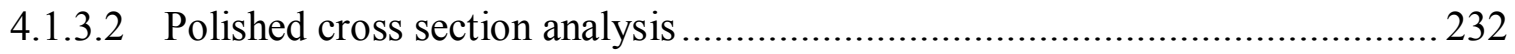

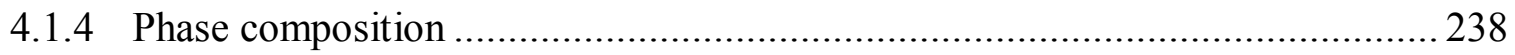

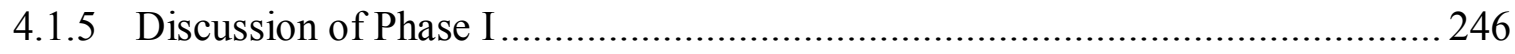

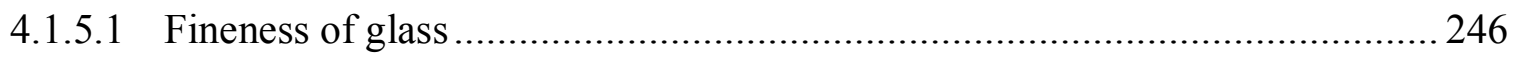

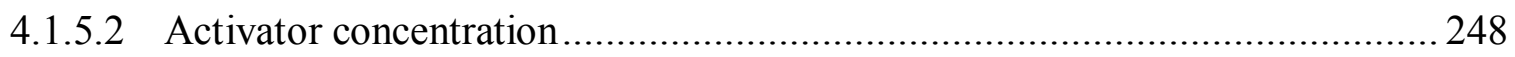

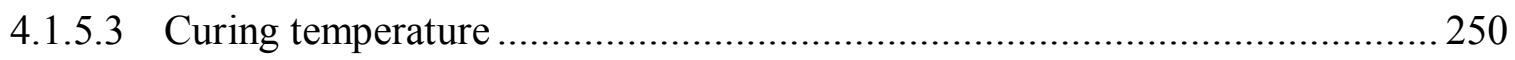

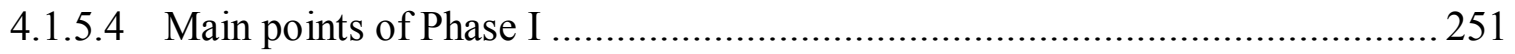




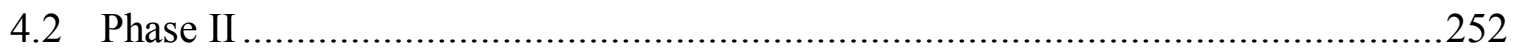

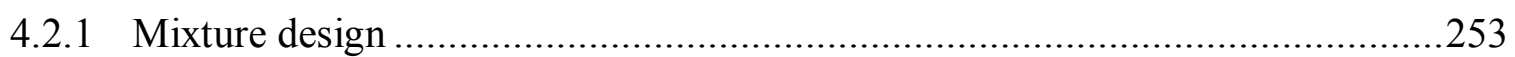

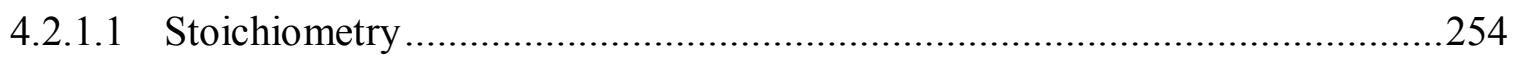

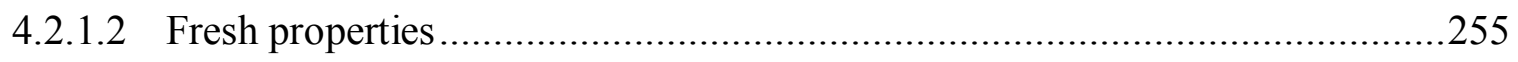

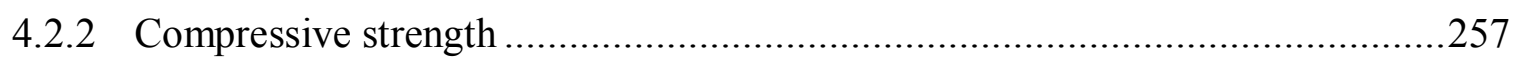

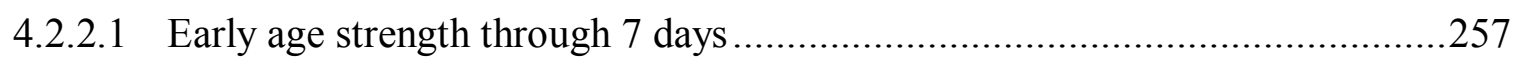

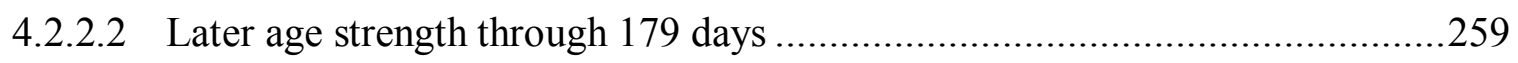

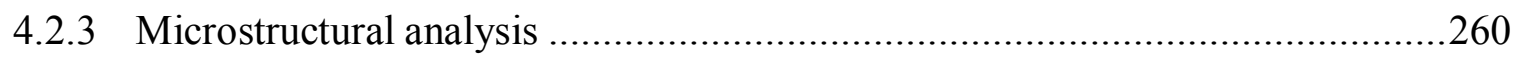

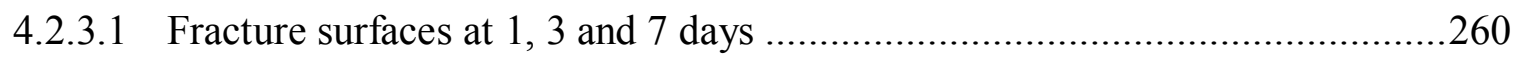

4.2.3.1.1 Unreacted particles ..................................................................263

4.2.3.1.2 Zeolites ..................................................................................... 264

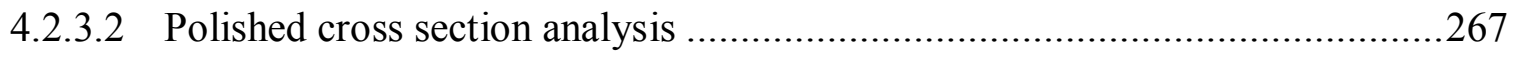

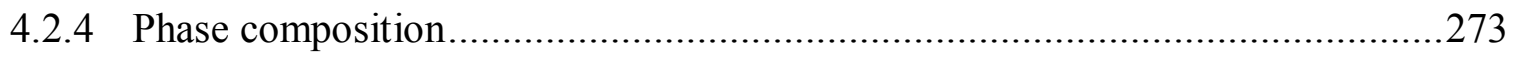

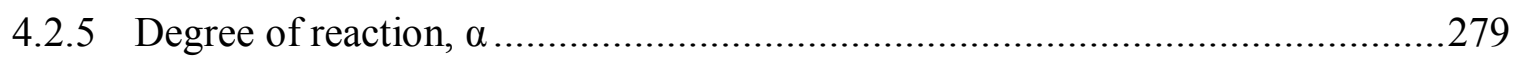

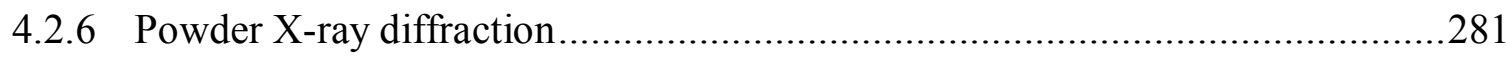

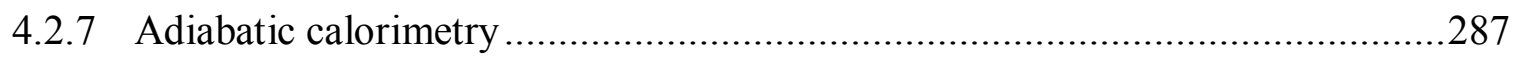

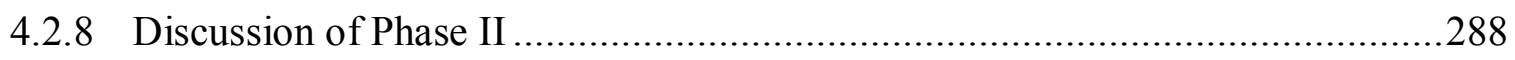

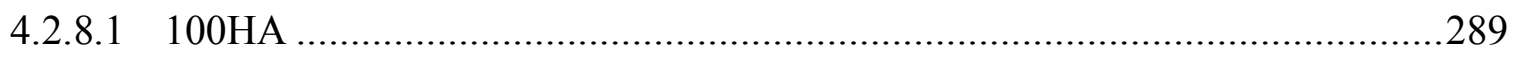

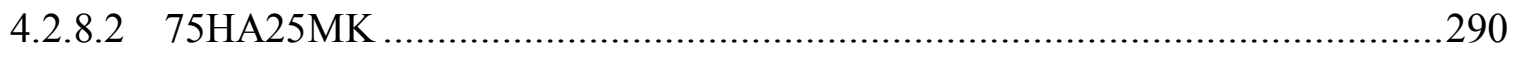

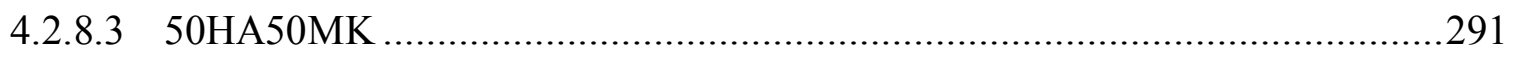

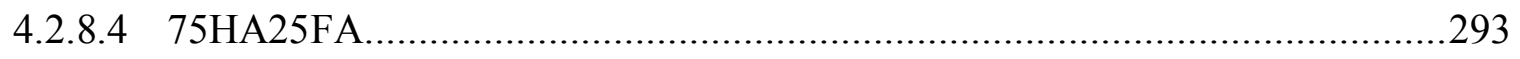

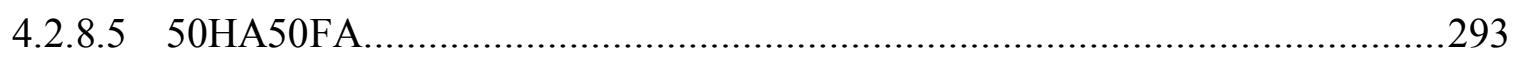

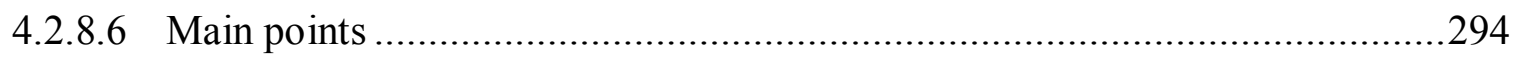

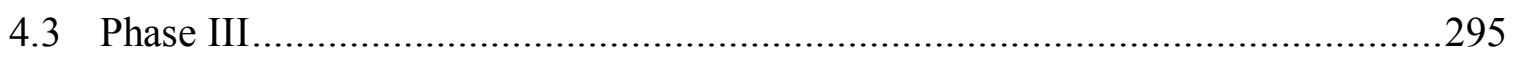




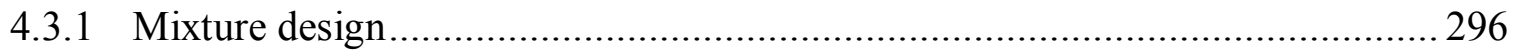

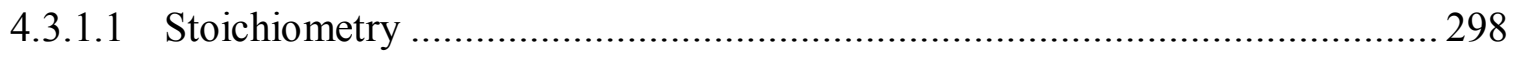

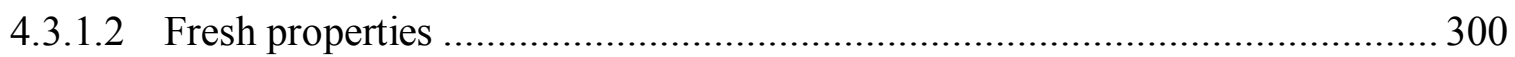

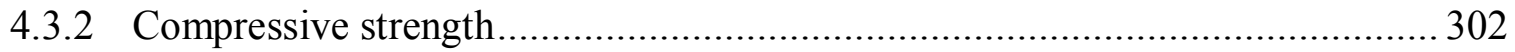

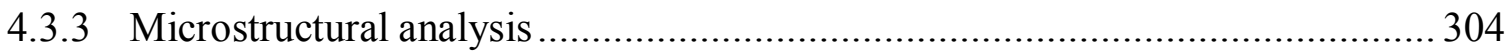

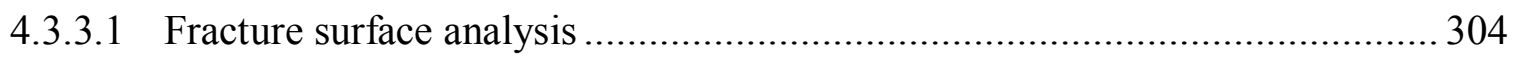

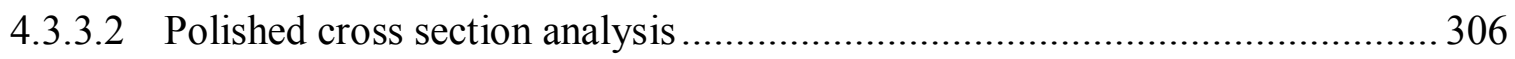

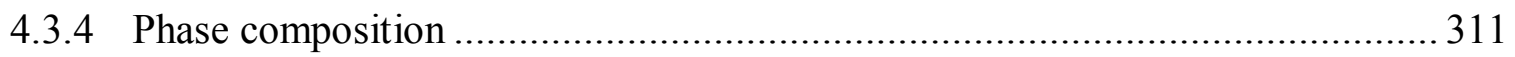

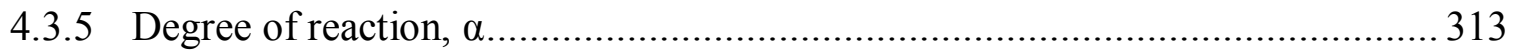

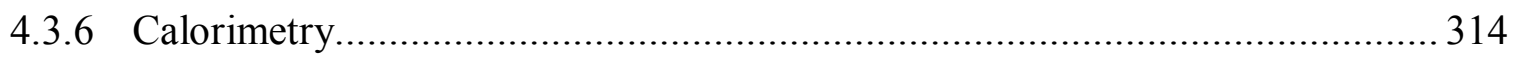

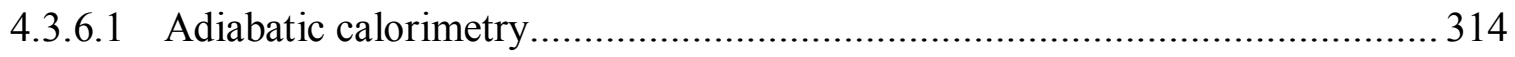

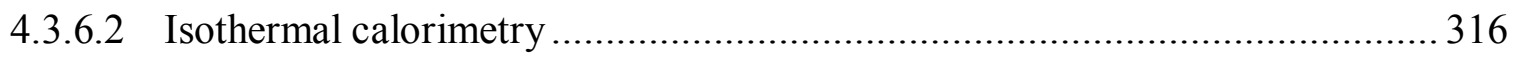

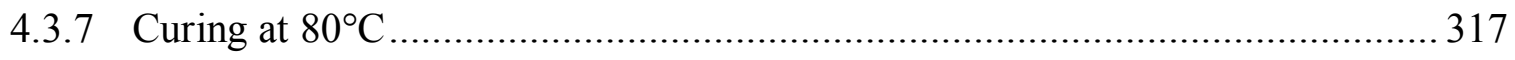

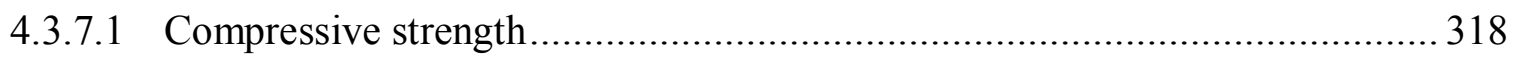

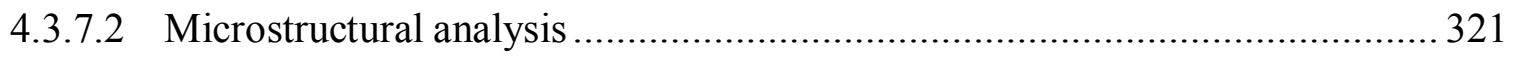

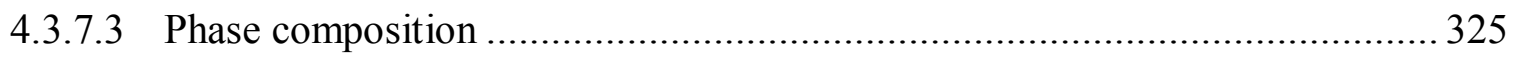

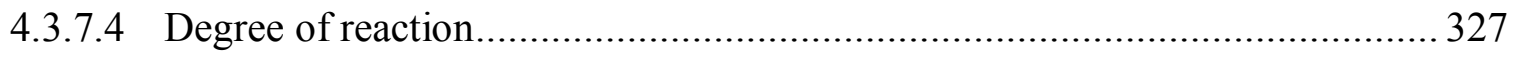

4.3.8 Ternary mixtures of glass, metakaolin and fly ash ..........................................328

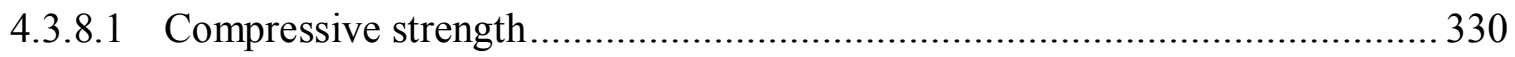

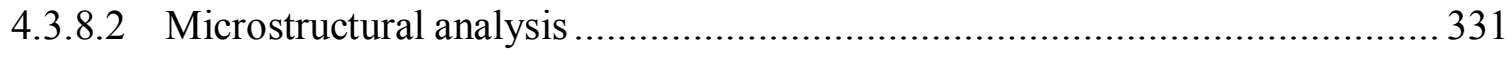

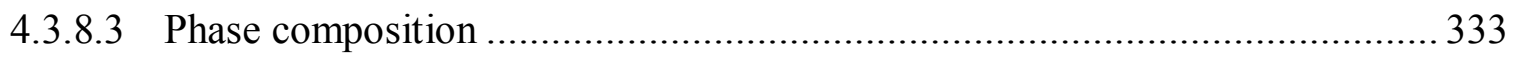

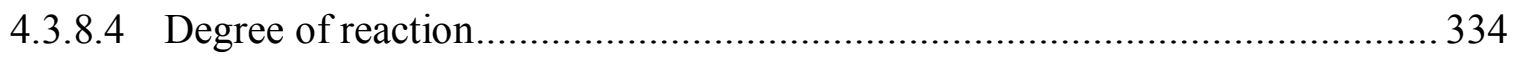

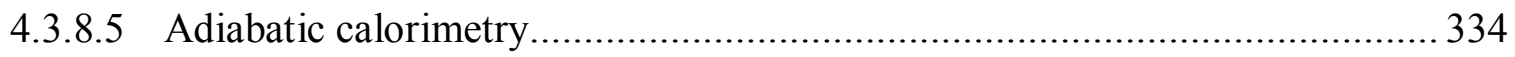

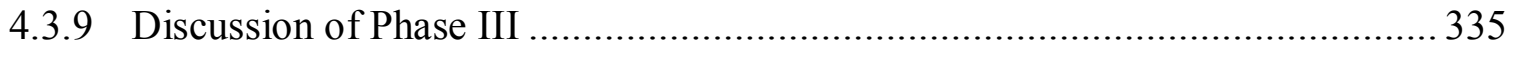




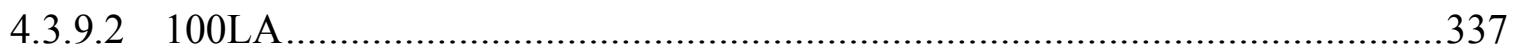

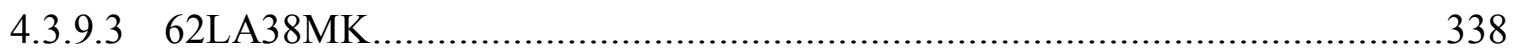

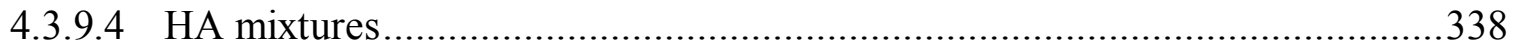

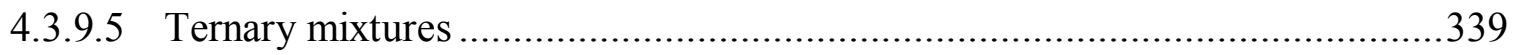

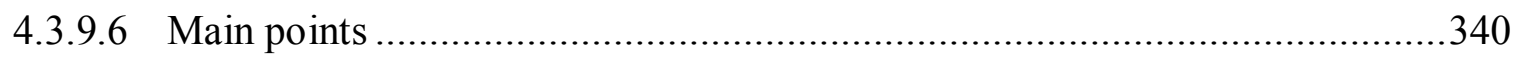

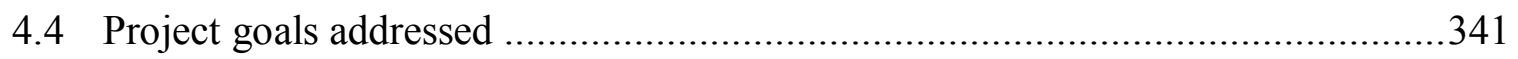

4.4.1 What are the phases formed by the alkali activation of waste glass and how is the microstructure and composition of these phases affected by the addition of metakaolin as a source of alumina? .

4.4.2 Is there a clear correlation between microstructure, composition and compressive

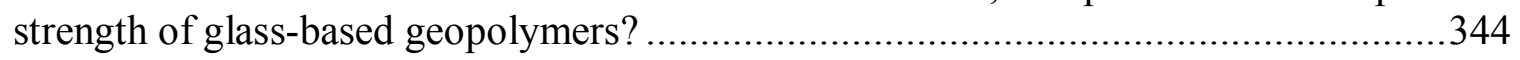

4.4.3 How does the bulk stoichiometry of the initial mixture compare to the actual stoichiometry of the geopolymer formed? What role does the degree of reaction play in this relationship?. .344

4.4.4 Does the addition of metakaolin or fly ash adequately lower the stoichiometry of the mixture to more acceptable ranges found in other geopolymers made of fly ash or metakaolin and does this enhance the mechanical performance? 345

5. Conclusions .347

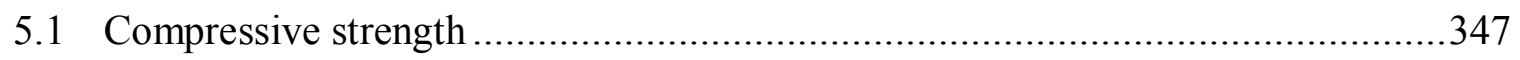

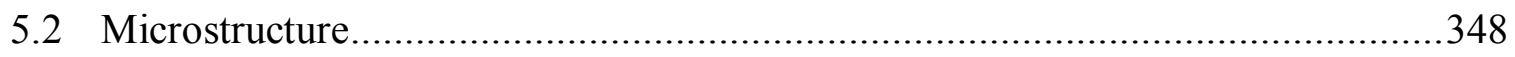

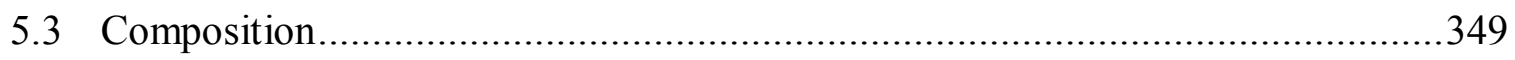

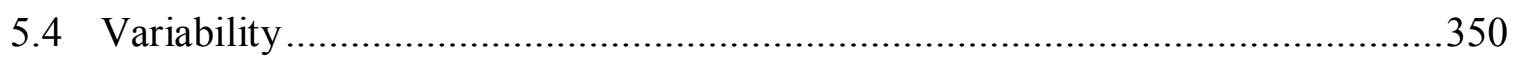

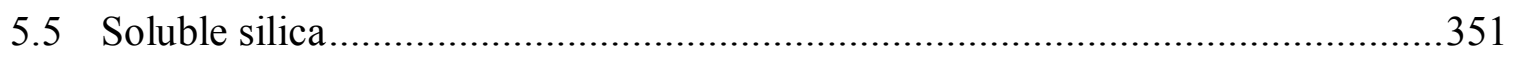

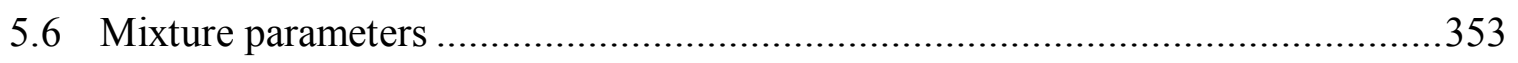

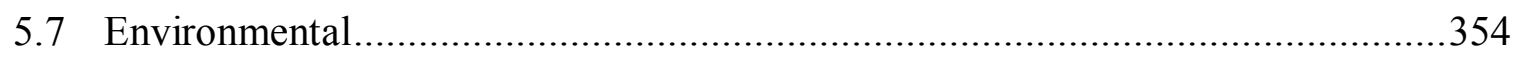

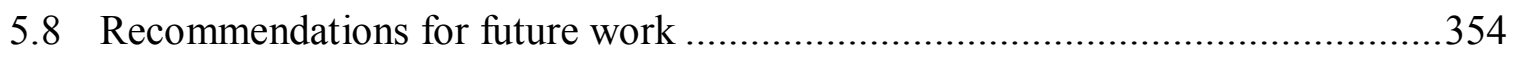




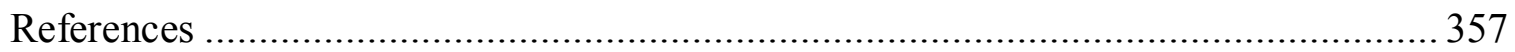

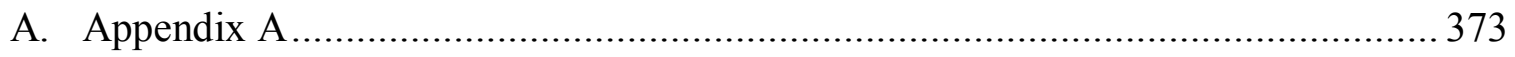

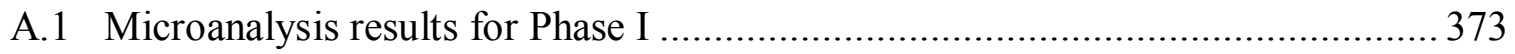

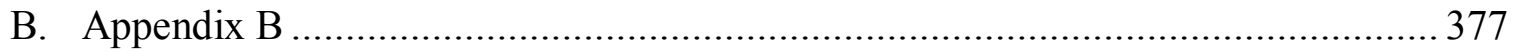

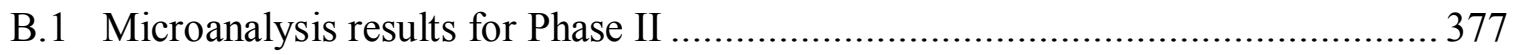

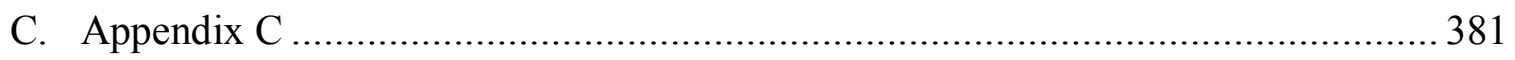

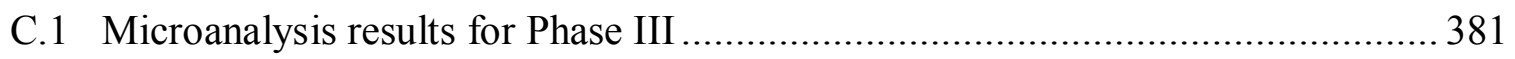

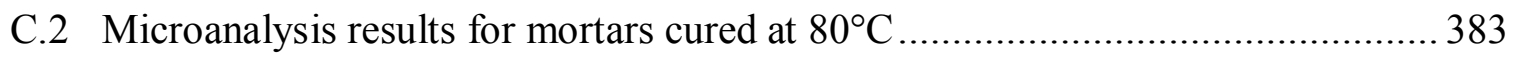

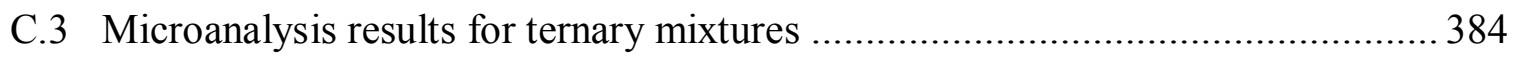

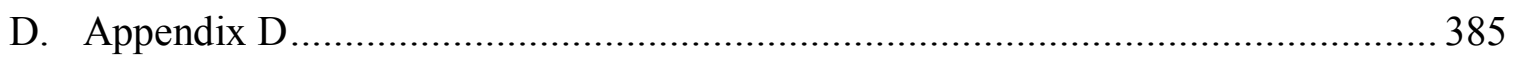

D.1 Copyright release for Figures 2.2, 2.4, 2.7, 2.9, 2.10, 2.11, 2.14...................... 385

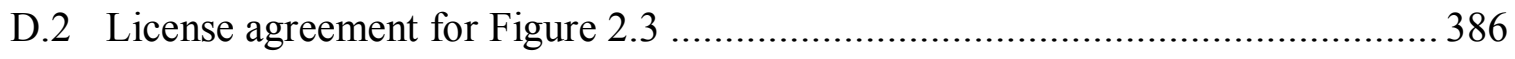

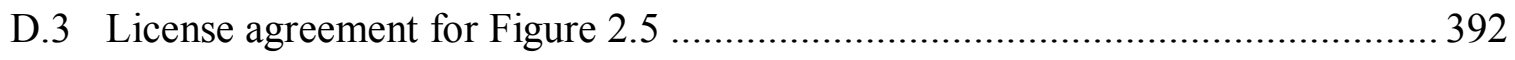

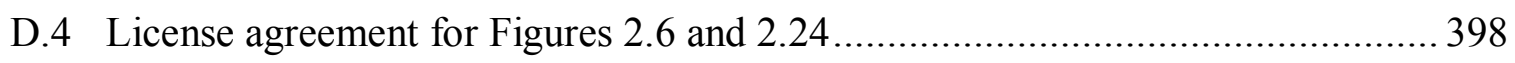

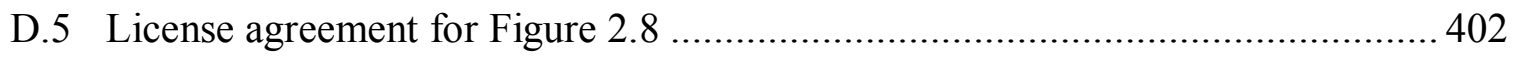

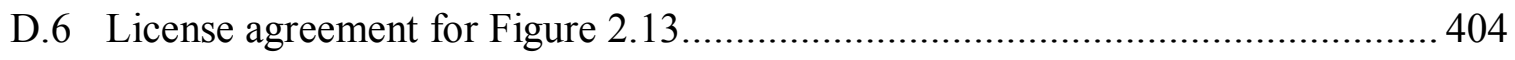

D.7 License agreement for Figures 2.16 and 2.17 .................................................. 406

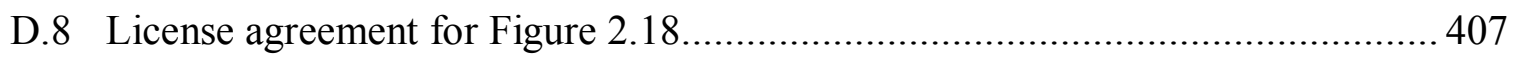

D.9 License agreement for Figures 2.21 and 2.22 ….......................................... 408

D.10 License agreement for Figure 2.23 ............................................................ 410

D.11 License agreement for Figure 2.25 .......................................................... 412

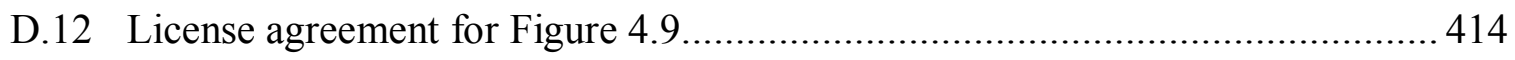




\section{List of Figures}

Figure 2.1. Global cement production from 1930 to 2011 (van Oss 2012).

Figure 2.2. Schematic of sialate systems where $\mathrm{z}=1$ (top), 2 (middle) or 3 (bottom) (Davidovits 1994).

Figure 2.3. Recent schematic model of geopolymerization (Shi et al. 2011). Reprinted by permission of Elsevier. See Appendix D for documentation of permission to reprint this material. .76

Figure 2.4. Schematic of silica dissolution in water containing hydroxyl ions, $\mathrm{OH}^{-}$(Iler 1979). .78

Figure 2.5. Solubility of amorphous silica vs. pH (Iler 1979). Reprinted by permission of John Wiley and Sons. See Appendix D for documentation of permission to reprint this material. .79

Figure 2.6. $\mathrm{Si}$ and $\mathrm{Al}$ dissolved from metakaolin in solution at varying $\mathrm{NaOH}$ concentrations (Sagoe-Crentsil and Weng 2007). Reprinted by permission of Springer. See Appendix D for documentation of permission to reprint this material. .81

Figure 2.7. $\mathrm{Al}(\mathrm{OH})_{4}{ }^{-}$and $\mathrm{Si}(\mathrm{OH})_{4}$ tetrahedrons. .83

Figure 2.8. Distribution of monomeric Si anions vs. pH (Šefč́́k and McCormick 1997). Reprinted by permission of Elsevier. See Appendix D for documentation of permission to reprint this material. 83

Figure 2.9. Condensation reactions between monomers. .85

Figure 2.10. An example of a monomer (top left), dimer (top right), cyclic trimer (bottom left) and trimer (bottom right). .86

Figure 2.11. Two-dimensional schematic of a gel and precipitate after Iler (Iler 1979)...90

Figure 2.12. $\mathrm{Q}^{4}(\mathrm{mAl})$ units in aluminosilicates where $\mathrm{m}=4,3,2,1,0$ from left to right. . .94

Figure 2.13. Schematic of the structure of K-based geopolymer (Davidovits 1994). Figure courtesy of the Geopolymer Institute (www.geopolymer.org). Please see Appendix D for license information. .95

Figure 2.14. Two-dimensional schematic of crystalline silica (left), glassy silica (middle) and binary silicate glass (right) (Hemmings and Berry 1988). 101 
Figure 2.15. Typical composition of common solid materials used in geopolymer cements and $\mathrm{OPC}$.

Figure 2.16. Metakaolin particles (Steveson and Sagoe-Crentsil 2005). Reprinted by permission of Springer. See Appendix D for documentation of permission to reprint this material.

Figure 2.17. Morphology of fly ash particles (Steveson and Sagoe-Crentsil 2005). Reprinted by permission of Springer. See Appendix D for documentation of permission to reprint this material.

Figure 2.18. Typical morphology of soda-lime silica bottle glass (Cyr et al. 2012). Reprinted by permission of Springer. See Appendix D for documentation of permission to reprint this material.

Figure 2.19. Relationship between recovered and discarded glass in MSW from 1960-2010. Black represents discarded glass, green represents recovered glass (US EPA 2010).... 121

Figure 2.20. No glass sign at Waste Management in Houghton, MI.

Figure 2.21. Gel, zeolite and remaining vitreous phases for fly ash activated with various alkali activating solutions (Criado et al. 2007). Reprinted by permission of Elsevier. See Appendix D for documentation of permission to reprint this material. 138

Figure 2.22. Compressive strength of fly ash geopolymers activated with various activators over time (Criado et al. 2007). Reprinted by permission of Elsevier. See Appendix D for documentation of permission to reprint this material. 139

Figure 2.23. Schematic of geopolymer synthesis kinetics: based on metakaolin activated by $\mathrm{NaOH}$ (Zhang et al. 2012). Reprinted by permission of Elsevier. See Appendix D for documentation of permission to reprint this material. 142

Figure 2.24. Influence of different $\mathrm{Si}$ sources on calorimetry curves for metakaolin activation (Sagoe-Crentsil and Weng 2007). Reprinted by permission of Springer. See Appendix D for documentation of permission to reprint this material. 143

Figure 2.25. $\mathrm{pH}$ vs. $\mathrm{Al}_{2} \mathrm{O}_{3} / \mathrm{K}_{2} \mathrm{O}$ molar ratio in aluminosilicate gels (Fernández-Jiménez et al. 2006). Reprinted by permission of Elsevier. See Appendix D for documentation of permission to reprint this material.

Figure 3.1. Waste packaging glass being crushed in a jaw crusher (left) and a gyratory crusher (right). Wrappers, cap rings, etc. are quite easy to remove by sieving once the glass gets down to a certain size. 175

Figure 3.2. Morphology of glass particles shown in secondary electron imaging. 177 
Figure 3.3. Glass shown in polished sections under secondary electron imaging: LA500 (top) and HA500 (bottom).

Figure 3.4. Morphology of metakaolin particles as shown in a powder mount in secondary electron imaging (left) and flocs of particles in a polished section in backscatter electron imaging (right).

Figure 3.5. Metakaolin in polished section in backscatter electron imaging. Flocs of particles can clearly be seen on the right. 181

Figure 3.6. Fly ash in polished section in backscatter electron imaging........................182

Figure 3.7. $\mathrm{NaOH}$ flake pellets prior to solution preparation. 183

Figure 3.8. Backscatter electron image of the interface between Ottawa sand embedded in epoxy (top) and sand embedded in geopolymer (bottom). 184

Figure 3.9. Theoretical stoichiometry of soda-lime glass-metakaolin geopolymer activated with $10 \mathrm{M} \mathrm{NaOH}$ 186

Figure 3.10. Balls formed in mixture with not enough liquid present. 188

Figure 3.11. Visible difference in water demand for $100 \%$ metakaolin (left) and $100 \%$ glass (right) activated with the same amount of activator, water and source material by mass.

Figure 3.12. Benedict Laboratory and mortar mixing room. 190

Figure 3.13. Flow table test (left) and unit weight setup (right). 191

Figure 3.14. Molds after vibration on vibration table. 192

Figure 3.15. Internal (left) and external curing (right) conditions used to maintain desired curing conditions. 193

Figure 3.16. Specimen damage during demolding in samples containing metakaolin. ..193

Figure 3.17. Fracture surface specimen preparation prior to (left) and after (right) carbon coating. 196

Figure 3.18. Circular sample molds filled with samples prior to vacuum impregnation. 197

Figure 3.19. Billet boxes filled with samples, then graded Ottawa sand. 197

Figure 3.20. Vacuum impregnation system. 198 
Figure 3.21. Thin section machine used for grinding into samples and samples exposed. 198

Figure 3.22. Diamond Pacific grinding wheel, used for holding pressure sensitive adhesive backed mineralogical papers. 199

Figure 3.23. Beuhler Isomet used to do the finer polishing with diamond paste media on nylon cloths. 200

Figure 3.24. Polished sections prior to carbon sputter coating. 200

Figure 3.25. ESEM and inside the ESEM. 201

Figure 3.26. Powder X-ray diffraction (XRD) machine. 204

Figure 3.27. Powder X-ray diffraction pattern for HA600 glass used in Phases I and II. 205

Figure 3.28. Powder X-ray diffraction pattern for metakaolin used in all Phases.......... 205

Figure 3.29. Powder X-ray diffraction pattern for fly ash used in Phase II................. 206

Figure 3.30. Cured paste samples (left), paste sample being crushed by mortar and pestle (center) and various pastes ground into powders in preparation of degree of reaction experiments (right). 207

Figure 3.31 Degree of reaction setup for acid attack (left) and filtration (right)........... 207

Figure 3.32 Degree of reaction tests following calcination in muffle furnace...............208

Figure 3.33. Grace AdiaCal collecting calorimetry data on geopolymer mortars......... 209

Figure 3.34. Isothermal calorimeter at University of Toronto. 210

Figure 3.35. Compressive strength testing set up on the Material Testing System (MTS) machine. 211

Figure 4.1. $\mathrm{Si} / \mathrm{Al}$ vs $\mathrm{Na} / \mathrm{Al}$ molar ratios for mixtures in Phase I. A dashed line at $\mathrm{Na} / \mathrm{Al}=1$ is shown since that is widely accepted as an optimum ratio for geopolymers.

Figure 4.2. Seven and 28 day compressive strength of Phase I mortars made of 100\% HA glass. Each data point is the average of two cylinders. Error bars were calculated from the standard error, $\mathrm{SD} / \sqrt{ } \mathrm{n}$, where $\mathrm{SD}$ is standard deviation and $\mathrm{n}$ is the sample size. 224

Figure 4.3. Compressive strength of Phase I mortars made of 100\% HA glass through 201 days. Data points for 7 and 28 days are based on the average of two cylinders; data for 201 
days is based on one cylinder. Error bars were calculated from the standard error, $\mathrm{SD} / \sqrt{ } \mathrm{n}$, where SD is standard deviation and $\mathrm{n}$ is the sample size. 226

Figure 4.4. Secondary electron imaging of fracture surfaces at 28 days, showing the finer glass mixtures on the left and the corresponding coarser glass mixtures on the right. ...230

Figure 4.5. Microstructural comparison of the highest compressive strength mortar (left), F.10.80, and the lowest compressive strength mortar (right), C.5.40, at 28 days..........231

Figure 4.6. Unreacted glass particles as seen under secondary electron imaging 231

Figure 4.7 Backscatter electron imaging of polished sections at 201 days, with the finer glass mixtures on the left and the corresponding coarser glass mixtures on the right. ...233

Figure 4.8. Comparison of reaction rim around a glass particle in the fine (left) and the coarse (coarse) glass mixtures. 235

Figure 4.9. Microstructure of OPC concrete, showing C-S-H forming around unhydrated cement grains (Diamond 2004). Reprinted by permission of Elsevier. See Appendix D for documentation of permission to reprint this material. 235

Figure 4.10. A larger image showing the microstructure of the F.5.80 mixture. Note the webbed look of the bulk matrix of the finer glass mixtures...... 236

Figure 4.11. A larger image of the microstructure of the C.5.80 mixture. .237

Figure 4.12. Molar ratios of all eight mixtures as a function of compressive strength at 201 days. No clear trends exist other than the divide between mixtures made with fine glass and those made with coarse glass. 240

Figure 4.13. $\mathrm{Si} / \mathrm{Al}$ and $\mathrm{Na} / \mathrm{Al}$ molar ratios as a function of compressive strength. The fine and coarse mixtures are separated by different colored markers as shown in the legend.

Figure 4.14. $\mathrm{Na} / \mathrm{Si}$ and $\mathrm{Ca} / \mathrm{Si}$ molar ratios as a function of compressive strength. Different colored markers, as shown in the legend, separate the fine and coarse mixtures. 242

Figure 4.15. Comparison of the $\mathrm{Si} / \mathrm{Al}$ ratio of the coarse and fine glass mixtures and the bulk $\mathrm{Si} / \mathrm{Al}$ ratio of the mixtures, shown as a line at 8.39 . 243

Figure 4.16. Comparison of the $\mathrm{Na} / \mathrm{Al}$ ratio of the coarse and fine glass mixtures and the bulk Na/Al ratio of the mixtures, shown as a line at 0.99 and 1.61 . .244

Figure 4.17. Comparison of the $\mathrm{Na} / \mathrm{Si}$ ratio of the coarse and fine glass mixtures and the bulk $\mathrm{Na} / \mathrm{Si}$ ratios of the mixtures, shown as lines at 0.12 and 0.19 . 245 
Figure 4.18. Comparison of the $\mathrm{Ca} / \mathrm{Si}$ ratio of the coarse and fine glass mixtures and the

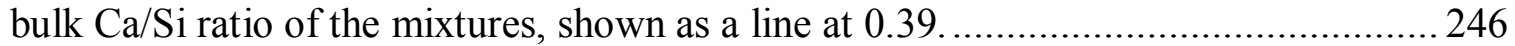

Figure 4.19. White growth on the surface of the C.5.80 mortar during storage............ 249

Figure 4.20. Powder X-ray diffraction pattern and identification for the white growth found on the C.5.80 geopolymer surface in Figure 4.19. 250

Figure 4.21. $\mathrm{Si} / \mathrm{Al}$ vs $\mathrm{Na} / \mathrm{Al}$ molar ratios for mixtures in Phase II. A dashed line at $\mathrm{Na} / \mathrm{Al}$ $=1$ is shown since that is widely accepted as an optimum ratio for geopolymers. 255

Figure 4.22. Phase II mixtures, from left to right: 100HA, 75HA25MK, 50HA50MK,

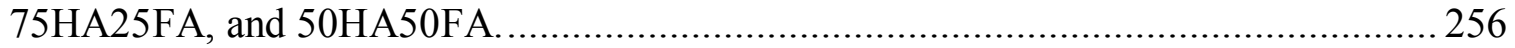

Figure 4.23. Compressive strength through 7 days for mixtures in Phase II. Each data point is the average of three cylinders. Error bars were calculated from the standard error, $\mathrm{SD} / \sqrt{ } \mathrm{n}$, where SD is standard deviation and $\mathrm{n}$ is the sample size. 258

Figure 4.24. Compressive strength of Phase II mixtures through 179 days. Each data point is the average of three cylinders. The 107-day measurements were taken on a Baldwin compression-testing machine. Error bars were calculated from the standard error, $\mathrm{SD} / \sqrt{ } \mathrm{n}$, where SD is standard deviation and $\mathrm{n}$ is the sample size. .259

Figure 4.25. Secondary electron imaging of Phase II fracture surfaces at 1 day (left), 3 days (middle) and 7 days (right). 261

Figure 4.26. Unreacted metakaolin particles (top) and partially reacted fly ash particles (bottom) as shown in secondary electron imaging. 264

Figure 4.27. Examples of the widespread cubic structures found in the 50HA50MK mixture at 3 days. 265

Figure 4.28. Morphologically crystalline phases found growing on the surface of voids in 100HA (left) and 50HA50FA (right) mixtures. 266

Figure 4.29. Secondary electron images of crystalline phases found in each of the mortars in Phase II. .267

Figure 4.30. Backscatter electron imaging of Phase II mortars at 179 days. .268

Figure 4.31. Backscatter electron images of the reaction rim around glass particles in the 100HA matrix. 269

Figure 4.32. Micrographs of 100HA showing areas of uniform homogeneity interrupted only by embedded glass particles (left) and areas exhibiting multiple phases (right) as shown by the varying brightness levels under backscatter electron imaging. 270 
Figure 4.33. Micrographs of 75HA25MK showing areas exhibiting multiple phases as shown by the varying brightness levels under backscatter electron imaging. Unreacted glass particles did not have a reaction rim around them as in the HA100 mixture.........271

Figure 4.34. Micrographs of 75HA25FA showing areas exhibiting multiple phases as shown by the varying brightness levels under backscatter electron imaging.

Figure 4.35. Micrographs of 50HA50FA showing areas exhibiting multiple phases as shown by the varying brightness levels under backscatter electron imaging. 272

Figure 4.36. Unreacted and partially reacted fly ash particles in mortars containing fly ash. .273

Figure 4.37. 100HA showing multiple phases present. The micrograph on the right is a blow up of a center section of the micrograph on the left. 274

Figure 4.38. Molar ratios of Phase II as a function of compressive strength. 275

Figure 4.39. $\mathrm{Si} / \mathrm{Al}$ and $\mathrm{Na} / \mathrm{Al}$ ratios of the mixtures in Phase II versus compressive strength. 276

Figure 4.40. $\mathrm{Na} / \mathrm{Si}$ and $\mathrm{Ca} / \mathrm{Si}$ ratios of the mixtures in Phase II versus compressive strength. .277

Figure 4.41. Bulk vs actual molar ratios for the 100HA mixture (top) and 75HA25MK mixture (bottom). 278

Figure 4.42. Bulk vs actual molar ratios for the 75HA25FA mixture (top) and 50HA50FA mixture (bottom). 279

Figure 4.43. Degree of reaction results for the first seven days in Phase II. Each data point is the average of two tests. Error bars were calculated from the standard error, $\mathrm{SD} / \sqrt{ } \mathrm{n}$, where $\mathrm{SD}$ is standard deviation and $\mathrm{n}$ is the sample size. .281

Figure 4.44 Degree of reaction versus age through 179 days. Each data point is the average of two tests. Error bars were calculated from the standard error, SD/ $/ \sqrt{ }$, where $\mathrm{SD}$ is standard deviation and $\mathrm{n}$ is the sample size. 281

Figure 4.45. X-ray diffraction patterns for the 100HA mixture at 1 (blue), 3 (red) and 7 (light blue) days. 282

Figure 4.46. X-ray diffraction patterns for the 75HA25MK mixture at 1 (blue), 3 (red) and 7 (light blue) days. 283

Figure 4.47. X-ray diffraction patterns for the 50HA50MK mixture at 1 (blue), 3 (red) and 7 (light blue) days. .284 
Figure 4.48. Phase identification for 50HA50MK mixture at 7 days. Calcium aluminum silicate hydrate. 285

Figure 4.49. X-ray diffraction patterns for the 75HA25FA mixture at 1 (blue), 3 (red) and 7 (light blue) days. 285

Figure 4.50. X-ray diffraction patterns for the 50HA50FA mixture at 1 (blue), 3 (red) and 7 (light blue) days. 286

Figure 4.51. Adiabatic calorimetry curves for mixtures 100HA, 75HA25MK and $50 \mathrm{HA} 50 \mathrm{MK}$. Values shown represent the value measured every 30 seconds. 288

Figure 4.52. Si/Al vs Na/Al of the mixtures in Phase III, not including 100LA mixture, so other molar ratios could be better viewed. A dashed line at $\mathrm{Na} / \mathrm{Al}=1$ is shown since that is widely accepted as an optimum ratio for geopolymers. 299

Figure 4.53. A depiction of how wet the low-Al glass was even after 14 days of curing as compared to the other mixtures. 301

Figure 4.54. Compressive strength through 28 days for mixtures in Phase III cured at $60^{\circ} \mathrm{C}$. Each data point is the average of three cylinders. Error bars were calculated from the standard error, $\mathrm{SD} / \sqrt{ } \mathrm{n}$, where $\mathrm{SD}$ is standard deviation and $\mathrm{n}$ is the sample size. 302

Figure 4.55. 100LA mixture after compression testing showing color differences between interior and exterior of cylinder at 14 days. The interior still appeared and felt damp and slimy despite being very dense. 303

Figure 4.56. Secondary electron imaging of Phase III fracture surfaces at 28 days....... 305

Figure 4.57. Polished cross sections of Phase III mortars at 14 days. 307

Figure 4.58. Micrograph illustrating the extensive cracking in the 100LA mixture at 14 days. 308

Figure 4.59. Bright crystalline phase found embedded in 100LA mixture consisting of mainly $\mathrm{Si}$, and a small amount of $\mathrm{Al}$ and alkalis. 309

Figure 4.60. Micrograph illustrating the large flocs of metakaolin particles present within the $100 \mathrm{MK}$ matrix at 14 days. 310

Figure 4.61. Bulk vs actual molar ratios for the 100LA mixture. 313

Figure 4.62. Bulk vs actual molar ratios for the 100HA mixture (left) and 75HA25MK mixture (right). 313

Figure 4.63. Degree of reaction results from Phase III mortars cured at $60^{\circ} \mathrm{C}$. 314 
Figure 4.64. Adiabatic calorimetry curves measured for LA500 glass with three different water/solids ratios. 315

Figure 4.65. Comparison of all six mixtures in Phase III............................................316

Figure 4.66. Isothermal calorimetry curves for all six mixtures cured at $60^{\circ} \mathrm{C}$ for 72 hours.

Figure 4.67. Comparison of the compressive strength measured for the $60^{\circ} \mathrm{C}$ and $80^{\circ} \mathrm{C}$ curing regimes through 28 days for the 100LA mixture. Each data point is the average of three cylinders. 318

Figure 4.68. Comparison of the compressive strength measured for the $60^{\circ} \mathrm{C}$ and $80^{\circ} \mathrm{C}$ curing regimes through 14 days for the $62 \mathrm{LA} 38 \mathrm{MK}$ mixture. Each data point is the average of three cylinders.

Figure 4.69. Comparison of the compressive strength measured for the $60^{\circ} \mathrm{C}$ and $80^{\circ} \mathrm{C}$ curing regimes through 14 days for the $37 \mathrm{LA} 63 \mathrm{MK}$ mixture. Each data point is the average of three cylinders. 320

Figure 4.70. Comparison of Phase III mixtures at 14 days under various curing regimes. 321

Figure 4.71. Polished sections of the mortars cured at $60^{\circ} \mathrm{C}$ compared to those cured at $80^{\circ} \mathrm{C}$ in Phase III. 322

Figure 4.72. Microstructure of $62 \mathrm{LA} 38 \mathrm{MK}$ mixture cured at $80^{\circ} \mathrm{C}$ shown under backscatter electron imaging. 324

Figure 4.73. Magnified regions of $62 \mathrm{LA} 38 \mathrm{MK}$ mixture cured at $80^{\circ} \mathrm{C}$ showing unreacted glass particles and reaction layer separated by space between matrix and glass. .324

Figure 4.74. Bulk vs actual molar ratios for the $100 \mathrm{LA}$ mixture cured at $80^{\circ} \mathrm{C}$ (left) and the $62 \mathrm{LA} 38 \mathrm{MK}$ mixture cured at $80^{\circ} \mathrm{C}$ (right). 326

Figure 4.75. Si/Al and $\mathrm{Na} / \mathrm{Al}$ ratios comparing the bulk stoichiometry of the 100LA mixture and those measured for mortars cured at $60^{\circ} \mathrm{C}$ and $80^{\circ} \mathrm{C}$ 326

Figure 4.76. $\mathrm{Na} / \mathrm{Si}$ and $\mathrm{Ca} / \mathrm{Si}$ ratios comparing the bulk stoichiometry of the 100LA mixture and those measured for mortars cured at $60^{\circ} \mathrm{C}$ and $80^{\circ} \mathrm{C}$. 327

Figure 4.77. 14 day degree of reaction results from Phase III mortars containing LA glass cured at $60^{\circ} \mathrm{C}$ versus $80^{\circ} \mathrm{C}$. 328

Figure 4.78. Si/Al vs Na/Al of the ternary mixtures, 50LA25MK25FA and 50HA25MK25FA. 329 
Figure 4.79. Comparison of the compressive strength measured for the ternary mixtures. Each data point is the average of three cylinders. Error bars were calculated from the standard error, $\mathrm{SD} / \sqrt{ } \mathrm{n}$, where $\mathrm{SD}$ is standard deviation and $\mathrm{n}$ is the sample size...... 331

Figure 4.80. Polished sections of the 50LA25MK25FA mixture (left) and the 50HA25MK25FA mixture (right)

Figure 4.81. 50LA25MK25FA mixture showing rim of reaction products around unreacted glass particles, but in this case the cracks are through the particle rather than around it indicating a stronger matrix. 332

Figure 4.82. Bulk vs actual molar ratios for the 50LA25MK25FA mixture (left) and the 50HA25MK25FA mixture (right) .333

Figure 4.83. Degree of reaction results at 14 days for the ternary mixtures. 334

Figure 4.84. Adiabatic calorimetry curves of ternary mixtures. 335 


\section{List of Tables}

Table 2.1. Common oxides shown in cement chemist notation as well as geopolymer science.

Table 2.2. The five main phases and composition of a typical Type I portland cement (Mindess et al. 2002).

Table 2.3. Embodied energy and carbon for selected construction materials (Hammond and Jones 2008) .56

Table 2.4. Classification of various cements based on composition of hydration products (Krivenko 2007).

Table 2.5. Products created through different synthesis parameters, after (Provis et al. 2005).

Table 2.6. Composition of a typical metakaolin by mass (Kosmatka 2011). 107

Table 2.7. Typical composition of Class F and C fly ashes by mass (Kosmatka and Wilson 2011)

Table 2.8. Raw materials and their purpose in glass production (Glass Packaging Institute 2013). 117

Table 2.9. Typical composition of soda-lime glass by mass (Glass Packaging Institute 2013). .118

Table 2.10. Reactive $\mathrm{Si}$ sources used to make sodium silicate activator solutions for geopolymers (Davidovits 2008). 135

Table 2.11. Proposed oxide-mole ratios for mineral polymers made of metakaolin (Davidovits 1979). .144

Table 2.12. Comparison of fly ash, metakaolin and glass based on important properties of a source material. A single X represents adequacy and two Xs represent substantial....168

Table 3.1. Composition of glasses from Vitro Minerals as determined by X-ray fluorescence (XRF) and typical soda-lime glass (Glass Packaging Institute 2013).......176

Table 3.2. Criteria used for selecting a supplementary alumina source. A single $X$ represents a good rating in that category, with XX representing a great rating and no $\mathrm{X}$ representing a poor rating. 179 
Table 3.3. Composition of metakaolin and fly ash by mass as determined by X-ray

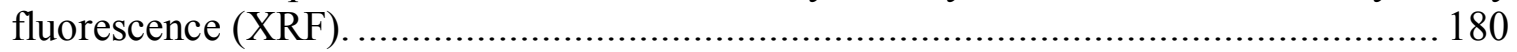

Table 3.4. EDS analysis on metakaolin particles as compared to XRF measurements. . 203

Table 3.5. EDS analysis on HA500 particles as compared to XRF measurements........ 203

Table 3.6. EDS analysis on LA500 particles as compared to XRF measurements. ....... 203

Table 4.1. Explanation of mixture ID for mortars in Phase I......................................220

Table 4.2. Molar ratios of the unreacted source materials and activator solution in Phase I mixtures.

Table 4.3. Fresh properties and water/solids ratio of the mixtures in Phase I. All reported values are based on the average of three measurements. 222

Table 4.4. Mixtures listed in order of maximum average compressive strength at 28 days. The relevant mixture parameters are also listed to aid in identifying trends and the dominant parameter bolded. 225

Table 4.5. Mixtures listed in order of maximum compressive strength at 201 days. ..... 227

Table 4.6. Average measured molar ratios of the mixtures ordered in terms of maximum compressive strength at 201 days. 239

Table 4.7. Mixture ID for mortars in Phase II, with percentages given by mass. .254

Table 4.8. Molar ratios of unreacted source materials and activator solution of Phase II mixtures. 255

Table 4.9. Fresh properties and water/solids ratio of the mixtures in Phase II. All reported values are based on the average of three measurements. 257

Table 4.10. Average measured bulk molar ratios ordered in terms of maximum average compressive strength at 179 days. 275

Table 4.11. Mixture ID for mortars in Phase III, with percentages given by mass. 297

Table 4.12. Molar ratios of unreacted source materials and activator solution of Phase III mixtures. 299

Table 4.13. Fresh properties of Phase III mixtures cured at $60^{\circ} \mathrm{C}$. All of the values reported are the average of three measurements. 300

Table 4.14. Average bulk molar ratios ordered in terms of maximum compressive strength at 14 days 
Table 4.15. Fresh properties of Phase III mixtures cured at $80^{\circ} \mathrm{C}$. All of the values reported are the average of three measurements. 318

Table 4.16. Average bulk molar ratios ordered in terms of maximum compressive strength at 14 days. 325

Table 4.17. Mixture ID for mortars in Phase III, with percentages given by mass.........328

Table 4.18. Molar stoichiometry of unreacted source materials and activator solution of ternary mixtures.

Table 4.19. Fresh properties of the ternary mixtures. Values reported are the average of three measurements. .330

Table 4.20. Average bulk molar ratios ordered in terms of maximum compressive strength at 14 days. 333

Table 5.1. Microanalysis of phases found in F.5.80, which measured $4^{\text {th }}$ in order of maximum compressive strength at 201 days. The results are based on 6 analyses. 373

Table 5.2. Microanalysis of phases found in F.5.40, which measured $6^{\text {th }}$ in order of maximum compressive strength at 201 days. The results are based on 6 analyses. .......373

Table 5.3. Microanalysis of phases found in F.10.80, which measured $3^{\text {rd }}$ in order of maximum compressive strength at 201 days. The results are based on 6 analyses. .......373

Table 5.4. Microanalysis of phases found in F.10.40, which measured $1^{\text {st }}$ in order of maximum compressive strength at 201 days. The results are based on 6 analyses. 374

Table 5.5. Microanalysis of phases found in C.5.80, which measured $8^{\text {th }}$ in order of maximum compressive strength at 201 days. The results are based on 6 analyses. .......374

Table 5.6. Microanalysis of phases found in C.5.40, which measured $7^{\text {th }}$ in order of maximum compressive strength at 201 days. The results are based on 6 analyses. 374

Table 5.7. Microanalysis of phases found in C.10.80, which measured $5^{\text {th }}$ in order of maximum compressive strength at 201 days. The results are based on 6 analyses. 375

Table 5.8. Microanalysis of lighter phase found in C.10.40, which measured $2^{\text {nd }}$ in order of maximum compressive strength at 201 days. The results are based on 6 analyses. .......375

Table 5.9. Microanalysis of dark phase found in C.10.40, which measured $2^{\text {nd }}$ in order of maximum compressive strength at 201 days. The results are based on 3 analyses. .......375

Table 5.10. Microanalysis of dark phase found in 100HA, which measured 2nd in order of maximum compressive strength at 179 days. The results are based on 6 analyses. 377 
Table 5.11. Microanalysis of dark and light phases found in 100HA, which measured 2nd in order of maximum compressive strength at 179 days. 2 spots each of the darker and lighter phase were analyzed.

Table 5.12. Microanalysis of dark phase found in 75HA25MK, which measured 1st in order of maximum compressive strength at 179 days. The results are based on 6 analyses.

Table 5.13. Microanalysis of dark phase found in 75HA25MK, which measured 1 st in order of maximum compressive strength at 179 days. 2 spots each were analyzed of the darker and lighter phases. 378

Table 5.14. Microanalysis of dark phase found in 50HA50MK, which measured 5th in order of maximum compressive strength at 179 days. 2 spots of unreacted metakaolin were confirmed with EDS. 378

Table 5.15. Microanalysis of dark phase found in 75HA25FA, which measured 3rd in order of maximum compressive strength at 179 days. The results are based on 6 analyses.... 378

Table 5.16. EDS analysis of dark phase found in 50HA50FA, which measured 4th in order of maximum compressive strength at 179 days. The results are based on 6 analyses.... 379

Table 5.17. Microanalysis of phases found in $100 \mathrm{LA}$ cured at $60^{\circ} \mathrm{C}$. The results are based on 6 analyses. 381

Table 5.18. Microanalysis of phases found in $62 \mathrm{LA} 38 \mathrm{MK}$ cured at $60^{\circ} \mathrm{C}$. The results are based on 6 analyses. 381

Table 5.19. Microanalysis of phases found in $37 \mathrm{LA} 63 \mathrm{MK}$ cured at $60^{\circ} \mathrm{C}$. The results are based on 6 analyses. 381

Table 5.20. Microanalysis of phases found in 100HA. The results are based on 6 analyses. 382

Table 5.21. Microanalysis of phases found in 75HA25MK. The results are based on 6 analyses. 382

Table 5.22. Microanalysis of phases found in 100MK. The results are based on 6 analyses. 382

Table 5.23. Microanalysis of phases found in $100 \mathrm{LA}$ cured at $80^{\circ} \mathrm{C}$. The results are based on 6 analyses. 383

Table 5.24. Microanalysis of phases found in $62 \mathrm{LA} 38 \mathrm{MK}$ cured at $80^{\circ} \mathrm{C}$. The results are based on 6 analyses. 383 
Table 5.25. Microanalysis of phases found in $37 \mathrm{LA} 63 \mathrm{MK}$ cured at $80^{\circ} \mathrm{C}$. The results are

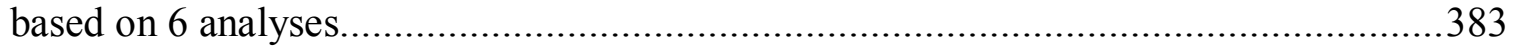

Table 5.26. Microanalysis of phases found in LA-FA-MK. The results are based on 6

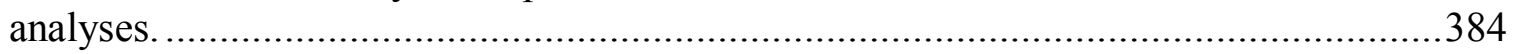

Table 5.27. Microanalysis of phases found in HA-FA-MK. The results are based on 6

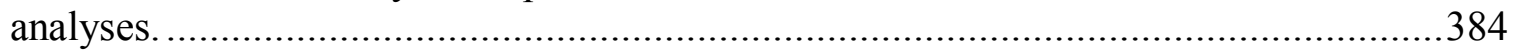





\section{Acknowledgements}

First and foremost, I'd like to thank my advisor, Dr. Larry Sutter. He perfectly executed the role of advisor in that he gave me the freedom to make my own mistakes, taught me the value of "flipping rocks," answered nearly every question with "there's a short answer and a long answer," and never shied away from explaining materials-related concepts to my non-materials brain. But most importantly, he was always, always there when I needed him. His support and "I got your back" attitude have been incredibly appreciated. Thanks, Larry!

Dr. Tess Ahlborn was the first person I talked to about coming to Tech on the phone and since the moment I got here (and even before) she has made me feel welcome and comfortable. I know I can always get a straight and honest answer from Tess and will miss our talks. Tess taught me a great deal about life in academia and also was incredibly helpful and supportive as I tackled teaching my first class. Thanks, Tess!

Jerry Anzalone started at Tech at the same time I did and over the past five years has turned into a real friend and a wonderful colleague. Despite the fact that I have broken and epoxied together so many things in his labs that I've lost track, he is always quick with a smile, a hearty laugh and a minute to spare when I need it. Thanks, Jerry!

Khatereh Vaghefi always kept me up to date on the goings on in the department with her daily visits to catch up and commiserate on research mishaps. I will miss you! 
From day one, Beth Hoy has been incredibly helpful - helping me with funding issues, taking the time to step me through the tedious process of writing a budget proposal several times and offering friendly conversation. Thanks, Beth!

Kiko, Pam Hannon, Jodi Lehman, Rob Fritz, Tim Eisele, Matt King, Mike Yokie, Paul Frayley, Danielle Klimek, have all been a great help to me by explaining how to use equipment and preventing me from hurting myself. Thanks, guys!

Without the help of my fellow students Emily Lang, Eric Kreiger, Jake Clark and Chris Mullen, I would probably still be in the basement of Benedict filling cylinders or pulverizing cement paste. Thanks for all your hard work and for making mixing mortars such a fun time!

Dr. Karl Peterson and Ali Dehghan at the University of Toronto bent over backwards to get the isothermal calorimetry measurements taken in time for my defense, thanks! And to Karl, who had the great idea to make geopolymers out of ash from Mt. St. Helens five years ago - you're geopolyrific!

I'd also like to thank my other committee members, Dr. George Dewey, Dr. George Robinson and Dr. Aaron Sakulich for taking the time to help me through this process and making sure I'm on the right track.

To everyone mentioned above and those at MTU not mentioned, thank you so much for being the type of kind, honest, hard-working people that have made living and working here such a pleasure. I'm going to miss you all! 
The University Transportation Center, Graduate School, CEE department and KCP fellowship program all had a hand in keeping me financially afloat throughout most of this journey. Jerry Turner and Vitro Minerals graciously donated all of the glass for this research.

And, of course, last but certainly not least, I'd like to thank my wonderful family and friends for their love and support over the last five years, and many years before that as well. I would not have been able to get through this without you. I love you all.

To my parents, what else is there to say but thank you, for teaching me the value of education and learning, for always supporting me in whichever direction or school I was attending at any given time, for showing me how to work hard, be honest and fair and appreciate life. You are always there when I need you with love and support and that means more than anything to me.

To Faye, thanks, first of all for drawing the awesome illustrations in this dissertation, they turned out great! Also, thanks for being such a kind, supportive and fun sister - you're phone calls and visits have always been a highlight of my days.

To my grandparents, thank you for always reminding me that I am in the right place and that I will be in the right place when things seem uncertain. Thanks also for the card in the mail every month and holiday since September of 2001, I have enjoyed reading every single one. 
To Sharon, you've been my \#1 cheerleader since way back at Lake State and not much has changed since then. Your unending support has been invaluable and your hard work ethic a benchmark I strive to reach every day. Thank you! I can't wait to have time to go on vacation again!

To Kristen (Paddles), thank you for always being there to remind me to smell the flowers, listen to the waves of Lake Superior and check out the moon on a clear night. I have so enjoyed our time spent together in Houghton and picking rocks on the beach.

To Murphy, thanks for always telling me about all the reports you have to write so I don't feel so bad about my own workload. :- I often think of you when I am running low on energy and your endless energy and "this too shall pass" mentality is always the pick-up I need!

And, thanks for everyone who has ever listened to me talk about my research and acted interested, I appreciate it. 


\section{List of Abbreviations}

\begin{tabular}{|c|c|}
\hline ASR & alkali silica reaction \\
\hline ASTM & American Society of Testing Materials \\
\hline $\mathrm{C}_{2} \mathrm{~S}$ & dicalcium silicate \\
\hline $\mathrm{C}_{3} \mathrm{~S}$ & tricalcium silicate \\
\hline $\mathrm{C}_{3} \mathrm{~A}$ & tricalcium aluminate \\
\hline $\mathrm{C}_{4} \mathrm{AF}$ & tetracalcium aluminoferrite \\
\hline C-A-S-H & calcium-aluminum-silicon-hydrate \\
\hline $\mathrm{C}-\mathrm{S}-\mathrm{H}$ & calcium silicate hydrate \\
\hline $\mathrm{CSH}_{2}$ & calcium sulfate \\
\hline EDS & energy dispersive X-ray \\
\hline ESEM & environmental scanning electron microscope \\
\hline FA & fly ash \\
\hline FDA & Food and Drug Administration \\
\hline FM & fineness modulus \\
\hline GPC & geopolymer cement \\
\hline GPI & Glass Packaging Institute \\
\hline HA & high-aluminum \\
\hline ITZ & interfacial transition zone \\
\hline IUPAC & International Union of Pure and Applied Chemistry \\
\hline $\mathrm{kJ}$ & kilojoule \\
\hline $\mathrm{KOH}$ & potassium hydroxide \\
\hline LA & low-aluminum \\
\hline
\end{tabular}




\begin{tabular}{|c|c|}
\hline$\mu \mathrm{m}$ & micron \\
\hline $\mathrm{M}^{+}$ & monovalent cation \\
\hline $\mathrm{M}^{++}$ & divalent cation \\
\hline MAS-NMR & magic angle spinning nuclear magnetic resonance \\
\hline MK & metakaolin \\
\hline MRF & material recycling facility \\
\hline $\mathrm{NaOH}$ & sodium hydroxide \\
\hline $\mathrm{N}-\mathrm{A}-\mathrm{S}-\mathrm{H}$ & sodium-aluminum-silicon-hydrate \\
\hline $\mathrm{NBO}$ & non-bridging oxygen \\
\hline NMR & nuclear magnetic resonance \\
\hline OPC & ordinary portland cement \\
\hline $\mathrm{PCM}$ & partial charge model \\
\hline $\mathrm{pH}$ & $\mathrm{pH}$ \\
\hline $\mathrm{SCM}$ & supplementary cementitious material \\
\hline SEM & scanning electron microscope \\
\hline TEM & transmission electron microscope \\
\hline US EPA & United States Environmental Protection Agency \\
\hline XRD & $\mathrm{X}$-ray diffraction \\
\hline
\end{tabular}




\begin{abstract}
An increased consideration of sustainability throughout society has resulted in a surge of research investigating sustainable alternatives to existing construction materials. A new binder system, called a geopolymer, is being investigated to supplement ordinary portland cement (OPC) concrete, which has come under scrutiny because of the $\mathrm{CO}_{2}$ emissions inherent in its production.
\end{abstract}

Geopolymers are produced from the alkali activation of a powdered aluminosilicate source by an alkaline solution, which results in a dense three-dimensional matrix of tetrahedrally linked aluminosilicates. Geopolymers have shown great potential as a building construction material, offering similar mechanical and durability properties to OPC. Additionally, geopolymers have the added value of a considerably smaller carbon footprint than OPC.

This research considered the compressive strength, microstructure and composition of geopolymers made from two types of waste glass with varying aluminum contents. Waste glass shows great potential for mainstream use in geopolymers due to its chemical and physical homogeneity as well as its high content of amorphous silica, which could eliminate the need for sodium silicate. However, the lack of aluminum is thought to negatively affect the mechanical performance and alkali stability of the geopolymer system. 
Mortars were designed using various combinations of glass and metakaolin or fly ash to supplement the aluminum in the system. Mortar made from the high- $\mathrm{Al}$ glass $\left(12 \% \mathrm{Al}_{2} \mathrm{O}_{3}\right)$ reached over 10,000 psi at six months. Mortar made from the low-Al glass $\left(<1 \% \mathrm{Al}_{2} \mathrm{O}_{3}\right)$ did not perform as well and remained sticky even after several weeks of curing, most likely due to the lack of Al which is believed to cause hardening in geopolymers. A moderate metakaolin replacement (25-38\% by mass) was found to positively affect the compressive strength of mortars made with either type of glass.

Though the microstructure of the mortar was quite indicative of mechanical performance, composition was also found to be important. The initial stoichiometry of the bulk mixture was maintained fairly closely, especially in mixtures made with fine glass. This research has shown that glass has great potential for use in geopolymers, when care is given to consider the compositional and physical properties of the glass in mixture design. 


\section{Introduction}

\subsection{Motivation}

Concrete, in one form or another, has been around since ancient Egypt and throughout history has played an integral role in the advancement of civilization. Today, much of the nation's infrastructure is still made of concrete because no other building material can offer the same ease of handling and economic benefit along with the dependable mechanical and durability properties that can be achieved with the right mixture design and materials.

Since its development in the early $19^{\text {th }}$ century, ordinary portland cement (OPC) has been the dominant choice in the global concrete market based on its reputation for producing a reliable and functional building material. This success, however, comes at a cost. The world-wide production of OPC is reported to be responsible for $5-8 \%$ of global anthropogenic carbon emissions annually (Scrivener and Kirkpatrick 2008). Efforts to reduce the carbon footprint of this heavily relied upon building material have been somewhat successful. However, much of the $\mathrm{CO}_{2}$ emitted during OPC production is inherent in the process and cannot be avoided. This realization has led researchers toward developing alternative low- $\mathrm{CO}_{2}$ binders such as geopolymers.

Geopolymers are based on the alkali activation of a powdered aluminosilicate source material with an alkali hydroxide solution that often contains pre-dissolved silica. Concrete made with a geopolymer binder has been shown to perform equal to or better than OPC concrete in terms of mechanical and durability performance. Additionally, geopolymer 
concrete has the added value of a considerably smaller carbon footprint, with reported $\mathrm{CO}_{2}$ emission reductions of up to $80 \%$ as compared to OPC (Davidovits 1994; Duxson et al. 2007).

Thus far, the majority of research concerning geopolymers has been based on using fly ash or metakaolin as the main sources of silica $\left(\mathrm{SiO}_{2}\right)$ and alumina $\left(\mathrm{Al}_{2} \mathrm{O}_{3}\right)$. Upon initial investigation of geopolymers in this research, it was noted that most geopolymers require the use of sodium silicate in order to achieve quality performance. It was further noted that one of the steps in the process of sodium silicate production is to first form a solid glass that is then "melted" to form sodium silicate, or waterglass. This research initially examined the "activation" of waste glass by reacting it with $\mathrm{NaOH}$ in mild hydrothermal stirred conditions in the attempt to create low- $\mathrm{CO}_{2}$ sodium silicate for use in activating other geopolymers made of fly ash or metakaolin.

However, it soon became apparent that a more efficient way to use the glass was as the source material rather than as a part of the activator. This led to the investigation of glass as a source material for geopolymers and to the realization that most waste glass contains insufficient reactive Al for the formation of a non-water soluble geopolymer. This research has investigated a geopolymer system based primarily on the alkali activation of waste glass and the effects of increasing the naturally insufficient Al content through the addition of metakaolin or fly ash.

It has been mentioned on many occasions that one of the biggest hurdles geopolymers face is the question of availability of aluminosilicate materials and the variability within the 
materials that are available. Research performed thus far has been focused on optimizing mixture conditions for a specific source material and as such has resulted in very specific data that in many ways is not applicable to other materials. However, any step forward is important in the advancement of this technology and this research will hopefully lead to Si-rich materials such as waste glass being used as geopolymer source materials.

A geopolymer binder system based on waste glass has the potential to:

- Further reduce the carbon footprint of geopolymer cement by eliminating the need for pre-dissolved silica in the form of sodium silicate in the activator solution

- Expand the compositional allowances of source materials for geopolymers to include high silica waste materials

- Develop a dependable market for unsorted waste glass, which is currently an issue in many countries, including the United States

\subsection{Project goals}

Broadly speaking, the goal of this research was to investigate the products formed through the alkali activation of glass-based geopolymers activated by $\mathrm{NaOH}$. More specifically, this research sought to answer the following questions:

1. What are the phases formed by the alkali activation of waste glass and how is the microstructure and composition of these phases affected by the addition of metakaolin as a source of alumina?

2. Is there a clear correlation between microstructure, composition and compressive strength of glass-based geopolymers?

3. How does the bulk stoichiometry of the initial mixture compare to the actual stoichiometry of the geopolymer formed? What role does the degree of reaction play in this relationship? 
4. Does the addition of metakaolin or fly ash adequately lower the stoichiometry of the mixture to more acceptable ranges found in other geopolymers made of fly ash or metakaolin and does this enhance the mechanical performance?

It should be noted, the purpose of this research is not to develop the best or strongest possible glass-based geopolymer, but rather to identify the characteristics of baseline glass geopolymers and to document and observe the changes that occur when an alumina source is introduced.

The aforementioned goals were achieved through a series of tasks, beginning with a thorough review of the available literature, which covers all manner of geopolymers as well as silica chemistry and zeolite formation. Using information gathered from the literature review, representative materials were chosen; mixture designs were developed and microstructural characterization applied. Three phases of experimental work were then carried out, described briefly below:

- Phase I - Preliminary mixtures made of $100 \%$ high-Al glass were designed to investigate the effects of $\mathrm{NaOH}$ concentration, glass fineness and curing temperature.

- Phase II - Mixtures made of high-Al glass and varying replacement rates of metakaolin and fly ash were designed to investigate the effects of adding in a supplementary Al source.

- Phase III - Stoichiometric design-based mixtures using both high-Al glass and low-Al glass with metakaolin as a supplementary Al source were designed to apply the concepts learned in Phases I and II to a low-Al glass.

Material characterization investigation was performed at various ages of the mixtures that included scanning electron microscope (SEM) and energy dispersive spectroscopy (EDS) 
analysis of polished sections, $\mathrm{x}$-ray diffraction (XRD) measurements and degree of reaction calculations. Compressive strength was also measured to determine a strength gain profile for the mortars that could be related to the microstructural information gathered. Isothermal and adiabatic calorimetry was also performed on select mixtures.

\subsection{Organization}

This dissertation is presented beginning with a literature review in Chapter 2 covering the relevant literature and general knowledge needed to understand this unique binder system. The final section in Chapter 2 includes a summary of relevant information from the literature review and how it was used to formulate the experimental plan. Chapter 3 covers the material selection process and various equipment and procedures used in the research as well as the mixture design and experimental approach for each of the phases listed previously. Chapter 4 covers the results and discussion of each of the three phases. Chapter 5 summarizes the research project and offers conclusions and recommendations for future work. A brief introduction is included in each section to aid the reader in the direction of the work.

Figures 2.2, 2.4, 2.7, 2.9, 2.10, 2.11 and 2.14 were drawn by artist Faye L. Christiansen, please see Appendix D for documentation of permission to print this material. 



\section{Literature Review}

The literature review is broken up into nine main sections with an introduction and explanation of relevancy to the project at the beginning of each major section. Briefly, the sections are:

2.1 Ordinary portland cement

2.2 Geopolymer cement

2.3 Geopolymerization

2.4 Source materials

2.5 Activator solution
This section covers the necessary raw materials, production, hydration and environmental concerns regarding ordinary portland cement.

This section presents an introduction to geopolymers including the history, recent developments and environmental impacts. A brief summary of the reported physical and durability properties of geopolymer binders is also presented.

This section discusses geopolymerization and includes a description of each step in the process based on current models.

This section presents a discussion of the idyllic qualities of a successful source material as well as a review of metakaolin, fly ash and glass and how they perform in a geopolymer system.

This section provides a discussion of sodium hydroxide and sodium silicate as well as the effects changing the composition and form of the activator has on the kinetics of geopolymerization and the final product. 
2.6 Mixture design stoichiometry

2.7 Synthesis parameters

2.8 Characterization of binder

This section explains basic mixture design principles and the currently accepted stoichiometric ranges as well as limits that exist based on the materials that are used.

This section includes information on synthesis parameters such as water content and curing conditions.

This section covers the general microstructure and composition of fly ash and metakaolin geopolymers and discusses the relationship that has been reported to exist between microstructure and physical properties.

2.9 Significance of literature review This section includes a summary of the literature review and a review of the experimental plan.

\subsection{Ordinary portland cement (OPC) concrete}

Despite this research focusing on geopolymer cements, the literature review begins with a summary of basic facts and information on the current environmental situation of ordinary portland cement. Beginning on this note will not only clearly establish the motivation for pursuing research into the development of the geopolymer binder but will also help to highlight the fact these binders are based on two very different chemical systems.

Note: Cement chemistry has its own nomenclature where single letter abbreviations are used to represent various common oxides. Alternately, elemental abbreviations are typically used in geopolymer science to represent the same common oxides, as is the case in this dissertation. The most commonly used oxides are shown in Table 2.1. Additionally, 
within this document, in reference to geopolymers, the oxide abbreviations will always signify molar concentrations or ratios unless otherwise specified.

Table 2.1. Common oxides shown in cement chemist notation as well as geopolymer science.

\begin{tabular}{|c|l|c|c|}
\hline Oxide & Common Names & $\begin{array}{c}\text { Cement Chemist } \\
\text { Notation }\end{array}$ & $\begin{array}{c}\text { Geopolymer } \\
\text { Science }\end{array}$ \\
\hline $\mathrm{CaO}$ & lime, calcium oxide, calcia & $\mathrm{C}$ & $\mathrm{Ca}$ \\
\hline $\mathrm{SiO}_{2}$ & silica, silicon oxide & $\mathrm{S}$ & $\mathrm{Si}$ \\
\hline $\mathrm{Al}_{2} \mathrm{O}_{3}$ & alumina, aluminum oxide & $\mathrm{A}$ & $\mathrm{Al}$ \\
\hline $\mathrm{Fe}_{2} \mathrm{O}_{3}$ & ferric oxide, iron oxide & $\mathrm{F}$ & $\mathrm{Fe}$ \\
\hline $\mathrm{MgO}$ & magnesia, periclase & $\mathrm{M}$ & $\mathrm{Mg}$ \\
\hline $\mathrm{K}_{2} \mathrm{O}$ & potassium oxide & $\mathrm{K}$ & $\mathrm{K}$ \\
\hline $\mathrm{Na}_{2} \mathrm{O}$ & sodium oxide & $\mathrm{N}$ & $\mathrm{Na}$ \\
\hline $\mathrm{SO}_{3}$ & sulfur trioxide & $\overline{\mathrm{S}}$ & \\
\hline $\mathrm{CO}_{2}$ & carbon dioxide & $\overline{\mathrm{C}}$ & \\
\hline $\mathrm{H}_{2} \mathrm{O}$ & water & $\mathrm{H}$ & $\mathrm{H}_{2} \mathrm{O}$ \\
\hline
\end{tabular}

\subsubsection{Production of ordinary portland cement}

"Portland cement constitutes one of the most important technological advances in the history of humanity" (Shi et al. 2011).

Concrete, in one form or another, has been around for many, many centuries, with reports dating back to as far as the Egyptian civilization where gypsum mortars were used to construct the Pyramid of Cheops. In 1824, Joseph Aspdin invented an early version of the portland cement used today and since that time concrete made from ordinary portland cement (OPC) has dominated the construction industry, with an estimated $95 \%$ of all concrete used being made with OPC (Mindess et al. 2002). 
Typical OPC concrete consists of portland cement, water, fine aggregate, coarse aggregate, and may contain chemical admixtures, supplementary cementitious materials (SCMs), and reinforcement in various combinations. Portland cement comes in the form of an anhydrous gray powder that gains strength upon mixing with water. A basic understanding of the raw materials, production process and hydration of portland cement is important as it relates directly to the fresh and hardened properties of the concrete. It will also be useful later on in this dissertation when comparing binder systems.

There are five crucial elements necessary to produce the portland cement used today; calcium, silicon, aluminum, iron and calcium sulfate. Calcium and silicon are most commonly provided in limestone, shale or clay, though other sources are also used depending on availability. A blended powder made of raw materials containing these elements and others is transformed into portland cement through a series of processes outlined briefly below.

1. Raw material processing - raw materials are ground and blended according to their oxide composition; great care is taken to ensure a consistent final product. Two methods for feeding this raw meal into the kiln exist:

a. Wet process - the raw meal is blended with water to form a suspension that is fed into the cement kiln in the form of a slurry

b. Dry process - the raw meal is blended dry and fed into the kiln as a powder

2. Preheating/precalcining - the raw meal is preheated before it enters the kiln in a preheater or flash furnace; this equipment is most common in newer cement plants running on a dry process. 
3. Heating in the kiln - cement kilns are typically in the form of a long, slowly rotating cylindrical tube made of steel plates, lined on the inside with refractory brick and set at a slight incline from the horizon. At the lower end of the kiln, a mixture of air and fuel are burned in a $2000^{\circ} \mathrm{C}$ flame set above the raw meal, which forms an increasing temperature gradient from the top of the kiln to the bottom. As the raw meal passes slowly through the kiln, increasing steadily in temperature, various chemical reactions occur at specific temperatures. A brief summary of the kiln reactions follows:

a. $500-600^{\circ} \mathrm{C}$ - free water is driven off leading to clay decomposition

b. $700^{\circ} \mathrm{C}$ - carbon dioxide, $\mathrm{CO}_{2}$, and free lime, $\mathrm{CaO}$, are released through the calcination of calcium carbonate, $\mathrm{CaCO}_{3}$, in the limestone

c. $800^{\circ} \mathrm{C}$ - free lime reacts with silica from the decomposed clay to form impure dicalcium silicate, or belite $\left(\mathrm{C}_{2} \mathrm{~S}\right)$, aluminate $\left(\mathrm{C}_{3} \mathrm{~A}\right)$ and ferrite $\left(\mathrm{C}_{4} \mathrm{AF}\right)$ phases

d. $1300-1450^{\circ} \mathrm{C}-\mathrm{a}$ partial liquid melt is formed from the aluminate and ferrite phases, which acts as a flux for the formation of impure tricalcium silicate, or alite $\left(\mathrm{C}_{3} \mathrm{~S}\right)$, through the reaction of free lime and belite at $1450^{\circ} \mathrm{C}$

4. Clinker cooler - nodules called clinker are formed in the kiln and cooled quickly by cool air in the clinker cooler in order to maximize the reactivity of the cement phases by hindering crystal growth

5. Final grinding - the cooled clinker are interground with calcium sulfate $\left(\mathrm{CS} \mathrm{H}_{2}\right)$, usually in the form of gypsum. The calcium sulfate is crucial to regulate set times during cement hydration. The resulting powder is known as portland cement.

Through careful temperature control and stringent composition and fineness requirements, five main types of portland cement are produced and are specified through ASTM C150 including various specialty blends that allow for air entrainment, increased sulfate resistance and lower heat of hydration (ASTM International 2009). 


\subsubsection{Hydration}

"An adequate understanding of the chemistry of hydration is necessary for a full appreciation of the properties of cements and concretes ..." (Mindess et al. 2002).

Hydration consists of a series of chemical reactions that occur between the five main phases of portland cement, shown in Table 2.2, and water. Each of the cement phases forms unique hydration products that in some cases go on to participate in further reactions with other phases or products. Hydration is a complicated, multi-step process, with many of the steps occurring concomitantly.

Table 2.2. The five main phases and composition of a typical Type I portland cement (Mindess et al. 2002).

\begin{tabular}{|c|c|c|c|c|}
\hline $\begin{array}{c}\text { Chemical } \\
\text { Formula }\end{array}$ & Chemical Name & $\begin{array}{c}\text { Common } \\
\text { Name }\end{array}$ & $\begin{array}{c}\text { Cement } \\
\text { Chemist } \\
\text { Notation }\end{array}$ & Wt \% \\
\hline $3 \mathrm{CaO} \cdot \mathrm{SiO}_{2}$ & tricalcium silicate & alite & $\mathrm{C}_{3} \mathrm{~S}$ & 55 \\
\hline $2 \mathrm{CaO} \cdot \mathrm{SiO}_{2}$ & dicalcium silicate & belite & $\mathrm{C}_{2} \mathrm{~S}$ & 18 \\
\hline $3 \mathrm{CaO} \cdot \mathrm{Al}_{2} \mathrm{O}_{3}$ & $\begin{array}{c}\text { tricalcium } \\
\text { aluminate }\end{array}$ & aluminate & $\mathrm{C}_{3} \mathrm{~A}$ & 10 \\
\hline $4 \mathrm{CaO} \cdot \mathrm{Al}_{2} \mathrm{O}_{3} \cdot \mathrm{Fe}_{2} \mathrm{O}_{3}$ & $\begin{array}{c}\text { tetracalcium } \\
\text { aluminoferrite }\end{array}$ & ferrite & $\mathrm{C}_{4} \mathrm{AF}$ & 8 \\
\hline $\mathrm{CaSO}$ & calcium sulfate \\
dihydrate & gypsum & $\mathrm{CS} \mathrm{H}_{2}$ & 6 \\
\hline
\end{tabular}

All of the phases in portland cement play a role in hydration and are important in their own way but none so much as the calcium silicates, which make up the bulk of portland cement. The hydration of alite (and later belite) results in the formation of calcium silicate hydrate, or C-S-H gel, and calcium hydroxide, $\mathrm{CH}$; C-S-H is responsible for the majority of strength in concrete. In general C-S-H is said to have a "degenerate clay structure," (Mindess et al. 
2002) and is mostly amorphous with a $\mathrm{C} / \mathrm{S}$ ratio typically ranging between $1.5-2.0$ and water content depending heavily on the extent of drying the paste has undergone. Hydration products are also formed from the other phases, which results in a complex multi-phase microstructure (Mindess et al. 2002).

Hydration will continue until the reaction products take up all the space once occupied by the mixture water or until there are no unreacted cement particles available. The environment of the concrete during hydration is very important. Curing is the act of making available the water needed for hydration and keeping the concrete externally and internally at a temperature and relative humidity that allows hydration to continue for as long as possible. The presence of water during curing is particularly important to the structural resilience of $\mathrm{C}-\mathrm{S}-\mathrm{H}$, and the extent to which hydration occurs has a direct effect on the strength and durability of the concrete.

Some of the water that is consumed during hydration is chemically bound in the hydration products, while the rest remains among the hydration products forming a pore network upon evaporation. Pores exist in a variety of sizes based on factors such as the initial w/c (water-to-cement ratio) and curing conditions. Excess water (high w/c) leads to increased porosity which can lead to lower mechanical strength and decreased durability, where durability is defined as the concretes resistance to chemical and physical attack within its intended service environment. 


\subsubsection{Environmental concerns}

"The success of this material throughout the Twentieth Century can be attributed to its mechanical properties, cost-effectiveness, and overall performance (Fernández-Jiménez et al. 2006). ”

In an article entitled, "The Greening of The Concrete Industry," Dr. Christian Meyer of Columbia University states that concrete is naturally an environmentally friendly building material and it is namely portland cement that gives concrete a bad name (Meyer 2009). Despite the worldwide success of OPC concrete, environmental concerns regarding carbon emissions related to OPC production have attracted negative attention, forcing the $\$ 150$ billion concrete industry (Scrivener and Kirkpatrick 2008) to try and add a touch of green to an otherwise gray material.

Many attempts to improve the sustainability of concrete have been attempted. Unfortunately for the cement industry, however, most of the $\mathrm{CO}_{2}$ emissions from cement production are an inherent part of the current manufacturing process. The calcination of calcite, usually in the form of limestone emits a tremendous amount of $\mathrm{CO}_{2}$ as seen in Equation 1.

$$
\mathrm{CaCO}_{3} \text { (limestone) }+ \text { heat } \rightarrow \mathrm{CaO} \text { (lime) }+\mathrm{CO}_{2}
$$

In addition, combustion-related emissions resulting from maintaining a kiln temperature of nearly $2000^{\circ} \mathrm{C}$ are also unavoidable unless industry decides alite, which is formed at $1450^{\circ} \mathrm{C}$ is not necessary, at which point a lower temperature could be used. This would 
severely decrease the early strength gain and is unlikely to be easily accepted within the fast paced construction industry of today. Kiln feed preparation and finish grinding also require energy and fuel, which contribute to total $\mathrm{CO}_{2}$ emissions.

Total carbon emissions from creating one ton of portland cement is estimated to be approximately 0.87 tons of $\mathrm{CO}_{2}$; where about $60 \%$ is process-related (limestone calcination) and $40 \%$ is combustion-related (Damtoft et al. 2008). $\mathrm{CO}_{2}$ is not the only greenhouse gas that is emitted by cement production; methane, nitrous oxide, sulfur hexafluoride, hydrofluorocarbons (HFCs) and perfluorocarbons (PFCs) are as well.

Compared to other common building materials such as steel or wood, ordinary portland cement has a relatively low carbon footprint per ton produced (Hammond and Jones 2008). Table 2.3 shows the embodied energy and embodied carbon for the most common construction materials. However, the true atmospheric impact of OPC production is not realized until global production numbers are considered as well. 
Table 2.3. Embodied energy and carbon for selected construction materials (Hammond and Jones 2008)

\begin{tabular}{|c|c|c|}
\hline Material & $\begin{array}{c}\text { Embodied energy } \\
\text { (MJ/kg) }\end{array}$ & $\begin{array}{c}\text { Embodied carbon } \\
\mathbf{( k g C / k g )}\end{array}$ \\
\hline Portland cement (dry kiln) & 3.3 & 0.196 \\
\hline Portland cement (wet kiln) & 5.9 & 0.248 \\
\hline Concrete (general, 1:2:4) & 0.95 & 0.035 \\
\hline Precast concrete (general) & 2 & 0.059 \\
\hline Glass (general) & 15 & 0.232 \\
\hline $\begin{array}{c}\text { Steel (general, 42.3\% } \\
\text { recycled content) }\end{array}$ & 24.4 & 0.125 \\
\hline Timber (general) & 8.5 & 0.482 \\
\hline
\end{tabular}

In 2011, 3.4 billion tons of portland cement were produced globally (van Oss 2012); this is said to account for $5-8 \%$ of total worldwide anthropogenic carbon emissions (Gartner 2004; Scrivener and Kirkpatrick 2008; Sakulich 2011). Figure 2.1 shows the increase in global cement production since 1930. In 2011, the United States was the world's third largest cement producer behind China and India (van Oss 2012). 


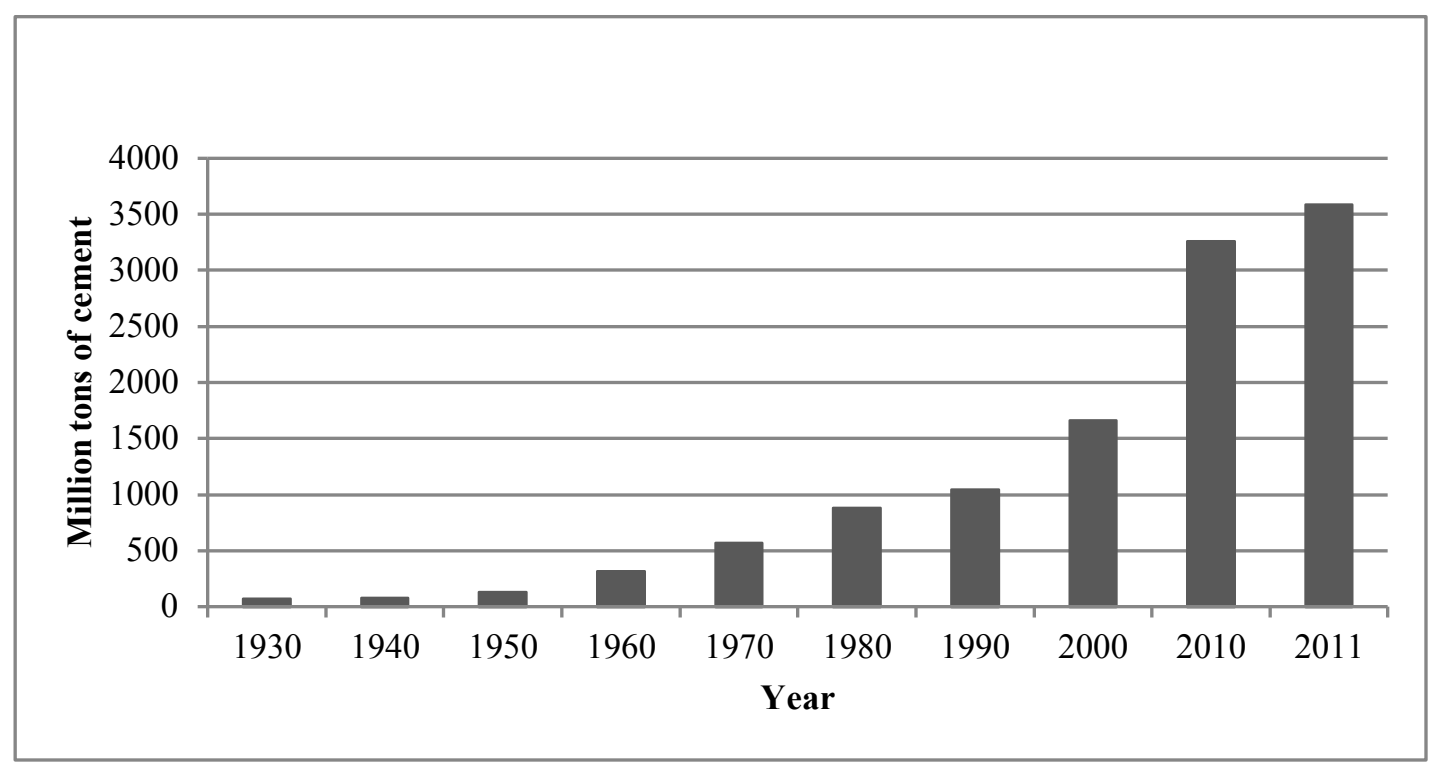

Figure 2.1. Global cement production from 1930 to 2011 (van Oss 2012).

For the last 40 years the cement industry has strived to improve the sustainability of its product through cement plant improvements, the widespread use of SCMs and blended cements to reduce the usage of OPC and even the development of alternative low- $\mathrm{CO}_{2}$ cement systems.

\subsubsection{Cement plant improvements}

Following the 1970's OPEC oil embargo, a great deal of research focused on improving the efficiency of kilns and raw material and cement processing equipment, including the advent of preheaters and pre-calciners, and improved efficiency of closed-circuit finish mills and clinker coolers (Gartner 2004). Wet process plants transitioned to the dry process and installed preheater cyclones and/or pre-calciner vessels, which use recovered heat from the kiln and lower energy fuels to preheat the raw meal before it enters the kiln. These plant additions have led to increased energy efficiencies and less time commitments per ton of portland cement produced (Hanle 2001; Kosmatka and Wilson 2011). Additionally, 
many plants now use liquid and solid waste fuels, waste tires, biomass and other waste streams as fuel to heat the kilns.

\subsubsection{SCMs and blended cements}

Supplementary cementitious materials (SCMs) are often added to concrete as a partial portland cement replacement to enhance specific properties such as permeability, or to mitigate an ASR reaction, or for economic reasons. While SCM usage in the United States has become fairly commonplace and is quite readily accepted within the concrete industry, there still exist limits on the replacement rates of these materials in prescriptive specifications and standards.

SCMs that contain a great deal of amorphous (non-crystalline) silica or aluminosilicate content are called pozzolans. In a finely divided form and at high $\mathrm{pH}$, these materials are very reactive; silica dissolves into solution and combines with $\mathrm{CH}$ from the hydration of the calcium silicates to form a secondary C-S-H phase, or C-A-H phase if aluminum is present. A mixed phase called calcium aluminosilicate hydrate, C-A-S-H, is also sometimes formed. SCMs that contain calcium in addition to silica and alumina are said to be latently hydraulic as well as pozzolanic.

Since many SCMs are byproducts from other industrial processes, such as fly ash from coal burning power plants or slag from the iron industry, replacing OPC with these materials effectively cuts down on the carbon footprint of that mixture. SCM usage depends a great deal on the availability and proximity of the material to the ready-mixed plant or jobsite, as transportation costs can be very high and reduce the environmental or 
economic advantage of using an SCM in the first place. Some of the more common SCMs are:

- Class C or F fly ash (FA)

- Granulated blast furnace slag (GBFS) or slag cement

- metakaolin (MK) or other calcined clays

- silica fume (SF)

- rice husk ash (RHA)

- diatomaceous earth

- limestone dust

\subsubsection{Alternative cement systems}

Improvements in cement plant efficiency, the widespread use of supplementary cementitious materials ( $\mathrm{SCMs}$ ) to partially replace $\mathrm{OPC}$ in concrete mixtures and the introduction of waste materials such as tires or biomass for use as fuel in cement kilns are a few examples of the steps the cement industry has taken to enhance the sustainability of concrete (Damtoft et al. 2008). Despite these and other improvements, the truth of the matter is, as long as the binder system is based on the calcination of $\mathrm{CaCO}_{3}$, there is an inherent amount of $\mathrm{CO}_{2}$ that will be produced during production.

Many types of alternative cements have been considered, including pozzolan-based cements, calcium sulfoaluminate-based cements or magnesium-based cements, but none

of these have emerged as a realistic replacement for OPC (Gartner 2004). Of all of the 
possible alternative binders, the one that has shown the most potential due to its low carbon footprint and comparable performance to OPC is geopolymer cement.

For a replacement cement system to be successful, it must be able to meet the current standards set forth by OPC. In general, these can be summed up in four main points:

1. Fresh properties (workability, air content, placeability, reliable set times, etc.)

2. Hardened properties (strength, durability, volume stability, etc.)

3. Environmental concerns $\left(\mathrm{CO}_{2}\right.$ and other greenhouse gas emissions, natural resource use, end of life issues, etc.)

4. Economy (OPC is an affordable material)

\subsection{Geopolymer cement (GPC) concrete}

"Environmentally friendly, low-cost alkaline cements with similar or even better bonding properties are a promising alternative to portland cement" (FernándezJiménez et al. 2006).

A geopolymer is a binder formed from the alkali activation of an aluminosilicate source that behaves similar to or better than OPC in terms of mechanical performance and durability and possesses a markedly lower carbon footprint than OPC. Chemically, geopolymers are based on an entirely different system than OPC. While OPC is a hydraulic cement based primarily on the hydration of calcium silicates, GPC is based on the polycondensation of aluminosilicates by alkali activation and often contains very little calcium at all. There are many different types of geopolymers that can be made from a variety of sources, each with their own set of unique properties. As was discussed with regard to OPC, the materials used, conditions of synthesis and subsequent curing can all 
have an effect on the resulting reaction products, which in turn affect the fresh and hardened properties of the concrete. These and other considerations will be discussed in later sections of the literature review. This section contains information on the classification, history and developments of GPC as well as a general overview of mechanical and durability performance.

\subsubsection{Classification}

Geopolymer cements fall under a class of binders commonly known as alkali-activated cements. Alkali-activated cements can be further classified into the following five groups based on the material being activated and the resulting reaction phases formed (Shi et al. 2011; Shi et al. 2012):

1. Alkali-activated slag-based cements

2. Alkali-activated pozzolan cements

3. Alkali-activated lime-pozzolan/slag cements

4. Alkali-activated calcium aluminate blended cements

5. Alkali-activated portland blended cements (hybrid cements)

Broadly, these alkali-activated cements can be divided into two main categories with regard to composition (Palomo et al. 1999). The first is the activation of materials rich in silica and calcium (such as OPC, slag or class C fly ash) with mild alkaline solutions, which yields a calcium silicate hydrate (C-S-H) gel product (this would include \#1,3,4,5 from the list above). The second is the activation of materials rich in silica and alumina (such as metakaolin or Class F fly ash) with strong alkaline solutions, which yields a solid three- 
dimensional aluminosilicate matrix (this would include \#2 from the list above). Only the latter category is considered in this research; this category is referred to as geopolymers.

It should be noted that while "geopolymer" is a commonly used name for an alkaliactivated cement, other names include: inorganic polymers, alkali activated cements, low temperature aluminosilicate glass, geocements, zeocements, alkali-bonded ceramics, mineral polymers, hydroceramics, etc.

Within the literature there is a fair amount of discussion on exactly what constitutes a geopolymer, with many believing that materials rich in calcium should not be called geopolymers (Fletcher et al. 2005). For example, since slag contains so much calcium, the resulting binder is a calcium silicate system, more similar to OPC than to any other system and therefore not a geopolymer under that definition (Provis 2009). Ukranian researcher, Krivenko, came up with a classification of various cements based on the composition of the initial materials and hydration products using his own terminology, shown in Table 2.4 (Krivenko 2007).

Table 2.4. Classification of various cements based on composition of hydration products (Krivenko 2007).

\begin{tabular}{|c|c|c|c|c|c|}
\hline $\begin{array}{c}\text { Cement } \\
\text { type }\end{array}$ & OPC & $\begin{array}{c}\text { OPC } \\
\text { alkaline } \\
\text { cement }\end{array}$ & $\begin{array}{l}\text { Slag alkaline } \\
\text { cement }\end{array}$ & $\begin{array}{c}\text { Fly ash alkaline } \\
\text { cement }\end{array}$ & $\begin{array}{c}\text { Geo- } \\
\text { cement }\end{array}$ \\
\hline $\begin{array}{l}\text { Initial } \\
\text { solid } \\
\text { phase }\end{array}$ & $\begin{array}{l}\text { OPC } \\
\text { clinker }\end{array}$ & $\begin{array}{l}\text { OPC clinker } \\
\quad+\mathrm{R}_{2} \mathrm{O}\end{array}$ & $\begin{array}{l}\text { Metallurgical } \\
\text { slags }+\mathrm{R}_{2} \mathrm{O}\end{array}$ & $\begin{array}{c}\text { Fly ash of best } \\
\text { power stations } \\
\text { (product of coal } \\
\text { combustion) }+\mathrm{R}_{2} \mathrm{O}\end{array}$ & $\begin{array}{c}\text { Clay }+ \\
\mathrm{R}_{2} \mathrm{O}\end{array}$ \\
\hline $\begin{array}{l}\text { Hydratio } \\
\text { n } \\
\text { product }\end{array}$ & \multicolumn{4}{|c|}{$\begin{array}{l}0 \% \\
100 \%\end{array}$} & $\begin{array}{r}100 \% \\
0 \%\end{array}$ \\
\hline
\end{tabular}


Within this dissertation, the term geopolymer shall refer to a binder that is based on a silicon aluminum tetrahedral framework where the calcium content is decidedly less than silica and alumina combined, and activation is carried out with highly alkaline solutions.

\subsubsection{History and development}

The exact origin of alkali-activated cement technology is widely disputed, with some believing it was first used in ancient Egypt in the construction of the outer casings of the Great Pyramids (Davidovits 1987; Barsoum et al. 2006). Geopolymer technology seemed to disappear after that, reemerging in the 1930s when German scientist, Kuhl, experimented with ground slag powder and caustic potash and soda solutions to determine the reactivity of slag for use in portland cement concrete. In 1940, a Belgian scientist named Purdon began experimenting with the cementitious properties of high-calcium metallurgical slags activated by alkali solutions made up of $\mathrm{NaOH}$ (Shi 2006).

Research on these alkali activated slags, sometimes called Trief cements, continued for the next several decades until 1957, when Ukranian scientist and engineer, Victor Glukhovsky observed the similar hydraulic binding properties between alkali metals ( $\mathrm{Li}, \mathrm{Na}, \mathrm{K}, \mathrm{Rb}, \mathrm{Cs}$, Fr) and alkali earth metals $(\mathrm{Ca}, \mathrm{Mg})$ and the presence of sodium, potassium and calcium aluminosilicates alongside calcium compounds in nature. Subsequent experimentation led to the realization the hydration products formed from combining alkali hydroxides and salts with aluminosilicate glasses and clays are similar to those of natural zeolites and micas (Krivenko 2007). Base on these observations, Glukhovsky began research on alkali activated slag concrete that he called soil silicates or soil cements (Davidovits 2008; Shi et 
al. 2011). He classified these binders into two groups, one containing "alkaline binding systems" and the other containing "alkali-alkaline-earth binding systems (Shi et al. 2011)." As stated previously, this classification is still considered today, with calcium being the deciding factor between the two groups. Glukhovsky later went on to develop a rough model for the alkali activation of aluminosilicates, which is the basis for today's models of geopolymerization (Duxson et al. 2007; Shi et al. 2011):

1. destruction-coagulation

2. coagulation-condensation

3. condensation-crystallization

During the 1970s, alkali-activated slag cements were used for many applications, such as agricultural, industrial, residential, transportation, mining, oil-well and sealing applications (Roy 1999). Around this same time, Dr. Joseph Davidovits, driven by the desire to find a building material with a high heat and fire resistance after a series of devastating fires in France, began experimentally reacting kaolinite powders with alkaline solutions (100$150^{\circ} \mathrm{C}$ ) to form hydroxysodalite (Davidovits 2002; Davidovits 2008).

This research resulted in the development of a wide range of materials including fireresistant wood panels, low energy ceramic tiles, refractory items, high-tech resin systems and a binder for concrete (Davidovits 2002). He named the resulting concrete binders "geopolymers" based on the idea that these new materials were "polymers resulting from geochemistry" (Davidovits 2002). 
In the mid-1980s, Lone Star Industries, Inc. in Houston, Texas developed a portland/geopolymer blended cement called Pyrament ${ }^{\circledR}$ Blended Cement made out of very fine portland cement, blast furnace slag and metakaolin activated with potassium carbonate and retarded with citric acid. This cement made history by reaching 6000 psi and withstanding the landing of a jet after just four hours of curing (Davidovits 1994; Davidovits 2008).

In 1988, Davidovits organized the first-ever international conference on geopolymers, which attracted many scientists and sparked interest among researchers in a variety of disciplines including civil engineering, materials science, ceramics and chemical engineering. In 1994, Belgian scientist, Wastiels published an article citing the first documented use of fly ash in geopolymers, calling the resulting binder "fly ash based mineral polymers" (Wastiels et al. 1994). This development spurred another wave of research into using fly ash in geopolymer technology and was followed a few years later by the beginning of a series of four important articles concerning the alkaline activation of metakaolinite powder (Rahier et al. 1996; Rahier et al. 1996; Rahier et al. 1997; Rahier et al. 2003). To date, most of the geopolymer research performed has focused primarily on fly ash- or metakaolin-based systems.

Over the past several decades, research on geopolymer cements and concretes has continued to steadily gain interest and popularity in academic and commercial circles, with many well-established research groups focusing primarily on this new technology. Some of the more prominent international groups are listed below: 
- Geopolymer Institute - Saint-Quentin, France (J. Davidovits)

- Kiev National University of Civil Engineering and Architecture - Kiev, Ukraine (V. Glukhovsky, P. Krivenko, et al.)

- Eduardo Torroja Institute (CSIC) - Madrid, Spain (A. Fernandez-Jimenez, A. Palomo, et al.)

- University of Melbourne - Melbourne, Australia (J. van Deventer, J. Provis, P. Duxson, et al.)

Additionally, three textbooks focused on geopolymer technology have also been published within the past seven years, attesting to the ever-increasing popularity of this sustainable, new binder system. The texts are:

- $\quad$ Alkali-Activated Cements and Concretes (Shi et al. 2006)

- Geopolymers (Davidovits 2008)

- Geopolymers - Structure, processing, properties and industrial application (Provis and vanDeventer 2009)

There also currently exist several commercial companies creating geopolymer technology: CeraTech in the United States and Zeobond in Australia are two examples. Other applications of geopolymers currently being explored include the physical stabilization of mineralogical wastes such as contaminated top soil, fly ash, landfill leachate and mine tailings containing heavy metals (Van Jaarsveld et al. 1997; Duxson et al. 2007).

\subsubsection{Environmental impacts}

\subsubsection{Carbon footprint}

One of the leading reasons why geopolymer concretes have gained such rapid popularity over the past few decades is due to the low carbon footprint associated with its production. 
The elimination of the need for calcium carbonate carbonation as well as reduced kiln combustion requirements allow for estimated $\mathrm{CO}_{2}$ emission reductions of nearly $80 \%$ per ton of GPC produced as compared to OPC (Davidovits 1994; Duxson et al. 2007; Nowak 2008; Van Deventer et al. 2010).

Since fly ash is an industrial byproduct, it has reduced carbon emissions associated with it; $\mathrm{CO}_{2}$ emissions calculated for metakaolin based geopolymers are based on the $\mathrm{CO}_{2}$ emitted from the heat treatment necessary to make metakaolin from pure kaolin clay and the emissions associated with the production of the activator solution. It has been estimated that $\mathrm{CO}_{2}$ emissions for the production of both $\mathrm{NaOH}$ and sodium silicate solution are of a 1:1 ratio, as in one ton of product results in one ton of $\mathrm{CO}_{2}$ released. However, it has also been suggested that since $\mathrm{NaOH}$ is produced alongside with $\mathrm{HCl}$ in the chlor-alkali process, perhaps this total should be decreased for $\mathrm{NaOH}$ (Duxson et al. 2007).

\subsubsection{Utilization of waste materials}

Natural resources such as limestone, clay and shale, among other materials, are necessary for the production of portland cement. While these materials are very common, issues associated with mining operations, pollution and land disturbance must be considered. Geopolymer cements possess the potential to utilize materials such as high LOI (loss on ignition) or high alkali fly ashes, which typically are landfilled because they cannot be used in OPC concrete.

Increasing the sustainability of the alkaline activating solution in geopolymers would further lower the carbon footprint of the already low- $\mathrm{CO}_{2}$ binder. There has been some 
research looking into the development of low- $\mathrm{CO}_{2}$ activator solutions, using waste materials such as effluent from paper and poly-fiber industries (Deevasan and Ranganath 2011).

\subsubsection{Performance}

In a 2001 article in Concrete International entitled, "Reducing the Environmental Impact of Concrete,” P. Kumar Mehta stated:

"Except for blended portland cements containing mineral additions, no other hydraulic cements seem to satisfy the setting, hardening, and durability characteristics of portland cement-based products" (Mehta 2001).

\subsubsection{Mechanical performance}

In general, geopolymer cement concretes, have been shown to perform similarly to OPC concretes in terms of mechanical properties. However, just like OPC, each system must be tailored through source material and batching manipulation as well as curing conditions to generate a material with specific desired properties. The following is a cumulative list from the literature listing mechanical and physical properties that are common in most geopolymers (Duxson et al. 2007; Duxson et al. 2007; Sofi et al. 2007):

- High early compressive strength without a compromise in ultimate strength (Davidovits 1994; Fernández-Jiménez and Palomo 2003; Fernández-Jiménez et al. 2006)

- High early flexural strength (Fernández-Jiménez et al. 2006) 
- Similar density to ordinary portland cement concretes of a similar strength design (Sofi et al. 2007)

- Good adhesion properties to new and old concrete substrates as well as steel, glass and ceramics (Xie and Xi 2001; Fernández-Jiménez and Palomo 2003)

- High surface definition that works well in molds

- Good pull out strength (Xie and Xi 2001; Fernández-Jiménez and Palomo 2003; Fernández-Jiménez et al. 2006)

- Good bond with aggregate (Xie and Xi 2001; Fernández-Jiménez and Palomo 2005)

\subsubsection{Durability}

"More than any other technological aspect or engineering property, durability will be the factor that overrides all other technological drivers in determining the success or failure of geopolymer technology in the construction industry" (Duxson et al. 2007).

In a 2013 report published by the American Society of Civil Engineers (ASCE), the United States infrastructure received a grade of " $\mathrm{D}+$," citing the need for a $\$ 3.6$ trillion investment by 2020 (ASCE 2013). It is common for structures in the United States to be designed for a service life of 50 years, but require extreme repair or replacement at 20-30 years. This is a clear sign that long-term durability of OPC concrete is in many cases not adequate for its environment.

As is the case with OPC, the durability of GPC has a great deal to do with the microstructure, where decreased porosity results in decreased permeability and therefore increased durability (Van Deventer et al. 2010). Davidovits claims geopolymer 
permeability to be $10^{-9} \mathrm{~cm} / \mathrm{s}$ (Davidovits 1994) as compared to OPC at $6 \times 10^{-11} \mathrm{~cm} / \mathrm{s}$ (Mehta and Monteiro 2006). However, the raw materials as well as mixture proportioning and curing conditions are very important when it comes to durability. The following is a cumulative list from the literature listing durability properties that are common in most geopolymers:

- Fire resistance and low thermal conductivity (Davidovits 1989; Duxson et al. 2007)

- Thermal resistance up to $700-800^{\circ} \mathrm{C}$ (Duxson et al. 2007)

- Good resistance to chemical attack from acids, salt (including seawater), sulfates and chlorides (Davidovits 1989; Palomo and Glasser 1992; Davidovits 1994; Davidovits 2002; Hardjito et al. 2004; Duxson et al. 2007; Fernández-Jiménez et al. 2007; Provis and vanDeventer 2009)

- Toxic waste immobilization (Duxson et al. 2007)

- Freeze-thaw durability (Davidovits 1994)

- Lower heat of hydration than OPC

- Low shrinkage and excellent dimensional stability (Davidovits 1994; FernándezJiménez and Palomo 2003; Hardjito et al. 2004; Fernández-Jiménez et al. 2006)

Further, geopolymers have been shown to significantly reduce the leaching of iron, cobalt, cadmium, nickel, zinc, lead, arsenic, radium and uranium (Davidovits 1994) (Davidovits et al. 1990; Fernández-Jiménez et al. 2004) as well as $\mathrm{Cu}$ and Pb (Van Jaarsveld et al. 1999). 


\subsubsection{A note on ASR}

“... the durability of traditional Portland cement concrete is limited by a number of factors, most prominently the developments associated with the alkali-aggregate reaction" (Garcia-Lodeiro et al. 2007).

To those working with ordinary portland cement concrete, terms like "alkalis" and "reactive silica" are cause for concern. However, this is not the case in geopolymers. Varying reports of geopolymers resistance to ASR have surfaced within the literature (Davidovits 1994; Provis and vanDeventer 2009). Low mortar expansion has been attributed to the fact that alkalis are tied up in the geopolymer framework, and so are not available to react with the silica ( $\mathrm{Li}$ et al. 2006). Those systems with poor performance have been linked to the presence of $\mathrm{Ca}$ within the system, which can lead to the formation of expansive ASR gels (Garcia-Lodeiro et al. 2007).

\subsection{Geopolymerization}

Geopolymerization is the reorganization of amorphous aluminosilicates, by an alkali hydroxide or silicate solution, to form an amorphous to semi-crystalline three-dimensional matrix of tetrahedrally coordinated alumina and silica. Geopolymer cements are typically produced from a mixture of a powdered solid aluminosilicate source, such as fly ash or metakaolin and an "activating" solution usually consisting of an alkali hydroxide containing dissolved silica (where the alkali is usually sodium or potassium). Geopolymerization begins with dissolution, which is followed by the precipitation and 
nucleation of an aluminosilicate gel that later hardens into a three-dimensional matrix of tetrahedral aluminosilicates (Duxson et al. 2007).

Essentially, geopolymerization is to GPC as hydration is to OPC. Understanding geopolymerization is important in that it helps to illustrate the extreme differences between

the OPC and GPC systems. Additionally, a fundamental understanding of geopolymerization is necessary to understand how changing the system parameters can affect the kinetics, microstructure and fresh and hardened properties. This is much like understanding how the hydration of OPC explains a great deal with regard to concrete performance.

\subsubsection{Silica chemistry and polymerization}

"As water is a unique liquid, so is amorphous silica a unique solid" (Iler 1979).

Since geopolymer cements are based around the dissolution and polycondensation of a silica- based framework, it is important to understand the behavior of silica, which will be discussed in the following sections. Ralph K. Iler is a pioneer in the world of silicate chemistry, authoring The Chemistry of Silica and The Colloid Chemistry of Silica and Silicates, which are commonly referenced in articles concerning alkali-activated cements (Iler 1955; Iler 1979). 
Iler lists three main stages in the polymerization of silica (Iler 1979):

1. polymerization

2. growth

3. gelation/precipitation

However, it is important to note the "polymerization mechanism [of silica] is entirely different from that of any organic system" (Iler 1979). It should also be noted that a 'silicone' is an inorganic-organic polymer made of Si-O-Si bonds connecting organic groups (e.g., $\mathrm{CH}_{3}, \mathrm{C}_{2} \mathrm{H}_{6}, \mathrm{C}_{6} \mathrm{H}_{5}$ ). These are vastly different from the inorganic polymer bonds that make up geopolymers (e.g., Si-O-Si, Si-O-Al).

\subsubsection{Davidovits' nomenclature}

Davidovits, who coined the term "geopolymer," also established his own set of geopolymer terminology and while it is not used exclusively in current research, for reasons stated later, it is referenced commonly enough in the literature that it should be mentioned.

Davidovits uses the following terminology for alkali silicates of varying compositions (Davidovits 2008):

siloxo -Si-O- unit involved in a poly(siloxo) (-Si-O-Si-O-) macromolecule siloxonate alkali-siloxo unit, the alkali being $\mathrm{Na}, \mathrm{K}, \mathrm{Li}, \mathrm{Ca}$

silanol -Si-OH side or end groups included in poly(siloxo) macromolecules 
The condensation of two silanol groups (-SiOH + OHSi-) results in a siloxane group, SiO-Si through the following condensation reaction (Davidovits 2008):

$$
-\mathrm{SiOH}+\mathrm{OHSi}-\rightarrow-\mathrm{Si}-\mathrm{O}-\mathrm{Si}-+\mathrm{H}_{2} \mathrm{O}
$$

The following empirical formula is used to represent the aluminosilicate binder formed through alkali activation (Davidovits 1979; Davidovits 1991; Davidovits 2008):

$$
\mathrm{M}_{\mathrm{n}}\left[-\left(\mathrm{Si}-\mathrm{O}_{2}\right)_{\mathrm{z}}-\mathrm{Al}-\mathrm{O}_{2}-\right]_{n}, \mathrm{wH}_{2} \mathrm{O}
$$

Where $\mathrm{M}$ refers to a monovalent cation $\left(\mathrm{K}^{+}, \mathrm{Na}^{+}\right), \mathrm{n}$ is the degree of polycondensation, $\mathrm{z}$ is $1,2,3$ or higher, depending on the $\mathrm{Si} / \mathrm{Al}$ ratio within the binder and $\mathrm{w}$ describes the amount of water present.

Davidovits named the amorphous to semi-crystalline 3D structures containing both Si and Al using the term poly(sialate); sialate is an abbreviation for alkali silicon-oxo-aluminate. Alternately linked $\mathrm{SiO}_{4}$ and $\mathrm{AlO}_{4}$ tetrahedra, connected by bridging oxygens make up the sialate network. "Poly(sialates) consist of ring and chain polymers with $\mathrm{Si}^{4+}$ and $\mathrm{Al}^{3+}$ in IV-fold coordination with oxygen" (Davidovits 1991). Nomenclature was also developed for each $\mathrm{Si} / \mathrm{Al}$ ratio achieved $(\mathrm{z}=1,2,3,>3)$ (Davidovits 2002; Davidovits 2008). A graphical depiction of these systems is shown in Error! Reference source not found..

$$
\begin{aligned}
& \mathrm{z}=\mathrm{Si}: \mathrm{Al}=1 \quad \text { sialate, } \operatorname{poly}(\text { sialate }) \\
& \mathrm{z}=\mathrm{Si}: \mathrm{Al}=2 \text { sialate-siloxo, poly( sialate-siloxo }) \\
& \mathrm{z}=\mathrm{Si}: \mathrm{Al}=3 \quad \text { sialate-disiloxo, poly(sialate-disiloxo }) \\
& \mathrm{z}=\mathrm{Si}: \mathrm{Al}>3 \quad \text { sialate link, poly(sialate-multisiloxo) } \\
& \text { (-Si-O-Al-O-Si-O-) } \\
& \text { (-Si-O-Al-O-Si-O-Si-O-) }
\end{aligned}
$$



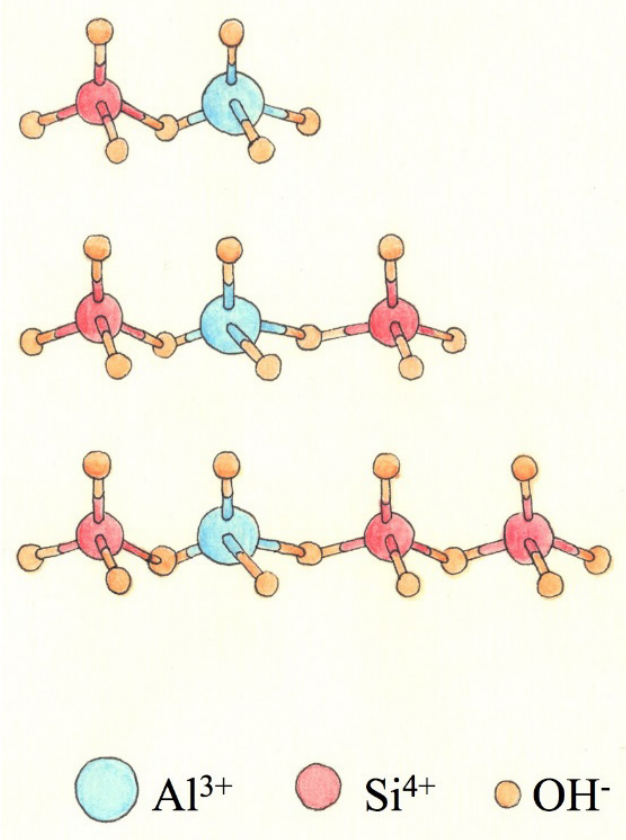

Figure 2.2. Schematic of sialate systems where $\mathrm{z}=1$ (top), 2 (middle) or 3 (bottom) (Davidovits 1994).

Davidovits' nomenclature is not generally accepted due primarily to the fact that it illustrates a one-dimensional framework, when in reality; the framework is threedimensional (Van Jaarsveld et al. 1997; Provis et al. 2005; Provis and vanDeventer 2009). Also causing debate is the fact it only accounts for integer $\mathrm{Si} / \mathrm{Al}$ ratios $(\mathrm{z}=1,2,3)$, which are rarely achieved (Fletcher et al. 2005).

\subsubsection{Current model of geopolymerization}

Since Glukhovsky's early model of geopolymerization, many details of the reaction mechanisms have been revealed thanks to vigorous research from around the world and technological advances. Knowledge of zeolite synthesis, structural data from Magic Angle 
Spinning - Nuclear Magnetic Resonance (MAS-NMR) and Fourier Transform Infrared (FTIR) spectroscopy, and microstructural data from scanning electron microscopy (SEM) and compositional data from energy dispersive X-ray spectroscopy (EDS) have been particularly helpful. As new knowledge has emerged regarding the reaction mechanisms, structure and composition of geopolymer cements, the model has evolved accordingly (Fernández-Jiménez et al. 2005; Duxson et al. 2007; Shi et al. 2011). Figure 2.7 illustrates one of the more recent models.

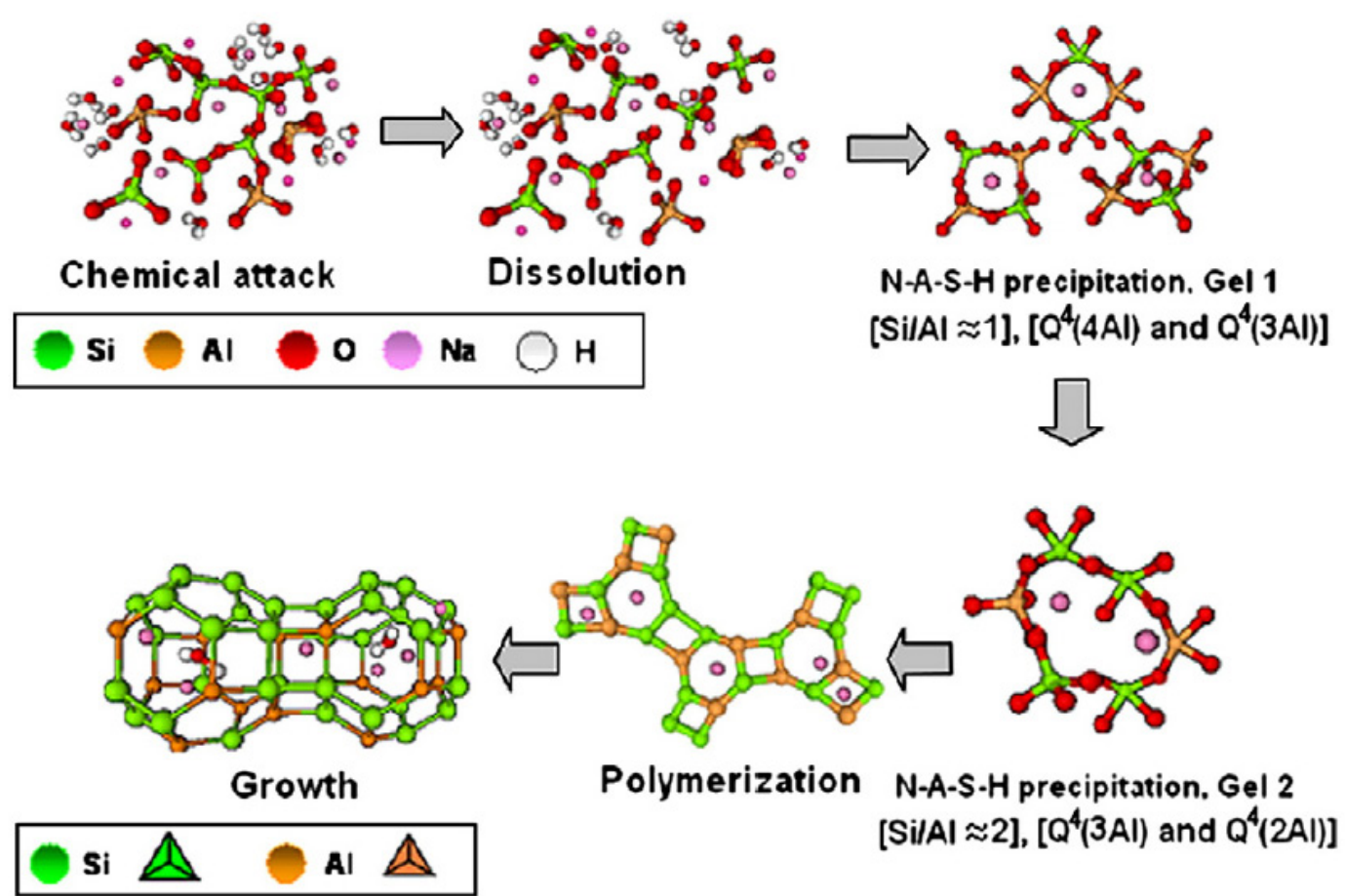

Figure 2.3. Recent schematic model of geopolymerization (Shi et al. 2011). Reprinted by permission of Elsevier. See Appendix D for documentation of permission to reprint this material.

It is important to note that while most models of geopolymerization depict a series of linear processes, this is not the case in reality. Upon initial mixing, any number of processes can 
and do occur simultaneously throughout geopolymerization and under specific parameters, some reactions occur so quickly they are considered to be spontaneous.

It is believed by many, based upon NMR and SEM evidence, the mechanisms of geopolymerization as well as the final structure produced from different raw materials is basically the same and synthesis conditions mainly affect the kinetics of the reactions (Fernández-Jiménez et al. 2005; Duxson et al. 2007). An explanation of the various steps in geopolymerization follows; this will be based on a simple system of metakaolin reacted with $\mathrm{NaOH}$ of a moderate concentration. Synthesis parameters such as the physical and compositional properties of the source material and activating solutions, mixture proportions, water content, curing conditions, etc. can have a significant effect on the reaction products as well as the kinetics (Fernández-Jiménez et al. 2005) and will be covered in future sections.

\subsubsection{Dissolution and hydrolysis}

The first step in geopolymerization is dissolution. The dissociation of an alkali hydroxide in water is extremely exothermic and results in alkali metal cations $\left(\mathrm{M}^{+}\right)$and hydroxide anions $\left(\mathrm{OH}^{-}\right)$in aqueous solution. When a powdered aluminosilicate source is introduced, negatively charged hydroxyl anions quickly adsorb onto positively charged $\mathrm{Si}^{+4}$ or $\mathrm{Al}^{+3}$ cations at the particle surface where they are held in place by Si-O and Al-O covalent bonds (Duxson et al. 2007).

Amorphous silica typically has an "open structure" on the surface where spaces between oxygen ions exist that are large enough for hydroxyl ions to fit (Iler 1979). The presence 
of the adsorbed $\mathrm{OH}^{-}$ions weakens the covalent bonds in the source material until the $\mathrm{Si}^{+4}$ or $\mathrm{Al}^{+3}$ ion is pulled away into solution. They are then quickly hydrolyzed with $\mathrm{OH}^{-}$ions to form $\mathrm{Si}-\mathrm{OH}$ and $\mathrm{Al}-\mathrm{OH}$ groups, which later lead to various species including $\left[\mathrm{Si}(\mathrm{OH})_{4}\right]$ and $\left[\mathrm{Al}(\mathrm{OH})_{4}\right]^{-}$monomers (Fernández-Jiménez and Palomo 2005). The removal of a Si or Al cation results in the exposure of other internally bound cations, which are then attacked by more hydroxyl ions. Figure 2.4 shows a schematic representation of silica dissolution.
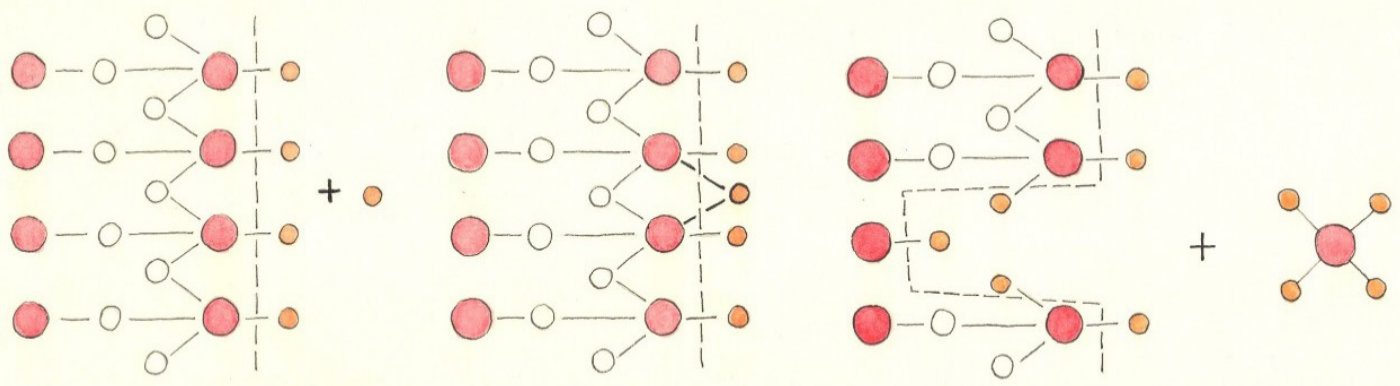

$\mathrm{Si}^{4+} \bigcirc \mathrm{O}^{2-} \quad \circ \mathrm{OH}^{-}$

Figure 2.4. Schematic of silica dissolution in water containing hydroxyl ions, $\mathrm{OH}^{-}$ (Iler 1979).

While silica dissolves into solution, a concomitant deposition reaction also occurs where a very thin layer of amorphous soluble silica is deposited on any surfaces present, be they crystalline or amorphous. However, at high $\mathrm{pH}$, dissolution occurs much faster than deposition and the solution quickly becomes supersaturated with Si monomers (and Al monomers if present), which is desired. Figure 2.5 shows the increasing solubility of amorphous silica at increasing $\mathrm{pH}$. 


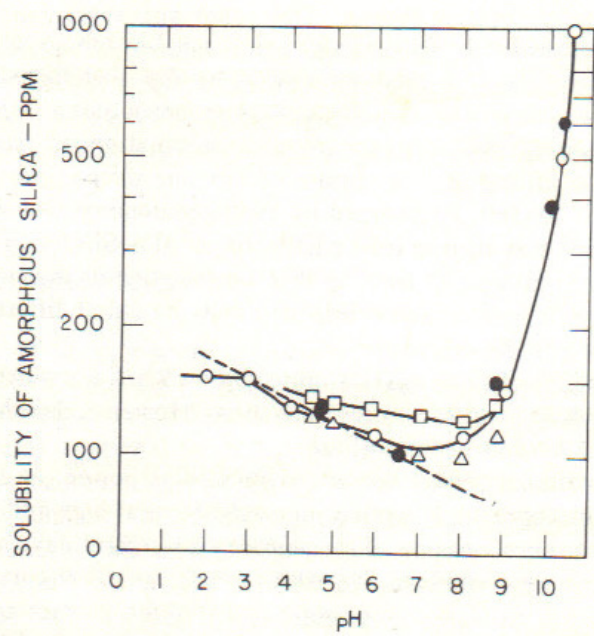

Figure 2.5. Solubility of amorphous silica vs. pH (Iler 1979). Reprinted by permission of John Wiley and Sons. See Appendix D for documentation of permission to reprint this material.

The rate and extent to which dissolution occurs is very important when it comes to geopolymerization as it sets the tone for later reactions, faster dissolution typically leads to a faster set time and in some cases a higher compressive strength (Xu and Van Deventer 2002). The greater the degree of reaction $(\alpha)$ that occurs, the more $\mathrm{Si}$ and $\mathrm{Al}$ is available to create reaction products, resulting in a denser matrix.

Factors affecting the dissolution rates of aluminosilicate particles and the solubility of $\mathrm{Si}$ and Al include (Iler 1979; Oelkers et al. 1994; Swaddle et al. 1994; Xu and Van Deventer 2000; Duxson et al. 2005; Fernández-Jiménez et al. 2005; Sagoe-Crentsil and Weng 2007; Li et al. 2011; Ryu et al. 2011):

- $\mathrm{pH}$ of the dissolving solution

- particle size and surface area

- degree of crystallinity of the solid 
- $\quad$ presence of network modifiers such as $\mathrm{Na}^{+}, \mathrm{Ca}^{++}$ions, etc.

- presence of dissolved Si and degree of undersaturation in solution

- previous mechanical, heat or water treatment of the solid particle

- temperature and pressure

- mixing time

\subsection{Synchronous vs. incongruent dissolution}

The dissolution of $\mathrm{Si}$ and $\mathrm{Al}$ is not always synchronous, meaning $\mathrm{Si}$ and $\mathrm{Al}$ dissolve at different rates depending on the structure of the source material as well as system conditions such as pH (Xu and Deventer 1999; Xu and Van Deventer 2000; FernándezJiménez et al. 2006). Figure 2.6 shows this phenomenon occurring during metakaolin dissolution. Varying dissolution rates are most likely due to the fact that Al-O bonds are more easily broken than Si-O bonds (Duxson et al. 2005; Fernández-Jiménez et al. 2006). 


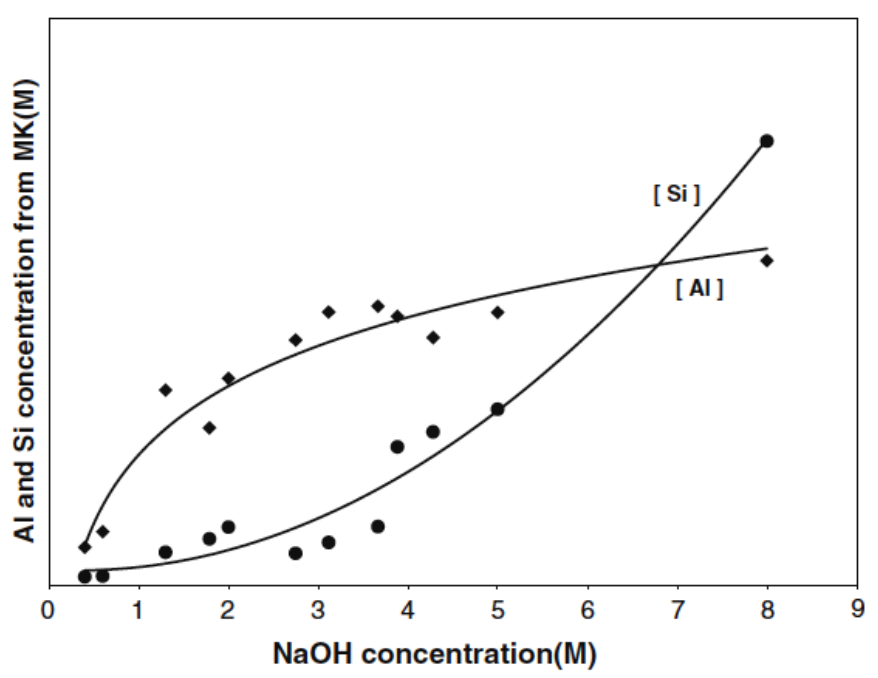

Figure 2.6. Si and $\mathrm{Al}$ dissolved from metakaolin in solution at varying $\mathrm{NaOH}$ concentrations (SagoeCrentsil and Weng 2007). Reprinted by permission of Springer. See Appendix D for documentation of permission to reprint this material.

\subsection{Network modifiers and impurities}

Precursor materials that contain higher quantities of network modifiers (i.e., alkali or alkali earth cations) typically are more easily dissolved as they often contain a higher than normal non-bridging oxygen (NBO) content within the particle and are more disordered than a more pure Si glass (Maekawa et al. 1990; Rees et al. 2005). Divalent alkaline earth cations enhance dissolution more than monovalent alkali cations, causing more damage when they are removed from the system by ion exchange of $\mathrm{H}^{+}$for $\mathrm{Na}^{+}$or $\mathrm{Ca}^{2+}$, mainly because the divalent cation has two bonds compared to the single bond on a monovalent cation (Duxson and Provis 2008).

Incongruent dissolution has also been found to occur in sodium silicate glass, where alkalioxygen ionic bonds present in the precursor material are easily broken by the action of 
water, leaving behind a corroded layer on the surface of the particles. The alkali ions released into solution serve to increase the $\mathrm{pH}$ of the solution which helps to break the stronger Si-O covalent bonds (Shi 2006).

\subsection{Speciation of monomers}

Once the Si and Al cations are removed to solution, they are affected by the system's constant effort to reach equilibrium. The speciation of silica in solution is by no means simple. In order to understand the solubility of silica and therefore the speciation of a system of both silica and alumina, it is first necessary to define the processes by which silica reaches equilibrium. Silica in solution is extremely labile and very sensitive to changing conditions such as $\mathrm{pH}$ and solution concentration. Silica species can and do exist in many different forms in solution at equilibrium. However, the rapid dissolution of $\mathrm{Si}$ and $\mathrm{Al}$ monomers into solution and the fact that geopolymerization is a chaotic and dynamic process, do not allow for equilibrium to be reached. Silica in solution can be unpredictable and it is difficult to isolate the many variables that can influence its speciation at any given time since the system is constantly changing.

Weng and Sagoe-Crentsil used Livage's partial charge model (PCM) along with experimental data from NMR to determine the chemistry and speciation of dissolution, hydrolysis and condensation processes for a metakaolin-based geopolymer system. They found that in early stages, in low $\mathrm{Si} / \mathrm{Al}$ systems $(\mathrm{Si} / \mathrm{Al} \leq 1),\left[\mathrm{Si}(\mathrm{OH})_{4}\right]$, also known as silicic acid, shown in Figure 2.7, is present in high quantities at low $\mathrm{pH}$, but reacts to an increase 
in hydroxyl ions in solution (increase in $\mathrm{pH}$ ) through the reactions in Equations 4 and 5. A graph of these speciation changes with regard to $\mathrm{pH}$ can be seen in Figure 2.8.
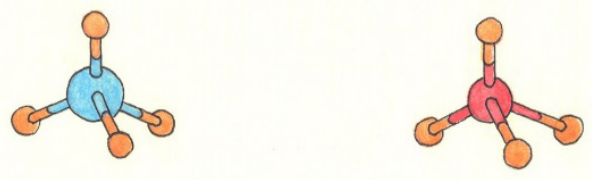

$\begin{array}{ll}\mathrm{Al}^{3+} & \bigcirc \mathrm{Si}^{4+} \\ \mathrm{OH}^{-} & \circ \mathrm{OH}^{-}\end{array}$

Figure 2.7. $\mathrm{Al}(\mathrm{OH})_{4}{ }^{-}$and $\mathrm{Si}(\mathrm{OH})_{4}$ tetrahedrons.

$\mathrm{Si}(\mathrm{OH})_{4}+\mathrm{OH}^{-} \rightarrow(\mathrm{HO})_{3} \mathrm{SiO}^{-}+\mathrm{H}_{2} \mathrm{O}$

(Equation 4)

$(\mathrm{HO})_{3} \mathrm{SiO}^{-}+\mathrm{OH}^{-} \rightarrow(\mathrm{HO})_{2} \mathrm{SiO}_{2}{ }^{2-}+\mathrm{H}_{2} \mathrm{O}$

(Equation 5)

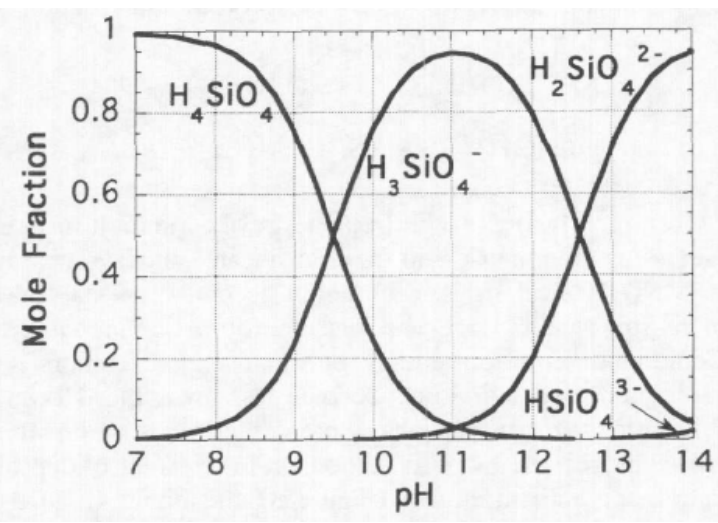

Figure 2.8. Distribution of monomeric Si anions vs. pH (Šefćík and McCormick 1997). Reprinted by permission of Elsevier. See Appendix D for documentation of permission to reprint this material.

$\left[(\mathrm{HO}) 2 \mathrm{SiO}_{2}\right]^{2-}$ and $\left[(\mathrm{HO})_{3} \mathrm{SiO}^{-}\right.$were found to be the major $\mathrm{Si}$ species present at higher $\mathrm{pH}$, which is the $\mathrm{pH}$ at which geopolymers are created. This is important to note because 
$\left[(\mathrm{HO}) 2 \mathrm{SiO}_{2}\right]^{2-}$ species are less apt to polymerize as compared to $\left[(\mathrm{HO})_{3} \mathrm{SiO}\right]^{-}$species (Fernández-Jiménez et al. 2006; Weng and Sagoe-Crentsil 2007). The major Al species at high $\mathrm{pH}$ was found to be $\left[\mathrm{Al}(\mathrm{OH})_{4}\right]^{-}$, however, in North and Swaddle's research, no free $\left[\mathrm{Al}(\mathrm{OH})_{4}\right]^{-}$was found in solution when the $\mathrm{Si} / \mathrm{Al}$ ratio is very high, signifying that it condenses with other Si species quickly at high pH (North and Saddle 2000).

Aside from monomeric species present in the solution, there are also oligomeric and polymeric species as well, containing various combinations of Si and Al. These larger species are created through polycondensation reactions, which are covered in the next section.

\subsubsection{Polycondensation}

Solubility is a measure of the saturation concentration of a solute in a solvent. Saturation occurs when the rate of dissolution and precipitation of a solute are equal, meaning that if more solute is added to the system, the dissolved concentration, or solution concentration, remains constant. Under certain conditions, such as very high $\mathrm{pH}$, supersaturation is possible. Dissolution and precipitation are kinetic processes (i.e., time dependent) and are therefore measured by their rate. Geopolymerization requires a supersaturated solution of $\mathrm{Si}$ and $\mathrm{Al}$ monomers before condensation reactions will occur, which is the next step in geopolymerization.

Condensation occurs when two or more $\mathrm{OH}^{-}$groups on two different monomers condense together to form an oxygen bond (also known as an oxygen bridge), thereby releasing a 
molecule of water. A basic condensation reaction between two silanol groups ( $\mathrm{SiOH})$ is shown below in Equation 6 and schematically in Figure 2.9.

$$
\mathrm{SiOH}+\mathrm{HOSi}-\rightarrow-\mathrm{SiOSi}-+\mathrm{H}_{2} \mathrm{O}
$$
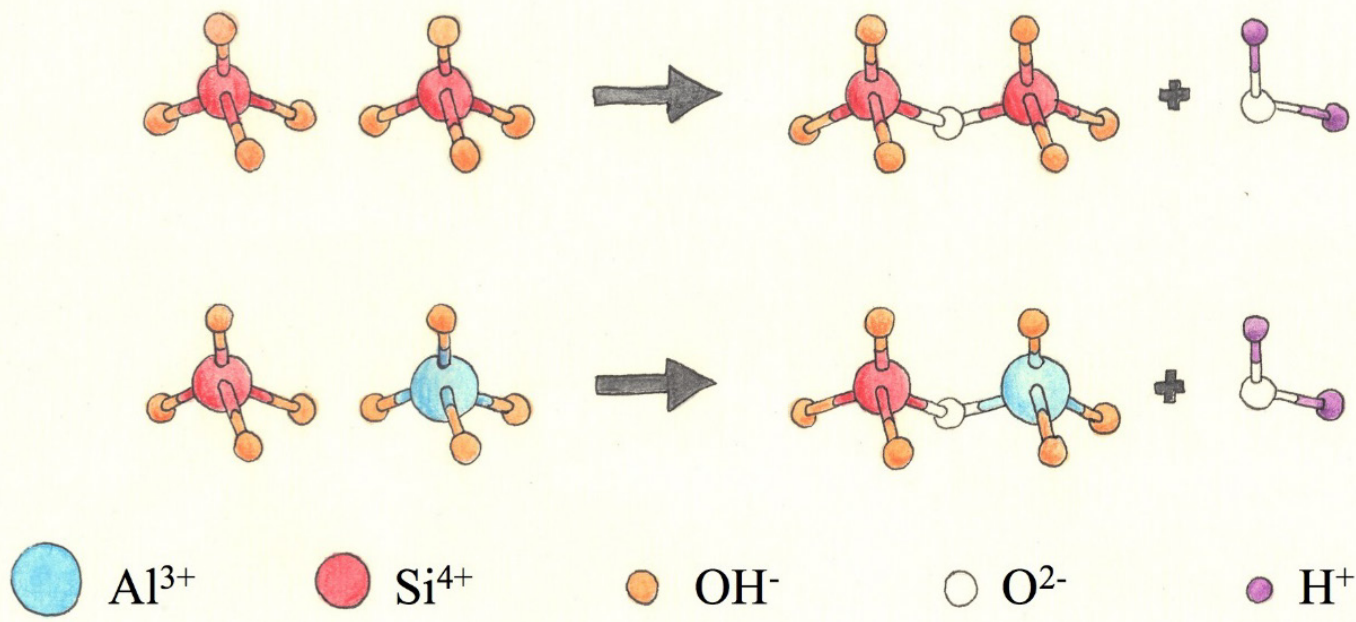

$\mathrm{OH}^{-}$

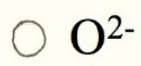

$\circ \mathrm{H}^{+}$

Figure 2.9. Condensation reactions between monomers.

Iler defines polymerization as "a linking together of monomer units to form a polymer of the same composition (Iler 1979)." However, for polymerization to take place in this case, condensation must first occur. "Polymerization by a repeated condensation process" is technically called polycondensation (IUPAC 2012). However, polymerization, condensation and polycondensation are often used interchangeably within the literature.

The polycondensation of two monomers yields a dimer. If another monomer is added it is called a trimer, etc. Dimers, trimers, etc. are considered to be low polymers, and collectively are called oligomers, shown in Figure 2.10, which Iler defines as particles less than $5 \mathrm{~nm}$ in diameter (Iler 1979). 

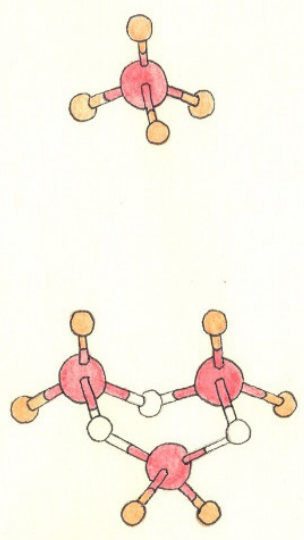

$\mathrm{Si}^{4}$
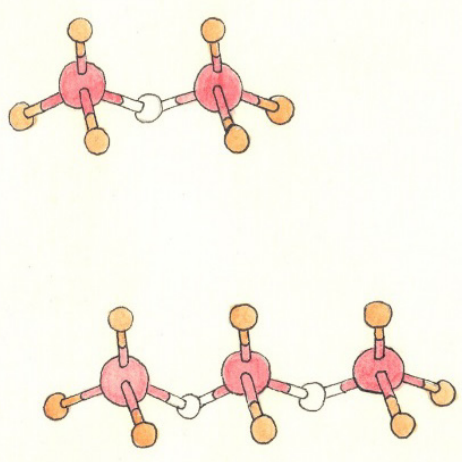

$\circ \mathrm{OH}^{-}$

Figure 2.10. An example of a monomer (top left), dimer (top right), cyclic trimer (bottom left) and trimer (bottom right).

The rapid polycondensation of monomers to form oligomers at high $\mathrm{pH}$ is also known as spontaneous homogenous nucleation. Davidovits states that geopolymerization "evolves through the condensation, step by step, from monomers to dimers, trimers and higher molecules, yielding the polymeric covalent bonding of poly(siloxonate) Si-O-Si-O-, poly(sialate) Si-O-Al-O, and poly(sialate-disiloxo) Si-O-Al-O-Si-O-Si-O” (Davidovits 2008). At high $\mathrm{pH}$ in a supersaturated solution, polymerization occurs very rapidly, especially between aluminate and silicate species as compared to silicate species among themselves - so fast the reaction cannot usually be detected at room temperature.

Small oligomers (or nuclei) provide surfaces where monomeric silica can be deposited and larger and larger oligomers form. At high $\mathrm{pH}$, monomers can polymerize very quickly to 1-2 nm sized particles; so fast that it is said to be spontaneous. Large oligomers are sometimes called macromolecules or polymer molecules. When the diameter of a 
macromolecule reaches between 1 and $1000 \mathrm{~nm}$ in at least one dimension, the molecule is considered to be a colloidal particle (McMurry and Fay 2001). Generally speaking, if the diameter of all of the species is less than $1 \mathrm{~nm}$ it is considered a solution, if the diameter is between 1 and $1000 \mathrm{~nm}$ and the system is still fluid it is called a sol; once it turns into a solid it is called a gel (McMurry and Fay 2001; IUPAC 2012).

Silica tends to polycondense in such a way as to maximize the internal Si-O-Si bonds and minimize outer uncondensed $\mathrm{OH}$ groups. This tendency results in ring structures such as the cyclic tetramer, which grow in size as more monomers are added. These particles are made of anhydrous $\mathrm{SiO}_{2}$ inside and $\mathrm{SiOH}$ on the outside and tend to be spherical due to the ring structures inside (Iler 1979).

At $\mathrm{pH}$ greater than 7 , low polymers quickly grow to the size of colloids due to Ostwald ripening. Ostwald ripening is the phenomenon of smaller particles dissolving and precipitating onto larger particles, resulting in more larger polymerized aluminosilicate species and less, smaller oligomeric species in the system (Fernández-Jiménez et al. 2006). While smaller crystals dissolve (due to their higher solubility), they form a local area of high concentration as compared to the areas around a larger particle. This concentration difference drives a precipitation reaction at the site of the larger crystal until the smaller crystal is completely dissolved and the solution concentration difference is eliminated. If there exists a larger particle than the aforementioned, then the same thing will happen again (Pankow 1991). 


\subsection{Speciation of oligomers and polymers}

Early in the dissolution of an aluminosilicate material, both Si and Al monomers are present in solution. Tetrahedral $\mathrm{Al}$ monomers $\left[\mathrm{Al}(\mathrm{OH})_{4}\right]^{-}$take part in the polycondensation of $\mathrm{Si}$ monomers in what is called isomorphic substitution. The exact speciation of aluminosilicates in solution is very difficult to quantify without first stating the reaction parameters. Varying dissolution rates and the presence or lack of soluble silica in solution at the start of mixing have a huge effect on the speciation at any given time.

Condensation between aluminate and silicate species is favored kinetically over the condensation of just silicate species among themselves, even in very low $\mathrm{Si} / \mathrm{Al}$ systems (Fernández-Jiménez et al. 2006; De Silva et al. 2007). Aluminum in solution will tend to not bond with other aluminum, but favor bonding with an Si monomer or other aluminosilicate species (Swaddle et al. 1994). This phenomenon is explained by Lowenstein's avoidance principle, which states that Al-O-Al bonds are never thermodynamically favored in the case that both $\mathrm{Al}$ ions are tetrahedrally coordinated because the oxygen bridge between them is not stable (Lowenstein 1954). However, Australian researchers have found the presence of $\mathrm{Al}-\mathrm{O}-\mathrm{Al}$ bonding when $\mathrm{Si} / \mathrm{Al}$ is very close to 1 , such as when metakaolin alone is reacted with $\mathrm{NaOH}$; the presence of soluble silica as well as a higher $\mathrm{Si} / \mathrm{Al}$ typically do not ever result in the formation of Al-O-Al bonds (Duxson et al. 2005). MAS-NMR has also shown that Si-O-Al bonds are formed nearly 100-1000 times faster than Si-O-Si bonds, which could be why Al content affects the setting time (North and Saddle 2000). Higher alkalinity results in higher Al content, 
which results in faster setting, this has been confirmed by calorimetry (Sagoe-Crentsil and Weng 2007).

Weng et al. used the partial charge model (PCM) to determine that at high $\mathrm{pH}(10-14)$, $\left[\mathrm{Al}(\mathrm{OH})_{4}\right]^{-}$tetrahedra are more likely to attract negatively charged $\mathrm{OH}^{-}$groups from other species than Si tetrahedra under the same conditions, which means Al species are more likely to be involved in condensation reactions due to the higher activity of the $\mathrm{Al}$ species. This is because $\left[\mathrm{Al}(\mathrm{OH})_{4}\right]^{-}$was found to be the major $\mathrm{Al}$ species at $\mathrm{pH} 12-14$ and has four hydroxyl groups where as the major $\mathrm{Si}$ species at this $\mathrm{pH}$ were $\left[\mathrm{SiO}_{2}(\mathrm{OH})_{2}\right]^{2-}$ and $\left[\mathrm{SiO}(\mathrm{OH})_{3}\right]$; which have two or three hydroxyl groups, respectively (Weng et al. 2005; Weng and Sagoe-Crentsil 2007).

Condensation of $\left[\mathrm{SiO}_{2}(\mathrm{OH})_{2}\right]^{2-}$ with $\left[\mathrm{Al}(\mathrm{OH})_{4}\right]^{-}$yields small oligomers like dimers or trimers. Condensation of $\left[\mathrm{SiO}(\mathrm{OH})_{3}\right]^{-}$with $\left[\mathrm{Al}(\mathrm{OH})_{4}\right]^{-}$yields an aluminosilicate which then will react with $\left[\mathrm{Al}(\mathrm{OH})_{4}\right]^{-}$until all hydroxyl groups on the aluminate species are consumed, generally resulting in larger oligomers or polymers. So, in general, the concentration of $\left[\mathrm{SiO}(\mathrm{OH})_{3}\right]^{-}$will determine the rate of formation of the geopolymer network, and the ratio of $\left[\mathrm{SiO}_{2}(\mathrm{OH})_{2}\right]^{2-}$ to $\left[\mathrm{SiO}(\mathrm{OH})_{3}\right]^{-}$depends on $\mathrm{pH}$ (Weng and SagoeCrentsil 2007). ${ }^{29} \mathrm{Si}$ MAS NMR spectra indicate that it may take up to five days for silicate condensation to complete, which coincides with PCM predictions (Sagoe-Crentsil and Weng 2007). 


\subsubsection{Gelation and precipitation}

In his book, Davidovits points out that a polymer is "a macromolecule with definite size and molecular weight" whereas a gel "designates an indefinite amorphous compound with unresolved dimension" (Davidovits 2008). There are many factors that play a role in determining if $\mathrm{Si}$ in solution will remain as a sol, aggregate together into a gel network or coagulate to form a precipitate, such as $\mathrm{pH}$, temperature, concentration, etc. (Iler 1979). Figure 2.11 shows a two-dimensional model of the difference between a gel and precipitate.
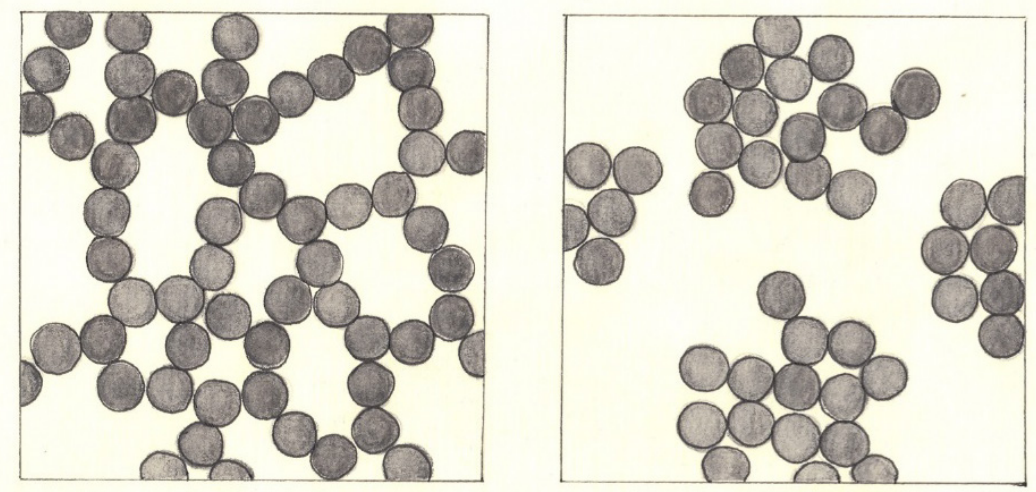

Figure 2.11. Two-dimensional schematic of a gel and precipitate after Iler (Iler 1979).

"The difference between formation of microgel and formation of a precipitate is that in a microgel region the concentration of silica particles in the three-dimensional network is the same as in the surrounding sol but in the flocs or aggregates of a precipitate the concentration is higher than in the surrounding liquid" (Iler 1979).

Crystal growth is usually defined in terms of two different phases, called nucleation and particle growth. Nucleation occurs when molecules in a solution randomly come together in what is called an aggregate. This can either occur at phase boundaries or on particle 
surfaces, called heterogeneous nucleation, or it can occur spontaneously in solution, called homogenous nucleation. Particle growth occurs after enough molecules have come together to form a crystal. In a highly supersaturated solution, nucleation occurs faster than particle growth, which can result in a colloid; whereas in a less supersaturated solution, particle growth occurs faster, which allows particles to grow larger. The activity of the monomeric species has a great deal to do with wither gelation or precipitation occurs (Kallala et al. 1991). Heat can promote particle growth as well as very low concentrations of solvents in a solute (Harris 2007). If particles become larger than colloidal particles, they will tend to precipitate.

$\mathrm{pH}$ has also been shown to have a significant impact on whether gelation of precipitation occurs, where aggregation tends to occur more at higher $\mathrm{pH}$ and gelation occurs more at lower pH (Fernández-Jiménez et al. 2006). The presence of dissolved Si will also affect whether a gel or a precipitate forms. Eventually the particles condense together to form an interconnected cage-like structure, where the lability of the ionic species within solution decreases until a solid three-dimensional matrix is formed (Fernández-Jiménez et al. 2006).

"The initial setting of geopolymers will occur when the rate of dissolution is surpassed by the rate of condensation and precipitation of aluminosilicate species" (Duxson et al. 2005). Many factors can affect the time it takes for a continuous network to form such as the raw material processing conditions, composition of the solution and reaction conditions (Duxson et al. 2007). 


\subsubsection{Reorganization}

"The lability of the anionic silicate species present in alkaline solution means that the structures observed in solution are unlikely to be fully representative of the solid phases formed upon solidification (Provis et al. 2005)."

The speciation in solution prior to polycondensation is important to understand because it will give clues about when set time will occur, etc. However, as per the quote above, initial concentrations and speciation are not necessarily indicative of the final composition of the reaction products.

Once initial setting has occurred, the lability of the system typically allows reordering and reorganizing in the form of multiple stages, where the connectivity and therefore density of the network increase with each stage. Within the literature, these stages are typically referred to as "gels." In general, the first gel is a metastable Al-rich gel, whose presence signals the initial set. Al-O bonds have been found to break more readily than Si-O bonds, and so the $\mathrm{Si} / \mathrm{Al}$ of this initial gel is generally around 1 , which would mean alternating $\mathrm{Si}$ and Al tetrahedral with no Si-O-Si bonds formed (Fernández-Jiménez et al. 2006; Shi et al. 2011).

Si-O-Si bonds are more thermodynamically stable than Si-O-Al bonds though, so over time as more and more $\mathrm{Si}-\mathrm{O}$ bonds are broken and more $\mathrm{Si}$ comes into solution, the gel evolves into a more stable Si-rich gel, which is more similar in composition to the final product. The formation of this Si-rich gel typically triggers an increase in the mechanical properties 
(Fernández-Jiménez et al. 2005; Fernández-Jiménez et al. 2006; Fernández-Jiménez et al. 2006; Duxson et al. 2007; Weng and Sagoe-Crentsil 2007; Shi et al. 2011).

The evolution from an Al-rich gel to a Si-rich gel infers that early reactions are most likely kinetically driven at first and then later toward thermodynamic stability. A threshold Si/Al value of 2 has been suggested as "the composition toward which different systems tend regardless of the initial conditions, possibly because it constitutes the most thermodynamically stable state" (Criado et al. 2008). The speed at which the Al-rich gel transforms to the Si-rich gel has been found to occur faster when higher reactive Al contents are available and usually result in a higher $\mathrm{Si} / \mathrm{Al}$ ratio in the final product (Fernández-Jiménez et al. 2006).

\subsection{Magic-angle spinning nuclear magnetic resonance (MAS-NMR) spectroscopy}

Davidovits was the first to use NMR technology to investigate the structure of metakaolinbased geopolymers in the 1980s. Since then, ${ }^{27} \mathrm{Al}$ and ${ }^{29} \mathrm{Si}$ MAS-NMR has become an important tool in investigating the structure of seemingly amorphous materials, such as geopolymers (Fernández-Jiménez et al. 2006; Kolouek et al. 2007).

The following notation is used in ${ }^{29} \mathrm{Si}$ MAS-NMR studies to describe the connectivity of Si with other Si and $\mathrm{Al}$ through $\mathrm{O}$ bonds: $\mathrm{Q}^{n}(m \mathrm{Al})$, where $0 \leq m \leq n \leq 4$ and $n$ is the coordination number of the silica center in question and $m$ is the number of connections to Al. This notation was first brought about by Engelhardt and is commonly used to describe aluminosilicate systems such as glasses, zeolites, gels and minerals (Duxson et al. 2005). NMR studies have verified that in geopolymer gels, all silicon and aluminum sites are in 
tetrahedral coordination which means $n=4$. Through analysis involving the Gaussian peak deconvolution of NMR spectra, a distribution and quantification of each of the $\mathrm{Q}^{4}(m \mathrm{Al})$ species can be attained (Duxson et al. 2005). Figure 2.12 shows a two-dimensional model of the five possible tetrahedrally coordinated aluminosilicate species, providing Lowenstein's aluminum avoidance principle holds true.

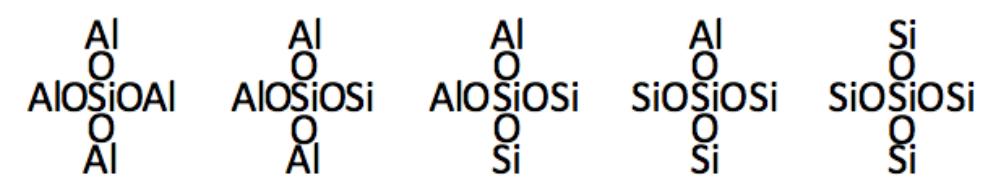

Figure 2.12. $\mathrm{Q}^{4}(m \mathrm{Al})$ units in aluminosilicates where $\mathrm{m}=$ $4,3,2,1,0$ from left to right.

${ }^{29} \mathrm{Si}$ NMR spectra supports the theory that an Al-rich gel is first developed which over time leads to a more Si-rich gel. This is evidenced by the fact that concentrations of $\operatorname{Si}(3 \mathrm{Al})$, $\mathrm{Si}(2 \mathrm{Al}), \mathrm{Si}(1 \mathrm{Al})$ and $\mathrm{Si}(0 \mathrm{Al})$ all increase over time, and the concentration of $\mathrm{Si}(4 \mathrm{Al})$ goes down (Fernández-Jiménez et al. 2006).

\subsubsection{Hardening}

Syneresis, or the expulsion of a liquid from a gel, occurs as the gel network continues to condense, and the water that was initially consumed during dissolution is expelled, eventually leading to the hardening of the aluminosilicate matrix. The expelled water exists in the pores of the gel, creating a bi-phasic system of water and aluminosilicate binder (Duxson et al. 2005). There does exist some conflicting evidence regarding the presence of bound water in the system, but the majority of the literature reports that no bound water is present within the final product and that it just exists within the gel pores (Duxson et al. 2005). ${ }^{8} \mathrm{O}$ MAS NMR has shown the final aluminosilicate product is made 
up of cross-linked $\mathrm{AlO}_{4}$ and $\mathrm{SiO}_{4}$ groups with no non-bridging $\mathrm{O}$ groups, and only a few hydroxyl groups that most likely are just on the surfaces of the gel (Duxson et al. 2007). Figure 2.13 shows a schematic of a geopolymer activated with potassium activator solution.

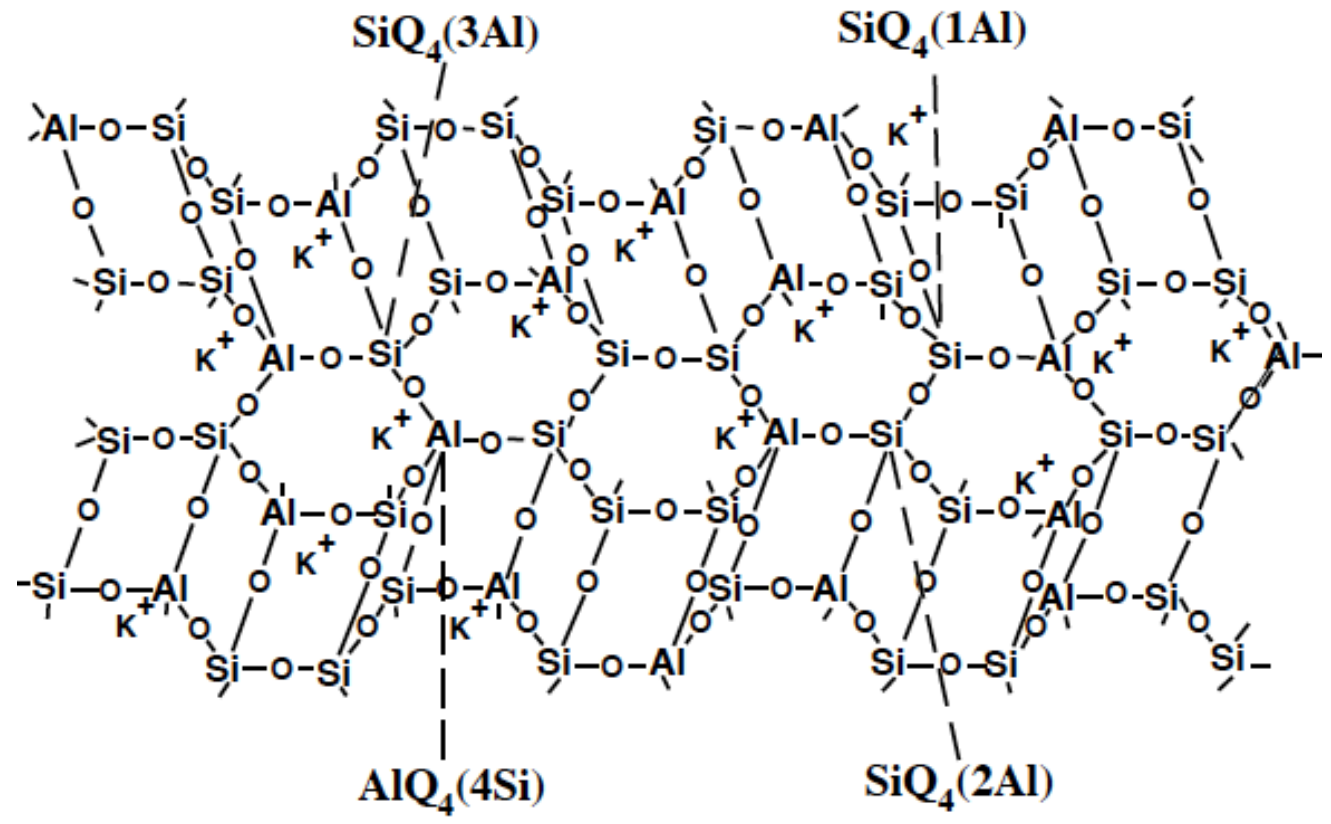

Figure 2.13. Schematic of the structure of K-based geopolymer (Davidovits 1994). Figure courtesy of the Geopolymer Institute (www.geopolymer.org). Please see Appendix D for license information.

\subsubsection{Zeolite synthesis}

"Crystalline zeolites are the thermodynamically stable phases towards which the system should evolve with time” (Fernández-Jiménez and Palomo 2005).

The similarity between geopolymer synthesis and zeolite synthesis has not gone unnoticed within the literature, and should be commented on (Granizo et al. 2002). Both geopolymers and zeolites can be formed under hydrothermal conditions, with water content and temperature dictating what exactly will be produced. 
"Zeolites are porous tectoaluminosilicates with a complex framework of $\mathrm{SiO}_{4}$ and $\mathrm{AlO}_{4}$ tetrahedra forming a regular system of interconnected cavities and channels of molecular dimensions (Engelhardt 1989)." Sometimes referred to as molecular sieves, over 35 natural zeolites have been discovered and over 100 synthetic zeolites have been produced from all manner of aluminosilicate materials (Davidovits 2008). In general, the Si:Al ratio varies from 1:1 to $6: 1$, and most natural zeolites occur through geological hydrothermal processes from $(\mathrm{Na}, \mathrm{Ca})$-aluminosilicates like plagioclase or nepheline (Breck 1974; Swaddle et al. 1994; Davidovits 2008). The open structure of zeolites is usually filled by charge balancing cations like $\mathrm{Na}^{+}$or $\mathrm{K}^{+}$that are solvated, meaning water molecules surround them. The presence of this water allows the cations to be mobile and allows for the possibility of ion exchange with other cations (Grutzeck and Marks 1999).

Synthetic zeolites are formed from dilute solutions rich in $\mathrm{SiO}_{2}, \mathrm{Al}_{2} \mathrm{O}_{3}, \mathrm{Na}_{2} \mathrm{O}$ and $\mathrm{H}_{2} \mathrm{O}$, at temperatures between $50-150^{\circ} \mathrm{C}$ (Breck 1974) and a $\mathrm{pH}$ greater than 13. One common method of synthetic zeolite synthesis is the alkali leaching of silicates, where an aluminosilicate mineral is dissolved in an alkaline solution until an amorphous aluminosilicate gel forms. Ageing and heat are often necessary for nuclei to appear and zeolite crystals can take anywhere from hours to days to form. Sometimes seeding is used to speed up this process. Factors that affect zeolite synthesis and the type of zeolite that is formed include alkalinity, temperature, reactivity of the silicon source and solid surfaces available (Madani et al. 1990). It has been observed in alkaline aluminosilicate solutions that smaller silicate species are more labile than larger species, and as such are able to reorganize themselves rapidly, which leads to faster crystal growth (Swaddle et al. 1994). 
It is generally accepted that aluminosilicate gels created in geopolymerization could be considered zeolite precursors; one research group even calls geopolymer cements zeocements for just this reason (Fernández-Jiménez et al. 2007). Increased water content (i.e., the $\mathrm{H}_{2} \mathrm{O} / \mathrm{Na}_{2} \mathrm{O}$ ratio in zeolite synthesis is typically 5-10 times higher than in geopolymers (Davidovits 2008)) and high temperatures are the only real differences between the two processes; however, these differences are enough to result in completely opposite microstructures. Zeolites are almost 100\% crystalline under XRD and geopolymer cements are nearly $100 \%$ amorphous. Table 2.5 shows the dramatic effects on the products created by changing these two synthesis parameters.

Table 2.5. Products created through different synthesis parameters, after (Provis et al. 2005).

\begin{tabular}{|c|c|c|}
\hline Water content & Low Temperature & High Temperature \\
\hline Low & Geopolymer & Geopolymer or zeolite \\
\hline High & Aluminosilicate gel & Zeolite \\
\hline
\end{tabular}

In general, it is considered that formation of zeolites involves a cyclic process of dissolution and precipitation, where meta-stable zeolite species are formed along the way toward a more stable final zeolite phase; this is in comparison with the internal reordering of the geopolymer gel (Swaddle et al. 1994). More solution available yields more zeolite formation, due to the increased ease of reorganization (Duxson et al. 2007).

Within the geopolymer system, there is neither time nor space allowed for zeolitization to occur, and the result is the quick precipitation of the aluminosilicate product that is unable to reorganize itself into a crystalline structure due to steric hindrance and remains 
amorphous upon hardening (Fernández-Jiménez and Palomo 2003; Fernández-Jiménez et al. 2005).

Some believe that given enough time and the right conditions, the geopolymer gel would eventually depolymerize and reorganize itself to form zeolite crystals (Fernández-Jiménez and Palomo 2003; Palomo et al. 2004; Fernández-Jiménez et al. 2005; Fernández-Jiménez et al. 2006). In some cases amorphous products have been found to transition into partially crystalline products over time or in high synthesis temperatures (Duxson et al. 2007). Zeolite crystals are commonly found on the surfaces of geopolymers exposed to the atmosphere and in voids.

\subsection{Are geopolymers amorphous zeolites?}

"... the exact boundary between "crystalline" and "amorphous" materials is very difficult to determine" (Provis et al. 2005).

It has been suggested that seemingly amorphous aluminosilicate geopolymers are in fact made of millions of nano-crystalline zeolite crystals embedded in an amorphous matrix and they are only considered amorphous due to the limitations of X-ray diffraction (XRD) (Provis et al. 2005). At the atomic to nanometric scale, zeolitic nanoscale structures have been found (Shi et al. 2011). Transmission electron microscopy (TEM) has shown that geopolymers are nanoparticulate, consisting of particles around $5 \mathrm{~nm}$ in diameter; likewise, high-resolution electron microscopy (HREM) has shown that this particulate phase contains distinct regions of short to midrange order (Provis et al. 2005). 
Iler referencing Frondel, states that:

"amorphous silica is not truly amorphous but consists of regions of local atomic order, or crystals of extremely small size, which by careful X-ray diffraction studies appear to have the cristobalite structure. Nevertheless, by ordinary diffraction procedures this material gives only a broad band, with no multiple peaks as are ordinarily obtained with macroscopic crystals, and is referred to here as “amorphous.” (Iler 1979).

\subsection{Source materials}

"Though many macroscopic characteristics of geopolymers prepared from different aluminosilicate sources may appear similar, their microstructure and physical, mechanical, chemical and thermal properties vary to a large extent depending predominantly on the raw material from which they are derived" (Duxson et al. 2007).

Since silica and alumina are the two most common elements in the Earth's crust after oxygen, there are seemingly endless materials available for use in geopolymers. However, not all of these options are realistic and the success of the solid aluminosilicate source depends a great deal on the properties listed below, which mainly relate to ease of dissolution.

- $\quad$ Reactive Si and Al content

- Amorphous or disordered structure

- Particle size and shape 
- Physical and compositional homogeneity

- Hardness

Reactive Si and Al content - Si and $\mathrm{Al}$ are the main network formers of the geopolymer matrix, so a generous amount of reactive $\mathrm{Si}$ and $\mathrm{Al}$ are crucial to success. The rate at which these two elements become available can have a large impact on the kinetics of geopolymerization, as well as the fresh and hardened properties of the concrete. Depending on the phase, some Si and Al may not be available for reaction, such as in the case of crystalline phases like quartz and mullite in fly ash; therefore the $(\mathrm{Si} / \mathrm{Al})_{\text {reactive }}$ is a more relevant number than $(\mathrm{Si} / \mathrm{Al})_{\text {total }}$ and should be considered instead (Fernández-Jiménez et al. 2006).

Amorphous or disordered structure - Amorphous (vitreous or glassy) phases are favored for geopolymer synthesis, since they dissolve easier and faster than crystalline phases due to the disorder of the structure, as shown in Figure 2.14. Increased dissolution leads to more Si and Al available in solution for polycondensation, which has been found to lead to higher compressive strengths (Fernández-Jiménez and Palomo 2003; Sofi et al. 2007). 

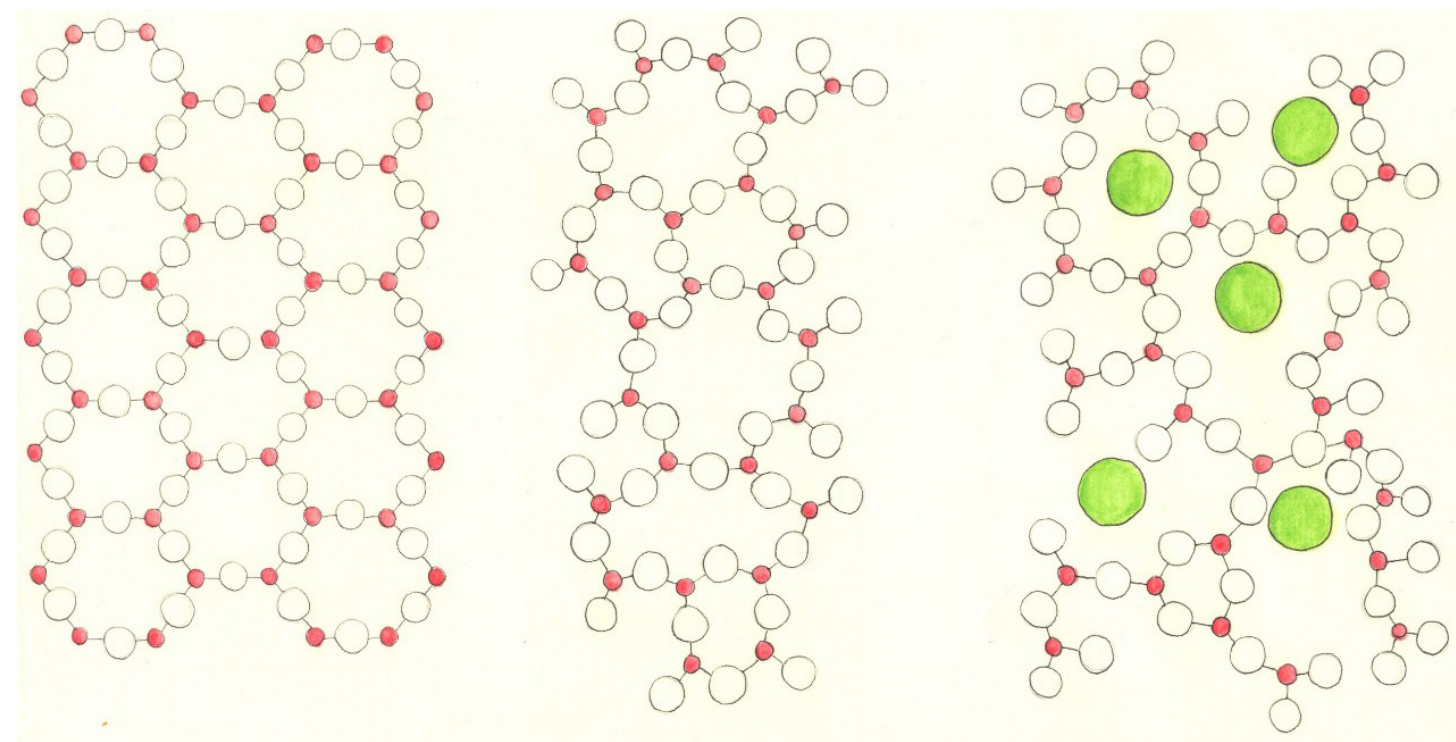

$\mathrm{Na}^{+} \bigcirc \mathrm{O}^{2-} \bigcirc \mathrm{Si}^{4+}$

Figure 2.14. Two-dimensional schematic of crystalline silica (left), glassy silica (middle) and binary silicate glass (right) (Hemmings and Berry 1988).

In a study considering the dissolution rates of $\mathrm{Si}$ and $\mathrm{Al}$ of 16 different natural aluminosilicate minerals, it was found that samples with a framework silicate structure had the highest dissolution, as compared to others with more ordered ortho-, di-, ring, chain and sheet silicate structures (Xu and Deventer 1999; Xu and Van Deventer 2000).

Calcined materials are also generally more reactive than their original crystalline counterparts, which tend to dissolve slower ( $\mathrm{Xu}$ and Van Deventer 2002). The raw materials used and their subsequent processing have been shown to have a major impact on geopolymer properties such as setting behavior and workability as well as other chemical and physical properties (Madani et al. 1990; Palomo and Glasser 1992; Duxson et al. 2007). 
Particle size and shape - The smaller, or more irregularly shaped the particle, the larger the specific surface area. The larger the surface area per unit volume of a particle that is in contact with the activating solution, the more dissolution will occur. Particle size, and therefore specific surface area, has a direct influence on the dissolution rate of a material, where smaller particles dissolve faster and have a higher solubility (Pankow 1991). In the case of a system with multiple sized particles, where dissolution rates will be different with each size, the dissolution rate is proportional to the specific surface area and the overall solubility is related to the particle size. Iler observed a direct relationship between the radius of curvature of a particle and the solubility of that particle, where particles with the smallest positive radii have the highest solubility (Iler 1979). In a system with coarser particles, reactions at the surface sometimes create a layer of reaction products around the particle preventing further reaction from occurring except through diffusion, which is very slow.

It is important to note that increasing the specific surface area or surface irregularities of a material will also increase the water necessary to create a workable mixture. Aggregation of particles can also play a role in affecting the reactivity of a material. Weng et al., found that aggregated metakaolin particles resulted in unreacted metakaolin which did not contribute to the overall geopolymer (Weng et al. 2005).

Physical and compositional homogeneity - Materials that are physically and compositionally homogeneous tend to dissolve more evenly and result in a more uniform final product. Heterogeneity within the source material can result in consistency issues due to variable and inconsistent dissolution rates. Also, when physical and compositional 
properties are unknown, producing a reliable and reproducible binder with predictable final properties can be difficult.

Hardness - Hardness is important in systems where the source material is not fully reacted and the unreacted particles remain embedded in the final matrix (Xu and Van Deventer 2000). If these unreacted particles are too soft, they can act as defect points within the matrix leading to early failure. However, particles that are hard can act as a microaggregate, in some cases adding strength to the matrix (Palomo and Glasser 1992).

\subsubsection{Material sources}

Many of the materials used in geopolymers are also employed in OPC concrete as supplementary cementitious materials (SCMs). The requirements for a successful SCM and a geopolymer source material are very similar. Materials that have been used to produce geopolymers include:

- Metakaolin

- Fly ash (Class F or C)

- Blast furnace slag

- Glass

- Silica fume

- Red mud

- Natural aluminosilicate minerals

- Kaolinite clay

- Natural pozzolans such as volcanic ash

- Mine tailings 
As stated previously, alkali activated cements can be separated into two groups based on the composition of the solid powdered material, with the deciding factor being the calcium content. A ternary diagram plotting typical $\mathrm{Si}, \mathrm{Al}$ and $\mathrm{Ca}$ contents of several common materials that have been used to make geopolymer cements as well as OPC is shown in Figure 2.15.

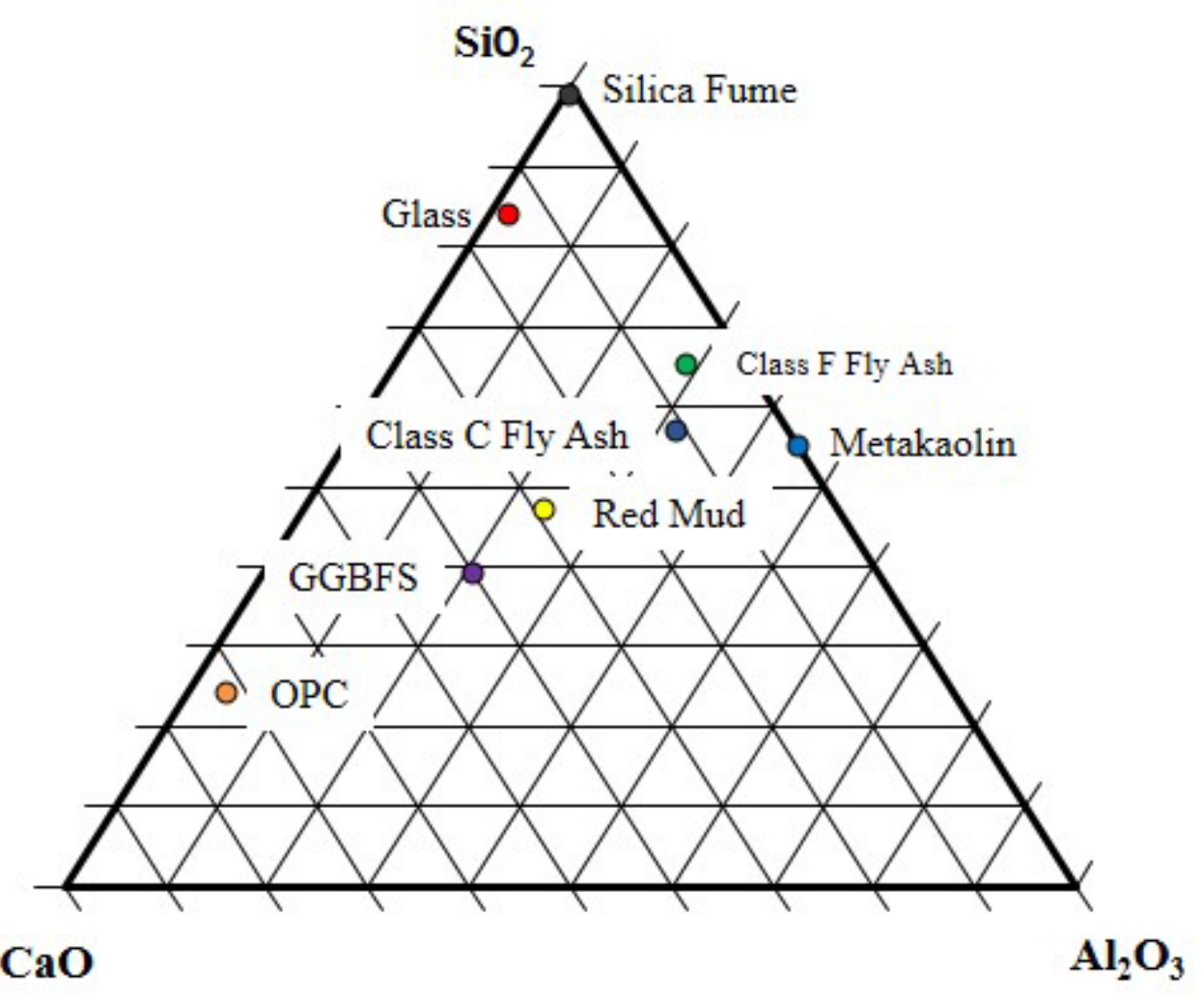

Figure 2.15. Typical composition of common solid materials used in geopolymer cements and OPC.

Though many macroscopic characteristics of geopolymers prepared from different aluminosilicate sources may appear similar, their microstructure and physical, mechanical, 
chemical and thermal properties vary to a large extent depending predominantly on the raw material from which they are derived (Duxson et al. 2007).

Materials such as kaolinite (Davidovits 2008), naturally occurring aluminosilicate minerals (Xu and Van Deventer 2000; Xu and Van Deventer 2002), cement kiln dust (Babaian et al. 2003; Buchwald and Schulz 2005), silica fume (Brew and MacKenzie 2007), natural pozzolans such as volcanic ash (Varela et al. 2009) and red mud (Pan et al. 2003; Zhang et al. 2010) have also been explored.

Due to their ample supply of available Si and Al, fly ash and metakaolin are the most commonly used aluminosilicate materials in geopolymer production today and are presented in more detail in the next section. Waste glass is also expanded upon at the end of the section.

\subsubsection{Metakaolin}

Metakaolin is produced from the heat treatment of kaolinite clay, $\mathrm{Al}_{2} \mathrm{Si}_{2} \mathrm{O}_{5}(\mathrm{OH})_{4}$ through air calcination. Kaolinite is formed from the weathering of feldspars, tuffs or volcanic ashes over hundreds to thousands of years (Grutzeck and Marks 1999) and is classified as a 1:1 dioctahedral phyllosilicate. This means it has a structure of 1:1 sheets of tetrahedral silica, $\mathrm{SiO}_{4}$ and octahedral alumina, $\mathrm{AlO}_{6}$ bound together by strong oxygen bonds (Sperinck et al. 2011). Alumina substitution for silica in clays is known as isomorphous substitution, which occurs when an atom of a lower oxidation state replaces an atom of a higher oxidation state. Since the Al has a +3 charge on it, compared to the Si with a charge of +4 , it must be 
balanced with cations, usually $\mathrm{Na}^{+}, \mathrm{K}^{+}$, etc. (Pankow 1991). For this reason, cations are adsorbed onto the layers or edges of the clay (Palomo and Glasser 1992).

When kaolinite is heated to above $500^{\circ} \mathrm{C}$, hydroxyl ions are removed to form metakaolin (Grim 1968); this can be done inexpensively in low tech kilns or furnaces. Dehydroxylation of the clay creates a structure that is distorted, made of irregular layers of $\mathrm{Si}$ and $\mathrm{Al}$, with the $\mathrm{Al}$ moving into vacant sites in between the layers and changing from $\mathrm{Al}(\mathrm{VI})$ to $\mathrm{Al}(\mathrm{IV})$ in tetrahedral coordination (Grim 1968; Sperinck et al. 2011). Heating transforms the flat, hexagonal kaolinite particles to a dinner plate shape with an extremely high specific surface area. The median size is typically five microns or smaller but depends on the calcination temperature and time of the base kaolin (Duxson et al. 2007).

The maximum heating temperature can affect the reactivity of the metakaolin formed; in comparing kaolin heated for 24 hours at $750^{\circ} \mathrm{C}, 2$ hours at $850^{\circ} \mathrm{C}$ and 2 hours at $980^{\circ} \mathrm{C}$, it was found that $750^{\circ} \mathrm{C}$ metakaolin (known as MK-750) was the most reactive (Madani et al. 1990; Palomo and Glasser 1992; Davidovits 2008). Higher temperatures or long calcination times sometimes result in the formation of mullite phases and segregated silica, which decrease the solubility of the metakaolin (Van Jaarsveld et al. 2002). While the heat treatment that clay undergoes has been found to greatly enhance the reactivity of the material, it also greatly increases the water demand (Provis et al. 2010). The rheology of mixtures containing metakaolin is unique due to the interlayer alkali attack upon initial mixing which increases the viscosity. Figure 2.16 shows the morphology of metakaolin particles, which tend to aggregate together. 


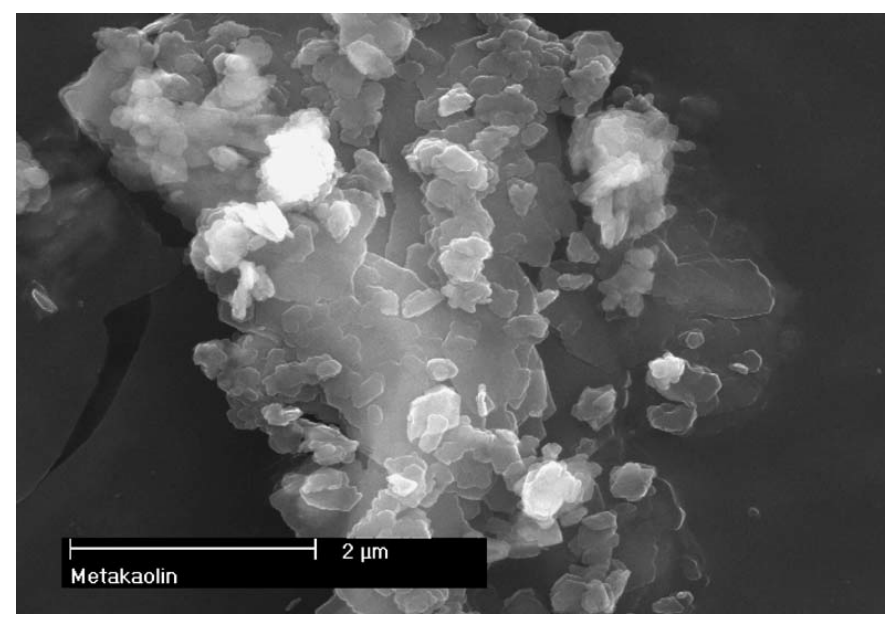

Figure 2.16. Metakaolin particles (Steveson and Sagoe-Crentsil 2005). Reprinted by permission of Springer. See Appendix D for documentation of permission to reprint this material.

Table 2.6 shows a typical composition of metakaolin. Typical impurities include titanium dioxide and muscovite, $\mathrm{KAl}_{2}\left(\mathrm{Si}_{3} \mathrm{Al}\right) \mathrm{O}_{10}(\mathrm{OH}, \mathrm{F})_{2}$, neither of which has been found to effect geopolymerization.

Table 2.6. Composition of a typical metakaolin by mass (Kosmatka 2011).

\begin{tabular}{|c|c|}
\hline & Metakaolin \\
\hline $\mathrm{SiO}_{2}$ & $53 \%$ \\
\hline $\mathrm{Al}_{2} \mathrm{O}_{3}$ & $43 \%$ \\
\hline $\mathrm{Fe}_{2} \mathrm{O}_{3}$ & $0.5 \%$ \\
\hline $\mathrm{CaO}$ & $0.1 \%$ \\
\hline $\mathrm{SO}_{3}$ & $0.1 \%$ \\
\hline $\mathrm{Na}_{2} \mathrm{O}$ & $0.05 \%$ \\
\hline $\mathrm{K}_{2} \mathrm{O}$ & $0.4 \%$ \\
\hline Total Na equivalent alkali & $0.3 \%$ \\
\hline Loss On Ignition (LOI) & $0.7 \%$ \\
\hline Hardness (kaolinite) & $2-2.5$ \\
\hline
\end{tabular}

Metakaolin is also an effective pozzolan for use in ordinary portland cement concrete, and has been shown to improve the pore structure of the concrete, which in turn increases the materials resistance to deleterious substances (Sabir et al. 2001). Other markets for 
metakaolin include the food-processing industry, oil shale processing, ceramics, pozzolans and in geopolymers (Sperinck et al. 2011). Colored kaolinite is listed as a waste material (Kolouek et al. 2007).

\subsection{Metakaolin geopolymers}

The homogenous composition and uniform particle size and shape of the calcined clay result in a highly reactive material that freely contributes $\mathrm{Si}$ and $\mathrm{Al}$ to the geopolymer system. However, today metakaolin is most often used as a model material for research rather than in actual structural applications. This is due in part to the fact that unreacted particles following geopolymerization are thought to act as defect sites within the matrix due to their softness and the high water demand associated with the small, platy metakaolin particles (Duxson et al. 2007; Provis et al. 2010).

Metakaolin geopolymers are generally not as strong as fly ash geopolymers (Duxson et al. 2007). It is fairly commonplace, however, to mix metakaolin or kaolinite with another, less reactive precursor to create a successful geopolymer binder. The synergy between metakaolin and other aluminosilicate sources is important and has been shown to enhance the properties of the binary geopolymer as compared to the single material on its own (Xu and Van Deventer 2000; Xu and Van Deventer 2002). A mixture of 100\% metakaolin, M, and another of $50 \%$ metakaolin and 50\% fly ash, FM, were compared and the FM mixture was found to reach a much higher compressive strength under the same synthesis conditions (Fernández-Jiménez et al. 2007). 
During geopolymerization, it is believed the chemical attack starts on the outside of the metakaolin particles and then over time as the interlayers swell, $\mathrm{Na}^{+}$and $\mathrm{OH}^{-}$ions fit in between the layers and continue dissolution there. If soluble silicate particles are present, however, they cannot usually fit inside the layers, which often leads to a decreased degree of reaction (Davidovits 2008). It has been found that metakaolin-based geopolymers made with a high amount of soluble silica in the activating solution often result in a more porous final product. This is thought to be due to the fact that soluble silica hinders the reorganization of the initial gel products into a denser gel (Duxson et al. 2007). However, a subtle increase of the $\mathrm{Si} / \mathrm{Al}$ ratio to around 3.0-3.8 through the addition of soluble silica in the activator solution (De Silva et al. 2007) typically leads to an increase in the Young's modulus and mechanical strength (Duxson et al. 2007; Duxson et al. 2007; Provis 2009).

Sometimes microstructural studies on pure metakaolin geopolymers can be difficult because it is hard to distinguish between unreacted metakaolin and the final geopolymer product (Palomo et al. 2004; Fernández-Jiménez et al. 2007). During dehydroxylation of kaolinite, the Al changes from VI-fold to IV-fold coordination. Reacted samples of metakaolin geopolymer contain mainly $\mathrm{Al}(\mathrm{IV})$ with trace amounts of $\mathrm{Al}(\mathrm{VI})$; any $\mathrm{Al}(\mathrm{VI})$ found in the Al MAS NMR spectra can be used to determine the amount of unreacted metakaolin (Barbosa et al. 2000; Duxson et al. 2005; Duxson et al. 2007).

\subsubsection{Fly ash}

Fly ash is an industrial byproduct from coal burning power plants. Its composition can vary greatly from source to source, but the majority of particles are in the form of amorphous 
aluminosilicate spheres. To truly understand the complexities of fly ash, the source material and process of formation must first be considered.

Coal is formed through a process known as coalification. Coalification occurs when plants and trees growing in swamps die and sink down to the bottom of the swamp, forming peat, which over time becomes buried and compressed by silt and sand. Over millions of years, the water is squeezed out of the peat and sustained heat and pressure turn the peat into coal (ACF 2010). Coal deposits are usually found in beds or seams and are often separated by layers of shale, silt or sandstones. Additionally, coal can also contain clays, carbonates, sulphides and other oxides, which all serve to alter the composition of the fly ash. Coal can also contain a wide variety of embedded minerals containing elements such as iron, titanium, sulfur, phosphorous, boron, alkali metal and alkali earth cations (Provis 2009).

There are four major types of coal found in the United States, all containing varying amounts of carbon; lignite, subbituminous, bituminous and anthracite (ACF 2010). Mined coal is pulverized into a very fine powder and mixed with hot air then inserted into a furnace where it is burned. The heat generated from the burning coal boils water in a boiler, creating steam. The steam powers a spinning engine called a turbine, and a generator converts the mechanical energy from the spinning turbine into electric energy (ACF 2010).

Each power station has its own burning conditions designed to optimize the electrical output. Since the main purpose of burning coal is to produce electricity, the quality and consistency of the fly ash produced is not typically the main concern of the plant operator. Variations in composition and physical properties range widely depending on burning 
conditions, the type of coal burned, cooling rate, etc. making fly ash notoriously heterogeneous in nature. Impurities in the coal that are not burned or volatilized (clays, carbonates, sulphides, etc.) are carried away from the furnace in the form of airborne particles in the flue gas (Hemmings and Berry 1988). Close to $80 \%$ of the ash produced during combustion leaves the furnace in the flue gas and is typically collected using electrostatic precipitation.

Individual fly ash particles differ from each other even when they come from the same power plant at the same time. Interparticle speciation is common on the macroscale, especially with particles containing high iron contents and those containing crystalline quartz. Intraparticle speciation can also occur within individual particles containing iron. Iron rich particles can be separated using magnetic separation (Hemmings and Berry 1986).

Mineralogically, fly ash contains a large volume of amorphous phases or glass due to rapid cooling, and some smaller quantities of crystalline phases such as quartz, mullite, hematite, $\mathrm{TiO}_{2}$, etc. The glassy phase in fly ash is referred to as an aluminosilicate phase and is mainly a result of the melting of the clay impurities in the coal. When hot, these impurities create a homogenous melt but when cooled, they separate into two main phases. The two phases are a silica rich phase and an alumina rich phase. The silica rich phase requires more time to cool before crystallizing than the alumina phase and so usually remains amorphous. The alumina rich phase takes less time to crystallize and unless it is cooled extremely rapidly, will crystallize into mullite, which is common. This results in a decrease of the amount of reactive $\mathrm{Al}$ available for geopolymerization. The time that a particle has 
to cool depends on its size, time in the furnace and the method of quenching each power plant employs (Provis 2009).

Table 2.7. Typical composition of Class F and C fly ashes by mass (Kosmatka and Wilson 2011).

\begin{tabular}{|c|c|c|}
\hline & Class F & Class C \\
\hline $\mathrm{SiO}_{2}$ & $52 \%$ & $35 \%$ \\
\hline $\mathrm{Al}_{2} \mathrm{O}_{3}$ & $23 \%$ & $18 \%$ \\
\hline $\mathrm{Fe}_{2} \mathrm{O}_{3}$ & $11 \%$ & $6 \%$ \\
\hline $\mathrm{CaO}$ & $5 \%$ & $21 \%$ \\
\hline $\mathrm{SO}_{3}$ & $0.8 \%$ & $4.1 \%$ \\
\hline $\mathrm{Na}_{2} \mathrm{O}$ & $1.0 \%$ & $5.8 \%$ \\
\hline $\mathrm{K}_{2} \mathrm{O}$ & $2.0 \%$ & $0.7 \%$ \\
\hline
\end{tabular}

In the United States, fly ash is separated into two types, $\mathrm{C}$ and F, depending on composition. According to ASTM C618 - Standard Specification for Coal Fly Ash and Raw or Calcined Natural Pozzolan for Use in Concrete. Class F fly ash has a total sum of the silica, alumina and iron oxides of greater than 70\% (ASTM International 2008). Class C fly ash is defined as having a silica, alumina and iron oxides sum of more than $50 \%$.Generally Class $\mathrm{F}$ fly ashes have lower $\mathrm{CaO}$ contents and are the result of burning older anthracite or bituminous coal, which is found in the eastern United States; while class $\mathrm{C}$ ashes have a higher calcium content and are the product of burning younger sub-bituminous or lignite coal, which is found more in the western United States. Most ready-mix plants prefer Class C fly ash to Class F fly ash because of the increased calcium content, which can easily react with Si to form C-S-H. ASTM C618 also limits the LOI content to $6 \%$, but realistically, less than $1 \%$ is desired for concrete subject to freeze-thaw conditions (ASTM International 2008; PCA 2011). 
Economically, the cost of a ton of fly ash compared to a ton of portland cement is typically one half. Due to the very fine spherical particle shape of fly ash, it has found great use in the concrete industry. On average, builders use approximately $15-35 \%$ fly ash replacement in ordinary portland cement concrete mixtures by mass (NRC 2000). Ideal fly ashes for use in geopolymers may be available but they might not be geographically feasible to use or they might also be in high demand by OPC concrete manufacturers, so less ideal fly ash compositions must be considered. This includes ashes with high LOI or high alkali contents (Provis and vanDeventer 2009). If these unwanted fly ashes are not able to be used and are landfilled, issues with space problems, potential air pollution risks and contamination of water due to leaching could occur (Fernández-Jiménez and Palomo 2005). In 2007, approximately 72 million tons of fly ash were produced in the United States, but only $44 \%$ of that was used, mainly in concrete applications, the rest went to the landfill (ACAA).

\subsection{Fly ash in geopolymers}

“... the challenge of producing consistent geopolymer products from heterogeneous industrial waste sources such as fly ash requires a greater degree of characterization than is provided by an elemental composition analysis" (Duxson et al. 2007).

Fly ash is often favored over metakaolin as a base for geopolymer because it is an industrial byproduct and therefore does not contribute any carbon emissions to a total carbon footprint. Fly ash geopolymer cements have also been found to have higher mechanical 
and durability properties as compared to metakaolin geopolymer cements (Duxson et al. 2007).

The glassy phases of fly ash, consisting of silica and alumina, and sometimes calcia are readily dissolved in highly caustic solutions, and so despite its extreme variability, fly ash remains a prime material for use in geopolymer cement. It has been found the more vitreous (i.e., amorphous) phases present in the fly ash, the higher the degree of reaction during polymerization and the higher compressive strength (Fernández-Jiménez and Palomo 2003). Crystalline or insoluble phases prevent the possibility of achieving a $100 \%$ degree of reaction; however, unreacted fly ash particles have been found to act as micro-aggregate embedded within the aluminosilicate matrix, in some cases adding strength to the system (Fernández-Jiménez et al. 2005).

Some fly ash particles do not react at all, while others show signs of surface dimpling and others still are completely reacted, leaving behind just the outline of where it once was. This has been said to be due to differences in the fly ash properties per particle or to the fact that in some cases a hydration barrier (made of reaction product) prevents some particles from reaction, in a local manner, where $\mathrm{pH}$ is very important (Fernández-Jiménez et al. 2004).

Rapid cooling in air and surface tension forces cause fly ash particles to maintain a spherical shape; these spheres can be solid, hollow (cenospheres) or filled with other spheres (plerospheres) (Diamond 1986). Figure 2.17 shows the morphology of fly ash particles typically range in size from 0.5 to 100 microns. 


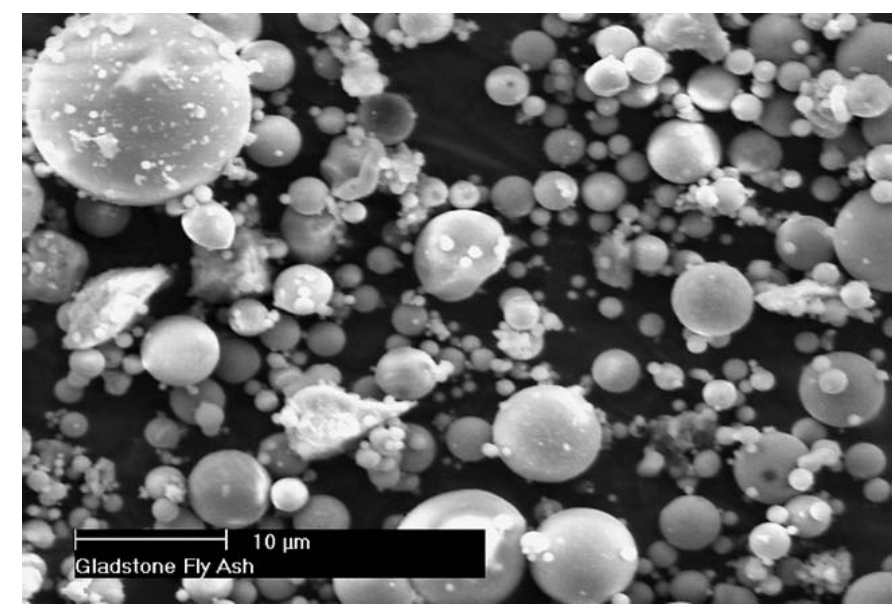

Figure 2.17. Morphology of fly ash particles (Steveson and Sagoe-Crentsil 2005). Reprinted by permission of Springer. See Appendix D for documentation of permission to reprint this material.

The spherical nature of fly ash particles is particularly useful in a binder system, as it reduces both the yield stress and viscosity of the paste in shear (Provis et al. 2010). This "ball bearing effect" increases the workability of a mixture without an increase in water demand. The fineness is affected by the type of coal, degree to which the coal was pulverized before it was burned and also the burning process and power plant equipment (Fernández-Jiménez and Palomo 2003). Mechanicochemical activation in a vibratory mill has shown to further increase the reactivity of fly ash particles, where "more fracture damage, chemical and physical changes, and defects" were added, which led to more geopolymerization (Kumar et al. 2007; Temuujin et al. 2009).

The spherical nature of the fly ash particles has also been helpful in understanding the steps of geopolymerization because evidence of reaction is easier to see on the particles as compared to other materials such as metakaolin, where it is more difficult to differentiate between the raw material and final product (Fernández-Jiménez et al. 2005). 
Many successful GPC mixtures have been made using fly ash; however, in most cases, just one or several fly ashes were considered at a time and mixture optimization was a fairly lengthy process. There has been little research reported on how to quickly identify the necessary material properties of a fly ash and design the activating solution accordingly. Compositional variability is an issue in mixture design and it is largely a process of trial and error to find the right design for a specific fly ash.

\subsubsection{Glass}

The first documented use of glass dates back to the Mesopotamian civilization of 3500 B.C., from which archeologists have found handmade rustic glass beads. Glass making technology has obviously advanced since then, with some modern plants capable of producing 700 bottles per minute (Glass Packaging Institute 2013).

Today, glass production begins with virgin materials including sand, soda ash and limestone as well as cullet (broken glass). These materials and various additives are batched and heated to $1430-1540^{\circ} \mathrm{C}$ molded into the desired shape and cooled (Glass Packaging Institute 2013). Table 2.8 lists the main raw materials and their purpose in glass. 
Table 2.8. Raw materials and their purpose in glass production (Glass Packaging Institute 2013).

\begin{tabular}{|c|c|c|c|}
\hline $\begin{array}{c}\text { Raw } \\
\text { Material }\end{array}$ & $\begin{array}{c}\text { Elements } \\
\text { Added }\end{array}$ & $\begin{array}{c}\text { Structural } \\
\text { Role }\end{array}$ & Purpose in Glass \\
\hline $\begin{array}{c}\text { Sand or } \\
\text { feldspathic } \\
\text { sand }\end{array}$ & $\mathrm{SiO}_{2}, \mathrm{Al}_{2} \mathrm{O}_{3}$ & $\begin{array}{c}\text { Network } \\
\text { former }\end{array}$ & Backbone of glassy phase \\
\hline $\begin{array}{c}\text { Soda ash } \\
\text { Limestone, } \\
\text { dolomite }\end{array}$ & $\mathrm{NaO}_{2} \mathrm{O}$ & Fluxing agent & Adds fluidity and promotes melting \\
\hline $\begin{array}{c}\text { Feldspar, } \\
\text { nepheline, } \\
\text { aplite }\end{array}$ & $\begin{array}{c}\mathrm{SiO}_{2}, \mathrm{Al}_{2} \mathrm{O}, \\
\mathrm{Na}_{2} \mathrm{O}, \mathrm{K}_{2} \mathrm{O}, \\
\mathrm{CaO}\end{array}$ & $\begin{array}{c}\text { Intermediate } \\
\text { formers }\end{array}$ & $\begin{array}{c}\text { Adds durability and increases } \\
\text { viscosity and workability of melt }\end{array}$ \\
\hline $\begin{array}{c}\text { Saltcake, } \\
\text { gypsum }\end{array}$ & $\begin{array}{c}\mathrm{SO}_{3}, \mathrm{Na}_{2} \mathrm{O}, \\
\mathrm{CaO}\end{array}$ & $\begin{array}{c}\text { Fining agent } \\
\text { Carbocite, } \\
\text { carbon }\end{array}$ & Source of $\mathrm{SO}_{2}$ gas and $\mathrm{Na}_{2} \mathrm{O}, \mathrm{CaO}$ \\
\hline
\end{tabular}

Coloring agents are also sometimes added to glass to prevent ultraviolet rays from penetrating into the glass container and also is marketable for branding. Decolorization is the introduction of selenium or cobalt to offset the yellow/green color in flint glass (Glass Packaging Institute 2013)(Glass Packaging Institute 2013)(Glass Packaging Institute 2013) (Glass Packaging Institute 2013). Pyrite, iron oxide, iron scale and melite are sources of iron and sulfur used to make amber glass, non-toxic chrome oxide colors glass green, cobalt oxide colors glass blue, selenium colors glass red and nickel colors glass violet or brown (Glass Packaging Institute 2013). 
Today, commercial glass falls into six major categories with soda-lime glass making up about $90 \%$ of all glass made in the United States (Burns 2012).

1. Soda-lime glass

2. Lead glass

3. Borosilicate glass

4. Aluminosilicate glass

5. $96 \%$ silica glass

6. Fused silica glass

Table 2.9 shows the typical composition of soda-lime glass used primarily in bottle and packaging applications.

Table 2.9. Typical composition of soda-lime glass by mass (Glass Packaging Institute 2013).

\begin{tabular}{|c|c|}
\hline & Soda-lime glass \\
\hline $\mathrm{SiO}_{2}(\%)$ & $72 \%$ \\
\hline $\mathrm{Al}_{2} \mathrm{O}_{3}(\%)$ & $2 \%$ \\
\hline $\mathrm{CaO}(\%)$ & $12 \%$ \\
\hline $\mathrm{Na}_{2} \mathrm{O}(\%)$ & $13 \%$ \\
\hline Minors $(\%)$ & $1 \%$ \\
\hline Hardness & $5.5-6.5$ \\
\hline
\end{tabular}

Most of the markets for waste glass involve the need for comminution (size reduction) and size separation. Cullet used to make new glass can be as large as 3/4 inch, however, in most other markets much smaller particle sizes are required. Crushed and ground glass particles have a varying shape depending on the size of the particle. Particles larger than 1/10 inch have been known to be plate-like and smooth with sharp edges and are found to be quite friable. Heavy gloves are usually necessary for handling these larger particles. Smaller 
particles, $<1.5 \mathrm{~mm}$, are typically subangular, with a more normal shape and are less friable and easier to handle. Crushed glass typically displays a conchoidal fracture resulting in sharp edges and smooth planes, but further grinding has been found to even out the particle shape (Polley et al. 1998). Figure 2.18 shows the morphology of finely ground glass particles.

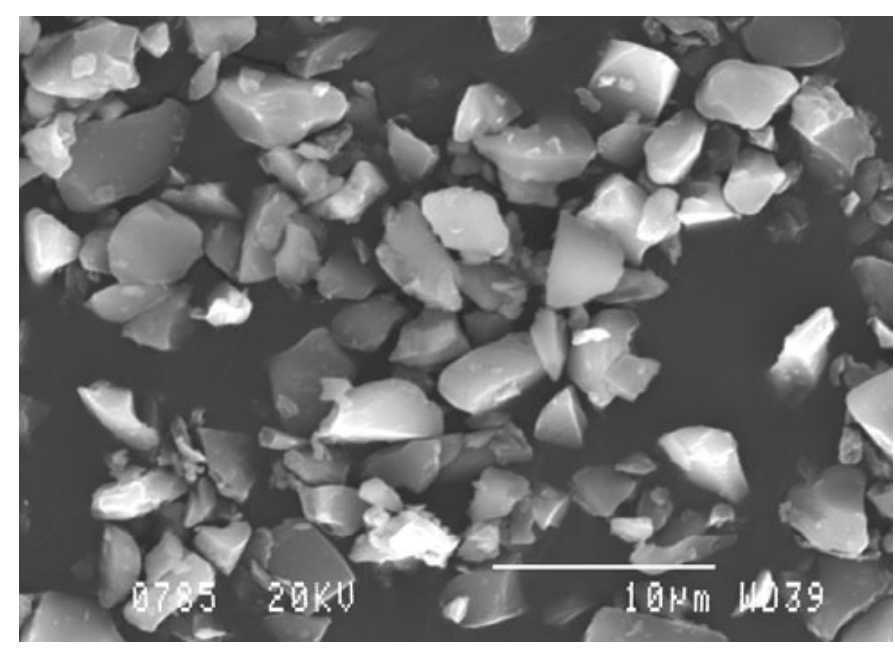

Figure 2.18. Typical morphology of soda-lime silica bottle glass (Cyr et al. 2012). Reprinted by permission of Springer. See Appendix D for documentation of permission to reprint this material.

Mining and aggregate industry equipment is often used to crush glass because of its abrasive nature; this includes both compression and impacting devices. The hammer mill has been used successfully with longer residence times leading to more rounded particle shape due to inter-particle attrition. Grinding mills such as ball mills, vertically stirred mills, fluid energy and rotary mills are used to process the glass down to powder size. The stirred attrition mill also works well to create rounded particles (Pascoe et al. 2001). 


\subsection{Recycling in the United States}

"Glass is $100 \%$ recyclable and can be recycled endlessly with no loss in quality or purity (Glass Packaging Institute 2013).",

Since cullet, or broken glass, can be used to make new glass simply by melting it together with other virgin raw materials, the most obvious use for waste glass is to make new glass. In fact, glass manufacturers want to reuse glass cullet because it lowers the required melt temperature, which results in substantial savings in energy and fuel, and also cuts down on the raw materials needed (Glass Packaging Institute 2013). However, despite this seemingly simple recycling loop, waste glass recovery rates in the United States are surprisingly low.

Total municipal solid waste (MSW) in the United States in 2010 was reported by the EPA to be 249.86 million tons of material, with glass making up about $4.6 \%$. Of the 11.53 millions tons of glass generated, only $27 \%$ was recovered. This follows a similar trend from the past twenty years, as shown in Figure 2.19 (US EPA 2010). Strict color and compositional requirements for cullet used to make new glass are the main cause of these low recovery rates. 


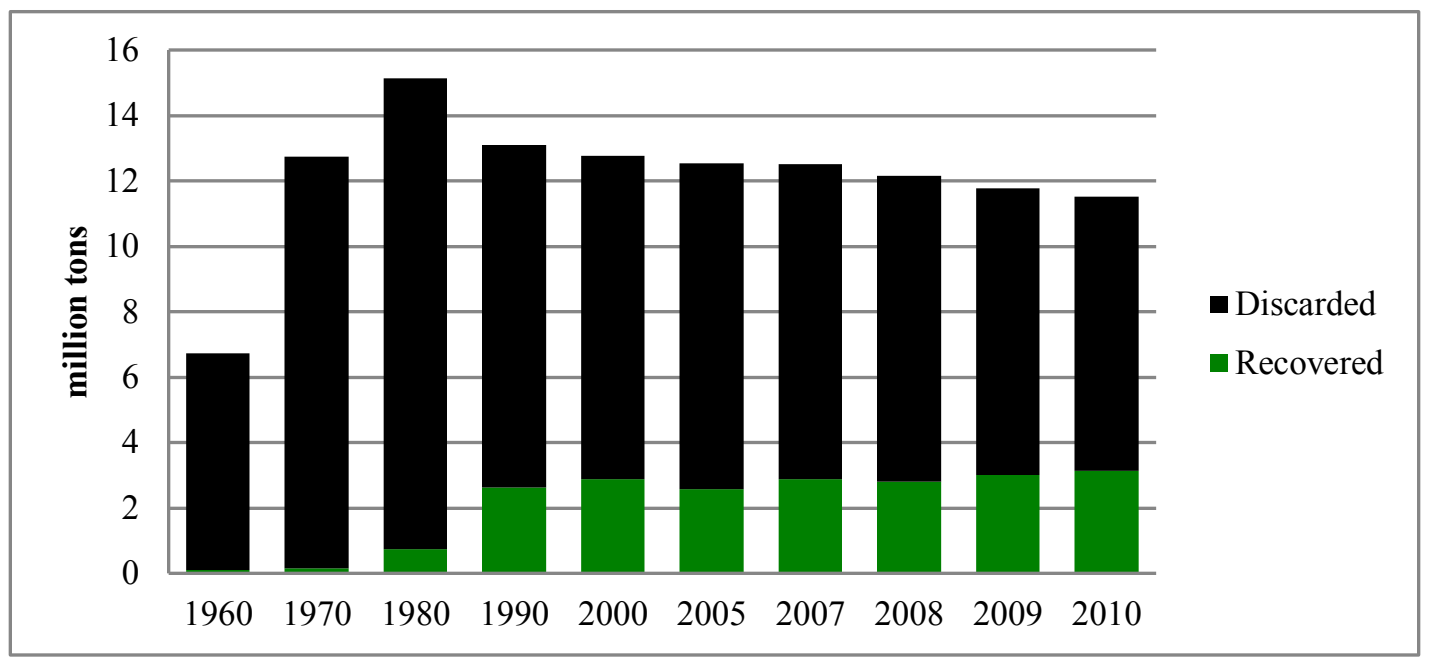

Figure 2.19. Relationship between recovered and discarded glass in MSW from 1960-2010. Black represents discarded glass, green represents recovered glass (US EPA 2010).

Post-industrial glass is collected directly from the manufacturing process and is easily used to make new glass since the producer of the waste is also the end market user and so can easily control the color and purity of the material, making it a closed loop system with no waste. In addition, glass collected through separated collection methods such as those employed at restaurants or bars or in states that have bottle deposits often yield glass that can quickly and inexpensively be made acceptable for glass recyclers. A report by the Container Recycling Institute states that those states with mandated bottle deposit programs have an average glass recovery rate of $63 \%$, which is much higher than that of the country as a whole (US EPA 2010; Glass Packaging Institute 2013), however, only ten states in the U.S. have bottle deposits: CA, CN, HI, IO, ME, MA, MI, NY, OR and VT.

Glass collected through curbside or single stream recycling programs are another story (Stoklosa 2012). When glass is collected through a single-stream or curbside recycling program, maintaining these strict color and purity requirements becomes extremely 
difficult. Post-consumer glass collected from these programs is often broken, laden with impurities and a mixture of many different colors and types of glass by the time it reaches the end of the sorting process at material recycling facilities (MRF).

Color-Glass in the United States is produced in three main colors: flint, amber and green. Cullet used to make new glass must be well sorted by color because too much of the wrong color can lead to the glass appearing cloudy or slightly off color, which is not acceptable.

Composition - Compositional impurities are also an issue with reusing cullet to make new glass. Specifically, any glass type or other material that melt at a higher temperature than the desired glass type can be detrimental to the glass production machinery (Glass Packaging Institute 2013). Contamination from these materials can result in damage to machines, quality fluctuations and the possibility of impurities (called stones) within the final product; which can also result in safety issues in the final product, especially if the contents are under pressure, such as champagne (Zeiger 2008). Common contaminants include (Glass Packaging Institute 2013):

- Ceramic cups, plates and pottery

- Clay garden pots

- Laboratory glass

- Crystal and opaque drinking glasses

- Mirrors

- Windshields and window glasses

- Heat-resistant ovenware (Pyrex or Visionware)

- Light bulbs

- Ceramic and wire caps for beer bottles 
- Lead collars from wine and champagne bottles

- Stones, gravel, dirt

- Metal caps, lids and neck rings

- Drinking glasses

- Hazardous glass containers (like acid containers)

Color sorting machines do exist, using optoelectronic sorting systems which can remove impurities like ceramics, stone, porcelain (CSP) or metals, sort by color and process the rejects for other uses. However, the time and high costs associated with this extra processing often deter MRFs from installing this equipment (Polley et al. 1998; Glusing and Conradt 2001; Zeiger 2008).

In addition to materials processing costs, transportation costs also play a big role on whether or not glass is recycled since it is such a heavy material to transport. This is common in many recycling markets. There are only 48 glass manufacturing plants and 76 cullet processors in the United States and so transportation costs to get the cullet to a recycler make glass recycling unfeasible in many locations (Polley et al. 1998; Glusing and Conradt 2001; Zeiger 2008; Glass Packaging Institute 2013). Glass is not recycled in Houghton, MI for this reason, as shown in Figure 2.20. 


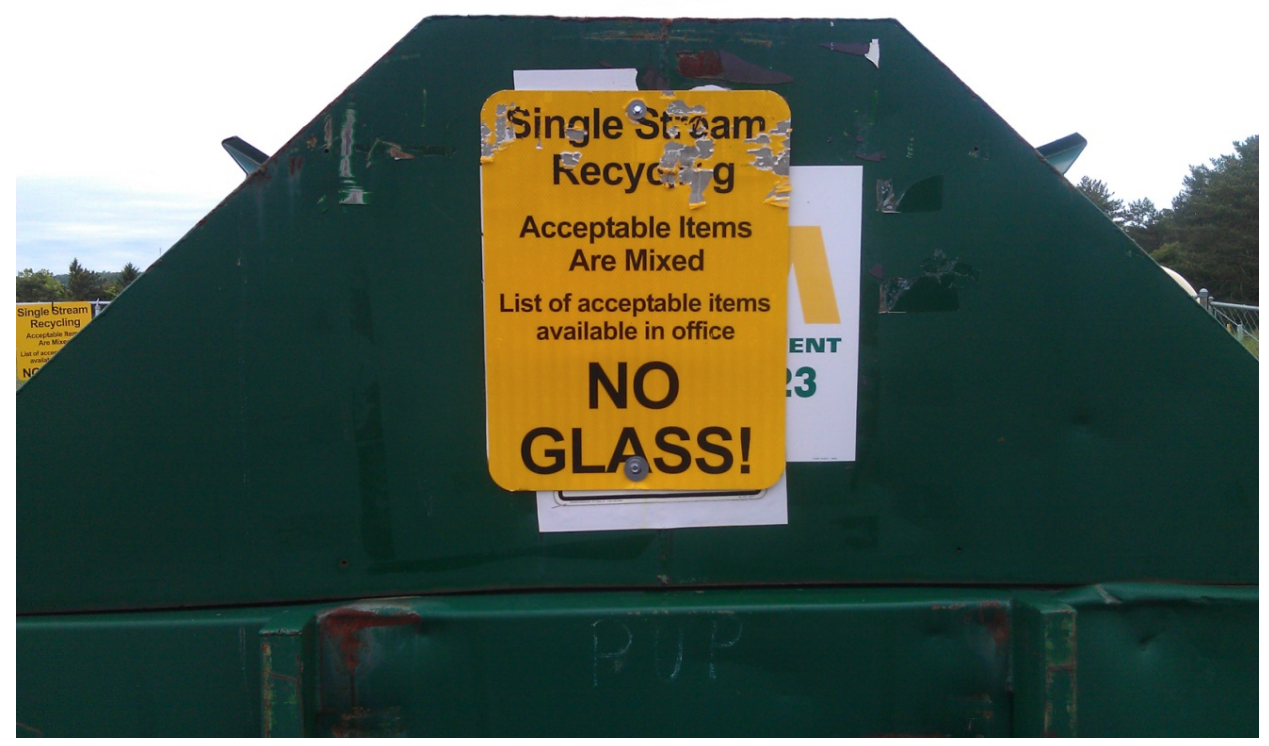

Figure 2.20. No glass sign at Waste Management in Houghton, MI.

Most post-consumer glass that cannot be easily processed and sorted for glass making is typically used to make fiberglass insulation or as abrasive media for sand-blasting (Turner 2013). However, these markets often have compositional limitations of their own and none are robust enough to handle all of the waste glass generated. Other markets include (IMP 1994; Pascoe et al. 2001; US EPA 2010; Glass Packaging Institute 2013):

- Decorative - countertops and flooring, tile and other decorative items

- Landscaping

- Construction - concrete pavements and parking lots, bead manufacturing (used in reflective paint for highways), brick manufacture, Glasphalt

- Aggregate (base course for roads, land, drains, backfill, decorative)

- Additive in clay bricks, plastics or paints

- Adsorbent and cation exchange material

- Filtration medium

- Fractionators for matches and ammunition

- Additive and flux in metal foundry work 
- Hydroponic rooting medium

Efforts to include glass in OPC concrete as either a cement replacement or aggregate have been successful in some cases, but issues with ASR (alkali-silica reactivity), poor workability, high water demand and poor bonding with the OPC matrix are common and must be dealt with proactively (Meyer et al. 1996; Polley et al. 1998; Xie et al. 2003). While other Si-rich materials such as fly ash or silica fume have been shown to be very effective at mitigating ASR and enhancing durability in OPC concrete, waste glass is still considered an orphan material. This is because it possesses many desirable properties of an SCM but does not as of yet have a solid foundation of research and success to support its widespread use.

\subsection{Market longevity}

Glass packaging trends have changed over time with the preferences of society. The $60 \mathrm{~s}$ and 70s saw an increase in glass production leading to a peak around 1980. By 1985, however, aluminum and plastic containers and bottles had become more popular and glass production diminished as seen in Figure 2.19. Since that time, glass generation in the MSW has remained fairly steady, with a slight decrease in the last 20 years (US EPA 2010). It should be noted however, that EPA statistics are based on total mass and glass bottles today are about $50 \%$ lighter in weight than they were 50 years ago (Glass Packaging Institute 2013), so these statistics do not necessarily represent consumer use of glass bottles or containers. 
In 2000, the GPI reported a consumer return to glass due to safety concerns over other commonly used packaging materials such as plastic. In 1960, the United States Food \& Drug Administration (FDA) gave glass the label Generally Recognized as Safe (GRAS); glass is the only packaging material to be given this designation (Glass Packaging Institute 2013). According to a poll given by the GPI, consumers prefer to buy their food and drinks in glass bottles because when comparing glass, paper, metal and plastic packaging materials, glass ranked highest by far in highest quality, truest flavor, most pure and healthiest package (Glass Packaging Institute 2013).

\subsection{Glass in geopolymers}

To date there has been very little research on geopolymer systems based solely on waste glass. Research carried out in Greece reacted finely ground glass $(<90 \mu \mathrm{m})$ with $1 \mathrm{M} \mathrm{NaOH}$, but the activator solution was not nearly strong enough for adequate activation or strength gain (Karamberi et al. 2004). Others looked at using common natural clays and infusible glass cullet rejects, containing stones and ceramic pieces, in an attempt to make a geopolymer cement. By mixing the cullet with the clays in small amounts; strengths around 30MPa were reached (Carvalho et al. 2008). Additional research considering glass as a component in geopolymers has also been recorded (Grutzeck and Marks 1999; Kourti et al. 2010; Hao et al. 2012; Lin et al. 2012).

There has only been one reported account of the production of pure glass-based geopolymer cement, by Cyr et al. who used green bottle glass activated with $\mathrm{NaOH}$ and $\mathrm{KOH}$. Due to the high Si content of the glass, sodium silicate was not included in the 
activator solution, nor was any substantial source of $\mathrm{Al}$, so final $\mathrm{Si} / \mathrm{Al}$ ratios were reported to be around 20 based on the composition of the glass used. With regard to liquid/solid (1/s) ratio, it was found that higher $1 / \mathrm{s}$ ratios resulted in lower compressive strengths (Cyr et al. 2012).

Moderate compressive strengths were reported when samples were cured at $60^{\circ} \mathrm{C}$. However, samples cured at $40^{\circ} \mathrm{C}$ and stored in water were found to have $45 \%$ lower strength. This was thought to be due to the leaching of alkalis, which was prevalent even after several weeks of submersion in distilled water. The cause of this excessive leaching "was believed to be due to the lack of Al in the system, which would normally hold in the alkali cations in a charge balancing capacity. The set times were also reported to be quite long, which again could be due to a lack of Al. "Higher Al content might be needed (by using a source of active aluminum) to improve the setting time at $20^{\circ} \mathrm{C}$ and stabilize the matrix and the alkalis for long-term durability (Cyr et al. 2012).

Using SEM, microstructural characterization of the samples made with the finest glass (14 $\mu \mathrm{m})$ showed all the glass reacted after curing for 56 days and the geopolymeric products were compared to the gel produced during alkali-silica reactions in OPC. It was assumed that some C-S-H gel was produced as well from the calcium in the glass (Cyr et al. 2012). Based on the reaction products, Cyr et al. believe "it seems reasonable to classify the alkaliactivated glass cullet materials as geopolymers, since they are closer to FA- and MK-based geopolymers than calcium-based binders such as OPC and slag (Cyr et al. 2012)." 


\subsection{Glass as an activator}

"It would be interesting to use glass cullet as a precursor for geopolymerization of other types of geopolymers instead of waterglass, since the latter has a very negative environmental impact. However, glass cullet would first need to be activated, by a preliminary dissolving process for instance" (Cyr et al. 2012).

Researchers in Italy reacted ground glass cullet with $\mathrm{NaOH}$ in an attempt to extract soluble silica for use in sodium silicate or as a silica source for zeolite synthesis. Variables they considered in this low energy treatment included temperature, pressure, molarity of the $\mathrm{NaOH}$, liquid to solid ratio, grain particle size and reaction time. The conditions at which the experiments were performed were more conducive to zeolite synthesis rather than geopolymerization, especially the $1 / \mathrm{s}$ ratio, which was varied from 1.5 to 5 (much higher than in geopolymer synthesis). A plateau in silica extraction was found despite an increase in $\mathrm{NaOH}$ concentration and contact time. Increased temperature resulted in more silica extraction, as did smaller particle size ( $<75$ microns). Through the use of a multi-stage reactor, over $75 \%$ of the silica in the glass was extracted into the liquid phase, which was found to be successful at creating zeolites after being combined with a sodium aluminate solution (Mavilia et al. 2001; Di Bella et al. 2003).

The solid phase leftover from the reaction was found to be a combination of unreacted glass and calcium silicates. SEM micrographs taken of the residue showed that some of the particles remained smooth or etched and solid, while others were pitted and covered in an extremely lightweight material with high macro-porosity and surface area. The reason 
for this is that as the Si goes into solution to form sodium silicate, insoluble calcium silicate remains as a porous coating on the glass particles. After a certain time, or from agitation, this coating falls off and the new surface is attacked and the process repeated. However, as the free alkalis in the system decrease, dropping the $\mathrm{pH}$, the reaction eventually stops, leaving some particles unreacted. The solid residue separated into an amorphous coarse phase, which had a very similar composition to the initial glass powder used, and a semicrystalline fine phase which had a lower $\mathrm{SiO}_{2}$ and $\mathrm{Na}_{2} \mathrm{O}$ composition and a higher $\mathrm{CaO}$ content (Mavilia et al. 2001; Mavilia and Corigliano 2001).

\subsection{Activator solution}

While water and possibly the inclusion of various admixtures act as the "activator" in OPC concrete, the alkali activating solution in geopolymers can vary greatly in terms of composition, where the concentration of alkalis, pre-dissolved $\mathrm{Si}, \mathrm{pH}$, viscosity, etc. can all influence the kinetics and resulting microstructure of the mixture.

The activator solution has many roles to play in geopolymerization. First, it provides a fluid in which transport reactions can occur. Second, the high $\mathrm{pH}$ of the system allows for rapid dissolution of the source material. Third, the alkali cations present play a role in the structure of the final geopolymer by acting as a charge balancer for tetrahedrally coordinated Al. Fourth, silica in solution can accelerate the geopolymerization process resulting in a faster setting time, higher compressive strength and often more uniform and homogenous microstructure. A balance of dissolution and polycondensation is required to 
optimize the product and this is often managed through alterations to the activator solution (Bondar et al. 2011).

The most basic form of activator solution is an alkali hydroxide such as $\mathrm{NaOH}$ or $\mathrm{KOH}$. The type of activator used depends a great deal on cost and availability; sodium based chemicals are typically less expensive and more readily available than potassium based chemicals (Bondar et al. 2011). In many cases, pre-dissolved silica is added to the alkali hydroxide to form what is commonly known as waterglass, or sodium silicate, $\mathrm{Na}_{2} \mathrm{SiO}_{3}$. Sodium silicate not only provides extra Si to the system but it also provides it in a readily available manner, which affects the kinetics and therefore geopolymerization of the system. This is discussed later in this section.

It should be noted that in some of the literature, the composition of the activator solution is presented as a formula such as $1.0 \mathrm{Na}_{2} \mathrm{O} \cdot \mathrm{Al}_{2} \mathrm{O}_{3} \cdot 4 \mathrm{SiO}_{2}$. However, simply stating the molar content of $\mathrm{Na}$ does not necessarily reflect the $\left[\mathrm{OH}^{-}\right]$content of the solution, which is important with regard to $\mathrm{pH}$ and dissolution (Sagoe-Crentsil and Weng 2007).

\subsubsection{Sodium hydroxide}

Sodium hydroxide, also known as lye or caustic soda, is a commonly used in many industrial chemical processes and is produced using the chlor-alkali process, which involves the electrolysis of brine, $\mathrm{NaCl}$, to create $\mathrm{NaOH}, \mathrm{HCl}$ and $\mathrm{H}_{2}$ gas. It is available commercially as a solution, a solid, or as pellets, flakes or beads, all of which have the same composition on a mass basis (Shi et al. 2006). 
The role of sodium hydroxide in geopolymerization is to provide hydroxyl ions in solution, which work to dissolve the solid aluminosilicate powder, releasing $\mathrm{Si}, \mathrm{Al}$ and other impurity ions into solution. The dissociation of sodium hydroxide into $\mathrm{Na}^{+}$and $\mathrm{OH}^{-}$ions in solution is extremely exothermic. An estimate of the heat released during dissolution of 10 moles of $\mathrm{NaOH}$ into one liter or water is approximately $400 \mathrm{~kJ}$, which is enough to increase the temperature of the water by close to $90^{\circ} \mathrm{C}$ (Provis 2009). This rapid temperature increase makes necessary certain safety concerns when working with this caustic substance and requires safety considerations for mixing geopolymer cement outside a controlled laboratory.

\subsubsection{Activator concentration effects}

The purpose of the alkali hydroxide, as stated earlier, is to dissolve the source material. A minimum concentration of $\mathrm{OH}^{-}$ions are needed for dissolution and it has been found repeatedly in the literature that an increase in $\mathrm{pH}\left(\mathrm{OH}^{-}\right.$concentration) results in an increase in dissolution of the system ( $\mathrm{Li}$ et al. 2011) which has also been linked to an increase in compressive strength (Xu and Van Deventer 2000; Hardjito et al. 2004; Palomo et al. 2004; Fernández-Jiménez and Palomo 2005; Ryu et al. 2011).

In general, a low concentration is considered to be around $1 \mathrm{M}$, a moderate concentration to be around $5-10 \mathrm{M}$ and a high concentration to be around $15 \mathrm{M}$. If the $\mathrm{NaOH}$ concentration is too low, not enough dissolution will occur and therefore not enough reaction product will form to successfully link the system together (Murayama et al. 2002). On the other hand, too high a concentration sometimes results in a flash set due to a rim of reaction 
products rapidly forming around the unreacted particles preventing further reaction. Even if a flash set does not occur, the degree of reaction of the mixture is often lower with very high alkali concentrations due to faster setting (Provis and vanDeventer 2009). Additionally, excess $\mathrm{OH}^{-}$in solution can lead to a decrease in compressive strength due to depolymerization of more advanced polymerized species (Palomo et al. 1999).

\subsubsection{Effect of the type of cation}

Both Na- and K-based hydroxides have been used in geopolymer synthesis but $\mathrm{NaOH}$ is used most prevalently due to its low cost. $\mathrm{NaOH}$ has typically been found to result in better dissolution than $\mathrm{KOH}$ at the same molarity, while in most cases the compressive strengths are higher with $\mathrm{KOH}(\mathrm{Xu}$ and Deventer 1999; Xu and Van Deventer 2000; Bondar et al. 2011). $\mathrm{Na}^{+}$cations in solution also typically result in a more ordered structure than $\mathrm{K}^{+}$ions; this is thought to be because sodium cations are smaller in size, which allows them to navigate through the gel easier than the larger potassium cations (Duxson et al. 2007). Aluminosilicates formed through the reaction of silicate and aluminate species were found to increase as Si content and cation size increased. Though the charge on $\mathrm{Na}^{+}$and $\mathrm{K}^{+}$ particles is the same, the size is different, and as such, $\mathrm{Na}^{+}$cations have a higher affinity to form ion pairs with smaller silicate oligomers, whereas $\mathrm{K}^{+}$ions prefer to pair with large silicate oligomers (McCormick et al. 1989; Hendricks et al. 1991). This reinforces the previously made claim that $\mathrm{Na}^{+}$accelerates dissolution, while $\mathrm{K}^{+}$accelerates gelation and condensation, which leads to more geopolymerization (Duxson et al. 2005). 


\subsubsection{Sodium silicate}

Sodium silicate, or waterglass, is believed to have been used as long as 5600 years ago in Ancient Egypt (Davidovits 2008). Today it is a very common industrial chemical used as an ingredient in cleaners, detergents, adhesives, binders, defloccullants, and to make precipitates, silicas, sols and gels (Iler 1979). There are two main processes for producing industrial grade sodium silicate $\mathrm{Na}_{2} \mathrm{SiO}_{3}\left(\mathrm{Na}_{2} \mathrm{O}-\mathrm{SiO}_{2}\right)$ : the furnace method and the hydrothermal method. The furnace method consists of fusing quartz sand $\left(\mathrm{SiO}_{2}\right)$ and soda ash (sodium carbonate, $\mathrm{Na}_{2} \mathrm{CO}_{3}$ ) at high temperatures to create a solid glass that is later dissolved in water into a viscous liquid by high-pressure steam in an autoclave at between $140-160^{\circ} \mathrm{C}$ (McDonald and LaRosa 2006; Shi 2006). The hydrothermal process is a more direct process, which involves dissolving a siliceous material such as sand in a caustic alkali solution in an autoclave. This method was originally developed to use with impure siliceous materials such as diatomaceous earth. However, the resulting sodium silicate does not possess the high purity necessary for applications such as detergents. Use of this impure sodium silicate could be applicable for geopolymers, however (Davidovits 2008).

The general formula for soluble silica is $\mathrm{xSiO}_{2}: \mathrm{M}_{2} \mathrm{O} \cdot \mathrm{zH}_{2} \mathrm{O}$, where $\mathrm{x}$ is the degree of polymerization, $\mathrm{M}_{2} \mathrm{O}$ is an alkali metal oxide $\left(\mathrm{Na}_{2} \mathrm{O}, \mathrm{K}_{2} \mathrm{O}, \mathrm{Li}_{2} \mathrm{O}\right)$, and $\mathrm{z}$ is the number of water molecules present. Liquid sodium silicate solutions can be expressed in composition by either the modulus, $\mathrm{SiO}_{2} / \mathrm{Na}_{2} \mathrm{O}$ or by the content of $\mathrm{SiO}_{2}, \mathrm{Na}_{2} \mathrm{O}$ or $\mathrm{SiO}_{2}+\mathrm{Na}_{2} \mathrm{O}(\mathrm{Shi}$ 2006). In industry, sodium silicate is graded based on the weight ratio (WR), or modulus; commercial silicates typically have moduli between 1.5 and 3.2 (McDonald and LaRosa 2006; Davidovits 2008). It should be noted the weight ratio (WR) is used in industry but 
the molar ratio (MR) is used in geopolymer science and this document (i.e., MR is similar to WR for sodium silicate and is the molar ratio of $\mathrm{SiO}_{2}$ to $\mathrm{Na}_{2} \mathrm{O}$ ).

With a high modulus, the $\mathrm{pH}$ is very important in determining the stability of a sodium silicate solution with respect to turning into a gel. Stability increases with pH (Lawrence and Vivian 1961; Shi 2006; Davidovits 2008; Bondar et al. 2011) and a higher pH leads to a longer gelation time (Tognonvi et al. 2011). The $\mathrm{pH}$ range of most commercial sodium silicates is from 10.9-13.5. Depending on the MR of the solution, and the dilution or extra alkali added, it will reach its own equilibrium consisting of different polymer species (Davidovits 2008). The speciation of the silica in solution at equilibrium depends a great deal on the modulus of the solution and the dilution or extra alkali added (Davidovits 2008). Through ${ }^{29}$ Si MAS NMR (nuclear magnetic resonance) spectroscopic analysis, 48 different aqueous silicate structures have been identified in concentrated alkaline solutions (Knight et al. 2007).

Silica from sodium silicate, or soluble silica, can exist in well-polymerized species depending on such factors as the $\mathrm{pH}$ and modulus of the solution. As the Si concentration in solution increases, more and more highly polymerized Si species are formed such as Q2, Q3 and Q4 (Criado et al. 2008). However, when the $\mathrm{pH}$ of the system is increased too high, depolymerization can occur resulting in oligomers of less connected species such as Q0 or Q1 (McDonald and LaRosa 2006). As the molar ratio increases, the molecular weight and degree of polymerization also increases (Dent Glasser and Lachowski 1980). 
In cases where $\mathrm{Si}$ dissolution is too slow to reach the required supersaturated solution necessary for condensation to occur, or if there is just not enough reactive network formers $(\mathrm{Si}, \mathrm{Al})$ available, extra $\mathrm{Si}$ is provided through the addition of pre-dissolved silica to the activating solution (Xu and Van Deventer 2000). The presence of sodium silicate has been found to alter the kinetics of geopolymerization as well as other properties including the set time, microstructure and flexural and compressive strength of the final binder (Steveson and Sagoe-Crentsil 2005).

Some researchers have made their own sodium silicate solutions by reacting amorphous silica fume in caustic $\mathrm{NaOH}$ or $\mathrm{KOH}$ solutions. Other types of reactive silica $\mathrm{SiO}_{2}$ used in geopolymer applications include (Davidovits 2008):

Table 2.10. Reactive Si sources used to make sodium silicate activator solutions for geopolymers (Davidovits 2008).

\begin{tabular}{|c|c|c|c|}
\hline Type & Content & Size range & Production \\
\hline Silica flour & $100 \%$ crystalline $\mathrm{SiO}_{2}$ & $3-10$ microns & $\begin{array}{c}\text { Finely ground pure } \\
\text { quartz sand }\end{array}$ \\
\hline Fume silica & $99.9 \%$ amorphous $\mathrm{SiO} 2$ & $0.05-0.1$ microns & $\begin{array}{c}\text { Vapor phase } \\
\text { hydrolysis }\end{array}$ \\
\hline $\begin{array}{c}\text { Silica fume/ } \\
\text { microsilica }\end{array}$ & $\begin{array}{r}\text { Roughly } 89 \%+\text { amorphous } \\
\mathrm{SiO}_{2}\end{array}$ & $0.05-1$ microns & $\begin{array}{c}\text { Byproduct of } \\
\text { silicon or } \\
\text { ferrosilicon steels }\end{array}$ \\
\hline $\begin{array}{c}\text { Rice husk } \\
\text { ash }\end{array}$ & $85-90 \%$ amorphous $\mathrm{SiO}_{2}$ & $15-30$ microns & $\begin{array}{c}\text { Ash from husk } \\
\text { used for fuel in } \\
\text { rice mills }\end{array}$ \\
\hline
\end{tabular}

Rees et al. experimented with reacting Class F fly ash with anhydrous sodium silicate and found the amount of Si released was less than when the sodium silicate was in an aqueous 
state. This is thought to be because there are more non-bridging oxygens (NBO) present in the liquid, where sodium as well as water can occupy a network modifying site (Rees et al. 2005).

It should also be noted there are possible health hazards associated with $\mathrm{SiO}_{2}$ nanoparticles and silicosis has been known to form from the inhalation of crystalline silica. Investigations into amorphous silica have deemed it safer but inhalation should still be avoided and caution should be taken either way (Davidovits 2008).

\subsubsection{Kinetic effects}

"The nature of the alkali activator plays an instrumental role in the kinetics, structure and composition of the gel initially formed" (Criado et al. 2008).

When soluble silica is included in an activating solution, dissolution of the aluminosilicate continues as normal, releasing $\mathrm{Si}$ and $\mathrm{Al}$ monomers into solution where they quickly condense together once the system reaches supersaturation. The time it takes to reach supersaturation, however, is greatly reduced due to the presence of the soluble silica in the form of more highly polymerized species (Xu and Deventer 1999).

The rate of nucleation depends on the degree of supersaturation in solution and on nucleation triggers such as "undissolved particles, newly formed crystals or amorphous aluminosilicate particles, or any other solid-liquid interface" (Provis et al. 2005). Nucleation occurs much faster and more often when sodium silicate is present, which leads to the formation of a great number of nuclei that all remain very small due to limited space, 
nutrients and growth; this eventually leads to the formation of a gel. In activator solutions containing only an alkali hydroxide, there are very few sites for nucleation to occur and so those sites that do nucleate are given time to grow, forming larger particles and often leading to precipitation (Provis et al. 2005).

The $\mathrm{Al}$ in the system also plays an important role in speeding up the condensation process especially when sodium silicate is present. During the dissolution of aluminosilicates, Al is typically released before $\mathrm{Si}$ and the initial $\mathrm{Si} / \mathrm{Al}$ ratio of released monomers in solution is less than unity. Al monomers preferentially react with other Si monomers, but as there are less Si monomers present than $\mathrm{Al}$ monomers and $\mathrm{Al}-\mathrm{O}-\mathrm{Al}$ bonds are not favored, the Al monomers will begin to condense with the more polymerized Si species from the sodium silicate (Bell 1999; Sagoe-Crentsil and Weng 2007). Since the soluble silica is well dispersed throughout the solution due to mixing, condensation reactions with $\mathrm{Al}$ occur rapidly and evenly throughout solution, rather than just in localized areas surrounding solid particles where $\mathrm{Si}$ is released slowly one monomer at a time. This leads to the aforementioned increased $\mathrm{Al}$ included in the system (Hajimohammadi et al. 2011).

The early condensation reactions between Al monomers and soluble silica species act as a "jumpstart," which spurs on subsequent reactions and decreases the time it takes for a gel to form. As gelation and initial set time go hand in hand, systems containing soluble silica typically have shorter set times (Steveson and Sagoe-Crentsil 2005). Reaction kinetics are not the only thing affected by the addition of soluble silica; the degree of reaction $(\alpha)$ as well as geopolymer product formation throughout geopolymerization and well after are also influenced (Criado et al. 2007). 


\subsubsection{Effects on reaction product phases}

Criado et al. reacted fly ash with activating solutions containing varying ratios of $\mathrm{SiO}_{2} / \mathrm{Na}_{2} \mathrm{O}$ and used XRD and Reitveld analysis to measure the gel, zeolite and vitreous (unreacted) phases present as well as the degree of reaction and compressive strength at various times following mixing. The results clearly show the effects that adding sodium silicate to the activator solution can have on geopolymerization as shown in Figure 2.21 and Figure 2.22. Sample N did not contain any soluble silica and samples W15, W50 and W84 contained increasing quantities, respectively.
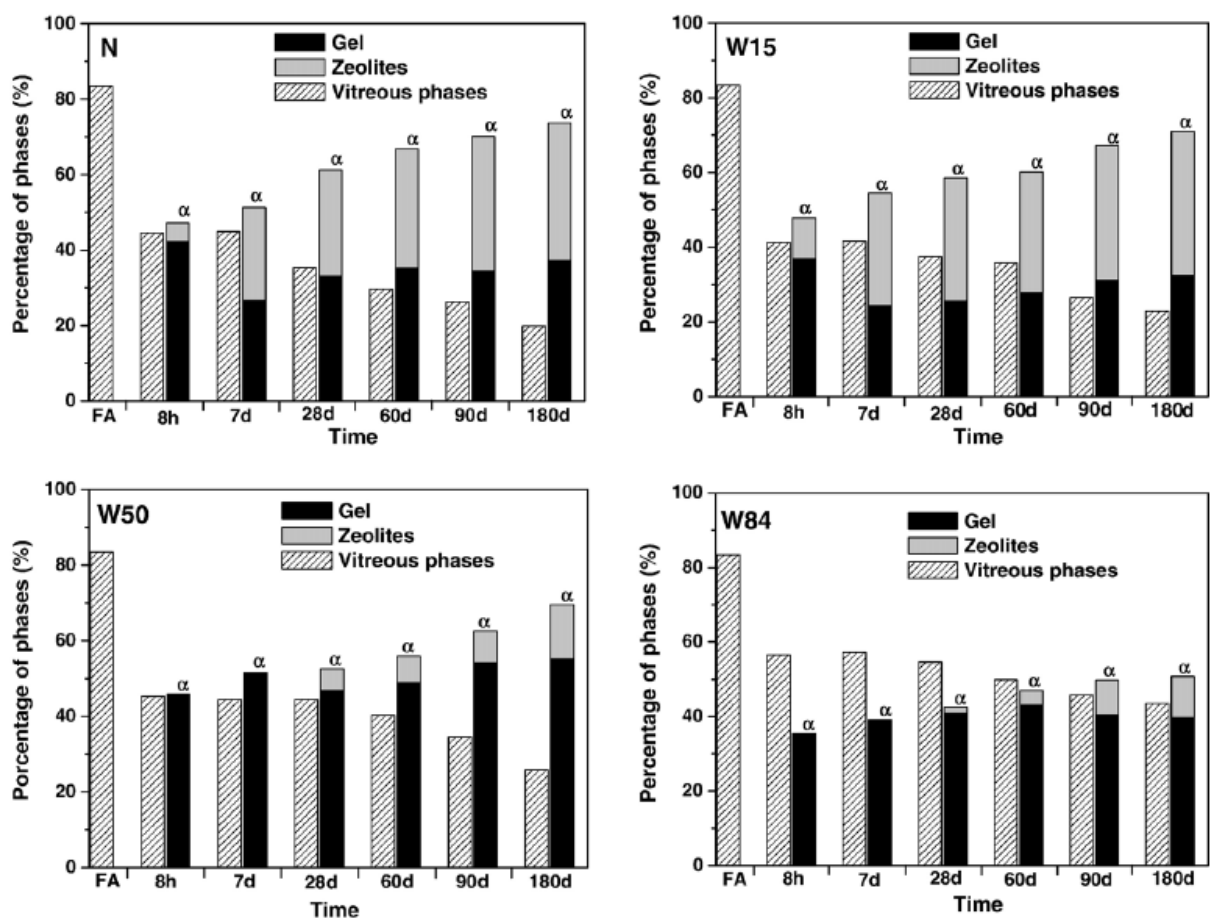

Figure 2.21. Gel, zeolite and remaining vitreous phases for fly ash activated with various alkali activating solutions (Criado et al. 2007). Reprinted by permission of Elsevier. See Appendix D for documentation of permission to reprint this material. 


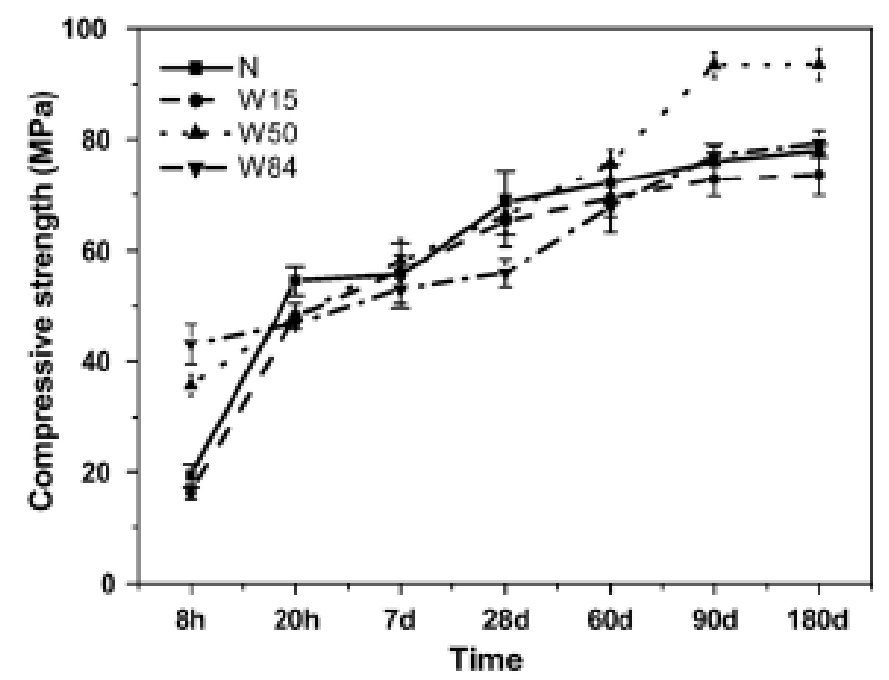

Figure 2.22. Compressive strength of fly ash geopolymers activated with various activators over time (Criado et al. 2007). Reprinted by permission of Elsevier. See Appendix D for documentation of permission to reprint this material.

At 180 days, sample W50 contained the largest gel content and yielded the highest compressive of all the samples, and likewise, sample W15 contained the lowest gel content and lowest compressive strength despite having a much higher degree of reaction. However, it can be seen from the figure the rate at which the gel forms, the rate of dissolution, and various other reaction kinetic are greatly affected by the soluble silica content. In all cases, the vitreous content went down as the gel content went up, indicating reaction. However in the cases where high doses of silicate was added in (W50, W84), the vitreous content went down much slower since dissolution was hindered by the large saturation of ionic silica species.

The maximum silica content is limited by the viscosity of the solution as the Si content goes up (Iler 1979). The viscosity of sodium silicate solutions is important when it comes to ease of mixing. Decreased $\mathrm{pH}$ and increased viscosity due to the excess of polymerized 
silica species in solution can hinder the mobility of the system and often resulting in the incomplete dissolution of the precursor material (Fernández-Jiménez et al. 2006; Duxson et al. 2007; Sagoe-Crentsil and Weng 2007).

The addition of soluble silica to the activating solution has been shown to increase the apparent structural stability of a geopolymer as well as to help prevent long term structural ordering from occurring (Duxson et al. 2007). EDS analysis of the final geopolymer also typically shows a higher $\mathrm{Si} / \mathrm{Al}$ and $\mathrm{Na} / \mathrm{Al}$ content when waterglass is included in the activator as compared to just $\mathrm{NaOH}$ (Fernández-Jiménez and Palomo 2005). Mixes containing soluble silica also yielded higher earlier compressive strengths and X-ray data showed there was no existence of crystalline phases except those originally found in the fly ash (Palomo et al. 1999) (Hardjito et al. 2004; Palomo et al. 2004). The microstructure is also typically more uniform when sodium silicate is present.

\subsubsection{Sodium Carbonate}

Sodium carbonate, or soda ash, can be acquired through the processing of natural sources containing sodium carbonate-bearing minerals generally found in shallow alkaline lakes. Synthetic soda ash can also be produced through the Solvay process and the waste materials from the ammonium chloride, New Asahi and caustic carbonation processes (Shi et al. 2006). Commercially produced soda ash is sold based on the percentage of $\mathrm{Na}_{2} \mathrm{O}$ content. Sodium carbonate comes in two main forms, as light soda ash, or dense soda ash, depending on the bulk density of the material (Shi et al. 2006). The presence of $\mathrm{CO}_{3}{ }^{2-}$ in an activator made of $\mathrm{NaOH}$ and $\mathrm{Na}_{2} \mathrm{CO}_{3}$ was found to result in lower mechanical strengths, compared 
to just $\mathrm{NaOH}$ or $\mathrm{NaOH}$ plus sodium silicate activators (Fernández-Jiménez and Palomo 2005) although it is used in some applications successfully.

\subsubsection{Calorimetry}

Calorimetry used in conjunction with cements and concretes is performed typically to provide an indication of the elapsed time and heat expelled during various chemical reactions, and to signal the start and finish of the various stages in the hydration of OPC. The main reactions in geopolymerization are dissolution and polycondensation, speaking very simply, and these two phases being exothermic are visible using calorimetry techniques. A spike in heat evolution due to dissolution (often occurring so fast it is difficult to capture) followed by a period of induction or low heat evolution and then an acceleration of heat evolution again signaling a mass condensation that lowers slowly over time have been found in metakaolin, fly ash and slag-based geopolymers (Granizo et al. 2002; Puertas et al. 2003; Sagoe-Crentsil and Weng 2007; Weng and Sagoe-Crentsil 2007; Zhang et al. 2012). Oddly, there is very little heat produced when a sol turns to a gel (Iler 1979). Figure 2.23 shows a schematic of geopolymerization based on metakaolin activated by $\mathrm{NaOH}$. 


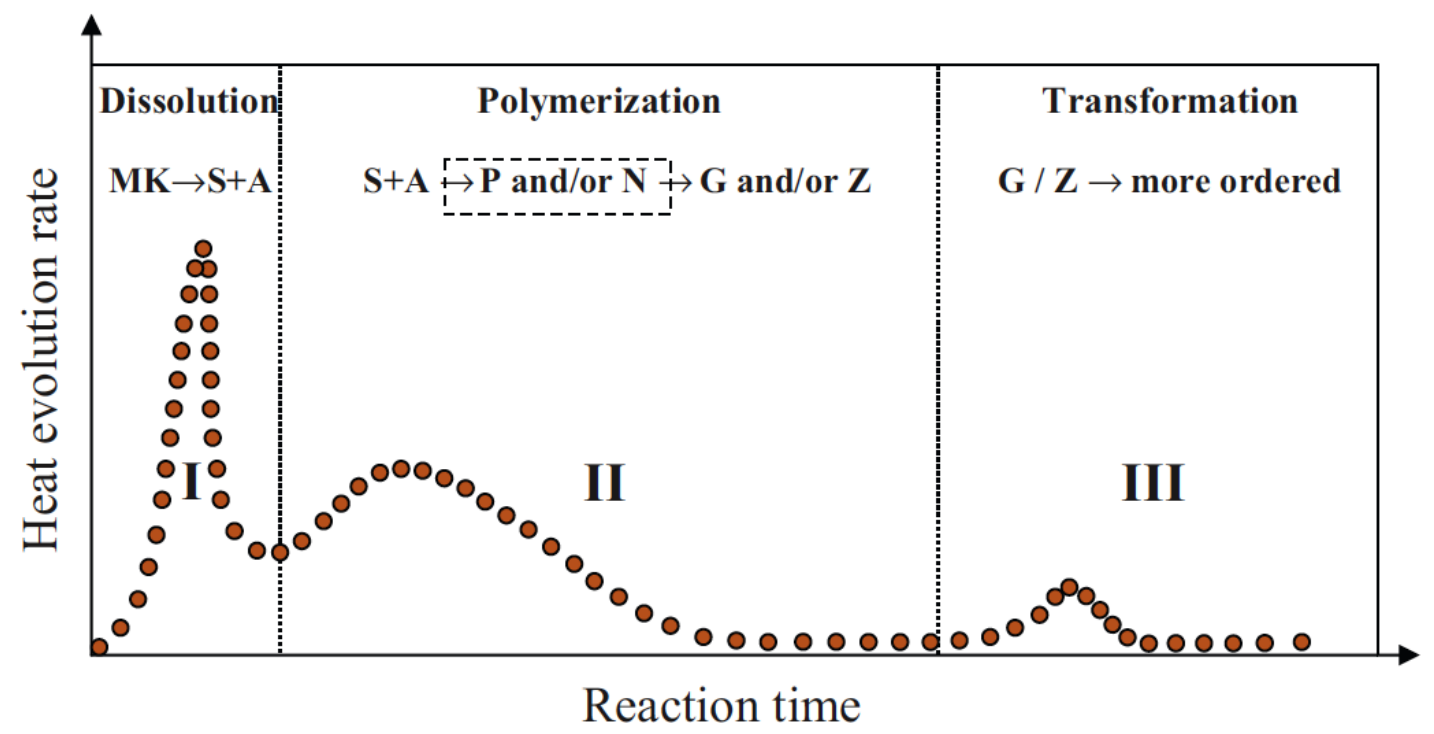

Figure 2.23. Schematic of geopolymer synthesis kinetics: based on metakaolin activated by $\mathrm{NaOH}$ (Zhang et al. 2012). Reprinted by permission of Elsevier. See Appendix D for documentation of permission to reprint this material.

A linear relationship exists between compressive strength and heat released for metakaolin geopolymers reacted with sodium silicate but this is not found to be true for fly ash (Provis et al. 2005).

Calorimetry measurements have been very useful in monitoring the steps of geopolymerization and the effects of activator concentration. If the dissolution rate is too slow to reach the necessary supersaturation in solution for precipitation to occur, the heat peak usually associated with polycondensation and setting does not occur and the sample remains plastic. If the activator concentration is too high, the polycondensation peak does not occur, this is thought to be because at very high $\mathrm{pH},\left[\mathrm{SiO}_{2}(\mathrm{OH})_{2}\right]^{2-}$ is the main species present and is not favored for condensation (Granizo et al. 2002; Weng and Sagoe-Crentsil 2007). 
Figure 2.24 shows the influence of varying the activator sources on the heat evolved during the alkali activation of metakaolin. It is obvious from the calorimetry curves, the kinetics of geopolymerization are affected despite the fact the stoichiometry of the activator solution is the same in all three samples.

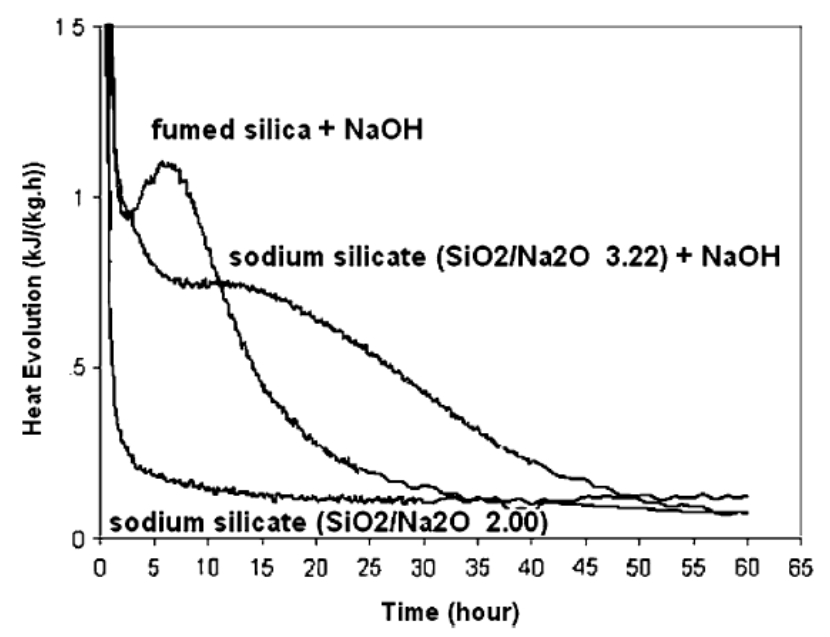

Figure 2.24. Influence of different Si sources on calorimetry curves for metakaolin activation (Sagoe-Crentsil and Weng 2007). Reprinted by permission of Springer. See Appendix D for documentation of permission to reprint this material.

\subsection{Mixture design stoichiometry}

Mixture design for geopolymers generally begins with the consideration of two molar stoichiometric ratios: $\mathrm{Si} / \mathrm{Al}$ and $\mathrm{M}^{+} / \mathrm{Al}$ where $\mathrm{M}^{+}$is either Na or $\mathrm{K}$. However, the presence of soluble silica or calcium, the alkalinity of the activator solution as well as the water content and curing conditions have all been found to influence geopolymerization and so must be considered in mixture design. 
Depending on the source material and activator solution employed, various stoichiometric ranges have been suggested for geopolymers. In his patent for mineral polymers made of metakaolin, Davidovits outlines the following oxide-mole ratios (Davidovits 1979) shown in Table 2.11. Alternately, a $\mathrm{Si} / \mathrm{Al}$ ratio of approximately $1.8-2.0$ is considered to be adequate for metakaolin by other groups (Duxson et al. 2005; Fernández-Jiménez et al. 2006).

Table 2.11. Proposed oxide-mole ratios for mineral polymers made of metakaolin (Davidovits 1979).

\begin{tabular}{|l|l|}
\hline$\left(\mathrm{Na}_{2} \mathrm{O}, \mathrm{K}_{2} \mathrm{O}\right) / \mathrm{SiO}_{2}$ & $0.20-0.28$ \\
\hline $\mathrm{SiO}_{2} / \mathrm{Al}_{2} \mathrm{O}_{3}$ & $3.5-4.5$ (about 4.0$)$ \\
\hline $\mathrm{H}_{2} \mathrm{O} /\left(\mathrm{Na}_{2} \mathrm{O}, \mathrm{K}_{2} \mathrm{O}\right)$ & $15-17.5$ \\
\hline$\left(\mathrm{NA}_{2} \mathrm{O}, \mathrm{K}_{2} \mathrm{O}\right) / \mathrm{Al}_{2} \mathrm{O}_{3}$ & $0.8-1.20$ (about 1.0$)$ \\
\hline
\end{tabular}

Rowles et al. considered a variety of mixtures with stoichiometric $\mathrm{Si} / \mathrm{Al}$ and $\mathrm{Na} / \mathrm{Al}$ ratios ranging from $\mathrm{Si} / \mathrm{Al}$ from 1-3 and Na/Al from 0.5-2 with $\mathrm{Si} / \mathrm{Na}$ ranging from 1, 1.5 and 2. The highest compressive strength, and also the most uniform microstructure, was found at Si:Al:Na of 1.5:1.0:1.29. Rowles et al. stated that compressive strength is dependent on both $\mathrm{Si} / \mathrm{Al}$ and $\mathrm{Na} / \mathrm{Al}$ (Rowles and O'Connor 2003).

Duxson, et al. specified a range of $\mathrm{Si} / \mathrm{Al}$ of $1-5$ and $\mathrm{Na} / \mathrm{Al}$ ratio of close to 1 for geopolymers used in the construction industry, since geopolymers with compositional ratios outside of these ranges are very possible, but not realistic to be used as binders in the construction industry. The $\mathrm{Na} / \mathrm{Al}$ ratio of close to 1 was further described as being necessary to achieve "optimal mechanical and durability performance" (Duxson et al. 2007). 
There have been various other suggestions as well, but the bulk of the literature recommends a system of $\mathrm{Si} / \mathrm{Al}=2-5$ and $\mathrm{Na} / \mathrm{Al}=1$.

\subsubsection{The role of $\mathrm{Al}$}

“... it is absolutely indispensable for a certain amount of Al to be initially present

in the system for the first bonds to form" (Fernández-Jiménez et al. 2006).

Since the two main ratios used for mixture design both include Al, it is safe to say that Al plays a very important role in geopolymer success and it is therefore necessary to explain the role that Al plays with relation to Si and alkali cations. Essentially, alumina can only occur in tetrahedral coordination with tetrahedral silica if a monovalent alkali cation $\left(\mathrm{Na}^{+}\right.$ or $\mathrm{K}^{+}$) is available to balance the charge.

Solutions made of simply alkali silicates ( $\mathrm{Si}$ and $\mathrm{Na}$ ) do not harden on their own except in cases of extreme drying and are usually water soluble to some degree, however alkali aluminosilicates have a very low solubility, and because of this, aluminum is thought to be the mechanism for which irreversible hardening occurs in geopolymers. While this main idea is considered true, unknowns exist in terms of how to control the release of available alumina during geopolymerization, which is very important as alumina is thought to have an effect on the rate, stoichiometry and reaction progress in geopolymerization (Duxson et al. 2007). These and other issues are considered in the following sections. 


\subsection{2 $\mathrm{Na} / \mathrm{Al}$}

The ratio of alkali (sodium or potassium) to alumina has been found to be very important to the success of a geopolymer mixture. These cations are believed to exist in a solvated state in between openings in the matrix (Barbosa et al. 2000) and are included in the final aluminosilicate matrix in a charge balancing capacity; ideally the available $\mathrm{Na} / \mathrm{Al}$ ratio will be as close to unity as possible.

It has been found that in pure aluminosilicate gels synthesized under basic conditions, only an equal amount of $\mathrm{Al}$ and $\mathrm{Na}$ will be included in the gel at higher pH (Fernández-Jiménez et al. 2006). This is shown in Figure 2.25. Additionally, Na NMR MAS does not show Na associated with non-bridging oxygen, meaning the $\mathrm{Na}$ is only associated with $\mathrm{Al}$ as a charge balancer (Duxson et al. 2005). 


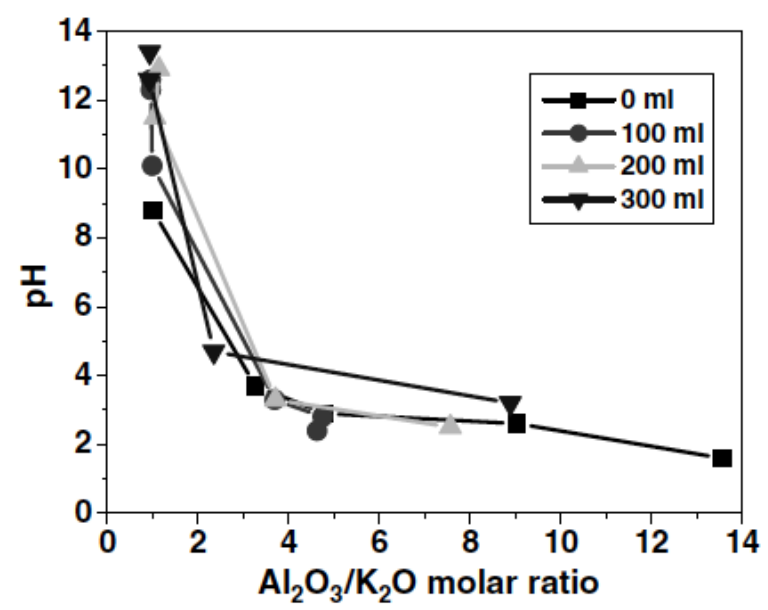

Figure 2.25. $\mathrm{pH}$ vs. $\mathrm{Al}_{2} \mathrm{O}_{3} / \mathrm{K}_{2} \mathrm{O}$ molar ratio in aluminosilicate gels (Fernández-Jiménez et al. 2006). Reprinted by permission of Elsevier. See Appendix D for documentation of permission to reprint this material.

Despite this basic theory and evidence supporting the ratio of $\mathrm{Na} / \mathrm{Al}=1$, it has been noted the need for 1:1 charge balancing is stronger in crystalline aluminosilicate structures like zeolites as compared to amorphous systems as their "less-ordered nature allows variation from strict tetrahedral geometry and therefore allows alternative methods of charge compensation [for Al]" (Provis et al. 2005; Steveson and Sagoe-Crentsil 2005).

\subsubsection{Na/Al $<1$}

Should excess Al exist in the system, it has been found to remain in the pore solution as aqueous $\left[\mathrm{Al}(\mathrm{OH})_{4}\right]^{-}($Duxson et al. 2005)(Duxson et al. 2005)(Duxson et al. 2005)(Duxson, Lukey et al. 2005). $\mathrm{Na}^{+}$ions have also been found in the pore solution with aqueous $\mathrm{Al}$ in an attempt to maintain charge neutrality (Duxson et al. 2005). A very low $\mathrm{M}^{+} / \mathrm{Al}$ ratio may also affect the setting if an insufficient amount of $\mathrm{Al}$ is not present in the matrix (Davidovits 1979). 


\subsubsection{Na/Al $>1$}

In systems with initial $\mathrm{Na} / \mathrm{Al}>1$, the final composition of geopolymer product typically remains at around 1 , however other phases such as crystalline $\mathrm{Na}_{2} \mathrm{CO}_{3}$ have been found to form. This indicates that "the charge-balancing positions will be filled preferentially to the formation of carbonate crystals in the absence of excess alkali cations" (Provis et al. 2005). These deleterious carbonates can lead to expansion, cracking, efflorescence or a loss in strength (Davidovits 1979; Rahier et al. 1997; Duxson et al. 2005; Provis 2009), but have been found to be less common when the samples are well cured (Barbosa et al. 2000).

In very high $\mathrm{Si} / \mathrm{Al}$ systems $(\mathrm{Si} / \mathrm{Al}=20)$ where the $\mathrm{Na} / \mathrm{Al}$ is also very high, $\mathrm{Na}^{+}$ions present in the pore solution have been found to be easily leached away from the hardened product in water (Cyr et al. 2012). In fly ash samples reacted with $\mathrm{NaOH}$ and sodium silicate, where the modulus went down to 1.0, tabular crystals were found which are believed to be sodium silicate hydrates: $\mathrm{Na}_{2} \mathrm{O} \cdot \mathrm{SiO}_{2} \cdot 5-9 \mathrm{H}_{2} \mathrm{O}$, which are very soluble in water and can dissolve easily in the moisture from the air, weakening the structure (Xie and Xi 2001).

\subsubsection{Si/Al}

"Recent surveys have shown that the Si/Al ratio of the aluminosilicate gel obtained from the alkali activation of fly ashes depends heavily on the chemical composition of the starting material, nature and concentration of alkali activator, synthesis temperature and thermal curing time” (Fernández-Jiménez et al. 2006). 
The optimal Si/Al ratio in the final product is related to the bulk $\mathrm{Si} / \mathrm{Al}$ in the initial products through the degree of reaction. General trends relating to $\mathrm{Si} / \mathrm{Al}$ ratio show that increasing the $\mathrm{Al}$ content speeds up the kinetics of reactions thereby decreasing the set time (Kovalchuk et al. 2007), while increasing the Si content during geopolymerization leads to an increase in mechanical performance (Fernández-Jiménez et al. 2006; De Silva et al. 2007).

Fletcher et al. investigated geopolymers with varying $\mathrm{Si} / \mathrm{Al}$ ratios from $0.5-300$ by starting with metakaolin and then adding amorphous $\mathrm{Al}_{2} \mathrm{O}_{3}$ or $\mathrm{SiO}_{2}$. The $\mathrm{H}_{2} \mathrm{O}: \mathrm{Na}_{2} \mathrm{O}$ ratio was held constant while the $\mathrm{H}_{2} \mathrm{O} / \mathrm{SiO}_{2}$ and $\mathrm{H}_{2} \mathrm{O} / \mathrm{Al}_{2} \mathrm{O}_{3}$ changed. Samples were cured for 1 hour at $40^{\circ} \mathrm{C}$ and then $90^{\circ} \mathrm{C}$ overnight (Fletcher et al. 2005). Low Si/Al geopolymers ( $\mathrm{Si} / \mathrm{Al}=0.5$ $\leq 2$ ) were found to have very low compressive strengths and a great deal of crystalline phases present in XRD analysis. On the other hand, extremely high $\mathrm{Si} / \mathrm{Al}$ systems ( $\mathrm{Si} / \mathrm{A} 1$ $>24$ ) were found to develop elastic-like properties, with failure mechanisms occurring in the form of deformation rather than brittle failure. It should be noted that in all of the Fletcher et al. work, the $\mathrm{Si} / \mathrm{Al}$ or $\mathrm{Na} / \mathrm{Al}$ ratio of the final product was not measured nor was the degree of reaction, only nominal starting molar ratios were given (Fletcher et al. 2005).

The amount of $\mathrm{Si}$ and $\mathrm{Al}$ incorporated into the final matrix is dependent on a number of variables, one of the most important being the release rate of each component.

\subsubsection{Si release rate}

A study on the effect of silica availability on geopolymerization was performed on three mixtures made of sodium aluminate mixed with different ratios of geothermal silica and 
sodium silicate. Geothermal silica is relatively slow to release $\mathrm{Si}$ as compared to sodium silicate, where the $\mathrm{Si}$ is available immediately and polymerized already. A relationship between the availability of $\mathrm{Si}$ and the $\mathrm{Al}$ content in the geopolymer gel was found, where more readily available $\mathrm{Si}$ resulted in more $\mathrm{Al}$ incorporated into the matrix. This is believed to be due to the fact that nucleation sites occur where $\mathrm{Si}$ and $\mathrm{Al}$ meet. This means that in the geothermal silica mixture, where the Si must first dissolve, nucleation will only occur in the area surrounding the dissolving particle, whereas when sodium silicate is present, nucleation sites can occur as soon as the sodium aluminate dissolves and anywhere in solution.

Spatially Resolved Fourier Transform Infrared (SR-FTIR) microscopy shows samples containing sodium silicate are more homogenous than those containing geothermal silica, indicating that more nucleation occurred in the former. This explains why the geothermal silica mixture results in a more Si-rich gel, because the gel forms near the Si particles, creating a Si-rich environment. When $\mathrm{Si}$ is ubiquitous in solution, the concentration gradients are nearly nonexistent and so a more even distribution of $\mathrm{Si}$ and $\mathrm{Al}$ is formed (Hajimohammadi et al. 2011).

\subsubsection{Al release rate}

"The absolute amount of available aluminum and the rate of its release throughout reaction not only affect final strength, but other properties in the wet and hardened states including setting characteristics, flexural strength, acid resistance, microstructure, and strength development profile" (Duxson and Provis 2008). 
The effect of the release rate of $\mathrm{Al}$ on geopolymer gel formation was analyzed on two alumina sources combined with amorphous silica; one containing a combination of $\mathrm{NaOH}$ and amorphous alumina and the other just sodium aluminate, representing a rapid Al release. The sodium aluminate mixture resulted in a higher $\mathrm{Al}$ incorporation into the final product; a faster set time and more homogenous gel. High early strength was also noted However, due to repressed Si dissolution from the high Al content in solution, further strength increase was not measured. In the amorphous alumina system, it was found that silica dissolution occurred faster and more thoroughly leading to slower strength development initially, but more strength gain over time due to continued Si incorporation. This geopolymer was more heterogeneous, containing both Al-rich phases as well as later Si-rich phases (Hajimohammadi et al. 2010).

\subsubsection{Degree of reaction}

As stated earlier, mixtures are typically designed based on the stoichiometric amounts of $\mathrm{Si}, \mathrm{Al}$ and $\mathrm{Na}$ in each mixture component; whether or not the desired $\mathrm{Si} / \mathrm{Al}$ or $\mathrm{Na} / \mathrm{Al}$ ratio is realized depends on the degree of reaction as well as other factors such as impurities that may take up the $\mathrm{Si}, \mathrm{Al}$ or $\mathrm{Na}$ to form phases other than aluminosilicate gel.

The degree of reaction, $\alpha$, is simply the percentage by weight of the source materials that have dissolved or reacted during geopolymerization. If $\alpha=100 \%$ that means complete dissolution has occurred. Any value below 100\% signifies the presence of unreacted source materials with in the matrix. Degree of reaction measurements are typically performed on pastes, where the paste is ground into a powder, weighed and then continuously stirred in 
dilute $\mathrm{HCl}(1: 20)$ for three hours to dissolve the aluminosilicate gel or zeolites that have formed but leave the unreacted particles alone. It has been shown that typically a great deal of the reaction occurs within the first few hours of mixing (Granizo et al. 2002; Palomo et al. 2004; Fernández-Jiménez et al. 2005) and more unreacted source material is typically found when soluble silica is added due to a decreased $\mathrm{pH}$ and more viscous solution. The degree of reaction was also found to increase with increased curing time (FernándezJiménez et al. 2006).

\subsubsection{Impurities}

Impurities in an aluminosilicate source such as calcium or iron can cause changes in setting time, workability, strength and shrinkage due to the side reactions that can occur with these impurities.

Calcium - Many of the aluminosilicate source materials used in geopolymer systems also contain small to moderate amounts of calcium. The form in which the $\mathrm{Ca}$ is present, the $\mathrm{pH}$ of the system and the available soluble $\mathrm{Si}$ in solution are all influential on the behavior

of calcium within the system and will help to dictate what phases are formed (Temuujin et al. 2009). Calcium in the system will most often form C-S-H hydrated gel or precipitate as $\mathrm{Ca}(\mathrm{OH})_{2}$. In the case of calcium hydroxide precipitation, the $\mathrm{pH}$ of the system is lowered, which can decrease dissolution of the Si and Al source materials (Iler 1979; Yip et al. 2005; Yip et al. 2008).

In general, those systems where both C-S-H and an aluminosilicate gel are present have been found to set faster and yield higher compressive strengths early on as compared to 
geopolymers with no C-S-H (Bondar et al. 2011). However, some of the literature reports lower long term strength due to there being less time for dissolution to occur (Sofi et al. 2007). It has been proposed this is because the C-S-H acts as a microaggregate within the geopolymeric matrix (Yip et al. 2005). However, in some cases, the final reaction products consist of an aluminosilicate gel with Ca-rich phases dispersed within (Granizo et al. 2002; Guo et al. 2010). Research into hybrid geopolymer-portland cements is ongoing and includes investigating the compatibility of C-S-H and N-A-S-H gels (Shi et al. 2011).

Iron - Iron has been found to react similarly to calcium and has been shown to precipitate out of solution even faster than $\mathrm{Al}$ and $\mathrm{Si}$, so it is assumed that both $\mathrm{Fe}$ and $\mathrm{Ca}$ will react very quickly in solution to form C-S-H phases or crystalline iron oxide phases, which will decrease the $\mathrm{OH}^{-}$concentration and therefore the $\mathrm{pH}$, which effects dissolution (Duxson et al. 2007).

Organics - Organic compounds have been found to both retard silica dissolution by adsorbing onto the surface or to accelerate dissolution by pulling away soluble silica monomers from the surface and creating soluble species (Iler 1979).

\subsection{Synthesis parameters}

Aside from the physical and compositional characteristics of the source material and activator, other important factors effecting GPC include (Xie and Xi 2001; FernándezJiménez and Palomo 2003; Kovalchuk et al. 2007):

- Water content

- Workability and flow 
- Water to solids ratio

- Curing conditions

- Time

- Temperature

- Moisture conditions

\subsubsection{Water content}

The role of water in GPC is very important in that it acts as a transport for chemical reactions to occur and allows for adequate workability of the final product.

Dissolution consumes water; therefore water must be available in such a quantity so as to allow for the presence of a solution amid rapid dissolution. Ideally this solution will reach supersaturation quickly, which will then lead to condensation, where water is expelled back into the system to be reused for dissolution. However, if the water content is too low, all of the water will get used up in dissolution reactions before condensation can occur, effectively ending the geopolymerization process and resulting in a material with a very low degree of reaction (Steveson and Sagoe-Crentsil 2005; Criado et al. 2010).

Syneresis is the process by which a gel expels water. In the case of geopolymers, syneresis leads to a bi-phasic gel structure, where the two phases are the final aluminosilicate product and water. The water is not chemically bound to the aluminosilicate product but rather exists alongside of it. Most of the available literature agrees with this theory, however, there is some conflict on this point, suggesting the presence of both bound and unbound water existing within the pore network as well as the framework structure (Duxson et al. 2005). 
The bi-phasic gel structure in geopolymers is different than in an OPC system, where during hydration some of the water is chemically bound within the reaction products. In OPC concrete, mixture water can be broken up into three main groups; evaporable water, chemically bound water and gel pore water. For weeks after mixing, hydration reactions continue to use up the water in the pore network to create new reaction products thereby reducing the pore volume over time. This is not the case for geopolymers, as the water is not consumed in the reaction, but rather expelled during condensation, which makes a low water/binder ratio crucial to producing a non-porous material (Kumar et al. 2007).

Despite the different behavior of water in OPC and GPC, the water/binder ratio is very important in both systems when it comes to fresh and hardened concrete properties. Abrams Law, which states the compressive strength of an OPC concrete is a function of the water/cement $(\mathrm{w} / \mathrm{c})$ ratio has also been found to be true for GPC concretes (Kosmatka and Wilson 2011), and so water demand must also be considered when designing a mixture (Barbosa et al. 2000; Hardjito et al. 2004; Hardjito and Rangan 2005; Steveson and SagoeCrentsil 2005; Steveson and Sagoe-Crentsil 2005; Sofi et al. 2007).

Since the source materials for geopolymerization are often very finely divided, water demand can be an issue. This has been found to be the case especially with metakaolin (Fernández-Jiménez et al. 2006). Duxson, et al. suggests a $\mathrm{H}_{2} \mathrm{O} / \mathrm{Na}_{2} \mathrm{O}$ ratio of 11 but depending on the fineness and specific surface area of the source material, this is not always possible (Duxson et al. 2005). 


\subsubsection{Curing conditions}

“... water is a key element in alkaline activation reactions, curing regime humidity has an obvious effect on the structural and mechanical properties of AAFA pastes, mortars and concretes" (Kovalchuk et al. 2007).

\subsubsection{Time and temperature}

Geopolymers have been found in most cases to reach much higher strengths when curing is done at mild hydrothermal temperatures $\left(40-85^{\circ} \mathrm{C}\right)$ as compared to ambient conditions $\left(20^{\circ} \mathrm{C}\right)$ (Palomo et al. 2004; Kovalchuk et al. 2007). Additionally, thermally cured geopolymers have been found to have a higher $\mathrm{Si} / \mathrm{Al}$ ratio, which is thought to be the cause for the increased strength (Palomo et al. 2004; Fernández-Jiménez et al. 2006).

In some cases, very high temperature curing $\left(>100^{\circ} \mathrm{C}\right)$ has resulted in lower mechanical properties, which is thought to be due to degradation of the gel (Palomo et al. 2004). Increased temperature curing has also been known to increase the long-range ordering of the aluminosilicate, sometimes resulting in small pockets of zeolites (Duxson et al. 2007). Higher temperatures and prolonged curing were thought to break down the granular structure, which causes shrinkage and dehydration (Van Jaarsveld et al. 2002; Guo et al. 2010).

Within the literature, many researchers have noted that a higher temperature cure for a short time and a lower temperature cure for a longer time often yield the same results (Davidovits 1979; Palomo et al. 1999; Xie and Xi 2001; Van Jaarsveld et al. 2002; 
Fernández-Jiménez and Palomo 2003; Hardjito et al. 2004; Palomo et al. 2004; Rovnanik 2010; Deevasan and Ranganath 2011).

It has also been noted that fly ash geopolymers that have been allowed to "rest" for up to 60 minutes before curing have not resulted in a decrease in compressive strength (Hardjito et al. 2004). This bodes well for precast applications, where there is often a delay between mixing and curing.

\subsubsection{Relative humidity}

Relative humidity has also been found to be important during curing. Specimens cured in high relative humidity were found to have a denser microstructure and higher Si/Al content than those cured in ambient conditions with a lower relative humidity (Criado et al. 2010). Curing at high temperatures and low relative humidity has also been shown to result in cracking due to rapid water evaporation.

Kovalchuk et al. explored the effect curing conditions had on compressive strength for three different setups; curing in covered molds, dry curing and steam curing. It was found that curing in covered molds, where mixture water was available, resulted in the highest compressive strength (Kovalchuk et al. 2007). A similar test by Criado et al. yielded similar results, where a higher relative humidity led to a much higher degree of reaction and increased mechanical strength (Criado et al. 2010). Van Jaarsveld et al. recorded the opposite results, citing the possibility that "the saturated atmosphere in the bags resulted in conditions more suitable to the formation of slightly weaker bonds" (Van Jaarsveld et al. 2002). 
Undesirable curing conditions can sometime lead to carbonation, which reduces the $\mathrm{pH}$ and leads to retarding of the activation and decreased strength gain. This can be avoided by using a high relative humidity or by raising the curing temperature from $45^{\circ} \mathrm{C}$ to $65^{\circ} \mathrm{C}$ (Kovalchuk et al. 2007). The diffusion coefficient of $\mathrm{CO}_{2}$ in air is ten times higher than in water and can occur rapidly with alkaline bases through the following equation:

$$
\mathrm{CO}_{2}+2 \mathrm{KOH}(\mathrm{NaOH}) \rightarrow(\mathrm{NaOH}) \mathrm{K}_{2} \mathrm{CO}_{3}\left(\mathrm{Na}_{2} \mathrm{CO}_{3}\right)+\mathrm{H}_{2} \mathrm{O} \quad \text { (Equation 7) }
$$

\subsection{Characterization of geopolymer binder}

Since the purpose of this research is a study of the microstructure and composition of these new binders, current knowledge on the microstructure of other similar geopolymers is presented which is helpful in terms of a starting point for the examination of glass-based binders.

\subsubsection{Microstructure}

In general, the microstructure of both fly ash- and metakaolin-based geopolymers has been found to be made of "rounded growths with bridging between them," which vary in size, packing density and the amount of bridging material present (Steveson and Sagoe-Crentsil 2005). More specifically, metakaolin geopolymers are typically homogenous resulting from a higher degree of reaction. Fly ash geopolymers, on the other hand, are more heterogeneous due to the presence of unreacted fly ash particles embedded in the matrix (Duxson et al. 2007; Fernández-Jiménez et al. 2007). 


\subsubsection{Effect of Si availability on microstructure}

The $\mathrm{Si} / \mathrm{Al}$ of the system as well as the presence of sodium silicate have been found to have a large impact on the microstructure. It should be noted that an increase in the $\mathrm{Si} / \mathrm{Al}$ ratio of a geopolymer typically comes about through the addition of soluble silica, which means the $\mathrm{Si}$ is coming first from the soluble silica and second from monomeric dissolution of the source material.

With regard to microstructure, it has been found that low $\mathrm{Si} / \mathrm{Al}$ systems $(\mathrm{Si} / \mathrm{Al} \leq 1)$ generally produce a matrix consisting of many tiny precipitates densely packed together containing large interconnected pores Alternately, the microstructure of high $\mathrm{Si} / \mathrm{Al}$ systems $(\mathrm{Si} / \mathrm{Al} \geq 3)$ is typically more uniform where individual particles are difficult to distinguish and the porosity consists of small, isolated pores (Fletcher et al. 2005; Steveson and SagoeCrentsil 2005).

\subsubsection{Composition}

The structure of the final matrix consists of $\mathrm{Si}$ and $\mathrm{Al}$ tetrahedra connected through oxygen bridges with monovalent cations $\left(\mathrm{Na}^{+}\right.$or $\left.\mathrm{K}^{+}\right)$existing within the cage-like structure in a charge-balancing capacity for the tetrahedrally coordinated trivalent Al cations within the matrix. The final product is sometimes called N-A-S-H, or sodium aluminosilicate hydrate and generally has the formula $\mathrm{Na}_{2} \mathrm{O} \cdot \mathrm{Al}_{2} \mathrm{O}_{3} \cdot 2 \mathrm{SiO}_{2} \cdot \mathrm{nH}_{2} \mathrm{O}$ (Shi et al. 2011). Depending on the constituents available within solution, an ASR, N-A-S-H, C-S-H or C-A-S-H gel could precipitate. Davidovits suggests calling the hardened structure a "solid solution" (Davidovits 2008) as opposed to a gel (Duxson et al. 2007). Typical Si/Al ratios of the 
geopolymer are around 1.5-2, but the presence of sodium silicate can easily increase this ratio to around 2.5-2.7 or higher (Fernández-Jiménez and Palomo 2003; Palomo et al. 2004).

\subsubsection{Relationship to mechanical properties}

"The microstructure and chemical composition of the reaction products have been found to have direct effects on the mechanical behavior and durability of a mix" (Fernández-Jiménez et al. 2007).

Throughout the literature it is widely agreed upon that increased homogeneity within the microstructure of a geopolymer corresponds directly to good mechanical performance (Rowles and O'Connor 2003). Porosity follows the same trend, where those samples containing large interconnected pores have poor strength and those containing small, isolated pores exhibit higher strength. It has also been noted repeatedly within the literature, the presence of soluble silica in the activator is usually responsible for a homogenous microstructure containing small pores (Steveson and Sagoe-Crentsil 2005).

In general, as the $\mathrm{Si} / \mathrm{Al}$ ratio increases, the microstructure becomes more homogenous, with a less aggregated look (Palomo et al. 2004; Steveson and Sagoe-Crentsil 2005; De Silva et al. 2007) and this typically relates directly to increased mechanical strength. However, at a certain point, the homogeneity and glassiness of the matrix continues to increase without an increase in mechanical strength, which implies there is a limit beyond which adding more soluble silica does not promote strength gain. 
The presence of unreacted particles embedded in the geopolymer matrix can also be linked to the mechanical performance, where softer particles such as metakaolin result in decreased strength and harder particles such as fly ash result in higher strength (FernándezJiménez et al. 2006). Mixtures activated with sodium silicate often contain more unreacted particles due to the increased setting and limited lability of the particles due to the polymerized Si species which results in lower dissolution (Duxson et al. 2005).

\subsubsection{Interfacial transition zone (ITZ)}

SEM microscopy has shown there is very little evidence that an ITZ (interfacial transition zone) exists between embedded objects and the ground matrix (Fernández-Jiménez and Palomo 2005). This could explain the increased bonding and mechanical properties, as the ITZ present in OPC concrete is well known as a point of weakness due to its increased porosity and high proportion of $\mathrm{CH}$ compared to C-S-H.

\subsubsection{X-ray diffraction}

Since geopolymer cements are for the most part amorphous, typically displaying a diffuse halo peak at around 27-29 29, $\mathrm{Cu} \mathrm{K \alpha}(3.05-3.30 \AA$ ) (Davidovits 2008), X-ray diffraction (XRD), a measure of the crystalline phases of a solid, is not entirely helpful in determining

the atomic structure. XRD is useful, however, in identifying the small bits of crystalline material that are often found embedded in the bulk matrix, such as muscovite, titania, quartz or corundum from fly ash that were not reacted as well as zeolites (discussed in Section 2.3.3.6) that may have formed (Fernández-Jiménez and Palomo 2003; Davidovits 2008). 


\subsubsection{Zeolites found in geopolymers}

Different zeolites are produced based on the source material and activator solution used as well as synthesis conditions such as the water content and curing time and temperature (Duxson et al. 2007). Small pockets of zeolites have been found in geopolymer systems with high water contents and/or low $\mathrm{Si} / \mathrm{Al}$ ratios, or in situations where very high temperature curing was involved. Zeolites are also commonly found in evacuated air voids or on fracture surfaces exposed to moist air (Fernández-Jiménez et al. 2007).

Overall it has been found that zeolite formation tends to take place when just $\mathrm{NaOH}$ is used to activate the aluminosilicate and no sodium silicate is involved (Fernández-Jiménez et al. 2007). Fernandez-Jimenez et al. reported the more crystalline a geopolymer is (i.e. reacted with $\mathrm{NaOH}$ as compared to sodium silicate), the better it performs in terms of durability (Fernández-Jiménez et al. 2007).

Zeolites found in fly ash geopolymers include herschelite (also called chabazite-Na), hydroxysodalite, or faujasite (zeolites X and/or Y) (Palomo and Glasser 1992; FernándezJiménez and Palomo 2003; Palomo et al. 2004; Fernández-Jiménez and Palomo 2005; Fernández-Jiménez et al. 2005; Provis et al. 2005). Philipsite has been found in metakaolin geopolymers and Zeolite $\mathrm{A}$ is formed when $\mathrm{NaOH}$ is added to metakaolin at $80-100^{\circ} \mathrm{C}$ (Breck 1974). 


\subsection{Significance of literature review}

\subsubsection{Obstacles in industry acceptance}

"Geopolymers are not necessarily a product competing with OPC, but rather a technology, which may be utilized by cement producers to offer a broader range of cementitious products to the market" (Duxson and Provis 2008).

Ordinary portland cement concrete is reliable, easy to work with and economical. However, as long as limestone or some other form of $\mathrm{CaCO}_{3}$ is used as the primary source of calcium and as long as the construction industry and society in general insists on high early strengths, OPC will remain connected to a substantial carbon footprint.

Geopolymers have an inherently lower carbon footprint than OPC, have the potential to use high volumes of waste products and when mixed correctly, are capable of excellent mechanical and durability performance. As is the case with any new technology, however, there are still matters that require further consideration and research. The following is a list of obstacles geopolymers face on the road toward acceptance by the concrete and construction industries:

1. Safety and ease of use

- The causticity of the activating solution presents safety issues with regard to mixing and placement.

- A one-step method of mixing similar to OPC concrete is not presently available for low-Ca geopolymers.

- Geopolymers usually require a thermal cure, which limits the application to mainly precast members (Fernández-Jiménez and Palomo 2003). 
- Changing production and distribution infrastructure currently in place may be expensive or difficult.

2. Activator solution

- The production of $\mathrm{NaOH}$ and sodium silicate are one of the main contributors to $\mathrm{CO}_{2}$ emissions associated with GPC (Van Deventer et al. 2010).

- More environmentally friendly sources of alkali silicates are needed (Sutter 2010).

3. Source materials

- There are a vast variety of materials rich in Si and Al out there that are currently being landfilled, more work is needed to determine which of these materials could be successful in a geopolymer application and what type of activation is necessary for each.

- Metakaolin-based geopolymers are not generally considered for structural or construction applications due to the lower strengths and high water demand of the particles; metakaolin also requires an initial heat treatment, which contributes to carbon emissions and fuel requirements.

- Fly ash is extremely heterogeneous in nature, which diminishes the reproducibility of a mix and makes it difficult to predict performance behavior. The long-term availability of this byproduct is also unknown.

- Much research is focused on specific source materials, yielding little data that can be easily applied to other materials.

4. Performance and reproducibility

- If GPC is to ever compete with OPC in the global market, progress must be made toward improving the reproducibility and predictability of this binder.

- Many long-term performance properties (durability) have not yet been determined (Van Deventer et al. 2010).

- Issues regarding variable set time and performance in relation to curing temperatures have been reported (Scrivener and Kirkpatrick 2008). 
- Compressive strength loss resulting from alkali leaching can be a problem in systems low in reactive $\mathrm{Al}$ (Cyr et al. 2012).

5. Further understanding

- More understanding of the role of $\mathrm{Ca}$ and $\mathrm{Fe}$ in geopolymer systems is necessary - this would allow materials with a wider composition range to be considered.

- Relationship between bulk chemistry and geopolymer chemistry as related through the degree of reaction (Duxson et al. 2007).

- Very little research regarding aggregate interactions in geopolymer cements has been done (Duxson et al. 2007).

- Methods for controlling the rate of Al release (Duxson et al. 2007).

- Microstructural characterization and compositional analysis on a wide range of geopolymers made from various source materials will help to strengthen the understanding of the relationship between microstructure and performance.

- The role of water in geopolymers (Duxson et al. 2007).

6. Communication and acceptance

- There exists a lack of communication and trust between academia and industry that must be overcome.

- Geopolymers lack a uniform nomenclature, and as such thorough research on this material is difficult

- The development of a database is needed to unite all of the current research on these materials (Roy 1999).

- Words like "alkalis" and "reactive silica" strike fear in the heart of concrete contractors, when in geopolymer science they represent necessary and desirable mixture components.

- A general acceptance of this new material within the concrete industry will be difficult, as OPC has a monopoly on the market, and is deeply entrenched within the concrete industry.

- "This lack of practical acceptance of the technology is rooted in the necessarily conservative nature of the construction industry, coupled with the very different 
chemistry of geopolymers when compared to OPC and related binders" (Duxson et al. 2007).

7. Standards and specifications

- There are no current standards for geopolymer cement (Roy 1999).

- Prescriptive regulatory standards currently in place have been designed with OPC in mind and must be altered to allow the use of new materials (Hooton 2008).

Despite the aforementioned obstacles, geopolymers still possess a great deal of potential for creating a more sustainable future for the concrete industry. Many of the obstacles mentioned are not necessarily negative problems that need to be solved, but rather are representations of research and experimentation that need to be investigated.

The needs most directly addressed by this research include:

- Increasing the data available on the relationship between microstructure, composition and performance of glass-based geopolymers.

- Expanding the acceptable range of source material composition to include Si-rich materials like waste glass.

- The elimination of sodium silicate, which cuts down on greenhouse gas emissions associated with production.

\subsubsection{Glass as a source material}

As discussed in previously, waste glass possesses nearly all of the desirable properties of a successful source material, including the following:

- Physically and compositionally

- Glass has a very high amorphous Si content, which dissolves quickly and easily in basic solutions 
- Glass possesses a hearty dose of $\mathrm{Na}$, which plays an important role in the network formation when $\mathrm{Al}$ is present

- Glass possesses a moderate Ca content, which has been shown to improve compressive strength in sodium-aluminosilicate systems

- The presence of monovalent and divalent alkali cations such as $\mathrm{Na}^{+}, \mathrm{K}^{+}$, $\mathrm{Ca}^{2+}$ and $\mathrm{Mg}^{2+}$ break up the silica network, making dissolution easier (Duxson and Provis 2008)

- The composition of waste glass is relatively uniform and homogenous when it comes from the same source

- Glass is hard, which is important in the case of incomplete dissolution

- Nearly all of the elements used in glass production have been successfully bound in geopolymer matrices, including boron, which is found in Pyrex, a common contaminant in waste glass (Provis and vanDeventer 2009; Van Deventer et al. 2010)

- Environmentally

- Glass is a waste product, which means a smaller carbon footprint for the resulting GPC

- The high Si content in glass eliminates the necessity for sodium silicate, further lowering the carbon footprint and simplifying the system

- Geopolymers offer a great opportunity to divert a valuable material from the landfill and cut down on the use of natural resources

A comparison of glass with the two most common materials used in geopolymer technology today, metakaolin and fly ash, based on the important properties of a source material listed in Section 2.4.1 is shown below in Table 2.12. 
Table 2.12. Comparison of fly ash, metakaolin and glass based on important properties of a source material. A single X represents adequacy and two Xs represent substantial.

\begin{tabular}{|c|c|c|c|}
\hline & Fly Ash & Metakaolin & Glass \\
\hline Reactive Si & $\mathrm{X}$ & $\mathrm{X}$ & $\mathrm{XX}$ \\
\hline Reactive Al & $\mathrm{X}$ & $\mathrm{XX}$ & \\
\hline Amorphous or disordered structure & $\mathrm{X}$ & $\mathrm{XX}$ & $\mathrm{XX}$ \\
\hline Particle size and shape & $\mathrm{XX}$ & $\mathrm{X}$ & $\mathrm{XX}$ \\
\hline Physical and compositional homogeneity & & $\mathrm{XX}$ & $\mathrm{X}$ \\
\hline Hardness & $\mathrm{X}$ & & $\mathrm{XX}$ \\
\hline
\end{tabular}

All three of the materials compared have most of the desirable properties. However, in the case of fly ash the lack of physical and compositional homogeneity cannot necessarily be remedied, as interparticle and intraparticle speciation is inherent within the material. The same is true for metakaolin, in that hardness cannot be enhanced. The property that glass lacks, reactive $\mathrm{Al}$, however, can be remedied through the addition of an alumina source to the mixture.

\subsubsection{Supplemental alumina}

As explained within the literature review, most source materials used to make geopolymers require the addition of predissolved silica in the activator solution to reach the necessary $\mathrm{Si} / \mathrm{Al}$ ratio fast enough for geopolymerization to occur. In the case of glass-based geopolymers, the glass itself is a substantial source of silica, and has the potential to create the desired $\mathrm{Si} / \mathrm{Al}$ ratio without the need for soluble silica. This is important because the production of sodium hydroxide and sodium silicate are the main contributors to $\mathrm{CO}_{2}$ emissions associated with geopolymer cement (Duxson et al. 2007). 
However, while glass has more than ample silica available for reaction, most waste glass is severely lacking in reactive alumina. Despite the fact that even geopolymers with fairly high Si/Al ratios have been shown to perform well (Fletcher et al. 2005; Idir et al. 2011; Cyr et al. 2012), a thorough review of the literature has resulted in the conclusion that the presence of $\mathrm{Al}$ is necessary to form a stable, non-soluble matrix with an acceptable set time and good mechanical performance (Fernández-Jiménez et al. 2006). Additionally, the presence of $\mathrm{Al}$ plays an extremely important role in balancing the $\mathrm{Na}^{+}$ions in solution and keeping them held within the final matrix.

\subsubsection{Stoichiometry}

The $\mathrm{Al}$ content of a geopolymer, or more specifically, the $\mathrm{Si} / \mathrm{Al}$ and $\mathrm{Na} / \mathrm{Al}$ molar ratios, have been shown to affect the set time, compressive strength and microstructure of the subsequent binder; where in most cases the presence of $\mathrm{Al}$ can drastically improve the performance of the geopolymer (Fernández-Jiménez et al. 2006).

Much of the literature available on geopolymers readily lists the stoichiometric molar ratios $(\mathrm{Si} / \mathrm{Al}, \mathrm{Na} / \mathrm{Al}, \mathrm{Si} / \mathrm{Na})$ of the source materials and activating solution, but fails to report on the actual stoichiometric molar ratios reached within the reaction products. Many authors assume, surprisingly, these ratios will be the same. This is of course a very weak assumption, as many factors play a role in how the various elements will combine together, such as the presence of $\mathrm{Ca}$ in the system, $\mathrm{pH}$, soluble silica, etc.; not to mention the supreme importance the degree of reaction of the source materials plays. 
This issue of initial and final stoichiometry is at the heart of this research. Simply put, glass by itself contains very high $\mathrm{Si} / \mathrm{Al}$ and $\mathrm{Na} / \mathrm{Al}$ ratios. Insufficient $\mathrm{Al}$ in the system has been found to lead to excess alkalis in the pore solution that can lead to deleterious carbonation on the surface as well as the formation of a water-soluble sodium silicate phase oozing out of the mortars in the case of extremely high $\mathrm{Si} / \mathrm{Al}$.

Considering the bulk stoichiometry of waste glass (very high $\mathrm{Si}$ and low $\mathrm{Al}$ ) and $\mathrm{NaOH}$ activator (high $\mathrm{Na}$ ), a supplementary source of $\mathrm{Al}$ must be added to combat the aforementioned issues by bringing the stoichiometric ratios of $\mathrm{Si} / \mathrm{Al}$ and $\mathrm{Na} / \mathrm{Al}$ down to more acceptable ratios. From the literature and structural studies of Si-Al tetrahedrally coordinated systems, it is known that an acceptable $\mathrm{Si} / \mathrm{Al}$ range is usually between 2-5 and ideally the $\mathrm{Na} / \mathrm{Al}$ ratio of a system will be 1 , where each tetrahedrally coordinated $\mathrm{Al}^{3+}$ cation is charge balanced with a corresponding $\mathrm{Na}^{+}$cation within the structure.

However, simply adding $\mathrm{Al}$ into the system does not necessarily imply that acceptable stoichiometric ratios will be reached. This research project would be easy and quite straightforward if the final stoichiometry matched the initial stoichiometry, but that is not the case. The bulk stoichiometry is obviously very important to obtaining a desirable reaction stoichiometry although other variables are also important and so the success of the "Al intervention" relies heavily upon the following issues:

- Rate of dissolution and degree of reaction

- Does the supplementary Al source dissolve first? Slowly? Rapidly? Does it remain unreacted? How much of the supplementary Al dissolved? 
- How much of the Si and $\mathrm{Na}$ from glass dissolved? How fast did it dissolve?

- What other elements are present in solution? $\mathrm{Ca}, \mathrm{Fe}$, etc.

- Formation of reaction product phases

- What phases form first? Do these phases change as further dissolution and polycondensation occur?

- Does C-S-H form first to use up all of the $\mathrm{Ca}$ and some of the $\mathrm{Si}$ in the system? Does a hybrid sort of C-A-S-H (calcium-aluminum-siliconhydrate) phase form?

○ Does a typical N-A-S-H (sodium-aluminum-silicon-hydrate) phase form that includes all of the $\mathrm{Al}$ and $\mathrm{Na}$ available?

\subsubsection{Plan}

Based on the literature, it is predicted that the sustainability of geopolymer cements can be further improved on by reacting waste glass and metakaolin with sodium hydroxide, eliminating the need for sodium silicate. The goal of this research is not necessarily to optimize a glass-based geopolymer cement design, but rather to observe the effects that introducing a supplementary alumina source will have on the kinetics of geopolymerization, the resulting microstructure and selected performance properties of the final product.

Based on the presented discussion of geopolymers, glass for use in geopolymers, and the stoichiometric ratios that must be considered, specific research questions were identified:

1. What are the phases formed by the alkali activation of waste glass and how is the microstructure and composition of these phases affected by the addition of metakaolin as a source of alumina? 
2. Is there a clear correlation between microstructure, composition and compressive strength of glass-based geopolymers?

3. How does the bulk stoichiometry of the initial mixture compare to the actual stoichiometry of the geopolymer formed? What role does the degree of reaction play in this relationship?

4. Does the addition of metakaolin or fly ash adequately lower the stoichiometry of the mixture to more acceptable ranges found in other geopolymers made of fly ash or metakaolin and does this enhance the mechanical performance?

It should be noted once again, the purpose of this research is not to develop the best or strongest possible glass-based geopolymer, but rather to identify the characteristics of baseline glass geopolymers and to document and observe the changes that occur when an alumina source is introduced. 


\section{Materials and Experimental Methods}

Chapter 3 provides details on the material selection process and characterization of those materials, as well as information and procedures outlining the methods used in this research. At the end of the chapter are three sections outlining the approach for each phase of testing. Actual details on the materials used as well as information on the mixture design and development for the mortars in each phase and the details of the experimental data collection plan are included in Chapter 4.

\subsection{Materials selection and characterization}

Material characterization of the source materials consisted of the following:

- Particle morphology using both secondary electron and backscatter electron imaging on the FEI XL-40 Environmental Scanning Microscope (ESEM)

- Compositional analysis by X-ray fluorescence (XRF) to obtain the elemental oxide analysis

- Powder X-ray diffraction (XRD) to get a baseline spectra for each material

\subsubsection{Glass}

In the world of recycling, it is widely known that compositionally pure materials are the most desirable, and those that contain impurities are often discarded due to high costs associated with sorting. The same holds true for glass, and since different types of glass are not labeled with a different number like plastics, various types of glass often get intermingled together during the recycling process. Single stream waste collection systems 
or curbside recycling programs yield a mixture of glass types, colors and impurities. This is the type of glass that will most likely be available for use in geopolymers. Part of the draw of this market is that color and compositional impurities should not have much of an influence on the success of the binder. However, it is important to realize the source of the waste glass can have a large impact on the composition, which must still be considered in mixture design.

Due to safety and handling issues associated with crushing and grinding local waste glass to the fineness required for this research, as shown in Figure 3.1, and a desire to use truly recycled materials, consumer source (CS) waste glass was obtained from Vitro Minerals, a leading glass processer in the United States. Consumer source glass powders are made from $100 \%$ recycled glass. 

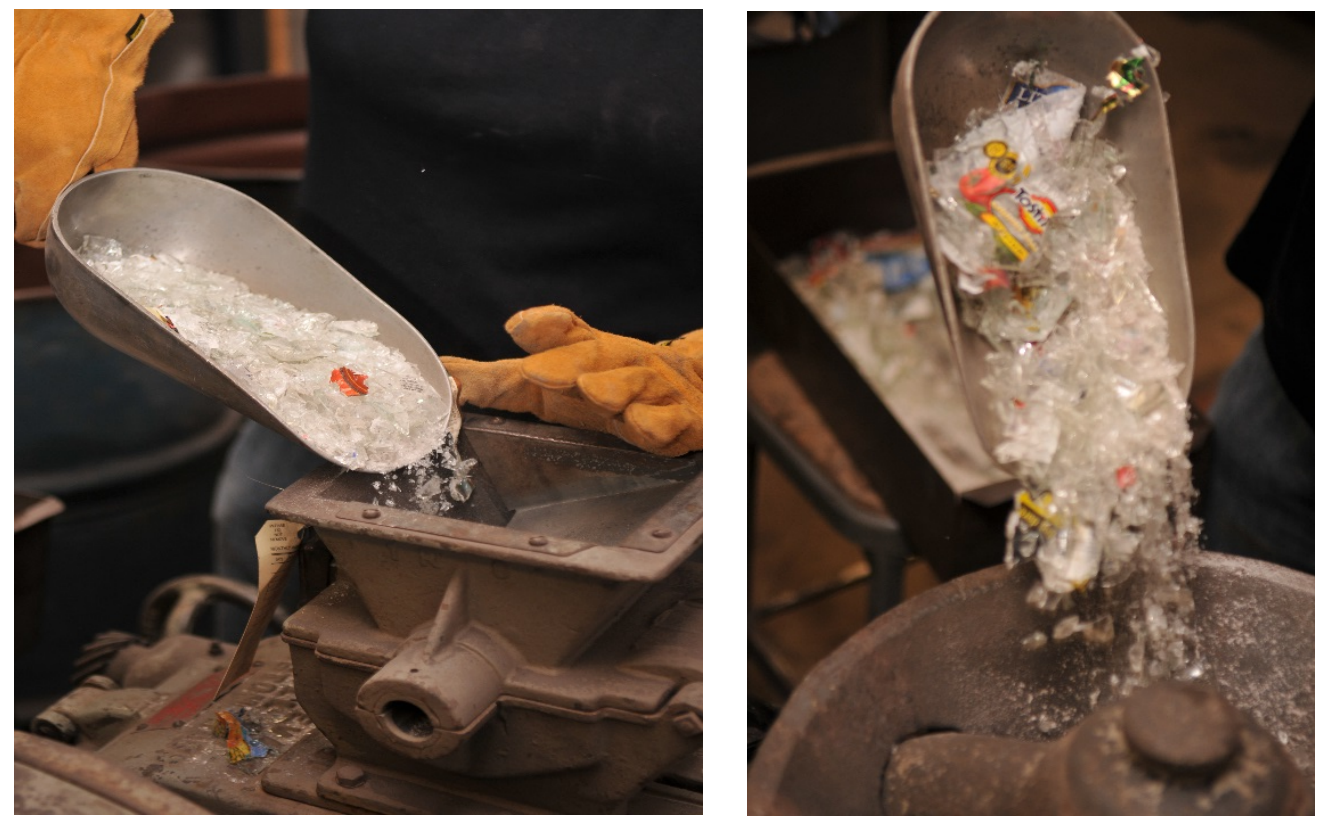

Figure 3.1. Waste packaging glass being crushed in a jaw crusher (left) and a gyratory crusher (right). Wrappers, cap rings, etc. are quite easy to remove by sieving once the glass gets down to a certain size.

Three different glasses were obtained from Vitro Minerals and analyzed by XRF for the elemental oxide composition, shown in Table 3.1. The glasses were labeled based on the alumina concentration, where HA means high-Al, MA means medium-Al and LA means low-Al. Also shown is the typical composition of soda-lime glass, which makes up the bulk of glass in the municipal solid waste stream. 
Table 3.1. Composition of glasses from Vitro Minerals as determined by X-ray fluorescence (XRF) and typical soda-lime glass (Glass Packaging Institute 2013).

\begin{tabular}{|c|c|c|c|c|}
\hline & High Al (HA) & Medium Al (MA) & Low Al (LA) & Soda-lime Glass \\
\hline $\mathrm{SiO}_{2}$ & 60.25 & 63.42 & 70.60 & 72 \\
\hline $\mathrm{Al}_{2} \mathrm{O}_{3}$ & 12.19 & 8.63 & 0.49 & $2-3$ \\
\hline $\mathrm{Fe}_{2} \mathrm{O}_{3}$ & 0.31 & 0.69 & 0.09 & - \\
\hline $\mathrm{TiO}_{2}$ & 0.89 & 0.35 & 0.06 & - \\
\hline $\mathrm{CaO}$ & 21.72 & 17.43 & 9.81 & - \\
\hline $\mathrm{SO}_{3}$ & 0.01 & 0.13 & 0.23 & - \\
\hline $\mathrm{P}_{2} \mathrm{O}_{5}$ & 0.04 & 0.03 & 0.01 & 12 \\
\hline $\mathrm{MgO}$ & 3.01 & 2.18 & 4.13 & - \\
\hline $\mathrm{NaO}$ & 0.87 & 5.84 & 14.30 & - \\
\hline $\mathrm{K}_{2} \mathrm{O}$ & 0.08 & 0.30 & 0.07 & - \\
\hline $\mathrm{MnO}$ & 0.01 & 0.03 & 0.01 & - \\
\hline $\mathrm{BaO}$ & 0.00 & 0.05 & 0.00 & 0.01 \\
\hline $\mathrm{SrO}$ & 0.03 & 0.03 & 0.19 & - \\
\hline $\mathrm{LOI}$ & 0.59 & 0.89 & & - \\
\hline
\end{tabular}

Since this research is aimed at considering waste glass from the post-consumer waste stream as opposed to the post-industrial waste stream, the two glasses with the widest variance in composition were chosen to represent the two ends of this spectrum. This includes the HA glass containing high $\mathrm{Al}$ and low $\mathrm{Na}$ contents and the LA glass containing low $\mathrm{Al}$ and high $\mathrm{Na}$ contents. The HA glass is double-recycled, as it originally came from the post-consumer waste stream before going to a glass recycling plant that specializes in making fiberglass insulation. The LA glass is made primarily of bottle glass and windshield glass - namely soda-lime glass. Both glasses are 100\% amorphous and contain no 
crystalline silica (Turner 2012). The specific gravity of all the glass is 2.50 and the hardness is 5.5, as reported in the MSDS (material safety data sheets). The glasses were obtained in various finenesses. Figure 3.2 shows the morphology and conchoidal fracture surfaces of the glass under secondary electron imaging and Figure 3.3 shows the shape and particle size array of both the HA and LA glasses under backscatter electron imaging. Both of the glasses shown are of similar fineness.

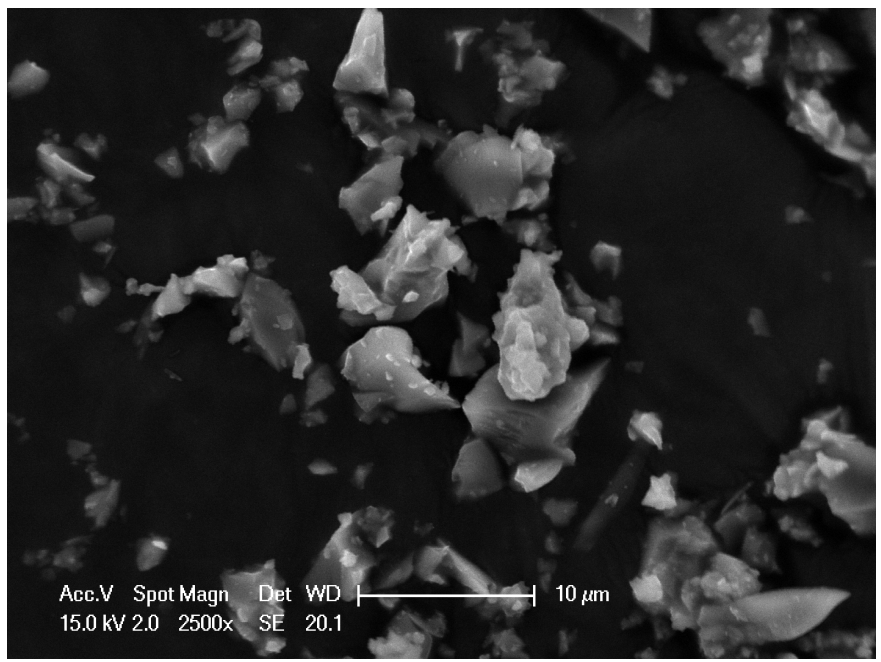

Figure 3.2. Morphology of glass particles shown in secondary electron imaging. 

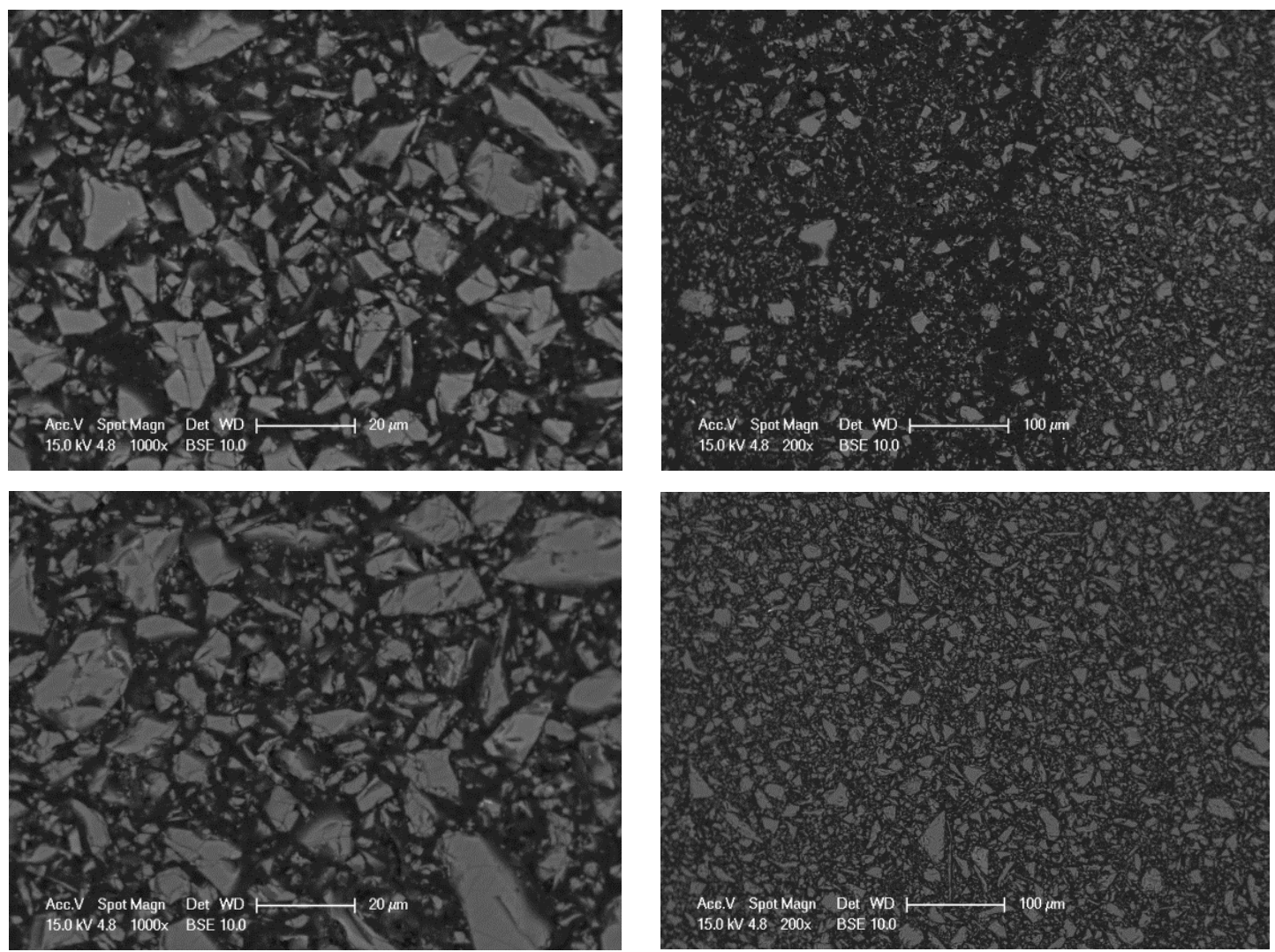

Figure 3.3. Glass shown in polished sections under secondary electron imaging: LA500 (top) and HA500 (bottom).

\subsubsection{Supplementary alumina sources}

As stated previously, the $\mathrm{Si} / \mathrm{Al}$ and $\mathrm{Na} / \mathrm{Al}$ ratios of glass in general are much higher than what is typically considered acceptable for geopolymers made of fly ash or metakaolin. Since fly ash and metakaolin both possess a significant amount of alumina, they were considered as a supplementary alumina source along with kaolin clay, red mud and reagent grade sodium aluminate. Table 3.2 lists the criteria for selecting the supplementary alumina sources used in this research. 
Table 3.2. Criteria used for selecting a supplementary alumina source. A single $X$ represents a good rating in that category, with $\mathrm{XX}$ representing a great rating and no $\mathrm{X}$ representing a poor rating.

\begin{tabular}{|c|c|c|c|c|c|c|}
\hline Material & $\begin{array}{c}\text { Compositional } \\
\text { homogeneity }\end{array}$ & Availability & Reactivity & $\begin{array}{c}\text { Prior } \\
\text { success }\end{array}$ & $\begin{array}{c}\text { Low } \\
\text { cost }\end{array}$ & $\begin{array}{c}\text { Environ- } \\
\text { mental }\end{array}$ \\
\hline $\begin{array}{c}\text { Kaolin } \\
\text { clay }\end{array}$ & $\mathrm{XX}$ & $\mathrm{X}$ & & & $\mathrm{X}$ & $\mathrm{X}$ \\
\hline Metakaolin & $\mathrm{XX}$ & $\mathrm{X}$ & $\mathrm{XX}$ & $\mathrm{X}$ & $\mathrm{X}$ & \\
\hline Fly ash & & $\mathrm{X}$ & $\mathrm{X}$ & $\mathrm{XX}$ & $\mathrm{X}$ & $\mathrm{XX}$ \\
\hline Red mud & & $\mathrm{XX}$ & & & & $\mathrm{XX}$ \\
\hline $\begin{array}{c}\text { Sodium } \\
\text { aluminate }\end{array}$ & $\mathrm{XX}$ & $\mathrm{XX}$ & & & \\
\hline
\end{tabular}

The following is an explanation of why each material was or was not chosen for use in this research:

- Kaolin clay was ruled out due to the fact it is typically not very reactive upon mixing (Xu and Van Deventer 2003).

- $\quad$ Red mud is a byproduct of the Bayer process, which is the process in which Al is removed from bauxite (aluminum ore) (Pan et al. 2003; Zhang et al. 2010). Red mud contains a great deal of iron, which is of yet an unknown with regard to geopolymerization, and is difficult to obtain unless locally available in an area where bauxite processing is performed, such as Louisiana.

- A number of research projects have used reagent grade sodium aluminate as an alumina source for reaction with Si-rich materials although sodium aluminate can be fairly expensive and has high energy emissions associated with its production (Phair and Van Deventer 2002; Brew and MacKenzie 2007; Hajimohammadi et al. 2008; Gluth et al. 2012).

- Despite the fact that metakaolin has a very high water demand, it was chosen based on its homogenous composition, high reactivity and prior success as a model material in geopolymer research.

- Fly ash was also considered based on its prior success in geopolymers, despite its heterogeneous composition. 
Table 3.3 shows the composition of the metakaolin and fly ash used in this research as determined by XRF. A discussion of how replacement levels of fly ash or metakaolin were decided on is included in Chapter 4.

Table 3.3. Composition of metakaolin and fly ash by mass as determined by X-ray fluorescence (XRF).

\begin{tabular}{|c|c|c|}
\hline & Metakaolin & Fly ash \\
\hline $\mathrm{SiO}_{2}$ & 52.60 & 39.2 \\
\hline $\mathrm{Al}_{2} \mathrm{O}_{3}$ & 42.86 & 20.3 \\
\hline $\mathrm{Fe}_{2} \mathrm{O}_{3}$ & 1.20 & 8.12 \\
\hline $\mathrm{TiO}_{2}$ & 1.69 & 1.24 \\
\hline $\mathrm{CaO}$ & 0.10 & 14.3 \\
\hline $\mathrm{SO}_{3}$ & 0.01 & 3.22 \\
\hline $\mathrm{P}_{2} \mathrm{O}_{5}$ & 0.09 & 0.56 \\
\hline $\mathrm{MgO}$ & 0.15 & 3.53 \\
\hline $\mathrm{Na}_{2} \mathrm{O}$ & 0.05 & 5.84 \\
\hline $\mathrm{K}_{2} \mathrm{O}$ & 0.57 & 1.10 \\
\hline $\mathrm{MnO}$ & 0.01 & 0.04 \\
\hline $\mathrm{BaO}$ & 0.03 & 1.15 \\
\hline $\mathrm{SrO}$ & 0.02 & 0.54 \\
\hline $\mathrm{LOI}$ & 0.62 & \\
\hline
\end{tabular}

\subsubsection{Metakaolin}

PowerPozz high reactivity metakaolin was used. PowerPozz is derived from purified kaolin clay, and contains less than $2 \%$ quartz $\mathrm{SiO}_{2}$. The specific gravity is 2.60 and the hardness is 2.5 as reported from the vendor. Figure 3.4 shows the morphology of tiny (5 micron) metakaolin particles under secondary electron imaging on the left, as well as 
aggregated flocs of particles under backscatter electron imaging on the right. Figure 3.5 shows the general shape of the platy metakaolin particles.
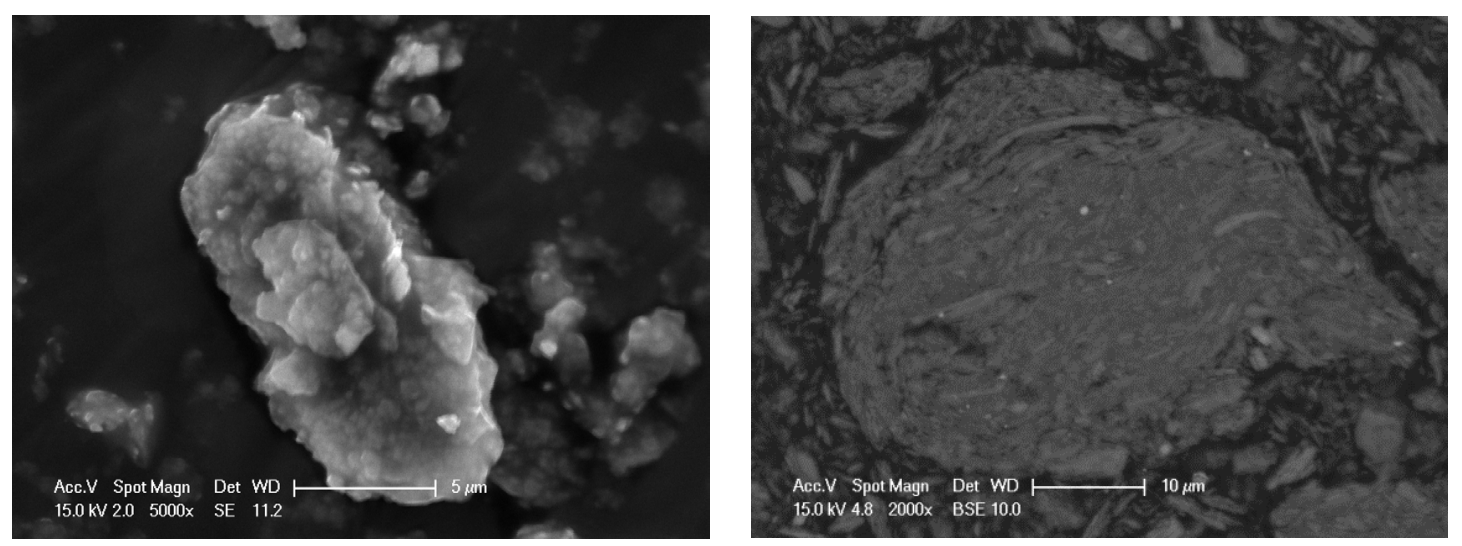

Figure 3.4. Morphology of metakaolin particles as shown in a powder mount in secondary electron imaging (left) and flocs of particles in a polished section in backscatter electron imaging (right).
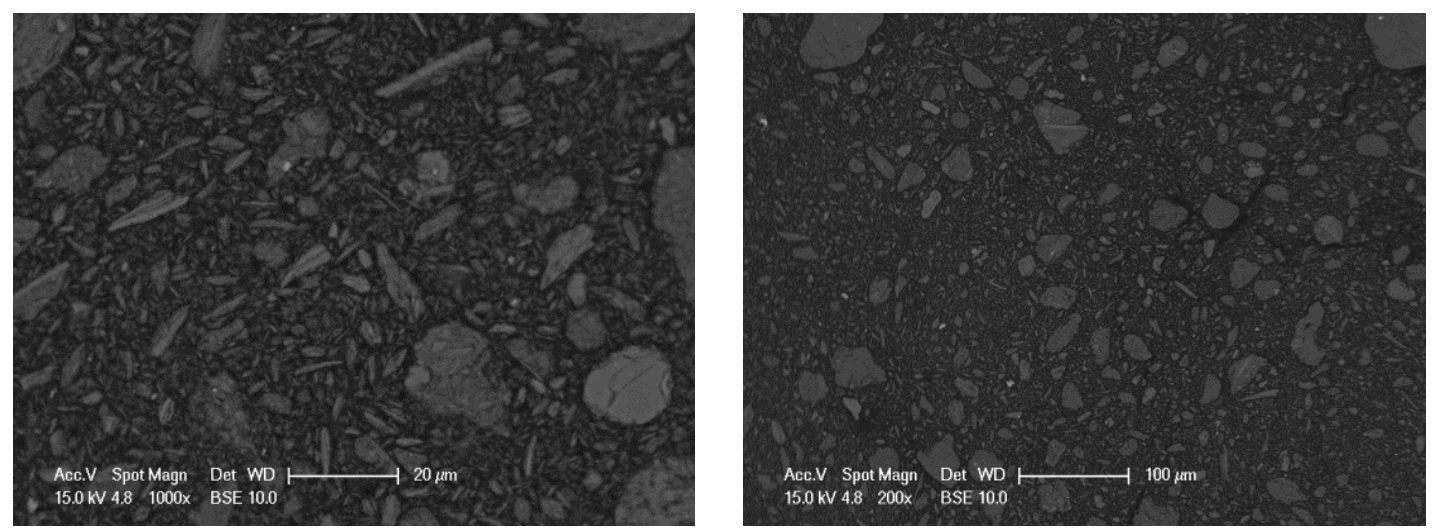

Figure 3.5. Metakaolin in polished section in backscatter electron imaging. Flocs of particles can clearly be seen on the right.

\subsubsection{Fly ash}

A Class C fly ash was chosen based on its high alumina and alkali contents. The high alkali content $\left(\mathrm{Na}_{2} \mathrm{O}_{(\mathrm{eq})}=6.6\right)$ renders this fly ash unusable in portland cement applications due to the increased likelihood for alkali silica reaction to occur if reactive aggregate is present in the concrete. The specific gravity of the fly ash is 2.56 . Figure 3.6 shows the spherical 
morphology of the fly ash particles in a polished section under backscatter electron imaging. It is clear from the different brightness intensities visible in the images that many phases are present within and among the fly ash particles. Cenospheres, plerospheres and solid particles are all visible as well.
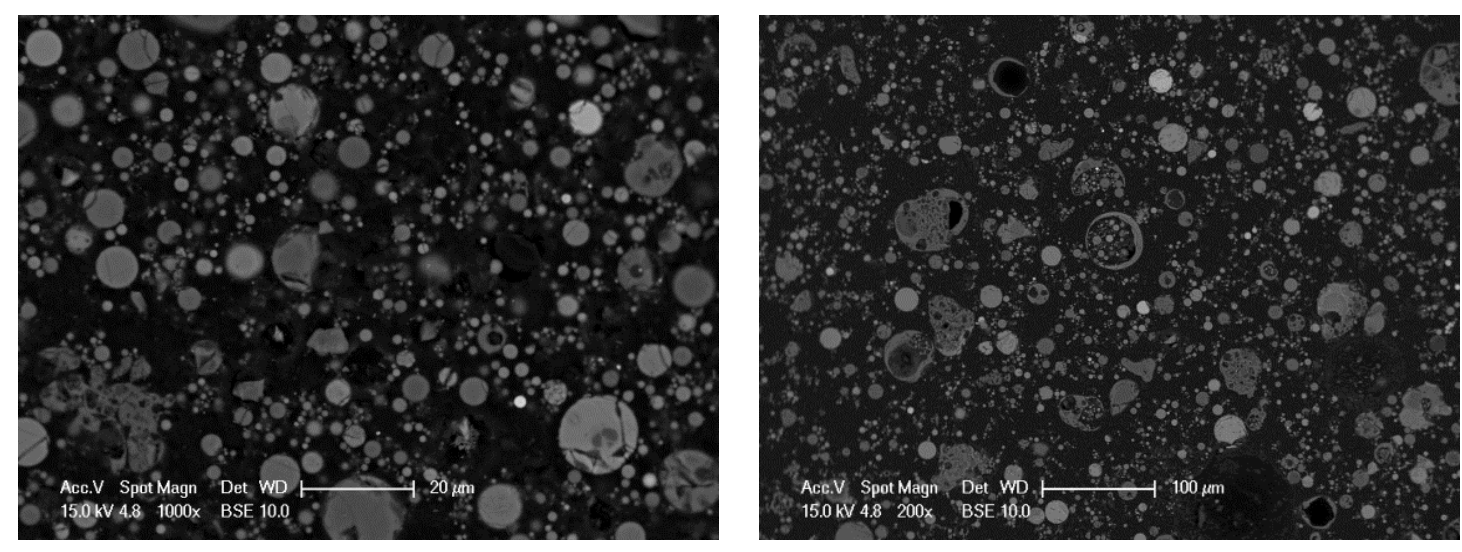

Figure 3.6. Fly ash in polished section in backscatter electron imaging.

\subsubsection{Activator solution}

Reagent grade sodium hydroxide from Spectrum Laboratories was used in the form of solid flake, as shown in Figure 3.7. The composition of the $\mathrm{NaOH}$ is $77.48 \% \mathrm{Na}_{2} \mathrm{O}$ and $22.53 \%$ $\mathrm{H}_{2} \mathrm{O} . \mathrm{NaOH}$ has a molecular weight of 39.997 grams per mole and a specific gravity of 2.13 at $20^{\circ} \mathrm{C}$ (Shi 2006). 


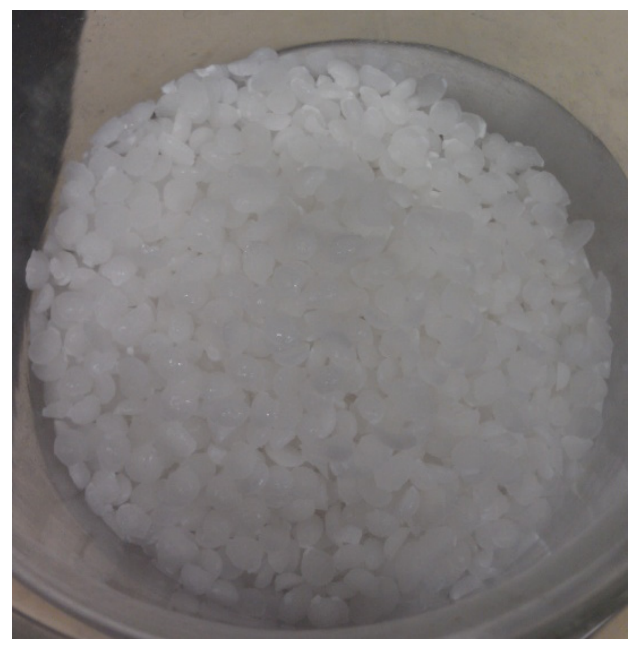

Figure 3.7. NaOH flake pellets prior to solution preparation.

\subsubsection{Sand}

Two types of sand were used to produce the mortars. Washed, oven dried and sieved sand from Superior Sand and Gravel in Hancock, Michigan was used in Phase I. ASTM graded Ottawa sand was used in Phases II and III(ASTM International 2012). Ottawa sand was also used in the sample preparation of vacuum impregnated polished section samples. A backscatter electron micrograph showing the interface between the sand embedded in epoxy (top) and sand embedded in geopolymer (bottom) is shown in Figure 3.8. It is clearly easy to distinguish between the two Si-rich materials. 


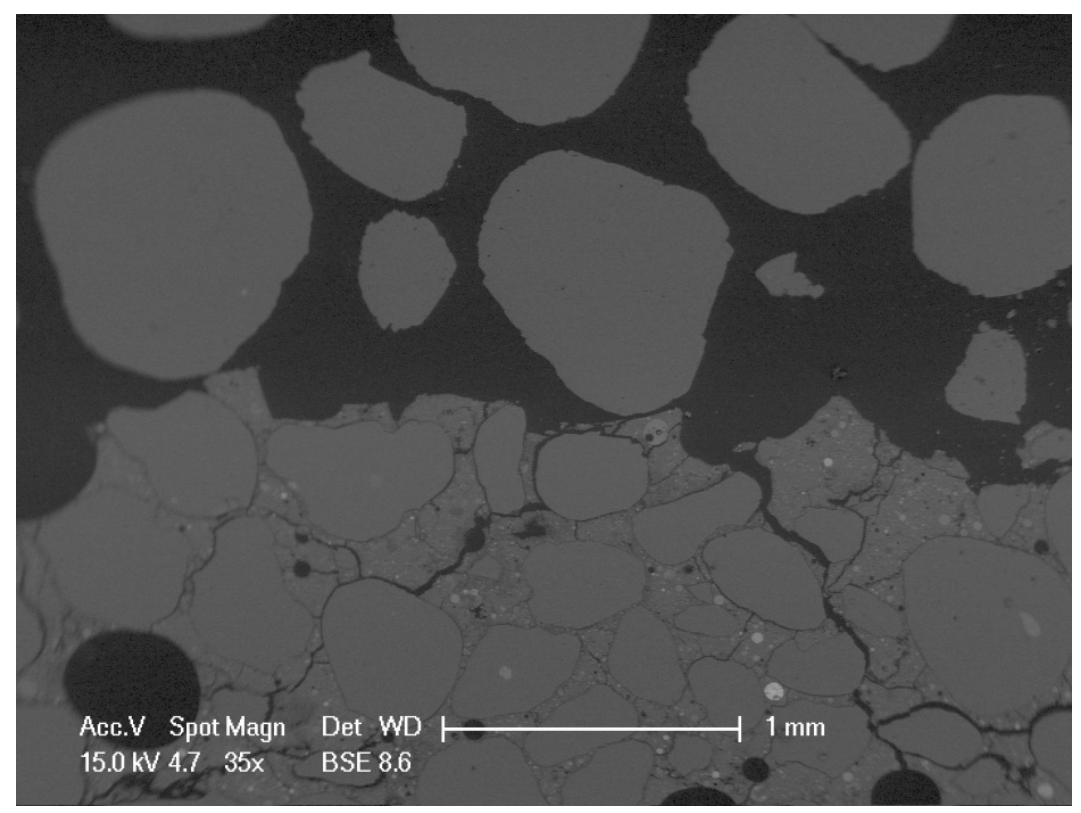

Figure 3.8. Backscatter electron image of the interface between Ottawa sand embedded in epoxy (top) and sand embedded in geopolymer (bottom).

\subsection{Mixture design and development}

Mortars and pastes were considered in this research in order to efficiently use the materials available and to better monitor the mixing process in smaller batches. Mortars were made in all three phases; paste samples were taken before the sand was added for degree of reaction measurements and XRD spectra.

There are many variables to consider when formulating a mortar mixture design, especially when a specific mixture design procedure does not already exist. While there is a great deal of literature available regarding geopolymer cements, very few divulge all details with regard to mixture design, development and mixing procedures. For this reason, a fair amount of trial and error was necessary to determine a proper mixture design and procedure. 
When designing a geopolymer, consideration must be given to the following issues, covered in the following sections:

1. Stoichiometry

2. Mixture proportioning and water content

3. Mixing procedure

4. Curing conditions

\subsubsection{Stoichiometry}

Due to the fact that numerous source materials exist that could be used for geopolymer creation, and the fact the activating solution can be altered by increasing or decreasing the $\mathrm{Na}_{2} \mathrm{O}$ or $\mathrm{SiO}_{2}$ content, it seems that mixture design based on stoichiometry would not have any restrictions. This is not the case, however, if one first considers that previous research has resoundingly concluded that a $\mathrm{Na} / \mathrm{Al}$ ratio of near unity is ideal for all geopolymers.

Beginning with a solid/activator ratio to achieve an adequate workability gives an idea of how much solid will be used per unit of mortar. Once the solid content is decided on, the activator must be added achieving a $\mathrm{Na} / \mathrm{Al}$ ratio near unity, or whatever the desired stoichiometry is. There are other parameters that can be changed such as the water content, which affects the $\mathrm{pH}$ of the activator. In some cases, where sodium silicate is added, the $\mathrm{Si}$ content will change with the activator. However, viscosity and $\mathrm{pH}$ limit the amount of predissolved silica that can be included in the activator solution, which puts a maximum on how much Si can be contributed to the system through the activator.

There are essentially two cases for the $\mathrm{Na} / \mathrm{Al}$ ratio if unity is not reached: 
1. In the case that $\mathrm{Na} / \mathrm{Al}$ is $>>1$, excess $\mathrm{Na}$ can create soluble sodium silicate phases or sodium carbonates on the surface of the material.

2. In the case that $\mathrm{Na} / \mathrm{Al}$ is $<<1, \mathrm{Al}$ present in solution will not be able to be included in the structure due to the lack of electric neutrality and therefore the $\mathrm{Si} / \mathrm{Al}$ ratio will suffer, which as been shown to affect set time, microstructure, mechanical performance, etc.

In the case of waste glass, situation 2 is most likely not a problem as an ample amount of $\mathrm{Na}$ is available immediately from the activating solution as well as from the dissolving glass and the only source of $\mathrm{Al}$ is from the metakaolin.

Figure 3.9 illustrates the maximum $\mathrm{Si} / \mathrm{Al}$ and $\mathrm{Na} / \mathrm{Al}$ ratios in a system activated by $10 \mathrm{M}$ $\mathrm{NaOH}$ where metakaolin replaces an example waste glass (of the same composition of soda-lime glass) incrementally by mass. Obviously, adding Al to the system will affect both the $\mathrm{Si} / \mathrm{Al}$ and $\mathrm{Na} / \mathrm{Al}$ ratio at the same time, decreasing both ratios as more alumina is added to the system.

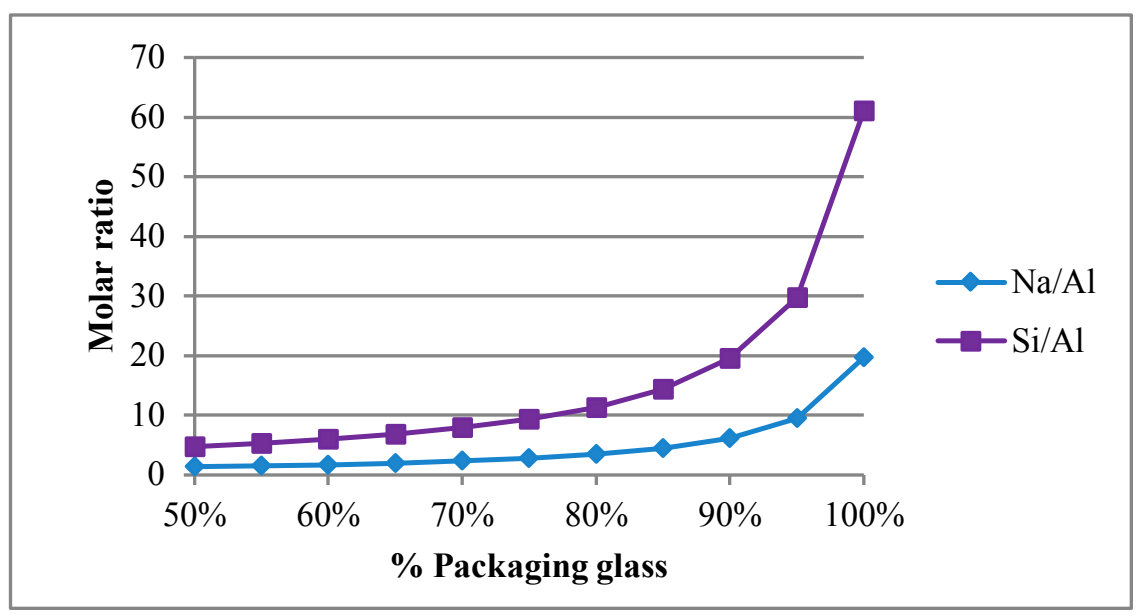

Figure 3.9. Theoretical stoichiometry of soda-lime glassmetakaolin geopolymer activated with $10 \mathrm{M} \mathrm{NaOH}$. 
The $\mathrm{Si} / \mathrm{Al}$ and $\mathrm{Na} / \mathrm{Al}$ ranges studied in this research changed with each mixture since each source material (glass, metakaolin, fly ash) all contributed varying amounts of silica and alumina and sodium in the system came from $\mathrm{NaOH}$ as well as from the glass and fly ash.

\subsubsection{Mixture proportioning and water content}

The baseline mixture proportions used in this research were originally based off those used by Cyr et al. in their research on waste glass geopolymers (Cyr et al. 2012). Cyr used a ratio of sand to glass of 3:1 and a ratio of 2:1 for glass to activator solution by mass. This was found to create a workable mixture when coarser glass was used, however when the finer glasses were used, and especially when the metakaolin was introduced, the water demand precluded using the desired activator ratio while maintaining a workable mixture. When not enough liquid was available, the result was the formation of tiny balls that were nearly impossible to consolidate, and more water had to be added. An example of these balls is shown in Figure 3.10. 


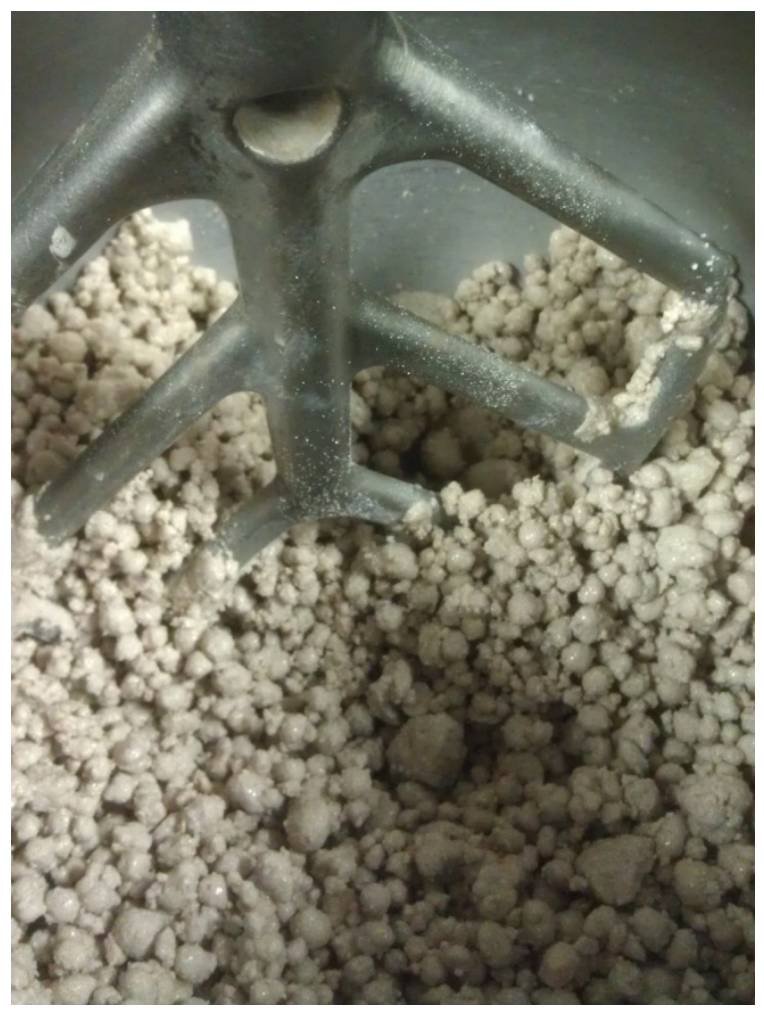

Figure 3.10. Balls formed in mixture with not enough liquid present.

Water content is a very important parameter in mixing glass geopolymers, or all geopolymers for that matter. Enough water for dissolution and ionic transport is necessary to react all of the material, however too much water will result in a porous microstructure, which decreases physical properties and durability.

The water/solids (w/s) ratio used in this research is based on the following definitions, after Hardjito et al. (Hardjito et al. 2004):

- Water - mass of water in $\mathrm{NaOH}$ flake and solution and extra water for mixing

- Geopolymer solids - mass of glass, metakaolin or fly ash plus the $\mathrm{Na}_{2} \mathrm{O}$ in sodium hydroxide flake 
Admixtures to aid in decreasing the water demand and increasing the workability of the mixtures were considered but the limited amount of literature regarding their effect on various geopolymer systems has suggested the extremely high alkalinity of the mixture decreases their effectiveness and so they were avoided (Puertas et al. 2003; Hardjito et al. 2004; Provis et al. 2010).

It was a difficult decision to decide whether to base the water content on a constant w/s ratio or on a consistent mortar flow, since replacing glass with various other materials had a drastic effect on the water demand; metakaolin increased the water demand and fly ash decreased it. Figure 3.11 shows the difference between a 100\% metakaolin mixture (left) and $100 \%$ glass mixture (right) both containing the same amount of activator and water by mass. The decision on how to address the water content is addressed in Chapter 4 for each phase.

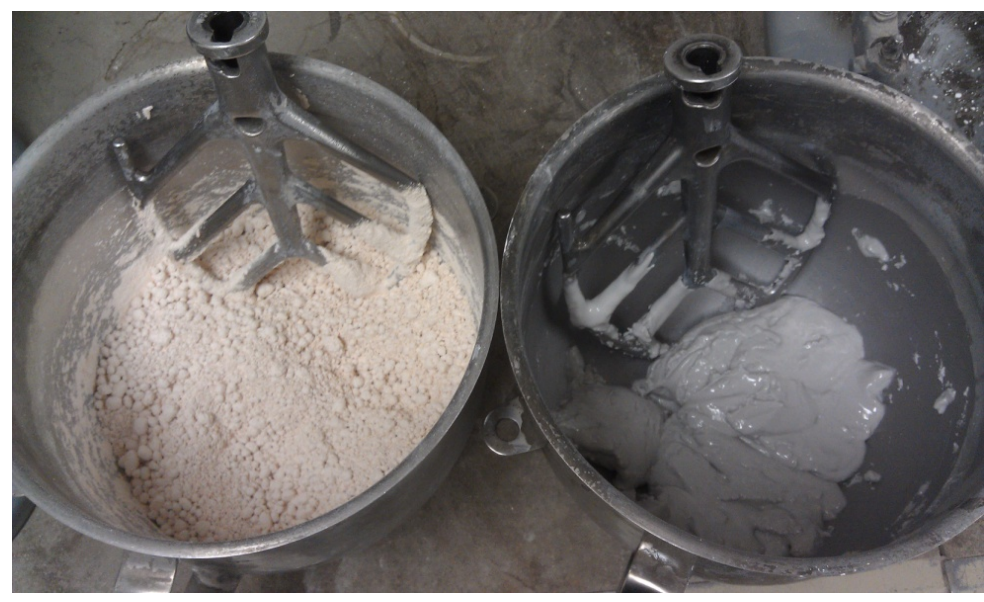

Figure 3.11. Visible difference in water demand for $100 \%$ metakaolin (left) and 100\% glass (right) activated with the same amount of activator, water and source material by mass. 


\subsubsection{Mixing procedure}
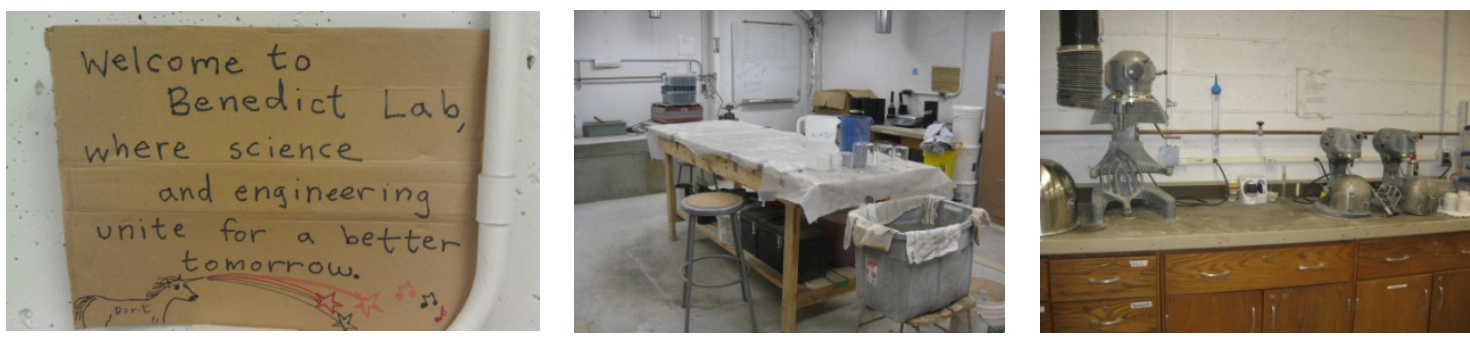

Figure 3.12. Benedict Laboratory and mortar mixing room.

Distilled water was used to create the $\mathrm{NaOH}$ solutions, which were prepared at least 24 hours in advance of mixing to allow time for cooling and equilibrating. Extra mixing water was also prepared so that it would reach room temperature in time for mixing.

The mortars were prepared by first pre-blending the dry ingredients in a 20 -quart allpurpose Hobart mixer for 2 minutes, then adding the activator slowly over one minute. The mixture was allowed to mix for 3 minutes, at which time the extra water, if any, was added. The extra water was not mixed with the activator solution in order to allow the full effect of the $\mathrm{NaOH}$ to work on dissolving the source materials. Mixing was continued for an additional four minutes at which time the mixer was stopped and a small container of paste was collected, if necessary, for degree of reaction measurements and powder XRD spectra collection. The mixer was started back up and the sand was added slowly over two minutes and the entire mixture was allowed to mix for an additional six minutes.

\subsubsection{Fresh properties}

Following the mixing, the temperature was taken three times by a MiniTemp gun and recorded. Fresh mortar flow was measured in accordance with ASTM C1437 - Standard 
Test Method for Flow of Hydraulic Cement Mortar using a drop table and the diameter recorded in four places (ASTM International 1999). Unit weight was measured using three tared coffee cups. The flow table test and unit weight cups are shown below in Figure 3.13.
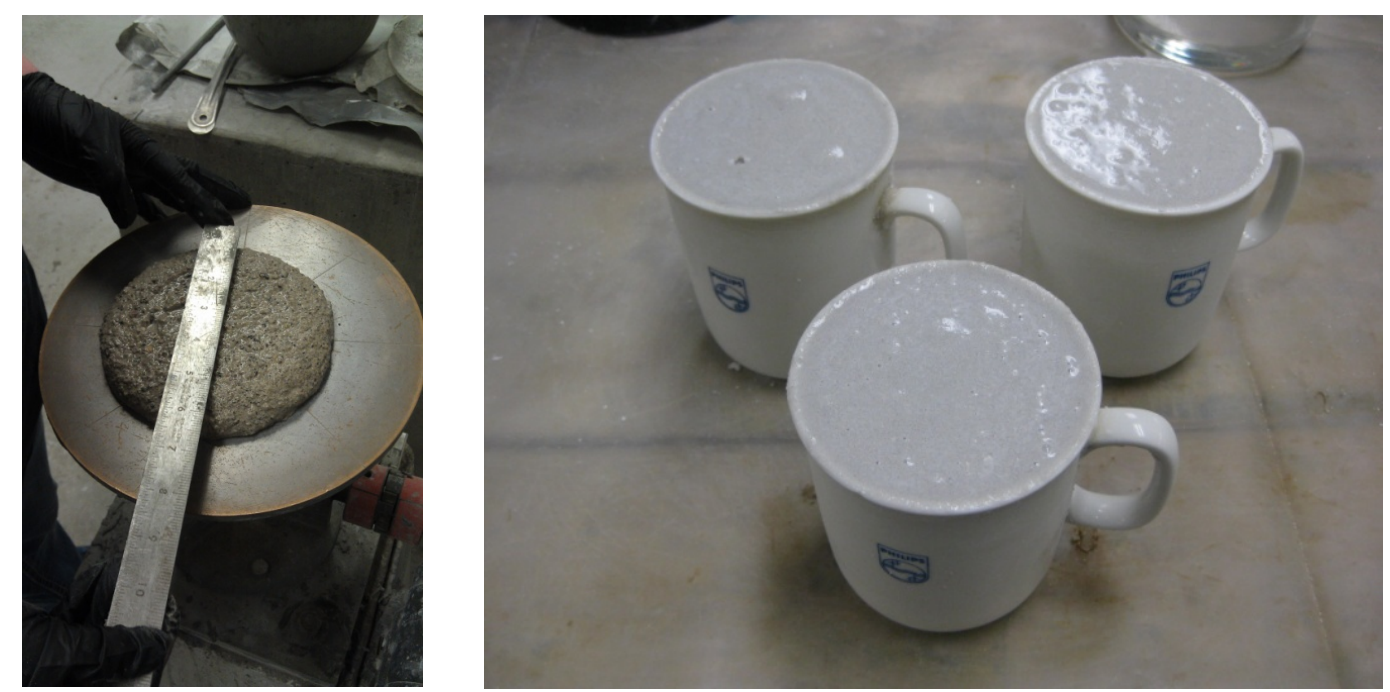

Figure 3.13. Flow table test (left) and unit weight setup (right).

\subsubsection{Cylinder preparation}

Following the fresh property tests, $2 \times 4$ inch plastic cylinders were filled in two lifts, with 1.5 minutes of vibration on a vibration table in between each lift, as shown in Figure 3.14, to help with consolidation and remove entrapped air. The tops were struck flat and the specimens put into sealed containers for curing. The molds were prepared with a thin layer of WD40 around the inside, which was used as a mold release agent. 


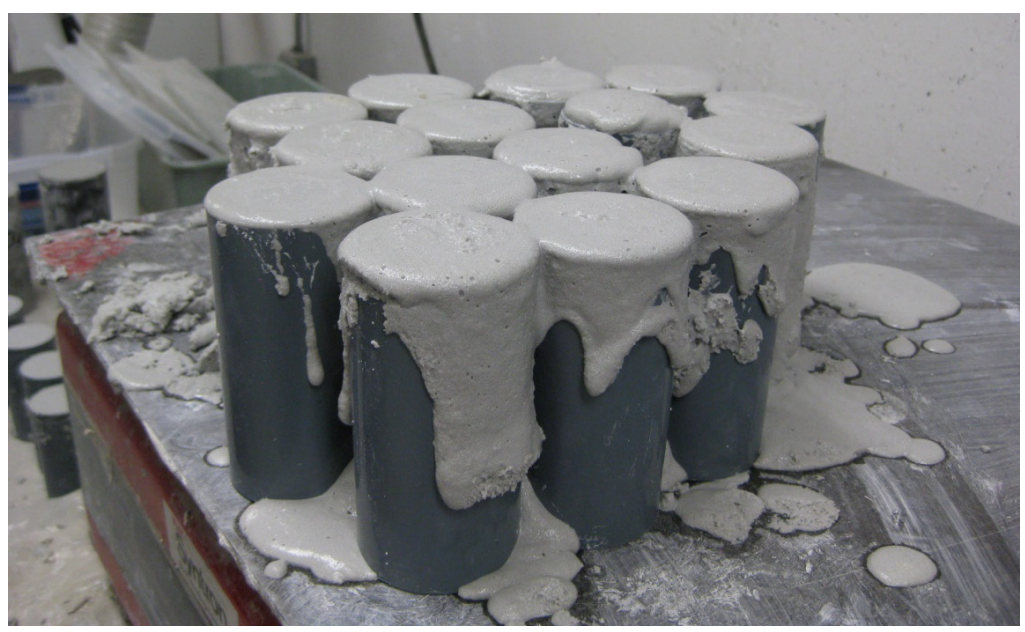

Figure 3.14. Molds after vibration on vibration table.

\subsubsection{Curing and demolding}

Discussions on the exact temperatures chosen for curing in each phase are found in later sections. Unless otherwise noted, all of the specimens were cured in sealed containers with open water available at the designated temperature for 24 hours. Following thermal curing for 24 hours, the specimens were demolded and then kept at a constant temperature $76^{\circ} \mathrm{F}$ $\left(24^{\circ} \mathrm{C}\right)$ and $95-100 \%$ relative humidity in sealed boxes with water available until they were ready to be tested. Figure 3.15 shows the internal and external setup for maintaining the desired curing conditions. 

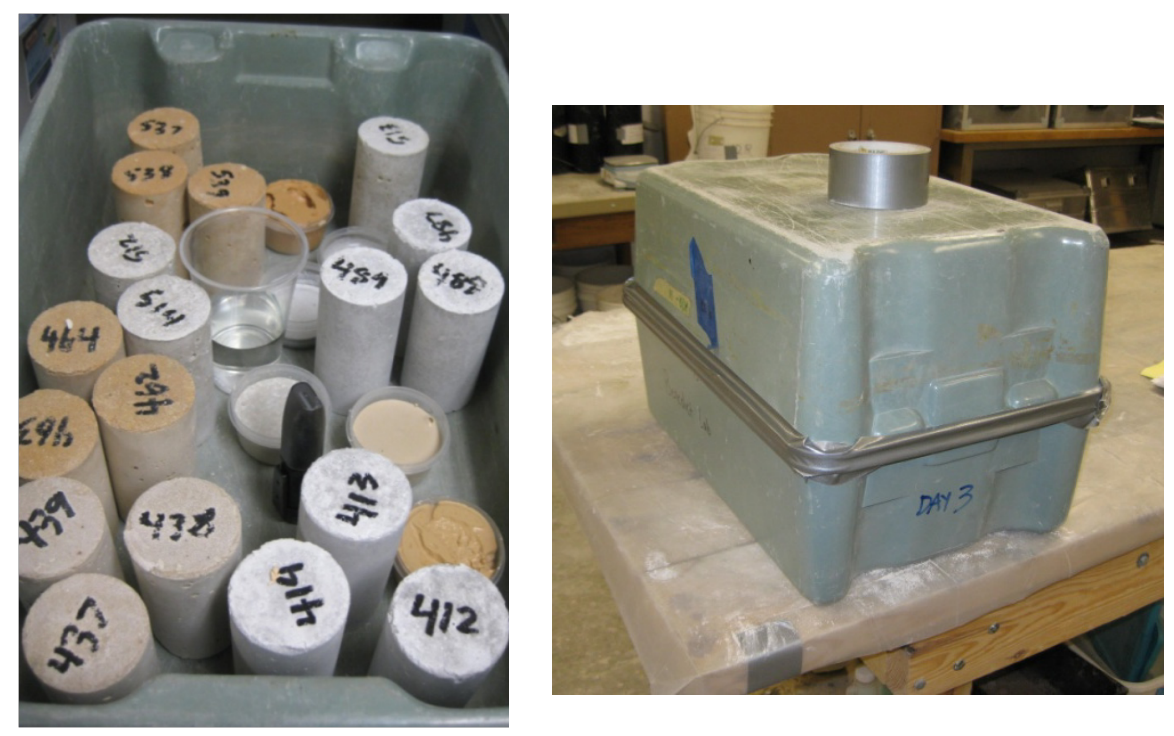

Figure 3.15. Internal (left) and external curing (right) conditions used to maintain desired curing conditions.

It should be noted that in some cases, especially with those mixes containing metakaolin, the bottom perimeter of the some of the specimens seemed to stick in the mold. This can be seen in Figure 3.16 below. Rubber end caps were used in compression testing.

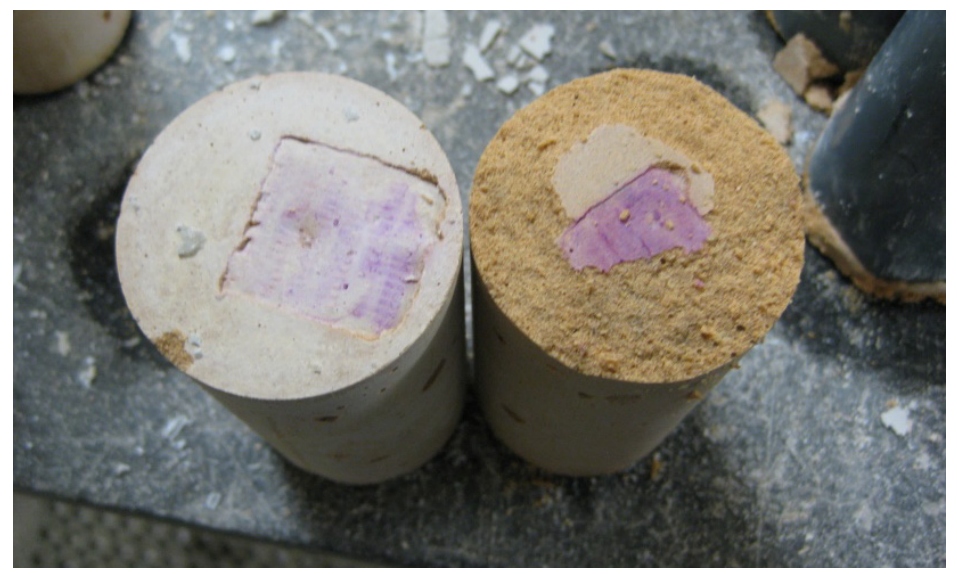

Figure 3.16. Specimen damage during demolding in samples containing metakaolin. 


\subsection{Microstructural characterization}

In many cases, the seminal factor in the determination of the success of a construction material is measured first and foremost by its compressive strength, but as anyone who has spent time learning about concrete will know, it is not just about strength at the end of the day. The failure mechanism of concrete structures is hardly ever due to a lack of compressive strength, but rather due to unexpected loading or, more commonly, material related distress caused by the ingress of water carrying deleterious substances. For this reason, the focus of this research has been on the microstructure, crystallographic phases present in the final geopolymer and their morphology, as well as the chemical composition of the reaction products formed from geopolymerization. Compressive strength was also measured to ensure the mortars formed were sound and to explore the link between microstructure, composition and mechanical performance.

Scanning electron microscopy (SEM) and energy dispersive x-ray spectroscopy (EDS) were used to observe the morphological and compositional variations in phases between the various mixtures. Analysis was performed both by secondary electron imaging on fractured surfaces as well as backscatter electron imaging on polished sections.

It should be mentioned that NMR is a commonly used tool in investigating the internal structure of geopolymers, however, this research focuses more on microstructure and composition. 


\subsubsection{Sample preparation}

Sample preparation is the first step toward microstructural analysis and a very important one. If the samples are not properly prepared, the accuracy of analysis by ESEM or EDS systems will suffer.

It has been shown in the literature the geopolymerization reaction can be stopped by bathing samples in acetone, $\mathrm{C}_{3} \mathrm{H}_{6} \mathrm{O}$, which acts as a desiccant, (Fernández-Jiménez et al. 2005) but in this research, the samples were vacuum impregnated on the desired day of testing in order to stop the reaction. Three sample preparation procedures were used in this research:

Powder mounts - Powder mounts were prepared by blowing powder samples onto doublesided carbon tape covered aluminum stubs and then sputter coating in carbon. The morphology of the source materials was analyzed with secondary electron imaging.

Fractured surfaces - Morphological investigation of the hardened geopolymers was performed on fractured surfaces at various ages. Mortar samples from compressive strength testing were chosen and pushed onto aluminum pin stubs covered in double-sided carbon tape, as shown in Figure 3.17, and then sputter coated with carbon to enhance the conductivity and reduce charging of the sample during analysis. 

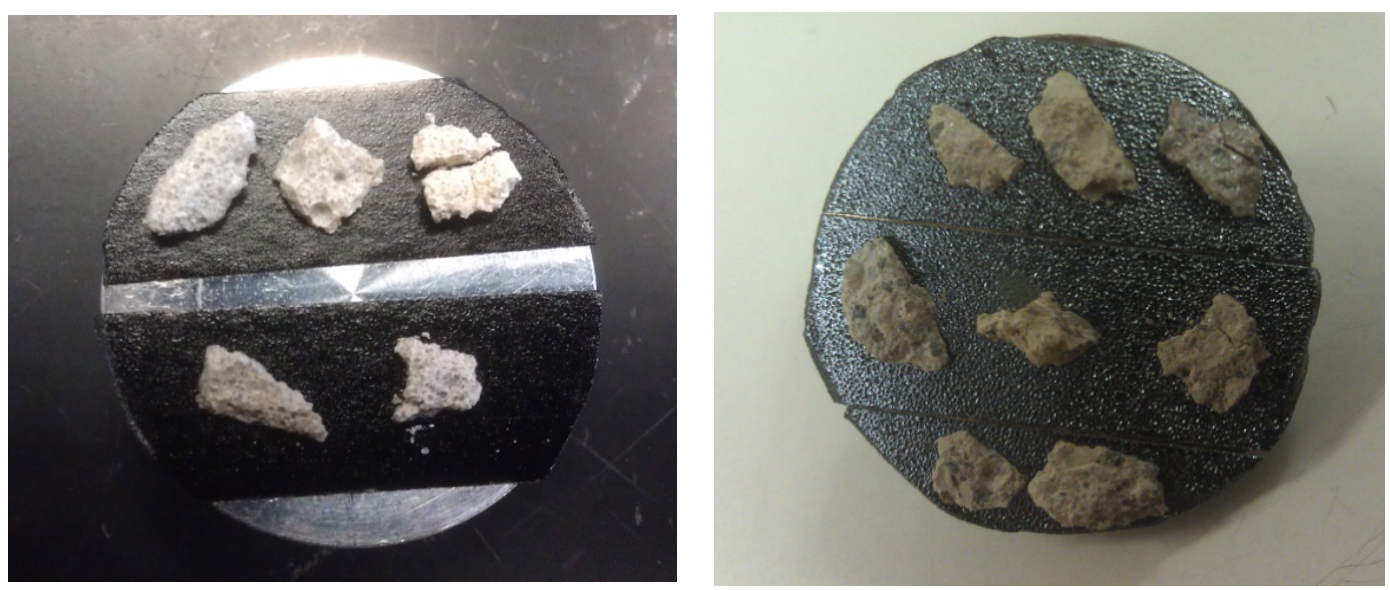

Figure 3.17. Fracture surface specimen preparation prior to (left) and after (right) carbon coating.

Polished sections - Mortar samples from compression testing were collected and sound non-friable sample pieces were chosen for analysis. Vacuum impregnation was employed in order to assure the integrity of the sample was maintained since some of the samples had significant porosity. If the pore system was not filled with epoxy resin, the samples may have deteriorated during further sample preparation or analysis.

Several different methods for preparing polished sections were employed depending on the shape of the mold used. Water was not employed in any of the methods due to the high leachability of alkalis $\left(\mathrm{Na}^{+}, \mathrm{K}^{+}\right.$, etc. $)$in water. Instead, kerosene was used as a cooling and grinding aid. The general procedure for polished section sample preparation is outlined below:

1. Samples were first fit into $1 \frac{1 / 4}{4}$ "diameter plastic molds, shown in Figure 3.18, or billet sized boxes, shown in Figure 3.19. The billet-sized boxes were made with a glass slide on the bottom of the box. 


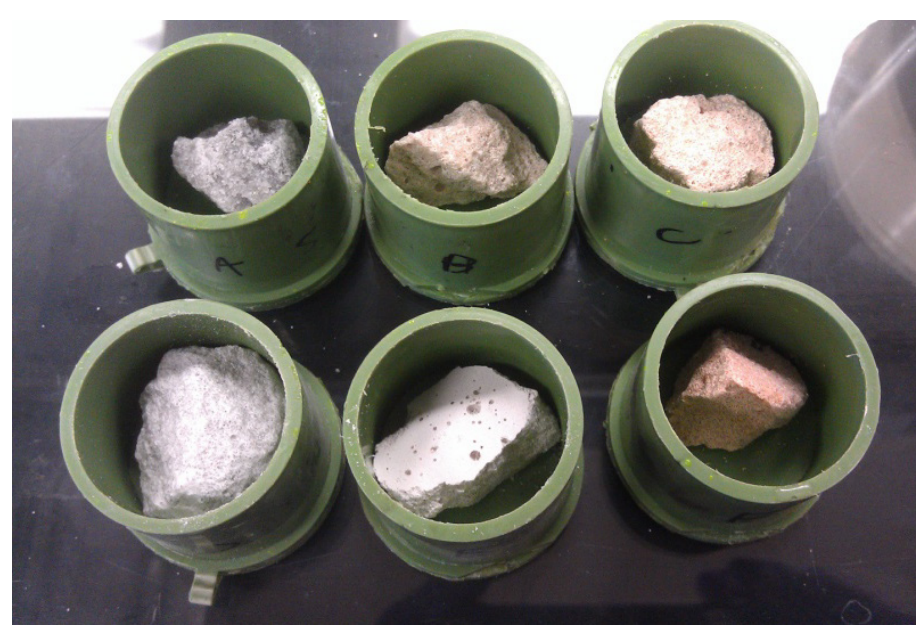

Figure 3.18. Circular sample molds filled with samples prior to vacuum impregnation.

2. The extra space surrounding the sample within the mold was filled with Ottawa sand, as shown in Figure 3.19, which helped to create an even grinding and polishing surface and also helped to avoid too much relief in the sample during polishing.
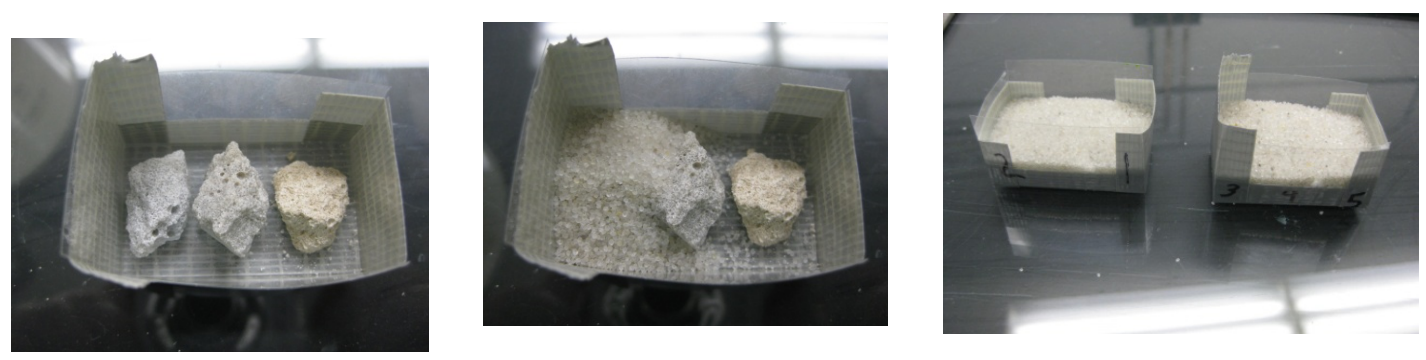

Figure 3.19. Billet boxes filled with samples, then graded Ottawa sand.

3. The molds were then vacuum impregnated with Epoxy Technology Epo-Tex epoxy and hardener resin in a Logitech 1430 Vacuum Impregnation System, as shown in Figure 3.20. It was found that using epoxy resin colored with fluorescent dye made the polishing process easier by enhancing the contrast between the sample and epoxy. 

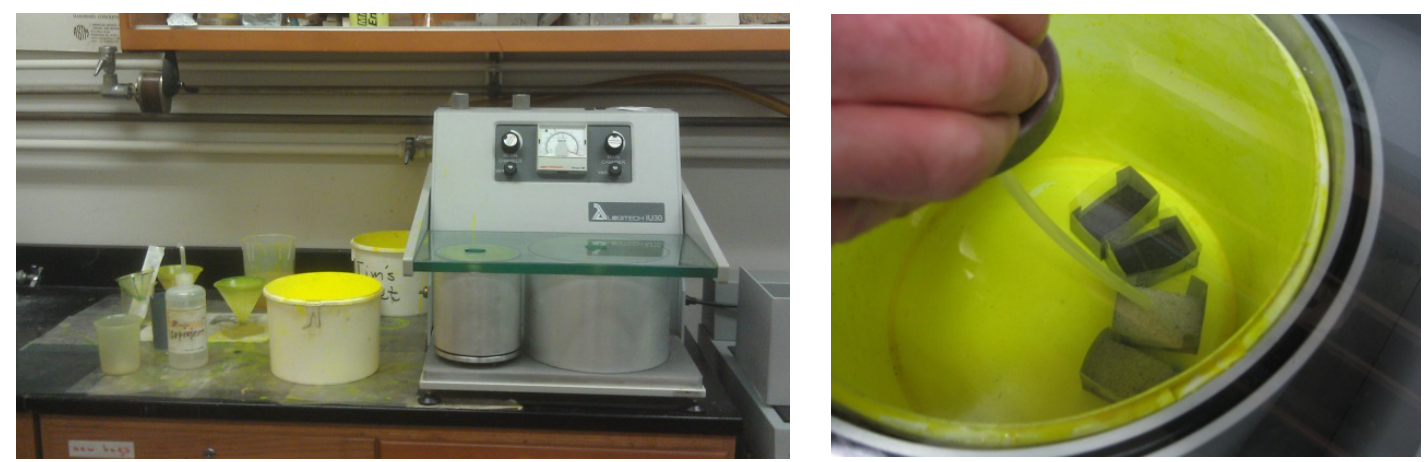

Figure 3.20. Vacuum impregnation system.

4. Upon impregnation, the samples were cured overnight in a sealed container with Drierite (anhydrous calcium sulfate).

5. After demolding the following day, the samples were ground with 60 grit $\mathrm{SiC}$ to ensure the sample was exposed and also to ensure parallel edges. A stereo-optical microscope was used to verify the sample was indeed exposed. Different methods were used depending on the shape of the sample.

a. The rectangular samples were fit into a thin section machine, shown in Figure 3.21, using the glass side to attach onto the vacuum chuck. The top of the sample was ground flat so that when flipped it would also attach to the vacuum chuck and the glass slide could be ground off. Further grinding was also necessary to ensure that all of the samples in the mount were exposed.
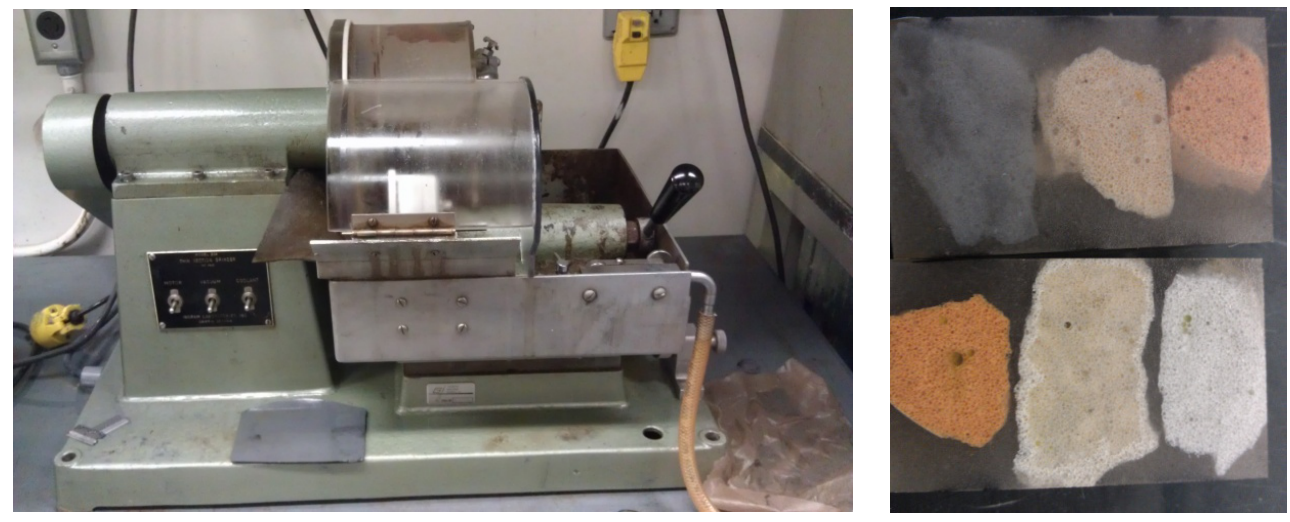

Figure 3.21. Thin section machine used for grinding into samples and samples exposed. 
b. The circular samples were first ground flat on 60 grit silica carbide (SiC) pressure backed adhesive mineralogical paper on a Diamond Pacific grinding wheel, using kerosene as the cooling liquid, as shown in Figure 3.22. The samples were ground until the mortar was exposed and the top and bottom were parallel.

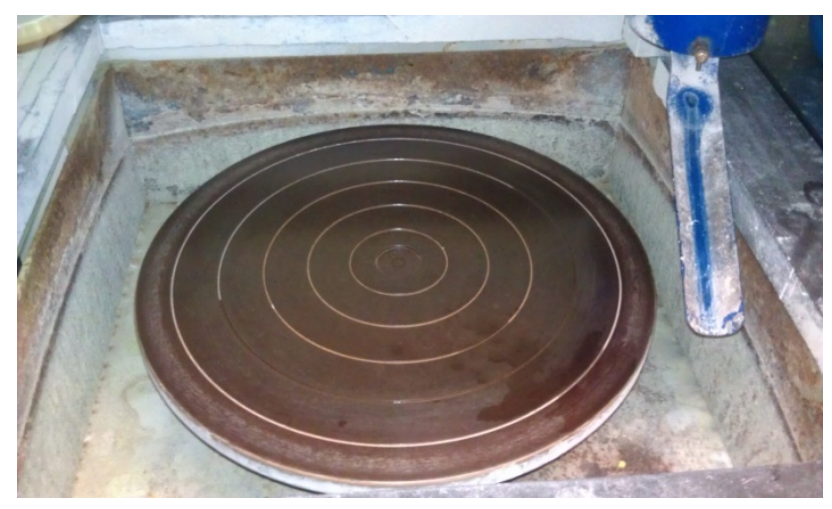

Figure 3.22. Diamond Pacific grinding wheel, used for holding pressure sensitive adhesive backed mineralogical papers.

6. Next, the samples were hand lapped on mineralogical paper stuck to glass plates with pressure sensitive adhesive backing and using kerosene as a lubricant. The samples were lapped successively on 120, 240, 400, 600 and 1000 grit $\mathrm{SiC}$ papers, with a thorough rinsing in clean kerosene in between each series.

7. Final polishing was performed on a Buehler Ecomet polishing wheel, shown in Figure 3.23. A series of $9,6,3,1$ and $1 / 4 \mu \mathrm{m}$ diamond pastes were used to polish the samples. Each grit size was used on a separate platen, covered with a nylon cloth, with diamond paste and kerosene, and a polishing speed of $250 \mathrm{rpm}$. The samples were cleaned in an ultrasonic cleaner for 4 minutes, rinsed with clean kerosene and blown off with clean moisture-free canned air in between each grit change to prevent contamination of the polishing papers and to make sure that coarser grit was not transferred to finer polishing platens. 


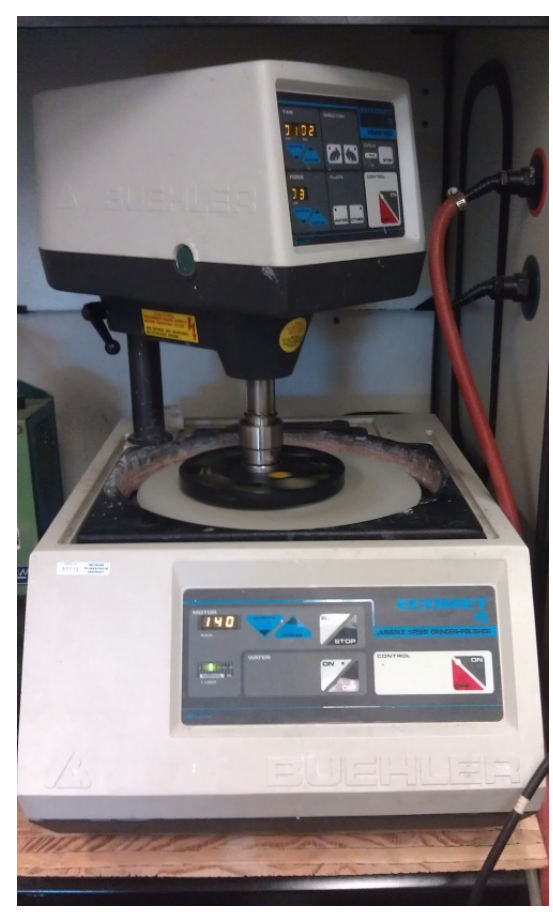

Figure 3.23. Beuhler Isomet used to do the finer polishing with diamond paste media on nylon cloths.

8. When the samples were adequately polished and thoroughly cleaned with clean kerosene, they were dried in an oven overnight. Figure 3.24 shows the polishes midway through polishing.
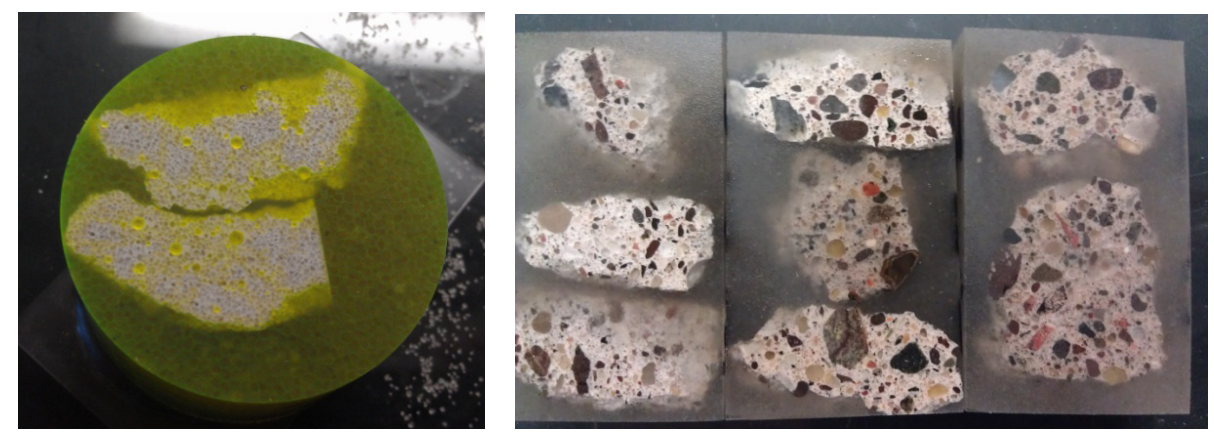

Figure 3.24. Polished sections prior to carbon sputter coating.

9. Next, the samples were sputter coated with carbon to account for the lack of conductivity in Si-based minerals. 
Polished sections were also made of the source materials, where epoxy resin was mixed together with each source material, mounted in a circular mold and polished just like the samples mentioned above. These samples were used to verify the composition of the source materials as a standard to compare the composition of unreacted particles to.

\subsubsection{Electron microscopy}

Electron microscopy was carried out on FEI XL-40 Environmental Scanning Microscope (ESEM), as shown in Figure 3.25.
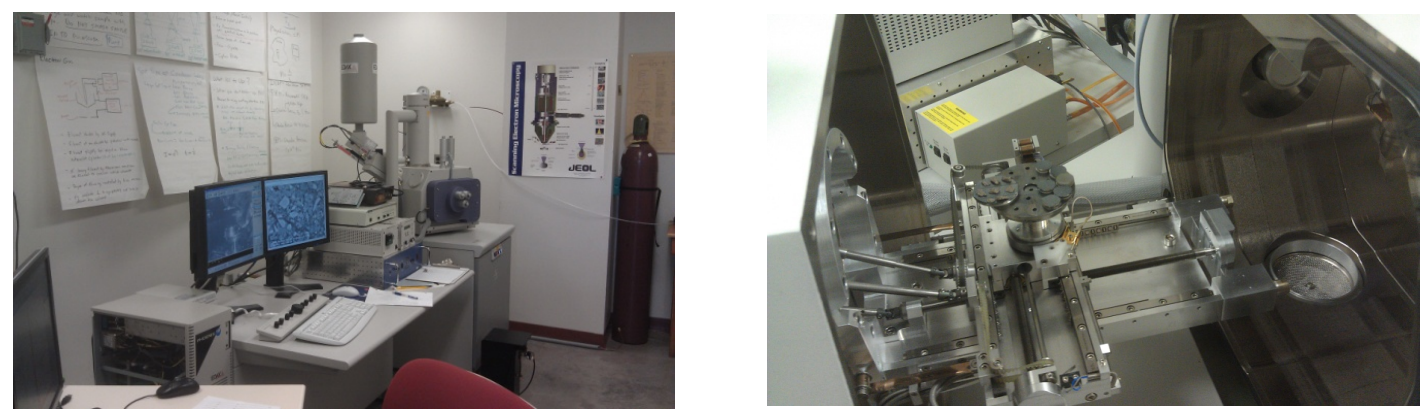

Figure 3.25. ESEM and inside the ESEM.

\subsubsection{Secondary electron imaging}

Secondary electron imaging of fracture surfaces allowed the surface microstructure and topographical details of the geopolymer to be resolved. The density and uniformity of the geopolymer was visible as well as the presence of unreacted particles and zeolites that had formed. Secondary electron imaging was done at a working distance of $15 \mathrm{~mm}$ and $15 \mathrm{kV}$.

\subsubsection{Backscatter electron imaging}

Polished sections allowed for backscatter electron imaging, which confirmed the presence of multiple phases, including unreacted particles. A working distance of $10 \mathrm{~mm}$ was used. 
BSE also helped to resolve the assemblage of phases within each sample as well as the size and shape of unreacted particles.

\subsubsection{Energy dispersive $X$-ray spectroscopy}

Compositional analysis was performed using energy dispersive X-ray spectroscopy on the various phases and unreacted particles shown. The composition of the phases present was measured and unreacted particles were verified based on their composition, as shown in Table 3.4, Table 3.5 and Table 3.6. Fly ash particles were not analyzed due to the broad range of compositions of individual particles. EDS was performed at $10 \mathrm{~mm}$ WD with $15 \mathrm{kV}$ beam and a spot size of 4.8, to ensure adequate counts per second (CPS) and a dead time of $20-25 \%$.

Quantitative phase analysis was performed using silicon as a beam current reference standard for ZAF correction. Analysis on the Si was done for 40 seconds live time and the beam correction factor $(\mathrm{BCF})$ saved and applied to the analysis of the geopolymer sample, also done for 40 seconds live time. The background was manually removed from the raw spectra and the resulting peaks analyzed against a suite of mineral standards. The unnormalized pure element cation results were then converted to cation oxides, normalized and converted to molar ratios. The analyses of the metakaolin particles are all quite similar to the XRF results as shown in Table 3.4. 
Table 3.4. EDS analysis on metakaolin particles as compared to XRF measurements.

\begin{tabular}{|c|c|c|c|c|c|c|c|}
\hline & XRF & MK01 & MK02 & MK03 & MK04 & MK05 & MK06 \\
\hline $\mathrm{Si} / \mathrm{Al}$ & 2.1 & 2.1 & 2.1 & 2.0 & 2.1 & 2.1 & 2.2 \\
\hline $\mathrm{Na} / \mathrm{Al}$ & 0.0 & 0.2 & 0.1 & 0.0 & 0.1 & 0.0 & 0.0 \\
\hline $\mathrm{Na} / \mathrm{Si}$ & 0.0 & 0.1 & 0.1 & 0.0 & 0.1 & 0.0 & 0.0 \\
\hline $\mathrm{Ca} / \mathrm{Si}$ & 0.0 & 0.0 & 0.0 & 0.0 & 0.0 & 0.0 & 0.0 \\
\hline
\end{tabular}

It is obvious from Table 3.5 that while most of the HA glass particles are close in composition to the bulk chemistry measured by XRF, there are some particles containing very low $\mathrm{Al}$ contents.

Table 3.5. EDS analysis on HA500 particles as compared to XRF measurements.

\begin{tabular}{|c|c|c|c|c|c|c|c|}
\hline & XRF & HA01 & HA02 & HA03 & HA04 & HA05 & HA06 \\
\hline $\mathrm{Si} / \mathrm{Al}$ & 8.4 & 161.9 & 8.6 & 8.5 & 198.7 & 7.9 & 8.1 \\
\hline $\mathrm{Na} / \mathrm{Al}$ & 0.1 & 36.3 & 0.0 & 0.2 & 33.6 & 0.2 & 0.0 \\
\hline $\mathrm{Na} / \mathrm{Si}$ & 0.0 & 0.2 & 0.0 & 0.0 & 0.2 & 0.0 & 0.0 \\
\hline $\mathrm{Ca} / \mathrm{Si}$ & 0.4 & 0.1 & 0.3 & 0.3 & 0.1 & 0.3 & 0.4 \\
\hline
\end{tabular}

As shown in Table 3.6, the LA glass particles all possess very high $\mathrm{Si} / \mathrm{Al}$ and $\mathrm{Na} / \mathrm{Al}$ ratios, similar to or higher than the XRF bulk chemistry. These particles should be easy to identify by EDS due to the extremely high ratios.

Table 3.6. EDS analysis on LA500 particles as compared to XRF measurements.

\begin{tabular}{|c|c|c|c|c|c|c|c|}
\hline & XRF & LA01 & LA02 & LA03 & LA04 & LA05 & LA06 \\
\hline $\mathrm{Si} / \mathrm{Al}$ & 244.5 & 371.1 & 299.4 & 796.3 & 248.8 & 272.3 & 250.9 \\
\hline $\mathrm{Na} / \mathrm{Al}$ & 48.0 & 75.0 & 51.3 & 150.9 & 38.8 & 46.0 & 64.8 \\
\hline $\mathrm{Na} / \mathrm{Si}$ & 0.2 & 0.2 & 0.12 & 0.2 & 0.2 & 0.2 & 0.3 \\
\hline $\mathrm{Ca} / \mathrm{Si}$ & 0.1 & 0.1 & 0.1 & 0.1 & 0.1 & 0.1 & 0.1 \\
\hline
\end{tabular}




\subsection{Powder X-ray diffraction (XRD)}

Geopolymers are typically considered to be amorphous but in some cases, small-localized areas of crystalline phases often identified as zeolites have been known to form. Powder $\mathrm{X}$-ray diffraction (XRD) on the source materials as well as on the hardened geopolymer at various ages demonstrated the formation of crystalline phases and the halo shift when different source materials were used. XRD was performed on a Scintag X2 Advanced Diffraction System using a continuous scan from $5-75^{\circ}$ at $2 \%$ minute, shown in Figure 3.26.

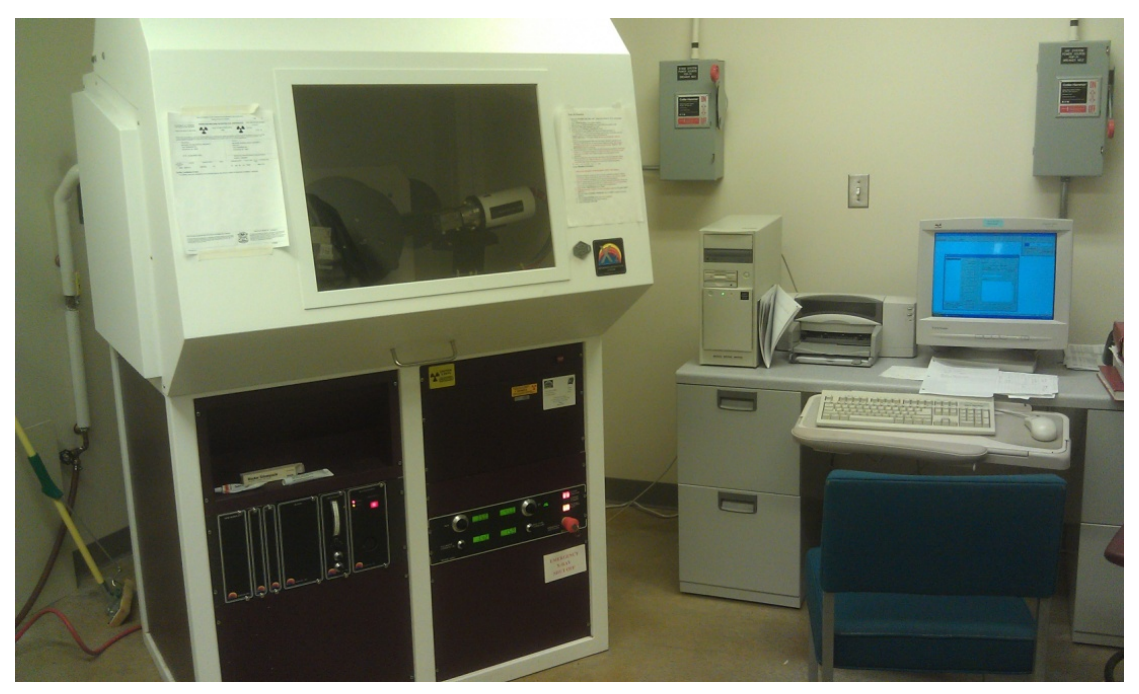

Figure 3.26. Powder X-ray diffraction (XRD) machine.

The XRD pattern collected for the raw source materials are shown here for reference in Figure 3.27, Figure 3.28 and Figure 3.29. 


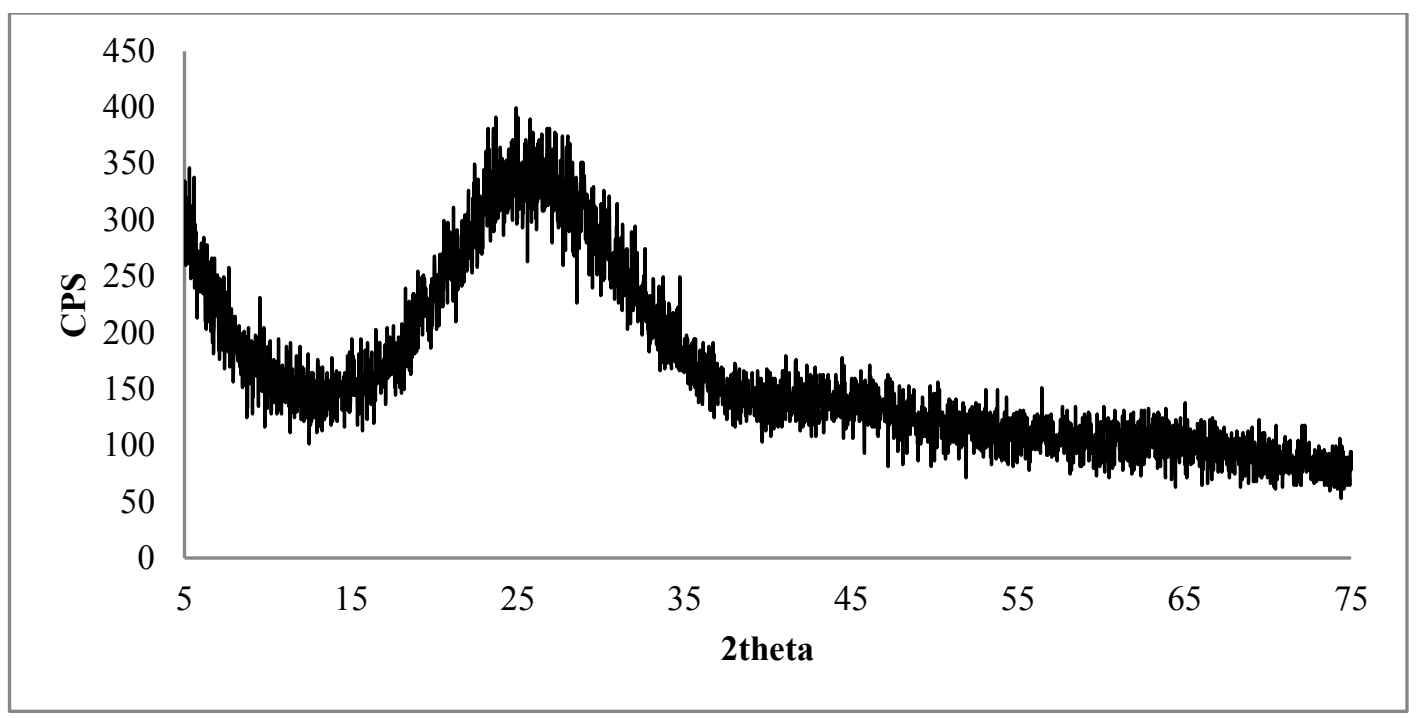

Figure 3.27. Powder X-ray diffraction pattern for HA600 glass used in Phases I and II.

It can be seen from Figure 3.27 the HA600 glass used was completely amorphous with a halo centered around 27 degrees.

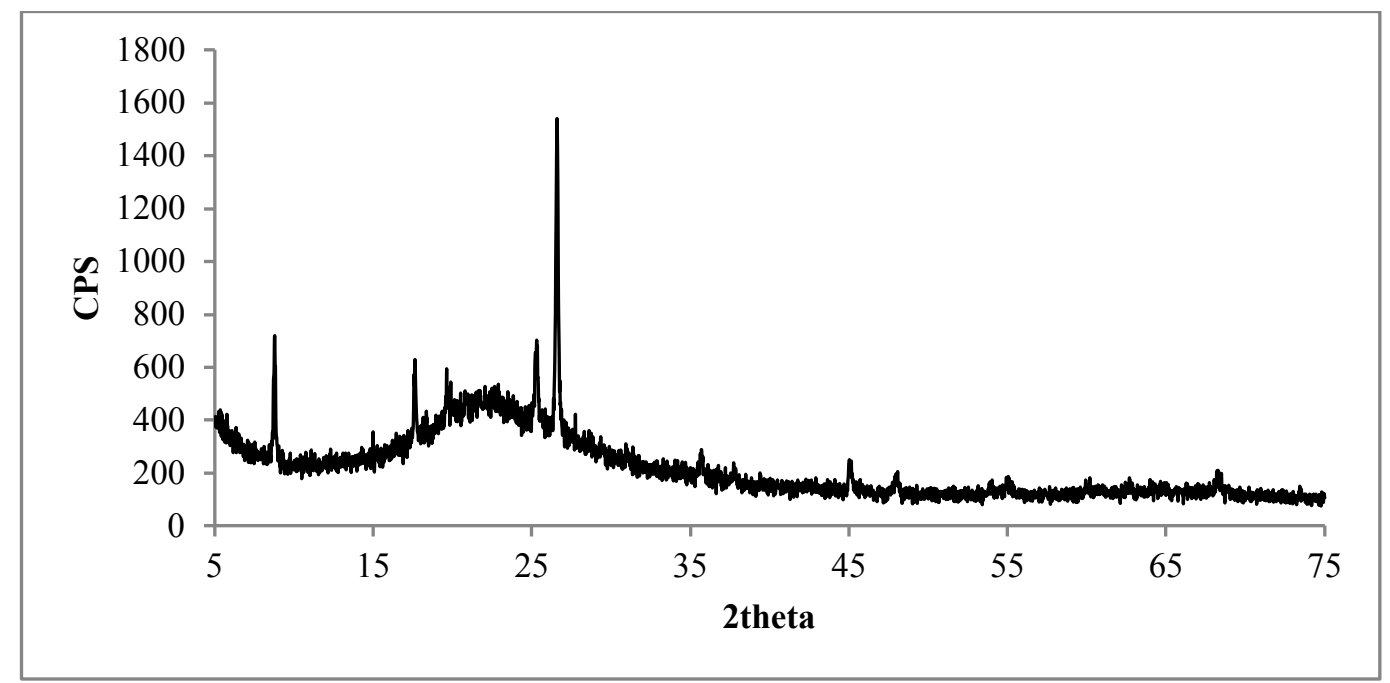

Figure 3.28. Powder X-ray diffraction pattern for metakaolin used in all Phases.

The XRD pattern for the metakaolin indicates a halo centered around 22-23 degrees with major peaks indicating the presence of quartz. Metakaolin commonly has small crystalline impurities of quartz, muscovite, titanium dioxide or iron oxide. 


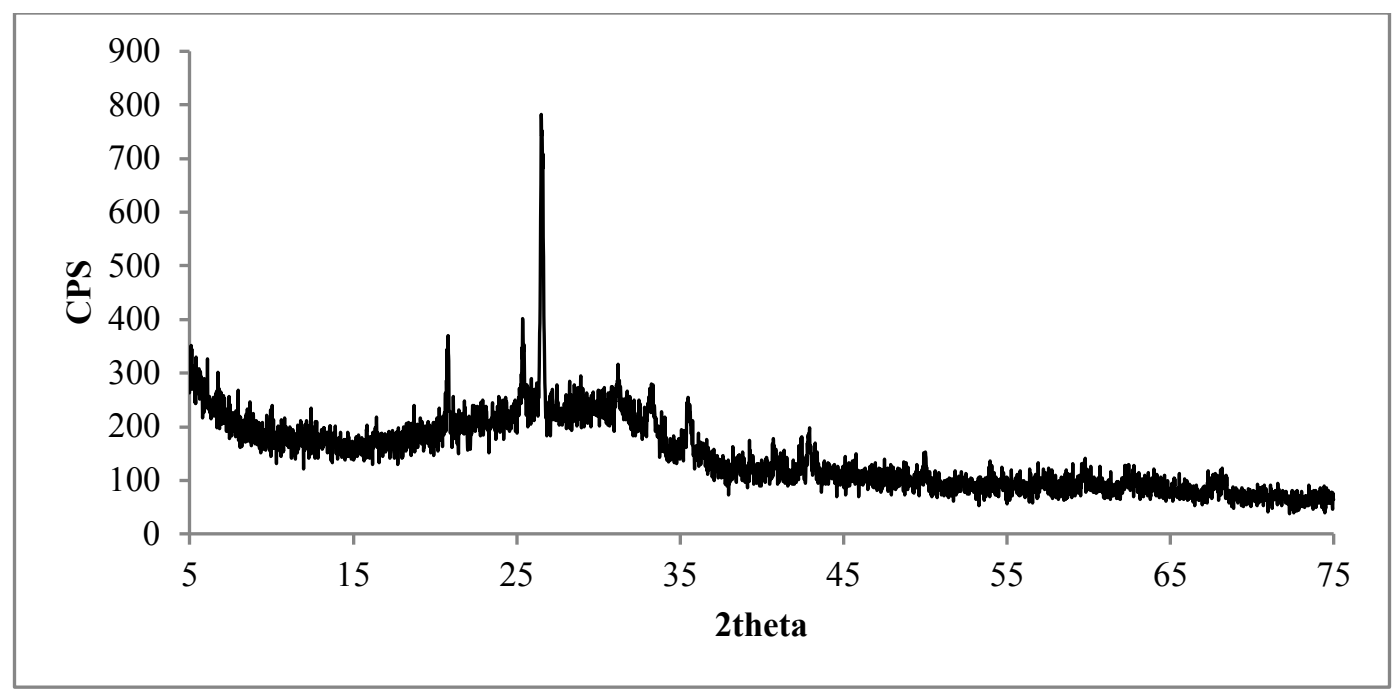

Figure 3.29. Powder X-ray diffraction pattern for fly ash used in Phase II.

The XRD pattern for the fly ash indicates a subtle halo centered around 30 degrees with peaks indicating the presence of quartz. Fly ash commonly has crystalline impurities in the form of quartz, mullite or iron-rich phases.

\subsection{Degree of reaction}

The degree of reaction is a measure of the dissolved/reacted source material as a function of time and was measured on paste to avoid the affects of the graded sand in the experiment. The degree of reaction $(\alpha)$ at a given age following mixing can be very useful with regard to determining the composition of geopolymers. The procedure to determine the amount of unreacted source material in the final geopolymer was based on the work of Criado et al. and others (Granizo et al. 2002; Fernández-Jiménez et al. 2006; Criado et al. 2007; Criado et al. 2010) and is as follows:

1. Paste samples were collected during mortar mixing prior to the addition of the sand and were cured under the same conditions as the corresponding mortars. 
Paste samples were typically approximately 50 grams and were cured in plastic bags or small plastic containers.

2. At predetermined ages, the hardened paste was ground into a powder with a mortar and pestle and separated into approximately 1-gram samples with great care taken to obtain an accurate mass.
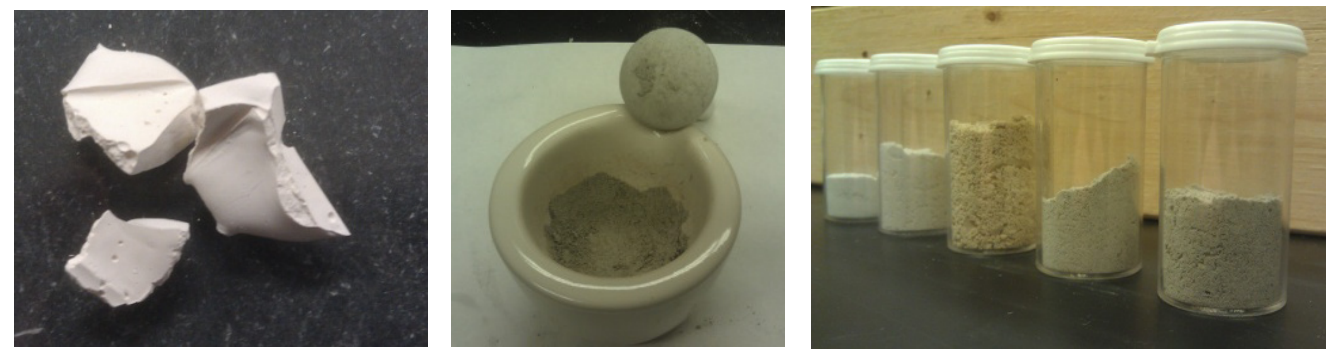

Figure 3.30. Cured paste samples (left), paste sample being crushed by mortar and pestle (center) and various pastes ground into powders in preparation of degree of reaction experiments (right).

3. Each 1-gram sample was then added to approximately $200 \mathrm{~mL}$ of $1: 20 \mathrm{HCl}$ solution in a beaker and stirred on a magnetic stirrer plate for 3 hours, as shown in Figure 3.31. Acid attack with $20: 1 \mathrm{HCl}$ by volume dissolves the aluminosilicate gel and/or zeolites that have formed, leaving the unreacted particles unaffected.
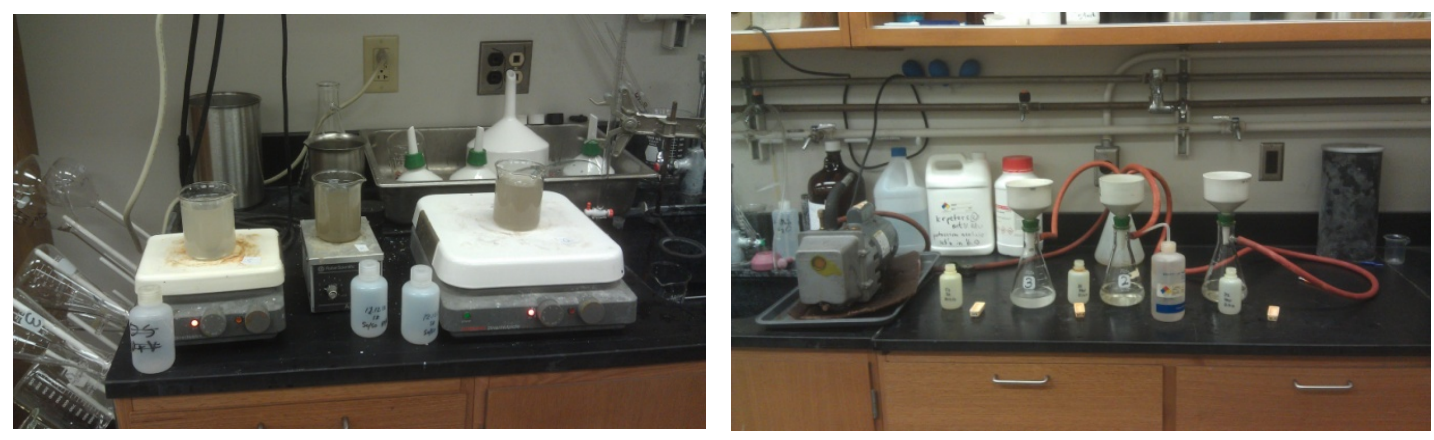

Figure 3.31 Degree of reaction setup for acid attack (left) and filtration (right).

4. Following stirring, the solution was vacuum filtered in a Buchner funnel, as shown in Figure 3.31, washed with distilled water and put into a labeled crucible along with the ashless filter paper that was used in order to make sure all of the sample was collected. 
5. The samples were then placed in an oven at $60-100^{\circ} \mathrm{C}$ overnight and the next day the samples were moved to a Thermolyne 22 muffle furnace where they were heated to $1000^{\circ} \mathrm{C}$ for 24 hours, as shown in Figure 3.32.
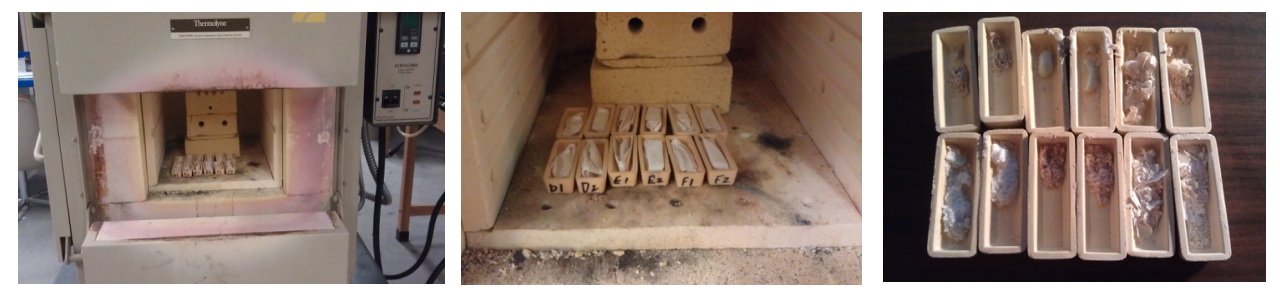

Figure 3.32 Degree of reaction tests following calcination in muffle furnace.

The degree of reaction is determined through the weight loss measurement outlined below in Equation 8 (Fernández-Jiménez et al. 2006). Each test was repeated twice.

$$
\alpha=\left(1-\mathrm{M}_{\text {final }} / \mathrm{M}_{\text {initial }}\right) * 100
$$

(Equation 8)

\subsection{Calorimetry}

Calorimetry is useful in concrete research in that it identifies differences in reaction kinetics between various mixtures.

\subsubsection{Adiabatic calorimetry}

A Grace AdiaCal was used to collect adiabatic calorimetry data for selected mortars. Following the mixing of the mortars, $4 \times 8$ inch plastic cylinders were filled half way with each mortar and vibrated for 30 seconds before being closed and put into the AdiaCal for measurement. The AdiaCal recorded temperature data for 180 hours. Figure 3.33 shows the Grace AdiaCal collecting data on geopolymer mortars. 

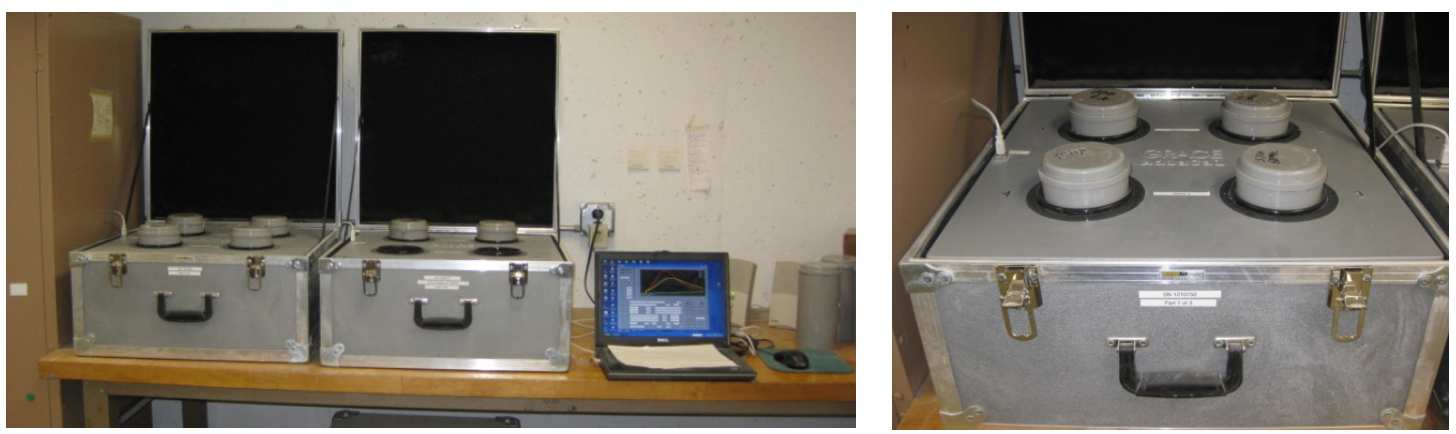

Figure 3.33. Grace AdiaCal collecting calorimetry data on geopolymer mortars.

It should be noted that adiabatic calorimetry involves curing at ambient temperatures and so the information collected was not indicative of the actual reactions occurring as the specimens were all thermally cured at higher temperatures. However, the Grace AdiaCal was useful in demonstrating the differences in reaction kinetics between various mixtures.

\subsubsection{Isothermal calorimetry}

Isothermal calorimetry measures the evolution of heat flow through a sample and has been very useful in monitoring the steps of geopolymerization and the effects of various activators. This information, coupled with other data such as $\mathrm{Si} / \mathrm{Al}$ and microstructural changes characterizes the processes taking place during geopolymerization. Isothermal calorimetry was carried out in cooperation with Dr. Karl Peterson and PhD student Mr. Alireza Dehghan at the University of Toronto. Figure 3.34 shows the ICal that was used in this research as well as the inside of the equipment. 

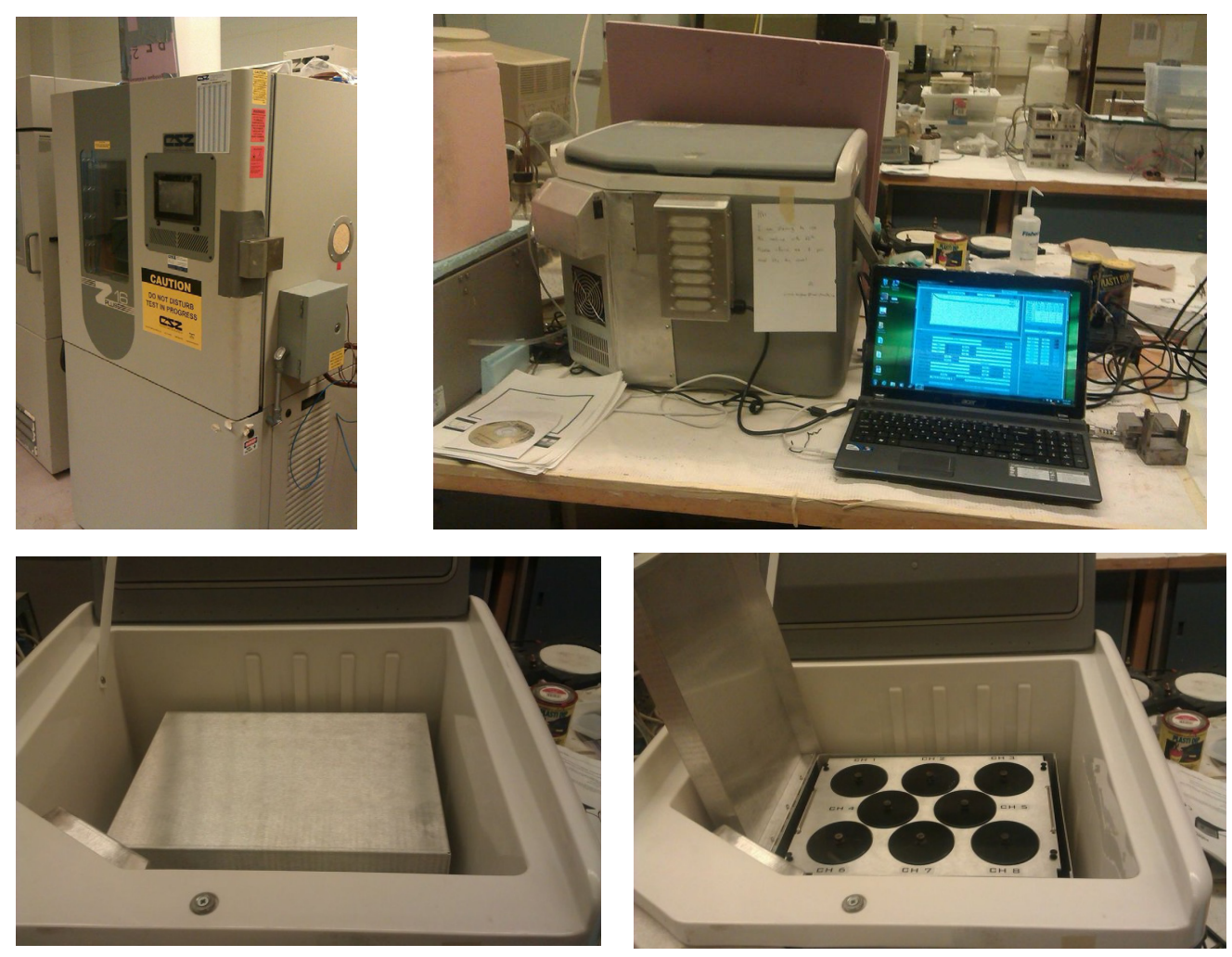

Figure 3.34. Isothermal calorimeter at University of Toronto.

Mortar materials were first heated to $60^{\circ} \mathrm{C}$ and then mixed inside an oven. The materials should be $60^{\circ} \mathrm{C}$ prior to being put in the isothermal calorimeter in $100 \mathrm{~g}$ sample sizes.

\subsection{Compressive strength}

While the focus of this research was not on attaining the highest compressive strength, it was important to verify the binders being studied were indeed capable of adequate mechanical performance and also to make correlations between microstructure, composition and mechanical performance. Compressive tests were performed on $2 \times 4$ cylinders in 2-inch end caps in accordance with ASTM C39/C39M - 11a Standard Test Method for Compressive Strength of Cylindrical Concrete Specimens (ASTM 210 
International 2011). Figure 3.35 shows the test set up for compressive strength testing. A Material Testing System (MTS) machine was used to test the compressive strength of the specimens at various ages in each phase.

As specified by ASTM C39, compressive strength was measured on an 810 Material Test System (MTS) material testing system, using a constant loading rate of 35 pounds per second $(156 \mathrm{kN} / \mathrm{s})$. Specimens were cylindrical with a 2:1 aspect ratio. Compressive strength was measured at various ages after mixing. The test procedure consisted of first a rate controlled loading and then a deflection controlled stop. The specimens were measured for diameter and height and weighed as per ASTM C39.

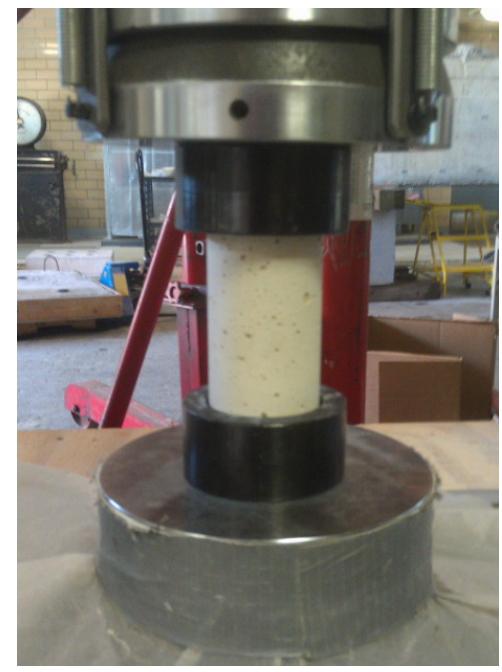

Figure 3.35. Compressive strength testing set up on the Material Testing System (MTS) machine. 


\subsection{Approach for each phase}

\subsubsection{Phase I}

One of the overall goals of this project was to contribute to the currently limited knowledge on the performance of waste glass in geopolymer cement. The first phase of this research involved basic mixture design and development of $100 \%$ glass-based geopolymer mixtures. The high-alumina glass was used. Three main variables were investigated:

1. Fineness of the glass

2. Concentration of $\mathrm{NaOH}$ activator

3. Curing temperature

For these preliminary mixtures, compressive strength was measured at 7, 28 and 201 days. At 28 days, fracture surfaces were analyzed and at 201 days polished sections were analyzed and the phases measured for composition.

It was hypothesized the finest glass, highest $\mathrm{NaOH}$ concentration and highest curing temperature would result in the most uniform microstructure and corresponding highest mechanical strength.

\subsubsection{Phase II}

In phase II, mixtures were designed using the mixture parameters from Phase I that yielded the highest 28-day compressive strength: the finer glass activated with $10 \mathrm{M} \mathrm{NaOH}$ and cured at $80^{\circ} \mathrm{C}$ for 24 hours. 
Again, the high alumina glass was used. In an attempt to decrease the $\mathrm{Si} / \mathrm{Al}$ and $\mathrm{Na} / \mathrm{Al}$ ratios down to levels that are more commonly accepted within geopolymer stoichiometry $(\mathrm{Si} / \mathrm{Al}=2-5$ and Na/Al = 1) (Rahier et al. 1996; Rowles and O'Connor 2003; Duxson et al. 2005; Duxson et al. 2005), additional reactive alumina was added through metakaolin and a Class $\mathrm{C}$ fly ash as a partial glass replacement. Five mixtures were used, considering metakaolin and fly ash replacements of 25 and $50 \%$ of the glass to provide Al to the system.

The purpose of these mixtures was to observe and measure the effects of increasing the available reactive alumina in the system and to analyze the early synergy between glass and metakaolin and glass and fly ash. Also, as one of the underlying goals of this research was to gather general information on glass-based geopolymers, early age data was gathered in this phase. Compressive strength, degree of reaction, powder X-ray diffraction and SEM secondary electron analysis on fracture surfaces was performed at 1,3 and 7 days. Longerterm analysis was also considered at 179 days including polished sections analyzed by ESEM and EDS, degree of reaction and compressive strength.

\subsubsection{Phase III}

Using the results of Phases I and II, Phase III consisted of a new set of mortars designed using the high-Al glass as well as a very low-Al glass and metakaolin as the sole supplementary alumina source. The mixture designs were based purely on initial stoichiometric molar ratios with the goal of exploring glass-based geopolymers that possess stoichiometric ratios similar to those accepted for fly ash and metakaolin geopolymers. 
The purpose of this phase was to apply the knowledge learned in Phases I and II to a lowAl glass. Six mixtures were made using metakaolin as the alumina source, and using stoichiometric $\mathrm{Na} / \mathrm{Al}$ ratios of 1 and 2 to determine how much metakaolin replacement was used. Keeping in mind the highest compressive strength in Phase II had a $\mathrm{Na} / \mathrm{Al}$ ratio of very nearly 1 in bulk stoichiometry. Additionally, the two highest mixtures from Phase II using the high-Al glass were also made up as well as a $100 \%$ metakaolin mixture for reference. All of the samples were cured at $60^{\circ} \mathrm{C}$ in order to coordinate with isothermal calorimetry measurements.

Compressive strength was measured at 1, 3, 7, 14 and 28 days, while degree of reaction and SEM and EDS work on polished sections were conducted at 14 and 28 days. At 28 days, powder XRD readings and fracture surfaces were analyzed as well. In addition, adiabatic calorimetry and isothermal calorimetry at $60^{\circ} \mathrm{C}$ were carried out on all of the mixtures.

The six mixtures had surprisingly low compressive strengths based on previous data recorded, and so the three mixtures containing the low-alumina glass were reproduced and cured at $80^{\circ} \mathrm{C}$. Data up to 14 days was collected and it was found that increasing the curing temperature had a significant impact on the mortars, as discussed in Chapter 4 and 5.

In addition, two ternary mixtures were also made, containing glass, metakaolin and fly ash. The intent was to counter the high water demand of the metakaolin with the low water demand of the fly ash in the hopes of coming up with a mixture that had adequate uniformity and density of microstructure while still supplying an adequate supply of $\mathrm{Al}$ to 
the system. When the high Al glass was used, a 25\% MK and 25\%FA substitution resulted in $\mathrm{Na} / \mathrm{Al}$ of 2 . When the low $\mathrm{Al}$ glass was used, the same replacements yielded a bulk $\mathrm{Na} / \mathrm{Al}$ of 1. 



\section{Results and Discussion}

This research was performed in three main stages. The results of each phase are presented in a separate major subsection of this chapter including information on the mixture design and corresponding bulk stoichiometry as well as results and discussion covering each type of analysis performed. At the end of each major section is a summary of the discussion for the entire phase and at the conclusion of the chapter is a cumulative discussion of the results of the entire project.

The main focus in each phase is on the compressive strength, microstructure and composition of the mortars; in some cases additional testing was employed to help understand trends or just to provide additional information on the mixtures.

Compressive strength, of course, is very important in concrete and material performance is linked to the microstructure. It should be noted there has been little research on the microstructure or composition of glass geopolymers. Additionally, most microstructural studies of geopolymers have been conducted on fracture surfaces, where actual measured compositional data is either not reported or inaccurate due to the lack of a prepared flat, polished section.

The relationship between compressive strength and microstructure is important and the microstructure is affected by the bulk composition of the material. With regard to composition, four main molar ratios were considered for each mortar. The $\mathrm{Si} / \mathrm{Al}$ and Na/Al molar ratios are the most commonly considered with $\mathrm{Si} / \mathrm{Al}$ often being connected to 
compressive strength and $\mathrm{Na} / \mathrm{Al}$ relating to the balance between $\mathrm{Na}^{+}$ions and tetrahedrally coordinated aluminum in the matrix. Additionally, the $\mathrm{Na} / \mathrm{Si}$ and $\mathrm{Ca} / \mathrm{Si}$ ratios were considered. The $\mathrm{Na} / \mathrm{Si}$ ratio is often considered when a sodium silicate activator is used; though sodium silicate is not used in these mortars, glass does possess an extremely high $\mathrm{Si}$ content and so the $\mathrm{Na} / \mathrm{Si}$ ratio was measured. The effect of calcium in geopolymer mixtures has been documented in the literature with calcium often precipitating out as $\mathrm{Ca}(\mathrm{OH})_{2}$ or $\mathrm{C}-\mathrm{S}-\mathrm{H}$ gel. The ratio of $\mathrm{Ca} / \mathrm{Si}$ in the geopolymer could help to determine how the calcium in these mixtures behaves.

\subsection{Phase I}

The first phase of testing began with an exploration of how to mix glass-based geopolymers and address issues such as water demand, curing time, safety precautions associated with using caustic chemicals, etc. Through structured trial and error, an acceptable mixture design was developed and a testing regime was organized for considering the affects of glass particle size, activator concentration and curing temperature on the ease of mixing, compressive strength, microstructure and composition of phases formed.

Particle size, activator concentration and curing temperature are commonly manipulated variables within a geopolymer mixture design and therefore were chosen for Phase I. Mixture parameters comparable to those employed in making fly ash or metakaolin geopolymers were selected to see if glass-based systems responded in a similar manner as other geopolymer source materials. 
Compressive strength was measured at 7 and 28 and again at 201 days. At 28 days, fracture surface samples were prepared and analyzed using secondary electron imaging to assess the general nature of the microstructure of the glass geopolymers. At 201 days, a polished section of each mortar was prepared for backscatter electron imaging and quantitative microanalysis by EDS to determine the composition of the phases present.

\subsubsection{Mixture design}

Two particle sizes were chosen from the available high-Al glasses, to represent a fine and a coarse fraction of ground glass. The finer glass was called HA-600 and had a median particle size of 3-4 $\mu \mathrm{m}$. The coarser glass was called HA-100 and had a median particle size of $15-20 \mu \mathrm{m}$. The particle size of the glass is very important as it has a direct impact on the rate and extent of dissolution, where smaller particles dissolve more rapidly (Iler 1979).

Two NaOH concentrations were chosen, $5 \mathrm{M}$ and 10M. The research of Cyr et al. indicated the highest compressive strengths of glass geopolymers were obtained at 5 and $10 \mathrm{M}$ concentrations (Cyr et al. 2012), these are also common concentrations used with other types of geopolymers as well, though most activator solutions also include dissolved silica. Rattanasak et al. also found that $10 \mathrm{M}$ was an optimal activator concentration when activating fly ash (Rattanasak and Chindaprasirt 2009).

Curing was performed at two temperatures, $40^{\circ} \mathrm{C}$ and $80^{\circ} \mathrm{C}$, which represent a fairly common range of curing temperatures for geopolymers. The samples were heat cured for 24 hours and then stored in ambient curing conditions until the time of testing; relative 
humidity was kept at $90-100 \%$ at all times to try to avoid any shrinkage or cracking due to drying. A moderate curing time of 24 hours was chosen to allow adequate time for reaction to occur while staying in the bounds of what may be realistic for precast members. Much of the published research performed on geopolymers allows for long-term curing of several weeks or even months; this may result in increased strength although it seems very unrealistic for real world construction applications. Ambient curing conditions were not considered in this research as they most always lead to a very low degree of reaction and therefore strength (Cyr et al. 2012).

Four mixtures were designed and two curing temperatures used, for a total of eight different geopolymer mortars to be tested, as shown in Table 4.1.

Table 4.1. Explanation of mixture ID for mortars in Phase I.

\begin{tabular}{|c|c|c|c|}
\hline $\begin{array}{c}\text { Mixture } \\
\text { ID }\end{array}$ & Glass size & $\begin{array}{c}\mathbf{N a O H} \text { concentration } \\
(\mathbf{m o l} / \mathbf{L})\end{array}$ & $\begin{array}{c}\text { Curing temperature } \\
\left({ }^{\circ} \mathbf{C}\right)\end{array}$ \\
\hline F.5.80 & HA-600 & 5 & 80 \\
\hline F.5.40 & HA-600 & 5 & 40 \\
\hline F.10.80 & HA-600 & 10 & 80 \\
\hline F.10.40 & HA-600 & 10 & 40 \\
\hline C.5.80 & HA-100 & 5 & 80 \\
\hline C.5.40 & HA-100 & 5 & 40 \\
\hline C.10.80 & HA-100 & 10 & 80 \\
\hline C.10.40 & HA-100 & 10 & 40 \\
\hline
\end{tabular}

\subsubsection{Stoichiometry}

Mortars were prepared using a baseline 3:1:0.5 ratio of sand to glass to activator solution by mass, respectively. Washed, dried and sieved Superior Sand and Gravel 2NS sand was 
used. The relevant molar ratios of the unreacted geopolymer mixtures are shown in Table 4.2 .

Table 4.2. Molar ratios of the unreacted source materials and activator solution in Phase I mixtures.

\begin{tabular}{|c|c|c|c|c|}
\hline Mixture ID & $\mathbf{S i} / \mathbf{A l}$ & $\mathbf{N a} / \mathbf{A l}$ & $\mathbf{N a} / \mathbf{S i}$ & $\mathbf{C a} / \mathbf{S i}$ \\
\hline F.5 & 8.39 & 0.99 & 0.12 & 0.39 \\
\hline F.10 & 8.39 & 1.61 & 0.19 & 0.39 \\
\hline C.5 & 8.39 & 0.99 & 0.12 & 0.39 \\
\hline C.10 & 8.39 & 1.61 & 0.19 & 0.39 \\
\hline
\end{tabular}

For all four mixtures, the $\mathrm{Si} / \mathrm{Al}$ and $\mathrm{Ca} / \mathrm{Si}$ ratios remained the same as the same type and weight of glass was used in each mortar and only the particle size was changed. The Na/Al and $\mathrm{Na} / \mathrm{Si}$ molar ratios changed as the activator concentration changed. Figure 4.1 shows the relationship between the $\mathrm{Si} / \mathrm{Al}$ and $\mathrm{Na} / \mathrm{Al}$ molar ratios for each mixture; each point on the graph refers to two mixtures, as shown in the legend.

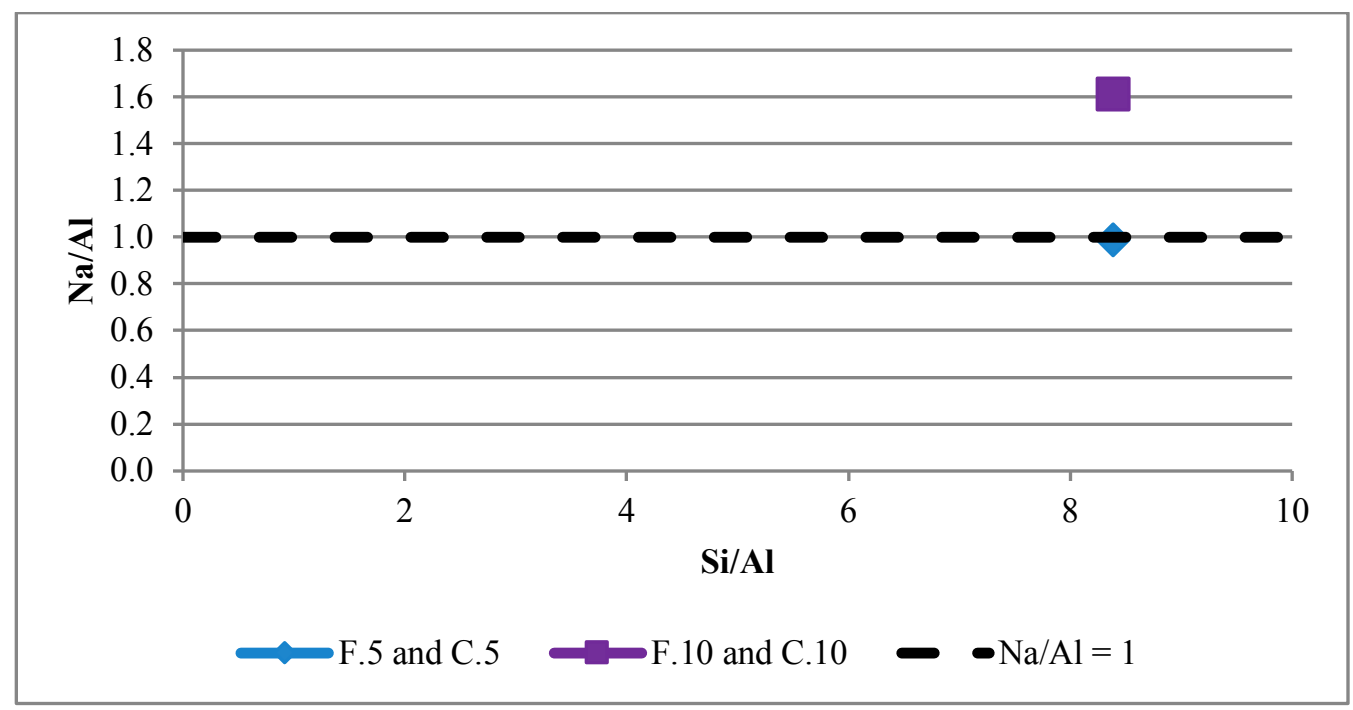

Figure 4.1. Si/Al vs Na/Al molar ratios for mixtures in Phase I. A dashed line at $\mathrm{Na} / \mathrm{Al}=1$ is shown since that is widely accepted as an optimum ratio for geopolymers. 


\subsubsection{Fresh properties}

All four mixtures were easy to mix and consisted of a light gray/brown colored paste that was lighter in color than typical OPC mortars. The water content and flow varied between each mixture as would be expected based on the changing variables. Increasing the concentration of the $\mathrm{NaOH}$ from $5 \mathrm{M}$ to $10 \mathrm{M}$ led to an increase in activator viscosity, which required more water as did an increase in glass fineness require more water. The water content was adjusted as necessary to reach a workable mixture that could be well consolidated. Flow was measured but was found not to be a universal indication of workability, as some mixtures with lower flow still exhibited good workability after consolidation on the vibrating table.

Table 4.3 shows the fresh properties measured for the mixtures in Phase I including the water/solids ratio. The mixture containing the finest glass and highest activator concentration also reached the highest temperature immediately after mixing, indicating that perhaps dissolution was occurring more quickly in that mixture.

Table 4.3. Fresh properties and water/solids ratio of the mixtures in Phase I. All reported values are based on the average of three measurements.

\begin{tabular}{|c|c|c|c|c|}
\hline $\begin{array}{c}\text { Mixture } \\
\text { ID }\end{array}$ & $\begin{array}{c}\text { Water/solids } \\
\text { ratio }\end{array}$ & Percent flow (\%) & $\begin{array}{c}\text { Temperature } \\
\left({ }^{\circ} \mathbf{F}\right)\end{array}$ & $\begin{array}{c}\text { Unit weight } \\
(\mathbf{g} / \mathbf{m L})\end{array}$ \\
\hline F.5 & 0.479 & $45 \%$ & 75.50 & 2.20 \\
\hline F.10 & 0.445 & $38 \%$ & 82.50 & 2.22 \\
\hline C.5 & 0.451 & $98 \%$ & 72.50 & 2.22 \\
\hline C.10 & 0.411 & $69 \%$ & 74.50 & 2.24 \\
\hline
\end{tabular}




\subsubsection{Compressive strength}

\subsubsection{Early age strength through 28 days}

Compressive strength at 7 and 28 days is shown in Figure 4.2. At 7 days, none of the mixtures had very high compressive strengths, with mixtures F.10.80, F.5.80 and C.10.80 being the highest. However, several of the mixtures gained a substantial amount of strength in the following weeks.

The mixture made using the finer glass and higher activator concentration and cured at a higher curing temperature, F.10.80, yielded the highest compressive strength at 28 days. This is not unexpected as smaller particle size, higher $\mathrm{OH}^{-}$concentration in the activator and higher curing temperatures are all parameters conducive to increasing the rate of dissolution and polycondensation, which has been linked to higher compressive strength (Fernández-Jiménez and Palomo 2003; Sofi et al. 2007). The mixture containing the coarser glass, lower $\mathrm{NaOH}$ concentration and lower curing temperature yielded the lowest compressive strength; this was not unexpected based on the literature. 


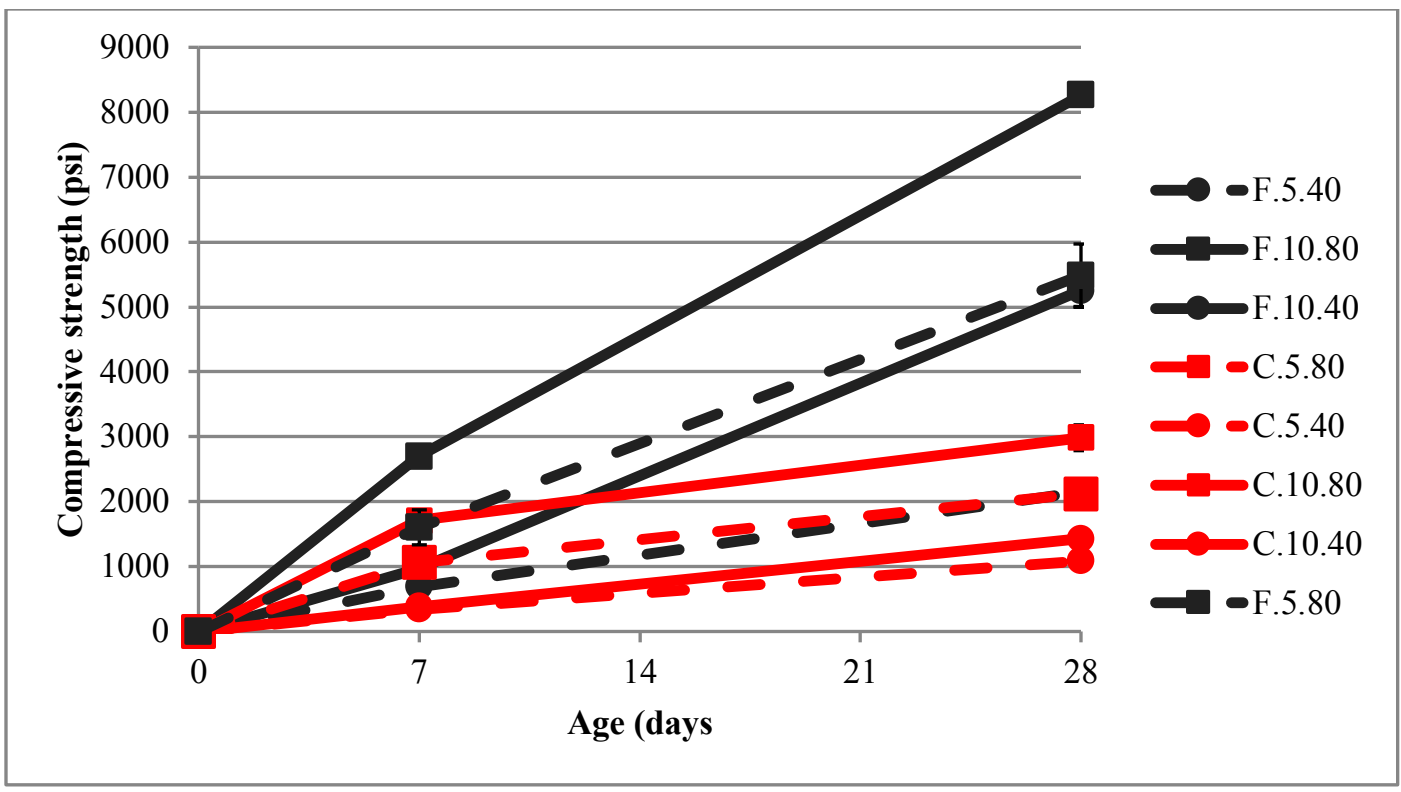

Figure 4.2. Seven and 28 day compressive strength of Phase I mortars made of $100 \%$ HA glass. Each data point is the average of two cylinders. Error bars were calculated from the standard error, $\mathrm{SD} / \sqrt{ } \mathrm{n}$, where $\mathrm{SD}$ is standard deviation and $\mathrm{n}$ is the sample size.

Table 4.4 lists the mortars in order of maximum average strength at 28 days as well as the mixture parameters used to make that mortar to aid in identifying trends among the parameters. Based on the 28-day compressive strength of the mortars tested, it appears that fineness had the most prominent effect on performance, followed by curing temperature and then activator concentration. 
Table 4.4. Mixtures listed in order of maximum average compressive strength at 28 days. The relevant mixture parameters are also listed to aid in identifying trends and the dominant parameter bolded.

\begin{tabular}{|c|c|c|c|c|c|}
\hline $\begin{array}{c}\text { Mixture } \\
\text { ID }\end{array}$ & Rank & $\begin{array}{c}\text { Compressive } \\
\text { strength (psi) }\end{array}$ & $\begin{array}{c}\text { Glass } \\
\text { fineness }\end{array}$ & $\begin{array}{c}\text { NaOH } \\
\text { concentration } \\
(\mathbf{m o l} / \mathbf{L})\end{array}$ & $\begin{array}{c}\text { Curing } \\
\text { temperature } \\
\left({ }^{\circ} \mathbf{C}\right)\end{array}$ \\
\hline F.10.80 & $1^{\text {st }}$ & 8262 & $\mathbf{F}$ & $\mathbf{1 0}$ & $\mathbf{8 0}$ \\
\hline F.5.80 & $2^{\text {nd }}$ & 5486 & $\mathbf{F}$ & 5 & $\mathbf{8 0}$ \\
\hline F.10.40 & $3^{\text {rd }}$ & 5254 & F & $\mathbf{1 0}$ & 40 \\
\hline C.10.80 & $4^{\text {th }}$ & 2987 & C & $\mathbf{1 0}$ & $\mathbf{8 0}$ \\
\hline F.5.40 & $5^{\text {th }}$ & 2157 & $\mathbf{F}$ & 5 & 40 \\
\hline C.5.80 & $6^{\text {th }}$ & 2124 & C & 5 & $\mathbf{8 0}$ \\
\hline C.10.40 & $7^{\text {th }}$ & 1431 & C & $\mathbf{1 0}$ & 40 \\
\hline C.5.40 & $8^{\text {th }}$ & 1091 & C & 5 & 40 \\
\hline
\end{tabular}

\subsubsection{Later age strength through 201 days}

Compressive strength through 201 days is shown in Figure 4.3. From 28 to 201 days several interesting changes occurred: 
- The strength of F.10.80 and F.5.80 both decreased, with F.10.80 dropping substantially from the highest compressive strength at 28 days, losing nearly 3,000 psi in strength.

- The strength of F.10.40 and C.10.40 both increased substantially as compared to the other mixtures.

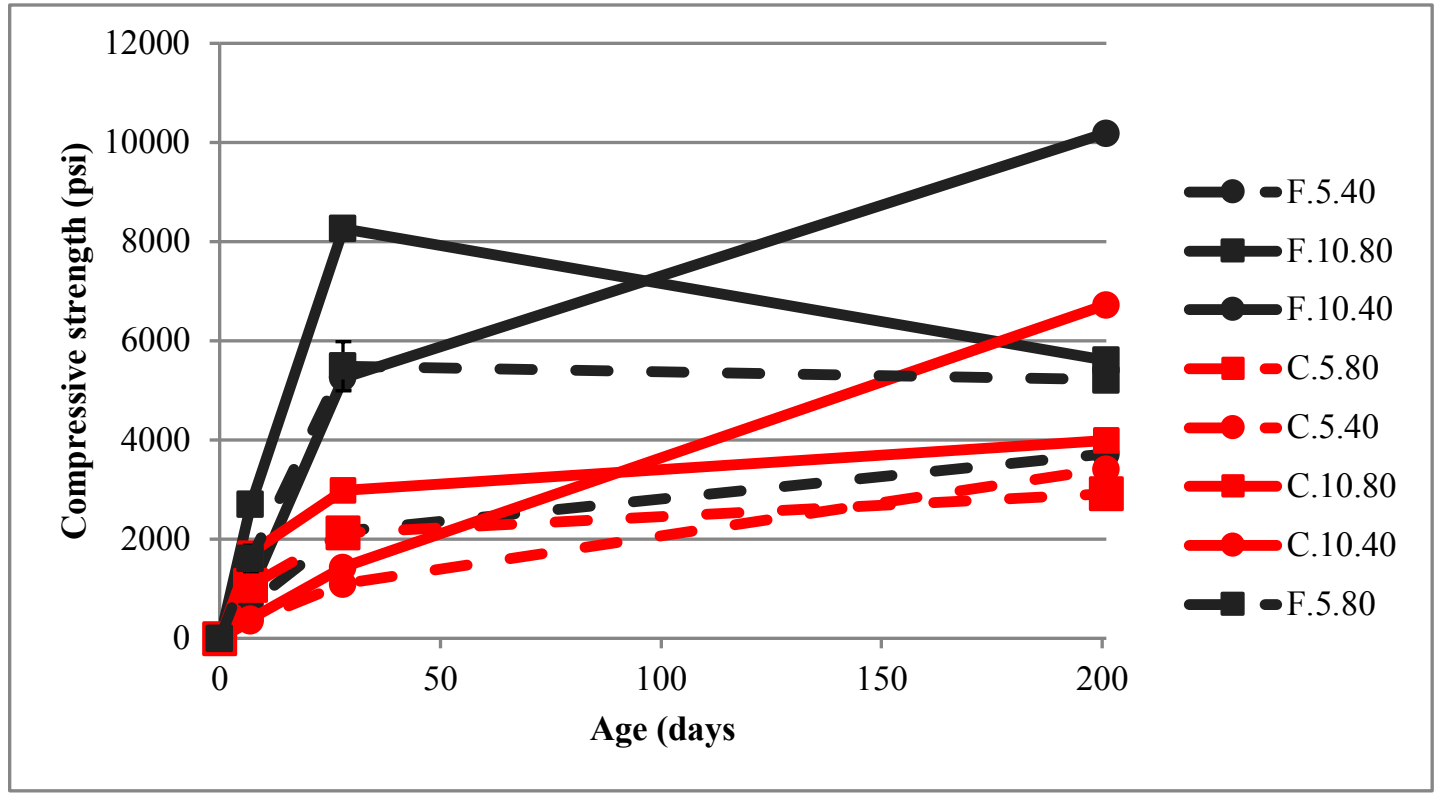

Figure 4.3. Compressive strength of Phase I mortars made of $100 \%$ HA glass through 201 days. Data points for 7 and 28 days are based on the average of two cylinders; data for 201 days is based on one cylinder. Error bars were calculated from the standard error, $\mathrm{SD} / \sqrt{ } \mathrm{n}$, where $\mathrm{SD}$ is standard deviation and $\mathrm{n}$ is the sample size.

The 201-day compressive strengths are listed in Table 4.5 in order of maximum compressive strength. The relevant mixture parameters are also listed to easily see which properties yielded the higher results and the dominant parameters are bolded 
Table 4.5. Mixtures listed in order of maximum compressive strength at 201 days.

\begin{tabular}{|c|c|c|c|c|c|}
\hline $\begin{array}{c}\text { Mixture } \\
\text { ID }\end{array}$ & Rank & $\begin{array}{c}\text { Compressive } \\
\text { strength (psi) }\end{array}$ & $\begin{array}{c}\text { Glass } \\
\text { fineness }\end{array}$ & $\begin{array}{c}\text { NaOH } \\
\text { concentration } \\
(\mathbf{m o l} / \mathbf{L})\end{array}$ & $\begin{array}{c}\text { Curing } \\
\text { temperature } \\
\left({ }^{\circ} \mathbf{C}\right)\end{array}$ \\
\hline F.10.40 & $1^{\text {st }}$ & 10196 & $\mathbf{F}$ & $\mathbf{1 0}$ & $\mathbf{4 0}$ \\
\hline C.10.40 & $2^{\text {nd }}$ & 6729 & C & $\mathbf{1 0}$ & $\mathbf{4 0}$ \\
\hline F.10.80 & $3^{\text {rd }}$ & 5607 & F & $\mathbf{1 0}$ & 80 \\
\hline F.5.80 & $4^{\text {th }}$ & 5217 & F & 5 & 80 \\
\hline C.10.80 & $5^{\text {th }}$ & 3995 & C & $\mathbf{1 0}$ & 80 \\
\hline F.5.40 & $6^{\text {th }}$ & 3714 & F & 5 & $\mathbf{4 0}$ \\
\hline C.5.40 & $7^{\text {th }}$ & 3409 & C & 5 & 40 \\
\hline C.5.80 & $8^{\text {th }}$ & 2917 & C & 5 & 80 \\
\hline
\end{tabular}

At 201 days, the mixtures made of the finer glass and higher $\mathrm{NaOH}$ concentrations (F.10) still yielded the highest compressive strengths overall. However, there was a reversal in the effect of the curing temperature as compared to the 28-day results. It is interesting to note that both mixtures under the F.80 conditions decreased in compressive strength at later ages. Both the F.10.80 and F.5.80 mixtures lost strength, though the F.5.80 mixture could have been due to statistical variance. It is unknown exactly when the strength reversal in mixture F.10.80 occurred.

Alternately, the F.10.40 and C.10.40 mixtures both showed a more significant increase in compressive strength from 28 to 201 days than any of the other mixtures. This implies that despite lower strengths at 28 days, mixtures made with a higher concentration activator solution and cured at a lower temperature follow a late strength gain profile. This could be because the higher activator concentration allows for more dissolution to occur initially, 
which may make available ample geopolymer species for more polycondensation and sustained strength gain over longer periods of time.

Sustained strength gain, of course, is a desirable property in concrete. However in today's fast paced construction industry, the delay before this strength is gained may not be acceptable. Mixture C.10.40 had a fairly low 28-day strength before reaching significant strengths at 201 days, while the F.10.40 mixture had a more acceptable compressive strength at 28 days.

\subsubsection{Microstructural analysis}

Electron microscopy on both fracture surfaces and polished cross sections illuminated differences between the microstructures of the eight mortars and revealed clues related to mechanical performance and reaction mechanisms.

\subsubsection{Fracture surface analysis}

The microstructures of all eight mortars were analyzed by secondary electron imaging on 28-day old fracture surfaces. The most notable observation while comparing these mixtures was the difference between mortars made with finer glass and those made with coarser glass. Regardless of the $\mathrm{NaOH}$ concentration and curing temperature, the microstructure of mixtures containing the finer glass consistently appeared more continuous and less aggregated than those made with the coarser glass. This is shown in Figure 4.4 where micrographs are organized in a manner so as to easily compare the effect of the glass 
fineness on the microstructure. Mixtures containing the finer glass are shown on the left and corresponding mixtures containing the coarser glass are shown on the right.

In comparing the mortar with the highest (F.10.80) and lowest compressive strength (C.5.40) at 28 days, the difference in matrix continuity is even more apparent, as shown in Figure 4.4. The F.10.80 mixture appears to be one continuous, monolithic matrix while the C.5.40 mixture appears pieced together, with large voids visible and no real continuity. The relationship between the continuity of the matrix and compressive strength has been observed in other geopolymers as well (Rowles and O'Connor 2003) though it is often also linked to the amount of soluble silica in the activator solution and there is none in these mixtures. Generally, higher $\mathrm{Si} / \mathrm{Al}$ ratios result in more continuous microstructure, with the $\mathrm{Si} / \mathrm{Al}$ ratio increase due to the presence of soluble silica (Steveson and Sagoe-Crentsil 2005; Steveson and Sagoe-Crentsil 2005). 


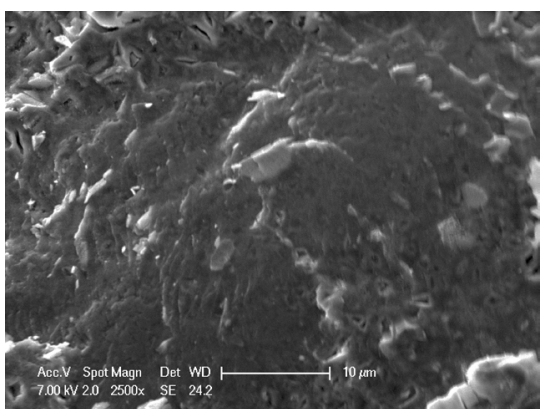

F.5.80

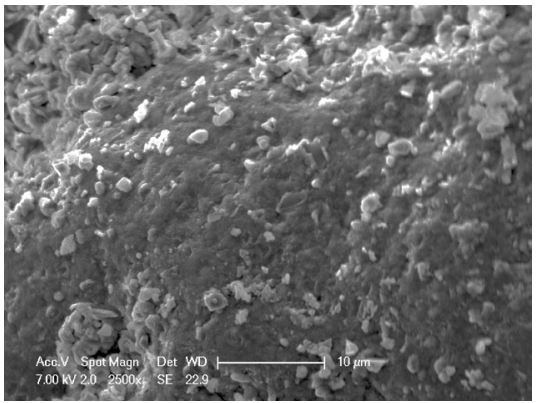

F.5.40

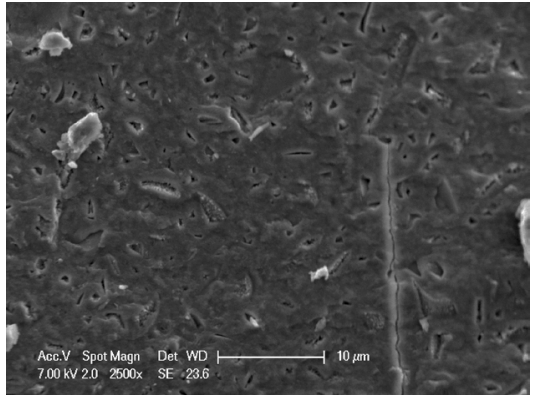

F. 10.80

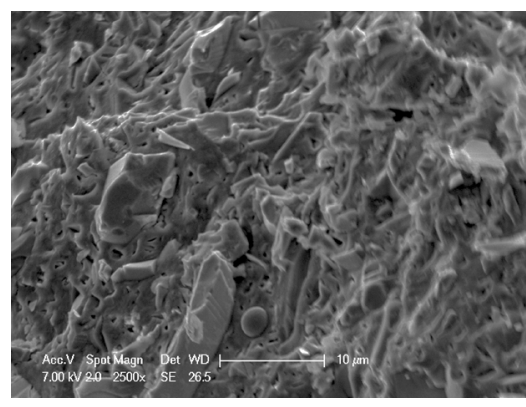

F.10.40

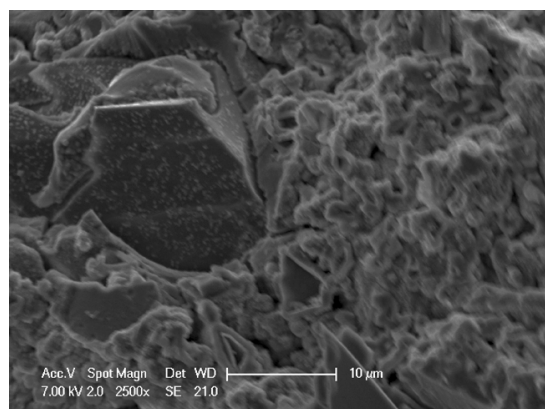

C. 5.80

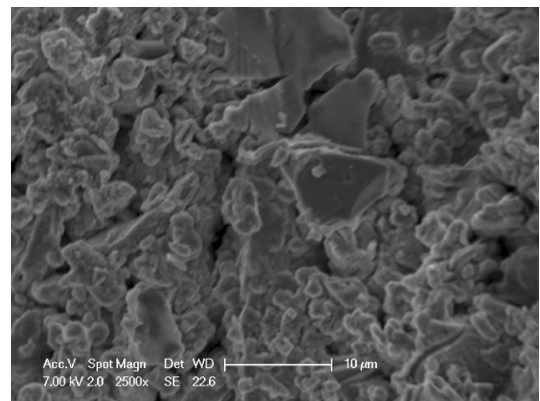

C.5.40

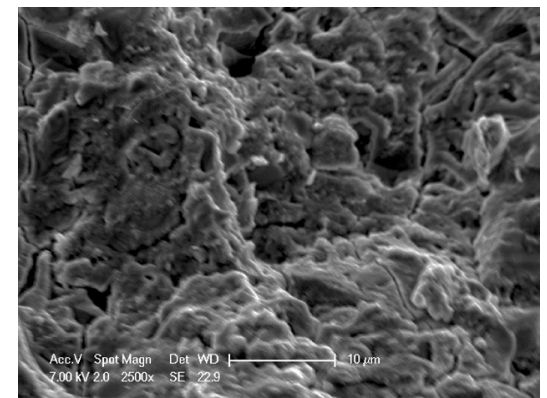

C. 10.80

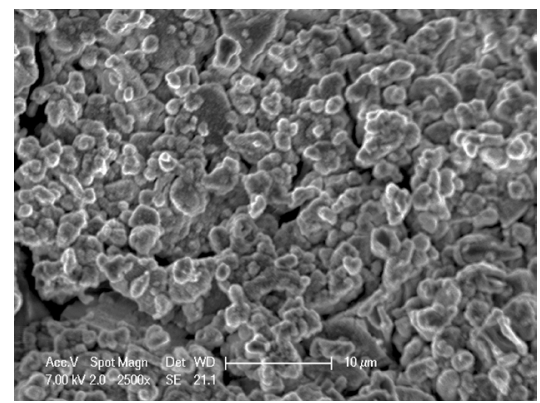

C. 10.40

Figure 4.4. Secondary electron imaging of fracture surfaces at 28 days, showing the finer glass mixtures on the left and the corresponding coarser glass mixtures on the right. 

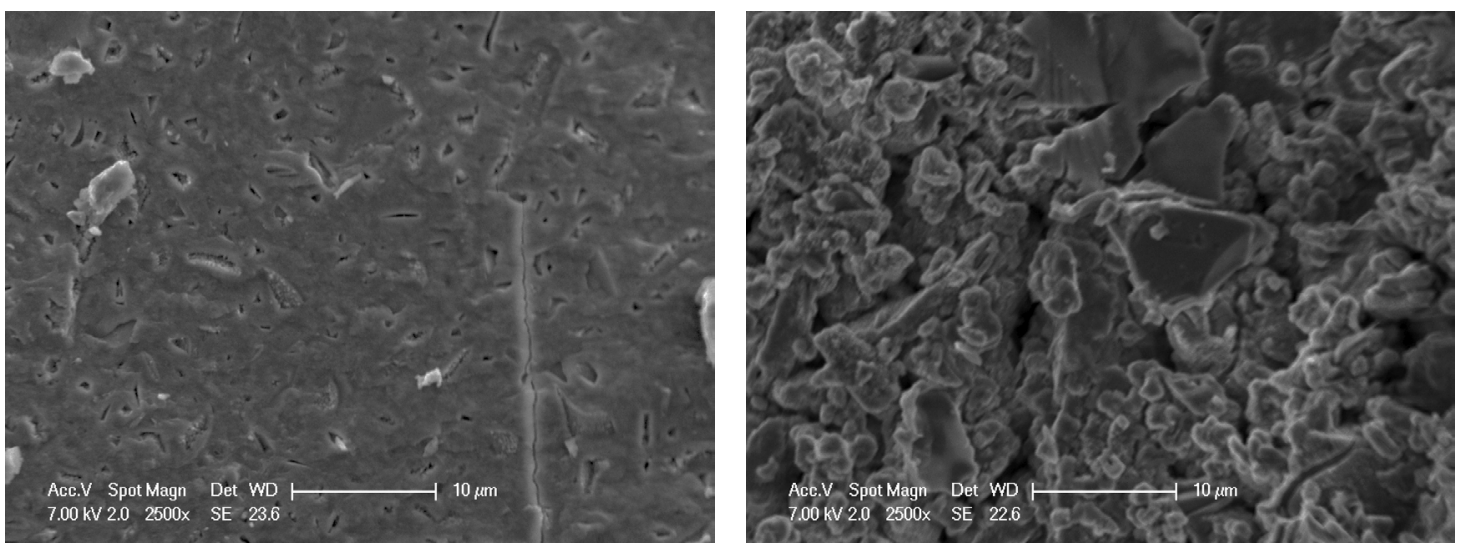

Figure 4.5. Microstructural comparison of the highest compressive strength mortar (left), F.10.80, and the lowest compressive strength mortar (right), C.5.40, at 28 days.

Unreacted glass particles were also quite prevalent in fracture surface imaging, as shown in Figure 4.6. The conchoidal fracture is typical of glassy breaks.
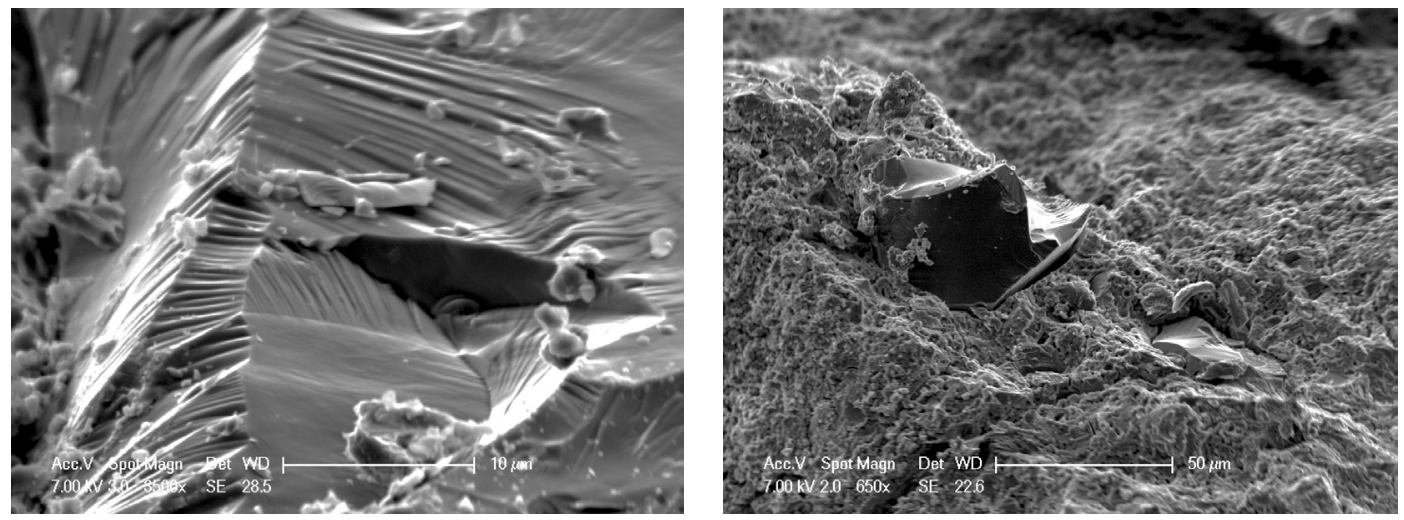

Figure 4.6. Unreacted glass particles as seen under secondary electron imaging. 


\subsubsection{Polished cross section analysis}

Polished cross sections were analyzed using backscatter electron imaging on 201-day old mortar samples. Aside from the obvious difference in residual glass particle size between the mixtures, there was also a very clear distinction between the microstructure of the mixtures using the fine and coarse sized glass. Figure 4.7 shows a backscatter image of all eight mortars, again organized to illustrate the microstructural difference between mixtures containing fine (left) and coarse (right) glass. The mixtures containing the finer glass typically possessed finer microstructural details, where the coarse mixtures appeared blockier and contained large regions of homogenous phases often surrounding unreacted glass particles. 


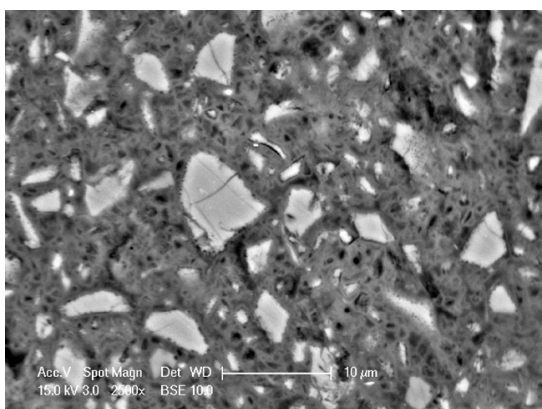

F.5.80

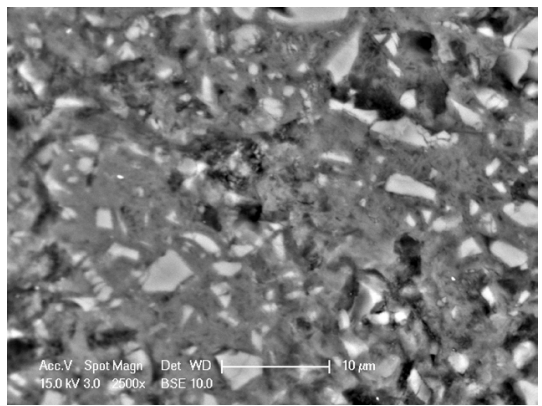

F.5.40

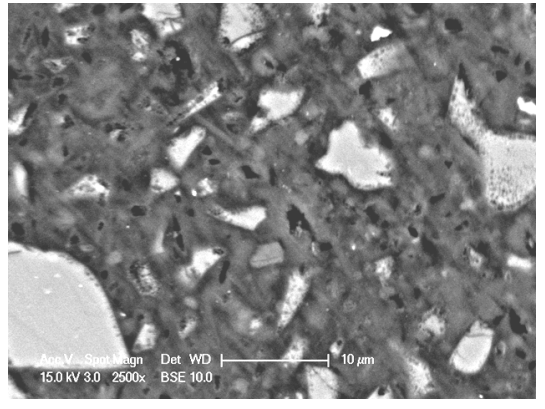

F. 10.80

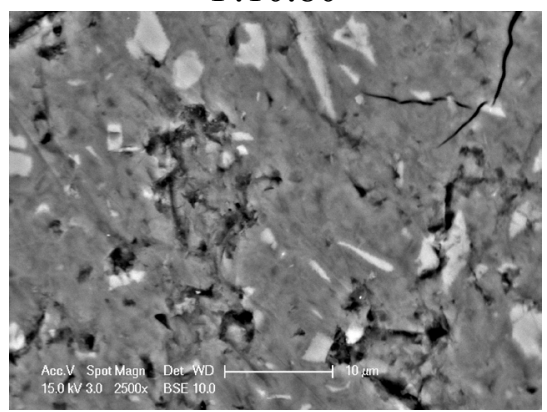

F. 10.40

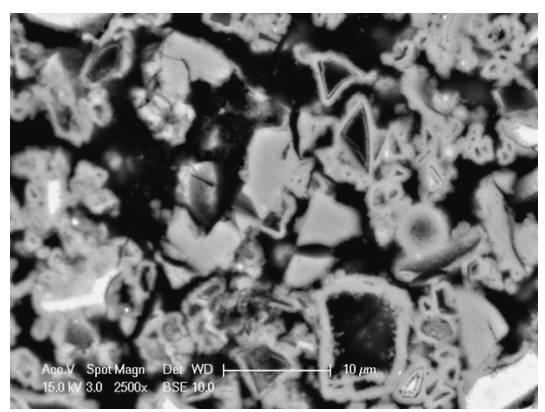

C. 5.80

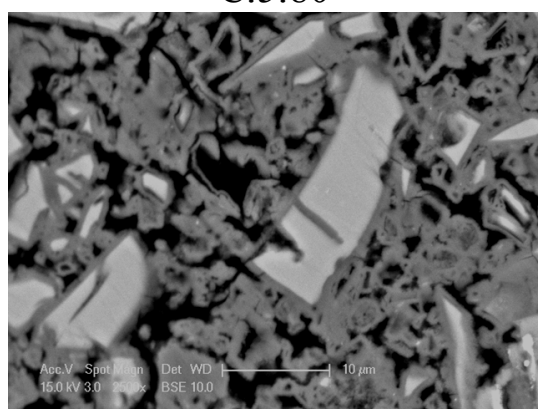

C.5.40

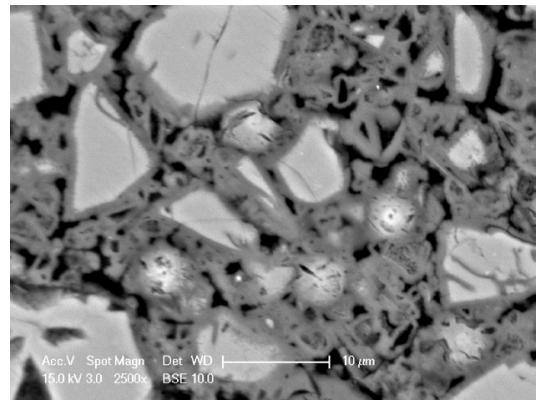

C. 10.80

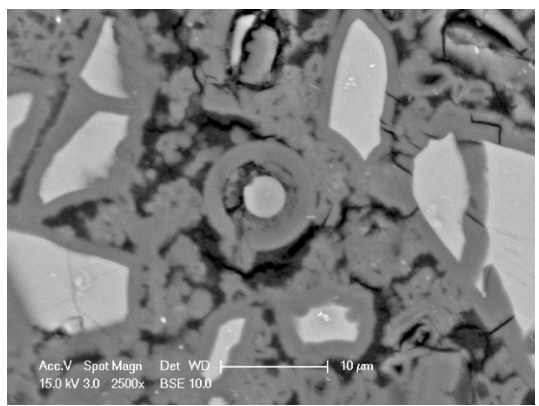

C. 10.40

Figure 4.7 Backscatter electron imaging of polished sections at 201 days, with the finer glass mixtures on the left and the corresponding coarser glass mixtures on the right. 
In the mixtures using the fine glass, a very narrow reaction rim was visible around the unreacted glass particles but the bulk of the microstructure was fairly uniform and continuous, with any voids present being very small. The dissolution glass typically begins with the removal of monovalent and divalent cations from the surface, followed by aluminum if present, and then silica (Oelkers and Gislason 2001). This reaction rim could be remnant of this, as a hydrated glass layer is known to exist between the pristine glass and outer gel phase formed, the thickness of this rim has been linked to corrosion rates as controlled by diffusion (Grambow and Muller 2001).

On the other hand, the mixtures made using the coarse glass did not show this reaction rim, but rather were surrounded by a continuous layer of geopolymer product. It is common in the dissolution of glass that a gel product is formed that readsorbs to the surface of the glass, forcing the reaction to become diffusion controlled (Litvan 1984). The border between the unreacted glass particle and the product appeared completely continuous and large voids or cracks appeared larger in these mixtures, occurring between where the reaction products did not contact each other. A closer look at the area surrounding an example of unreacted glass particle in each matrix is shown in Figure 4.8 for comparison. 

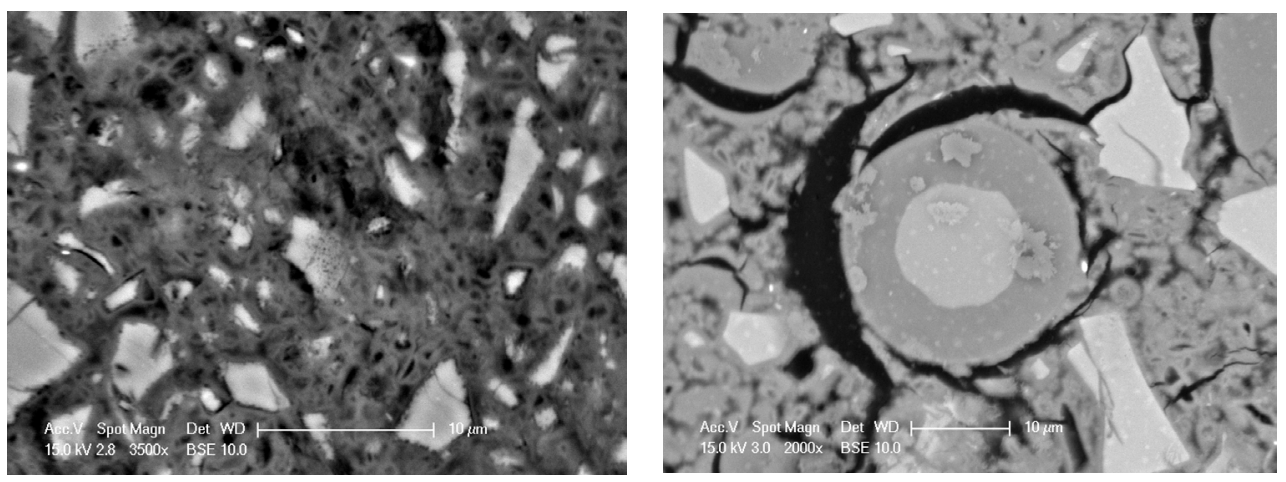

Figure 4.8. Comparison of reaction rim around a glass particle in the fine (left) and the coarse (coarse) glass mixtures.

The reaction product formed around the coarse glass particles appears similar to how C-S$\mathrm{H}$ (calcium silicate hydrate) forms around and in place of the reacting cement particle once hydration reactions become mainly diffusion controlled. The outline of the shape of the original glass particle is still visible in the matrix, similar to how a Hadley grain is visible in the microstructure of OPC concrete after hydration, as shown in Figure 4.9.

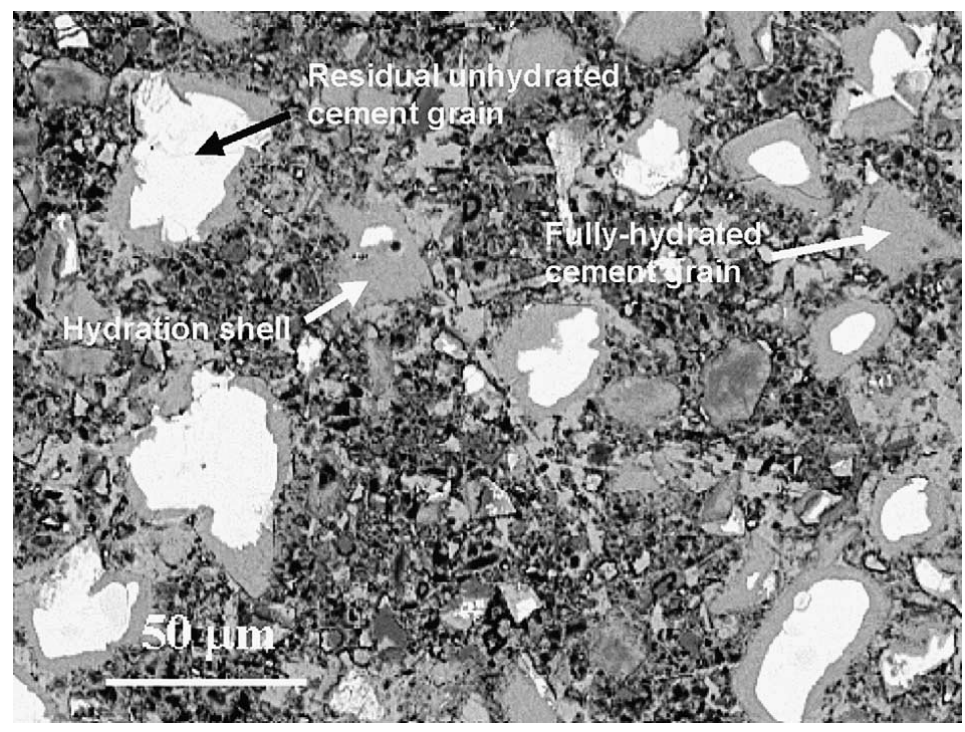

Figure 4.9. Microstructure of OPC concrete, showing C$\mathrm{S}-\mathrm{H}$ forming around unhydrated cement grains (Diamond 2004). Reprinted by permission of Elsevier. See Appendix $\mathrm{D}$ for documentation of permission to reprint this material. 
The bulk microstructure of the mixtures made with fine glass consisted of a web-like appearance, with very small voids of less than $1 \mu \mathrm{m}$, as shown in Figure 4.10.

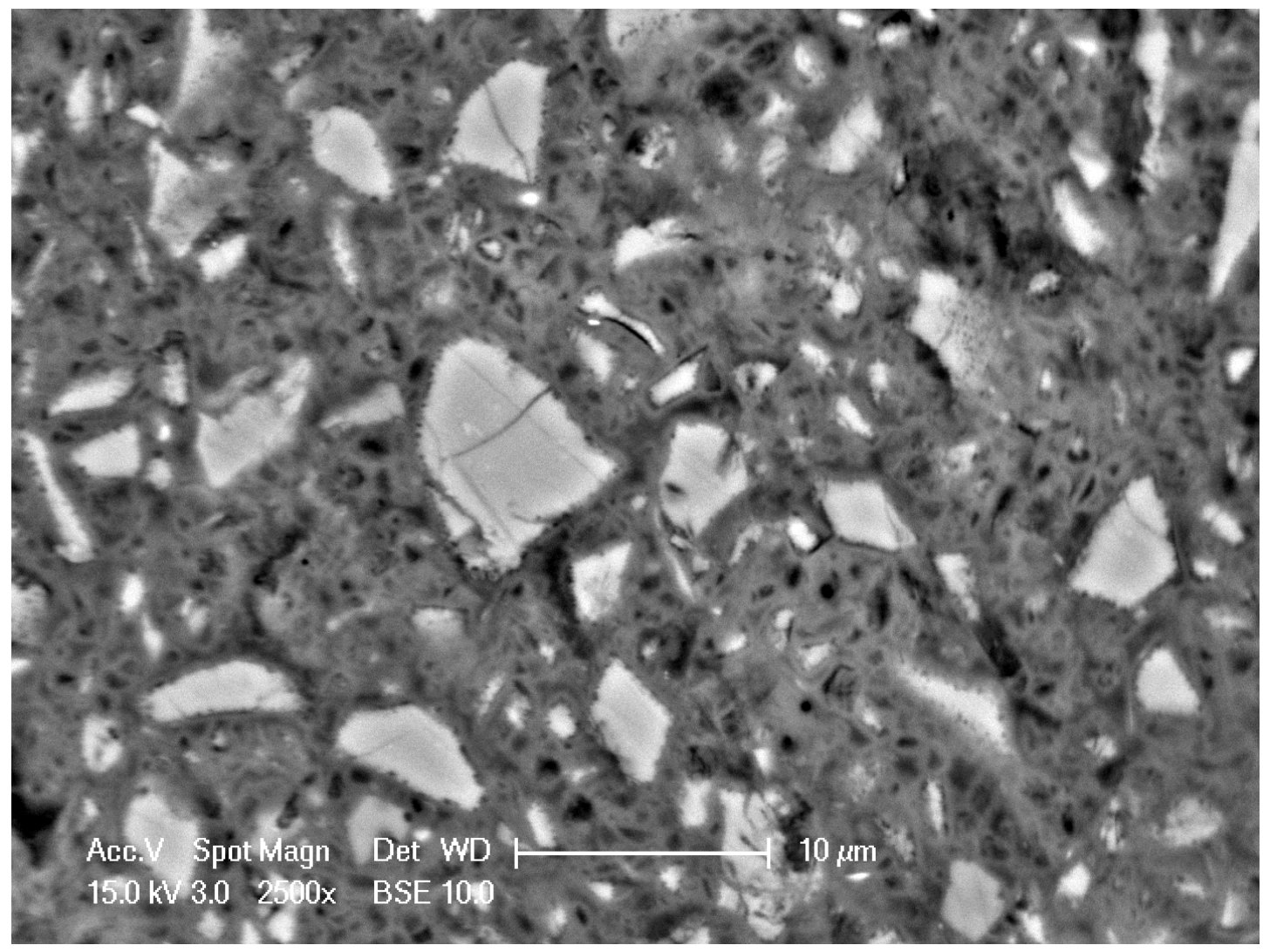

Figure 4.10. A larger image showing the microstructure of the F.5.80 mixture. Note the webbed look of the bulk matrix of the finer glass mixtures.

The bulk microstructure of the mixtures made with the coarse glass consisted of a significantly more cracking than the fine glass mixtures, as shown in Figure 4.11. This could be due to the improved particle packing of the smaller particles, leaving less large voids that need to be filled with geopolymer product in order to connect the entire matrix together. Also of note is the curved shape of the cracks as they seem to form between the layer of reaction product surrounding the glass particles and the rest of the bulk matrix, indicating a weaker zone in that area. These curved cracks are similar to the autogenous 
shrinkage cracks found in OPC concrete, but also could be in part due to sample preparation.

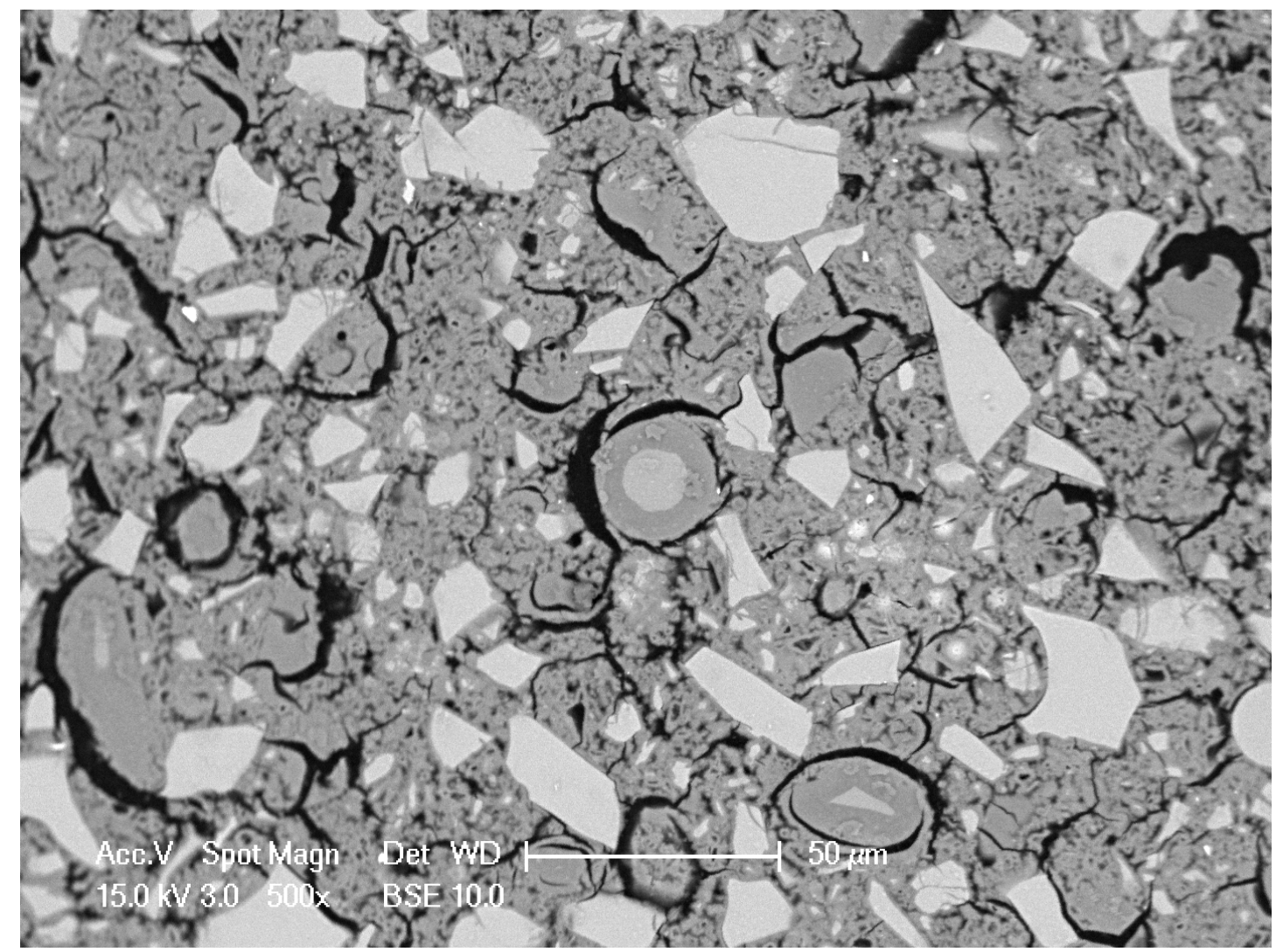

Figure 4.11. A larger image of the microstructure of the C.5.80 mixture.

The difference in microstructure between the fine and coarse glass mixtures could indicate the reaction occurring in both mixtures is similar in that reaction products form around the glass particles, but the voids in the finer glass microstructures are smaller due to the smaller size of the glass particles and greater number of particles present in the mixture.

Another explanation could be that dissolution of the fine glass particles occurs very rapidly creating a supersaturated solution, which then undergoes polycondensation to form a more homogenous matrix either through gelation or precipitation. In coarse glass mixtures, 
dissolution occurs much slower due to the lower specific surface areas of the particles and so layers of reaction product form around the glass particles, forcing the reaction to become diffusion controlled creating the airtight boundary between the unreacted glass and the reaction layer but also leaving voids between the particles.

The mixture with the highest 28-day strength that ended up with a drastic strength decrease at 201 days, F.10.80, appeared to have a dense, continuous microstructure. The two mixtures that had the highest strength at 201 days, F.10.40 and C.10.40, both showed a great deal of geopolymer product surrounding the unreacted particles. However the presence of more voids contradicted with the aforementioned relationship between continuity of microstructure and mechanical performance, indicating the composition of the products must also play an important role in physical properties.

\subsubsection{Phase composition}

Using backscatter electron imaging to identify varying elemental intensities and phases present within the microstructure, the elemental composition of the geopolymer reaction product was identified by EDS microanalysis. A minimum of six spots were analyzed on each mixture and statistics on the EDS analysis of each mixture can be found in Appendix A. Table 4.6 shows the mixtures listed in order of maximum 201-day compressive strength and the resulting average molar ratios in the geopolymer product measured through EDS microanalysis. 
Table 4.6. Average measured molar ratios of the mixtures ordered in terms of maximum compressive strength at 201 days.

\begin{tabular}{|c|c|c|c|c|c|c|}
\hline Mixture ID & Rank & $\begin{array}{c}\text { Compressive } \\
\text { strength (psi) }\end{array}$ & Si/Al & $\mathbf{N a} / \mathbf{A l}$ & $\mathbf{N a} / \mathbf{S i}$ & $\mathbf{C a} / \mathbf{S i}$ \\
\hline F.10.40 & $1^{\text {st }}$ & 10196 & 9.15 & 2.95 & 0.33 & 0.41 \\
\hline C.10.40 & $2^{\text {nd }}$ & 6729 & 15.01 & 11.65 & 0.77 & 0.31 \\
\hline F.10.80 & $3^{\text {rd }}$ & 5607 & 9.02 & 5.48 & 0.63 & 0.34 \\
\hline F.5.80 & $4^{\text {th }}$ & 5217 & 9.37 & 2.06 & 0.22 & 0.45 \\
\hline C.10.80 & $5^{\text {th }}$ & 3995 & 16.05 & 7.20 & 0.46 & 0.28 \\
\hline F.5.40 & $6^{\text {th }}$ & 3714 & 9.34 & 2.20 & 0.24 & 0.42 \\
\hline C.5.40 & $7^{\text {th }}$ & 3409 & 13.70 & 7.94 & 0.59 & 0.21 \\
\hline C.5.80 & $8^{\text {th }}$ & 2917 & 13.99 & 7.80 & 0.56 & 0.26 \\
\hline
\end{tabular}

The average $\mathrm{Si} / \mathrm{Al}, \mathrm{Na} / \mathrm{Al}, \mathrm{Na} / \mathrm{Si}$ and $\mathrm{Ca} / \mathrm{Si}$ molar ratios of each mixture are shown graphed against compressive strength at 201 days in Figure 4.12. It can be seen that no clear trends exist between compressive strength and molar ratios as measured by EDS other than to note the obvious differences in $\mathrm{Si} / \mathrm{Al}$ and $\mathrm{Na} / \mathrm{Al}$ ratios between the fine and coarse glass mixtures. 


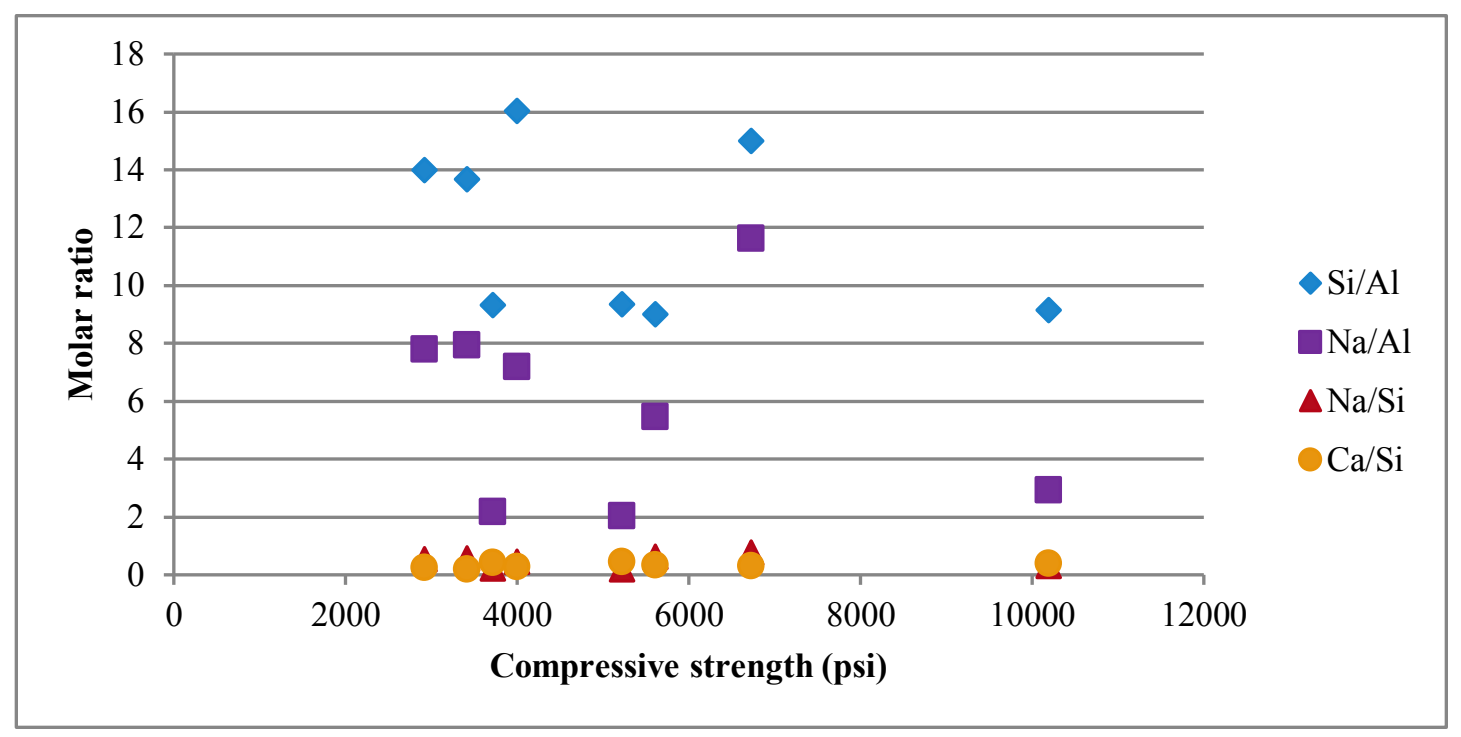

Figure 4.12. Molar ratios of all eight mixtures as a function of compressive strength at 201 days. No clear trends exist other than the divide between mixtures made with fine glass and those made with coarse glass.

Figure 4.13 shows the similarities among mixtures made with fine glass (shown in blue), as well as mixtures made with coarse glass (shown in green), where both the $\mathrm{Si} / \mathrm{Al}$ and $\mathrm{Na} / \mathrm{Al}$ ratios are generally higher for mixtures made with coarse glass. 


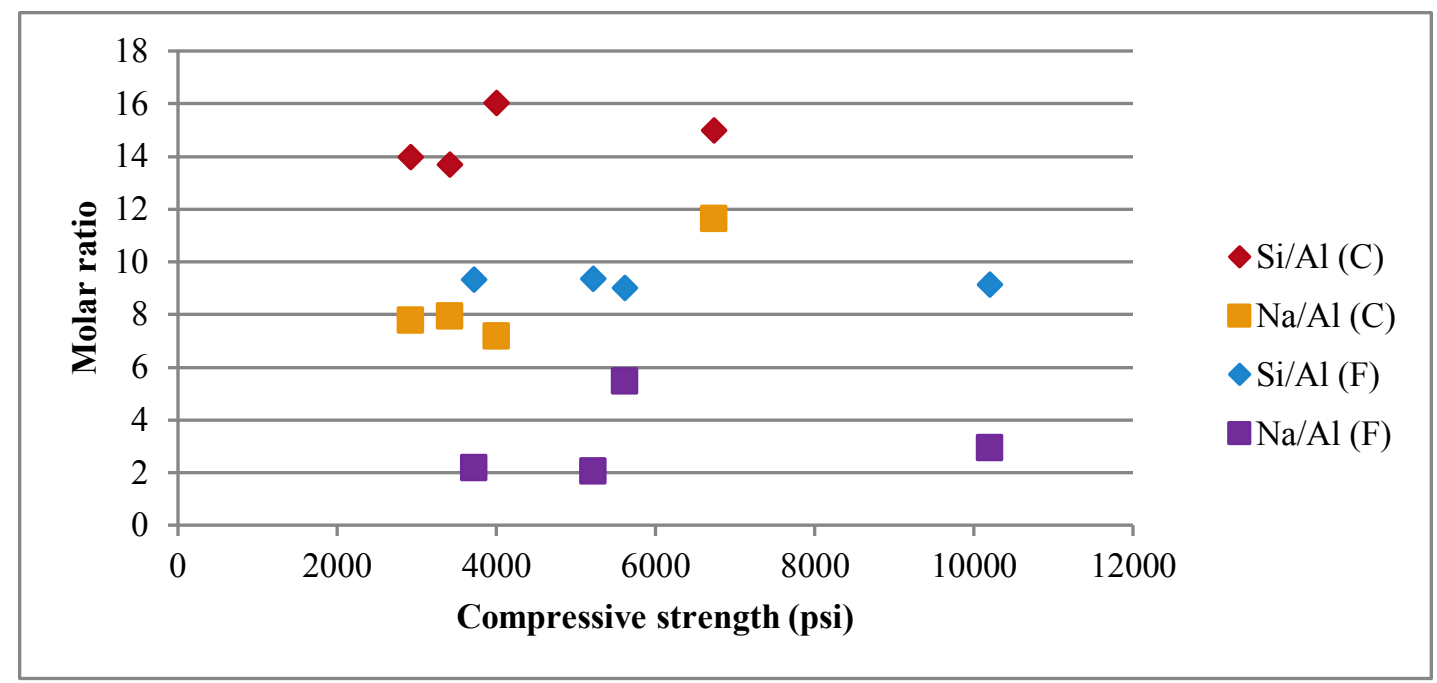

Figure 4.13. $\mathrm{Si} / \mathrm{Al}$ and $\mathrm{Na} / \mathrm{Al}$ molar ratios as a function of compressive strength. The fine and coarse mixtures are separated by different colored markers as shown in the legend.

$\mathrm{The} \mathrm{Si} / \mathrm{Al}$ ratio is very consistent among the mixtures containing the fine glass (9.02-9.37), with more variance and higher numbers overall in the mixtures containing the coarse glass (13.7-16.05).

The $\mathrm{Na} / \mathrm{Al}$ ratio was lower in the mixtures containing fine glass, perhaps indicating further reaction of the glass (2.06-5.48), where increased reaction would make more Al available to balance the $\mathrm{Na}$, lowering the ratio. The $\mathrm{Na} / \mathrm{Al}$ ratio was much higher in the coarse glass systems (7.20-11.65) and particularly high in the C.10.40 mixture, which was the mixture that had a large increase in terms of compressive strength from 28 to 201 days. The Na/Al ratio is also much higher in the mixture that had a decrease in compressive strength from 28 to 201 days (F.10.80) as compared to the other mixtures made of fine glass.

Figure 4.14 shows the $\mathrm{Na} / \mathrm{Si}$ and $\mathrm{Ca} / \mathrm{Si}$ ratios for both the fine glass mixtures (blue) and the coarse glass mixtures (green). The $\mathrm{Na} / \mathrm{Si}$ ratios were generally lower for the fine glass 
mixtures, with the exception of F.10.80, and higher in the coarse glass mixtures. This indicates further dissolution where more $\mathrm{Si}$ was made available. Alternately, the $\mathrm{Ca} / \mathrm{Si}$ ratios of the fine glass mixtures were typically higher than that of the coarse glass mixtures, with the exception of F.10.80, which was a bit lower. Moderate calcium contents in geopolymers have been shown to result in an increase in compressive strength as compared to mixtures containing little to no calcium.

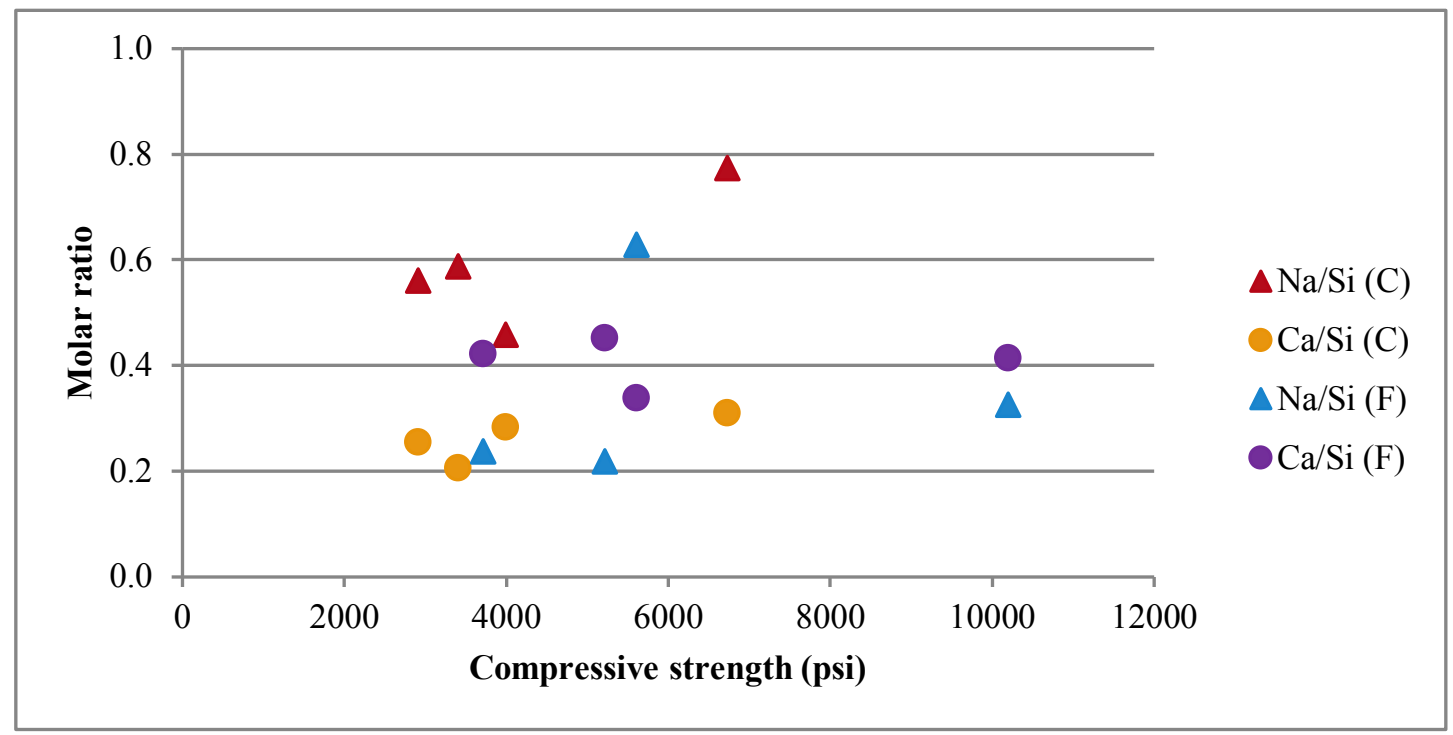

Figure 4.14. $\mathrm{Na} / \mathrm{Si}$ and $\mathrm{Ca} / \mathrm{Si}$ molar ratios as a function of compressive strength. Different colored markers, as shown in the legend, separate the fine and coarse mixtures.

With regard to the relationship between actual measured stoichiometry and bulk stoichiometry of the unreacted materials, it was clear the finer glass mixtures more closely resembled the bulk stoichiometry. Figure 4.15 shows how closely the $\mathrm{Si} / \mathrm{Al}$ ratio of the fine glass mixtures resembles the bulk $\mathrm{Si} / \mathrm{Al}$ ratio of 8.69 as compared to the coarse glass mixtures. 


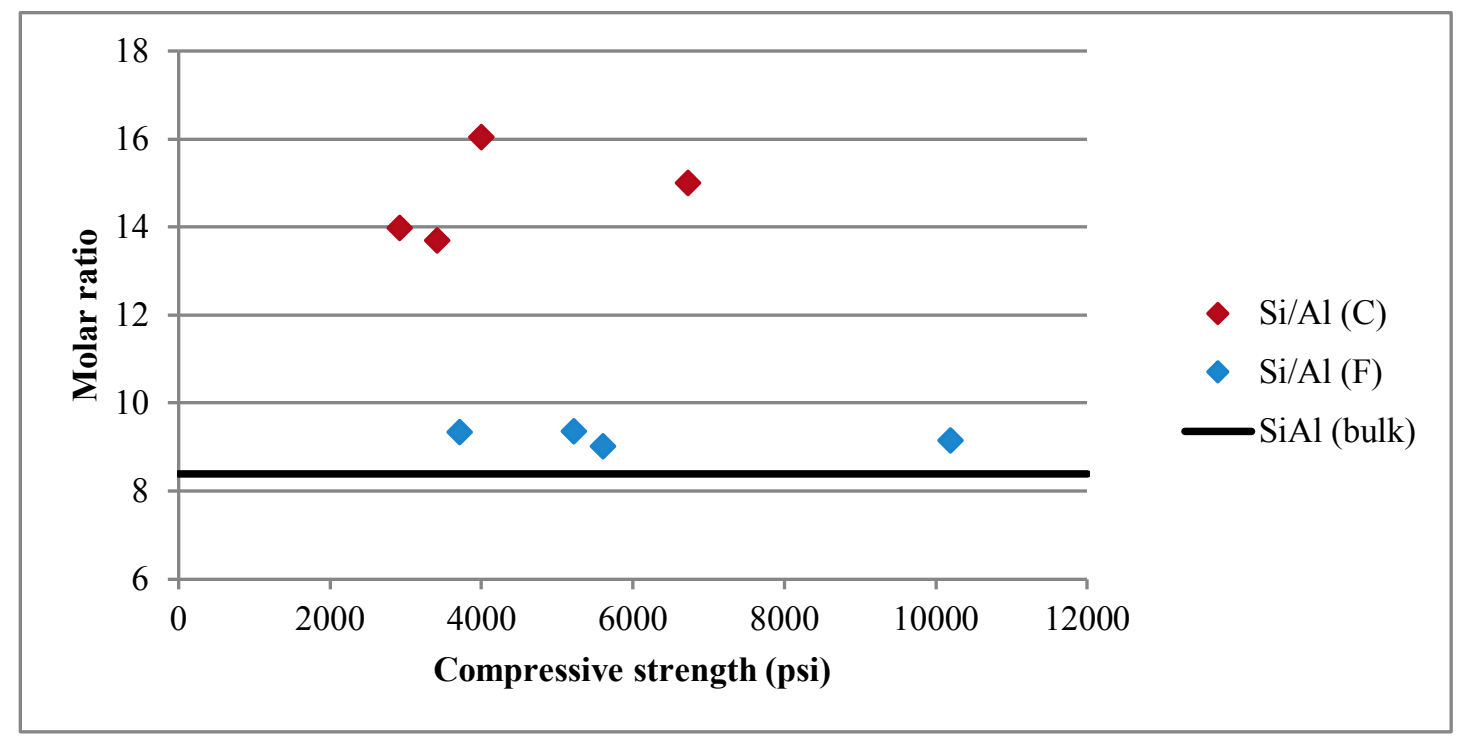

Figure 4.15. Comparison of the $\mathrm{Si} / \mathrm{Al}$ ratio of the coarse and fine glass mixtures and the bulk Si/Al ratio of the mixtures, shown as a line at 8.39.

Figure 4.16 shows the same is true for the $\mathrm{Na} / \mathrm{Al}$ ratio, where for the most part the $\mathrm{Na} / \mathrm{Al}$ ratio of the finer glass mixtures more closely resembled the bulk $\mathrm{Na} / \mathrm{Al}$ ratio. It is interesting to note the extremely high $\mathrm{Na} / \mathrm{Al}$ ratio point is the $\mathrm{C} .10 .40$ mixture, which possessed a very high compressive strength at 201 days. It is unknown why this is since most of the literature is adamant that a $\mathrm{Na} / \mathrm{Al}$ ratio of close to unity will give optimum mechanical performance. 


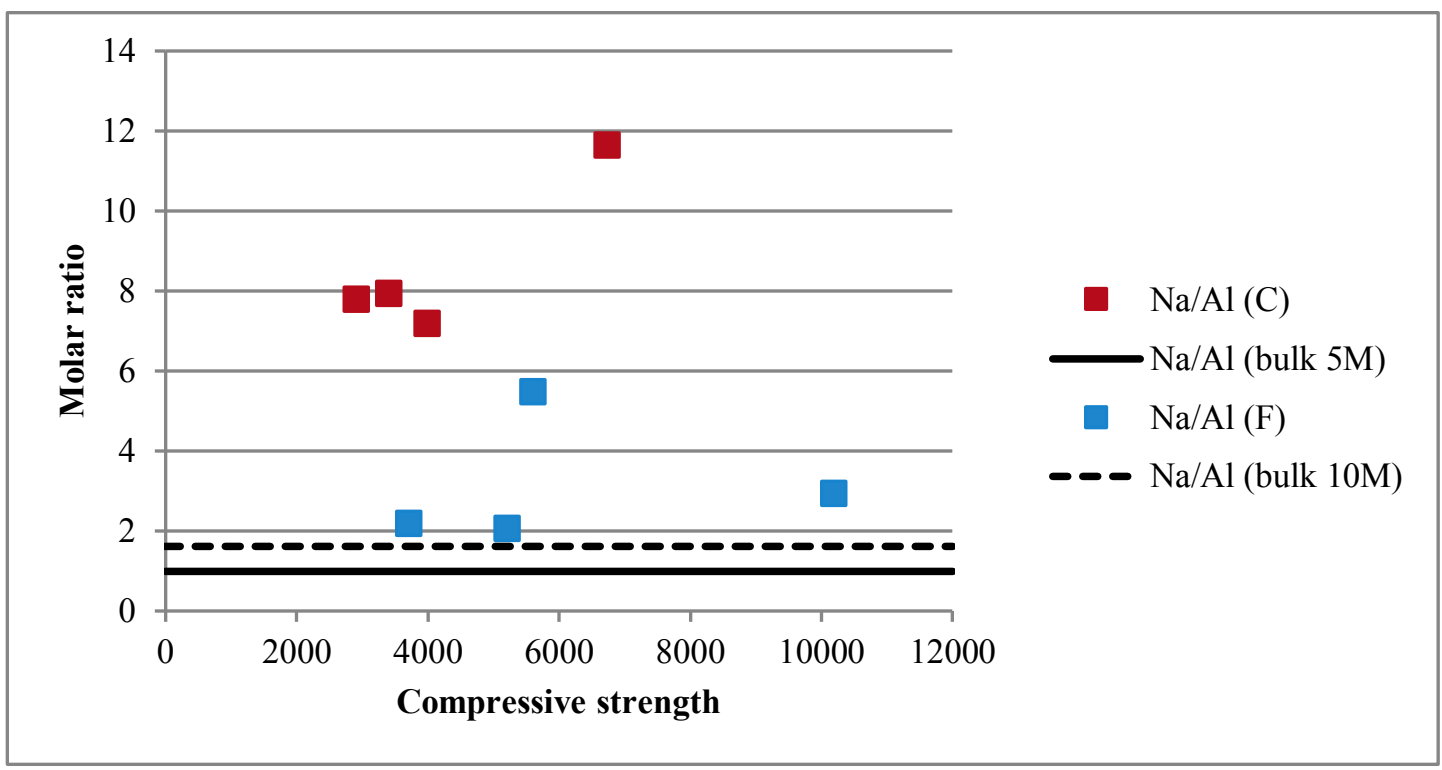

Figure 4.16. Comparison of the $\mathrm{Na} / \mathrm{Al}$ ratio of the coarse and fine glass mixtures and the bulk $\mathrm{Na} / \mathrm{Al}$ ratio of the mixtures, shown as a line at 0.99 and 1.61 .

Figure 4.17 shows that for the most part the same was true for the $\mathrm{Na} / \mathrm{Si}$ ratio, with the exception of the C.10.40 mixture again, which had a very high Na/Si ratio. The F.10.80 mixture also had a high $\mathrm{Na} / \mathrm{Si}$ ratio as compared to the other fine glass mixtures. 


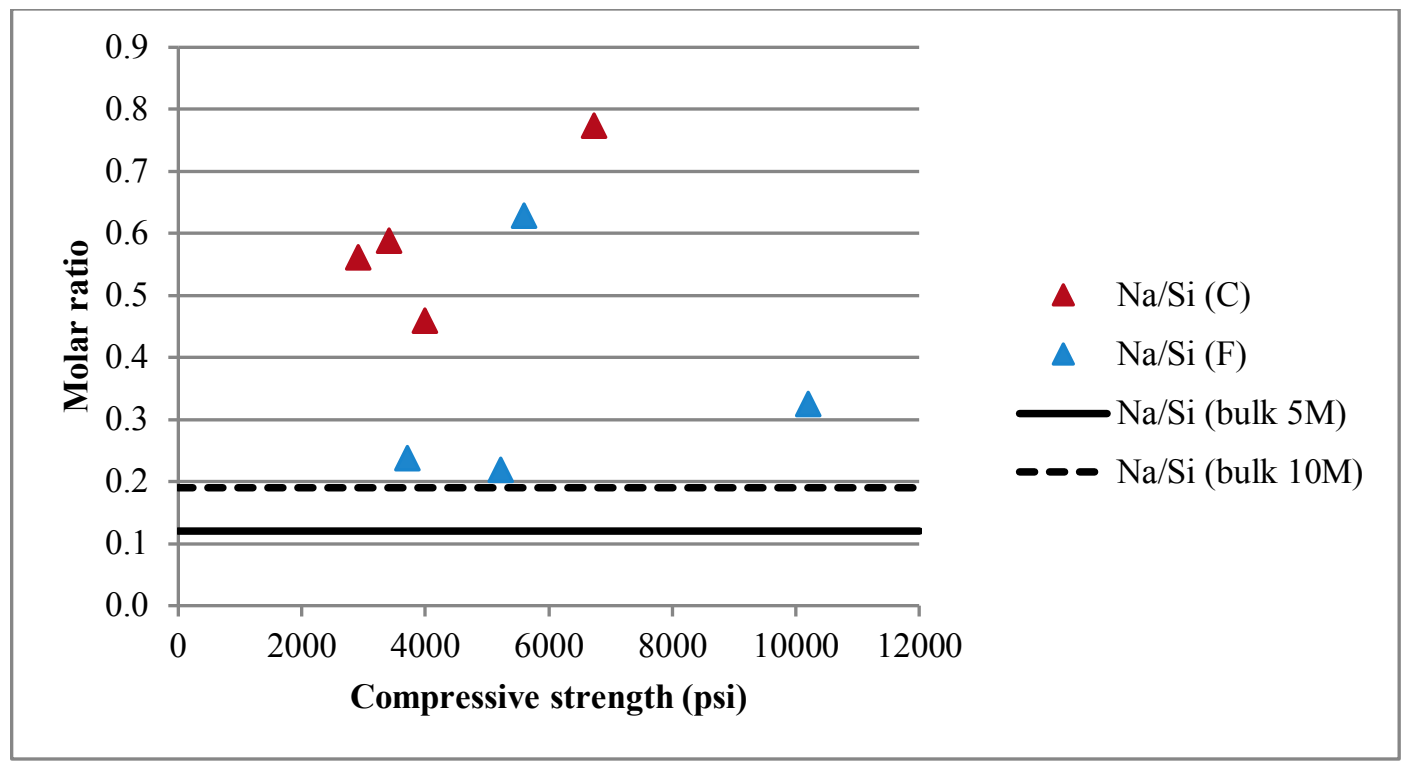

Figure 4.17. Comparison of the $\mathrm{Na} / \mathrm{Si}$ ratio of the coarse and fine glass mixtures and the bulk Na/Si ratios of the mixtures, shown as lines at 0.12 and 0.19 .

Figure 4.18 shows differing results, where the $\mathrm{Ca} / \mathrm{Si}$ ratio was lower than the bulk stoichiometry for the coarse glass mixtures but close for the fine glass mixtures. This was the only ratio that resulted in a lower actual ratio as compared to the bulk ratio. This could indicate that $\mathrm{Si}$ was preferentially dissolved in the coarse glass mixtures or that a calciumrich phase such as $\mathrm{Ca}(\mathrm{OH})_{2}$ or C-S-H formed which kept the calcium levels in the bulk matrix low. 


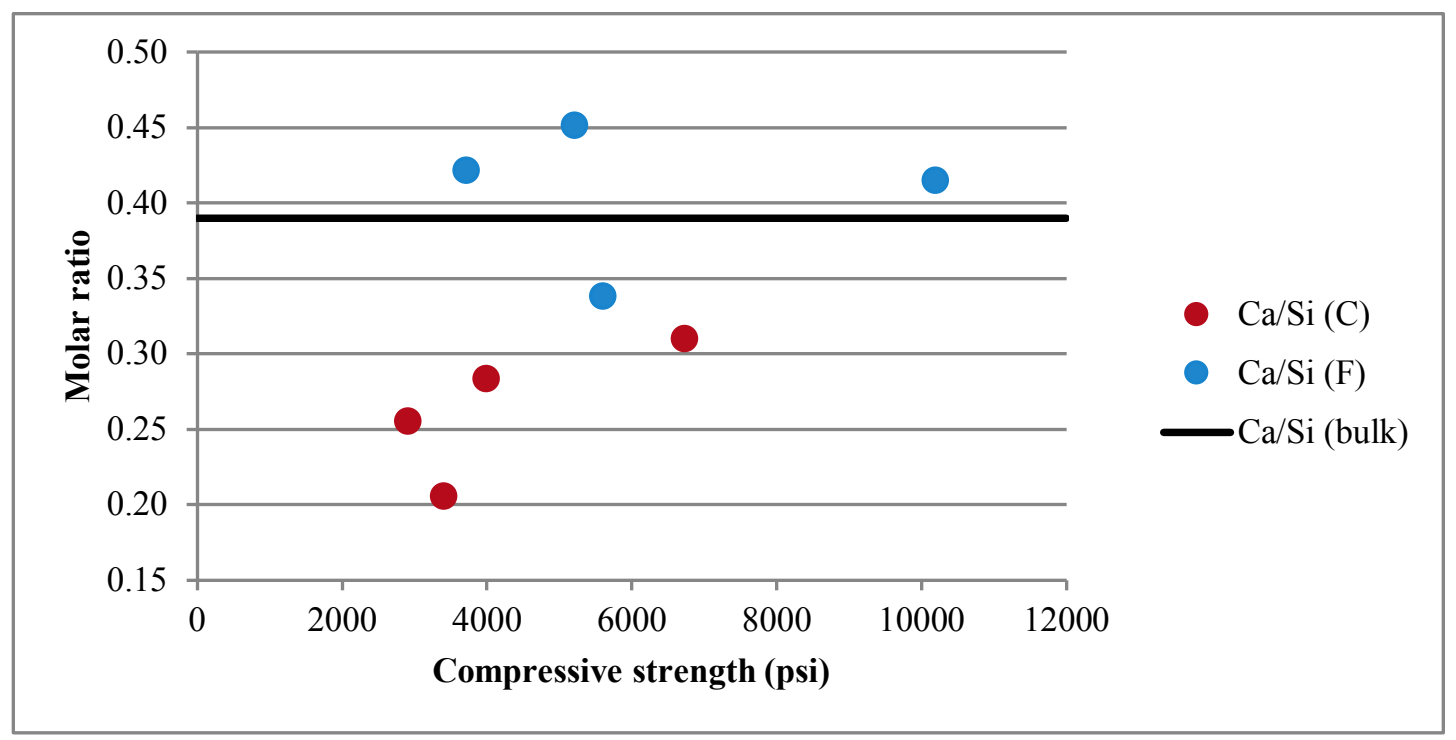

Figure 4.18. Comparison of the $\mathrm{Ca} / \mathrm{Si}$ ratio of the coarse and fine glass mixtures and the bulk $\mathrm{Ca} / \mathrm{Si}$ ratio of the mixtures, shown as a line at 0.39 .

\subsubsection{Discussion of Phase I}

As stated previously, aside from an exploration into making glass geopolymer, the main goals of this phase were to explore the effects of glass fineness, activator concentration and curing temperature on the compressive strength, microstructure and composition of phases present in the geopolymer.

\subsubsection{Fineness of glass}

In general, the glass fineness seemed to have the most impact on the compressive strength, microstructure and phase composition, with rather clear divides existing in each set of data separating mixtures made with fine glass and those made with coarse glass.

With regard to compressive strength, it seems it is not just one parameter, such as glass fineness, that dictates which mixtures will behave strongest, but rather a combination of parameters. At 201 days, mixtures made with $10 \mathrm{M} \mathrm{NaOH}$ and cured at $40^{\circ} \mathrm{C}$ performed 
better than all other mixtures, with both the fine and coarse glass mixtures performing well, indicating that important relationships exist between the various parameters.

With regard to microstructure however, the fineness of the glass had a clear impact on the microstructure, with a more uniform, continuous matrix forming in the fine glass mixtures and a more aggregated, heterogeneous matrix in the coarse glass mixtures. Also of note was the presence of the very thin reaction rim around the unreacted glass particles in the fine glass mixtures as compared to the smooth encapsulation of the glass particles by the surrounding reaction products in the coarse glass mixtures. This most likely indicates a surface reaction was occurring that later became diffusion controlled (Rajmohan et al. 2010), rather than widespread dissolution followed by precipitation or gelation via homogeneous nucleation within the bulk matrix. The great disparity between these two types of microstructures speaks to different reactions occurring, or at the very least, the same reaction occurring on a vastly different size scale.

Regarding phase composition, again, a fairly clear line was drawn between the fine and coarse glass mixtures, with $\mathrm{Si} / \mathrm{Al}$ and $\mathrm{Na} / \mathrm{Al}$ ratios being much lower in the fine glass mixture and higher in the coarse glass mixtures. Since both of these ratios are dependent on $\mathrm{Al}$ content, this indicates that more $\mathrm{Al}$ was included into the fine matrix, which leads one to believe that all things being equal, more glass was dissolved in the fine glass matrices. Degree of reaction experiments were not conducted in this phase but the presence of very large unreacted particles in the matrix of the coarse glass mixtures indicates that a large portion of glass particles was not reacted. 
The stoichiometry of the geopolymers was very similar to that of the bulk unreacted materials in the fine glass mixtures. However, the $\mathrm{Si} / \mathrm{Al}$ and $\mathrm{Na} / \mathrm{Al}$ ratios were significantly higher in the coarse glass mixtures.

\subsubsection{Activator concentration}

With regard to activator concentration, it was found that overall, a higher activator concentration resulted in higher compressive strengths both at 28 and 201 days. This contradicts the work of Cyr et al., who found that a concentration of 5M performed better than 10M (Cyr et al. 2012). Other research has not defined a clear choice in terms of activator concentration, with a variety of results being put forth indicating the optimum activator concentration depends heavily on other variables.

Also of note is the fact that most other geopolymers made of fly ash or metakaolin also include sodium silicate in the activator, which changes the kinetics, often lowering the degree of reaction since a great deal of $\mathrm{Si}$ is provided from the activator. In glass geopolymers, all of the Si and Al network formers come from the glass or other source materials, so dissolution is key and therefore a higher concentration is needed to provide more hydroxyl ions for dissolution. This could explain why the higher activator concentration was found to result in higher compressive strength in this research.

Another observation to note is the importance of the $\mathrm{Na} / \mathrm{Al}$ ratio with regard to excess sodium present in the hardened mortar. Consider the C.5.80 mixture as an example. Even though the unreacted bulk Na/Al ratio for the C.5.80 mixture was 0.99 , the actual $\mathrm{Na} / \mathrm{Al}$ ratio was upwards of 8 . This means there was nearly eight times as much sodium measured 
in the geopolymer as aluminum. This excess sodium has been known to migrate to the surface and form carbonates in the atmosphere. This was observed in several samples stored in plastic cups where white fibers grew on the surface of the geopolymer as shown in Figure 4.19.

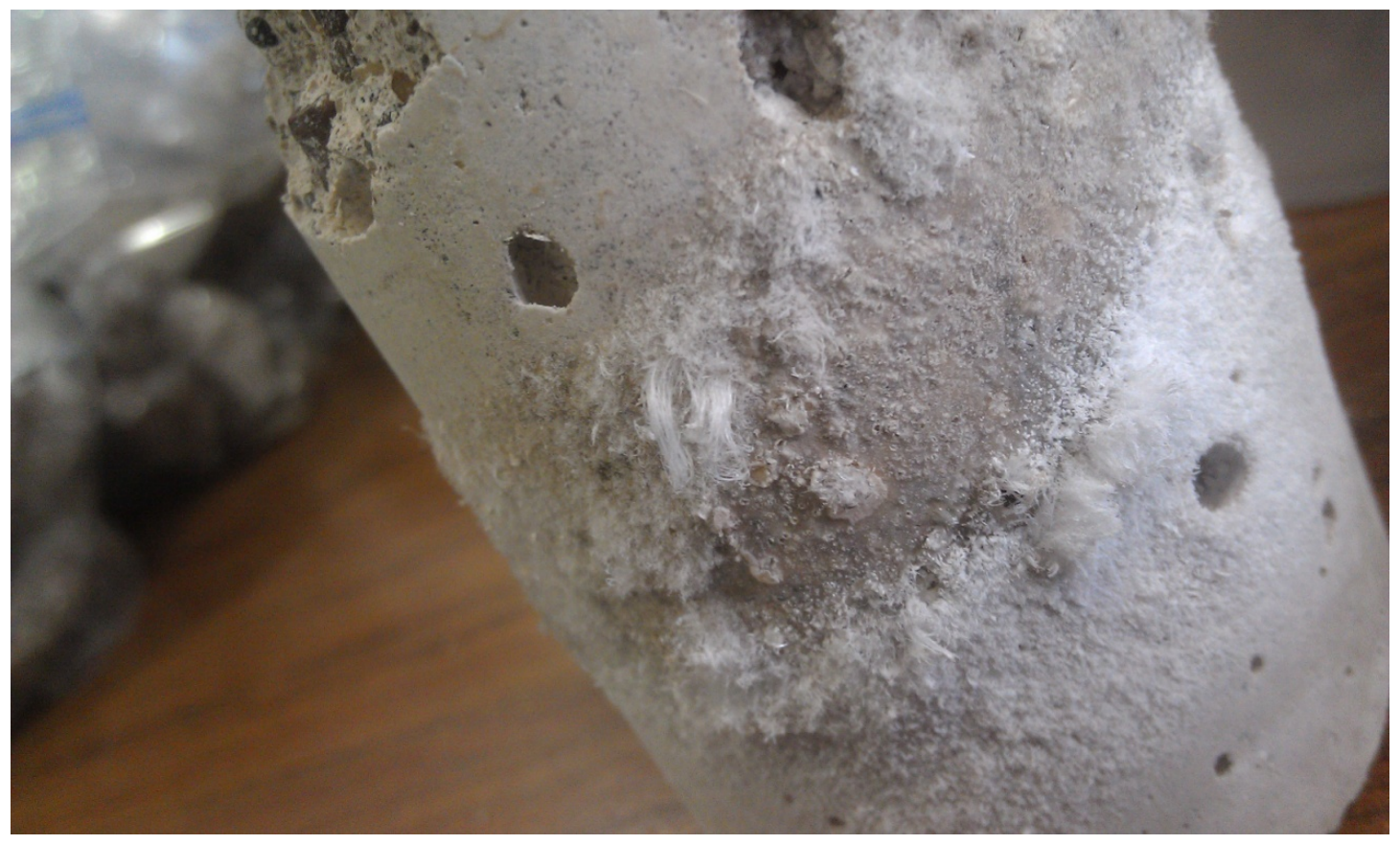

Figure 4.19. White growth on the surface of the C.5.80 mortar during storage.

Powder X-ray diffraction confirmed the white growth was crystalline sodium carbonate hydrate, as shown in Figure 4.20. The Na/Al ratio is of great concern when it comes to using glass in geopolymers, and was one of the driving factors of this research. Phases II and III address this issue of excess sodium in glass geopolymers. 


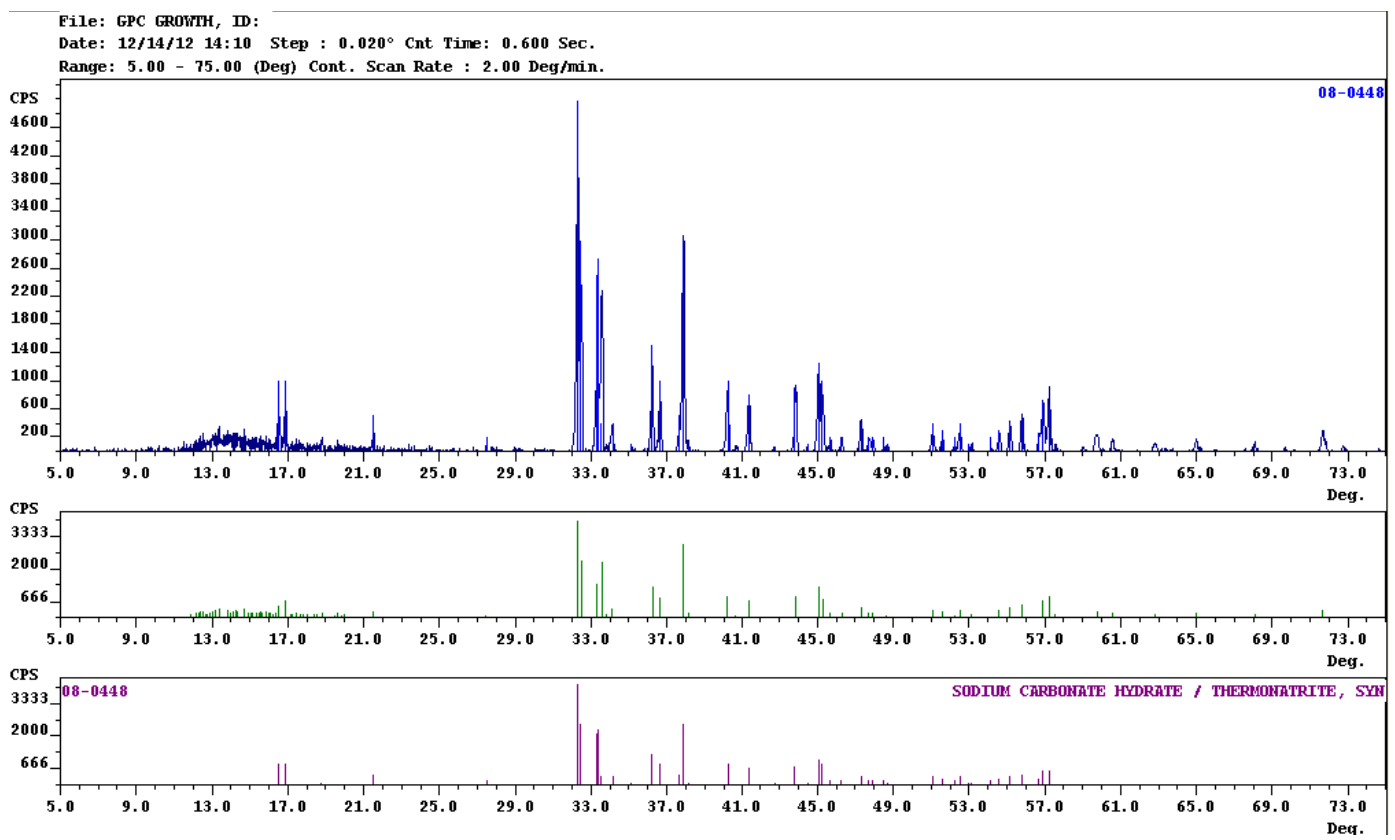

Figure 4.20. Powder X-ray diffraction pattern and identification for the white growth found on the C.5.80 geopolymer surface in Figure 4.19.

\subsubsection{Curing temperature}

The effects of the curing temperature were interesting in Phase $\mathrm{I}$ in that curing at $40^{\circ} \mathrm{C}$ for 24 hours resulted in enhanced strength gain over time as compared to mixtures cured at $80^{\circ} \mathrm{C}$. Similar mixtures cured at $80^{\circ} \mathrm{C}$ for the same amount of time not only stagnated in compressive strength past 28 days, but actually lost strength.

Severe strength loss in geopolymers is not common within the literature. Under conditions of very high temperatures, crystallization of the geopolymer could occur leading to a loss in strength, or if the samples were stored in water, leaching could occur, which has been shown to lead to a strength loss (Cyr et al. 2012). However, the sample F.10.80 was not kept under either of those conditions and it is unknown why the strength decrease was so substantial. Higher curing temperatures typically lead to a higher degree of dissolution 
initially, but could also indicate a quicker buildup of reaction products around the dissolving species, preventing further reaction. However, that does not account for a loss in strength, nor was this layer of reaction products around unreacted glass found in microstructural analysis.

\subsubsection{Main points of Phase I}

- Fineness had the greatest impact on compressive strength, microstructure and composition, most likely due to the resulting increase in rate and extent of dissolution. More dissolution releases more $\mathrm{Si}$ and $\mathrm{Al}$ species to make more geopolymer. More geopolymer formed means less voids and a denser matrix, which physically contribute to increased compressive strength.

- Fineness is not, however, the dominant parameter as evidenced by the C.10.40 mixture, which reached the second highest compressive strength of all the mixtures at 201 days and was made with coarse glass.

- Since dissolution is necessary to free the network formers in a mixture not containing soluble silica, a higher activator concentration yields superior mechanical strength as it causes more dissolution to occur.

- Higher temperature curing leads to higher early strengths, while lower temperature curing results in lower early strength but a more sustained increase in compressive strength over time.

- In all of these cases, it is important to note there is a synergy between the various parameters, where it is not necessarily one single parameter than dictate a mortar 
performance but rather the combination of parameters that is most important. It is clear that relationships between the various mixture parameters exist that are more powerful than any one individual parameter.

- There did not appear to be any clear trends between molar composition of the geopolymer and compressive strength aside from the general differences having to do with the fineness of the glass used.

- There did not appear to be any clear correlation between microstructure and compressive strength since several mixtures appearing to have a lot of voids and cracks behaved better than other more uniform mixtures The overall continuity of the fine glass mixtures did result in higher compressive strengths overall according to the fracture surface at 28 days.

- The F.10.80 mixture should be investigated further to determine the cause for the strength decrease from 28 to 201 days.

\subsection{Phase II}

The second phase of testing considered a new set of mortar mixtures that addressed the issue of too much sodium and not enough aluminum in glass geopolymers. Phase II explored the effects of replacing selected amounts of glass with metakaolin or fly ash, effectively increasing the aluminum content in the mixtures and decreasing the $\mathrm{Si} / \mathrm{Al}$ and $\mathrm{Na} / \mathrm{Al}$ ratios to more generally acceptable stoichiometric ratios (i.e. $\mathrm{Si} / \mathrm{Al}=2-5, \mathrm{Na} / \mathrm{Al}=$ 1). 
As in Phase I, compressive strength, microstructure and phase composition were the most important characteristics considered. Special attention was paid to investigating the geopolymers at early ages of 1, 3 and 7 days in addition to several later ages. Compressive strength was measured at 1, 3, 7, 107 and 179 days. Samples were prepared and analyzed using secondary electron imaging at 1,3 and 7 days to assess the microstructure of the various geopolymers. At 179 days, a polished cross section of each mortar was prepared for backscatter electron imaging and EDS microanalysis was used to obtain quantitative compositional information on the phases present. In addition, Phase II also considered degree of reaction measurements at 1, 3,7 and 179 days as well as powder $\mathrm{X}$-ray diffraction at 1, 3 and 7 days. Adiabatic calorimetry was also performed on the mixtures containing glass and metakaolin to get a general look at the kinetics of reaction between various mixtures.

\subsubsection{Mixture design}

Mortars were prepared using the high- $\mathrm{Al}$ (HA) glass and 25\% and 50\% replacements of metakaolin or fly ash by mass. Replacement rates past $50 \%$ were not considered, as the purpose of this research was to explore glass-based geopolymer systems. $25 \%$ and $50 \%$ were chosen as replacement rates because they offered an acceptable range of $\mathrm{Si} / \mathrm{Al}$ and $\mathrm{Na} / \mathrm{Al}$ ratios as seen in Figure 4.21. Other research has explored binary systems of metakaolin coupled with another source material and this combination has often been found to yield geopolymers that perform better than those based on a single source material. The synergy between metakaolin and other source materials is a unique one and was explored as well. 
Based on the 28-day compressive strength results in Phase I and general trends from the literature regarding optimal synthesis parameters, the finer glass, HA600 was activated with $10 \mathrm{M} \mathrm{NaOH}$ and cured at $80^{\circ} \mathrm{C}$ for 24 hours. Five mixtures were designed as shown in Table 4.8. Mixtures were named according to the amounts of each source material used, where $75 \mathrm{HA} 25 \mathrm{MK}$ means $75 \%$ HA glass, $25 \%$ metakaolin by mass.

Table 4.7. Mixture ID for mortars in Phase II, with percentages given by mass.

\begin{tabular}{|c|c|c|c|}
\hline Mixture ID & HA-600 glass (HA) & Metakaolin (MK) & Fly ash (FA) \\
\hline $100 \mathrm{HA}$ & $100 \%$ & $0 \%$ & $0 \%$ \\
\hline $75 \mathrm{HA} 25 \mathrm{MK}$ & $75 \%$ & $25 \%$ & $0 \%$ \\
\hline $50 \mathrm{HA} 50 \mathrm{MK}$ & $50 \%$ & $50 \%$ & $0 \%$ \\
\hline $75 \mathrm{HA} 25 \mathrm{FA}$ & $75 \%$ & $0 \%$ & $25 \%$ \\
\hline 50HA50FA & $50 \%$ & $0 \%$ & $50 \%$ \\
\hline
\end{tabular}

\subsubsection{Stoichiometry}

Mortars were prepared using a baseline 3:1:0.5 ratio of sand to glass to activator solution by mass, respectively. Graded Ottawa sand was used as the fine aggregate. The relevant molar ratios of the unreacted bulk geopolymer are shown in Table 4.8. For all five mixtures, the molar ratios changed since the glass, metakaolin and fly ash all supplied varying amounts of $\mathrm{Si}, \mathrm{Al}, \mathrm{Na}$ and $\mathrm{Ca} .10 \mathrm{M} \mathrm{NaOH}$ was used as the activator in all mixtures. 
Table 4.8. Molar ratios of unreacted source materials and activator solution of Phase II mixtures.

\begin{tabular}{|c|c|c|c|c|}
\hline Mixture ID & $\mathbf{S i} / \mathbf{A l}$ & $\mathbf{N a} / \mathbf{A l}$ & $\mathbf{N a} / \mathbf{S i}$ & $\mathbf{C a} / \mathbf{S i}$ \\
\hline 100HA & 8.39 & 1.61 & 0.19 & 0.39 \\
\hline 75HA25MK & 4.99 & 0.97 & 0.19 & 0.30 \\
\hline 50HA50MK & 3.48 & 0.69 & 0.20 & 0.21 \\
\hline 75HA25FA & 6.56 & 1.53 & 0.23 & 0.39 \\
\hline 50HA50FA & 5.19 & 1.46 & 0.28 & 0.39 \\
\hline
\end{tabular}

Figure 4.21 shows the relationship between the $\mathrm{Si} / \mathrm{Al}$ and $\mathrm{Na} / \mathrm{Al}$ molar ratios of the bulk stoichiometry in the five mixtures considered in this phase. It should be noted the unreactive fraction of the fly ash was not calculated.

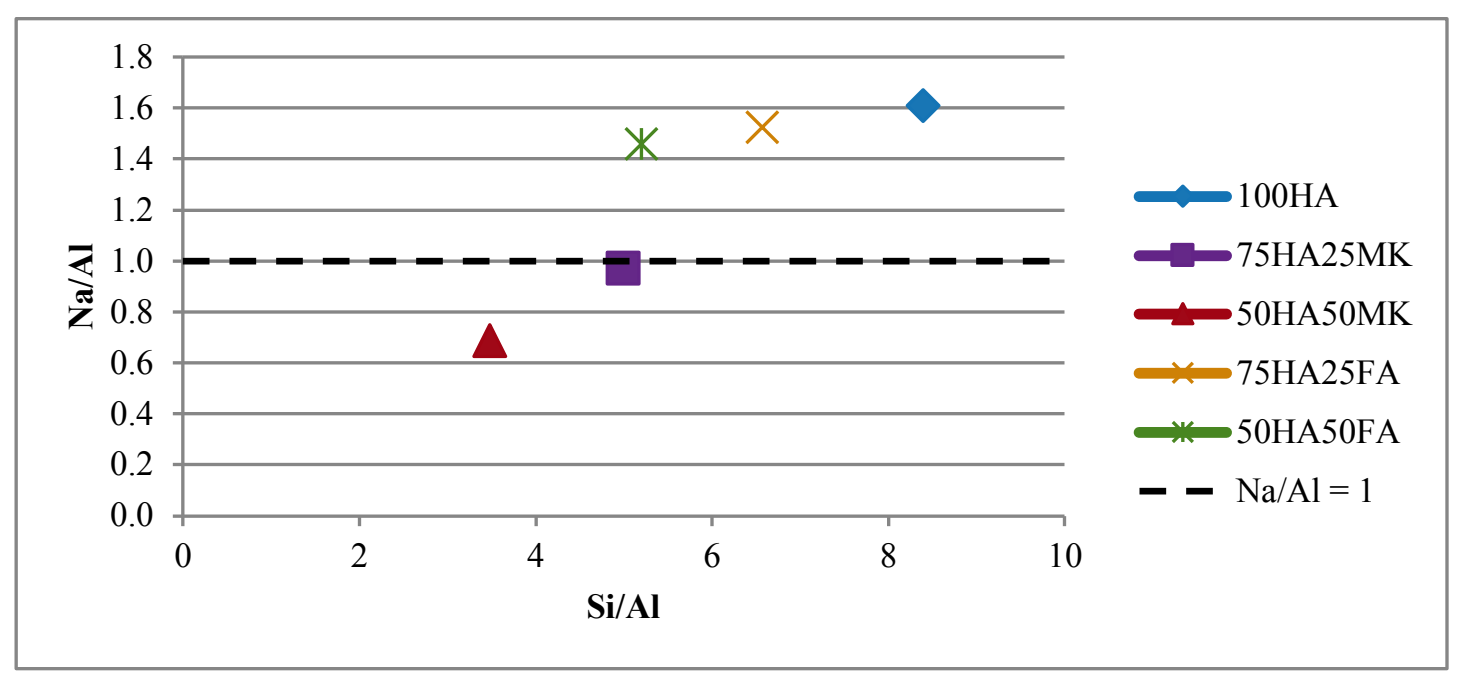

Figure 4.21. Si/Al vs Na/Al molar ratios for mixtures in Phase II. A dashed line at $\mathrm{Na} / \mathrm{Al}=1$ is shown since that is widely accepted as an optimum ratio for geopolymers.

\subsubsection{Fresh properties}

Varying the components of the mortars not only affected the molar ratios of the mixtures but also the water demand and color as well. Figure 4.22 shows the color difference 
between the five mortars, with more metakaolin leading to a more yellow/oranges color and more fly ash just turning the mortar browner.

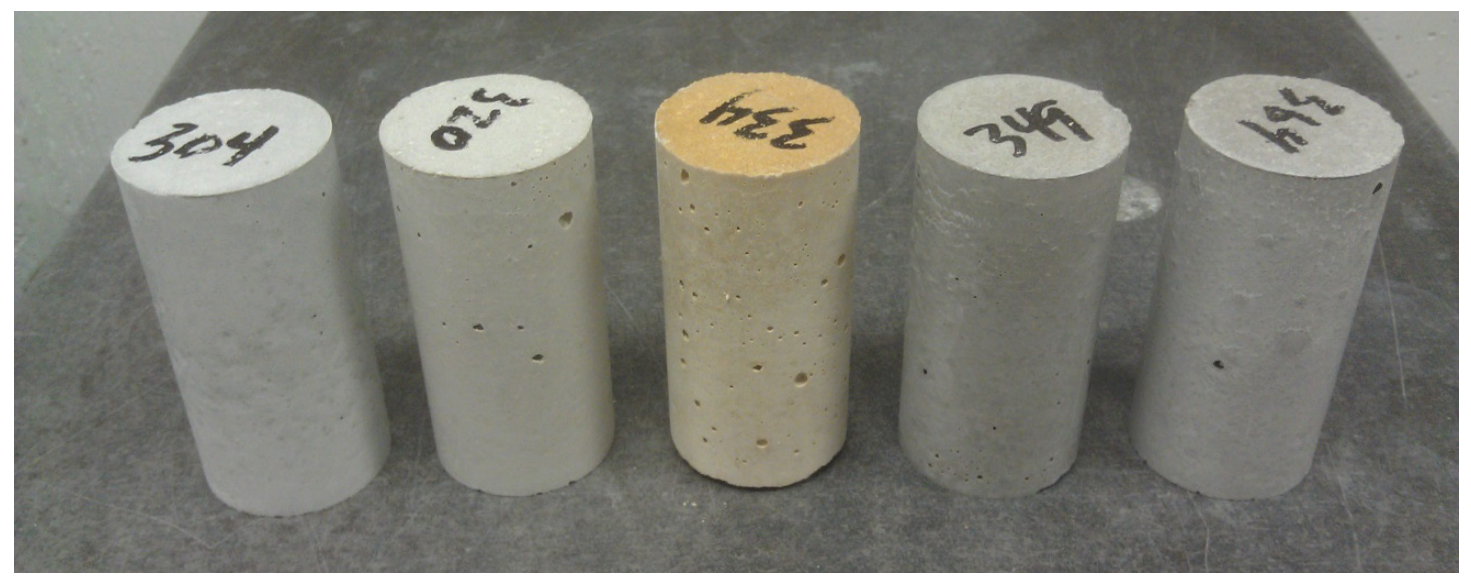

Figure 4.22. Phase II mixtures, from left to right: 100HA, 75HA25MK, 50HA50MK, 75HA25FA, and 50HA50FA.

The sheet-like structure of the metakaolin particles significantly increased the water demand when it replaced the glass. Alternately, the spherical particles of the fly ash drastically reduced the water demand when they replaced the more angular shaped glass particles. Water content was adjusted as needed to achieve an adequate workability and similar flow. Flow was found not to be a universal indication of workability, as some mixtures with lower flow still exhibited good workability after consolidation on the vibrating table. The presence of metakaolin also served to make the mixture sticky, whereas the presence of fly ash increased the fluidity making the mixture more liquid.

Fresh properties and water/solids ratio for each mortar are shown in Table 4.9. The two mixtures containing metakaolin had a higher temperature immediately after mixing than the rest of the mixtures after mixing, perhaps indicating a reaction beginning early. Also of note was the presence of a crackling sound during mixing and for several minutes after. 
Table 4.9. Fresh properties and water/solids ratio of the mixtures in Phase II. All reported values are based on the average of three measurements.

\begin{tabular}{|c|c|c|c|c|}
\hline Mixture ID & $\begin{array}{c}\text { Water/solids } \\
\text { ratio }\end{array}$ & $\begin{array}{c}\text { Percent Flow } \\
\mathbf{( \% )}\end{array}$ & $\begin{array}{c}\text { Temperature } \\
(\mathbf{}\end{array}$ & $\begin{array}{c}\text { Unit weight } \\
(\mathbf{g} / \mathbf{m L})\end{array}$ \\
\hline 100HA & 0.504 & $77 \%$ & 73.00 & 2.06 \\
\hline $75 \mathrm{HA} 25 \mathrm{MK}$ & 0.540 & $59 \%$ & 77.00 & 2.04 \\
\hline 50HA50MK & 0.617 & $56 \%$ & 77.00 & 2.02 \\
\hline 75HA25FA & 0.504 & $77 \%$ & 73.50 & 2.03 \\
\hline 50HA50FA & 0.464 & $63 \%$ & 73.50 & 2.04 \\
\hline
\end{tabular}

\subsubsection{Compressive strength}

\subsubsection{Early age strength through 7 days}

Compressive strength results through 7 days are shown in Figure 4.23. Several mixtures had very high compressive strengths at 1 day, with the $75 \mathrm{HA} 25 \mathrm{MK}$ mixture reaching more than 5000 psi at 24 hours. In nearly all cases, there was a slight decrease measured in compressive strength from 1 to 7 days. 


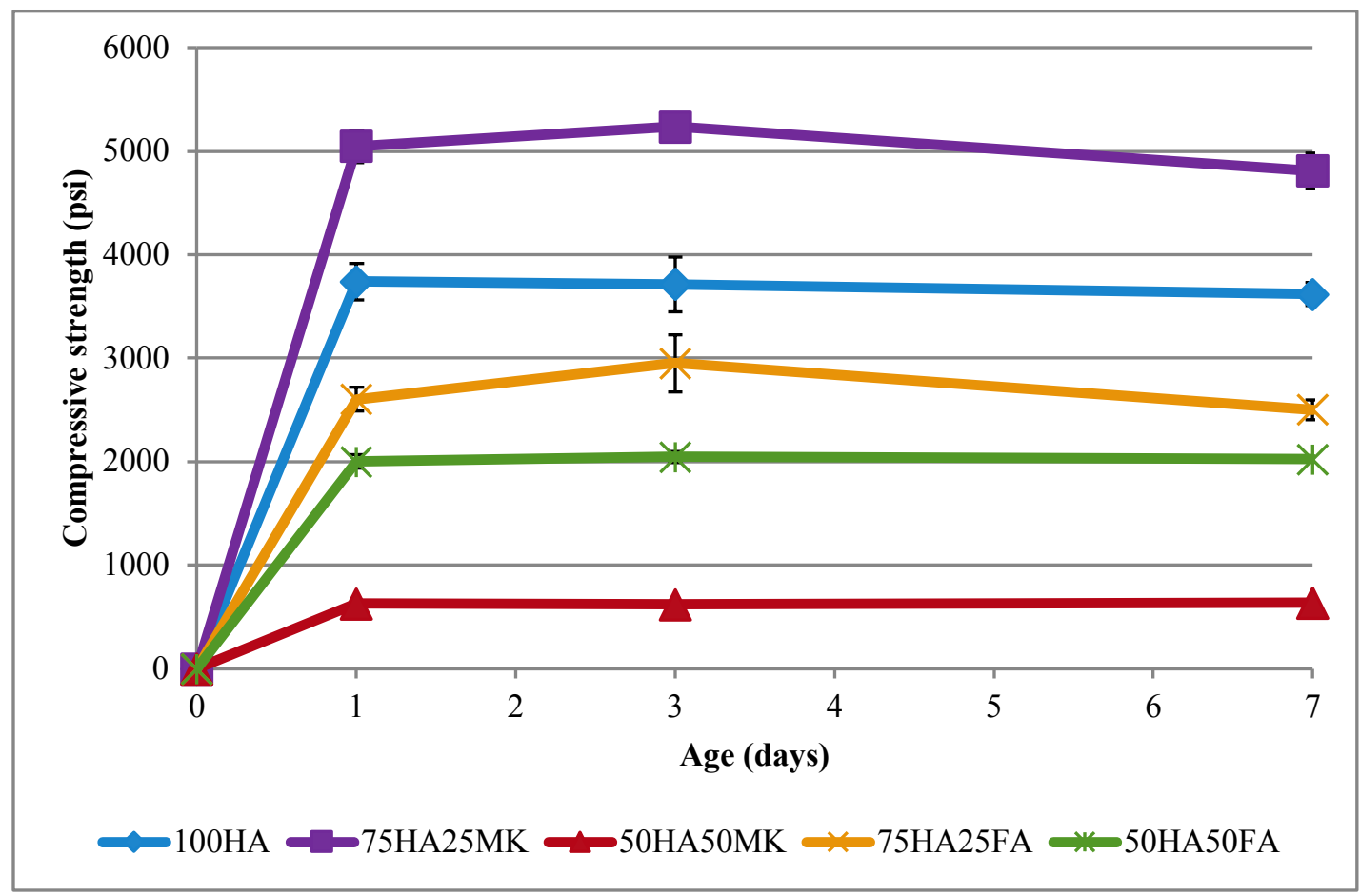

Figure 4.23. Compressive strength through 7 days for mixtures in Phase II. Each data point is the average of three cylinders. Error bars were calculated from the standard error, $\mathrm{SD} / \sqrt{ } \mathrm{n}$, where $\mathrm{SD}$ is standard deviation and $\mathrm{n}$ is the sample size.

The 100HA mixture reached past 3500 psi at 1 day and did not gain much more compressive strength through 7 days. In Phase I, a similar mixture was made using the HA600 glass, $10 \mathrm{M} \mathrm{NaOH}$ and $80^{\circ} \mathrm{C}$ curing temperature. This mixture achieved slightly less than 3000 psi at 7 days. The difference in strength between the two phases can be attributed to the difference in aggregate. Washed sand was used in Phase I and Ottawa sand in Phase II, and a higher water/solids ratio was used in Phase II (0.504 as compared to $0.445)$.

The 50HA50MK mixture did not perform well, not even achieving 1000 psi even after a week. The fly ash mortars behaved respectably, with the 75HA25FA mixture gaining more 
strength at 1 day than the 50HA50FA mixture. The 75HA25MK and 75HA25FA mixtures both exhibited a strength loss over 7 days.

\subsubsection{Later age strength through 179 days}

Unlike in Phase I, all the mortars kept the same rank in terms of maximum compressive strength from day 1 through 179 with no strength loss measured other than a minimal loss within the first week. Figure 4.24 shows the compressive strength of the mixtures through 179 days.

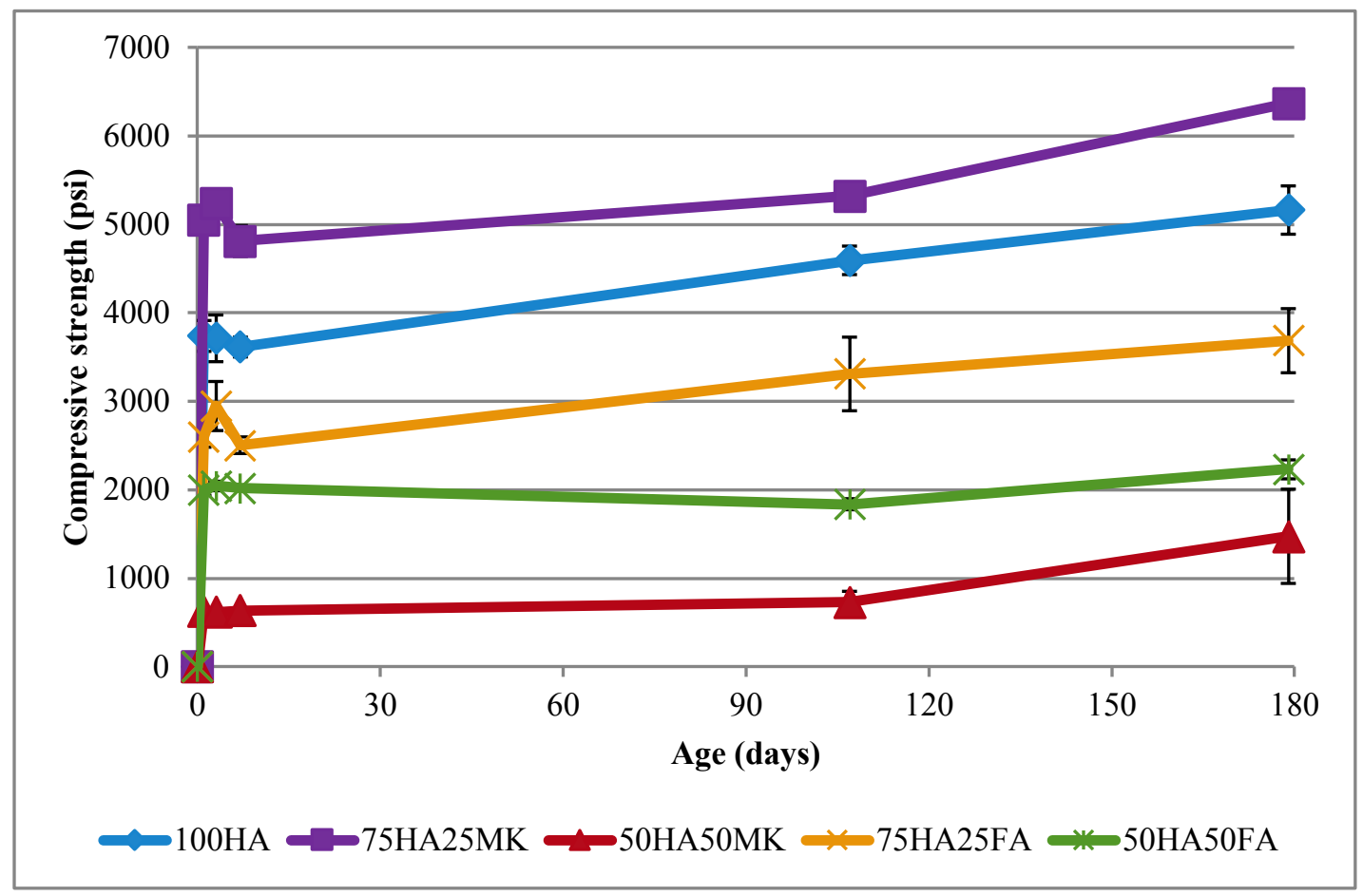

Figure 4.24. Compressive strength of Phase II mixtures through 179 days. Each data point is the average of three cylinders. The 107-day measurements were taken on a Baldwin compression-testing machine. Error bars were calculated from the standard error, $\mathrm{SD} / \sqrt{ } \mathrm{n}$, where $\mathrm{SD}$ is standard deviation and $\mathrm{n}$ is the sample size.

At 179 days, the $75 \mathrm{HA} 25 \mathrm{MK}$ mixture still had the highest compressive strength overall, followed by the 100HA mixture and then the mixtures containing fly ash. The mixture 
containing 50\% metakaolin still exhibited extremely low compressive strengths, crumbling apart easily upon fracture. This could be due to a higher water/solids ratio, where the extra water left behind a low-density microstructure upon drying and hardening.

\subsubsection{Microstructural analysis}

Electron microscopy on both fracture surfaces and polished cross sections helped illustrate the differences between the microstructures of the five mortars and revealed clues related to mechanical performance and reaction mechanisms.

\subsubsection{Fracture surfaces at 1, 3 and 7 days}

Microstructural analysis by way of secondary electron imaging on carbon coated fracture surfaces was performed. Figure 4.25 shows the bulk fracture surface of the five mixtures at 1, 3 and 7 days for the purpose of comparison. 

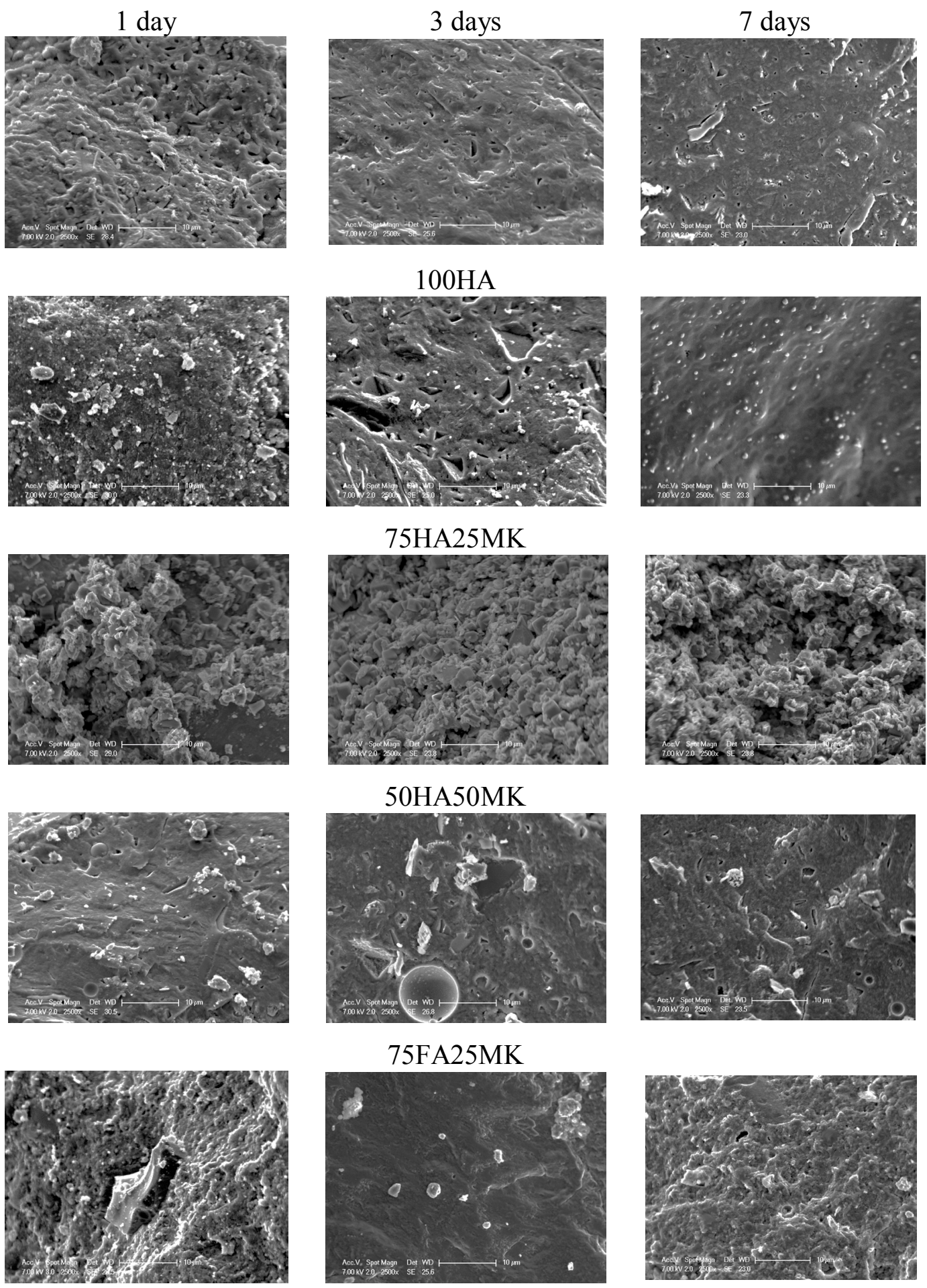

50HA50FA

Figure 4.25. Secondary electron imaging of Phase II fracture surfaces at 1 day (left), 3 days (middle) and 7 days (right). 
The microstructure of the 100HA and 75HA25MK mixtures, which yielded the highest compressive strengths (see Figure 4.24), appeared continuous and homogenous, with angular voids most likely remnant of unreacted glass particles that were pulled out during sample preparation. In comparing the micrographs from day 1 through 7 , it appears the matrix may become slightly denser over time although there is no apparent strength gain during this time.

The microstructure of the 50HA50MK mixture appeared to be composed of aggregated pieces of reaction product intermingled with unreacted glass and metakaolin and zeolites rather than a monolithic structure as was found in the other mixtures. The aggregated microstructure was similar to that found in low $\mathrm{Si} / \mathrm{Al}$ systems $(\mathrm{Si} / \mathrm{Al}=1.15,1.4)$ in other research investigating the $\mathrm{Si} / \mathrm{Al}$ ratio of metakaolin geopolymers (Duxson et al. 2005). It is important to note that many of the other microstructural studies considering composition often include sodium silicate in the activator solution, which is different from this situation where network formers available for polycondensation must first be dissolved.

The microstructure of the mixtures containing fly ash appeared continuous for the most part, with partially or unreacted fly ash and glass particles present. Voids similar to those found in the 100HA and 75HA25MK mixtures were also found, most likely remnant of particles lost during sample preparation or compressive strength testing. Despite the continuity and apparent density of the microstructure, the lower compressive strengths developed through one week speak to the importance of composition with regard to mechanical performance. This is addressed in later sections. 


\subsection{Unreacted particles}

Upon closer examination, all the mortars revealed the presence of unreacted source material particles embedded within the bulk matrix of the geopolymer. This does not coincide with data from Cyr et al., who reported 100\% dissolution of the glass after 56 days with no unreacted particles visible in the microstructure. It is important to note that prolonged curing was employed in that research, which would have most likely led to a further extent of dissolution. However, even in ordinary portland cement concrete, unreacted cement particles are quite common even after many years of curing.

From fracture surface analysis by secondary electron imaging, examples of platy unreacted metakaolin particles and partially reacted spherical fly ash particles are shown in Figure 4.26. Examples of unreacted glass particles can be seen in Figure 4.6. 

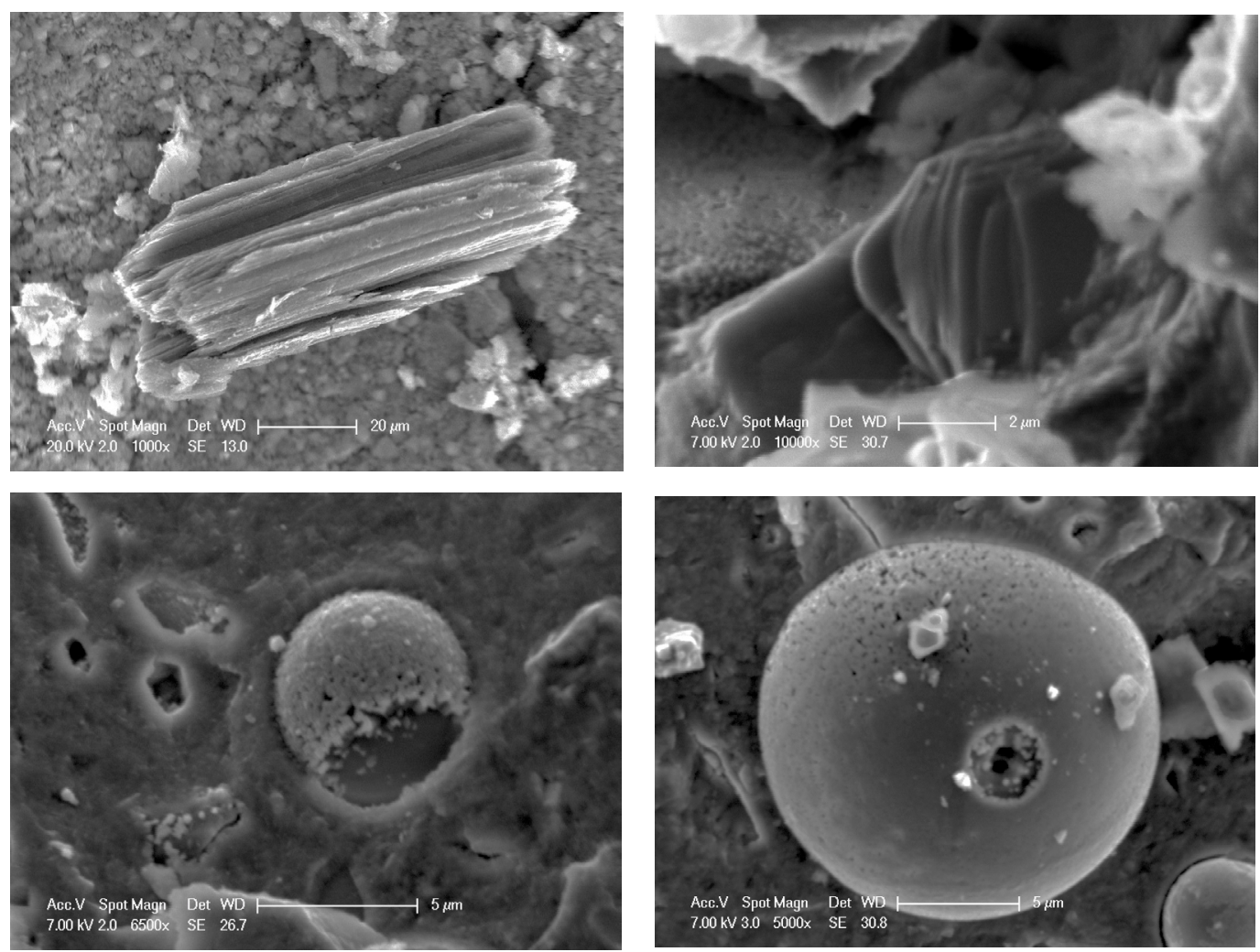

Figure 4.26. Unreacted metakaolin particles (top) and partially reacted fly ash particles (bottom) as shown in secondary electron imaging.

\subsection{Zeolites}

Secondary electron imaging on fracture surfaces also revealed the presence of morphologically crystalline phases. Geopolymers are thought by many to be the amorphous analogues to zeolites (Duxson et al. 2005), where both can be synthesized in similar conditions, with zeolites requiring higher temperatures, more time and a high liquid/solid environment.

Crystalline phases were found in all of the mixtures in Phase II, particularly in the 50HA50MK mortar. Examples of the large quantity of cubic structures found in the 50HA50MK mixture are shown in Figure 4.27. Similar structures in the literature have 
been identified as Zeolite A have been found in other similar mixtures (Palomo and Glasser 1992; Fernández-Jiménez et al. 2007). The large quantity of crystalline phases in this mixture could be due to the higher water/solids ratio, where the excess water available may have allowed for more organization of the network forming species to occur which led to crystalline phase formation rather than amorphous geopolymer formation.
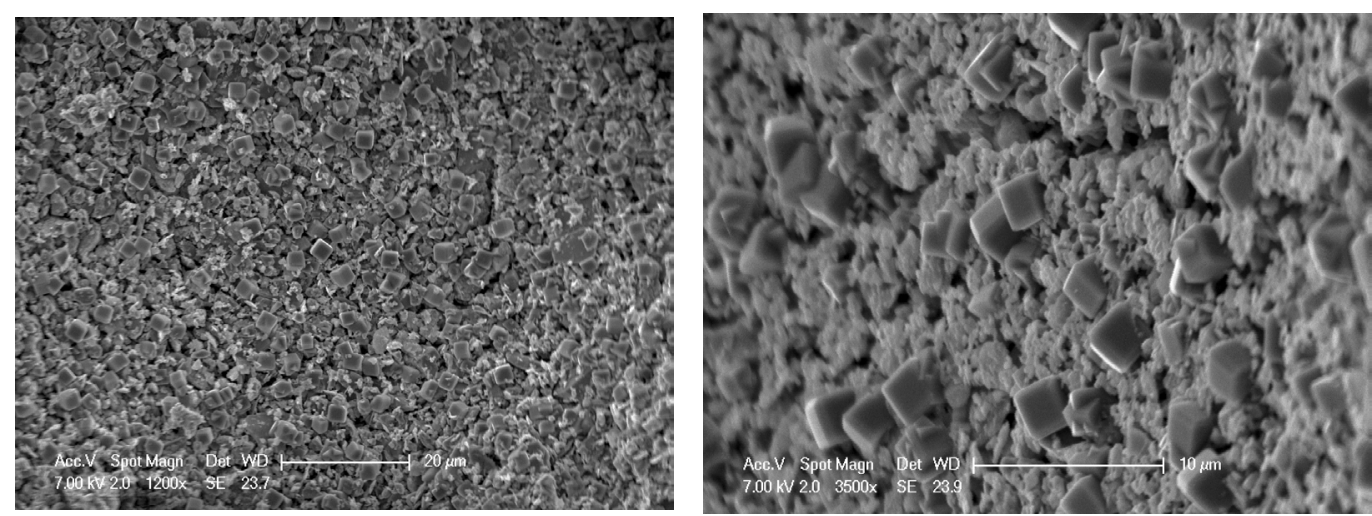

Figure 4.27. Examples of the widespread cubic structures found in the 50HA50MK mixture at 3 days.

In the other mixtures, most of the crystalline phases were found within air voids or holes left behind from unreacted particles as shown in Figure 4.28. It is unknown if these phases exist within the matrix or if they just form on the surface in air or in voids. 

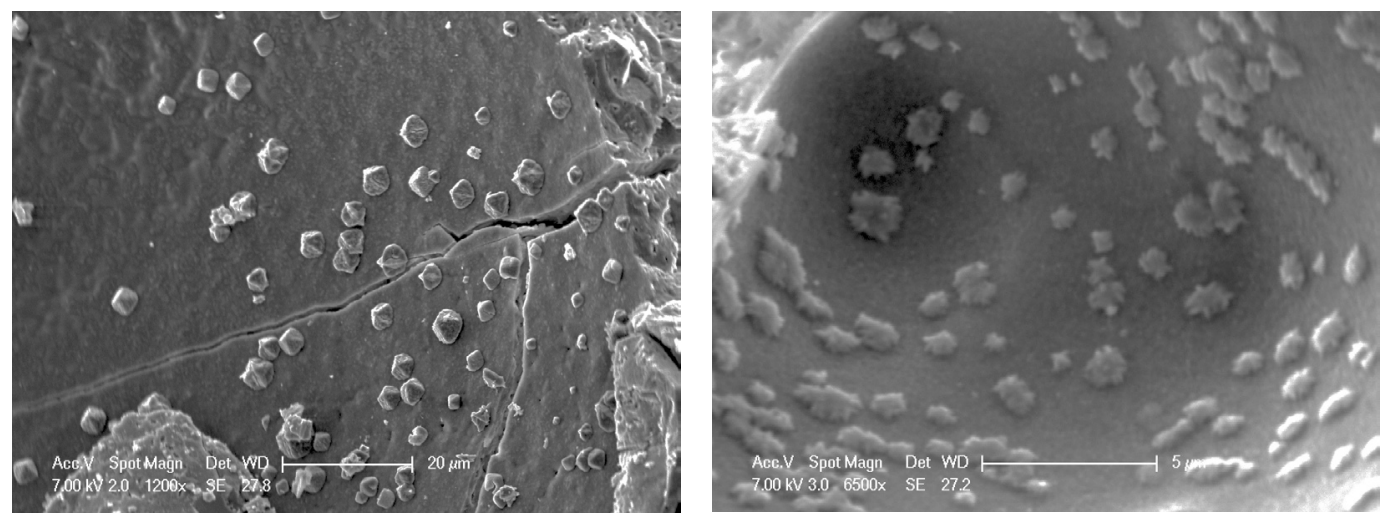

Figure 4.28. Morphologically crystalline phases found growing on the surface of voids in 100HA (left) and 50HA50FA (right) mixtures.

Figure 4.29 shows examples of the variety of crystalline structures found in each of the mortars. It is clear that different types of phases have formed in each mortar based on the varying crystal form and shape. 

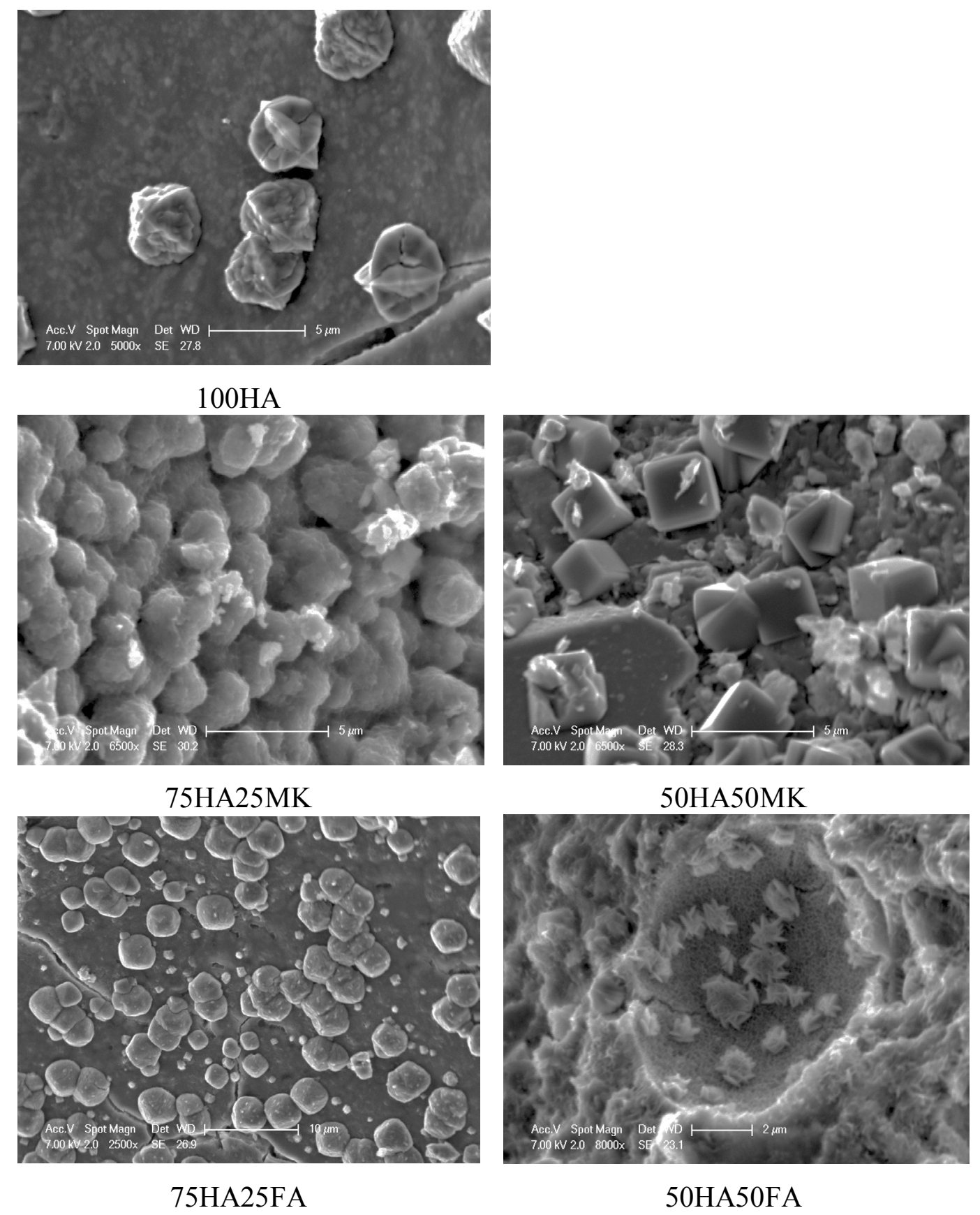

Figure 4.29. Secondary electron images of crystalline phases found in each of the mortars in Phase II.

\subsubsection{Polished cross section analysis}

Polished cross sections of each mortar were analyzed using backscatter electron imaging on carbon-coated sections at 179 days. This analysis further elucidated the differences in 
the microstructure of the mortars, as shown in Figure 4.30, where a micrograph of the bulk matrix in each mortar is shown for comparison.
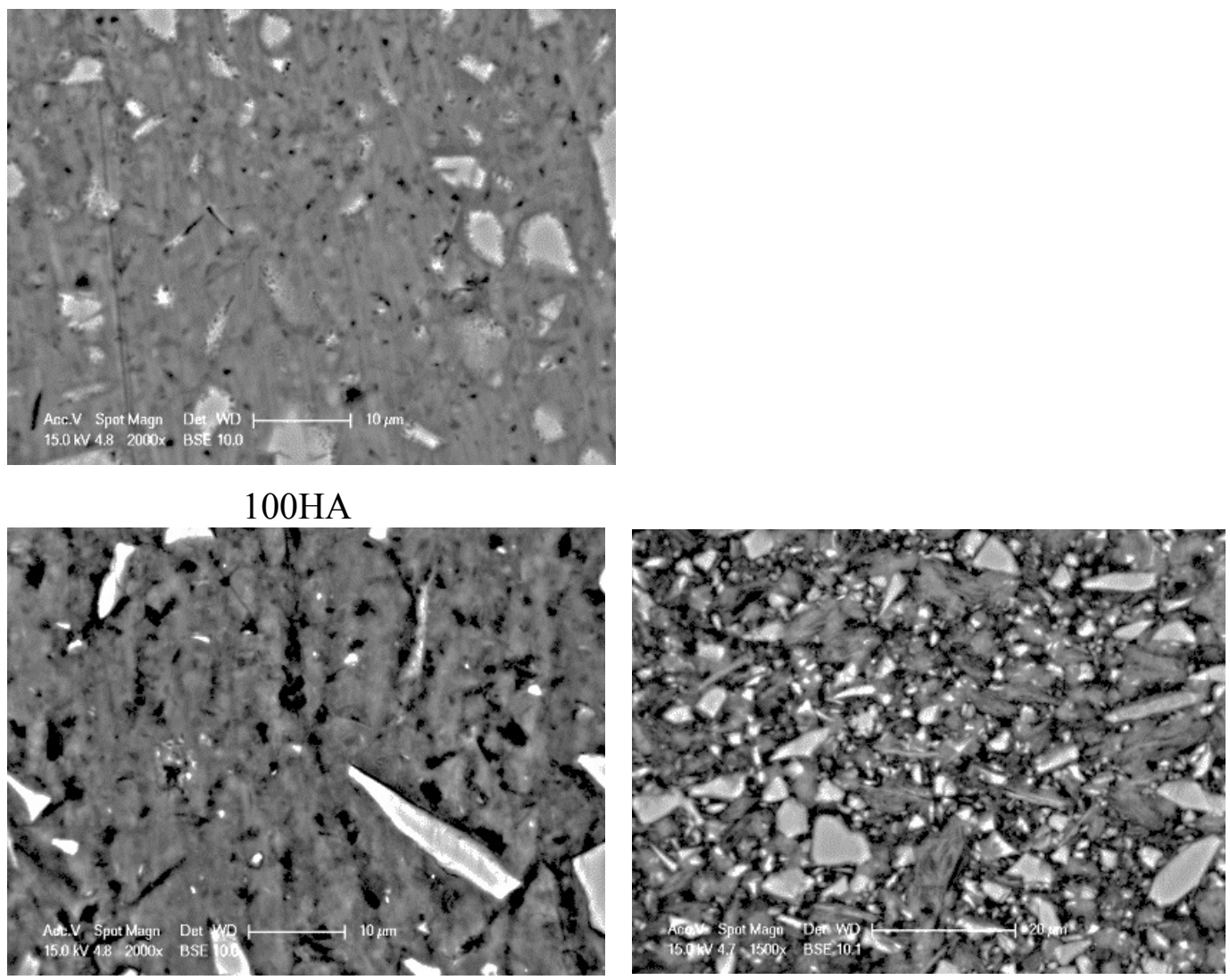

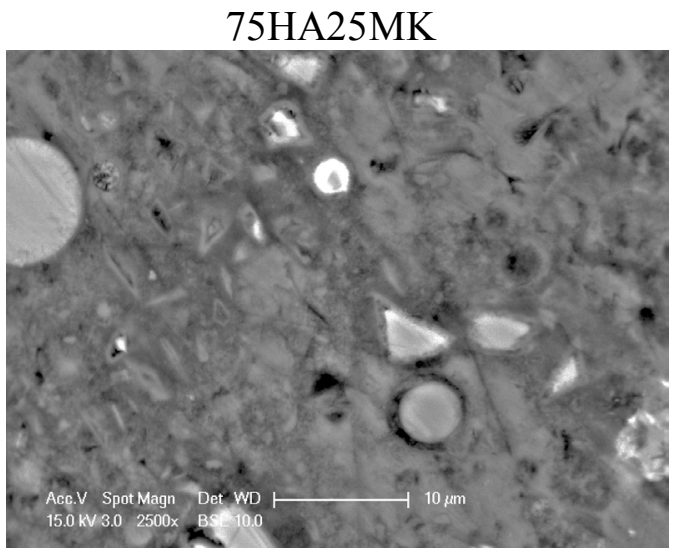

75HA25FA

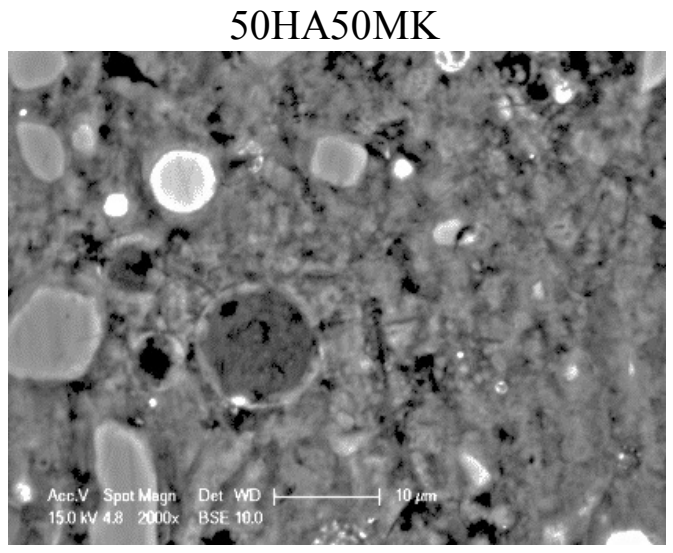

50HA50FA

Figure 4.30. Backscatter electron imaging of Phase II mortars at 179 days. 
The 100HA mortar showed a continuous and uniform geopolymer microstructure embedded with small, unreacted glass particles. Most of the glass particles had a very thin reaction rim around them, as shown in Figure 4.31; this reaction rim was not found in the other mixtures. However, it was found in the mixtures in Phase I made with the fine glass, HA600.
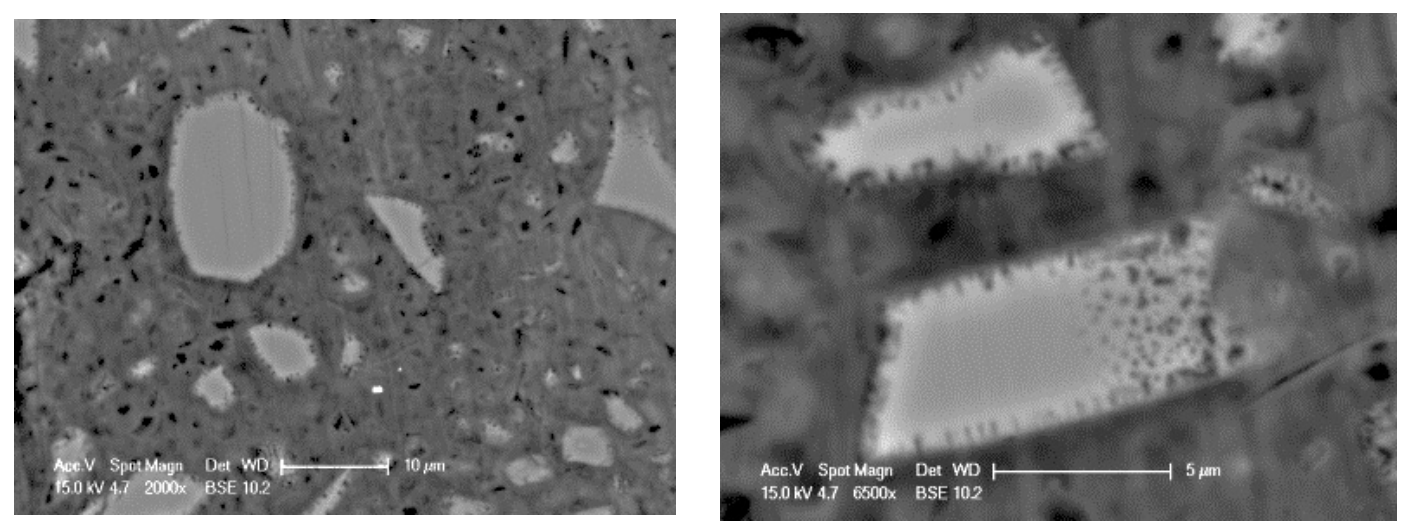

Figure 4.31. Backscatter electron images of the reaction rim around glass particles in the 100HA matrix.

The 100HA microstructure was the most continuous of all of the mortars, interrupted only by embedded glass particles in some areas. Other areas showed the presence of a higher intensity phase interspersed with the darker bulk matrix. The differences between these two regions of microstructure are shown in Figure 4.32. 

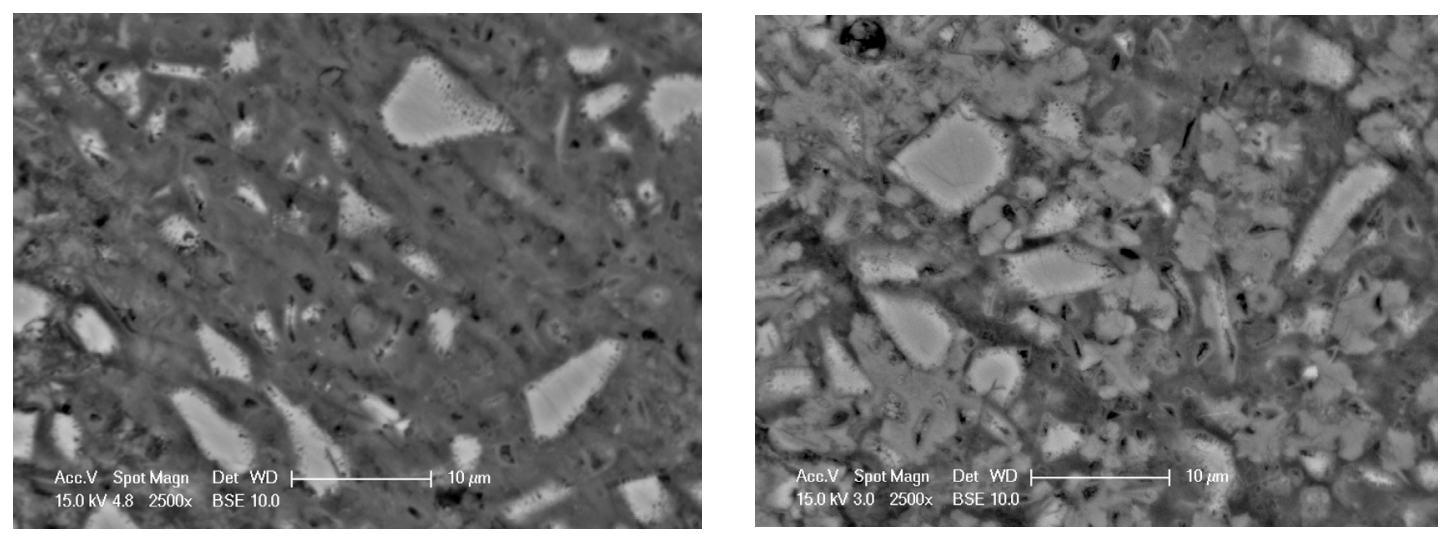

Figure 4.32. Micrographs of 100HA showing areas of uniform homogeneity interrupted only by embedded glass particles (left) and areas exhibiting multiple phases (right) as shown by the varying brightness levels under backscatter electron imaging.

The 75HA25MK mixture yielded the highest compressive strength, yet appeared less continuous in both secondary and backscatter analysis than the 100HA and 75HA25FA mixtures. Embedded glass particles did not have the reaction rim around them, characteristic of a fine glass mortar, nor were any unreacted metakaolin particles identified within the matrix. Again, several phases seemed to be visible within the matrix, as shown in Figure 4.33. Once again, the fact a less continuous microstructure resulted in a higher compressive strength, speaks to the importance of composition. The $75 \mathrm{HA} 25 \mathrm{MK}$ mixture did possess the bulk Na/Al molar ratio closest to unity, which many consider to be the optimal value for $\mathrm{Na} / \mathrm{Al}$. 

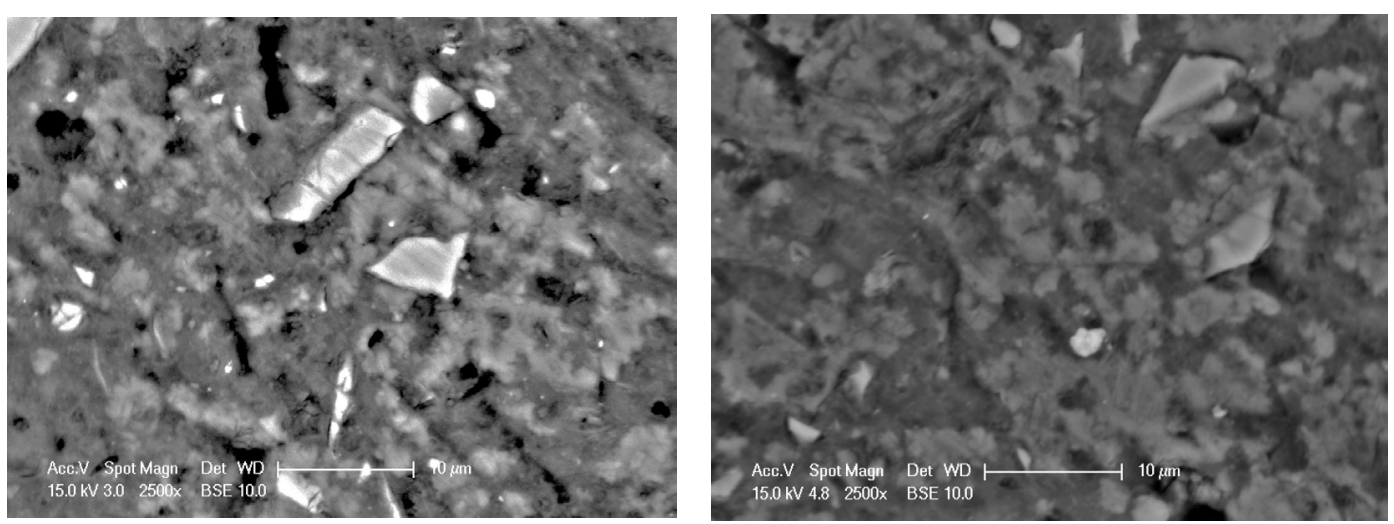

Figure 4.33. Micrographs of 75HA25MK showing areas exhibiting multiple phases as shown by the varying brightness levels under backscatter electron imaging. Unreacted glass particles did not have a reaction rim around them as in the HA100 mixture.

The 75HA25FA mixture also appeared to consist of multiple phases, as shown in Figure 4.34. Despite the fairly continuous microstructure, the compressive strength of this mixture was lower than the 100HA and 75HA25MK mixtures. Fly ash and unreacted glass particles appeared well embedded in the mixture with a very narrow rim of reaction product visible around the glass particle, remnant of the coarse glass mixtures of Phase I.
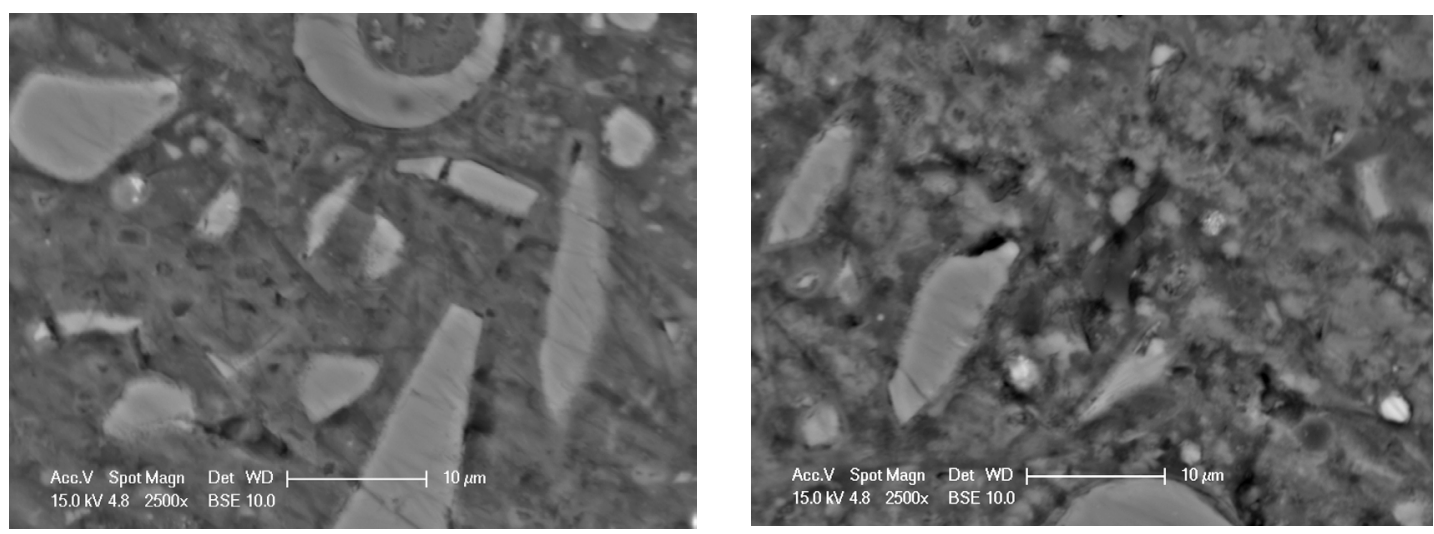

Figure 4.34. Micrographs of 75HA25FA showing areas exhibiting multiple phases as shown by the varying brightness levels under backscatter electron imaging.

Both the 50HA50FA and 50HA50MK mixtures indicated a less dense microstructure, with the 50HA50MK mixture being very disjointed with a great quantity of unreacted glass and 
metakaolin particles as illustrated by the scattered black areas where no product was present, only epoxy. No real geopolymer was visible though there must have been some reaction occurring to hold the mortar together. Unreacted metakaolin and glass particles were identified using EDS microanalysis.

The 50HA50FA microstructure showed many more unreacted fly ash particles than the 75HA25FA mixture, which was expected because it contained more fly ash. Similar to the 100HA and 75HA25Mk mixtures, the 75HA25FA mixture also had areas where multiple phases or densities appeared to be present, as shown in Figure 4.35.
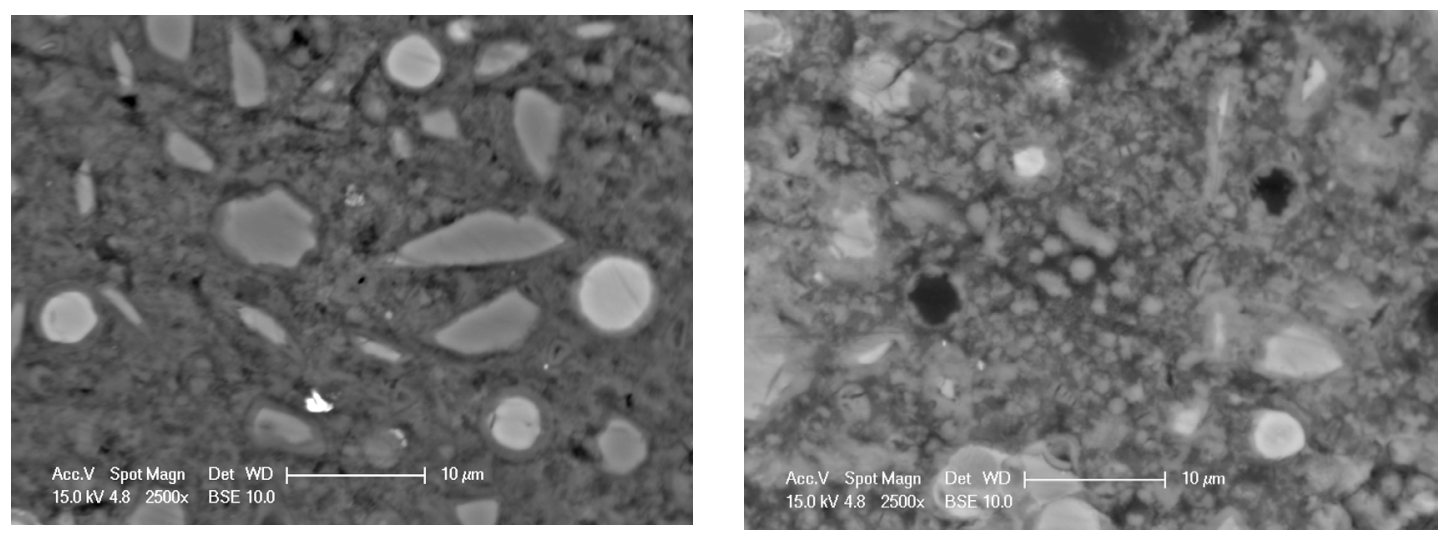

Figure 4.35. Micrographs of 50HA50FA showing areas exhibiting multiple phases as shown by the varying brightness levels under backscatter electron imaging.

Figure 4.36 shows backscatter electron images of unreacted or partially reacted fly ash particles found in the 50G50FA mixture. Fly ash often contains crystalline or unreactive particles, many of them rich in iron; those particles rich in iron often show up as very bright spots on a backscatter electron image. 

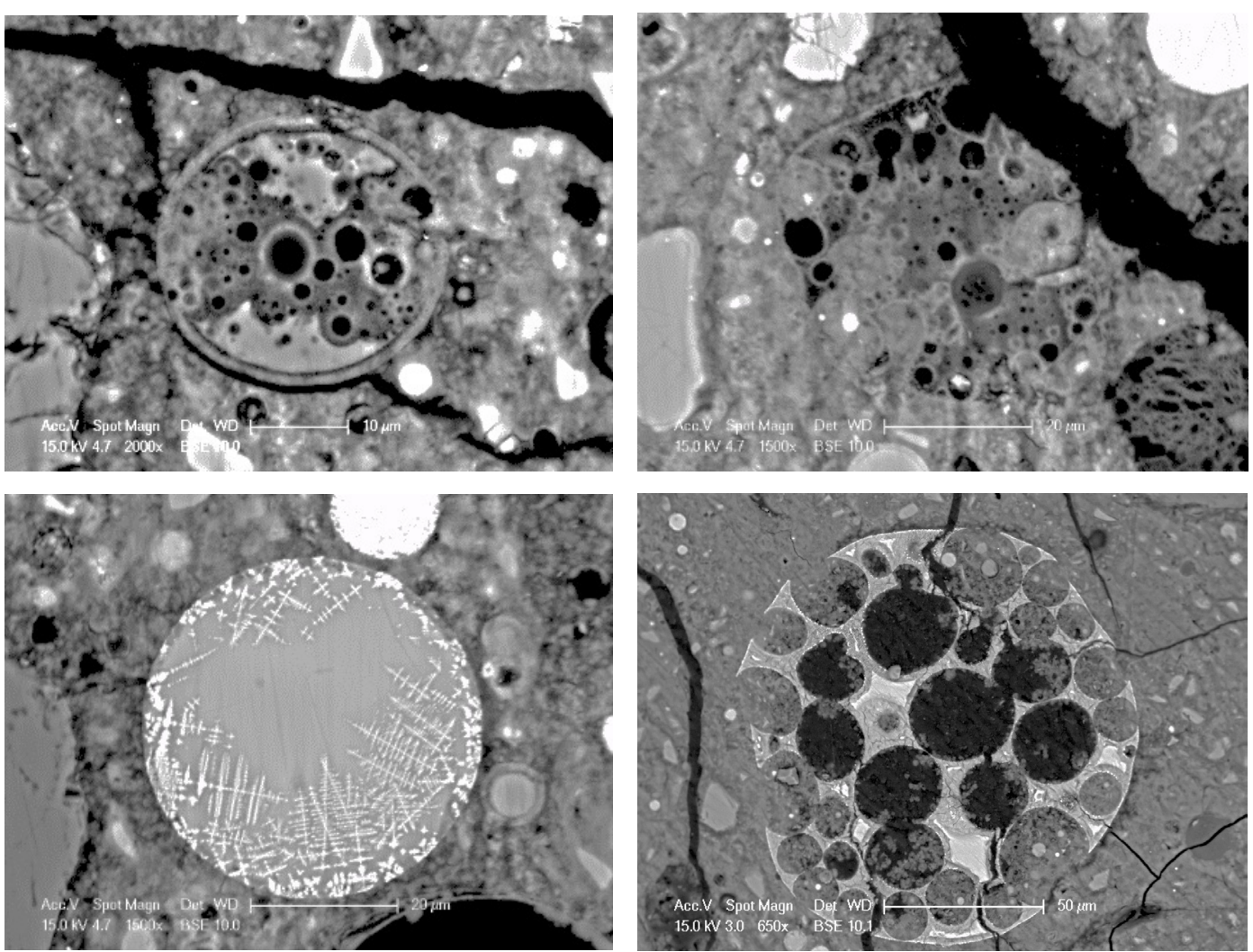

Figure 4.36. Unreacted and partially reacted fly ash particles in mortars containing fly ash.

Unlike in the fracture surface analysis, zeolites were very difficult to identify in polished cross section analysis. This could be because in most cases, they form on the interior of voids or they were lost during the polishing required to prepare the sample.

\subsubsection{Phase composition}

As shown in Figure 4.37, the microstructure of several of the mortars varied considerably from local area to area. In general, the brighter areas had a higher calcium content than the darker areas. This is consistent since calcium is a heavier element than silicon and therefore shows up brighter under backscatter electron imaging due to its higher intensity. 

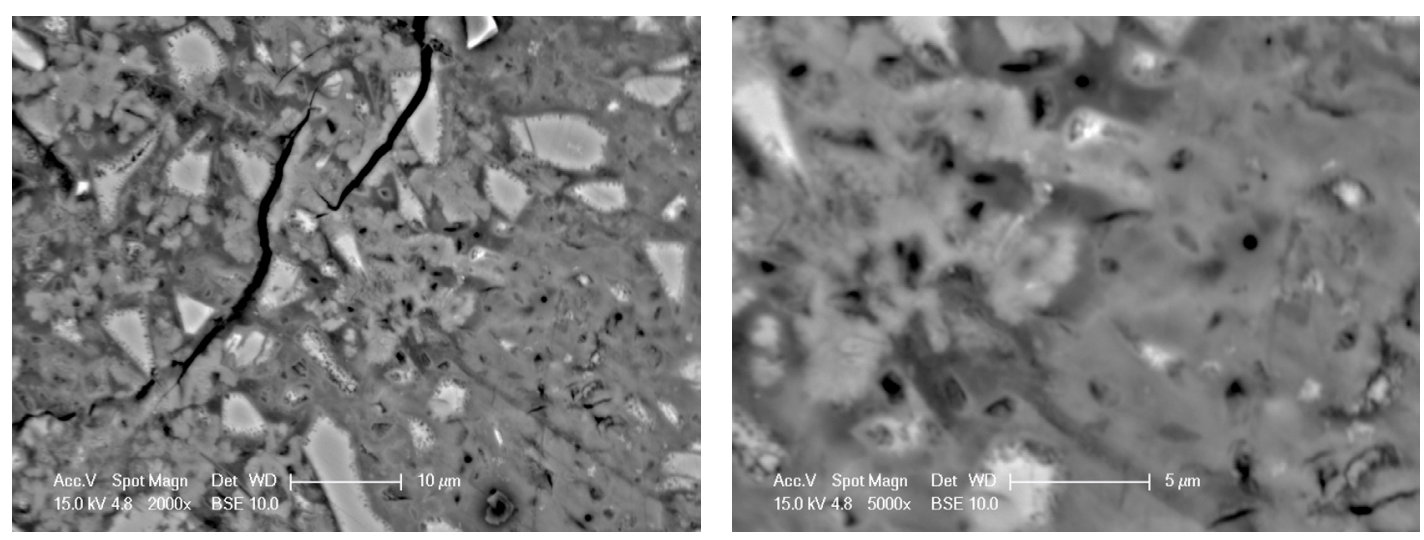

Figure 4.37. 100HA showing multiple phases present. The micrograph on the right is a blow up of a center section of the micrograph on the left.

Using backscatter electron imaging to identify varying elemental intensities and phases present within the microstructure, the elemental composition of the geopolymer reaction products were identified by EDS microanalysis. To understand the general relationship between phase composition and compressive strength, microanalysis on the most prevalent bulk phase present was performed.

Table 4.10 shows the mixtures listed in order of maximum average compressive strength at 179 days and the resulting average molar ratios in the geopolymer product measured through EDS microanalysis. A minimum of six spots were analyzed on each mixture; statistics on the EDS analysis of each mixture can be found in Appendix B. There was inadequate geopolymer product visible in the 50HA50MK mixture to analyze. 
Table 4.10. Average measured bulk molar ratios ordered in terms of maximum average compressive strength at 179 days.

\begin{tabular}{|c|c|c|c|c|c|c|}
\hline Mixture ID & Rank & $\begin{array}{c}\text { Compressive } \\
\text { strength (psi) }\end{array}$ & $\mathbf{S i} / \mathbf{A l}$ & $\mathbf{N a} / \mathbf{A l}$ & $\mathbf{N a} / \mathbf{S i}$ & $\mathbf{C a} / \mathbf{S i}$ \\
\hline $75 \mathrm{HA} 25 \mathrm{MK}$ & $1^{\text {st }}$ & 6367 & 3.87 & 0.83 & 0.24 & 0.44 \\
\hline $100 \mathrm{HA}$ & $2^{\text {nd }}$ & 5163 & 7.75 & 1.03 & 0.23 & 0.51 \\
\hline $75 \mathrm{HA} 25 \mathrm{FA}$ & $3^{\text {rd }}$ & 3688 & 7.11 & 1.54 & 0.32 & 0.61 \\
\hline $50 \mathrm{HA} 50 \mathrm{HA}$ & $4^{\text {th }}$ & 2234 & 5.32 & 1.91 & 0.64 & 0.66 \\
\hline $50 \mathrm{HA} 50 \mathrm{MK}$ & $5^{\text {th }}$ & 1473 & - & - & - & - \\
\hline
\end{tabular}

The average $\mathrm{Si} / \mathrm{Al}, \mathrm{Na} / \mathrm{Al}, \mathrm{Na} / \mathrm{Si}$ and $\mathrm{Ca} / \mathrm{Si}$ molar ratios of each mixture are shown graphed against compressive strength at 179 days in Figure 4.38. Several trends can be seen between compressive strength and molar ratios as measured by EDS.

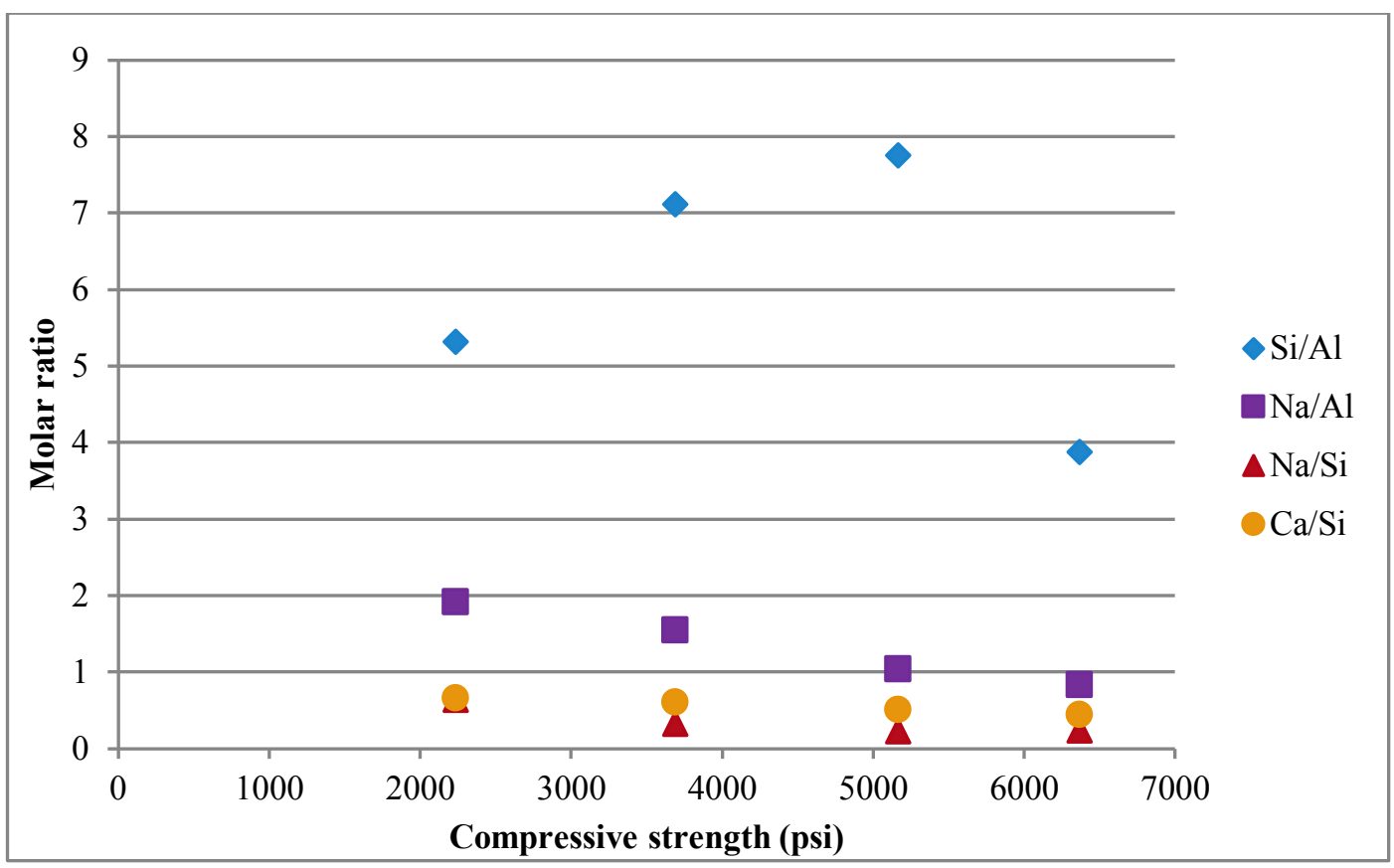

Figure 4.38. Molar ratios of Phase II as a function of compressive strength.

The $\mathrm{Si} / \mathrm{Al}$ and $\mathrm{Na} / \mathrm{Al}$ molar ratios are graphed in Figure 4.39 for clarity. There appears to be a trend in $\mathrm{Si} / \mathrm{Al}$ versus compressive strength up to a certain point. The $\mathrm{Na} / \mathrm{Al}$ ratio is related to the compressive strength with the lower $\mathrm{Na} / \mathrm{Al}$ ratio having the higher the 275 
compressive strength. However, once the $\mathrm{Na} / \mathrm{Al}$ ratio dropped below 1, the trend of $\mathrm{Si} / \mathrm{Al}$ and compressive strength ended. Rowles et al. has reported that compressive strength depends both on the $\mathrm{Si} / \mathrm{Al}$ and $\mathrm{Na} / \mathrm{Al}$ ratio (Rowles and $\mathrm{O}^{\prime}$ Connor 2003) and it has been well documented within the literature, the optimum $\mathrm{Na} / \mathrm{Al}$ ratio for geopolymers is 1 and the $\mathrm{Si} / \mathrm{Al}$ ratio is more arbitrary. It is also well known there are innumerable variables that can affect compressive strength in a mortar, including both chemical and physical. It is believed this anomaly within the $\mathrm{Si} / \mathrm{Al}$ trend is simply due to the interaction between the various other variables at play.

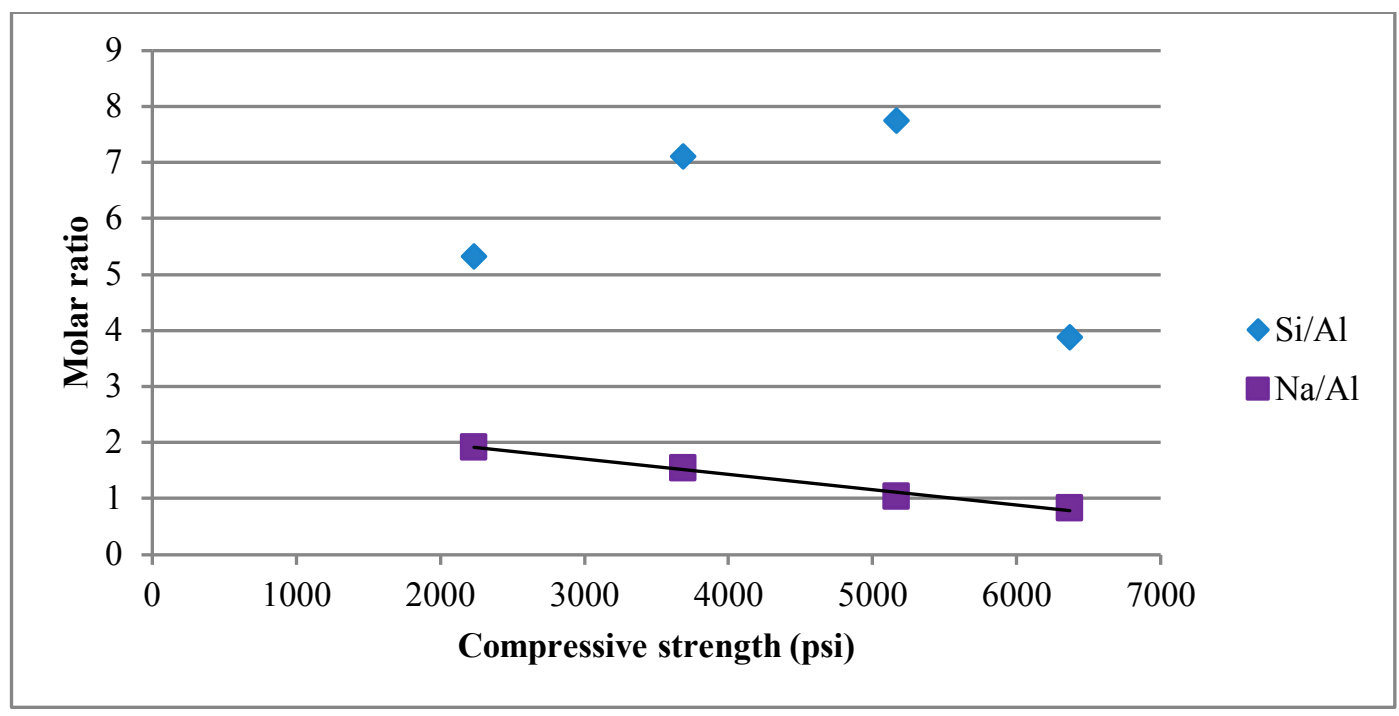

Figure 4.39. $\mathrm{Si} / \mathrm{Al}$ and $\mathrm{Na} / \mathrm{Al}$ ratios of the mixtures in Phase II versus compressive strength.

$\mathrm{The} \mathrm{Na} / \mathrm{Si}$ and $\mathrm{Ca} / \mathrm{Si}$ molar ratios are graphed alone in Figure 4.40 for better viewing. The $\mathrm{Na} / \mathrm{Si}$ and $\mathrm{Ca} / \mathrm{Si}$ ratios both decreased as compressive strength increased. 


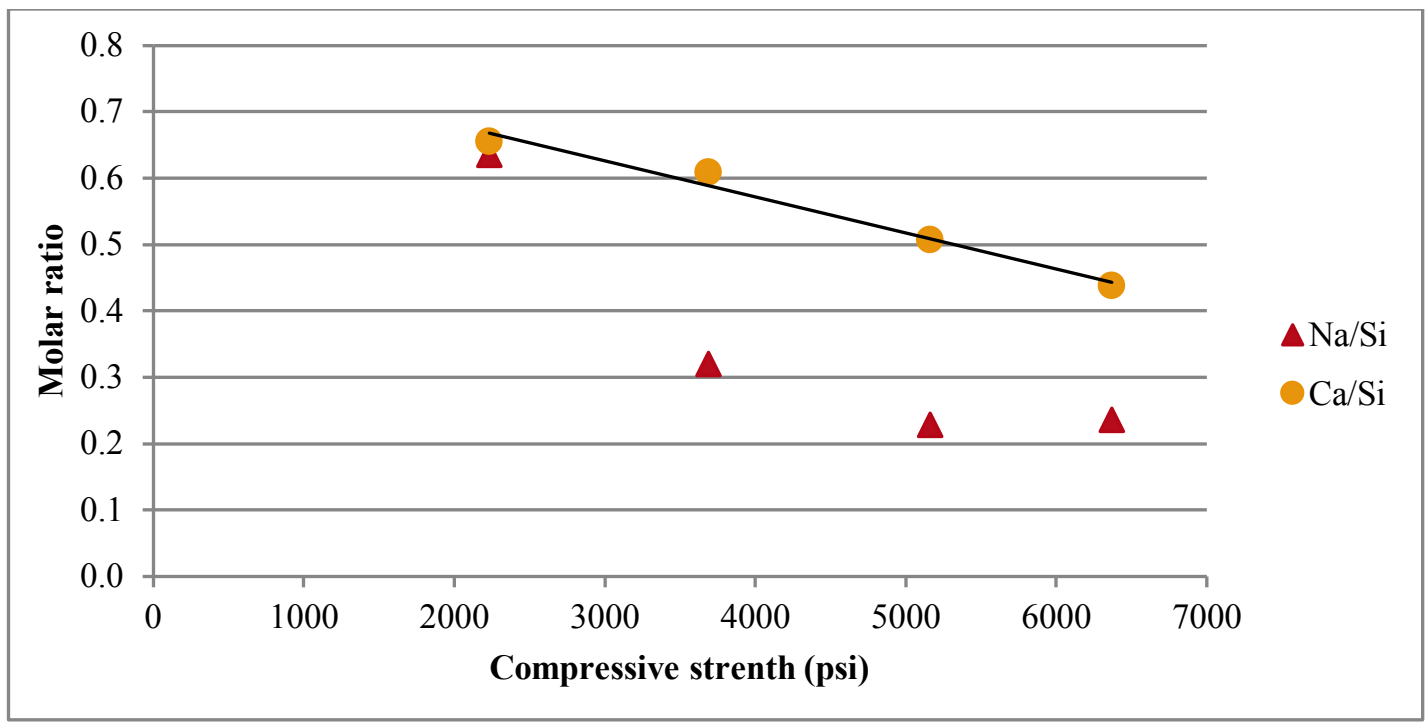

Figure 4.40. $\mathrm{Na} / \mathrm{Si}$ and $\mathrm{Ca} / \mathrm{Si}$ ratios of the mixtures in Phase II versus compressive strength.

The calculated bulk and actual measured molar ratios for all of the mixtures were quite similar as shown in the radar graphs in Figure 4.41 and Figure 4.42. 

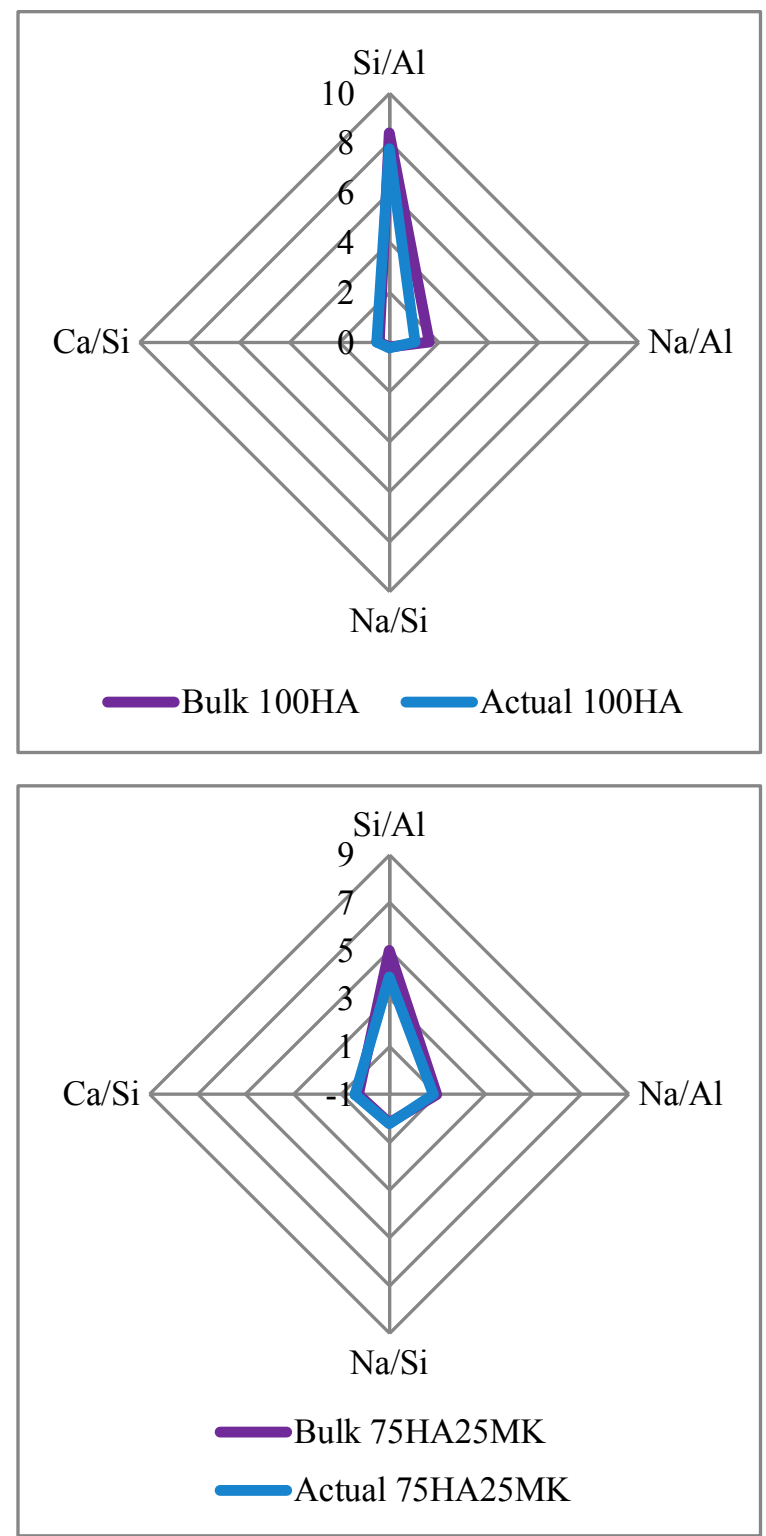

Figure 4.41. Bulk vs actual molar ratios for the 100HA mixture (top) and 75HA25MK mixture (bottom). 

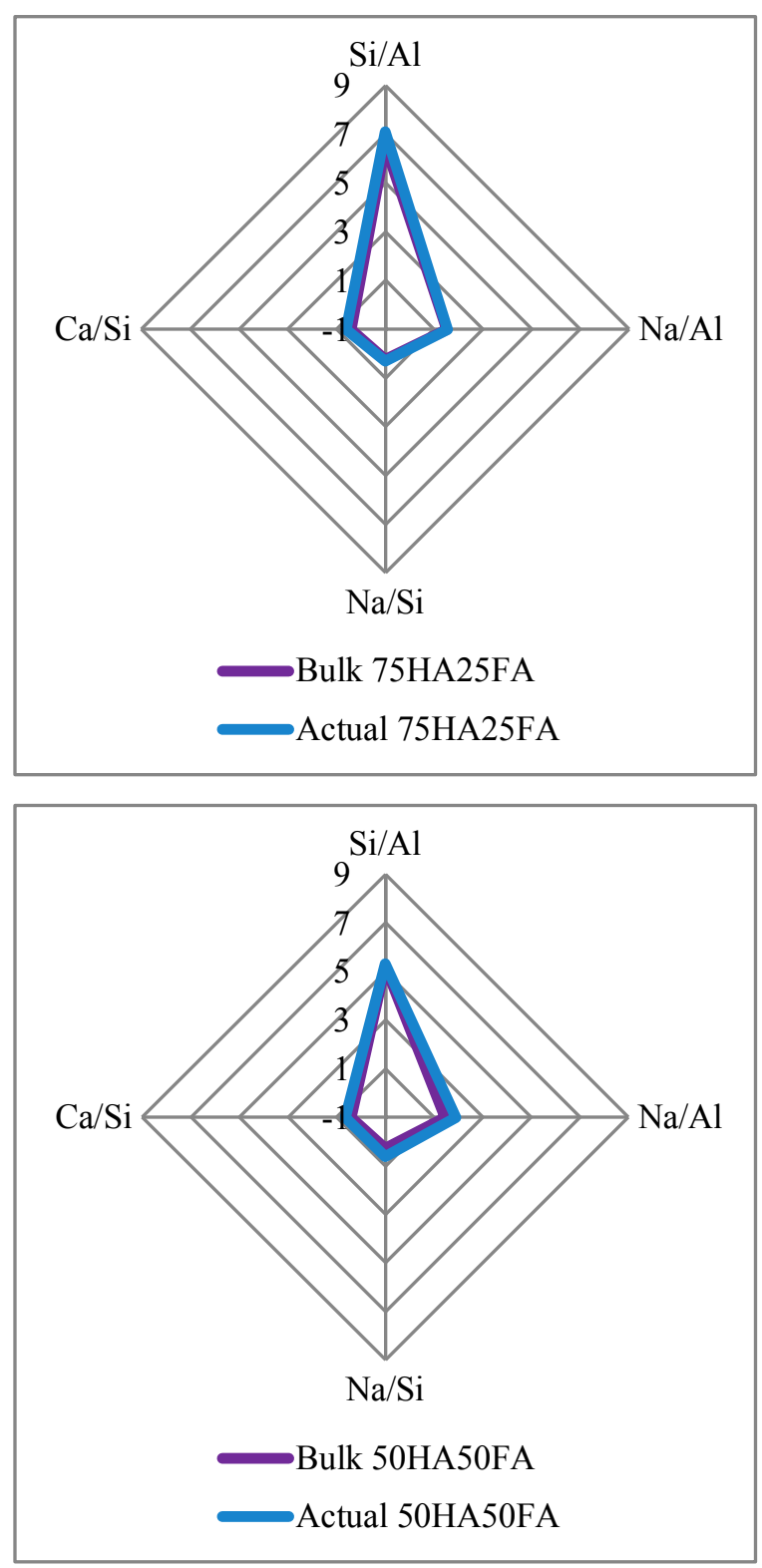

Figure 4.42. Bulk vs actual molar ratios for the 75HA25FA mixture (top) and 50HA50FA mixture (bottom).

\subsubsection{Degree of reaction, $\alpha$}

Geopolymer mixtures are typically designed based on the stoichiometric amounts of $\mathrm{Si}$, $\mathrm{Al}, \mathrm{Na}$, etc. in the source materials; whether or not the desired $\mathrm{Si} / \mathrm{Al}$ ratio, etc. is realized or not depends on the degree of reaction $(\alpha)$ as well as the content of nonreactive phases 
(i.e. mullite, quartz, etc. in fly ash). The bulk stoichiometry reported is not necessarily the same as what is measured in the bulk geopolymer formed; depending on the degree of reaction, whether or not incongruent dissolution occurred and what phases formed, these stoichiometries could differ. This was found to be the case in Phase II, where incomplete dissolution occurred and since most of the mixtures contained two source materials; it was impossible to determine the actual dissolution of each material.

The results of the degree of reaction experiments through 7 days on pastes from Phase II are shown in Figure 4.43. Each data point is the average of two tests. The degree of reaction stayed fairly constant after 1 day with all mixtures showing similar levels of reaction with the exception of the 50HA50MK mixture, which was lower. This lower $\alpha$ is believed to be due to the higher water content of the mixture, where more water diluted the hydroxyl ions in solution leading to less dissolution. The literature has reported that typically a great deal of the reaction occurs within the first few hours of mixing (Granizo et al. 2002; Palomo et al. 2004; Fernández-Jiménez et al. 2005) and that seems to be the case here as well.

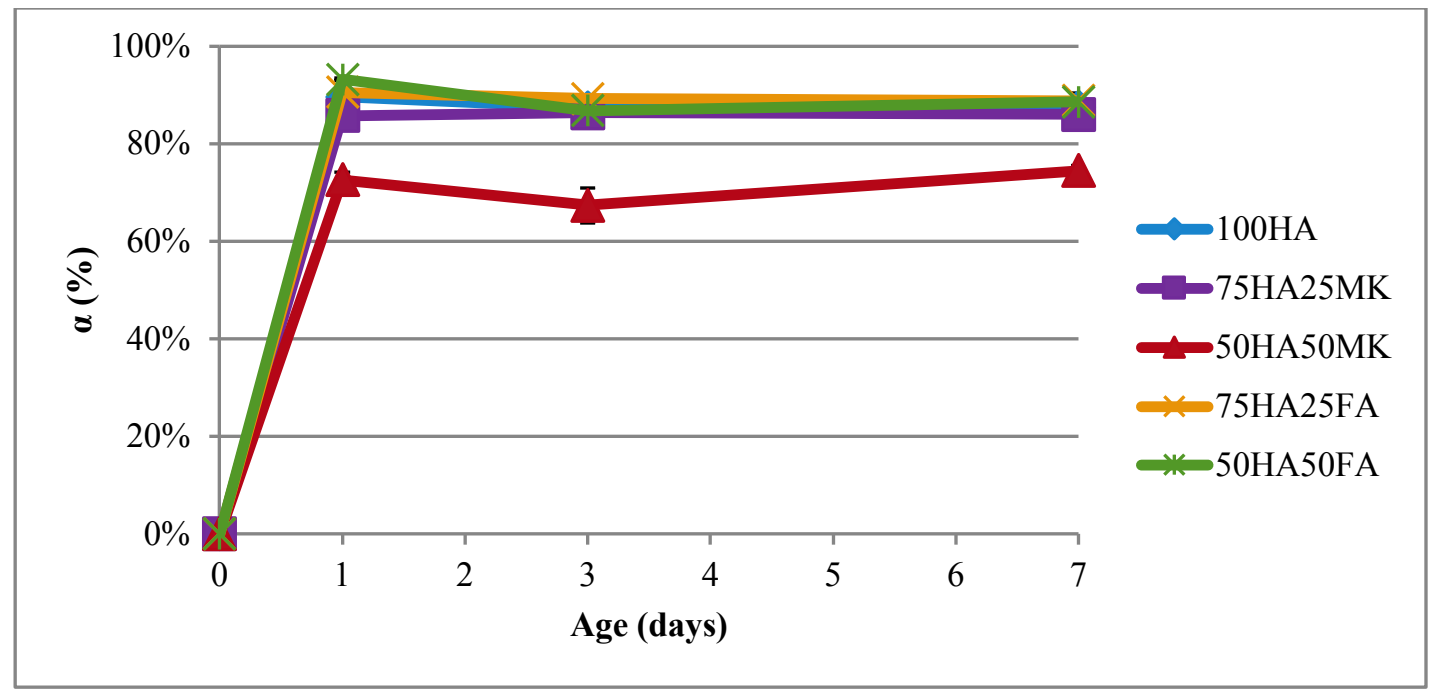


Figure 4.43. Degree of reaction results for the first seven days in Phase II. Each data point is the average of two tests. Error bars were calculated from the standard error, $\mathrm{SD} / \sqrt{ } \mathrm{n}$, where $\mathrm{SD}$ is standard deviation and $\mathrm{n}$ is the sample size.

Figure 4.44 shows $\alpha$ through 179 days. It is clear there was not any major increase over that time and none of the mixtures reached $100 \%$, which was reinforced by the presence of unreacted glass particles in the matrix observed during electron microscopy. However, there was strength gain past 1 day, which indicates there must have been microstructural change taking place, perhaps reorganization or further syneresis.

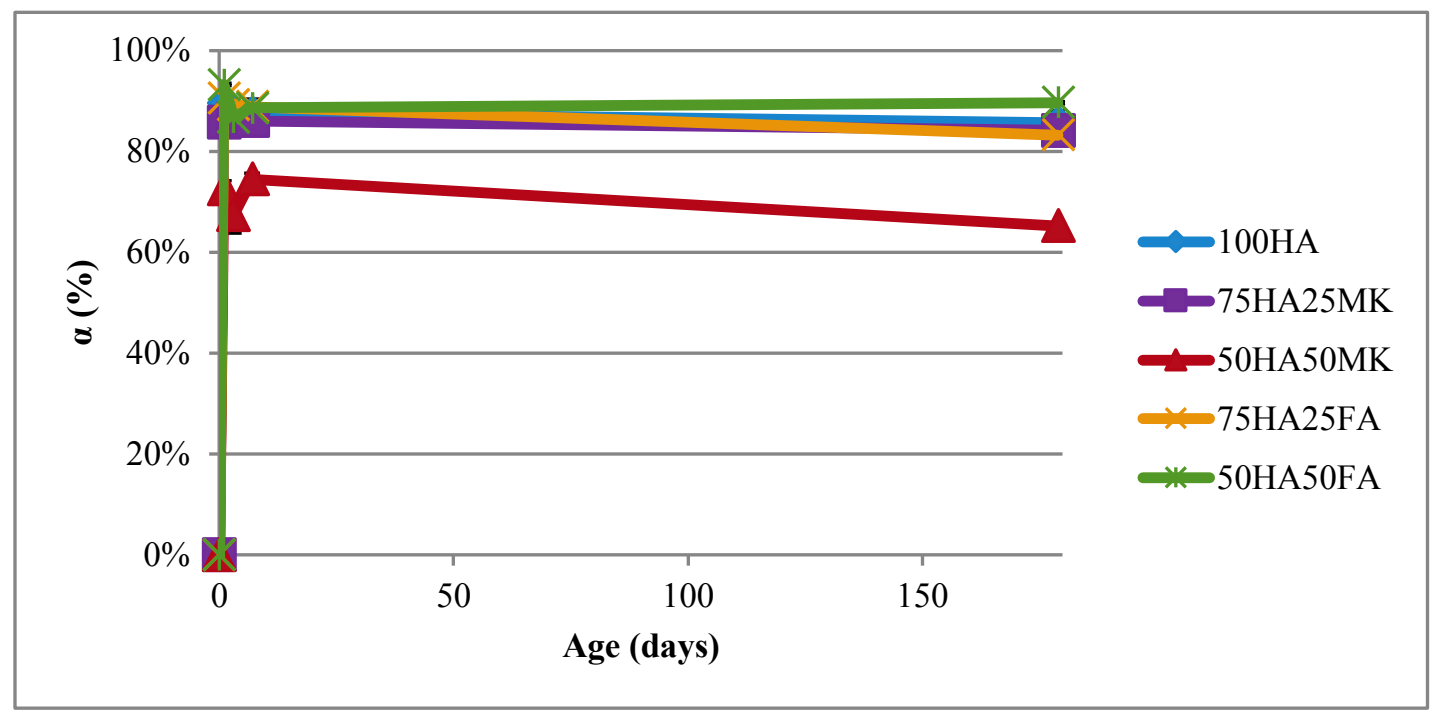

Figure 4.44 Degree of reaction versus age through 179 days. Each data point is the average of two tests. Error bars were calculated from the standard error, $\mathrm{SD} / \mathrm{V}_{\mathrm{n}}$, where $\mathrm{SD}$ is standard deviation and $\mathrm{n}$ is the sample size.

\subsubsection{Powder X-ray diffraction}

Powder X-ray diffraction data was collected for all of the mixtures in Phase II at 1, 3 and 7 days after mixing. Quantitative XRD was not performed in this research; the goal of collecting XRD spectra was to observe if there were any general trends between microstructure or compressive strength and crystallinity. The pattern showing the presence 
of any progression in crystallinity from 1 to 7 days, with 1 day in blue, 3 days in red and 7 days in light blue, are shown in Figure 4.45, Figure 4.46, Figure 4.47, Figure 4.49 and Figure 4.50.

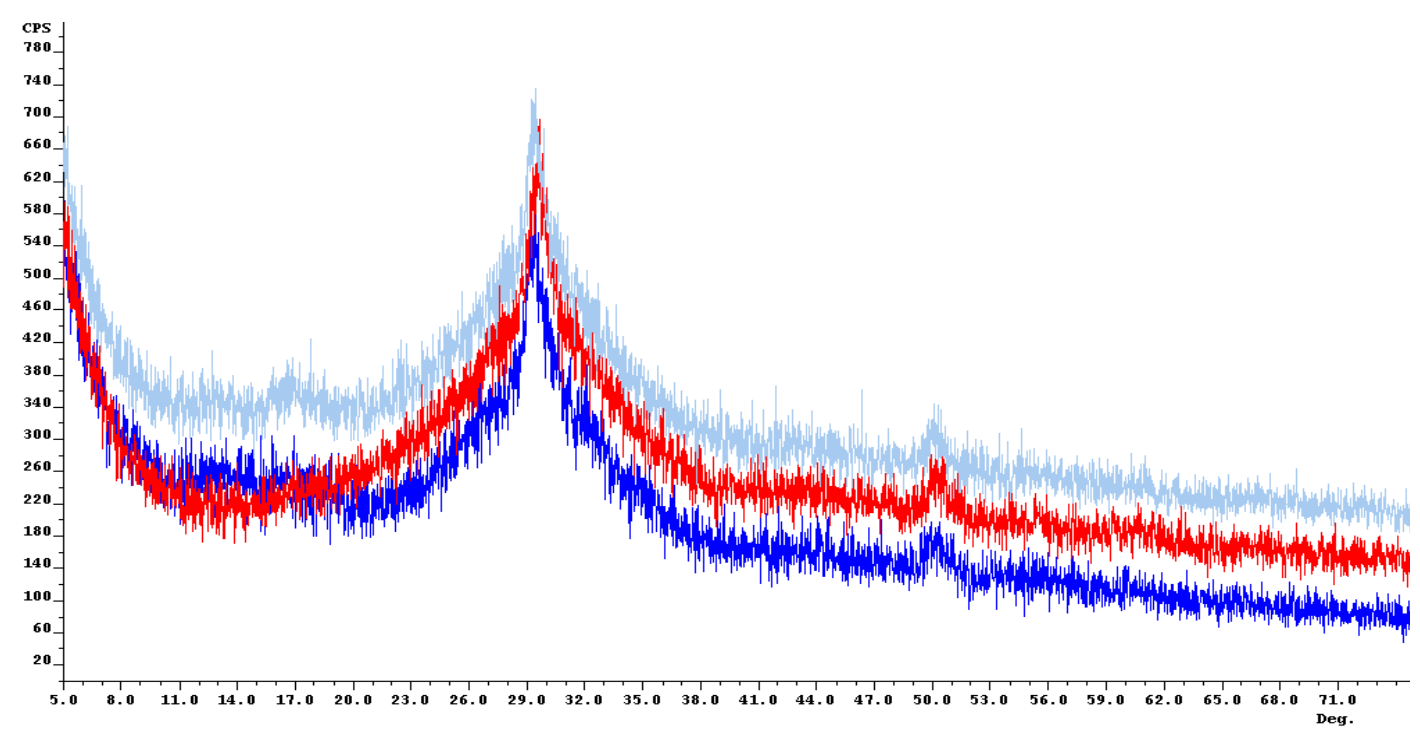

Figure 4.45. X-ray diffraction patterns for the 100HA mixture at 1 (blue), 3 (red) and 7 (light blue) days.

It was expected to see the 100HA mixtures having the least crystallinity of all of the mixtures over the first week of curing, since the glass is $100 \%$ amorphous to begin with. 


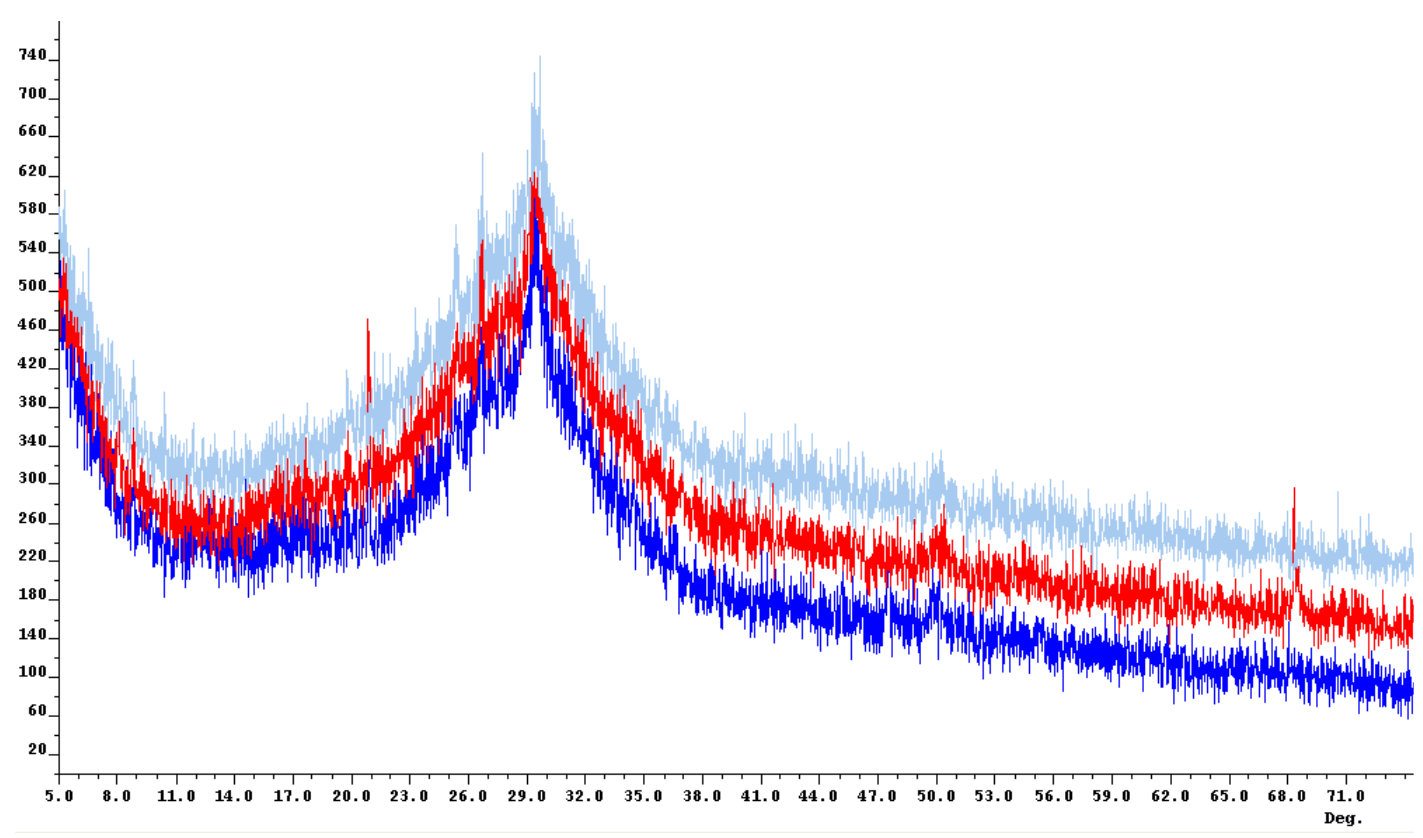

Figure 4.46. X-ray diffraction patterns for the 75HA25MK mixture at 1 (blue), 3 (red) and 7 (light blue) days.

When metakaolin replaced $25 \%$ of the glass, the resulting XRD patterns were very similar. Several very small peaks were evident in the pattern that were not present in the $100 \mathrm{HA}$ pattern. The lack of crystalline peaks in XRD and lack of unreacted particles visible in the polished cross sections indicate the metakaolin was most likely dissolved. 


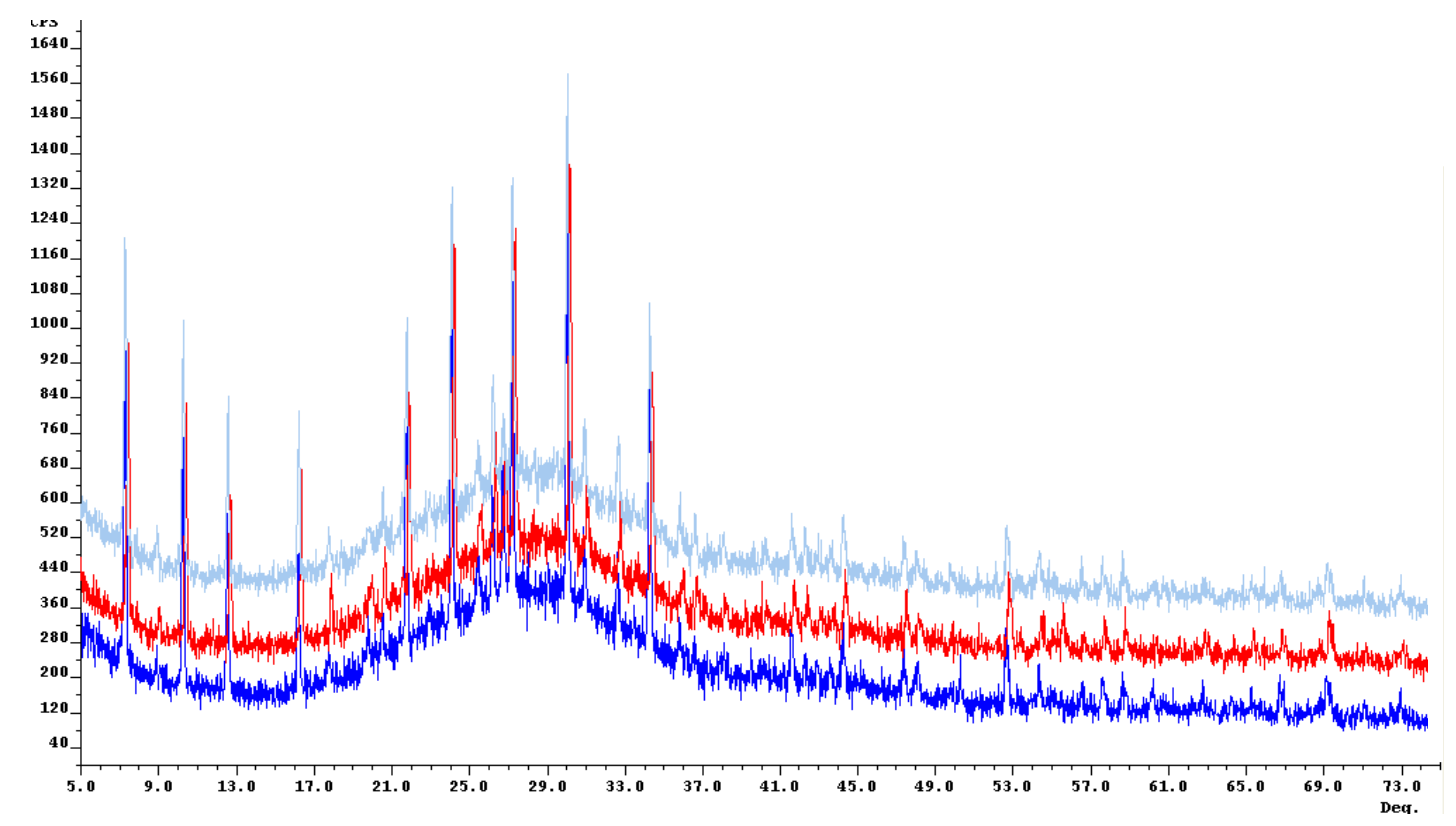

Figure 4.47. X-ray diffraction patterns for the 50HA50MK mixture at 1 (blue), 3 (red) and 7 (light blue) days.

When $50 \%$ of the glass was replaced with metakaolin, the crystallinity increased substantially as shown in Figure 4.47. There was no peaked halo as in the 100HA and 75HA25MK mixtures but rather a subtle hump. Some of the crystalline peaks coincide with peaks present in the raw metakaolin pattern indicating unreacted metakaolin in the geopolymer mortar, and additional peaks new to this material indicate the presence of new crystalline phases. This is further evidenced by the widespread presence of morphologically crystalline phases visible on the fracture surfaces of the $50 \mathrm{HA} 50 \mathrm{MK}$ mixture. Figure 4.48 shows the peak identification for the sample at 7 days, calcium aluminum silicate hydrate was identified. 


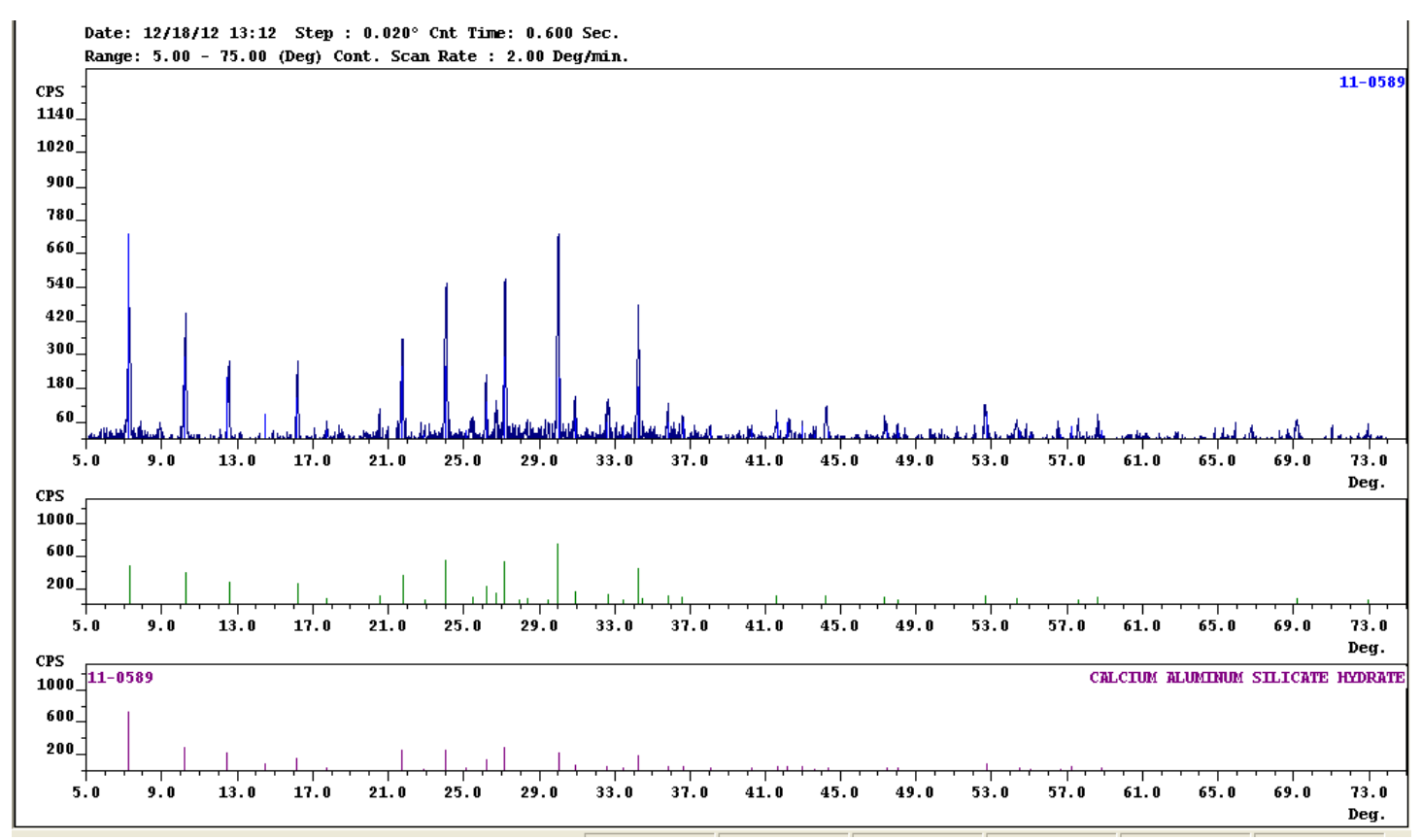

Figure 4.48. Phase identification for 50HA50MK mixture at 7 days. Calcium aluminum silicate hydrate.

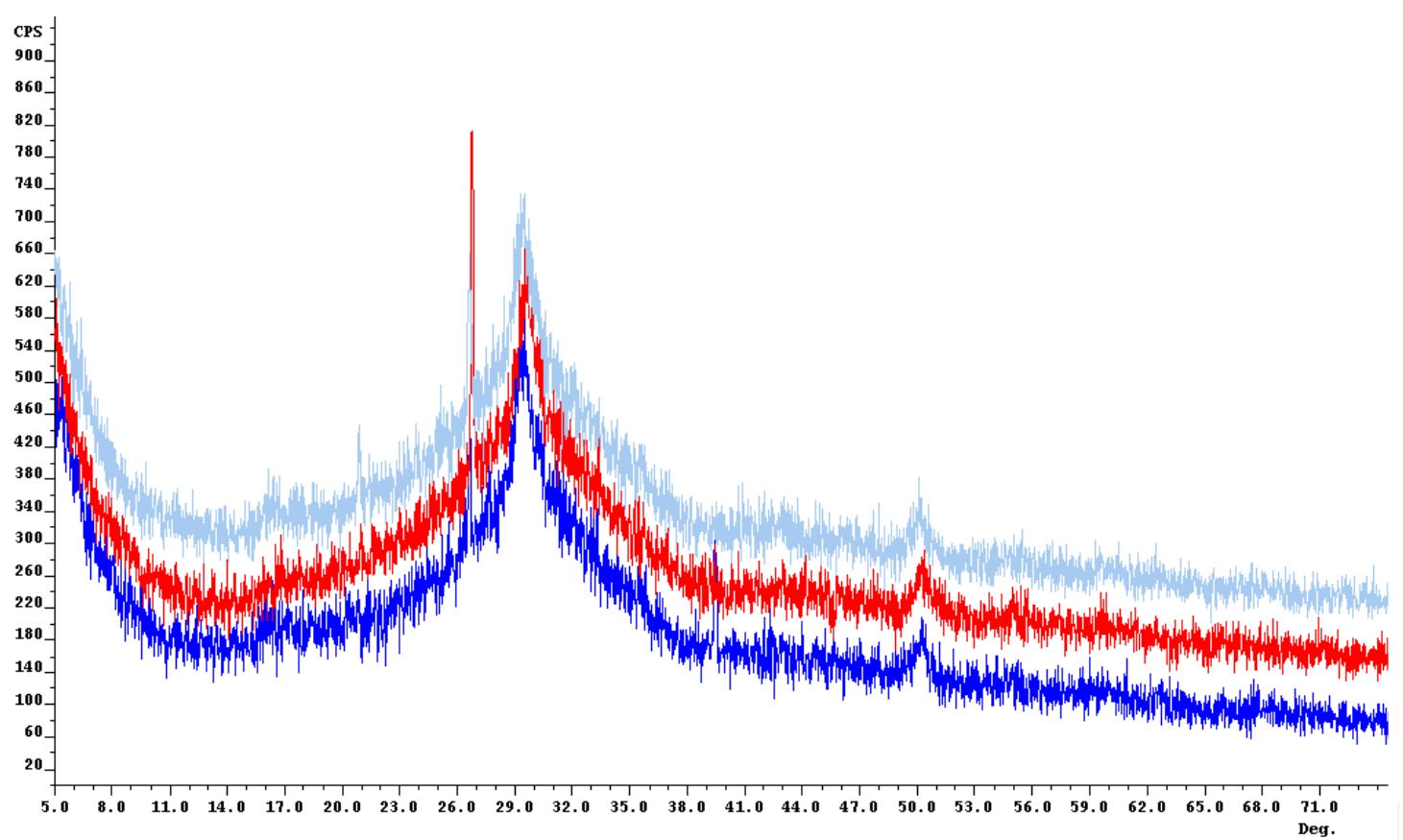

Figure 4.49. X-ray diffraction patterns for the 75HA25FA mixture at 1 (blue), 3 (red) and 7 (light blue) days. 
The 75HA25FA mixture exhibited a similar pattern as the 100HA and 75HA25MK mixtures, with a peaked halo centered at around $30^{\circ}$. Crystalline peaks were also present.

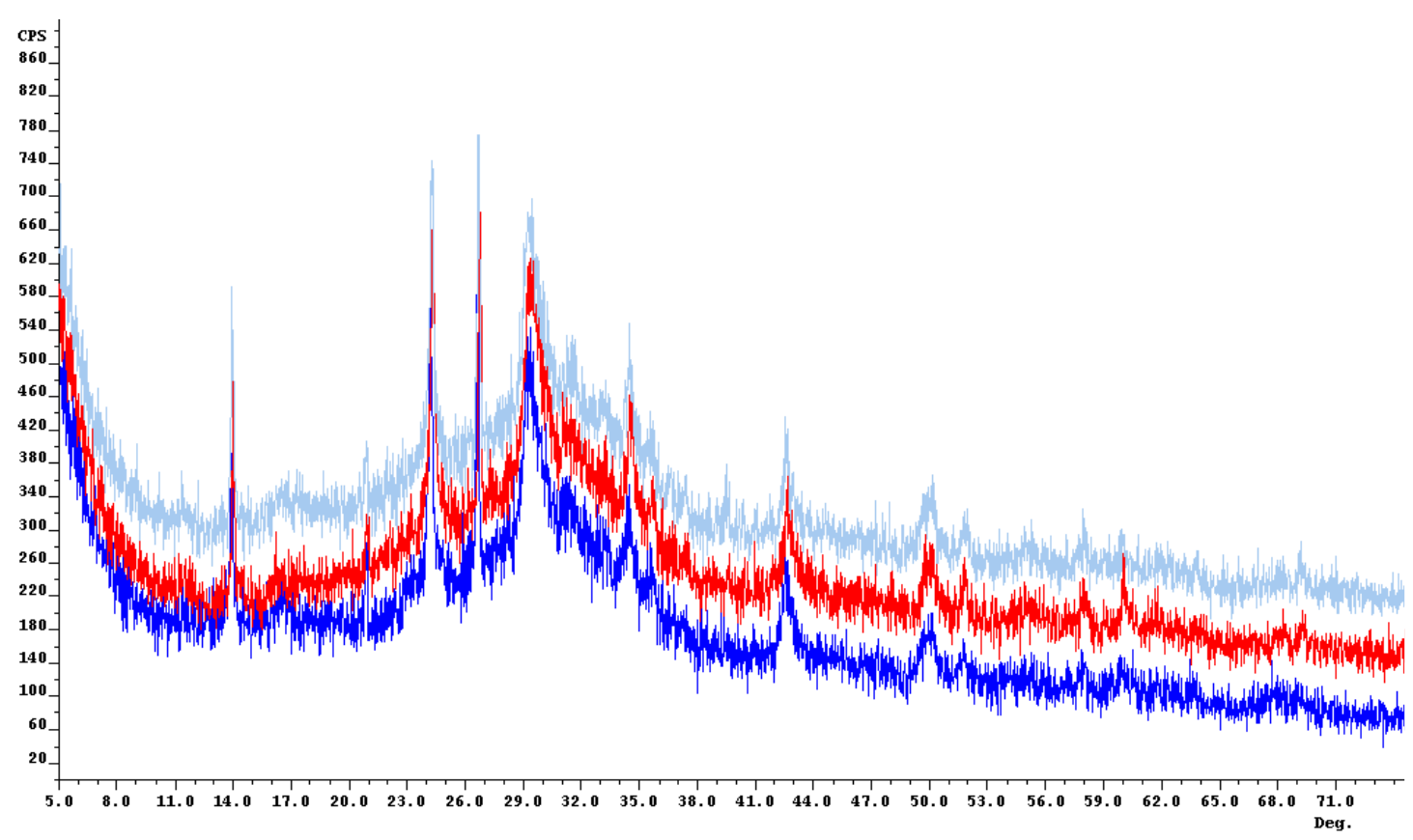

Figure 4.50. X-ray diffraction patterns for the 50HA50FA mixture at 1 (blue), 3 (red) and 7 (light blue) days.

The 50HA50FA mixture exhibited more crystallinity than the 75HA25FA mixture as shown in Figure 4.50. The peaked halo was still present at around $30^{\circ}$ but taller crystalline peaks were visible with some corresponding to crystalline peaks in the fly ash and others representing new phases.

Both the 50HA50MK and 50HA50FA mixtures had the lowest compressive strength and the most crystalline phases present under XRD measurements. This relationship between crystallinity and compressive strength has been noted within the literature with a decrease 
in strength usually associated with an increase in crystalline phases, typically identified as zeolites (Fernández-Jiménez et al. 2007).

\subsubsection{Adiabatic calorimetry}

Three of the mixtures in Phase II, 100HA, 75HA25MK and 50HA50MK, were measured on the AdiaCal at room temperature as shown in Figure 4.51 to learn if differences in reaction kinetics existed. In both cases where metakaolin was included, the temperature spiked higher than when just glass was included. The mixture with the highest compressive strength, shown in dark blue, also had the most delayed second temperature peak, which is usually considered to represent polycondensation (Zhang et al. 2012). The mixture not containing any metakaolin had a very steady temperature but still resulted in substantial strength, indicating that calorimetry results do not necessarily indicate compressive strength but rather just indicate that different reactions or reaction rates are occurring between mixtures. 


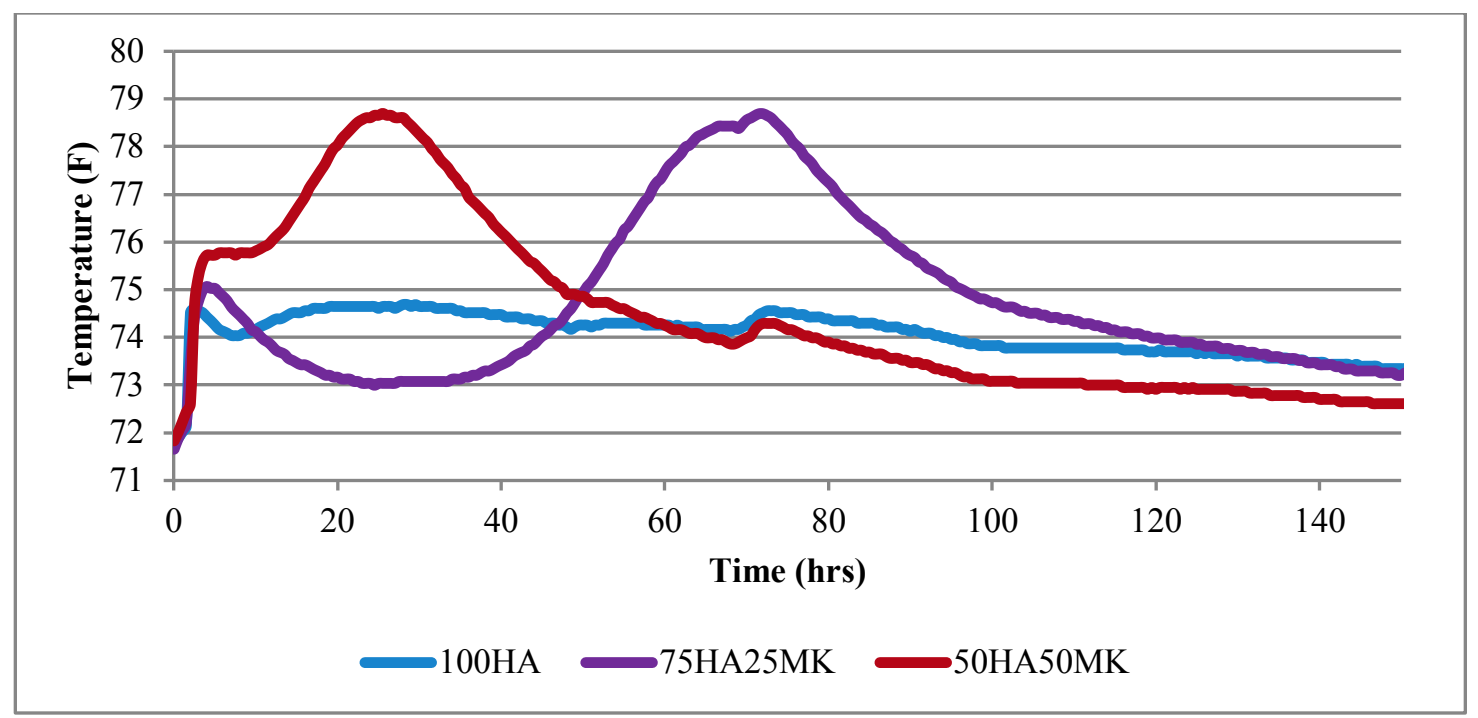

Figure 4.51. Adiabatic calorimetry curves for mixtures 100HA, 75HA25MK and 50HA50MK. Values shown represent the value measured every 30 seconds.

The water/solids ratio also affects the magnitude of the peaks measured on adiabatic calorimetry; this is discussed further in Phase III results.

\subsubsection{Discussion of Phase II}

As stated previously, the goal of Phase II was to discern if stoichiometric molar ratios can be decreased to more widely accepted geopolymer levels through the addition of metakaolin or fly ash as a partial glass replacement and if by doing so mechanical performance would improve. Phase II also investigated the behavior of the mortars at early ages of 1, 3 and 7 days. Additionally, degree of reaction experiments were conducted to see if they are helpful in explaining the changes in compressive strength, microstructure and composition of phases. Adiabatic calorimetry was also performed on selected mixtures in an exploratory context. 
Since a goal in Phase II was lowering the stoichiometric ratios to realistic levels through the addition of alumina, the results will be presented for each type of alumina replacement followed by general trends across all of the mixtures.

\subsubsection{1 $100 H A$}

The purpose of the 100HA mixture was to act as a reference to compare with the other mixtures where aluminum was supplemented with metakaolin or fly ash. This mixture was essentially explored in Phase I, under the name F.10.80. However, an increase in the water/solids ratio and a different type of aggregate apparently had a moderate impact on the mortar as the strength was higher earlier and no decrease in strength over time was measured, instead compressive strength continued to increase all the way to 179 days. This indicates the strength loss in the F.10.80 mixture in Phase I may have been an anomaly or experimental error.

Microstructurally, the 100HA mixture appeared similar to the mixtures using fine glass in Phase I, with the same reaction rim visible in the polished section images. It is interesting to note the reaction rim was not present in any of the other mixtures in Phase II. Also of note is the subtle difference between the stoichiometric ratios of the F.10.80 mixture and the 100HA mixture; the $\mathrm{Si} / \mathrm{Al}$ ratio in the 100HA mixture was a bit lower than the F.10.80 mixture and the $\mathrm{Na} / \mathrm{Al}$ ratio quite a bit higher in the F.10.80 mixture. The 100HA mixture reached a Na/Al ratio of near unity. This is interesting data since the two ratios are not moving together, this implies that more than just the $\mathrm{Al}$ content changed between the mixtures, or the $\mathrm{Al}$ did not change and the $\mathrm{Si}$ and/or Na did. 
The degree of reaction of $100 \mathrm{HA}$ indicated that a great deal of the reaction occurred in the first day (i.e., $>90 \%$ ) with no clear increase in the degree of reaction at later ages. Strength continued to increase at later ages, which indicates reorganization or syneresis occurring.

Adiabatic calorimetry did not indicate any significant increase in temperature at, which was unexpected as typically there is at least a temperature increase during dissolution. This may not have been captured on the calorimeter due to experimental conditions. Also, there was not a temperature spike later on representing polycondensation. High compressive strength was still reached despite the lack of calorimetric changes, either indicating slow reactions or non-exothermic ones. Iler stated there is no heat generated when a sol turns to a gel and that could be the case here (Iler 1979).

\subsubsection{2 $75 \mathrm{HA25MK}$}

The fact the 75HA25MK mixture reached the highest strength of all the mixtures in Phase II, performing better than the 100HA mixture is attributed to the addition of $\mathrm{Al}$ to the system through the metakaolin. Significant compressive strength was reached at just 1 day and continued to increase over time. The microstructure of the 75HA25MK mixture was not the most uniform or continuous despite having the highest strength. There were no unreacted metakaolin particles visible in the matrix. However glass particles were present, minus the reaction rim found in the 100HA mixture.

Stoichiometrically, this was the only mixture to achieve a $\mathrm{Na} / \mathrm{Al}$ ratio of below unity, indicating there was more than adequate $\mathrm{Al}$ available in the system to bind the alkalis. The $\mathrm{Si} / \mathrm{Al}$ ratio was substantially lower than the other mixtures, which did not go along with 
the noted trend between $\mathrm{Si} / \mathrm{Al}$ and compressive strength. This is most likely due to the interaction of other variables, specifically the relationship between $\mathrm{Si} / \mathrm{Al}$ and $\mathrm{Na} / \mathrm{Al}$ (Rowles and O'Connor 2003). However, the $\mathrm{Si} / \mathrm{Al}$ and $\mathrm{Na} / \mathrm{Al}$ ratios did agree with the range suggested by other geopolymer researchers of 2-5 for $\mathrm{Si} / \mathrm{Al}$ ratio and $\mathrm{Na} / \mathrm{Al}$ of 1 .

The $75 \mathrm{HA} 25 \mathrm{MK}$ mortar had the highest degree of reaction, which is most likely attributed to the metakaolin particles, which are known to dissolve easily in basic solutions. The similarities between the XRD patterns of the 100HA and 75HA25MK mixtures confirmed the idea of the metakaolin dissolving completely. The degree of reaction of the 75HA25MK mixture was in line with the other four mixtures that performed well, not resulting in any increase over time past 1 day. This indicates strength is gained through reorganization or syneresis.

Adiabatic calorimetry indicated the mixture had a spike in the temperature, which occurred nearly three days after mixing. This likely is dissolution continuing to occur during that time and the spike represented a supersaturated solution beginning to condense together. However, the degree of reaction did not change much from 1 to 3 days.

\subsubsection{50HA50MK}

The 50HA50MK mixture performed surprisingly poor, showing very low compressive strength even through 179 days. At 179 days the compressive strength began to show an increase but in the world of concrete six months is a little long to wait for adequate compressive strength. 
The microstructure of the mixture was primarily unreacted glass and metakaolin particles, which could clearly be seen in the polished cross section. From the fracture surface analysis it appeared that reaction product had formed. The reaction product appeared very aggregated with perhaps only thin layers forming around the mostly unreacted particles, serving to hold them together into a mass but providing no real strength.

The low $\mathrm{Na} / \mathrm{Al}$ ratio of the bulk materials implies that $\mathrm{Al}$ would exist in the pore solution of the mortar; however this does not seem likely since such a high quantity of unreacted materials were present in the microstructure. The poor performance could be attributed to the higher water content of the mixture, where the higher water content resulted in the dilution of the activator solution, negatively affecting the degree of reaction. This is supported by the lower degree of reaction as determined through experimentation. However, this still does not account for the $70 \%$ of the glass and/or metakaolin that was reported to have reacted.

It is postulated that in a liquid-rich environment, crystalline zeolites formed instead of geopolymer product. This would explain the large quantity of zeolites seen in the fracture surface images, the lack of geopolymer product seen in the polished cross section analysis and the very crystalline XRD spectra collected. Zeolites were not visible in the polished section analysis, whether it was because they were too small and too easily damaged during sample preparation or because they did not exist within the matrix but rather just on the surfaces and in air voids. If so, the higher water content most likely resulted in a higher porosity, offering more surface area for zeolites to grow. 
The measured adiabatic calorimetry curve appeared very similar to the $75 \mathrm{HA} 25 \mathrm{MK}$ mixture except the second peak occurred much sooner, at around 24 hours after mixing as opposed to 72 hours. This could indicate a restrictive reaction layer formed around the glass early on, which prevented further reaction.

\subsubsection{75HA25FA}

The microstructure of the 75HA25FA mixture appeared quite continuous but had lower strength, which speaks again to the importance of composition and the relationship between composition and microstructure. Unreacted glass and fly ash particles existed but appeared well embedded within the matrix. The geopolymer had a higher $\mathrm{Na} / \mathrm{Al}$ ratio and higher $\mathrm{Si} / \mathrm{Al}$ ratio with the $\mathrm{Si} / \mathrm{Al}$ ratio being similar to that recorded for the $100 \mathrm{HA}$ mixture.

The degree of reaction appeared to be similar to the other mixtures so it was not for a lack of dissolution occurring. It is possible that different ratios of materials dissolved, where as in the 75HA25MK mixture, perhaps all of the metakaolin dissolved, but in the 75HA25FA mixture not all of the fly ash dissolved and instead glass did. This would lead to a higher

$\mathrm{Si} / \mathrm{Al}$ ratio as opposed to the metakaolin mixture. Additionally, XRD spectra indicated a mainly amorphous mortar similar to the $100 \mathrm{HA}$ and $75 \mathrm{HA} 25 \mathrm{MK}$ mixtures that performed well in terms of mechanical strength.

\subsubsection{50HA50FA}

The 50HA50FA mortar achieved very low compressive strengths despite the continuity of the matrix. There were a great deal of unreacted fly ash particles present in the 
microstructure, which would lead one to believe the degree of reaction was lower. However, measurement of the degree of reaction indicated this mixture was similar to other mixtures. The microstructure did appear less continuous than the 75HA25FA mixture.

Stoichiometrically, the $\mathrm{Si} / \mathrm{Al}$ ratio was higher, $\mathrm{Na} / \mathrm{Al}$ was nearly 2 and the $\mathrm{Na} / \mathrm{Si}$ ratio was higher than the other mixtures indicating that more $\mathrm{Na}$ was available in the system. The $\mathrm{Ca} / \mathrm{Si}$ ratio was also elevated.

\subsubsection{Main points}

- There was no strength reversal for any of the mortars as there was in Phase I, even when curing conditions and activator concentrations were the same.

- The 100HA mixture performed very well. However, the 75HA25MK mixture had the highest compressive strength, lowest $\mathrm{Si} / \mathrm{Al}$ and $\mathrm{Na} / \mathrm{Al}$ ratios, implying the most Al present in the mixture. An improvement over the 100HA mixture indicates the metakaolin had a positive effect on the mortar by adding more aluminum into the system.

- The water/solids ratio plays a role in degree of reaction as evidenced in the 50HA50MK mixture.

- The physical nature of the microstructure alone is not always indicative of the mechanical performance.

- Apparently there exists a limit at which adding more metakaolin will weaken the matrix and result in very little geopolymer product forming. This could be due to 
the increased water demand, which also creates more porosity in the matrix or increase zeolite formation.

- The 75HA25FA mixture had low strength despite a continuous microstructure once again alluding to the fact there is not necessarily a clear-cut relationship between physical microstructure and physical performance.

- Overall, there was a trend between compressive strength $\mathrm{Na} / \mathrm{Al}, \mathrm{Si} / \mathrm{NA}$ and $\mathrm{Ca} / \mathrm{Si}$ between all four mixtures. However, Si/Al exhibited one anomaly.

- Metakaolin causes a spike in temperature during curing as shown by adiabatic calorimetry curves.

- The molar ratios of the mixtures were very similar to the bulk molar ratios.

\subsection{Phase III}

The third phase of testing applied the lessons learned in Phases I and II to a geopolymer system based on extremely low-Al glass. Metakaolin was used as the alumina source because it performed better in Phase II than did the fly ash. It was of interest to see if there exist limits on how much metakaolin can be used in place of glass or if the 50HA50MK mixture in Phase II was an anomaly. Six mortars were made, three using the low-Al glass, two using the high-Al glass, and one made simply of metakaolin for reference. The replacement rates of the glass were based on stoichiometric ratios, namely the $\mathrm{Na} / \mathrm{Al}$ ratio.

As in Phases I and II, compressive strength, microstructure and phase composition were the main properties considered. Compressive strength was measured at 1, 3, 7, 14 and 28 days. Samples were prepared and analyzed using secondary electron imaging at 28 days to 
get a general idea of the microstructure of the various geopolymers. At 14 days, a polished section of each mortar was prepared for backscatter electron imaging and EDS microanalysis was used to obtain quantitative compositional information on the phases present. In addition, Phase III also considered degree of reaction measurements at 14 and 28 days as well as both adiabatic and isothermal calorimetry for all six mixtures.

\subsubsection{Mixture design}

Both the HA and LA glasses were used in this phase. To keep particle size from being a variable, a slightly coarser version of the HA600 from Phase I was used, called HA500 and LA500. The vender reported the median size to be 6-7 $\mu \mathrm{m}$. Additionally, Blaine fineness as measured at the University of Toronto showed the fineness of the two glasses to be very similar, with LA500 having a Blaine fineness of $4470 \mathrm{~cm}^{2} / \mathrm{g}$ and HA500 having a Blaine fineness of $4390 \mathrm{~cm}^{2} / \mathrm{g}$.

The mixtures were designed based on stoichiometric $\mathrm{Na} / \mathrm{Al}$ ratios. A baseline 100LA mixture was considered as well as two more mixtures with metakaolin replacements adequate to decrease the $\mathrm{Na} / \mathrm{Al}$ ratio from nearly 85 down to 1 and 2 . A baseline mixture of $100 \mathrm{HA}$ was considered as well as the $75 \mathrm{HA} 25 \mathrm{MK}$ mixture from Phase II $(\mathrm{Na} / \mathrm{Al}=1)$. A sixth baseline mixture of $100 \%$ metakaolin was also included.

The six mixtures designed are shown in. Table 4.12. Mixtures were named according to the amounts of each source material used, where $75 \mathrm{HA} 25 \mathrm{MK}$ means $75 \%$ HA glass, $25 \%$ metakaolin by mass. 
Table 4.11. Mixture ID for mortars in Phase III, with percentages given by mass.

\begin{tabular}{|c|c|c|c|}
\hline Mixture ID & $\begin{array}{c}\text { HA500 glass } \\
\text { (HA) }\end{array}$ & $\begin{array}{c}\text { LA500 glass } \\
\text { (LA) }\end{array}$ & $\begin{array}{c}\text { Metakaolin } \\
\text { (MK) }\end{array}$ \\
\hline 100LA & $0 \%$ & $100 \%$ & $0 \%$ \\
\hline $62 \mathrm{LA} 38 \mathrm{MK}$ & $0 \%$ & $62 \%$ & $38 \%$ \\
\hline $37 \mathrm{LA} 63 \mathrm{MK}$ & $0 \%$ & $37 \%$ & $63 \%$ \\
\hline $100 \mathrm{HA}$ & $100 \%$ & $0 \%$ & $0 \%$ \\
\hline $75 \mathrm{HA} 25 \mathrm{MK}$ & $75 \%$ & $0 \%$ & $25 \%$ \\
\hline $100 \mathrm{MK}$ & $0 \%$ & $0 \%$ & $100 \%$ \\
\hline
\end{tabular}

The six mixtures in Phase III were cured at $60^{\circ} \mathrm{C}$ for 24 hours. This curing temperature was chosen for several reasons. Firstly, the long-term results from Phase I indicated that curing at $40^{\circ} \mathrm{C}$ for certain mixtures brought about a steady increase in compressive strength over time while curing at $80^{\circ} \mathrm{C}$ resulted in higher early strength. So, a temperature of $60^{\circ} \mathrm{C}$ was chosen to see if both short term and longer-term strength gain could be obtained. Another reason for this was the isothermal calorimeter available for testing at the University of Toronto had a limit of $60^{\circ} \mathrm{C}$ and out of a desire to coordinate the calorimetry measurements with actual curing conditions, the curing temperature was chosen to be $60^{\circ} \mathrm{C}$.

Because of this lower curing temperature, early compressive results showed very low strengths and high quantities of unreacted source materials in the microstructure as compared to the 50HA50MK mixture in Phase II. To see if the LA glasses could indeed gain early strength given a higher curing temperature, the three LA mixtures were repeated and cured at $80^{\circ} \mathrm{C}$ this time. 
Compressive strength through 14 days was measured as well as degree of reaction measurements at 14 days. In addition, microstructural and compositional analysis was also carried out at 14 days on fracture surface and polished sections for comparison. The information and discussion of the comparison between these mixtures and those corresponding mixtures cured at $60^{\circ} \mathrm{C}$ is in Section 4.3.7.

Additionally, since water content has been shown to have an impact on the performance and properties of glass geopolymers, two additional ternary mixtures were made using 50\% of each type of glass, $25 \%$ metakaolin and $25 \%$ fly ash by mass. The metakaolin increased the water demand, while the fly ash decreased it, resulting in a very workable mixture. Compressive strength through 14 days and degree of reaction measurements at 14 days are available as well as microstructural and compositional data analysis via secondary and backscatter electron imaging and adiabatic calorimetry curves. The information on the ternary mixtures is in section 4.3.8.

\subsubsection{Stoichiometry}

Mortars were prepared using a baseline 3:1:0.5 ratio of sand to glass to activator solution by mass, respectively. Graded Ottawa sand was used. Mixture designs were based around manipulating the $\mathrm{Na} / \mathrm{Al}$ ratio. Three of the mixtures contained only one source material so the molar ratios of those mixtures could not be changed. The relevant molar ratios of the bulk geopolymer are shown in Table 4.12. For all six mixtures, all of the molar ratios changed. 
Table 4.12. Molar ratios of unreacted source materials and activator solution of Phase III mixtures.

\begin{tabular}{|c|c|c|c|c|}
\hline Mixture ID & $\mathbf{S i} / \mathbf{A l}$ & $\mathbf{N a} / \mathbf{A l}$ & $\mathbf{N a} / \mathbf{S i}$ & $\mathbf{C a} / \mathbf{S i}$ \\
\hline 100LA & 244.50 & 85.17 & 0.35 & 0.15 \\
\hline 62LA38MK & 6.52 & 1.98 & 0.30 & 0.10 \\
\hline 37LA63MK & 3.70 & 0.99 & 0.27 & 0.07 \\
\hline 100HA & 8.39 & 1.61 & 0.19 & 0.39 \\
\hline 75HA25MK & 4.99 & 0.97 & 0.19 & 0.30 \\
\hline 100MK & 2.08 & 0.43 & 0.20 & 0.00 \\
\hline
\end{tabular}

Due to the extremely high ratios in the 100LA mixture, Figure 4.52 shows the $\mathrm{Si} / \mathrm{Al}$ and $\mathrm{Na} / \mathrm{Al}$ molar ratios graphed without the 100LA mixture. It is interesting to note that both the $75 \mathrm{HA} 25 \mathrm{MK}$ mixture and 37LA63MK mixture have a bulk Na/Al ratio of 1.0 and varying $\mathrm{Si} / \mathrm{Al}$ ratios. The $\mathrm{Na} / \mathrm{Al}$ ratio of the $100 \mathrm{MK}$ ratio was well below 1.0.

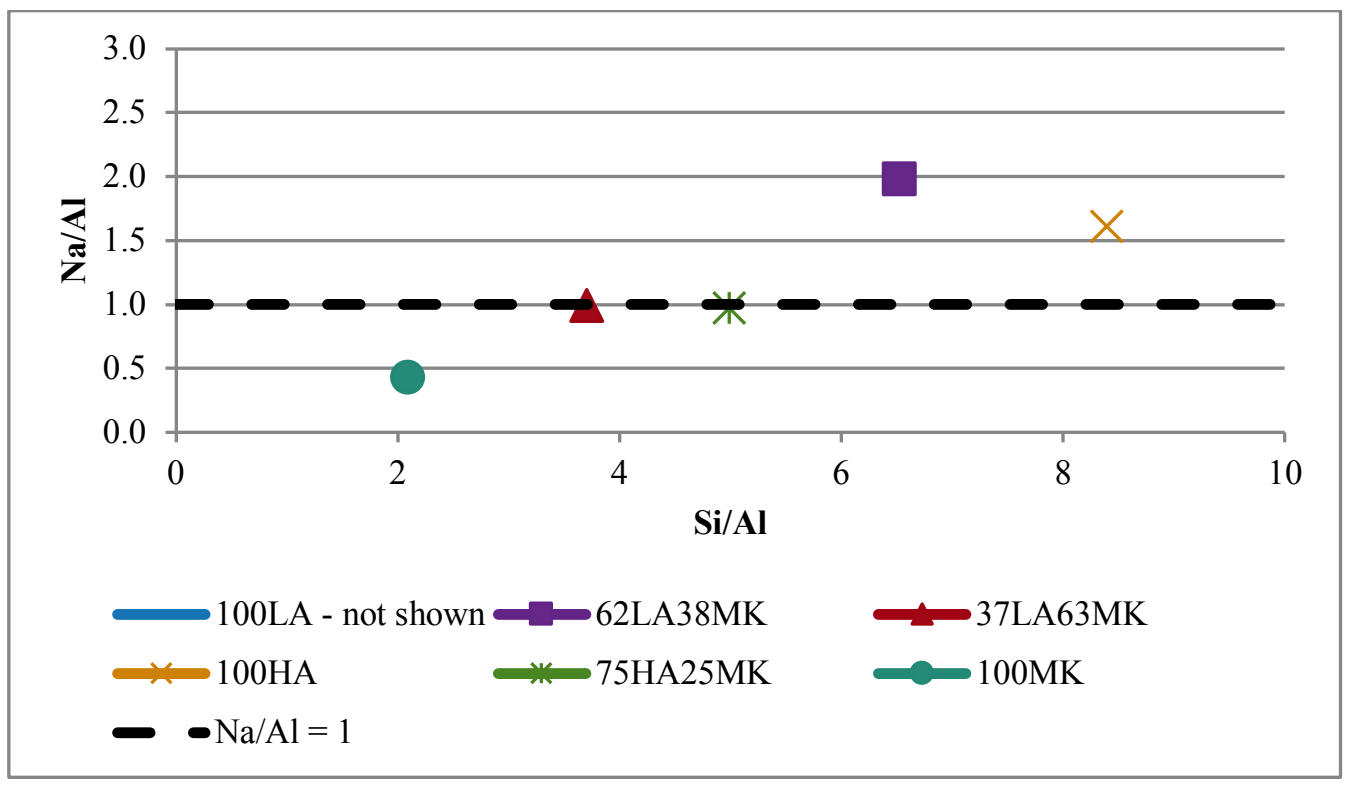

Figure 4.52. Si/Al vs Na/Al of the mixtures in Phase III, not including 100LA mixture, so other molar ratios could be better viewed. A dashed line at $\mathrm{Na} / \mathrm{Al}$ $=1$ is shown since that is widely accepted as an optimum ratio for geopolymers. 


\subsubsection{Fresh properties}

All of the mixtures in Phase III were made with a water/solids ratio of 0.55 with the exception of the $100 \mathrm{MK}$ mixture, which was higher at 0.733 ; this was necessary to reach a consistency that could be adequately consolidated into the cylinder molds. The 0.55 was chosen from Phase II based on the desire to keep the water/solids ratio constant. The flow of each mixture changed fairly drastically due to the constant water/solids ratio but it was found the flow was not necessarily representative of the workability of the mixture. The addition of large quantities of metakaolin increased the water demand. However, the mixtures were all still properly consolidated.

Table 4.13 lists the water/solids ratio and measured fresh properties for the mixtures in

Phase III. It was interesting to note the mixtures all exhibited a crackling sound during mixing and after for several minutes. Additionally, there appears to be a trend with regard to temperature immediately after mixing and the amount of metakaolin in each mixture, where the temperature increases with metakaolin content.

Table 4.13. Fresh properties of Phase III mixtures cured at $60^{\circ} \mathrm{C}$. All of the values reported are the average of three measurements.

\begin{tabular}{|c|c|c|c|c|}
\hline Mixture ID & $\begin{array}{c}\text { Water/solids } \\
\text { ratio }\end{array}$ & $\begin{array}{c}\text { Percent Flow } \\
\mathbf{( \% )}\end{array}$ & $\begin{array}{c}\text { Temperature } \\
(\mathbf{(} \mathbf{F})\end{array}$ & $\begin{array}{c}\text { Unit weight } \\
\mathbf{( g / m L )}\end{array}$ \\
\hline 100LA & 0.550 & $93 \%$ & 78.67 & 2.04 \\
\hline 62LA38MK & 0.550 & $38 \%$ & 81.50 & 2.06 \\
\hline 37LA63MK & 0.550 & $0 \%$ & 85.83 & 1.94 \\
\hline 100HA & 0.550 & $107 \%$ & 78.67 & 1.99 \\
\hline 75HA25MK & 0.550 & $63 \%$ & 81.00 & 2.09 \\
\hline 100MK & 0.733 & $30 \%$ & 85.50 & 2.06 \\
\hline
\end{tabular}

300 
The 100LA mixture bubbled upon consolidation and there was initial concern the top of the cylinders would be porous. However, the cylinders were adequate after curing. In fact, the 100LA mixture secreted a very viscous liquid through 14 days of curing. The exudate was sticky and extremely slippery, which is a sign of alkalis present. Figure 4.53 shows the shiny exudate at 14 days on a cylinder of the 100LA mortar as compared to the other mixtures.

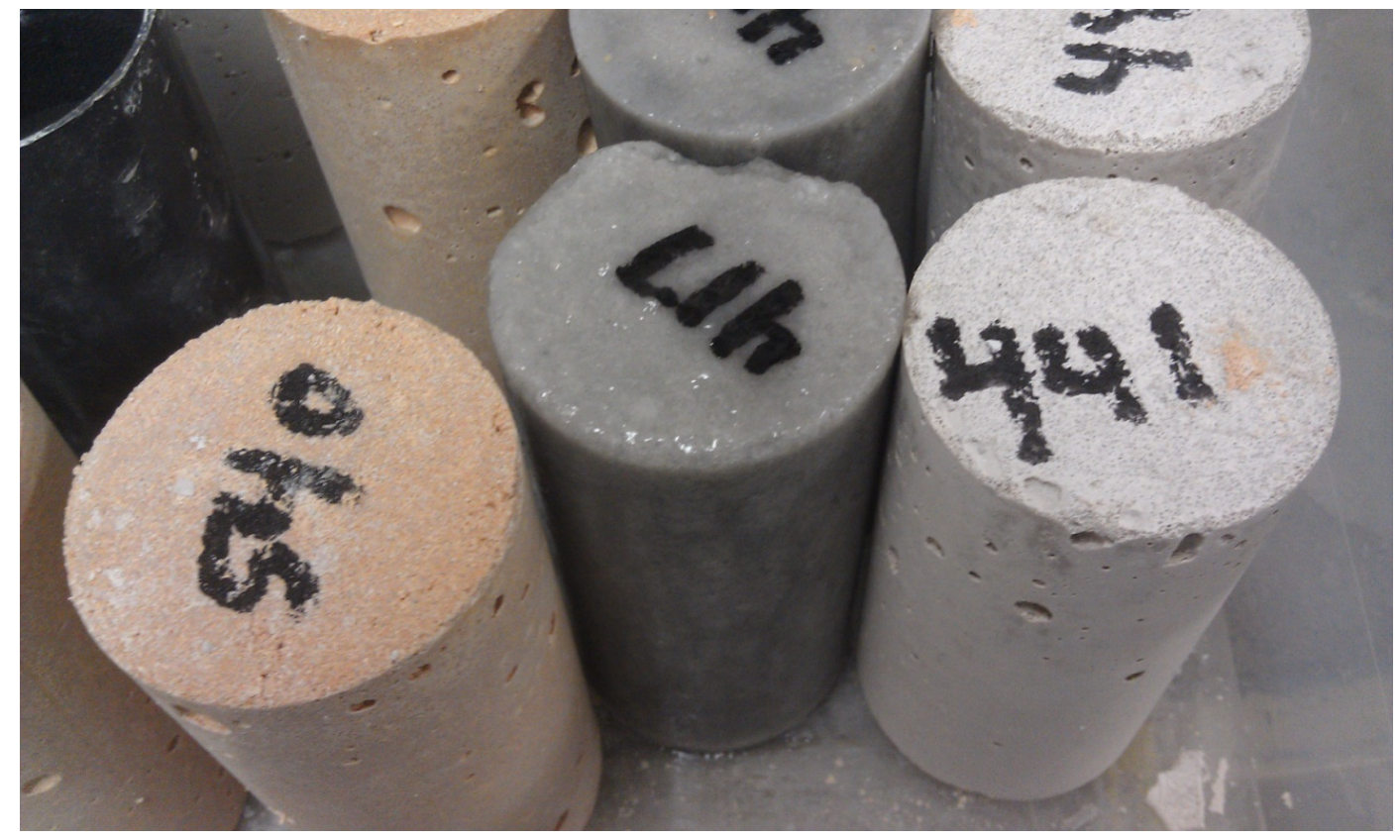

Figure 4.53. A depiction of how wet the low-Al glass was even after 14 days of curing as compared to the other mixtures.

The mixtures containing metakaolin appeared to have more entrapped air than the mixtures without, which is odd given all of the mixtures contained the same amount of water except 100MK. The higher metakaolin content mixtures were more difficult to consolidate and great care had to be taken to avoid large areas of entrapped air. The consistency of these mixtures was similar to wet sand. 


\subsubsection{Compressive strength}

Compressive strength of all six mixtures through 28 days is shown in Figure 4.54. It is clear the three mixtures containing varying amounts of the LA glass and $100 \%$ metakaolin did not obtain very high strengths, even at 28 days. As was the case in Phase II, the mixtures made with $\mathrm{HA}$ glass and a moderate amount of metakaolin performed quite well. At $60^{\circ} \mathrm{C}$ curing, the 100HA mixture performed better than the 75HA25MK mixture, which was the opposite as in Phase II. Additionally, the 1 day compressive strength of the 100HA and 75HA25MK mixtures were much higher in Phase II where curing was carried out at $80^{\circ} \mathrm{C}$; though it should be noted that Phase II was made using a finer glass and slightly lower water/solids ratio as well.

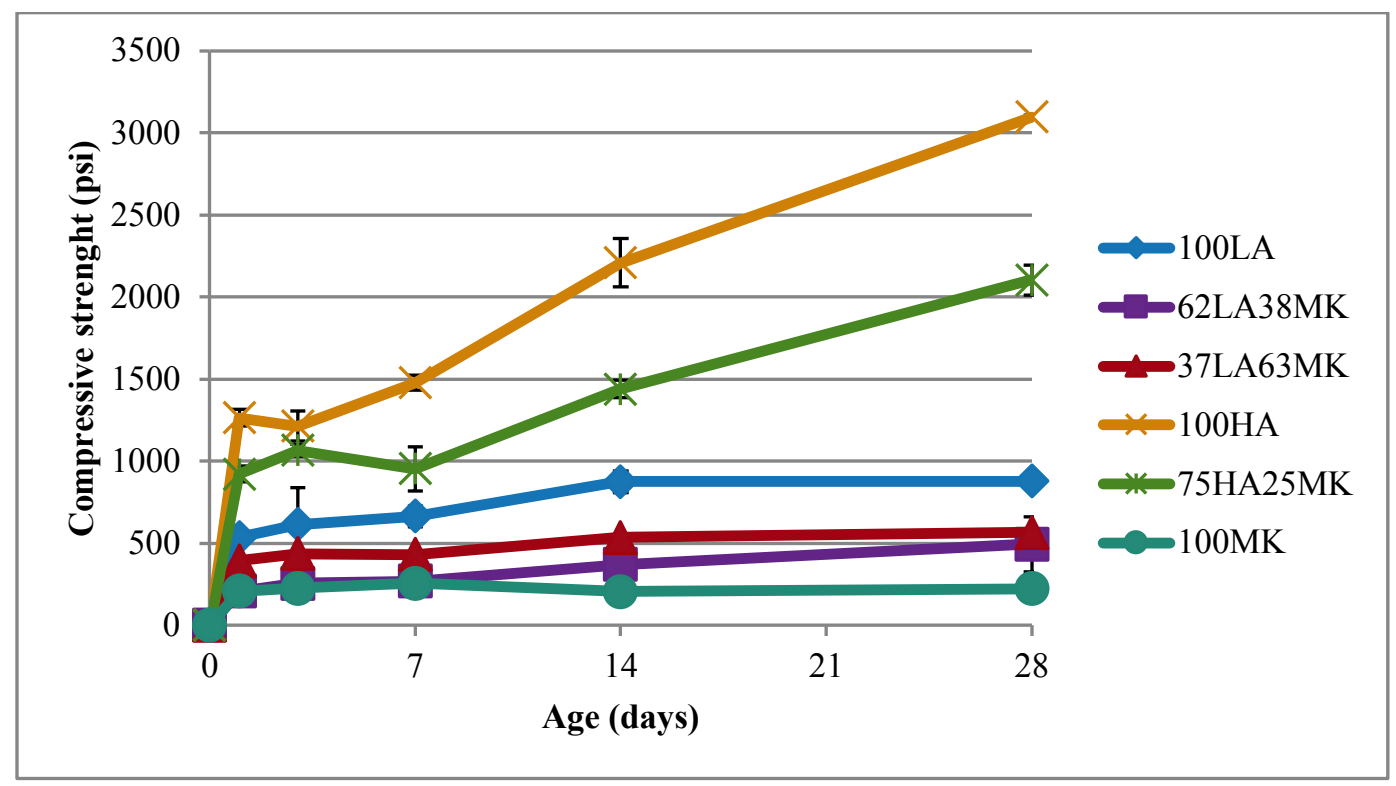

Figure 4.54. Compressive strength through 28 days for mixtures in Phase III cured at $60^{\circ} \mathrm{C}$. Each data point is the average of three cylinders. Error bars were calculated from the standard error, $\mathrm{SD} / \sqrt{\mathrm{n}}_{\mathrm{n}}$, where $\mathrm{SD}$ is standard deviation and $\mathrm{n}$ is the sample size. 
As stated previously, the 100LA mixture had a very wet appearance and secreted a sticky, viscous liquid. This was wiped off of the cylinders prior to compressive strength testing. Also of note is the difference between the interior and exterior of the 100LA cylinder upon breaking. This is shown in Figure 4.55 following a compression test where it can clearly be seen the exterior of the cylinder is a lighter white color and the interior is a darker gray color and appeared slightly damp and sticky. One reason for this prolonged stickiness could be attributed to the lack of $\mathrm{Al}$ in the system. Aluminum in the geopolymer systems has been credited with allowing hardening to occur and also helps speed up set times.

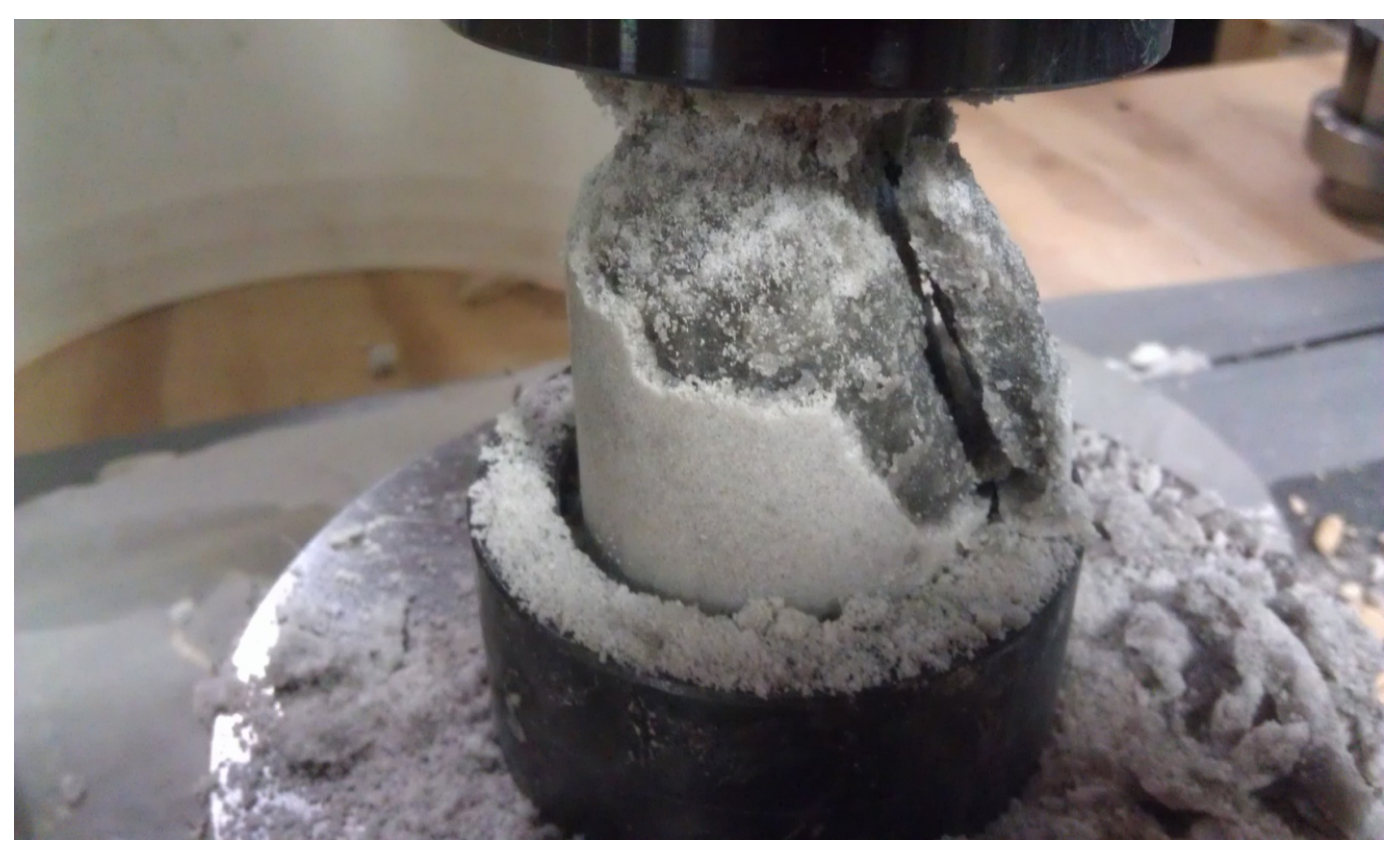

Figure 4.55. 100LA mixture after compression testing showing color differences between interior and exterior of cylinder at 14 days. The interior still appeared and felt damp and slimy despite being very dense. 


\subsubsection{Microstructural analysis}

Electron microscopy on both fracture surfaces and polished cross sections helped to show the differences between the microstructures of the six mortars and revealed clues related to mechanical performance and reaction mechanisms.

\subsubsection{Fracture surface analysis}

Microstructural analysis by way of secondary electron imaging on carbon coated fracture surfaces was performed. Figure 4.56 shows the bulk fracture surface of the six mixtures at 28 days for the purpose of comparison. 


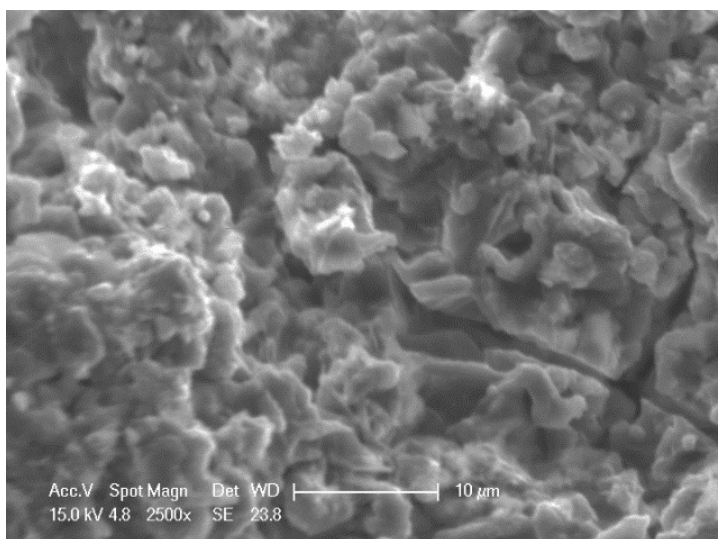

100LA

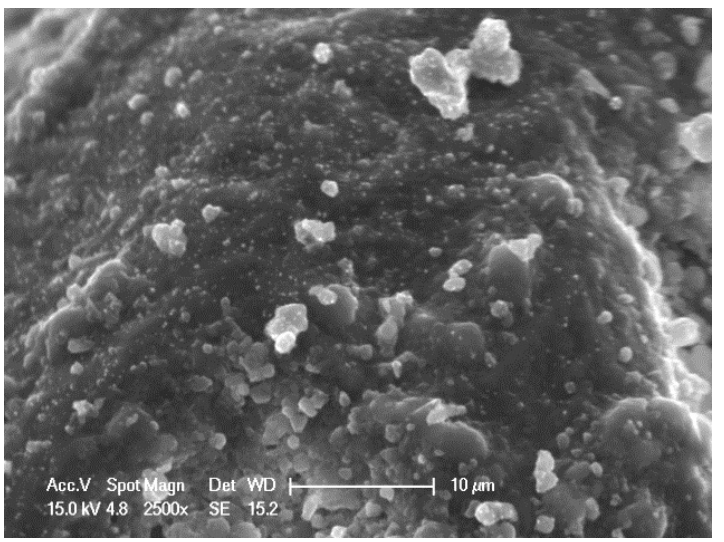

62LA38MK

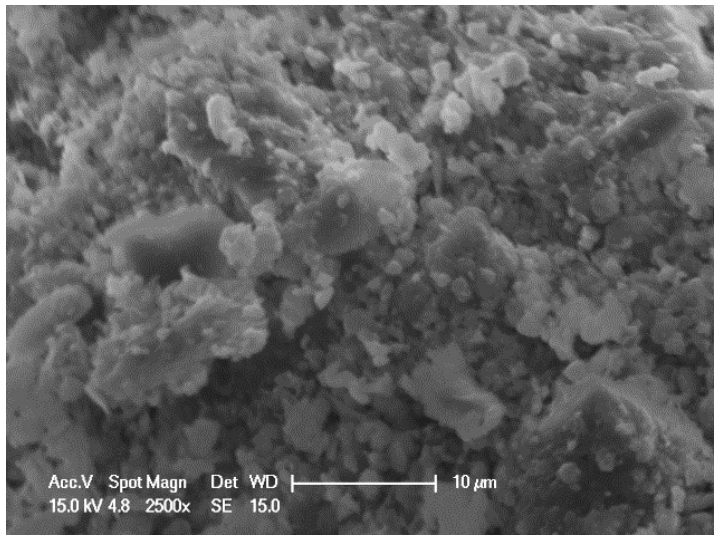

37LA63MK

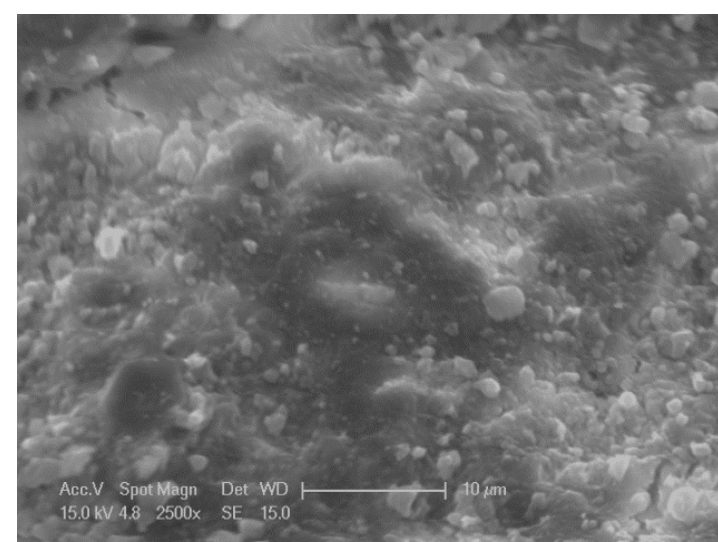

100HA

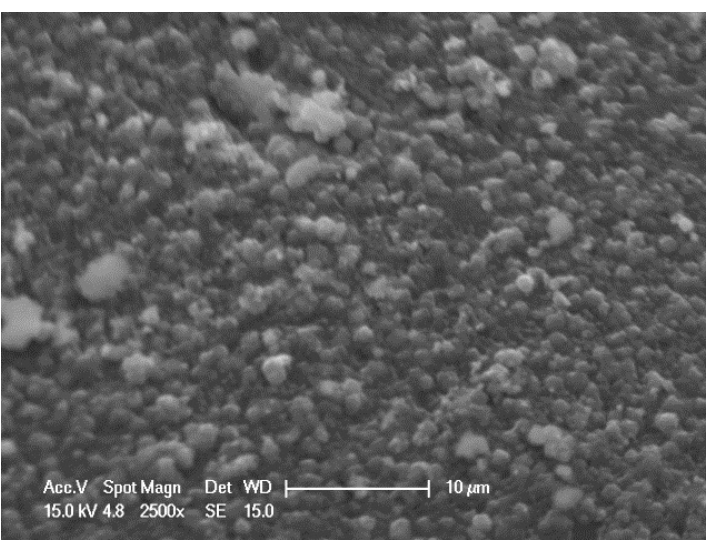

75HA25MK

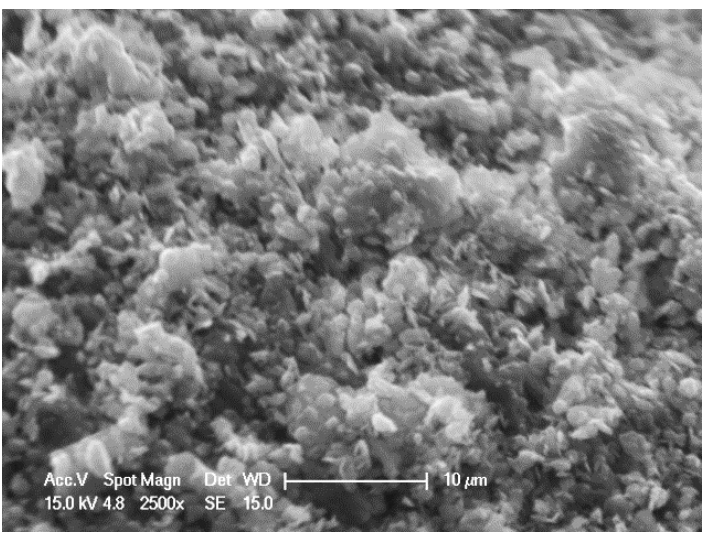

$100 \mathrm{MK}$

Figure 4.56. Secondary electron imaging of Phase III fracture surfaces at 28 days. 
Based on the fracture surfaces it appears the 100HA and 62LA38MK mixtures resulted in the densest most continuous microstructures, but fracture surfaces can be deceiving. Much more information is revealed in the next section covering polished cross section analysis.

\subsubsection{Polished cross section analysis}

Polished cross sections were analyzed using backscatter electron imaging on carbon-coated surfaces at 14 days. This analysis further elucidated the differences in the microstructure of the mortars, as shown in Figure 4.57 where a bulk matrix image of each mixture is shown for comparison. 


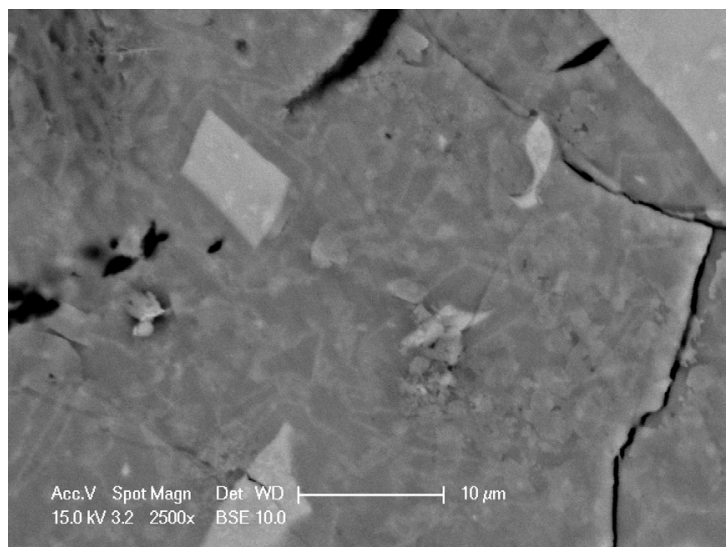

100LA
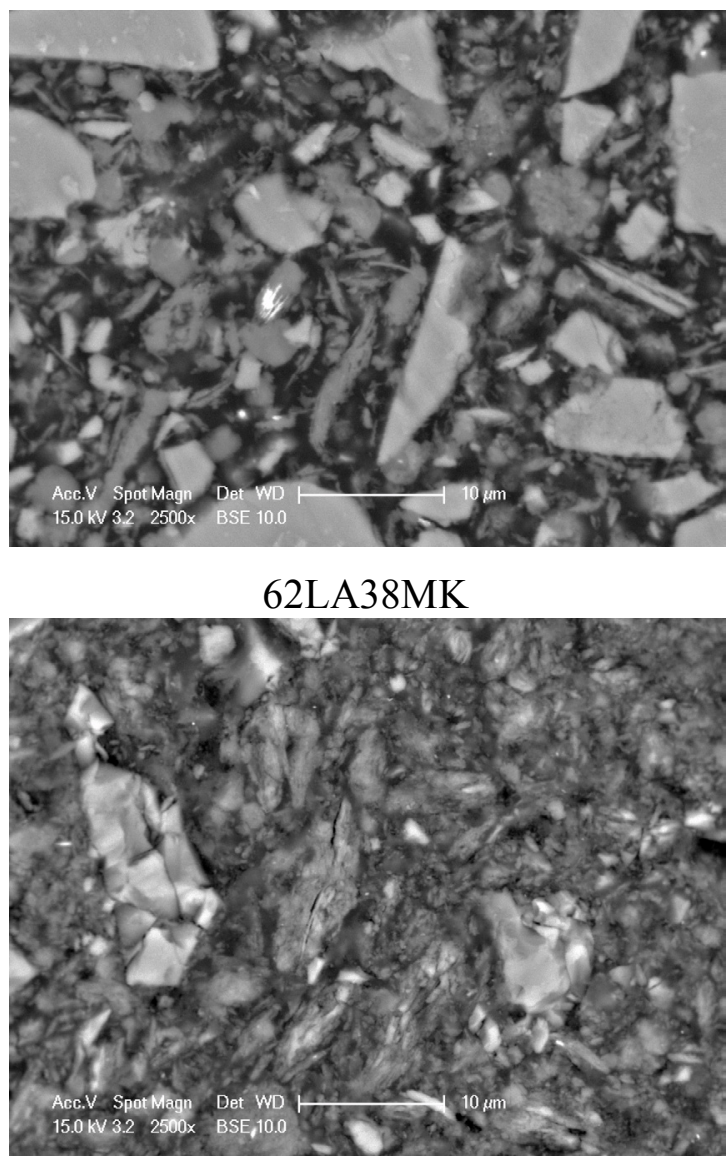

37LA63MK

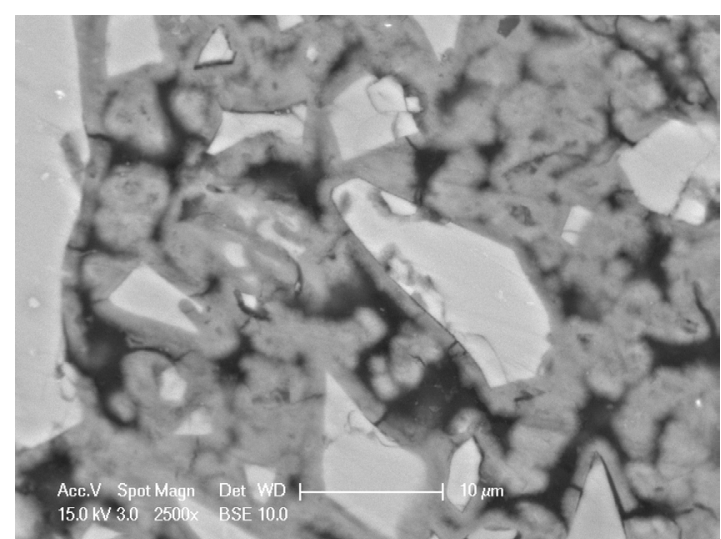

100HA

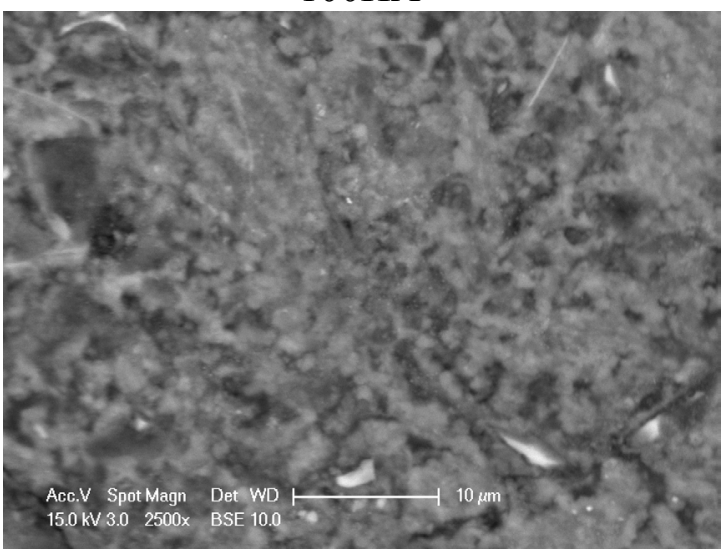

$75 \mathrm{HA} 25 \mathrm{MK}$

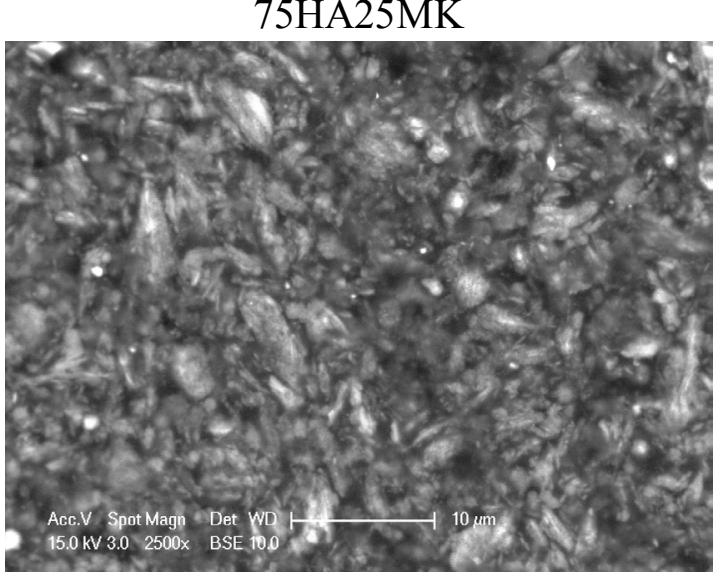

$100 \mathrm{MK}$

Figure 4.57. Polished cross sections of Phase III mortars at 14 days.

Beginning with the LA500 mixture, the microstructure was unique and exhibited signs of severe shrinkage, as shown at a decreased magnification in Figure 4.58. The paste 
separated from the aggregate particles in many places and cracking occurred throughout. The cracks within the matrix did not seem to occur around the interface of the unreacted glass particles but rather through them, indicating a very strong bond between the glass particles and the matrix; this can be seen in the microstructure.

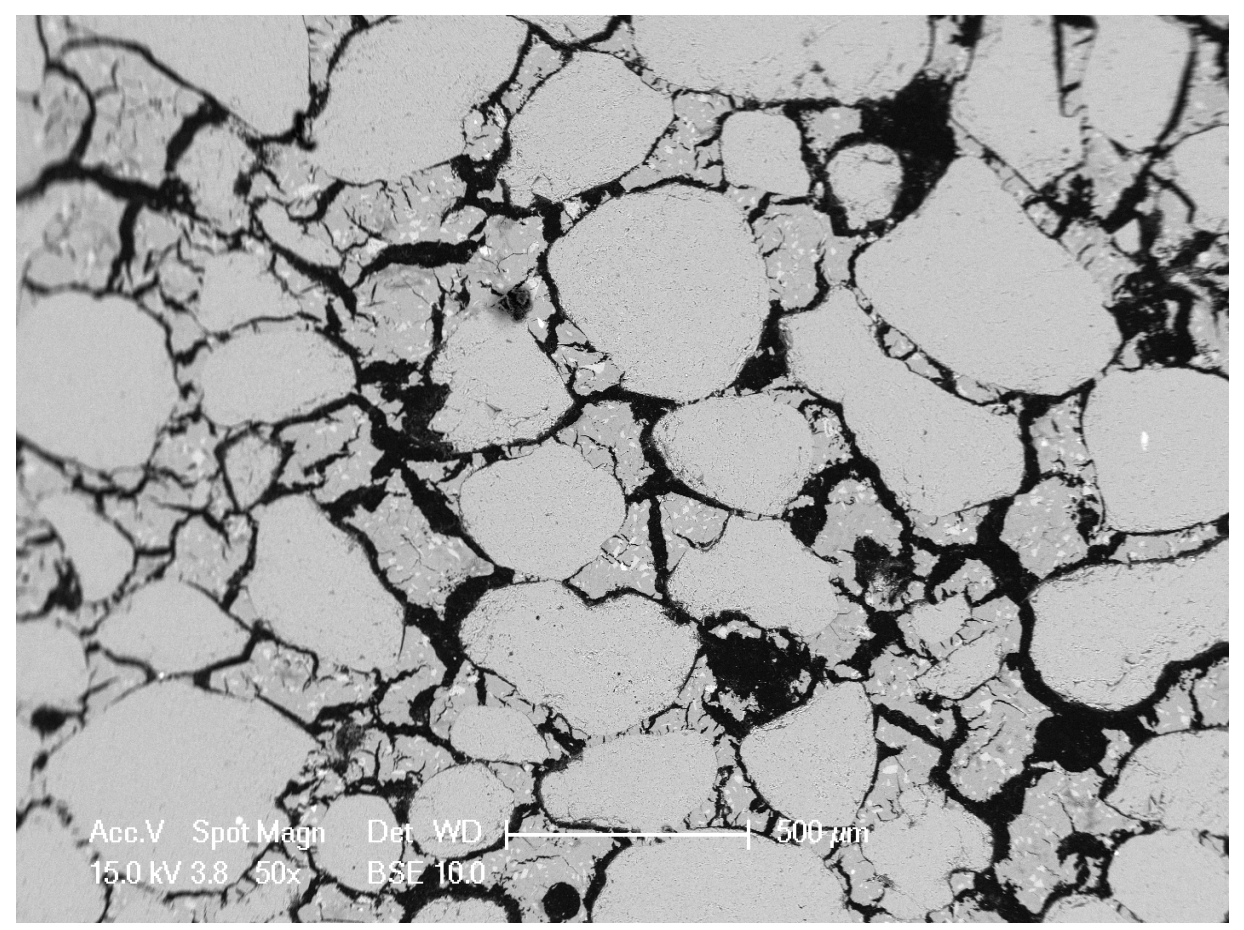

Figure 4.58. Micrograph illustrating the extensive cracking in the 100LA mixture at 14 days.

The 100LA matrix itself was extremely continuous, the most continuous of all of the mixtures analyzed. This smooth, dense continuous microstructure is indicative of a high $\mathrm{Si}$ content. Within the matrix, two main phases were visible, that of the continuous geopolymer that formed and what appeared to be unreacted glass particles as verified by EDS microanalysis. Within the continuous matrix, the very faint outlines of angular particles were visible indicating where reacted glass particles once were. 
In addition, several randomly distributed bright particles, like the one shown in Figure 4.59 were found. EDS microanalysis found these particles were made of mainly Si and alkalis $\left(\mathrm{Na}^{+}\right.$and $\left.\mathrm{K}^{+}\right)$. This could be a crystalline form of sodium silicate and most likely formed because there is very little aluminum to tie up the alkalis.

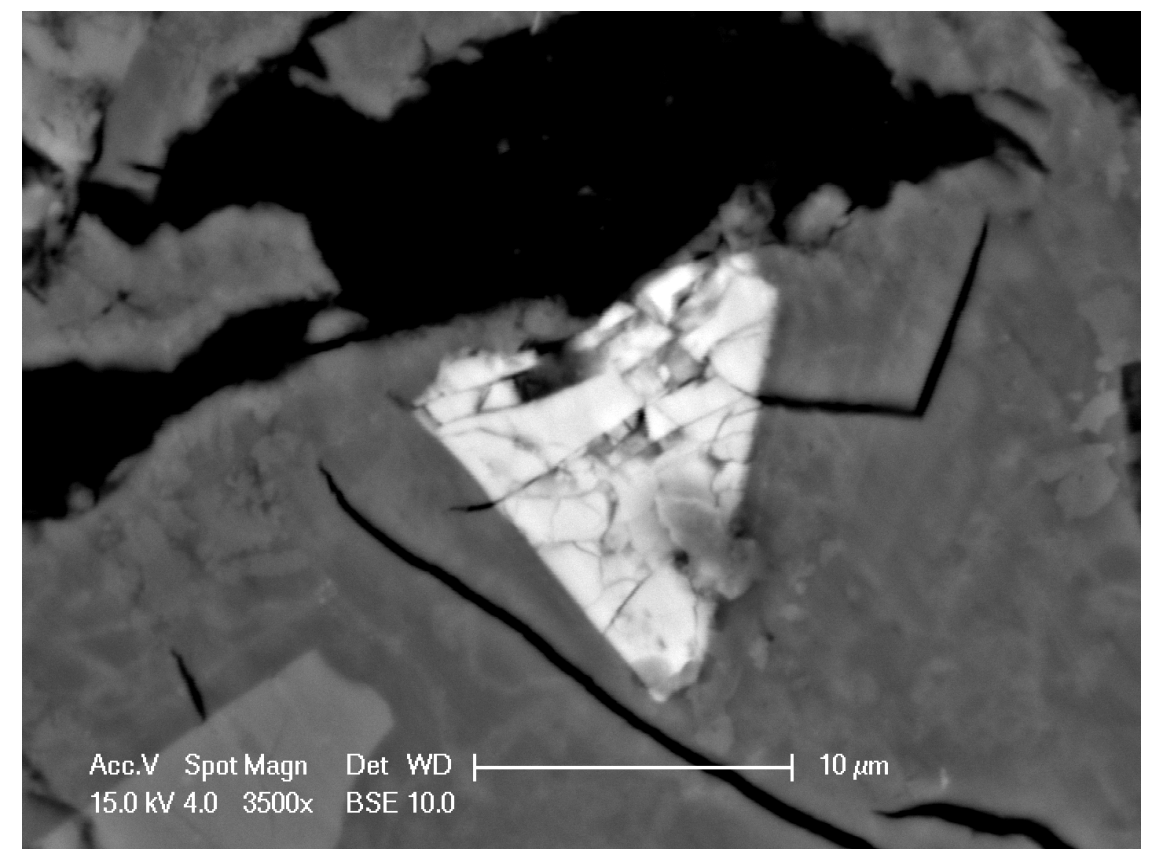

Figure 4.59. Bright crystalline phase found embedded in 100LA mixture consisting of mainly $\mathrm{Si}$, and a small amount of $\mathrm{Al}$ and alkalis.

The 62LA38MK mixture was remnant of the 50HA50MK mixture in Phase II, where significant void space (epoxy-filled) existed amongst unreacted metakaolin and glass particles. Since some strength was present there was obviously some geopolymer that formed to hold the mortar together, but little could be detected and when it was, it was too porous to analyze. Another possibility could be the geopolymer product existed as zeolites and a thin reaction layer around the unreacted particles holding them together but not giving any strength. A similar microstructure was found in the 37LA63MK mixture, except 
the metakaolin particles seemed more frequent and also smaller indicating that perhaps the smaller metakaolin particles in the 62LA38MK mixture reacted completely. Neither of these mixtures developed appreciable strength.

The 100MK mixture, which gained very little strength (practically crumbled when handled) also had the highest water/solids ratio and appeared like a fuzzy sweater under backscatter electron imaging. The metakaolin particles ranged from very small to large flocs as shown in Figure 4.60. The presence of these large flocs is likely what causes the low compressive strength.

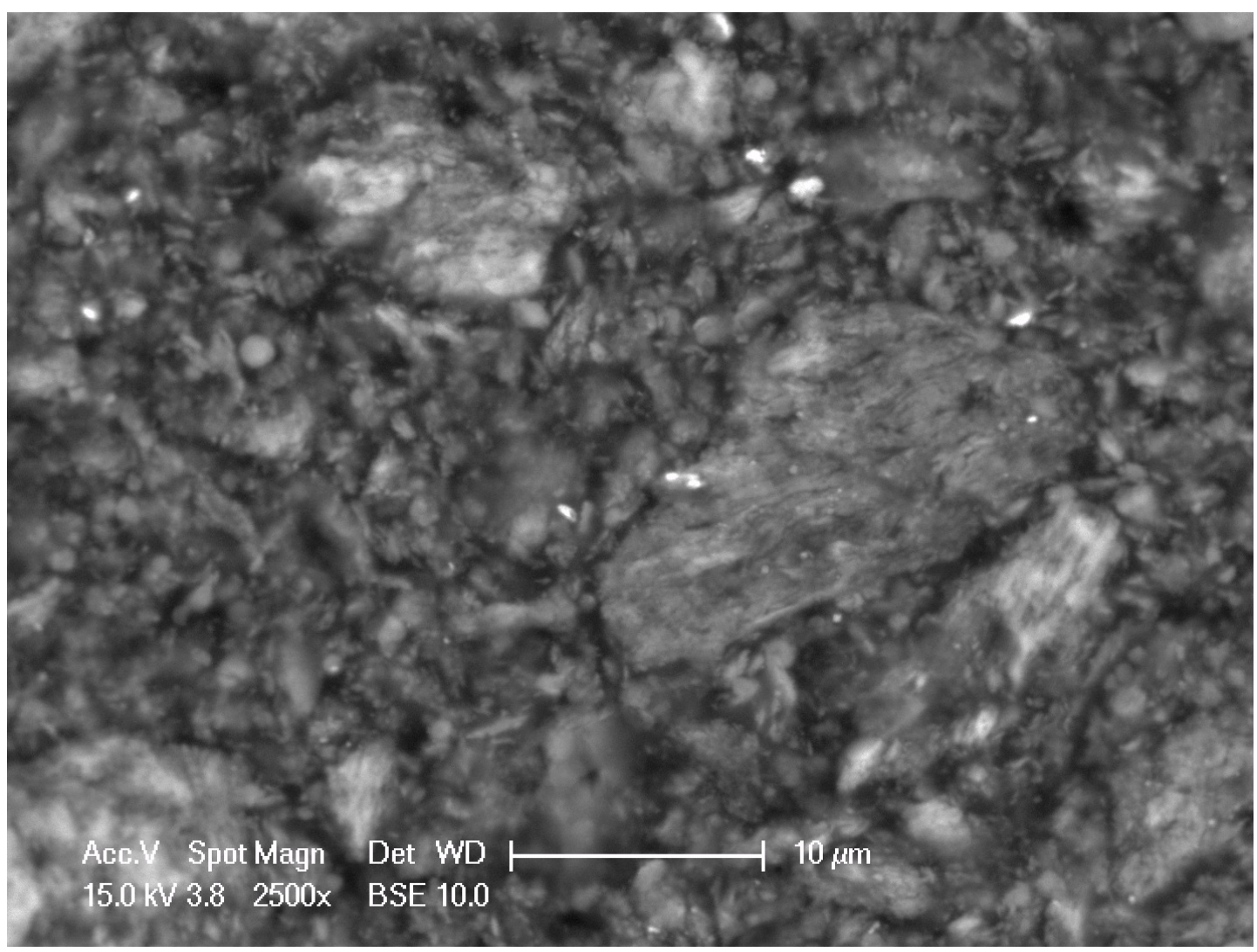

Figure 4.60. Micrograph illustrating the large flocs of metakaolin particles present within the $100 \mathrm{MK}$ matrix at 14 days. 
The microstructure of the mixtures in Phase III is quite different from those found in Phase II; even for the two mixtures using HA glass that were essentially the same as in Phase II, 100HA and 75HA25MK. The differences between Phase II and Phase III HA mixtures include the water/solids ratio, curing temperature and mean glass particle size. The microstructure of the 100HA mixture was interesting and remnant of the mixtures in Phase I made with the coarse glass. Layers of reaction product were tightly intermixed in and around the unreacted glass particles, with voids existing where reaction layers failed to reach each other. This does not seem like it would be strong, but it is and is the strongest mixture of Phase III. This is much different than results from Phase II when the dotted reaction rim was visible in the $100 \mathrm{HA}$ mixture.

The 75HA25MK mixture appeared much more continuous than the 100HA mixture and did not show the layer of reaction products around the glass particles but resulted in a lower compressive strength. No unreacted metakaolin particles were visible. Glass particles were well embedded into the matrix without the presence of the reaction rim present in $100 \mathrm{HA}$ glass mixtures or the layer of reaction product in Phase I.

\subsubsection{Phase composition}

Using backscatter electron imaging to identify varying elemental intensities and phases present within the microstructure, the elemental composition of the geopolymer reaction products were identified by microanalysis. A minimum of six analyses were performed on each mixture and statistics on the EDS analysis of each mixture can be found in Appendix C. 
Table 4.14 shows the mixtures listed in order of maximum 201-day compressive strength and the resulting average molar ratios in the geopolymer product measured through microanalysis. It should be noted the 62LA38MK, 37LA63MK and 100MK mixtures did not react enough to produce adequate volumes of geopolymer to measure and only unreacted particles were visible in cross section.

Any trends between molar ratio and compressive strength were difficult to discern based on the vast differences between the molar ratios of the 100LA mixture and the other mixtures as well as the fact that three did not form enough geopolymer to measure.

Table 4.14. Average bulk molar ratios ordered in terms of maximum compressive strength at 14 days

\begin{tabular}{|c|c|c|c|c|c|c|}
\hline Mix ID & Rank & $\begin{array}{c}\text { Compressive } \\
\text { strength } \\
\text { (psi) }\end{array}$ & $\mathbf{S i} / \mathbf{A l}$ & $\mathbf{N a} / \mathbf{A l}$ & $\mathbf{N a} / \mathbf{S i}$ & $\mathbf{C a} / \mathbf{S i}$ \\
\hline $100 \mathrm{HA}$ & $1^{\text {st }}$ & 2208 & 9.43 & 2.59 & 0.32 & 0.38 \\
\hline $75 \mathrm{HA} 25 \mathrm{MK}$ & $2^{\text {nd }}$ & 1440 & 3.56 & 1.19 & 0.34 & 0.21 \\
\hline $100 \mathrm{LA}$ & $3^{\text {rd }}$ & 876 & 193.55 & 49.59 & 0.25 & 0.16 \\
\hline $37 \mathrm{LA} 63 \mathrm{MK}$ & $4^{\text {th }}$ & 535 & - & - & - & - \\
\hline $62 \mathrm{LA38MK}$ & $5^{\text {th }}$ & 373 & - & - & - & - \\
\hline $100 \mathrm{MK}$ & $6^{\text {th }}$ & 206 & - & - & - & - \\
\hline
\end{tabular}

The calculated bulk and actual measured molar ratios for all of the mixtures were fairly close except in the 100LA mixture where the ratios were off by quite a bit. Radar graphs illustrating the comparison between actual and bulk molar ratios are shown in Figure 4.61 and Figure 4.62. 


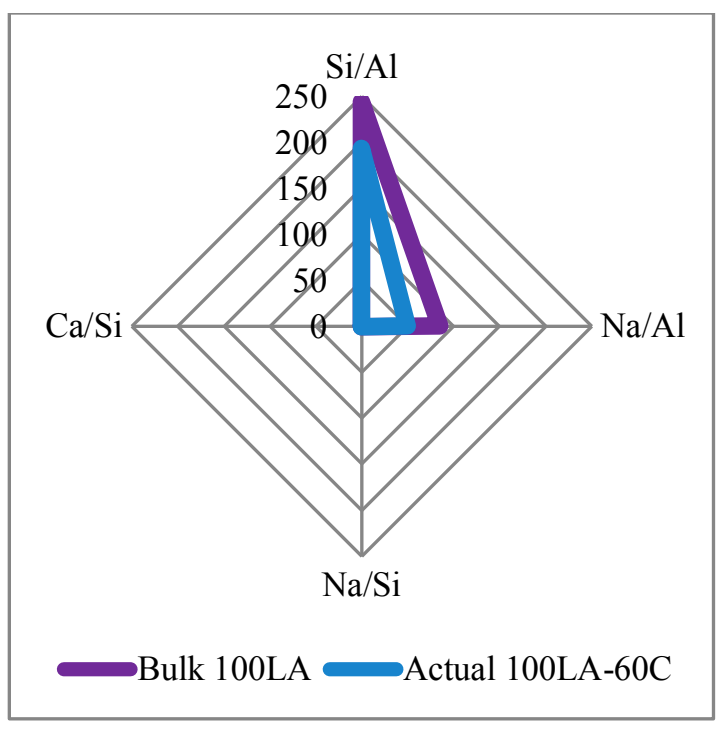

Figure 4.61. Bulk vs actual molar ratios for the 100LA mixture.
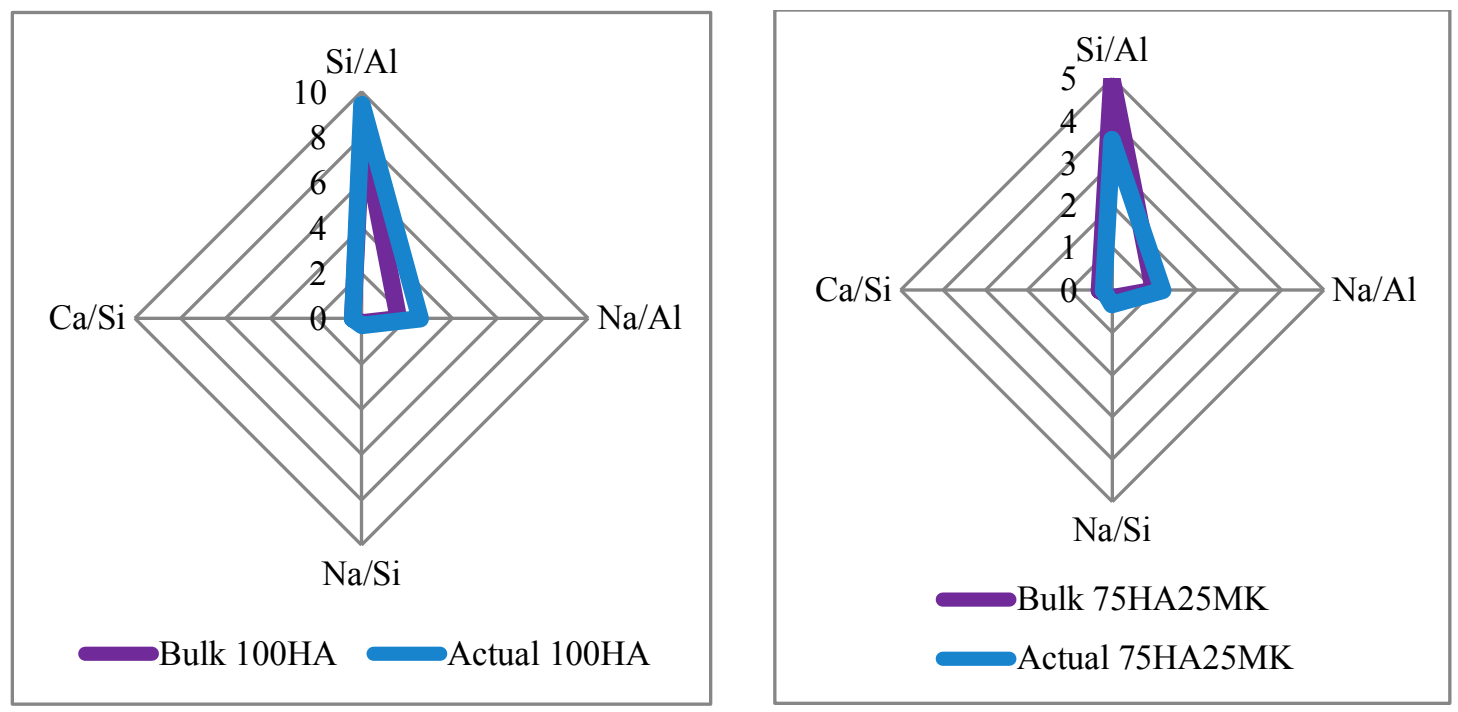

Figure 4.62. Bulk vs actual molar ratios for the 100HA mixture (left) and 75HA25MK mixture (right).

\subsubsection{Degree of reaction, $\alpha$}

Figure 4.63 shows the degree of reaction measurements for Phase III at 14 and 28 days. Nearly all of the mixtures in Phase III obtained 60-80\% degree of reaction at 14 days and only the 100HA mixture, which originally was the lowest, increased substantially from 14 
to 28 days. This was also the mixture that obtained the highest strength. This was overall lower than in Phase II mixtures except for the 50HA50MK mixture, which was similar.

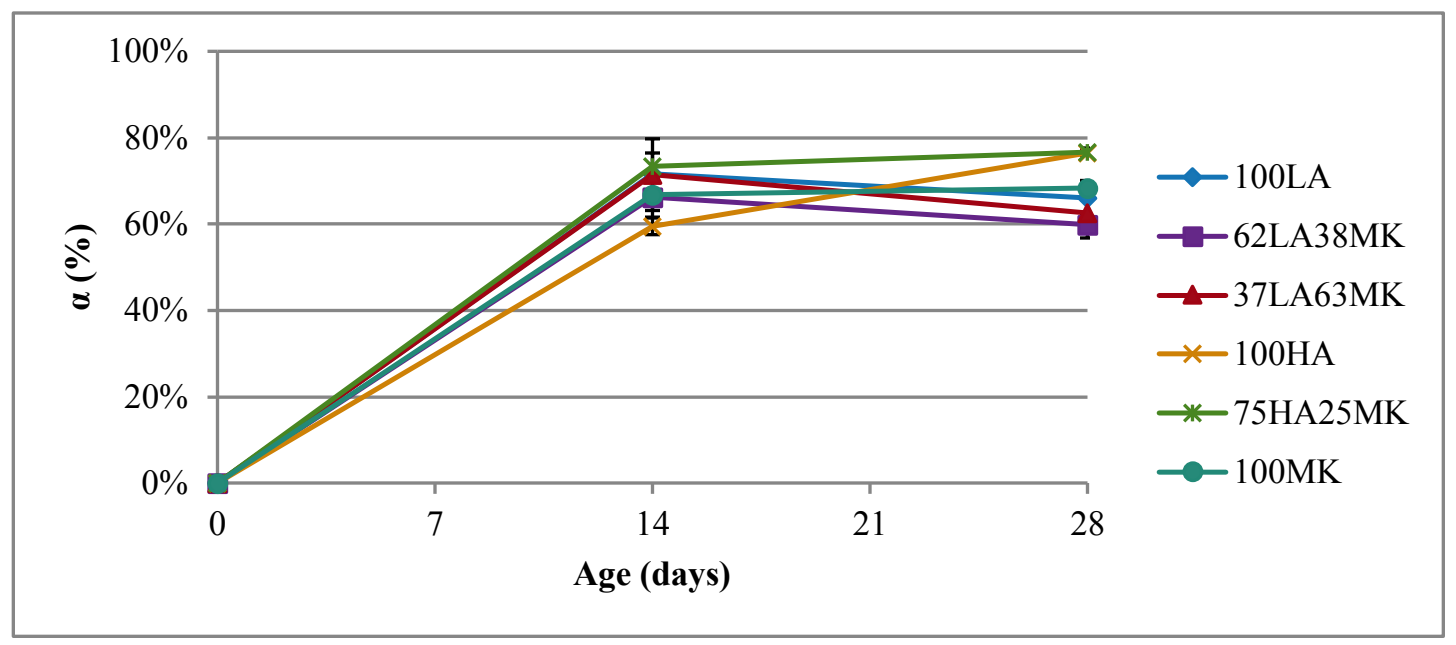

Figure 4.63. Degree of reaction results from Phase III mortars cured at $60^{\circ} \mathrm{C}$.

\subsubsection{Calorimetry}

\subsubsection{Adiabatic calorimetry}

Adiabatic calorimetry was performed on three mixtures, made entirely of LA500 glass and varying amounts of water, to assess the calorimetric effects of changing the water/solids. The results are shown in Figure 4.64 and indicate that a higher initial temperature was reached as water content was decreased, but after that not much was different and the mixtures behaved about the same through 150 hours. A higher temperature was reached at lower water/solids ratio. The first peak in calorimetry is known to be due to dissolution. However, this peak had passed by the time the calorimetry measurements began, 20-30 minutes after initial mixing. More water present in the mixture could dilute the activator solution leading to less dissolution. 


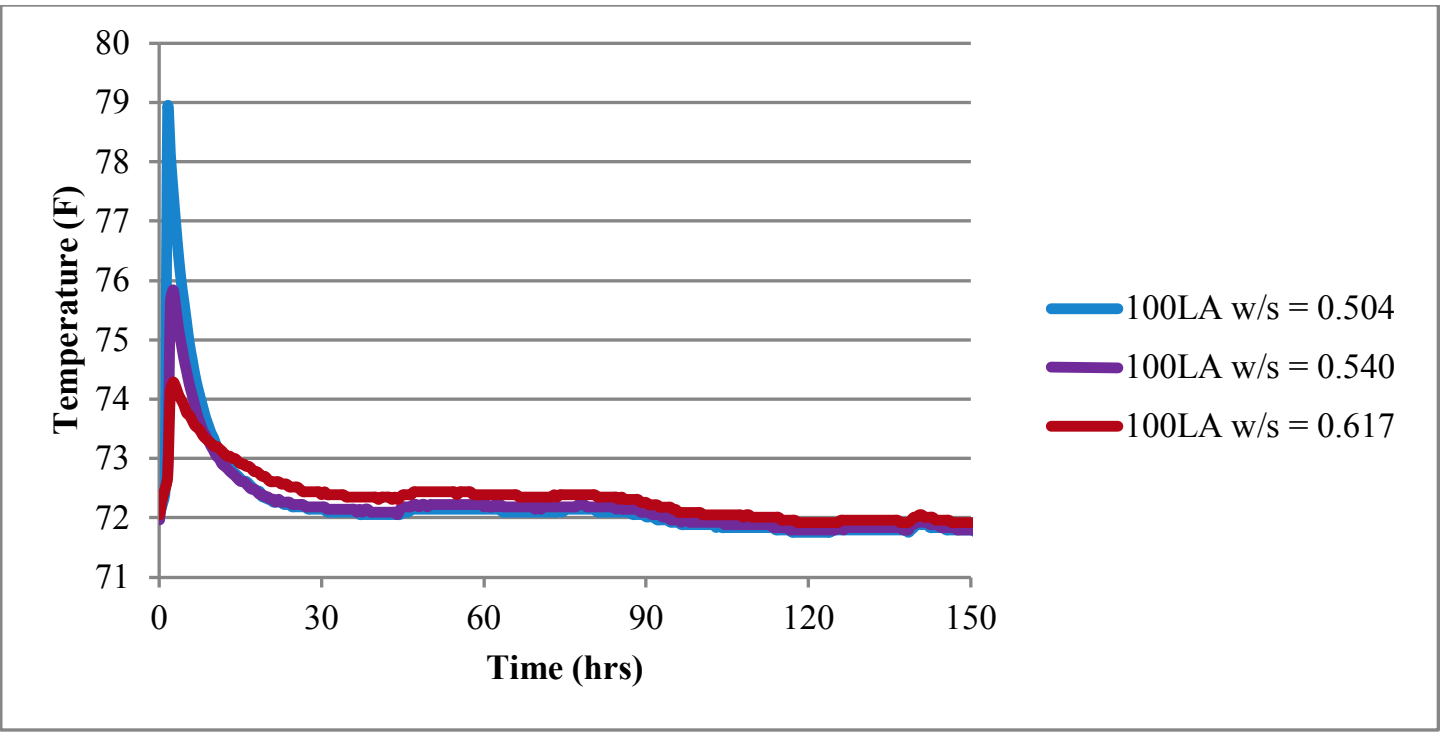

Figure 4.64. Adiabatic calorimetry curves measured for LA500 glass with three different water/solids ratios.

Figure 4.65 shows the adiabatic calorimetry curves for all six mixtures in Phase III. The 37LA63MK mixture showed the highest peak reading a temperature of over $95^{\circ} \mathrm{C}$. This may have been thought to be the $100 \mathrm{MK}$ mixture. However, the water/solids ratio of that mixture was higher and from Figure 4.64 it can be seen that a lower temperature peak is caused by a higher water/solids ratio. Also, the $62 \mathrm{LA} 38 \mathrm{MK}$ mixture had a moderate temperature. The two $100 \%$ glass mixtures both showed much lower, longer peaks with the $75 \mathrm{hA} 25 \mathrm{MK}$ being more similar to those mixtures but just a bit higher, most likely due to the metakaolin. It was also observed in Phase II that a higher temperature is reached when the mixtures include metakaolin; this is also true in this case as well. 


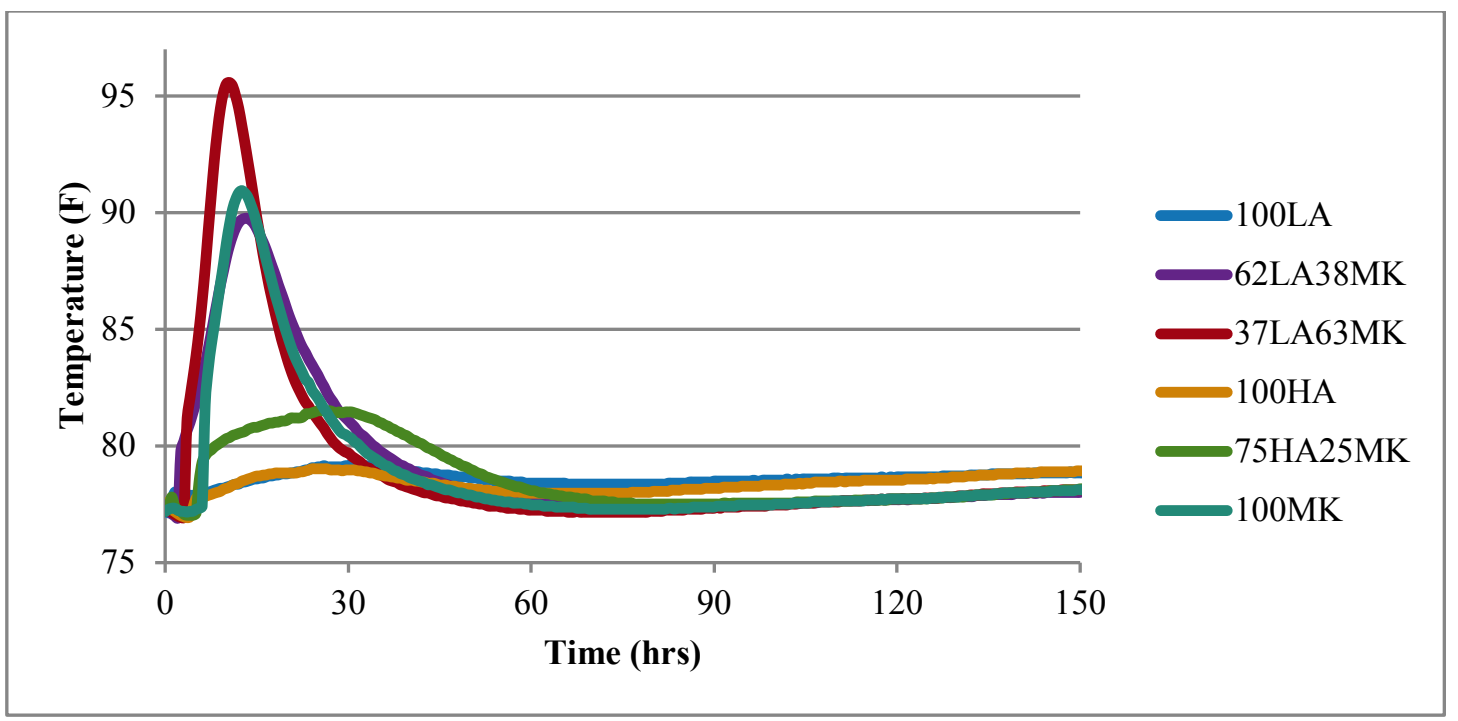

Figure 4.65. Comparison of all six mixtures in Phase III.

\subsubsection{Isothermal calorimetry}

Figure 4.66 shows the isothermal calorimetry curves for the six mixtures in Phase III. Calorimetry was conducted at $60^{\circ} \mathrm{C}$ and has yielded interesting results, especially as compared to the adiabatic calorimetry curves for the same mixtures cured in ambient temperatures.

There are clear differences between the shape of each curve as measured by adiabatic or isothermal calorimetry, but among all of the curves, the length of reaction is the opposite of what was expected. It was expected that curing at higher temperatures would speed up the rate of reaction significantly and that under ambient conditions, the reactions would appear more drawn out with less significant heat peaks.

It is clear that the opposite was true, where the reaction at $60^{\circ} \mathrm{C}$ clearly continued for a longer period of time. This most likely indicates that less reaction occurs at lower 
temperatures than at higher temperatures, which is often evidenced by the extremely low temperatures found in ambiently cured geopolymers with little calcium content.

The delayed peak of the $62 \mathrm{LA} 38 \mathrm{MK}$ mixture was interesting, especially since the microstructure of this mixture showed a lot of unreacted metakaolin and glass with little geopolymer product visible. Further studies concerning the calorimetry of glass geopolymers should be explored.

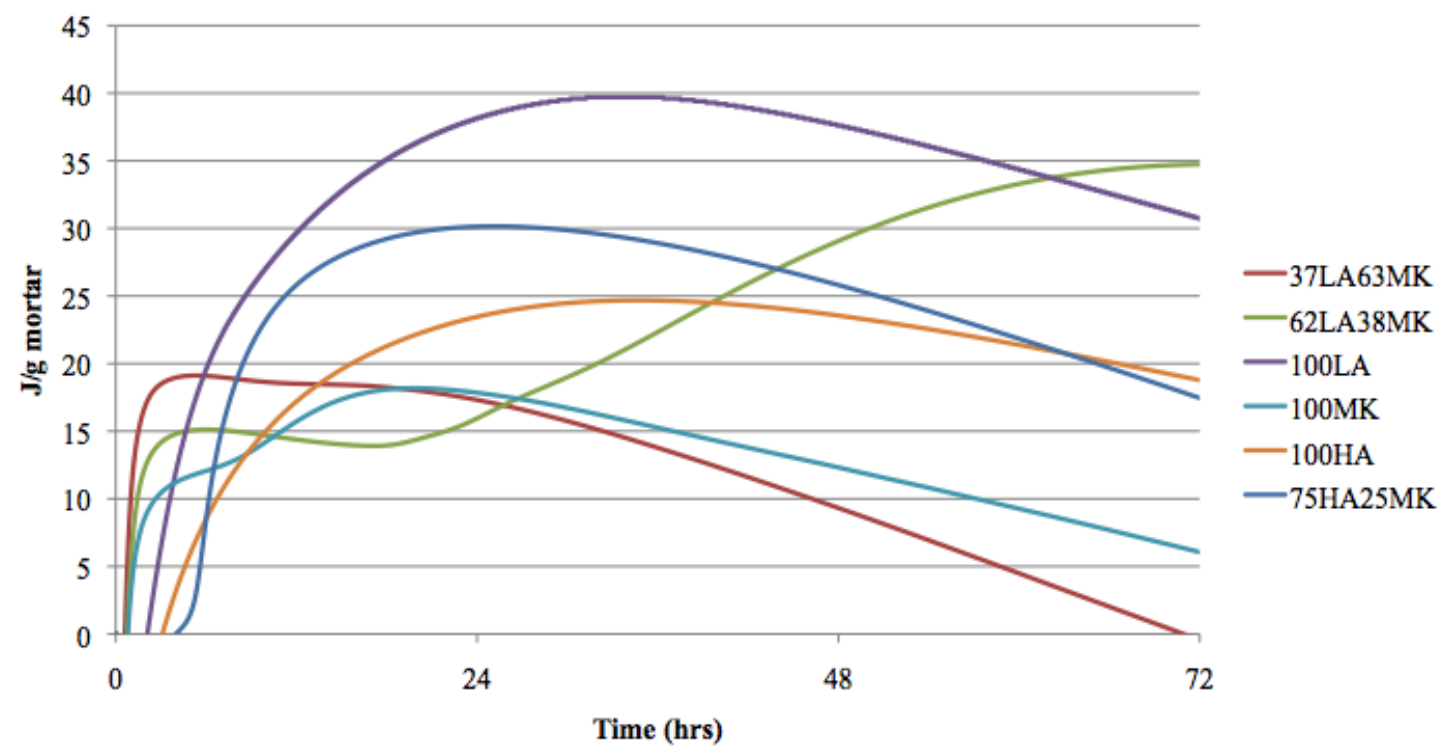

Figure 4.66. Isothermal calorimetry curves for all six mixtures cured at $60^{\circ} \mathrm{C}$ for 72 hours.

\subsubsection{Curing at $80^{\circ} \mathrm{C}$}

An additional investigation was carried out on three LA mortars cured at $80^{\circ} \mathrm{C}$ for 24 hours. Fresh properties are shown in Table 4.15; they were very similar to the initial mixtures cured at $60^{\circ} \mathrm{C}$. 
Table 4.15. Fresh properties of Phase III mixtures cured at $80^{\circ} \mathrm{C}$. All of the values reported are the average of three measurements.

\begin{tabular}{|c|c|c|c|c|}
\hline $\begin{array}{c}\text { Mixture } \\
\text { ID }\end{array}$ & $\begin{array}{c}\text { Water/solids } \\
\text { ratio }\end{array}$ & $\begin{array}{c}\text { Percent Flow } \\
(\mathbf{\%})\end{array}$ & $\begin{array}{c}\text { Temperature } \\
\left({ }^{\circ} \mathbf{F}\right)\end{array}$ & $\begin{array}{c}\text { Unit weight } \\
(\mathbf{g} / \mathbf{m L})\end{array}$ \\
\hline 100LA-80 & 0.550 & $120 \%$ & 85.83 & 2.05 \\
\hline $62 \mathrm{LA}-80$ & 0.550 & $51 \%$ & 89.17 & 2.09 \\
\hline $37 \mathrm{LA}-80$ & 0.550 & $0 \%$ & 96.17 & 1.95 \\
\hline
\end{tabular}

\subsubsection{Compressive strength}

Compressive strength was measured at 1, 3, 7, 14 and 28 days and compared to the results from the corresponding mortars cured at $60^{\circ} \mathrm{C}$. The results for each of the three mixtures are shown in Figure 4.67, Figure 4.68 and Figure 4.69.

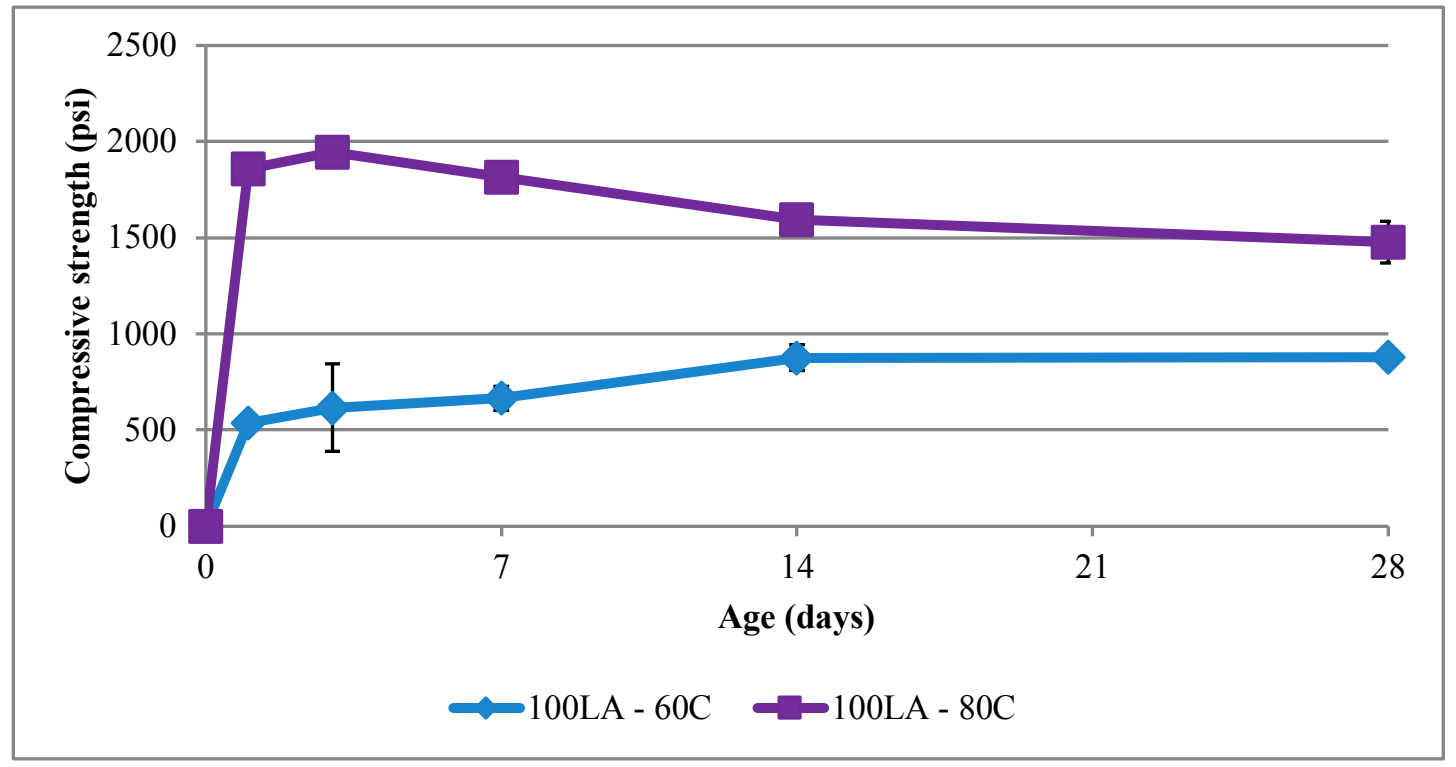

Figure 4.67. Comparison of the compressive strength measured for the $60^{\circ} \mathrm{C}$ and $80^{\circ} \mathrm{C}$ curing regimes through 28 days for the 100LA mixture. Each data point is the average of three cylinders.

There was a substantial increase of compressive strength in the 100LA mixture when the curing temperature was increased to $80^{\circ} \mathrm{C}$. However, the compressive strength profiles of 
the two mixtures seem to be converging with the lower cured mixture gaining strength and the higher cured mixture losing strength.

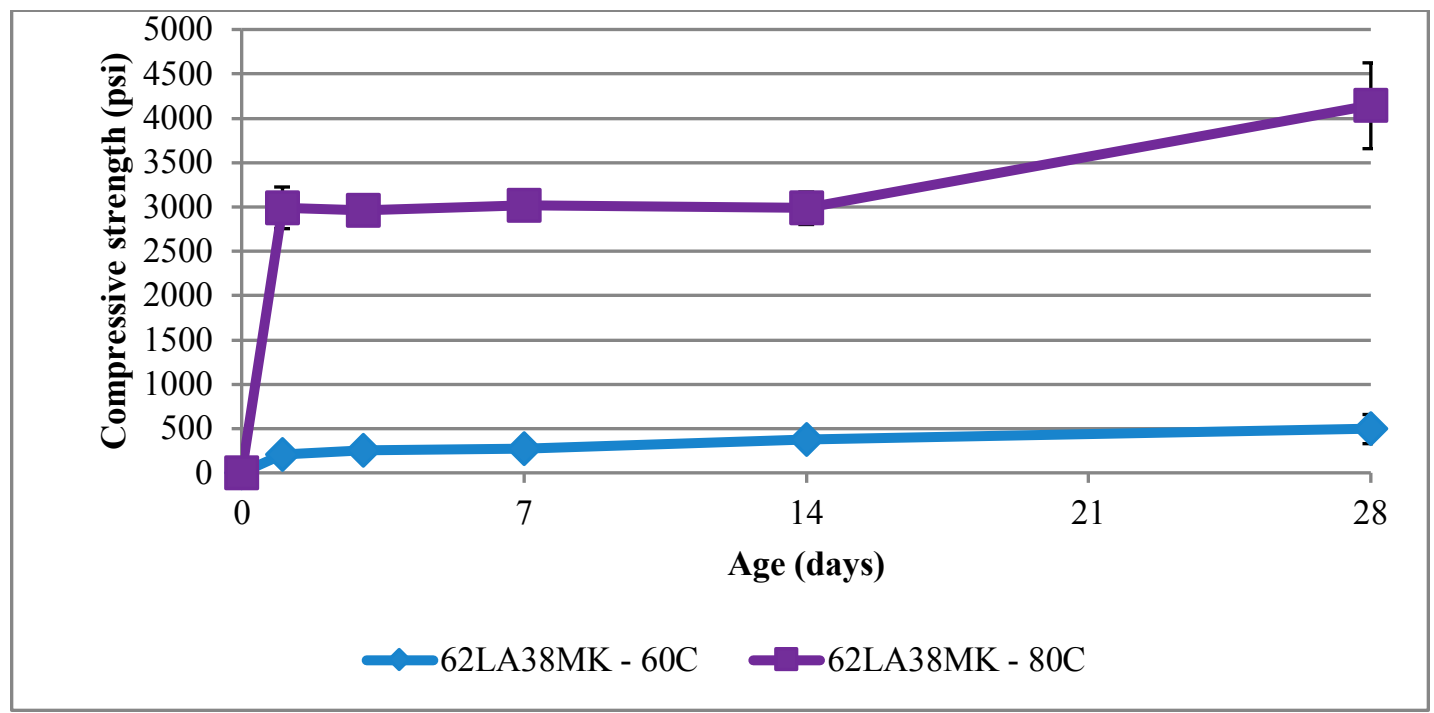

Figure 4.68. Comparison of the compressive strength measured for the $60^{\circ} \mathrm{C}$ and $80^{\circ} \mathrm{C}$ curing regimes through 14 days for the $62 \mathrm{LA} 38 \mathrm{MK}$ mixture. Each data point is the average of three cylinders.

The most substantial compressive strength increase between $60^{\circ} \mathrm{C}$ and $80^{\circ} \mathrm{C}$ curing conditions occurred in the 62LA38MK mixture. At one day, the compressive strength increased from $250 \mathrm{psi}$ to nearly $3000 \mathrm{psi}$. This is a drastic improvement, though no further strength gain had been measured at 14 days. 


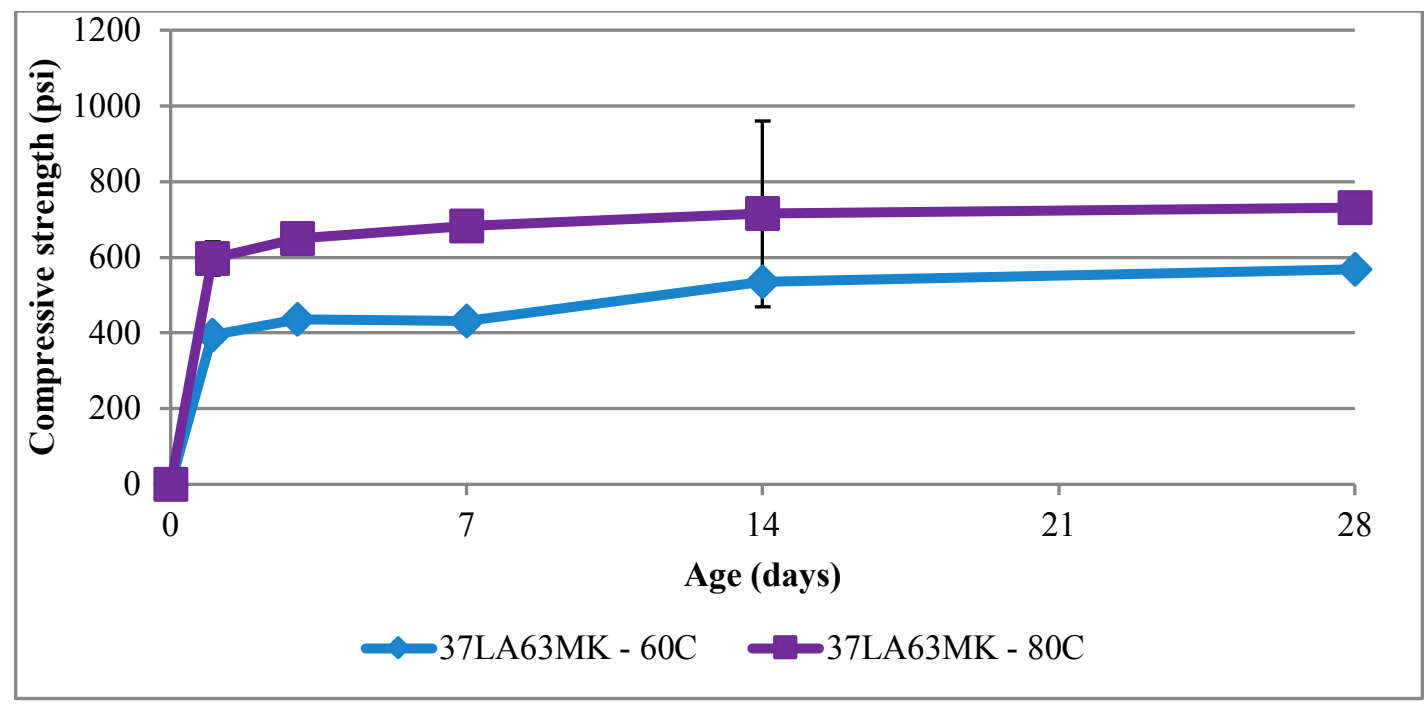

Figure 4.69. Comparison of the compressive strength measured for the $60^{\circ} \mathrm{C}$ and $80^{\circ} \mathrm{C}$ curing regimes through 14 days for the $37 \mathrm{LA} 63 \mathrm{MK}$ mixture. Each data point is the average of three cylinders.

Among the 37LA63MK mixture there was not a very significant increase in strength as compared to the other mixtures. Both mixtures appear to be continuing to gain strength through 14 days.

In addition to the comparison of $60^{\circ} \mathrm{C}$ or $80^{\circ} \mathrm{C}$ curing for 24 hours, samples of the six original mortars in Phase III were also cured at $60^{\circ} \mathrm{C}$ for 72 hours to see if increasing the curing time would result in a substantial compressive strength increase. The combination of all three curing regimes is shown in Figure 4.70. It is clear for the LA mixtures, the higher temperature curing resulted in higher compressive strength; this is also true for the HA mixtures if one considers the results of samples cured during Phase I and II. There was very little effect on the 37LA63MK mixture when cured under different conditions. 


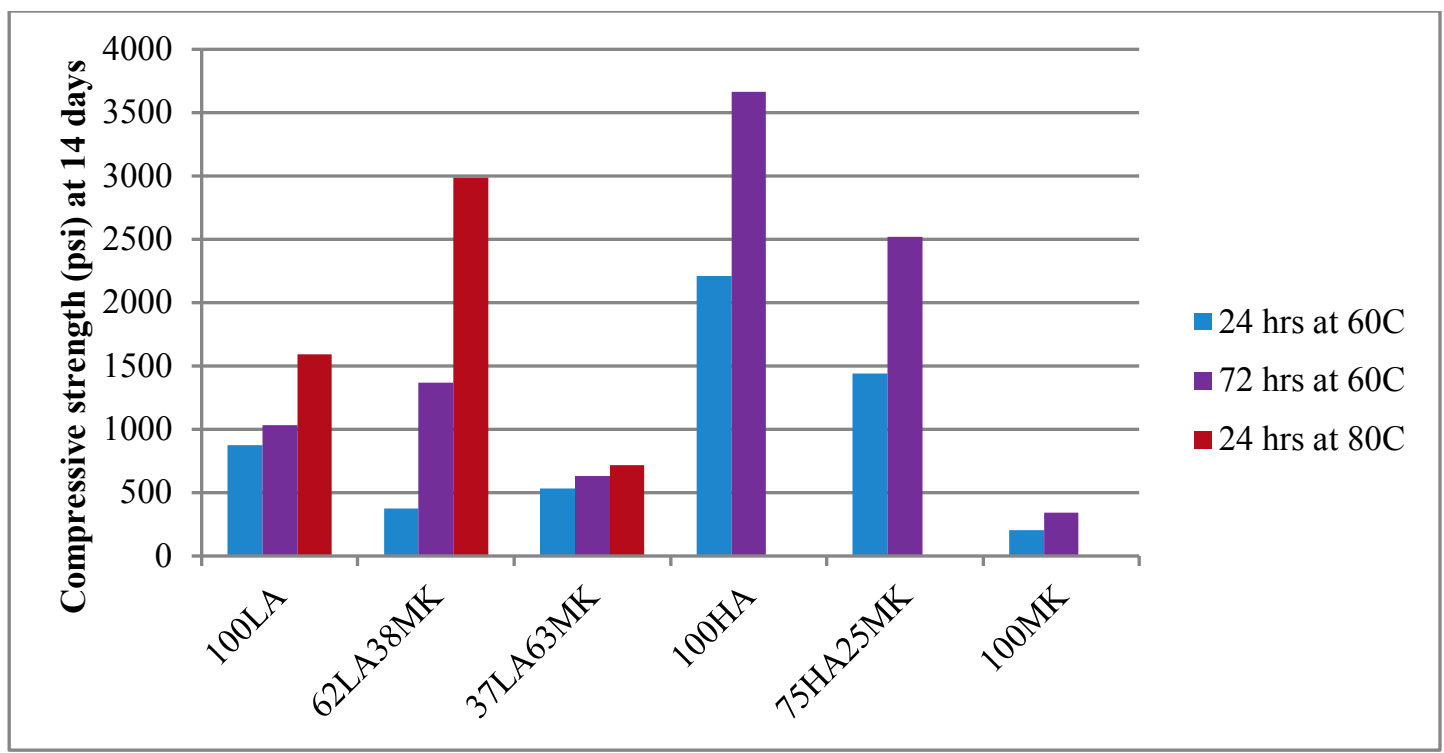

Figure 4.70. Comparison of Phase III mixtures at 14 days under various curing regimes.

\subsubsection{Microstructural analysis}

Polished cross sections of each LA mixture considered is shown in Figure 4.71 next to the corresponding mixture cured at $80^{\circ} \mathrm{C}$ for comparison. 

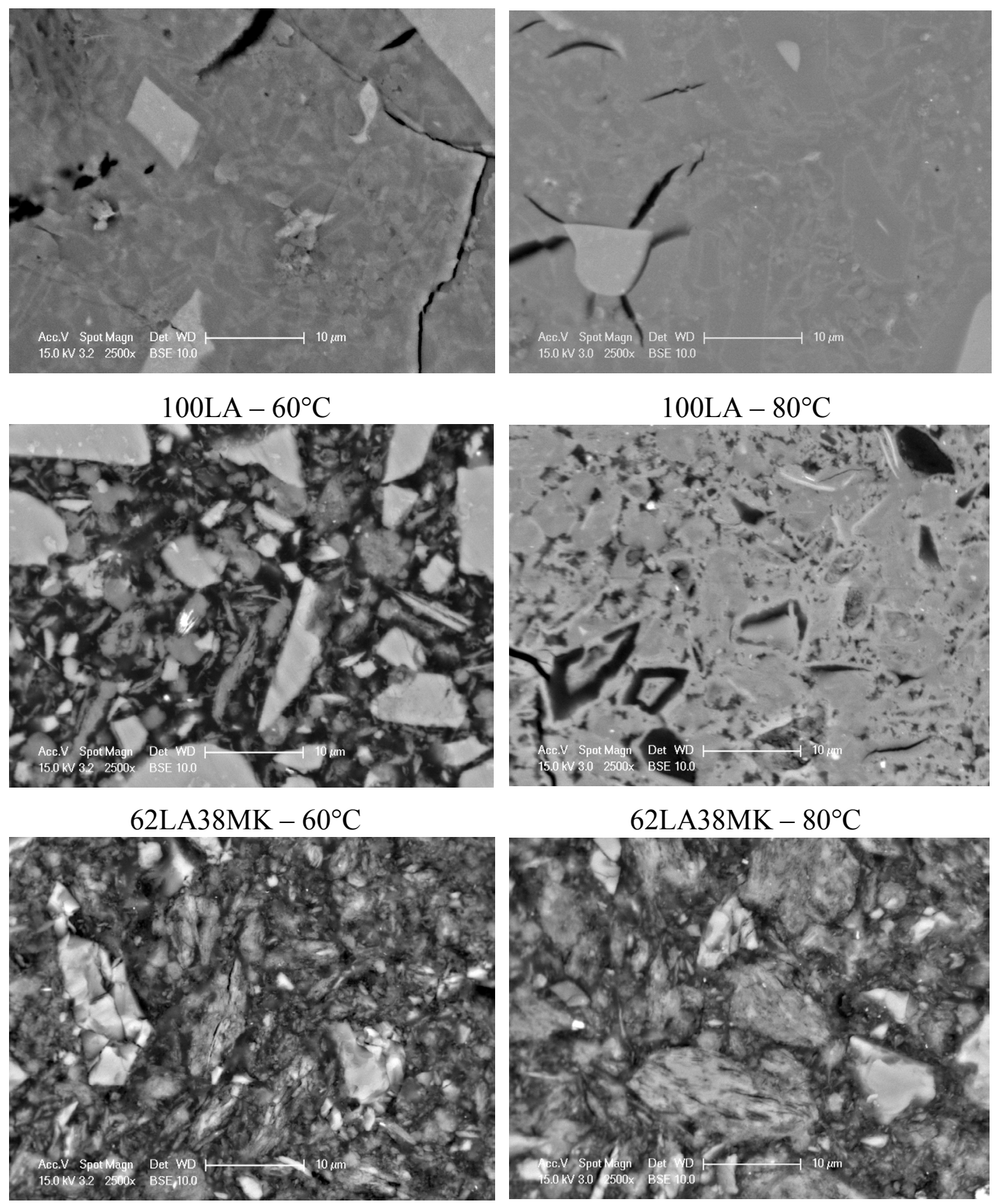

37LA63MK $-60^{\circ} \mathrm{C}$

$37 \mathrm{LA} 63 \mathrm{MK}-80^{\circ} \mathrm{C}$

Figure 4.71. Polished sections of the mortars cured at $60^{\circ} \mathrm{C}$ compared to those cured at $80^{\circ} \mathrm{C}$ in Phase III. 
There was not much change observed between the microstructures of the 100LA mixtures cured at $60^{\circ} \mathrm{C}$ or $80^{\circ} \mathrm{C}$. The paste was still extremely uniform with glass particles well embedded and it was still shrunken away from the aggregate and cracked quite severely. Likewise, the 37LA63MK mixture did not appear much different under the different curing temperatures.

However, there was a substantial and interesting change in the microstructure of the 62LA38MK mixture as evidenced in Figure 4.71 and by the drastic increase in compressive strength between $60^{\circ} \mathrm{C}$ and $80^{\circ} \mathrm{C}$ curing. Figure 4.72 shows a low magnification micrograph of the microstructure in question. The microstructure is really quite interesting as unreacted glass particles present appear to have a thick layer of reaction product surrounding them but there is a fairly wide space between this and the rest of the matrix. This phenomenon is shown magnified in Figure 4.73.

Additionally, though the large spaces exist between the unreacted glass and matrix, the shrinkage cracking as seen in the 100LA mixture was not present. 


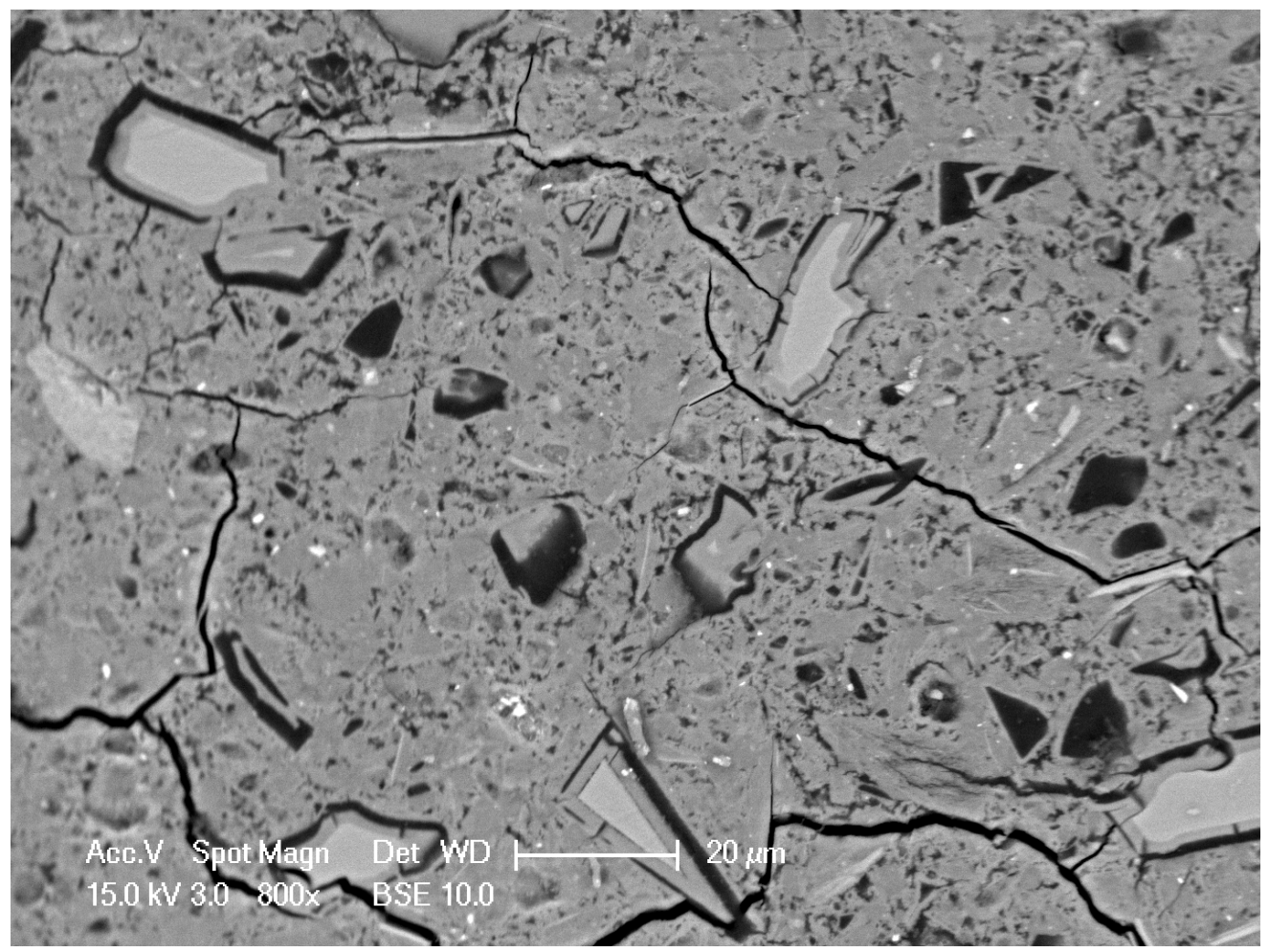

Figure 4.72. Microstructure of $62 \mathrm{LA} 38 \mathrm{MK}$ mixture cured at $80^{\circ} \mathrm{C}$ shown under backscatter electron imaging.
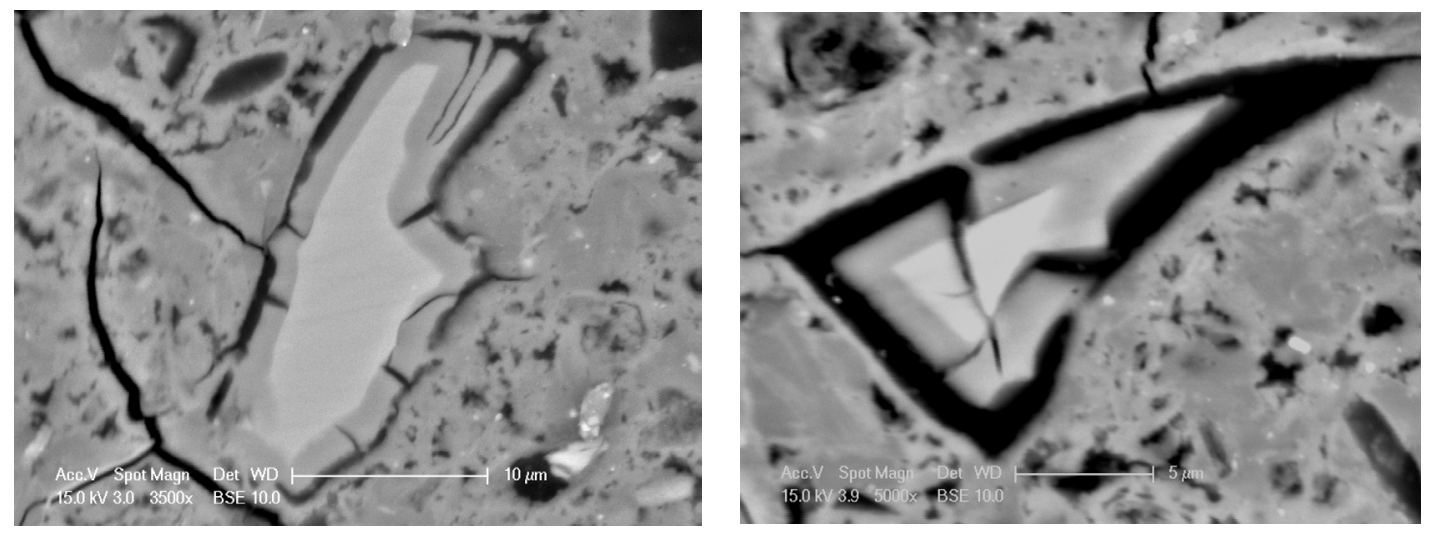

Figure 4.73. Magnified regions of $62 \mathrm{LA} 38 \mathrm{MK}$ mixture cured at $80^{\circ} \mathrm{C}$ showing unreacted glass particles and reaction layer separated by space between matrix and glass. 


\subsubsection{Phase composition}

Table 4.19 shows the molar ratios of the LA mixtures cured at $80^{\circ} \mathrm{C}$ as calculated by microanalysis. Each value presented is the average of 6 areas analyzed by microanalysis. Additional data on the microanalysis can be found in Appendix C. Obviously the addition of $38 \%$ metakaolin drastically lowered the $\mathrm{Si} / \mathrm{Al}$ and $\mathrm{Na} / \mathrm{Al}$ ratios.

Table 4.16. Average bulk molar ratios ordered in terms of maximum compressive strength at 14 days.

\begin{tabular}{|c|c|c|c|c|c|c|}
\hline Mix ID & Rank & $\begin{array}{c}\text { Compressive strength } \\
(\mathbf{p s i})\end{array}$ & $\mathbf{S i} / \mathbf{A l}$ & $\mathbf{N a} / \mathbf{A l}$ & $\mathbf{N a} / \mathbf{S i}$ & $\mathbf{C a} / \mathbf{S i}$ \\
\hline $62 \mathrm{LA} 38 \mathrm{MK}$ & $1^{\text {st }}$ & 3016 & 3.76 & 1.12 & 0.26 & 0.07 \\
\hline $100 \mathrm{LA}$ & $2^{\text {nd }}$ & 1815 & 151.23 & 40.17 & 0.25 & 0.14 \\
\hline $37 \mathrm{LA} 63 \mathrm{MK}$ & $3^{\text {rd }}$ & 684 & - & - & - & - \\
\hline
\end{tabular}

Figure 4.74 shows the bulk and actual molar ratios for the 100LA and 62KLA38MK mixtures. In both cases, the bulk $\mathrm{Si} / \mathrm{Al}$ and $\mathrm{Na} / \mathrm{Al}$ ratios were higher than the measured actual $\mathrm{Si} / \mathrm{Al}$ and $\mathrm{Na} / \mathrm{Al}$ ratios. 

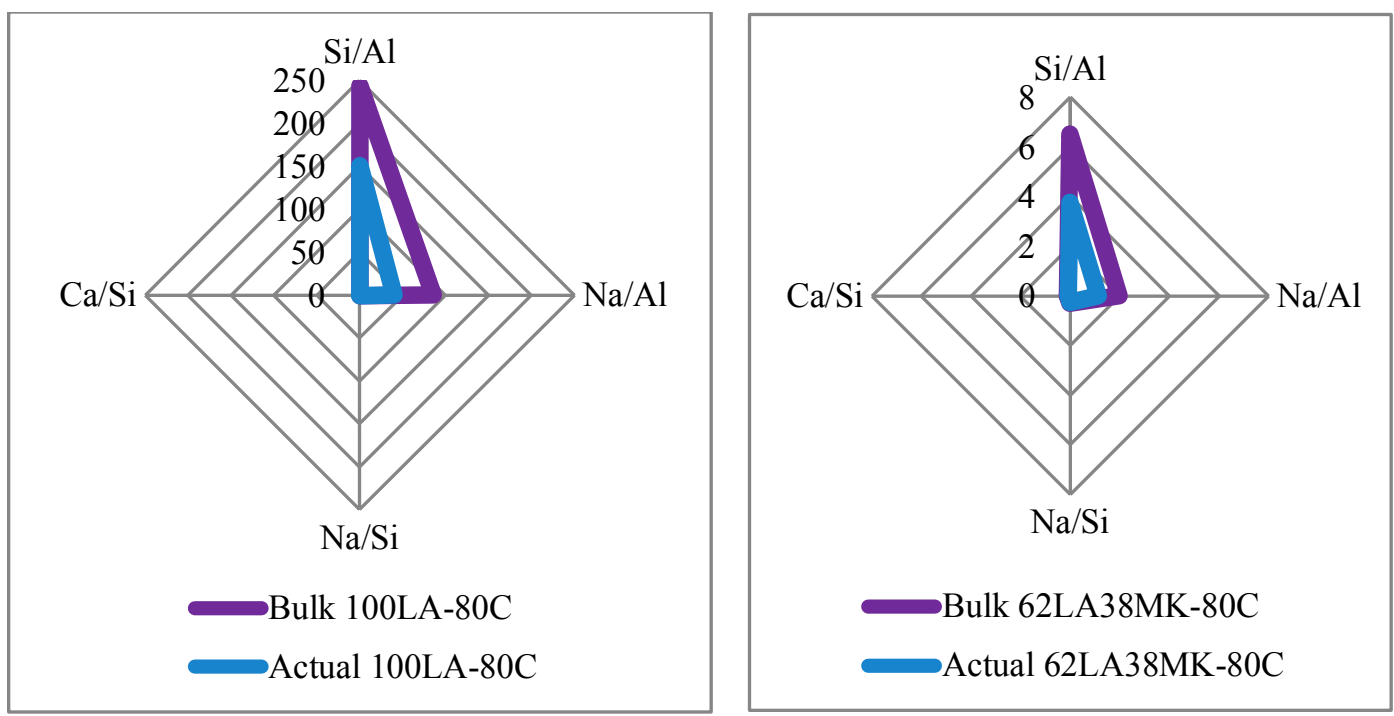

Figure 4.74. Bulk vs actual molar ratios for the $100 \mathrm{LA}$ mixture cured at $80^{\circ} \mathrm{C}$ (left) and the $62 \mathrm{LA} 38 \mathrm{MK}$ mixture cured at $80^{\circ} \mathrm{C}$ (right).

Figure 4.75 shows a comparison of the $\mathrm{Si} / \mathrm{Al}$ and $\mathrm{Na} / \mathrm{Al}$ molar ratios in the bulk 100LA mixture and those measured in the mixtures cured at $60^{\circ} \mathrm{C}$ and $80^{\circ} \mathrm{C}$. The $\mathrm{Si} / \mathrm{Al}$ ratios in both of the mortars were less than that calculated for the bulk, with the lower curing temperature showing a higher $\mathrm{Si} / \mathrm{Al}$ ratio. The trends seen with the $\mathrm{Si} / \mathrm{Al}$ ratio were very similar to those found with the $\mathrm{Na} / \mathrm{Al}$ ratio.

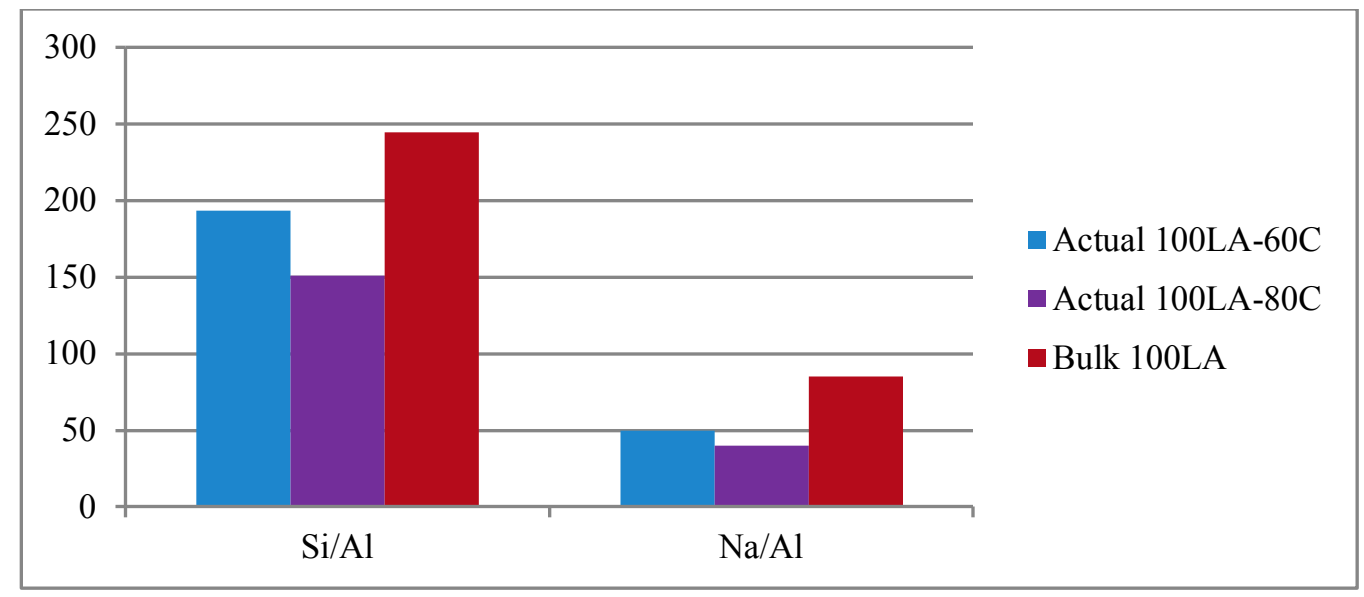

Figure 4.75. $\mathrm{Si} / \mathrm{Al}$ and $\mathrm{Na} / \mathrm{Al}$ ratios comparing the bulk stoichiometry of the $100 \mathrm{LA}$ mixture and those measured for mortars cured at $60^{\circ} \mathrm{C}$ and $80^{\circ} \mathrm{C}$. 
Figure 4.76 shows a comparison of the $\mathrm{Na} / \mathrm{Si}$ and $\mathrm{Ca} / \mathrm{Si}$ molar ratios in the bulk 100LA mixture and those measured in the mixtures cured at $60^{\circ} \mathrm{C}$ and $80^{\circ} \mathrm{C}$. The $\mathrm{Na} / \mathrm{Si}$ ratio in both of the mortars were nearly the same, lower in both cases than the bulk. Likewise, the $\mathrm{Ca} / \mathrm{Si}$ ratio was quite similar in all three cases.

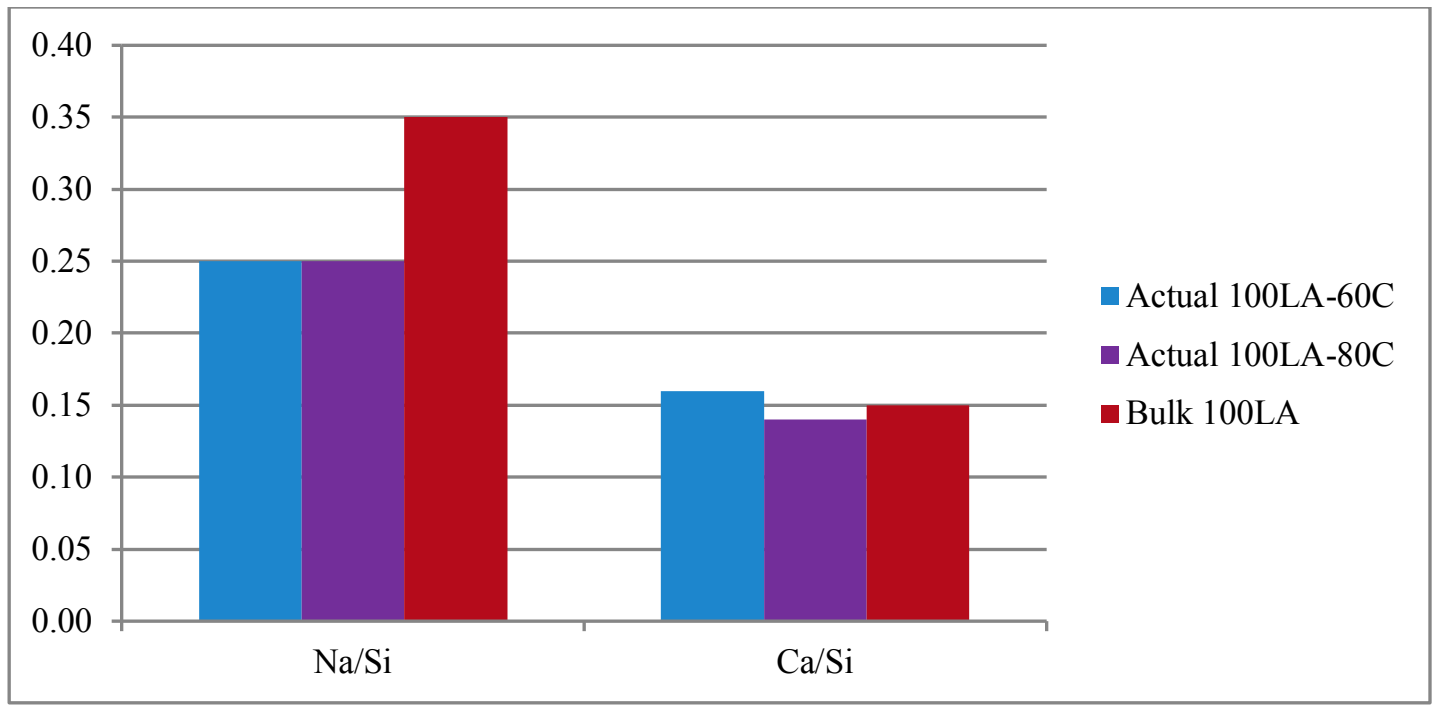

Figure 4.76. $\mathrm{Na} / \mathrm{Si}$ and $\mathrm{Ca} / \mathrm{Si}$ ratios comparing the bulk stoichiometry of the 100LA mixture and those measured for mortars cured at $60^{\circ} \mathrm{C}$ and $80^{\circ} \mathrm{C}$.

\subsubsection{Degree of reaction}

Degree of reaction results comparing the $60^{\circ} \mathrm{C}$ and $80^{\circ} \mathrm{C}$ cured mixtures can be seen in Figure 4.77. It was initially assumed the degree of reaction was behind the extremely low compressive strength measured for the mixtures cured at $60^{\circ} \mathrm{C}$. However, based on the degree of reaction results, this is not necessarily the case. In fact, each mixture had differing results from the degree of reaction measurements, where the 100LA mixture was the only one that saw an increase in dissolution with the higher curing temperature. Things stayed about the same for the 62LA38MK mixture and a decrease in degree of reaction was measured for the 37LA63 mixture indicating there is more to do with degree of reaction 
and dissolution than simply curing temperature. Overall, the degree of reactions measured were lower than those found in Phase II, except the 50HA50MK mixture.

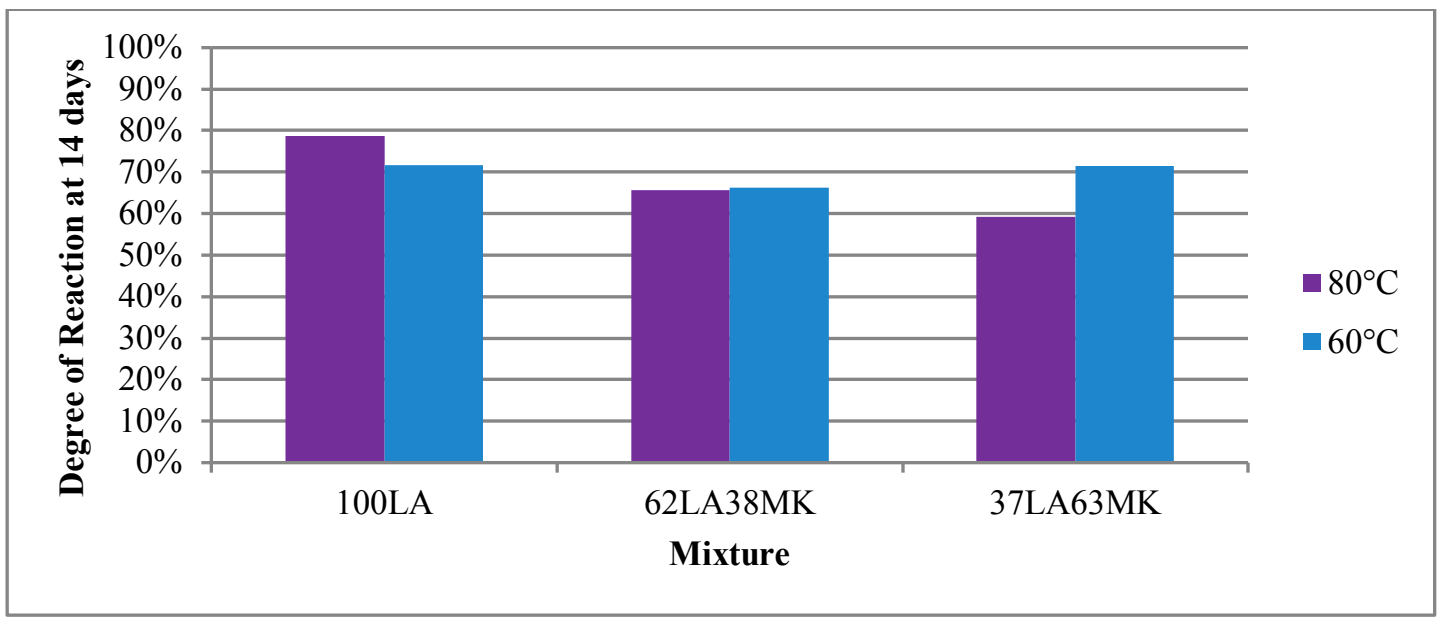

Figure 4.77. 14 day degree of reaction results from Phase III mortars containing LA glass cured at $60^{\circ} \mathrm{C}$ versus $80^{\circ} \mathrm{C}$.

\subsubsection{Ternary mixtures of glass, metakaolin and fly ash}

Additional mixtures made of a ternary mixture of glass, fly ash and metakaolin were also created using both the HA and LA glasses. The idea behind these mixtures was to counter the high water demand of the metakaolin with the low water demand of the fly ash. Two mixtures were designed as shown in Table 4.17. Mixtures were named according to the amounts of each source material used.

Table 4.17. Mixture ID for mortars in Phase III, with percentages given by mass.

\begin{tabular}{|c|c|c|c|c|}
\hline Mixture ID & $\begin{array}{c}\text { HA500 glass } \\
\text { (HA) }\end{array}$ & $\begin{array}{c}\text { LA500 glass } \\
\text { (LA) }\end{array}$ & $\begin{array}{c}\text { Metakaolin } \\
\text { (MK) }\end{array}$ & $\begin{array}{c}\text { Fly ash } \\
\text { (FA) }\end{array}$ \\
\hline 50HA25MK25FA & $50 \%$ & $0 \%$ & $25 \%$ & $25 \%$ \\
\hline 50LA25MK25FA & $0 \%$ & $50 \%$ & $25 \%$ & $25 \%$ \\
\hline
\end{tabular}


Table 4.18 shows the molar ratios of the unreacted geopolymer in the ternary mixtures. As shown, the $\mathrm{Na} / \mathrm{Al}$ ratios are near 1 and 2 and the $\mathrm{Si} / \mathrm{Al}$ and $\mathrm{Na} / \mathrm{Al}$ ratios fall near to the range most accepted for geopolymers.

Table 4.18. Molar stoichiometry of unreacted source materials and activator solution of ternary mixtures.

\begin{tabular}{|c|c|c|c|c|}
\hline Mixture ID & $\mathbf{S i} / \mathbf{A l}$ & $\mathbf{N a} / \mathbf{A l}$ & $\mathbf{N a} / \mathbf{S i}$ & $\mathbf{C a} / \mathbf{S i}$ \\
\hline 50HA25MK25FA & 4.12 & 0.98 & 0.24 & 0.29 \\
\hline 50LA25MK25FA & 6.16 & 2.02 & 0.33 & 0.16 \\
\hline
\end{tabular}

Figure 4.78 shows the $\mathrm{Si} / \mathrm{Al}$ and $\mathrm{Na} / \mathrm{Al}$ graphed against each other for the ternary mixtures.

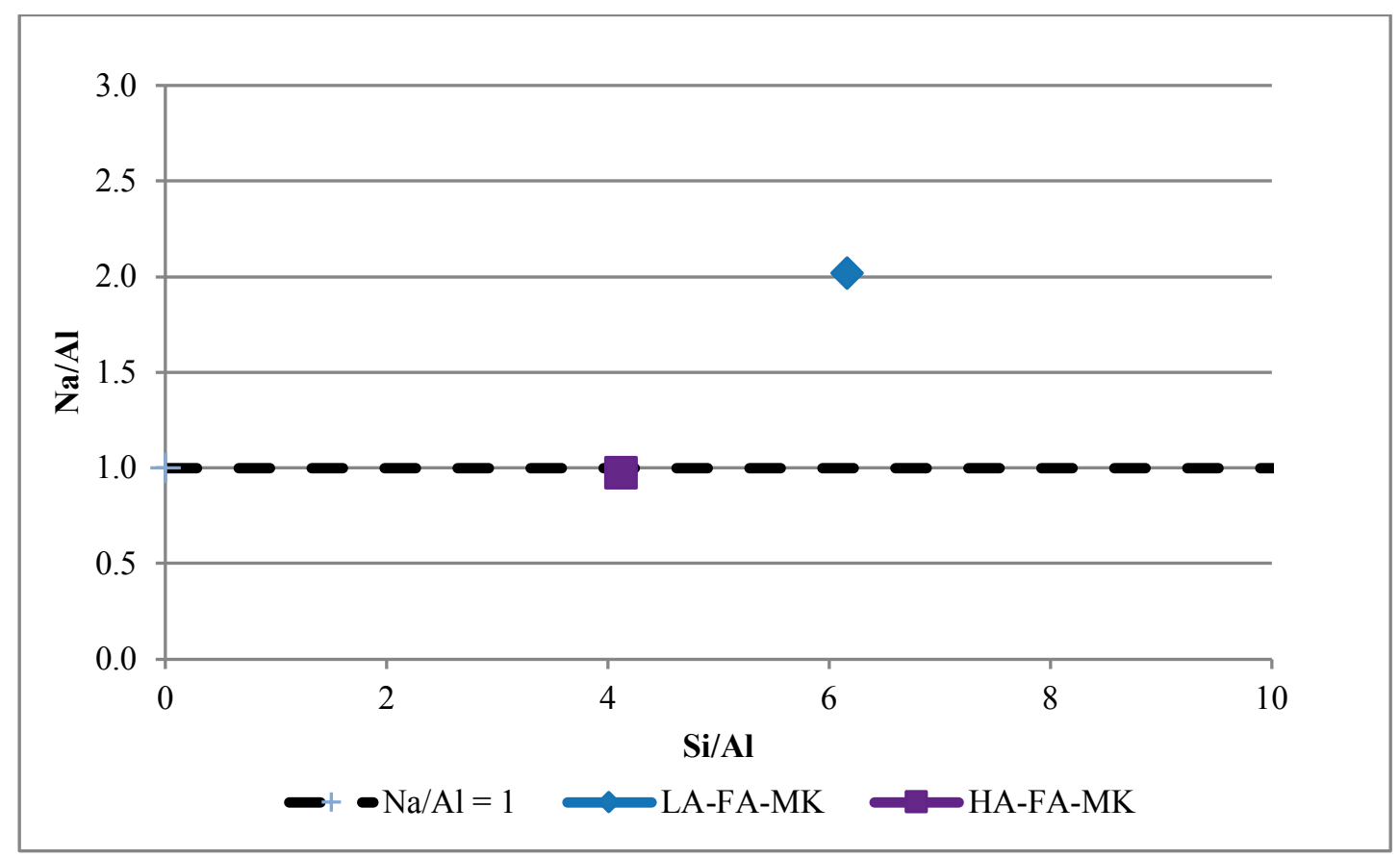

Figure 4.78. Si/Al vs Na/Al of the ternary mixtures, 50LA25MK25FA and 50HA25MK25FA.

Both of the mixtures were made with a water/solids ratio of 0.55 . Table 4.19 lists the water/solids ratio and measured fresh properties for the ternary mixtures. It was interesting 
to note the mixtures all exhibited a crackling sound during and after mixing for several minutes. Both of the ternary mixtures had very similar fresh properties and the mixtures were hard to tell apart. The workability of the mixture was really nice, providing easy consolidation without the liquid-nature sometimes found in the glass-only mixtures.

Table 4.19. Fresh properties of the ternary mixtures. Values reported are the average of three measurements.

\begin{tabular}{|c|c|c|c|c|}
\hline Mixture ID & $\begin{array}{c}\text { Water/solids } \\
\text { ratio }\end{array}$ & $\begin{array}{c}\text { Percent } \\
\text { Flow (\%) }\end{array}$ & $\begin{array}{c}\text { Temperature } \\
\left({ }^{\mathbf{}} \mathbf{F}\right)\end{array}$ & Unit weight $(\mathbf{g} / \mathbf{m L})$ \\
\hline LA-FA-MK & 0.550 & $91 \%$ & 88.50 & 2.06 \\
\hline HA-FA-MK & 0.550 & $94 \%$ & 88.50 & 2.14 \\
\hline
\end{tabular}

\subsubsection{Compressive strength}

Compressive strength was measured at 1, 3, 7 and 14 days and the results are shown Figure 4.79. Based on the previous results it was expected the mixture made with the HA glass would perform better than the LA glass. 


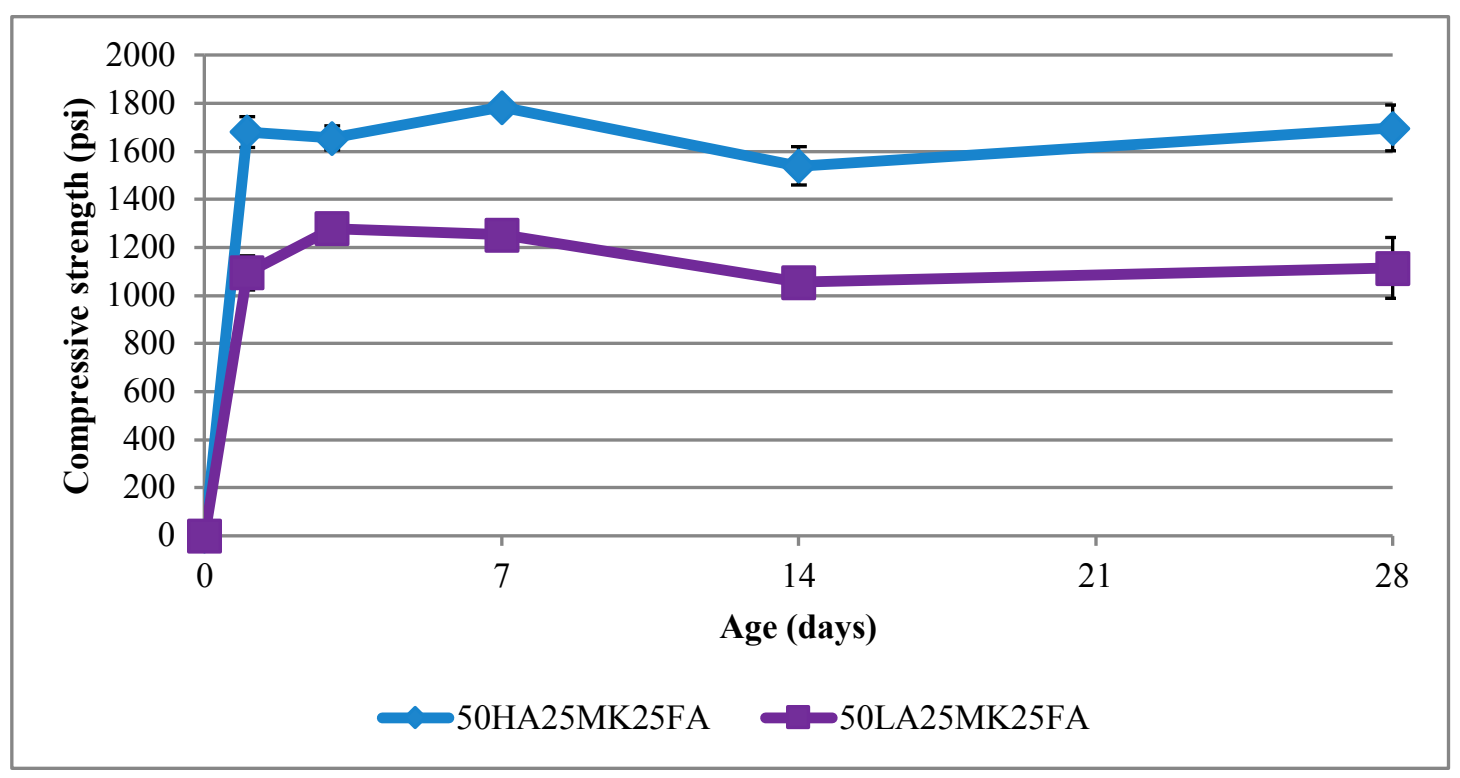

Figure 4.79. Comparison of the compressive strength measured for the ternary mixtures. Each data point is the average of three cylinders. Error bars were calculated from the standard error, $\mathrm{SD} / \sqrt{ } \mathrm{n}$, where $\mathrm{SD}$ is standard deviation and $\mathrm{n}$ is the sample size.

\subsubsection{Microstructural analysis}

Figure 4.80 shows the microstructures of the two ternary mixtures. The mixture made from the HA glass was denser and more uniform, with glass particles well embedded within the matrix. The LA ternary mixture showed more voids but was fairly homogenous. Unreacted fly ash particles were visible in both mixtures. 

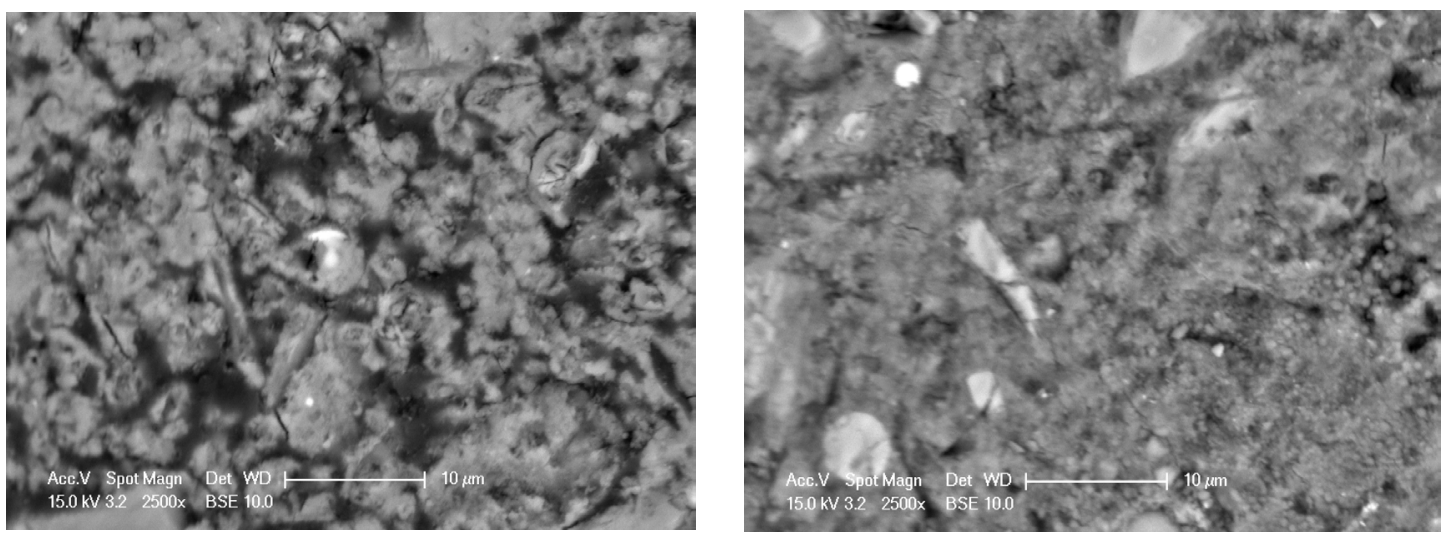

Figure 4.80. Polished sections of the 50LA25MK25FA mixture (left) and the 50HA25MK25FA mixture (right).

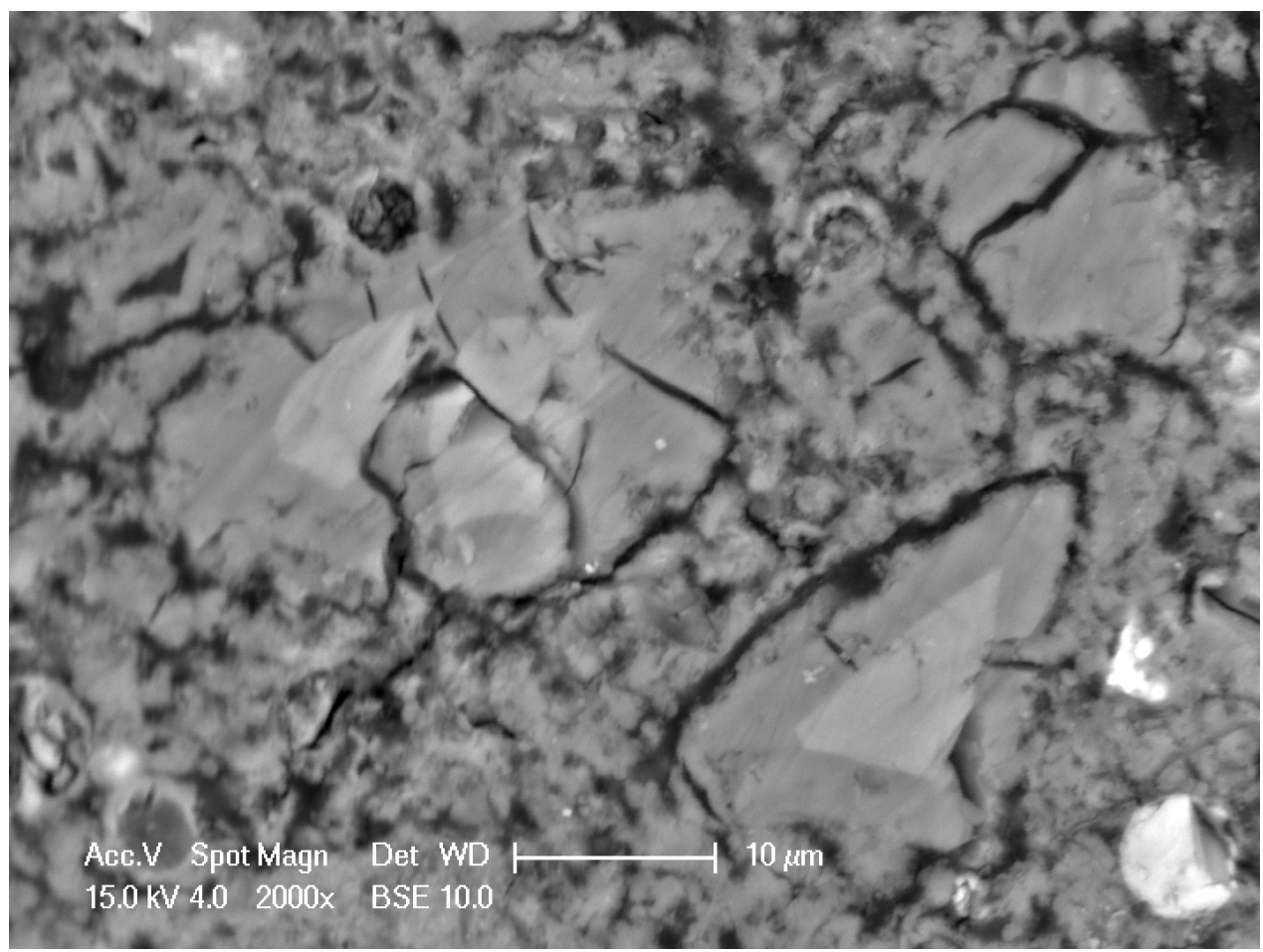

Figure 4.81. 50LA25MK25FA mixture showing rim of reaction products around unreacted glass particles, but in this case the cracks are through the particle rather than around it indicating a stronger matrix. 


\subsubsection{Phase composition}

Table 4.20 shows the molar ratios of the ternary mixtures as calculated by EDS microanalysis. Each value presented is the average of 6 spots analyzed by EDS microanalysis. Additional data on the microanalysis can be found in Appendix C. It is interesting to note the $\mathrm{Na} / \mathrm{Al}$ ratio was the same in both ternary mixtures.

Table 4.20. Average bulk molar ratios ordered in terms of maximum compressive strength at 14 days.

\begin{tabular}{|c|c|c|c|c|c|c|}
\hline Mix ID & Rank & $\begin{array}{c}\text { Compressive } \\
\text { strength (psi) }\end{array}$ & $\mathbf{S i} / \mathbf{A l}$ & $\mathbf{N a} / \mathbf{A l}$ & $\mathbf{N a} / \mathbf{S i}$ & $\mathbf{C a} / \mathbf{S i}$ \\
\hline 50HA25MK25FA & $1^{\text {st }}$ & 1539 & 3.60 & 1.31 & 0.35 & 0.23 \\
\hline 50LA25MK25FA & $2^{\text {nd }}$ & 1055 & 4.36 & 1.31 & 0.27 & 0.13 \\
\hline
\end{tabular}

The actual measured molar ratios were lower than the bulk ratios as shown below in Figure 4.82.
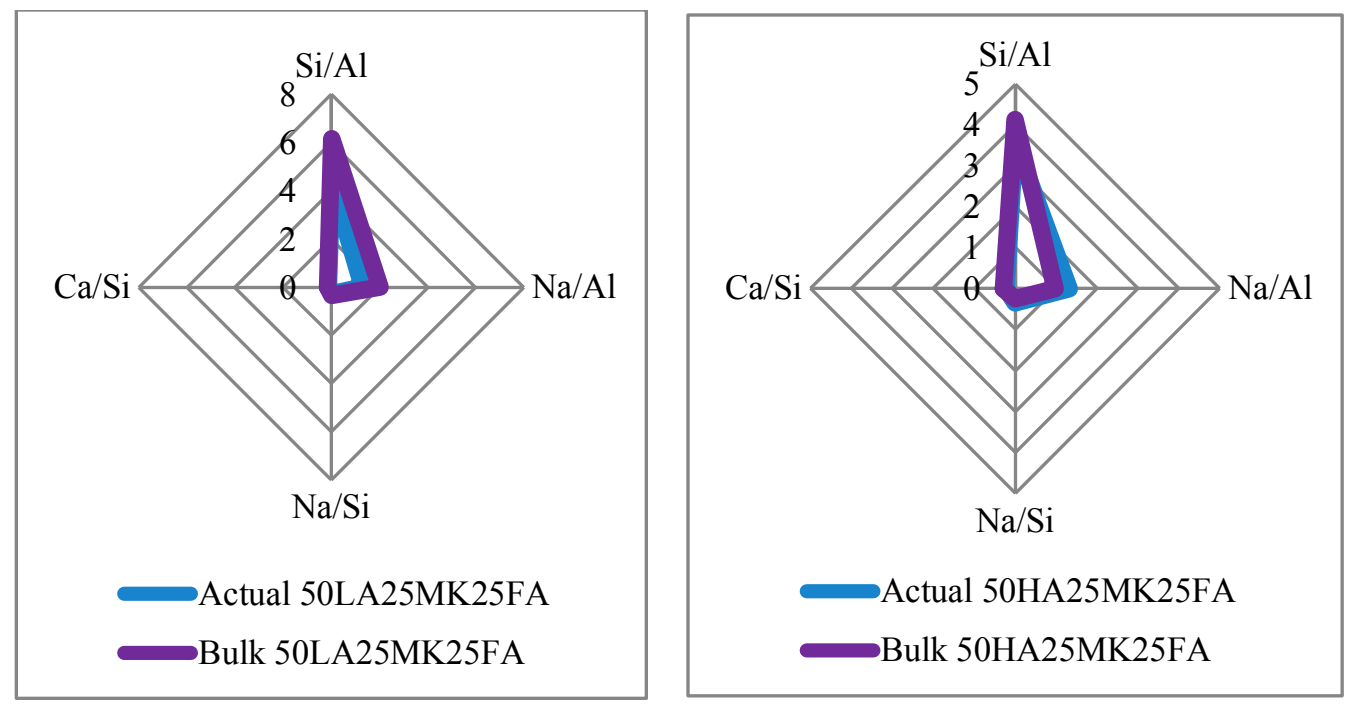

Figure 4.82. Bulk vs actual molar ratios for the 50LA25MK25FA mixture (left) and the 50HA25MK25FA mixture (right). 


\subsubsection{Degree of reaction}

Figure 4.83 shows the degree of reaction of the ternary mixtures at 14 days. The degree of reaction measured was not as high as those measured in Phase II but a slightly coarser glass was used. Unreacted fly ash and glass particles were visible within the microstructure of both mortars but no metakaolin was visible.

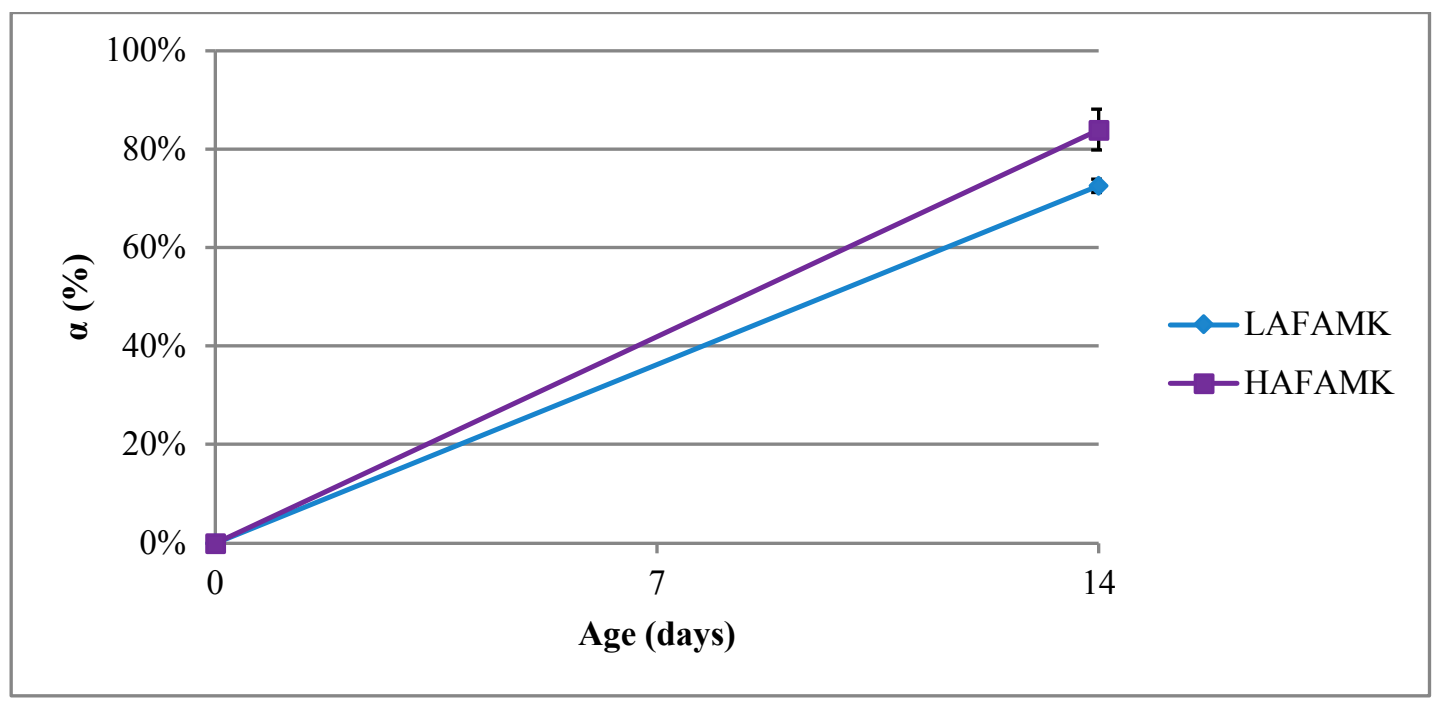

Figure 4.83. Degree of reaction results at 14 days for the ternary mixtures.

\subsubsection{Adiabatic calorimetry}

Adiabatic calorimetry curves for the ternary mixtures are shown in Figure 4.84. The curves show a unique delay in the secondary temperature spike, of a different shape than other mixtures made with glass or metakaolin. These mixtures had unique adiabatic calorimetry curves showing a higher temperature peak a few days out that is different than the other mixtures. The higher peak is indicative of mixtures containing metakaolin. 


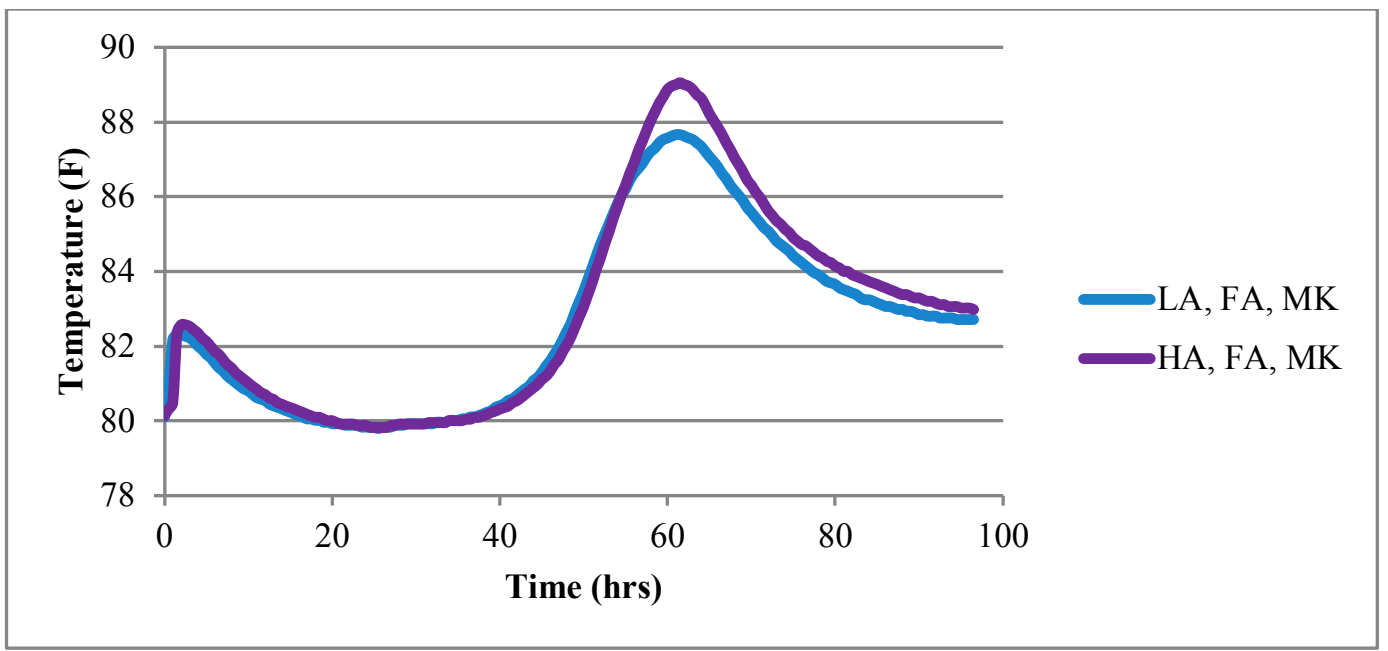

Figure 4.84. Adiabatic calorimetry curves of ternary mixtures.

\subsubsection{Discussion of Phase III}

Since Phase III had several insufficiently reacted mixtures as well as explorations into curing temperature and ternary mixtures the discussion of the entire phase will be broken up into several sections:

- Insufficiently reacted mixtures

- 100LA

- $62 \mathrm{LA} 38 \mathrm{MK}$

- HA mixtures

- Ternary mixtures

\subsubsection{Insufficiently reacted mixtures}

Of the mixtures in Phase III cured at $60^{\circ} \mathrm{C}$, the $62 \mathrm{LA} 38 \mathrm{MK}, 37 \mathrm{LA} 67 \mathrm{MK}$ and $100 \mathrm{MK}$ mixtures did not react sufficiently to produce enough geopolymerization for strength gain. Nor did the $37 \mathrm{LA} 63 \mathrm{MK}$ mixture cured at $80^{\circ} \mathrm{C}$. The obvious commonality between these 
mixtures is the presence of a lot of metakaolin, which was also true for the mixture 50HA50MK in Phase II. It appears there exists a threshold where too much metakaolin prevents adequate reaction from occurring under the mixture parameters of this research. From degree of reaction measurements it appears that seemingly adequate amounts of dissolution occurs, so it most likely could be one of several scenarios at work:

a. Not enough water was available to meet the water demand of the metakaolin. Since dissolution consumes water, a solution might never form to allow polycondensation reactions to occur.

b. Too much water was added to account for the water demand of the metakaolin. The presence of the water diluted the activator solution leading to less or slower dissolution. Since a supersaturated solution is necessary for polycondensation to occur, the more water present means more $\mathrm{Si}$ and $\mathrm{Al}$ species must go into solution to reach the point of supersaturation. Sedimentation of the metakaolin in mixtures with too much liquid has also been suggested, which serves to lower compressive strength due to large regions of soft, unreacted metakaolin particles (Rahier et al. 1997). These were observed in all of the mixtures mentioned here.

c. The presence of too much water could also lead to zeolite formation as opposed to geopolymer products. Zeolites do not contribute strength to geopolymers (Fernández-Jiménez et al. 2007).

It is true that many mixtures made entirely out of metakaolin have been reported in the literature, but those mixtures are nearly always activated with a solution containing dissolved silica. The dissolved silica serves to shorten the time it takes for the mixture to 336 
reach supersaturation and for polycondensation to occur, requiring less dissolution, which consumes less water. It is well known that mixtures made from $100 \%$ metakaolin are very tricky to work with (Provis et al. 2010).

\subsubsection{100LA}

The 100LA mixture was an interesting in that mortars cured at $60^{\circ} \mathrm{C}$ produced a physical release of sticky exudate ripe with alkalis. Increasing the curing temperature served to eliminate this stickiness but the mortars still maintained a sticky, malleable feel to them, especially on the interior. This has been reported for geopolymers with very high $\mathrm{Si} / \mathrm{Al}$ ratios, where failure is actually ductile rather than brittle (Fletcher et al. 2005; Songpiriyakij et al. 2010). The microstructure of the 100LA mortars was also interesting as the matrix was beautifully continuous and dense. However, that came at an apparent cost of extreme shrinkage.

The presence of the ITZ (interfacial transition zone) in OPC concrete is often a source of weakness, where large amounts of crystalline $\mathrm{CH}$ or ettringite crystals weaken the structure. The zone between the paste and the aggregate in the 100LA mixtures was a void where nothing but epoxy was present at many interfaces. All of these voids served to weaken the mortar.

Even when the $100 \mathrm{LA}$ mixture was cured at $80^{\circ} \mathrm{C}$, the presence of the reaction rim found in the mixtures in Phase I made of fine glass and in the 100HA mixture in Phase II was not found. In metakaolin geopolymers, an aluminum-deficient rim around metakaolin particles due to the preferred release of aluminum over silicon. The fact that this rim was not found 
around glass particles in the 100LA could be due to the lack of aluminum to be preferentially removed (Duxson et al. 2005)

\subsubsection{62LA38MK}

Upon adding $38 \%$ metakaolin to the mortar cured at $60^{\circ} \mathrm{C}$, the same thing that happened to the mixtures in 4.3.9.1 occurred where no real geopolymer formed, only unreacted particles were visible in cross section. However, a $20^{\circ} \mathrm{C}$ increase in curing temperature for 24 hours resulted in adequate geopolymer to create a fairly homogenous microstructure and nearly 12 times the compressive strength at 1 day.

The microstructure of this stronger mortar was very interesting. A layer of reaction product formed around the unreacted glass particle and that whole system was separated away from the rest of the paste forming voids in the outline of the original glass particle indicating the particle was shrinking.

\subsubsection{HA mixtures}

In Phase III two of the mixtures from Phase II were reproduced with the main differences being a lower curing temperature, slightly coarser glass and slightly higher water/solids ratio. The 100HA mixture in Phase III had a higher compressive strength than the $75 \mathrm{HA} 25 \mathrm{MK}$ mixture, which was opposite of when the mixtures were cured at $80^{\circ} \mathrm{C}$. The microstructure of the 100HA mixture was quite different between the two phases as well, with the microstructure in Phase II appearing very continuous and a narrow reaction rim visible around the residual unreacted glass particles. In Phase III, the microstructure was 
less continuous and a layer of reaction product was visible around the particle. This could be attributed to the change in curing temperature or the glass particle size or a combination of the two.

It seemed when looking at the $75 \mathrm{HA} 25 \mathrm{MK}$ and $62 \mathrm{LA} 38 \mathrm{MK}$ mixtures, the binary mixtures containing glass and metakaolin both responded readily to an increase in curing temperature both in terms of compressive strength and also microstructure. Curing temperature seems to have a large impact on the rate of strength gain as well as the actual amount of strength gained. This stands to reason since there is no sodium silicate involved in glass, all of the $\mathrm{Si}$ and $\mathrm{Al}$ available must come from dissolution. Increased temperature accelerates the dissolution process, creating a supersaturated mixture sooner and provides more $\mathrm{Si}$ and $\mathrm{Al}$ species for condensation reactions. The mixtures containing a small amounts of metakaolin, in particular, seemed to react the strongest to an increase in curing temperature in Phase III. Both the LA glass mixtures containing 38\% metakaolin and the HA mixture containing $25 \%$ metakaolin from Phase II performed better when cured at $60^{\circ} \mathrm{C}$ as compared to $80^{\circ} \mathrm{C}$, indicating the presence of metakaolin in moderate quantities favors higher curing temperatures.

\subsubsection{Ternary mixtures}

As stated previously, the ternary mixtures were expected to perform well due to overcoming the water demand obstacle of the metakaolin. However, no increased compressive strength was found and actually, compressive strengths were lower than the 
100HA mixture and 75HA mixture, which seems to imply the addition of the fly ash to the mixture caused a decrease in desired properties.

\subsubsection{Main points}

- The mixture made of $100 \%$ LA glass resulted in sticky mortar not conducive at all for real world applications. Increasing the curing temperature from $60^{\circ} \mathrm{C}$ to $80^{\circ} \mathrm{C}$ solved that problem, for the most part, though the interior still remained slightly tacky.

- The microstructure of the LA glass mixture was extremely continuous however extensive cracking and shrinkage were prevalent.

- The addition of $38 \%$ metakaolin and curing at $80^{\circ} \mathrm{C}$ resulted in an improved microstructure that gained 3000 psi at 1 day, as opposed to the microstructure when cured at $60^{\circ} \mathrm{C}$.

- Mixtures containing 63\% and 100\% metakaolin showed nearly $70 \%$ degree of reaction but did not produce adequate geopolymer for any strength gain or microstructure.

- It seems there is a threshold at which adding more metakaolin is not helpful; this could be due to stoichiometry but most likely is due to mixing. Excess metakaolin stiffens the mixture. This requires either excess water for mixing that leads to dilution of the activator solution or, when water is kept at a proper level, inadequate solids dissolution resulting from an inadequate liquid phase. Water reducers or superplasticizers could be useful. Also, sodium silicate is also usually used in the activator solution, which changes the kinetics and gives the mixture a jumpstart toward polycondensation (Provis et al. 2010). 
- The ternary mixtures had excellent workability but they did not perform as well as was expected.

\subsection{Project goals addressed}

At the beginning of this document, four questions were listed as goals of this research. Here, they will be addressed in the following sections using the results from all three phases of research.

\subsubsection{What are the phases formed by the alkali activation of waste glass and how is the microstructure and composition of these phases affected by the addition of metakaolin as a source of alumina?}

Two types of glass were considered in this research containing vastly different compositions. The HA glass had a little over $12 \%$ aluminum oxide by weight and as it turned out, when reacted with $10 \mathrm{M} \mathrm{NaOH}$, resulted in a dense, strong geopolymer. Depending on the variables of the mixture, varying strengths and microstructures were created but overall, the HA glass performed very well as a source material for geopolymers. Phase I showed that by altering the fineness of the glass and curing temperature, the strength gain profile could also be altered, where fine glass and higher curing temperatures resulted in higher early strength while fine or coarse glass cured at lower temperatures showed more sustained strength gain over time. With regard to compressive strength of fly ash geopolymers, it is typical to gain high early strength followed by a steady but slow climb in further strength gain after a few days (Fernández-Jiménez and Palomo 2003). 
The bulk Si/Al ratio of this HA glass was 8.39 for all mixtures and the measured $\mathrm{Si} / \mathrm{Al}$ ratio of the resulting geopolymer was quite similar to this bulk number when fine glass was used. Coarse glass resulted in a bit higher $\mathrm{Si} / \mathrm{Al}$ ratio over all, most likely due to decreased dissolution. With regard to $\mathrm{Na} / \mathrm{Al}$ ratio, the same trends held true for fine and coarse glass.

The addition of alumina to the HA glass changed the bulk $\mathrm{Si} / \mathrm{Al}$ and $\mathrm{Na} / \mathrm{Al}$ ratios and the resulting measured ratios changed along with the bulk ratios. In general, the resulting molar ratios of the geopolymer were very similar to the bulk molar ratios. Microstructure development was found to be an interesting investigation and the correlation of microstructure and compressive strength was not nearly as clear as it was initially thought to be.

The microstructure of the geopolymer seemed to be more affected by the physical properties of the supplementary alumina source than by the composition of that source, which brings the importance of mixture design and degree of reaction to the forefront. Despite the best of intentions, for the mixtures containing a lot of metakaolin, the physical limitations of reacting that much metakaolin with $\mathrm{NaOH}$ were reached and the reaction stunted.

Since dissolution consumes water, it is safe to assume that finding an adequate water/solids ratio is more complicated than just reaching a certain workability or flow. Water in a geopolymer mixture is not chemically bound within the reaction products, but rather exists alongside them in gel pores. This is different than the case with OPC, where some water is chemically bound in the calcium-silicate-hydrate (Provis and vanDeventer 2009). Despite 
this fundamental difference, the water/binder ratio in both OPC and GPC is very important when it comes to fresh and hardened concrete properties. In both systems, a high water/solids ratio can result in increased porosity, which has been linked to lower compressive strength (Hardjito and Rangan 2005; Steveson and Sagoe-Crentsil 2005).

As evidenced by the HA5050MK mixture (and others in Phase I and III), a mixture designed for a workable flow and optimal composition does not in any way signify that a quality geopolymer will be produced. As in life, the various variables in a mixture must be in sync with each other for success to be obtained.

The other glass used, LA had an incredibly high $\mathrm{Si} / \mathrm{Al}$ and $\mathrm{Na} / \mathrm{Al}$ molar ratio, thus mortar made of just the glass retained the high $\mathrm{Si} / \mathrm{Al}$ and $\mathrm{Na} / \mathrm{Al}$ ratios, thought a little bit less. The result was a mortar that literally oozed a silica gel rich in sodium as evidenced by the slippery texture. Upon higher temperature curing this oozing problem was solved but in both cases, the microstructure appeared very shrunken away from the fine aggregate particles resulting in only moderate compressive strength.

When metakaolin was added to this glass in moderate amounts, i.e. $38 \%$ and cured at $80^{\circ} \mathrm{C}$, the microstructure was improved as was the compressive strength and molar ratios. However, this mixture was still inferior to the mixtures made with the HA glass indicating that further manipulation of the LA glass must be carried out for it to be successful. 


\subsubsection{Is there a clear correlation between microstructure, composition and compressive strength of glass-based geopolymers?}

As stated in the previous section, for the mixtures studied here, there was not so much a correlation between microstructure, composition and compressive strength but rather a dependency. Compressive strength depends on both microstructure and composition. The microstructure also depends on the composition, as an adequate amount of network formers and a good balance of $\mathrm{Na}$ And $\mathrm{Al}$ must be present to create a decent microstructure.

It is true the physical properties of the microstructure have a large impact on compressive strength, but this research also showed the composition of the geopolymer formed also played a role. For example, if a geopolymer of the optimal composition created a porous microstructure, compressive strength will be sacrificed due to the high percentage of voids. Likewise, if a geopolymer of not ideal composition managed to create a dense microstructure, a certain amount of strength would be gained based on the continuity of the microstructure, but not optimized. So, the composition and microstructure seem to go hand in hand and only will result in substantial compressive strength when both are in harmony with each other.

\subsubsection{How does the bulk stoichiometry of the initial mixture compare to the actual stoichiometry of the geopolymer formed? What role does the degree of reaction play in this relationship?}

The bulk stoichiometry of the initial mixture as compared to the geopolymer formed was quite similar in most cases, especially when the finer glass was used. However, the role of 
degree of reaction was not as important as was originally thought. Even in the mixtures that did not produce enough geopolymer, nearly $60-70 \%$ degree of reaction was reached, which was adequate to create a geopolymer in other mixtures. Clearly other factors play a more important role in realizing the bulk stoichiometry of a mixture than simply the degree of reaction. It appears that decent dissolution can occur without polycondensation.

\subsubsection{Does the addition of metakaolin or fly ash adequately lower the stoichiometry of the mixture to more acceptable ranges found in other geopolymers made of fly ash or metakaolin and does this enhance the mechanical performance?}

The addition of metakaolin or fly ash to the HA and LA glass geopolymers did lower the stoichiometry of the mixture to more acceptable ranges. However, this did not ensure an increase in mechanical performance. In moderate amounts, the metakaolin did result in an increase in mechanical performance but the fly ash, despite reducing the $\mathrm{Si} / \mathrm{Al}$ and $\mathrm{Na} / \mathrm{Al}$ ratios, did not result in an increase of compressive strength as compared to the baseline glass geopolymer, indicating that as stated previously, the synergy between the various mixture parameters is incredibly important. 



\section{Conclusions}

It should be noted again, the purpose of this research was not to develop the best or strongest possible glass-based geopolymer, but rather to identify the characteristics of baseline glass geopolymers and to document and observe the changes that occur when an alumina source was introduced.

Three main areas of interest were considered in this research with regard to glass-based geopolymers: compressive strength, microstructure and composition. It is important to note that while the strength and composition can be measured, the microstructure is a subjective matter, born of observation. The conclusions for these three areas are presented in bullet form.

\subsection{Compressive strength}

- Adequate compressive strengths were reached in the mixtures made with the fine HA glass and when a moderate amount of metakaolin was introduced

- Curing temperature seemed to have a direct impact on both early and later age compressive strength

- Higher curing temperatures resulted in higher initial strengths as shown in all Phases of the project

- Lower curing temperatures resulted in more substantial strength gain at later ages, as shown in Phase I

- Rate of strength gain varied depending on the parameters of the mixture

- Some mortars gained a great deal of strength in one day, typically when higher curing temperature or finer glass was used 
Others gained it slower over time, typically when lower curing temperatures or coarser glass was used

- Most mortars resulted in a general strength gain over time

- $10 \mathrm{M} \mathrm{NaOH}$ appears to result in higher compressive strength in glass based geopolymers, probably because sodium silicate is not included, and dissolution must occur for geopolymerization to occur

- Finer glass resulted in higher compressive strengths in general

- Glass containing more Al within the glass resulted in higher compressive strengths than glass containing no Al, that was supplemented with Al from other sources

- Adding 25\% metakaolin resulted in the highest compressive strength in Phase II.

○ There was an anomaly with regard to this mixture and $\mathrm{Si} / \mathrm{Al}$ ratio in that it did not follow the trend

- Water appeared to play a role in compressive strength, with lower strengths typically associated with higher water contents

- However, even in fly ash mixtures where less water was present, more strength was not necessarily found

○ The amount of water in a mixture must be optimized so there is enough for dissolution and for a solution to exist, but not so much that it will create a lot of extra porosity

\subsection{Microstructure}

- The microstructure of the glass only mixtures varied significantly based on glass particle size

- Fine glass mixtures resulted in a more uniform, continuous structure and a thin reaction rim visible around the particles, indicating dissolution into solution

- Coarse glass mixtures resulted in a ring of reaction products circling the unreacted glass particles 
- When these rings met each other, a dense matrix was formed. However, this was not always the case and sometimes holes existed between each component

- In all mortars, unreacted particles existed, whether they were glass, fly ash or metakaolin, $100 \%$ degree of reaction was not reached.

- When metakaolin or fly ash was included, the continuity of the matrix appeared to decrease as compared to when $100 \%$ glass was used

- Microstructure was in some part related to compressive strength, in that a more continuous microstructure often resulted in higher compressive strength, but not always

- A uniform, continuous microstructure with minimal porosity resulted in a stronger matrix in general, but it was also found that composition plays a big role

- Unreacted metakaolin particles tend to flocculate together creating large areas of weakness in the matrix

- Unreacted fly ash particles were present sometimes because it was an unreactive or crystalline phase but sometimes the reaction just did not penetrate through and the outer walls of a plerosphere, for example, were reacted away leaving the inner species

- Fracture surfaces revealed the presence of zeolites

- It seemed the mixtures with higher water content also resulted in more zeolites

- Different types of zeolites were found in different mixtures

- The microstructure of the low-Al glass mixtures had significant cracking and shrinkage

\subsection{Composition}

- In general, the composition of the geopolymer that formed was quite similar to that of the bulk stoichiometry 
- In particular, the molar ratios were quite close when the glass was in a finer form, most likely due to increased dissolution

- The glasses that were made with the coarse glass were found to have a higher $\mathrm{Si} / \mathrm{Al}$ and $\mathrm{Na} / \mathrm{Al}$ ratio, probably due to the fact that less glass and, therefore, less Al was dissolved

- In Phase II a clear trend between compressive strength and $\mathrm{Na} / \mathrm{Al}, \mathrm{Na} / \mathrm{Si}$ and $\mathrm{Ca} / \mathrm{Si}$ ratios was found, where decreasing molar ratios corresponded to increasing compressive strength

- A trend between $\mathrm{Si} / \mathrm{Al}$ was found to a certain point with $\mathrm{Si} / \mathrm{Al}$ increasing with increasing compressive strength. However, there was an anomaly with the $75 \mathrm{HA} 25 \mathrm{MK}$ mixture where a lower $\mathrm{Si} / \mathrm{Al}$ ratio resulted in a higher compressive strength

- Many of the mixtures possessed multiple phases interspersed together with calcium being the main differing element

- Extremely high $\mathrm{Si} / \mathrm{Al}$ and $\mathrm{Na} / \mathrm{Al}$ ratios can be lowered to more reasonable levels with the addition of metakaolin or fly ash

\subsection{Variability}

Glass is a viable material for use in geopolymers. However, variability has proven to be a bigger issue than was originally thought. The source of the glass will dictate the composition of that glass. It is true that in this research two broad ends of the spectrum were analyzed. However, the glass that contained aluminum definitely performed better overall than the glass without even when supplemented with Al.

When dealing with a recycled material, variability is most always an issue. It is possible that glass could be a consistent composition if it is gathered from the same source each time and if that sources has a steady stream of input glasses. Glass would most likely offer 
a more reliable material stream than fly ash but from this research it is very clear the composition of the glass must be known and the mixture parameters adjusted appropriately.

Since the degree of reaction for both types of glass seemed to be fairly consistent, one possibility would be to measure the average composition of various glass streams and then

blend them as needed to reach a desired composition. If mixture parameters can be adjusted to allow for maximum dissolution possible, chances are this resulting geopolymer will be of a known and consistent composition.

\subsection{Soluble silica}

A great deal of the literature available on geopolymers is based on mixtures activated with soluble silica in conjunction with a high $\mathrm{pH}$ solution. The presence of soluble silica has been shown repeatedly to improve the homogeneity of the microstructure, increase the Si/Al ratio and improve mechanical properties (Fernández-Jiménez and Palomo 2005). However, this research and an increasing amount of other research are based upon the alkali activation of Si-rich materials without the inclusion of soluble silica (Brew and MacKenzie 2007; Hajimohammadi et al. 2008; Songpiriyakij et al. 2010; Cyr et al. 2012; Gluth et al. 2012).

High-Si source materials activated by an alkali hydroxide can easily achieve the Si/Al ratios reached in mixtures containing soluble silica, but it is clear that despite the stoichiometric similarities between these mixtures, the kinetics, reaction mechanisms and degree of reaction are quite different. 
Soluble silica offers pre-dissolved, pre-polymerized Si species, which allows the solution to reach supersaturation very quickly, which results in polycondensation and a continuous microstructure. Mixtures not containing soluble silica must first undergo dissolution to the point of supersaturation, which can take a much longer time, and as such concentration gradients are present throughout the solution that cause precipitation to occur rather than gelation, which can results in a less homogenous microstructure.

The homogeneity of the microstructure plays an important role in the mechanical performance of a binder based on the simple principle that smaller voids create a stronger matrix than larger voids, such as those often found in mixtures activated with alkali hydroxide only.

From this research, it can be seen that strong, homogenous microstructures can be obtained through the activation of Si-rich glass by sodium hydroxide without the presence of soluble silica. However, the $\mathrm{Si} / \mathrm{Al}$ ratio of many of these mixtures was outside the bounds of $\mathrm{Si} / \mathrm{Al}$ ratio normally quoted as optimal for geopolymers. Other research has also shown that activating high-Si materials results in an optimal $\mathrm{Si} / \mathrm{Al}$ ratio much higher than is typical. Fletcher et al. and Songpiriyakij et al., in separate research projects, both found an optimal $\mathrm{Si} / \mathrm{Al}$ ratio to be around 16 for reacting Si-rich materials without the presence of soluble silica (Fletcher et al. 2005; Songpiriyakij et al. 2010). Both groups also noted the failure mechanism switched from brittle to ductile at this point as well. For both of these mixtures the corresponding $\mathrm{Na} / \mathrm{Al}$ ratio was 5 and 3 , respectively, though Songpiriyakij et al. noted that strength increased in nearly all mixtures when $\mathrm{Na} / \mathrm{Al}$ and $\mathrm{Na} / \mathrm{Si}$ ratios decreased toward 1. 
This creates a difficult situation in terms of mixture design for Si-rich source materials activated with an alkali hydroxide. Higher mechanical performance and more uniform microstructures are found with higher $\mathrm{Si} / \mathrm{Al}$ and lower $\mathrm{Na} / \mathrm{Al}$ but $\mathrm{Na}$ is necessary for dissolution since no soluble silica is present. It was for this reason $\mathrm{Na} / \mathrm{Al}$ molar ratios of 1 or 2 were used as a basis for mixture design in this research. When the $\mathrm{Na} / \mathrm{Al}$ ratio is predefined between the metakaolin, which provides all of the $\mathrm{Al}$, and the activator, which provides most of the $\mathrm{Na}$, then the $\mathrm{Si} / \mathrm{Al}$ ratio can be adequately increased through the inclusion of a Si-rich source material such as glass. So, optimal stoichiometry of geopolymers made from the activation of Si-rich materials with alkali hydroxide most likely will be different than those made with soluble silica which may mean a different range of optimal molar ratios should be defined for these mixtures.

\subsection{Mixture parameters}

The synergy between various mixture parameters such as curing temperature and time, activator concentration, properties of the source materials, water/solids ratio, mixing time, consolidation methods, etc. is incredibly complex and important. This is not to say that designing optimized glass based geopolymers is not impossible, on the contrary, based on this research it is believed that it is very possible to design high quality glass geopolymers. However, vigorous testing is required that would cover all of these variables in various combinations. It would be important to determine which parameters are the ones with the most impact on the mixture, for example in this research, increasing the curing temperature from $60^{\circ} \mathrm{C}$ to $80^{\circ} \mathrm{C}$ had a substantial effect on microstructure, compressive strength and composition. 


\subsection{Environmental}

Geopolymers made of glass have a significantly smaller carbon footprint than ordinary portland cement and have the potential to utilize vast quantities of waste materials. Glassbased geopolymers also have the potential to produce a quality alternative binder capable of reaching high strengths at only 24 hours, as well as to create a stable market for waste glass. This will help to relieve pressure from the municipal waste stream and put a valuable material to good use. Further, the high Si and Na contents that waste glass offers, without the addition of sodium silicate, allow for activation with just an alkali hydroxide, further lowering the carbon footprint of the binder.

\subsection{Recommendations for future work}

While geopolymers are a potentially low- $\mathrm{CO}_{2}$ alternative concrete, there still remains much work to be done before wide-scale commercial applications can be considered. The following is a brief list of recommendations for future work:

- Since the degree of reaction did not increase for the most part past day 1 , reorganization within the matrix must have occurred, which could have included the formation and depletion of intermediate phases. Compositional phase analysis at various times throughout curing including at or before 1 day could help to understand these changes.

- Likewise, observation of polished cross sections prepared at various times during curing could allow observation of changes in the microstructure. Fracture surfaces can be very misleading as they show only the surface of the material; the interior of the matrix and the presence of layers of hydration products, unreacted particles and different phases is extremely helpful in understanding how the geopolymer was formed. 
- Investigation of other Al-rich materials as possible aluminum sources such as red mud, sodium aluminate, salt cake, spent potliner or waste water from Al refineries.

- Durability testing on the mortars or concrete to ensure the compressive strength measured in this research is stable. This could include leaching tests of mortars in water to determine if the presence of $\mathrm{Al}$ is indeed tying up the excess alkalis.

- Rigorous testing of variables such as glass fineness, activator concentration, curing time and temperature to develop trends for each of these variables and for the various combinations of them.

- Experimentation with a more complete spectrum of glass compositions as well as blended glasses.

- Experimentation with water reducers or superplasticizers for use with high metakaolin replacements to reduce the water demand.

- Experimentation with various fly ashes and glass to determine how the two materials react together and if composition of the fly ash plays a big role in success.

- Investigation into the effects of the water/solids ratio on performance could help to develop an acceptable range of water/solids ratio in geopolymers. 



\section{References}

ACAA Sustainable Construction with Coal Combustion Products. A. C. A. A. E. Foundation.

ACF, T. A. C. F.-. (2010). All About Coal. 2011.

ASCE, A. S. o. C. E. (2013). "2013 Report Card for America's Infrastructure." Retrieved 6.12.2013, 2013.

ASTM International (1999). Standard Test Method for Flow of Hydraulic Cement Mortar. Pennsylvania, ASTM International. C1437-99.

ASTM International (2008). Standard Specification for Coal Fly Ash or Calcined Natural Pozzolan for Use in Concrete. Pennsylvania, ASTM International. C618 - 08a.

ASTM International (2009). Standard Specification for Portland Cement. Pennsylvania, ASTM International. C150/C150M - 09.

ASTM International (2011). Standard Test Method for Compressive Strength of Cylindrical Concrete Specimens. Pennsylvania, ASTM International. C39/C39M $11 \mathrm{a}$.

ASTM International (2012). Standard Specification for Standard Sand. Pennsylvania, ASTM International. C778 - 12.

Babaian, P. M., K. Wang, A. Mishulovich, S. Bhattacharja and S. P. Shah (2003). "Effect of mechanochemical activation on reactivity of cement kiln dust-fly ash systems." ACI Materials Journal 100(1): 55-62.

Barbosa, V. F. F., K. J. D. MacKenzie and C. Thaumaturgo (2000). "Synthesis and characterisation of materials based on inorganic polymers of alumina and silica: sodium polysialate polymers." International Journal of Inorganic Materials 2(4): 309-317.

Barsoum, M. W., A. Ganguly and G. Hug (2006). "Microstructural evidence of reconstituted limestone blocks in the Great Pyramids of Egypt." Journal of the American Ceramic Society 89(Compendex): 3788-3796.

Bell, A. T. (1999). "NMR applied to zeolite synthesis." Colloids and Surfaces A: Physicochemical and Engineering Aspects 158(1, Äi2): 221-234. 
Bondar, D., C. J. Lynsdale, N. B. Milestone, N. Hassani and A. A. Ramezanianpour (2011). "Effect of type, form, and dosage of activators on strength of alkali-activated natural pozzolans." Cement and Concrete Composites 33(2): 251-260.

Breck, D. W. (1974). Zeolite molecular sieves: structure, chemistry and use. United States of America, John Wiley \& Sons, Inc.

Brew, D. and K. MacKenzie (2007). "Geopolymer synthesis using silica fume and sodium aluminate." Journal of Materials Science 42(11): 3990-3993.

Buchwald, A. and M. Schulz (2005). "Alkali-activated binders by use of industrial byproducts." Cement and Concrete Research 35(5): 968-973.

Burns, K. (2012). "What is modern glass made of?" Retrieved June 1, 2013, 2013.

Carvalho, J., P. Carvalho, A. T. Pinto and J. A. Labrincha (2008). "Activation of mixtures of natural clay and glass cullet rejects." Clay Minerals 43(Compendex): 657-667.

Criado, M., A. Fernandez-Jimenez, A. G. de la Torre, M. A. G. Aranda and A. Palomo (2007). "An XRD study of the effect of the $\mathrm{SiO} 2 / \mathrm{Na} 2 \mathrm{O}$ ratio on the alkali activation of fly ash." Cement and Concrete Research 37(Compendex): 671-679.

Criado, M., A. Fernández-Jiménez and A. Palomo (2010). "Alkali activation of fly ash. Part III: Effect of curing conditions on reaction and its graphical description." Fuel 89(11): 3185-3192.

Criado, M., A. Fernandez-Jimenez, A. Palomo, I. Sobrados and J. Sanz (2008). "Effect of the $\mathrm{SiO} 2 / \mathrm{Na} 2 \mathrm{O}$ ratio on the alkali activation of fly ash. Part II: 29Si MAS-NMR Survey." Microporous and Mesoporous Materials 109(Compendex): 525-534.

Cyr, M., R. Idir and T. Poinot (2012). "Properties of inorganic polymer (geopolymer) mortars made of glass cullet." Journal of Materials Science 47(6): 2782-2797.

Damtoft, J. S., J. Lukasik, D. Herfort, D. Sorrentino and E. M. Gartner (2008). "Sustainable development and climate change initiatives." Cement and Concrete Research 38(2): $115-127$.

Davidovits, J. (1979). Polymere mineral. F. Patent. France.

Davidovits, J. (1987). "ANCIENT AND MODERN CONCRETES: WHAT IS THE REAL DIFFERENCE?" Concrete International 9(Compendex): 23-29.

Davidovits, J. (1989). "Geopolymers and geopolymeric materials." Journal of thermal analysis 35(Compendex): 429-441. 
Davidovits, J. (1991). "Geopolymers - Inorganic Polymeric New Materials." Journal of Thermal Analysis 37(8): 1633-1656.

Davidovits, J. (1994). Properties of Geopolymer Cements. 1st International Conference on Alkaline Cements and Concretes, Kiev Ukraine.

Davidovits, J. (2002). 30 Years of Successes and Failures in Geopolymer Applications. Market Trends and Potential Breakthroughs. Geopolymer 2002 Conference, Melbourne, Australia.

Davidovits, J. (2008). Geopolymer chemistry and applications. Saint-Quentin, Institut Geopolymere.

Davidovits, J., D. C. Comrie, J. H. Paterson and D. J. Ritcey (1990). "Geopolymeric concretes for environmental protection." Concrete International 12(Compendex): 30-39.

De Silva, P., K. Sagoe-Crenstil and V. Sirivivatnanon (2007). "Kinetics of geopolymerization: Role of $\mathrm{Al} 2 \mathrm{O} 3$ and $\mathrm{SiO} 2 . "$ Cement and Concrete Research 37(Compendex): 512-518.

Deevasan, K. K. and R. V. Ranganath (2011). "Geopolymer concrete using industrial byproducts." Proceedings of Institution of Civil Engineers: Construction Materials 164(Compendex): 43-50.

Dent Glasser, L. S. and E. E. Lachowski (1980). "Silicate species in solution. Part 1. Experimental observations." Journal of the Chemical Society, Dalton Transactions(3): 393-398.

Di Bella, G., I. Arrigo, P. Catalfamo, F. Corigliano and L. Mavilia (2003). Advances in the extraction of silica from glass cullet. Recycling and Reuse of Waste Materials, Proceedings of the International Symposium, September 9, 2003 - September 11, 2003, Dundee, United kingdom, Thomas Telford Services Ltd.

Diamond, S. (1986). "Particle Morphologies in Fly Ash." Cement and Concrete Research 16(4): 569-579.

Diamond, S. (2004). "The microstructure of cement paste and concrete, Äì, Äìa visual primer." Cement and Concrete Composites 26(8): 919-933.

Duxson, P., A. Fernandez-Jimenez, J. L. Provis, G. C. Lukey, A. Palomo and J. S. J. van Deventer (2007). "Geopolymer technology: the current state of the art." Journal of Materials Science 42(9): 2917-2933. 
Duxson, P., G. C. Lukey, F. Separovic and J. S. J. van Deventer (2005). "Effect of Alkali Cations on Aluminum Incorporation in Geopolymeric Gels." Industrial \& Engineering Chemistry Research 44(4): 832-839.

Duxson, P., G. C. Lukey, J. S. J. Van De Venter, S. W. Mallicoat and W. M. Kriven (2005). Microstructural characterisation of metakaolin-based geopolymers. 106th Annual Meeting of the American Ceramic Society, April 18, 2004 - April 21, 2004, Indianapolis, IN, United states, American Ceramic Society.

Duxson, P. and J. L. Provis (2008). "Designing Precursors for Geopolymer Cements." Journal of the American Ceramic Society 91(12): 3864-3869.

Duxson, P., J. L. Provis and G. C. Lukey (2005). Structural ordering in geopolymers derived from metakaolin. Geopolymer 2005.

Duxson, P., J. L. Provis, G. C. Lukey, S. W. Mallicoat, W. M. Kriven and J. S. J. Van Deventer (2005). "Understanding the relationship between geopolymer composition, microstructure and mechanical properties." Colloids and Surfaces A: Physicochemical and Engineering Aspects 269(Compendex): 47-58.

Duxson, P., J. L. Provis, G. C. Lukey, F. Separovic and J. S. J. Van Deventer (2005). "Si NMR study of structural ordering in aluminosilicate geopolymer gels." Langmuir 21(Compendex): 3028-3036.

Duxson, P., J. L. Provis, G. C. Lukey and J. S. J. van Deventer (2007). "The role of inorganic polymer technology in the development of 'green concrete'." Cement and Concrete Research 37(Compendex): 1590-1597.

Engelhardt, G. n. (1989). "Multinuclear solid-state NMR in silicate and zeolite chemistry." TrAC Trends in Analytical Chemistry 8(9): 343-347.

Fernández-Jiménez, A., A. G. de la Torre, A. Palomo, G. Lopez-Olmo, M. M. Alonso and M. A. G. Aranda (2006). "Quantitative determination of phases in the alkali activation of fly ash. Part I. Potential ash reactivity." Fuel 85(5, Äi6): 625-634.

Fernández-Jiménez, A., A. G. de la Torre, A. Palomo, G. Lopez-Olmo, M. M. Alonso and M. A. G. Aranda (2006). "Quantitative determination of phases in the alkaline activation of fly ash. Part II: Degree of reaction." Fuel 85(14,Äì15): 1960-1969.

Fernández-Jiménez, A., I. Garcia-Lodeiro and A. Palomo (2007). "Durability of alkaliactivated fly ash cementitious materials." Journal of Materials Science 42(9): 30553065 .

Fernández-Jiménez, A., E. E. Lachowski, A. Palomo and D. E. Macphee (2004). "Microstructural characterisation of alkali-activated PFA matrices for waste immobilisation." Cement and Concrete Composites 26(8): 1001-1006. 
Fernández-Jiménez, A., M. Monzo, M. Vicent, A. Barba and A. Palomo (2007). "Alkaline activation of metakaolin-fly ash mixtures: Obtain of Zeoceramics and Zeocements." Microporous and Mesoporous Materials 108(1): 41-49.

Fernández-Jiménez, A. and A. Palomo (2003). Activating FLY-ashes: Enlarging the concept of cementitious material. Role of Concrete in Sustainable Development International Symposium Celebrating Concrete: People and Practice, September 3, 2003 - September 4, 2003, Dundee, United kingdom, Thomas Telford Services Ltd.

Fernández-Jiménez, A. and A. Palomo (2003). "Characterisation of fly ashes. Potential reactivity as alkaline cements." Fuel 82(Compendex): 2259-2265.

Fernández-Jiménez, A. and A. Palomo (2005). "Composition and microstructure of alkali activated fly ash binder: Effect of the activator." Cement and Concrete Research 35(10): 1984-1992.

Fernández-Jiménez, A., A. Palomo and M. Criado (2005). "Microstructure development of alkali-activated fly ash cement: A descriptive model." Cement and Concrete Research 35(Compendex): 1204-1209.

Fernández-Jiménez, A., A. Palomo and C. Lopez-Bombrados (2006). "Engineering Properties of Alkali-Activated Fly Ash Concrete." ACI Materials Journal 103(2): 106-112.

Fernández-Jiménez, A., A. Palomo, I. Sobrados and J. Sanz (2006). "The role played by the reactive alumina content in the alkaline activation of fly ashes." Microporous and Mesoporous Materials 91(1-3): 111-119.

Fernández-Jiménez, A., R. Vallepu, T. Terai, A. Palomo and K. Ikeda (2006). "Synthesis and thermal behavior of different aluminosilicate gels." Journal of Non-Crystalline Solids 352(21, Äì22): 2061-2066.

Fletcher, R. A., K. J. D. MacKenzie, C. L. Nicholson and S. Shimada (2005). "The composition range of aluminosilicate geopolymers." Journal of the European Ceramic Society 25(Compendex): 1471-1477.

Garcia-Lodeiro, I., A. Palomo and A. Fernandez-Jimenez (2007). "Alkali-aggregate reaction in activated fly ash systems." Cement and Concrete Research 37(Compendex): 175-183.

Gartner, E. (2004). "Industrially interesting approaches to ,Äúlow-CO2,Äù cements." Cement and Concrete Research 34(9): 1489-1498.

Glass Packaging Institute, G. (2013). "Glass Packaging Institute." Glass Education, 2013, from http://www.gpi.org/glassresources/education/. 
Glusing, A. K. and R. Conradt (2001). Dissolution Kinetics of Impurities in Recycled Cullet. Recycling and Reuse of Glass Cullet, Thomas Telford Publishing.

Gluth, G. J. G., C. Lehmann, K. R ${ }^{\vee}$ bner and H. C. K``hne (2012). "Geopolymerization of a silica residue from waste treatment of chlorosilane production." Materials and Structures: $1-8$.

Grambow, B. and R. Muller (2001). "First-order dissolution rate law and the role of surface layers in glass performance assessment." Journal of Nuclear Materials 298(Compendex): 112-124.

Granizo, M. L., S. Alonso, M. T. Blanco-Varela and A. Palomo (2002). Alkaline activation of metakaolin: Effect of calcium hydroxide in the products of reaction, American Ceramic Society.

Grim, R. E. (1968). Clay Mineralogy. United States of America, McGraw-Hill, Inc.

Grutzeck, M. W. and J. A. Marks (1999). "Synthesis of double-layer silicates from recycled glass cullet: A new type of chemical adsorbent." Environmental Science and Technology 33(Compendex): 312-317.

Guo, X., H. Shi and W. A. Dick (2010). "Compressive strength and microstructural characteristics of class $\mathrm{C}$ fly ash geopolymer." Cement and Concrete Composites 32(Compendex): 142-147.

Hajimohammadi, A., J. L. Provis and J. S. J. van Deventer (2008). "One-Part Geopolymer Mixes from Geothermal Silica and Sodium Aluminate." Industrial \& Engineering Chemistry Research 47(23): 9396-9405.

Hajimohammadi, A., J. L. Provis and J. S. J. van Deventer (2010). "Effect of Alumina Release Rate on the Mechanism of Geopolymer Gel Formation." Chemistry of Materials 22(18): 5199-5208.

Hajimohammadi, A., J. L. Provis and J. S. J. van Deventer (2011). "The effect of silica availability on the mechanism of geopolymerisation." Cement and Concrete Research 41(3): 210-216.

Hammond, G. P. and C. I. Jones (2008). "Embodied energy and carbon in construction materials." Proceedings of the Institution of Civil Engineers 161(2): 87-98.

Hanle, L. J. (2001). CO2 Emissions Profile of the U.S. Cement Industry. Washington DC, Environmental Protection Agency.

Hao, H., K.-L. Lin, D. Wang, S.-J. Chao, H.-S. Shiu, T.-W. Cheng and C.-L. Hwang (2012). "Utilization of solar panel waste glass for metakaolinite-based geopolymer synthesis." Environmental Progress \& Sustainable Energy: n/a-n/a. 
Hardjito, D. and B. Rangan (2005). Development and Properties of Low-Calcium Fly Ashbased Geopolymer Concrete. Research Report GC1. Perth, Australia, Curtin University of Technology.

Hardjito, D., S. E. Wallah, D. M. J. Sumajouw and B. V. Rangan (2004). "On the development of fly ash-based geopolymer concrete." Aci Materials Journal 101(6): 467-472.

Harris, D. C. (2007). Quantitative Chemical Analysis. New York, W.H. Freeman and Company.

Hemmings, R. T. and E. E. Berry (1986). Speciation in Size and Density Fractionated Fly Ash. Material Research Symposium, Materials Research Society.

Hemmings, R. T. and E. E. Berry (1988). On the glass in coal fly ashes: Recent advances. Material Research Society Symposium, Materials Research Society.

Hendricks, W. M., A. T. Bell and C. J. Radke (1991). "Effects of organic and alkali metal cations on the distribution of silicate anions in aqueous solutions." Journal of Physical Chemistry 95(Compendex): 9513-9513.

Hooton, R. D. (2008). "Bridging the gap between research and standards." Cement and Concrete Research 38(2): 247-258.

Idir, R., M. Cyr, T. Poinot and N. Khelil (2011). Properties of geopolymer mortars made of glass cullet. Cementing a sustainable future: XIII ICCC international congress on the chemistry of cement, Madrid, Spain.

Iler, R. K. (1955). The Colloid Chemistry of Silica and Silicates. Ithica, New York, Cornell University Press.

Iler, R. K. (1979). The Chemistry of Silica. United States of America, John Wiley \& Sons, Inc.

IMP, I. o. M. P. (1994). "Mining Glass from the Waste Stream." Retrieved 3/22/2012, 2012, from www.imp.mtu.edu/information/wgpc.html.

IUPAC (2012). IUPAC Compendium of Chemical Terminology, International Union of Pure and Applied Chemistry.

Kallala, M., R. Jullien and B. Cabane (1991). "Crossover from gelation to precipitation." Journal of Physics II France 2: 7-25.

Karamberi, A., M. Kerinis and A. Moutsatsou (2004). Innovative reuse of glass gullet in cement products. International Conference on Sustainable Waste Management and 
Recycling, September 14, 2005 - September 15, 2005, London, United kingdom, Thomas Telford Services Ltd.

Knight, C. T. G., R. J. Balec and S. D. Kinrade (2007). "The Structure of Silicate Anions in Aqueous Alkaline Solutions." Angewandte Chemie International Edition 46(43): 8148-8152.

Kolouek, D., J. Brus, M. Urbanova, J. Andertova, V. Hulinsky and J. Vorel (2007). "Preparation, structure and hydrothermal stability of alternative (sodium silicatefree) geopolymers." Journal of Materials Science 42(Compendex): 9267-9275.

Kosmatka, S. H. and M. L. Wilson (2011). Design and Control of Concrete Mixtures. Skokie, Illinois, Portland Cement Association.

Kosmatka, S. H. W., Michelle L. (2011). Design and Control of Concrete Mixtures. Skokie, IL, Portland Cement Association.

Kourti, I., D. A. Rani, D. Deegan, A. R. Boccaccini and C. R. Cheeseman (2010). "Production of geopolymers using glass produced from DC plasma treatment of air pollution control (APC) residues." Journal of Hazardous Materials 176(Compendex): 704-709.

Kovalchuk, G., A. Fernández-Jiménez and A. Palomo (2007). "Alkali-activated fly ash: Effect of thermal curing conditions on mechanical and microstructural development - Part II." Fuel 86(3): 315-322.

Krivenko, P. V. (2007). Performance of Alkali-Activated Cements - A Step towards True Sustainable Development. 2007 International Forum on Strategic Technology, IFOST, October 3, 2007 - October 6, 2007, Ulaanbaatar, Mogolia, Inst. of Elec. and Elec. Eng. Computer Society.

Kumar, S., R. Kumar, T. C. Alex, A. Bandopadhyay and S. P. Mehrotra (2007). "Influence of reactivity of fly ash on geopolymerisation." Advances in Applied Ceramics 106(3): 120-127.

Lawrence, M. and H. E. Vivian (1961). "Reactions of various alkalis with silica." Australian Journal of Applied Science 12(1): 96-103.

Li, H., S. Shi, D. Xu, L. Zhuge and L. Zhang (2011). Research on the dissolving character of active Si/Al in fly ash activated by alkali. 2010 International Conference on Advances in Materials and Manufacturing Processes, ICAMMP 2010, November 6, 2010 - November 8, 2010, Shenzhen, China, Trans Tech Publications.

Li, K. L., G. H. Huang, L. H. Jiang, Y. B. Cai, J. Chen and J. T. Ding (2006). "Study on abilities of mineral admixtures and geopolymer to restrain ASR." Environmental Ecology and Technology of Concrete 302-303: 248-254. 
Lin, K.-L., H.-S. Shiu, J.-L. Shie, T.-W. Cheng and C.-L. Hwang (2012). "Effect of composition on characteristics of thin film transistor liquid crystal display (TFTLCD) waste glass-metakaolin-based geopolymers." Construction and Building Materials 36(0): 501-507.

Litvan, G. G. (1984). "Volume instability of porous solids." Journal of Materials Science 19(8): 2473-2480.

Lowenstein, W. (1954). "The Distribution of Aluminum in the Tetrahedra of Silicates and Aluminates." American Mineralogist 39(1): 92-96.

Madani, A., A. Aznar, J. Sanz and J. M. Serratosa (1990). "Silicon-29 and aluminum-27 NMR study of zeolite formation from alkali-leached kaolinites: influence of thermal preactivation." The Journal of Physical Chemistry 94(2): 760-765.

Maekawa, H., T. Maekawa, K. Kawamura and T. Tokokawa (1990). "The structural groups of alkali silicate glasses determined from Si MAS-NMR." Journal of NonCrystalline Solids 127(1): 53-64.

Mavilia, L., G. D. Bella and F. Corigliano (2001). Characterization and Valorization of the Solid Residue from Glass Extraction with an Alkali Solution. Recycling and Reuse of Glass Cullet, Thomas Telford Publishing.

Mavilia, L. and F. Corigliano (2001). HIgh Added Value Products from Off-Quality Waste Glass. Recycling and Reuse of Glass Cullet, Thomas Telford Publishing.

McCormick, A. V., A. T. Bell and C. J. Radke (1989). "Multinuclear NMR investigation of the formation of aluminosilicate anions." The Journal of Physical Chemistry 93(5): 1741-1744.

McDonald, M. and J. LaRosa (2006). Sodium Silicate a Binder for the 21st Century. Valley Forge, PA, The PQ Corporation.

McMurry, J. and R. C. Fay (2001). Chemistry. Upper Saddle River, Prentice-Hall Inc.

Mehta, P. K. (2001). Reducing the Environmental Impact of Concrete. Concrete International. 23: 61-66.

Mehta, P. K. and P. J. M. Monteiro (2006). Concrete: Microstructure, Properties and Materials. New York City, McGraw-Hill.

Meyer, C. (2009). "The greening of the concrete industry." Cement and Concrete Composites 31(Compendex): 601-605. 
Meyer, C., S. Baxter and W. Jin (1996). Alkali-silica reaction in concrete with waste glass as aggregate. Proceedings of the 1996 4th Materials Engineering Conference. Part 2 (of 2), November 10, 1996 - November 14, 1996, Washington, DC, USA, ASCE.

Mindess, S., J. F. Young and D. Darwin (2002). Concrete.

Murayama, N., H. Yamamoto and J. Shibata (2002). "Mechanism of zeolite synthesis from coal fly ash by alkali hydrothermal reaction." International Journal of Mineral Processing 64(1): 1-17.

North, M. R. and T. W. Saddle (2000). "Kinetics of silicate exchange in alkaline aluminosilicate solutions." Journal of Inorganic Chemistry 39(12): 2661-2665.

Nowak, R. (2008). Build 'em high, and make them green. New Scientist. Melbourne: 2829.

NRC, N. R. C. (2000). Coal Ash Fact Sheet. National Recycling Coalition - Buy Recycled Business Alliance. Washington, DC.

Oelkers, E. H. and S. R. Gislason (2001). "The mechanism, rates and consequences of basaltic glass dissolution: I. An experimental study of the dissolution rates of basaltic glass as a function of aqueous $\mathrm{Al}, \mathrm{Si}$ and oxalic acid concentration at $25 \neg \infty \mathrm{C}$ and $\mathrm{pH}=3$ and 11." Geochimica et Cosmochimica Acta 65(21): 3671-3681.

Oelkers, E. H., J. Schott and J.-L. Devidal (1994). "The effect of aluminum, pH, and chemical affinity on the rates of aluminosilicate dissolution reactions." Geochimica et Cosmochimica Acta 58(9): 2011-2024.

Palomo, A., S. Alonso, A. Fernández-Jiménez, I. Sobrados and J. Sanz (2004). "Alkaline activation of fly ashes: NMR study of the reaction products." Journal of the American Ceramic Society 87(Compendex): 1141-1145.

Palomo, A., A. Fernández-Jiménez and M. Criado (2004). "Geopolimeros": una unica base que mica y diferentes microestructuras.

Palomo, A. and F. P. Glasser (1992). "Chemically-bonded Cementitious Materials Based on Metakaolin." British ceramic, transactions and journal 91: 107-112.

Palomo, A., M. W. Grutzeck and M. T. Blanco (1999). "Alkali-activated fly ashes - A cement for the future." Cement and Concrete Research 29(8): 1323-1329.

Pan, Z., D. Li, J. Yu and N. Yang (2003). "Properties and microstructure of the hardened alkali-activated red mud,Äìslag cementitious material." Cement and Concrete Research 33(9): 1437-1441.

Pankow, J. F. (1991). Aquatic Chemistry Concepts. Chelsea, Michigan, Lewis Publishers. 
Pascoe, R. D., R. W. Barley and P. R. Child (2001). Autogenous Grinding of Glass Cullet in a Stirred Mill. Recycling and Reuse of Glass Cullet, Thomas Telford Publishers.

PCA, P. C. A.-. (2011). "Technical Brief - Green in Practice 107 - Supplementary Cementitious Materials (SCMs)." Retrieved 8-23-2011, 2011, from http://www.concretethinker.com/technicalbrief/Supplementary-CementitiousMaterials.aspx.

Phair, J. W. and J. S. J. Van Deventer (2002). "Characterization of fly-ash-based geopolymeric binders activated with sodium aluminate." Industrial and Engineering Chemistry Research 41(Compendex): 4242-4251.

Polley, C., S. M. Cramer and R. V. de la Cruz (1998). "Potential for using waste glass in Portland cement concrete." Journal of Materials in Civil Engineering 10(Compendex): 210-219.

Provis, J. L., P. Duxson, G. C. Lukey, F. Separovic, W. M. Kriven and J. S. J. Van Deventer (2005). "Modeling speciation in highly concentrated alkaline silicate solutions." Industrial and Engineering Chemistry Research 44(Compendex): 8899-8908.

Provis, J. L., P. Duxson and J. S. J. van Deventer (2010). "The role of particle technology in developing sustainable construction materials." Advanced Powder Technology 21(Compendex): 2-7.

Provis, J. L., G. C. Lukey and J. S. J. Van Deventer (2005). "Do geopolymers actually contain nanocrystalline zeolites? a reexamination of existing results." Chemistry of Materials 17(Compendex): 3075-3085.

Provis, J. L. and J. S. J. vanDeventer (2009). Geopolymers - Structure, processing, properties and industrial applications. Boca Raton, Woodhead Publishing.

Provis, J. L. v., Jannie S.J. (2009). Geopolymers - Structure, processing, properties and industrial applications. Boca Raton, Woodhead Publishing.

Puertas, F., A. Palomo, A. Fernandez-Jimenez, J. D. Izquierdo and M. L. Granizo (2003). "Effect of superplasticisers on the behaviour and properties of alkaline cements." Advances in Cement Research 15(Compendex): 23-28.

Rahier, H., J. F. Denayer and B. van Mele (2003). "Low-temperature synthesized aluminosilicate glasses Part IV Modulated DSC study on the effect of particle size of metakaolinite on the production of inorganic polymer glasses." Journal of Materials Science 38(14): 3131-3136.

Rahier, H., W. Simons, B. Van Mele and M. Biesemans (1997). "Low-temperature synthesized aluminosilicate glasses: Part III Influence of the composition of the 
silicate solution on production, structure and properties." Journal of Materials Science 32(9): 2237-2247.

Rahier, H., B. Van Mele, M. Biesemans, J. Wastiels and X. Wu (1996). "Low-temperature synthesized aluminosilicate glasses Part I low-temperature reaction stoichiometry and structure of a model compound." Journal of Materials Science 31(Compendex): 71-79.

Rahier, H., B. Van Mele and J. Wastiels (1996). "Low-temperature synthesized aluminosilicate glasses Part II rheological transformations during low-temperature cure and high-temperature properties of a model compound." Journal of Materials Science 31(Compendex): 80-85.

Rajmohan, N., P. Frugier and S. Gin (2010). "Composition effects on synthetic glass alteration mechanisms: Part 1. Experiments." Chemical Geology 279(3-4): 106119.

Rattanasak, U. and P. Chindaprasirt (2009). "Influence of $\mathrm{NaOH}$ solution on the synthesis of fly ash geopolymer." Minerals Engineering 22(12): 1073-1078.

Rees, C., G. C. Lukey and J. S. J. v. Deventer (2005). The microstructural characterization of geopolymers derived from fly ash and solid silicates. Geopolymer 2005.

Rovnanik, P. (2010). "Effect of curing temperature on the development of hard structure of metakaolin-based geopolymer." Construction and Building Materials 24(Compendex): 1176-1183.

Rowles, M. and B. O'Connor (2003). "Chemical optimisation of the compressive strength of aluminosilicate geopolymers synthesised by sodium silicate activation of metakaolinite." Journal of Materials Chemistry 13(Compendex): 1161-1165.

Roy, D. M. (1999). "Alkali-activated cements Opportunities and challenges." Cement and Concrete Research 29(2): 249-254.

Ryu, G.-S., H. J. Kang, S.-T. Kang, G.-T. Koh and J.-H. Lee (2011). Mechanical characteristics analysis of alkali-activated fly ash cementitious materials. 9th International Conference on Fracture and Damage Mechanics, FDM 2010, September 20, 2009 - September 22, 2009, Nagasaki, Japan, Trans Tech Publications Ltd.

Sabir, B., S. Wild and J. Bai (2001). "Metakaolin and calcined clays as pozzolans for concrete: A review." Cement and Concrete Composites 23(Compendex): 441-454.

Sagoe-Crentsil, K. and L. Weng (2007). "Dissolution processes, hydrolysis and condensation reactions during geopolymer synthesis: Part II. High Si/Al ratio systems." Journal of Materials Science 42(Compendex): 3007-3014. 
Sakulich, A. R. (2011). "Reinforced geopolymer composites for enhanced material greenness and durability." Sustainable Cities and Society 1(4): 195-210.

Scrivener, K. L. and R. J. Kirkpatrick (2008). "Innovation in use and research on cementitious material." Cement and Concrete Research 38(2): 128-136.

Šefč́́k, J. and A. V. McCormick (1997). "Thermochemistry of aqueous silicate solution precursors to ceramics." AIChE Journal 43(S11): 2773-2784.

Shi, C., F. He, A. Fernandez-Jiminez, P. Krivenko and A. Palomo (2012). "Classification and characteristics of alkali-activated cements." Journal of the Chinese Ceramic Society 40(1).

Shi, C., A. F. Jimenez and A. Palomo (2011). "New cements for the 21st century: The pursuit of an alternative to Portland cement." Cement and Concrete Research 41(7): 750-763.

Shi, C., P. V. Krivenko and D. M. Roy (2006). Alkali-Activated Cements and Concretes, Taylor \& Francis.

Shi, C. K. P. V. R. D. M. (2006). "Alkali-activated cements and concretes." from http://www.myilibrary.com?id=43569

Materials specified: MyiLibraryhttp://www.myilibrary.com?id=43569.

Sofi, M., J. S. J. van Deventer, P. A. Mendis and G. C. Lukey (2007). "Engineering properties of inorganic polymer concretes (IPCs)." Cement and Concrete Research 37(2): 251-257.

Songpiriyakij, S., T. Kubprasit, C. Jaturapitakkul and P. Chindaprasirt (2010). "Compressive strength and degree of reaction of biomass- and fly ash-based geopolymer." Construction and Building Materials 24(3): 236-240.

Sperinck, S., P. Raiteri, N. Marks and K. Wright (2011). "Dehydroxylation of kaolinite to metakaolin - a molecular dynamics study." Journal of Materials Chemistry 21: 2118-2125.

Steveson, M. and K. Sagoe-Crentsil (2005). "Relationships between composition, structure and strength of inorganic polymers : Part 2 Fly ash-derived inorganic polymers." Journal of Materials Science 40(16): 4247-4259.

Steveson, M. and K. Sagoe-Crentsil (2005). "Relationships between composition, structure and strength of inorganic polymers : Part I Metakaolin-derived inorganic polymers." Journal of Materials Science 40(8): 2023-2036. 
Stoklosa, K. (2012). New Life for Glass. Recycling Today. Web, Recycling Today Media Group.

Sutter, L. (2010). International Cement Microscopy Association (ICMA). D. J. v. Deventer. New Orleans, LA.

Swaddle, T. W., J. Salerno and P. A. Tregloan (1994). "Aqueous aluminates, silicates, and aluminosilicates." Chemical Society Reviews 23(5): 319-325.

Taylor, H. (1997). Cement Chemistry. Heron Quay, England, Thomas Telford Publishing.

Temuujin, J., A. van Riessen and R. Williams (2009). "Influence of calcium compounds on the mechanical properties of fly ash geopolymer pastes." Journal of Hazardous Materials 167(1-3): 82-88.

Temuujin, J., R. P. Williams and A. van Riessen (2009). "Effect of mechanical activation of fly ash on the properties of geopolymer cured at ambient temperature." Journal of Materials Processing Technology 209(Compendex): 5276-5280.

Tognonvi, M., S. Rossignol and J.-P. Bonnet (2011). "Physical-chemistry of sodium silicate gelation in an alkaline medium." Journal of Sol-Gel Science and Technology 58(3): 625-635.

Turner, J. (2012). Telephone Interview., Vitro Minerals.

Turner, J. (2013). Telephone Interview., Vitro Minerals.

US EPA, U. S. E. P. A. (2010). Municipal Solid Waste Generation, Recycling, and Disposal in the United States. 2010 Facts and Figures, United States Environmental Protection Agency.

Van Deventer, J. S. J., J. L. Provis, P. Duxson and D. G. Brice (2010). "Chemical research and climate change as drivers in the commercial adoption of alkali activated materials." Waste and Biomass Valorization 1(Compendex): 145-155.

Van Jaarsveld, J. G. S., J. S. J. Van Deventer and L. Lorenzen (1997). "Potential use of geopolymeric materials to immobilize toxic metals: Part I. Theory and applications." Minerals Engineering 10(Compendex): 659-669.

Van Jaarsveld, J. G. S., J. S. J. Van Deventer and G. C. Lukey (2002). "The effect of composition and temperature on the properties of fly ash- and kaolinite-based geopolymers." Chemical Engineering Journal 89(Compendex): 63-73.

Van Jaarsveld, J. G. S., J. S. J. Van Deventer and A. Schwartzman (1999). "Potential use of geopolymeric materials to immobilize toxic metals: Part II. Material and leaching characteristics." Minerals Engineering 12(Compendex): 75-91. 
van Oss, H. G. (2012). Mineral Commodity Summaries. Cement, U.S. Geological Survey.

Varela, B., A. Teixeira-Pinto, P. Tavares, T. Fernandez and A. Palomo (2009). Alkaline activation of volcanic ashes: a preliminary study. Developments in Strategic Materials - 32nd International Conference on Advanced Ceramics and Composites, January 27, 2008 - February 1, 2008, Daytona Beach, FL, United states, American Ceramic Society.

Wastiels, J., X. Wu, S. Faignet and G. Patfoort (1994). "Mineral polymer based on fly ash." The Journal of resource management and technology 22(Compendex): 135-141.

Weng, L. and K. Sagoe-Crentsil (2007). "Dissolution processes, hydrolysis and condensation reactions during geopolymer synthesis: Part I-Low Si/Al ratio systems." Journal of Materials Science 42(Compendex): 2997-3006.

Weng, L., K. Sagoe-Crentsil, T. Brown and S. Song (2005). "Effects of aluminates on the formation of geopolymers." Materials Science and Engineering: B 117(2): 163-168.

Xie, Z. and Y. Xi (2001). "Hardening mechanisms of an alkaline-activated class F fly ash." Cement and Concrete Research 31(9): 1245-1249.

Xie, Z., W. Xiang and Y. Xi (2003). "ASR potentials of glass aggregates in water-glass activated fly ash and Portland cement mortars." Journal of Materials in Civil Engineering 15(Compendex): 67-74.

$\mathrm{Xu}, \mathrm{H}$. and J. S. J. v. Deventer (1999). The Geopolymerisation of Natural Alumino0silicates. Geopolymere ' 99 .

Xu, H. and J. S. J. Van Deventer (2000). "Geopolymerisation of alumino-silicate minerals." International Journal of Mineral Processing 59(Compendex): 247-266.

Xu, H. and J. S. J. Van Deventer (2002). "Geopolymerisation of multiple minerals." Minerals Engineering 15(12): 1131-1139.

Xu, H. and J. S. J. Van Deventer (2003). "Effect of source materials on geopolymerization." Industrial and Engineering Chemistry Research 42(Compendex): 1698-1706.

Yip, C. K., G. C. Lukey, J. L. Provis and J. S. J. van Deventer (2008). "Effect of calcium silicate sources on geopolymerisation." Cement and Concrete Research 38(Compendex): 554-564.

Yip, C. K., G. C. Lukey and J. S. J. Van Deventer (2005). "The coexistence of geopolymeric gel and calcium silicate hydrate at the early stage of alkaline activation." Cement and Concrete Research 35(Compendex): 1688-1697.

Zeiger, E. (2008). Glass Recycling. Bulk Solids Handling. Germany. 28. 
Zhang, G., J. He and R. Gambrell (2010). "Synthesis, Characterization, and Mechanical Properties of Red Mud-Based Geopolymers." Transportation Research Record: Journal of the Transportation Research Board 2167(-1): 1-9.

Zhang, Z., H. Wang, J. L. Provis, F. Bullen, A. Reid and Y. Zhu (2012). "Quantitative kinetic and structural analysis of geopolymers. Part 1 . The activation of metakaolin with sodium hydroxide." Thermochimica Acta 539(0): 23-33. 


\section{A. Appendix A}

\section{A.1 Microanalysis results for Phase I}

Table 5.1. Microanalysis of phases found in F.5.80, which measured $4^{\text {th }}$ in order of maximum compressive strength at 201 days. The results are based on 6 analyses.

\begin{tabular}{|c|c|c|c|c|c|}
\hline & Bulk & Average & $\begin{array}{c}\text { Standard } \\
\text { deviation }\end{array}$ & Minimum & Maximum \\
\hline $\mathrm{Si} / \mathrm{Al}$ & 8.39 & 9.4 & 0.3 & 8.8 & 9.8 \\
\hline $\mathrm{Na} / \mathrm{Al}$ & 1.0 & 2.1 & 0.7 & 1.1 & 3.1 \\
\hline $\mathrm{Na} / \mathrm{Si}$ & 0.1 & 0.2 & 0.1 & 0.1 & 0.3 \\
\hline $\mathrm{Ca} / \mathrm{Si}$ & 0.4 & 0.5 & 0.0 & 0.4 & 0.5 \\
\hline
\end{tabular}

Table 5.2. Microanalysis of phases found in F.5.40, which measured $6^{\text {th }}$ in order of maximum compressive strength at 201 days. The results are based on 6 analyses.

\begin{tabular}{|c|c|c|c|c|c|}
\hline & Bulk & Average & Standard deviation & Minimum & Maximum \\
\hline $\mathrm{Si} / \mathrm{Al}$ & 8.4 & 9.2 & 0.9 & 7.4 & 10.0 \\
\hline $\mathrm{Na} / \mathrm{Al}$ & 1.0 & 3.0 & 0.6 & 2.3 & 4.0 \\
\hline $\mathrm{Na} / \mathrm{Si}$ & 0.1 & 0.3 & 0.1 & 0.2 & 0.4 \\
\hline $\mathrm{Ca} / \mathrm{Si}$ & 0.4 & 0.4 & 0.1 & 0.3 & 0.5 \\
\hline
\end{tabular}

Table 5.3. Microanalysis of phases found in F.10.80, which measured $3^{\text {rd }}$ in order of maximum compressive strength at 201 days. The results are based on 6 analyses.

\begin{tabular}{|c|c|c|c|c|c|}
\hline & Bulk & Average & Standard deviation & Minimum & Maximum \\
\hline $\mathrm{Si} / \mathrm{Al}$ & 8.4 & 9.0 & 0.9 & 7.8 & 10.2 \\
\hline $\mathrm{Na} / \mathrm{Al}$ & 1.6 & 5.5 & 2.7 & 3.4 & 10.6 \\
\hline $\mathrm{Na} / \mathrm{Si}$ & 0.2 & 0.6 & 0.4 & 0.4 & 1.4 \\
\hline $\mathrm{Ca} / \mathrm{Si}$ & 0.4 & 0.3 & 0.1 & 0.2 & 0.4 \\
\hline
\end{tabular}


Table 5.4. Microanalysis of phases found in F.10.40, which measured $1^{\text {st }}$ in order of maximum compressive strength at 201 days. The results are based on 6 analyses.

\begin{tabular}{|l|c|c|c|c|c|}
\hline & Bulk & Average & Standard deviation & Minimum & Maximum \\
\hline $\mathrm{Si} / \mathrm{Al}$ & 8.4 & 9.2 & 0.9 & 7.4 & 10.0 \\
\hline $\mathrm{Na} / \mathrm{Al}$ & 1.6 & 3.0 & 0.6 & 2.3 & 4.0 \\
\hline $\mathrm{Na} / \mathrm{Si}$ & 0.2 & 0.3 & 0.1 & 0.2 & 0.4 \\
\hline $\mathrm{Ca} / \mathrm{Si}$ & 0.4 & 0.4 & 0.1 & 0.3 & 0.5 \\
\hline
\end{tabular}

Table 5.5. Microanalysis of phases found in C.5.80, which measured $8^{\text {th }}$ in order of maximum compressive strength at 201 days. The results are based on 6 analyses.

\begin{tabular}{|c|c|c|c|c|c|}
\hline & Bulk & Average & Standard deviation & Minimum & Maximum \\
\hline $\mathrm{Si} / \mathrm{Al}$ & 8.4 & 14.0 & 3.0 & 10.1 & 17.6 \\
\hline $\mathrm{Na} / \mathrm{Al}$ & 1.0 & 7.8 & 1.5 & 5.8 & 9.7 \\
\hline $\mathrm{Na} / \mathrm{Si}$ & 0.1 & 0.6 & 0.1 & 0.5 & 0.7 \\
\hline $\mathrm{Ca} / \mathrm{Si}$ & 0.4 & 0.3 & 0.0 & 0.2 & 0.3 \\
\hline
\end{tabular}

Table 5.6. Microanalysis of phases found in C.5.40, which measured $7^{\text {th }}$ in order of maximum compressive strength at 201 days. The results are based on 6 analyses.

\begin{tabular}{|c|c|c|c|c|c|}
\hline & Bulk & Average & Standard deviation & Minimum & Maximum \\
\hline $\mathrm{Si} / \mathrm{Al}$ & 8.4 & 13.7 & 2.1 & 11.8 & 17.7 \\
\hline $\mathrm{Na} / \mathrm{Al}$ & 1.0 & 7.9 & 1.3 & 6.6 & 9.7 \\
\hline $\mathrm{Na} / \mathrm{Si}$ & 0.1 & 0.6 & 0.1 & 0.4 & 0.7 \\
\hline $\mathrm{Ca} / \mathrm{Si}$ & 0.4 & 0.2 & 0.1 & 0.0 & 0.3 \\
\hline
\end{tabular}


Table 5.7. Microanalysis of phases found in C.10.80, which measured $5^{\text {th }}$ in order of maximum compressive strength at 201 days. The results are based on 6 analyses.

\begin{tabular}{|c|c|c|c|c|c|}
\hline & Bulk & Average & Standard deviation & Minimum & Maximum \\
\hline $\mathrm{Si} / \mathrm{Al}$ & 8.4 & 16.1 & 3.4 & 11.5 & 21.1 \\
\hline $\mathrm{Na} / \mathrm{Al}$ & 1.6 & 7.2 & 0.8 & 6.2 & 8.0 \\
\hline $\mathrm{Na} / \mathrm{Si}$ & 0.2 & 0.5 & 0.1 & 0.4 & 0.5 \\
\hline $\mathrm{Ca} / \mathrm{Si}$ & 0.4 & 0.3 & 0.0 & 0.3 & 0.4 \\
\hline
\end{tabular}

Table 5.8. Microanalysis of lighter phase found in C.10.40, which measured $2^{\text {nd }}$ in order of maximum compressive strength at 201 days. The results are based on 6 analyses.

\begin{tabular}{|c|c|c|c|c|c|}
\hline & Bulk & Average & Standard deviation & Minimum & Maximum \\
\hline $\mathrm{Si} / \mathrm{Al}$ & 8.4 & 15.0 & 0.7 & 13.7 & 15.7 \\
\hline $\mathrm{Na} / \mathrm{Al}$ & 1.6 & 11.7 & 1.6 & 9.5 & 13.8 \\
\hline $\mathrm{Na} / \mathrm{Si}$ & 0.2 & 0.8 & 0.1 & 0.7 & 0.9 \\
\hline $\mathrm{Ca} / \mathrm{Si}$ & 0.4 & 0.3 & 0.0 & 0.3 & 0.3 \\
\hline
\end{tabular}

Table 5.9. Microanalysis of dark phase found in C.10.40, which measured $2^{\text {nd }}$ in order of maximum compressive strength at 201 days. The results are based on 3 analyses.

\begin{tabular}{|c|c|c|c|c|c|}
\hline & Bulk & Average & Standard deviation & Minimum & Maximum \\
\hline $\mathrm{Si} / \mathrm{Al}$ & 8.4 & 15.5 & 1.3 & 14.1 & 16.4 \\
\hline $\mathrm{Na} / \mathrm{Al}$ & 1.6 & 13.0 & 4.1 & 10.5 & 17.7 \\
\hline $\mathrm{Na} / \mathrm{Si}$ & 0.2 & 0.8 & 0.2 & 0.6 & 1.1 \\
\hline $\mathrm{Ca} / \mathrm{Si}$ & 0.4 & 0.3 & 0.0 & 0.3 & 0.3 \\
\hline
\end{tabular}





\section{B. Appendix B}

\section{B.1 Microanalysis results for Phase II}

Table 5.10. Microanalysis of dark phase found in 100HA, which measured 2nd in order of maximum compressive strength at 179 days. The results are based on 6 analyses.

\begin{tabular}{|c|c|c|c|c|c|}
\hline & Bulk & Average & Standard deviation & Minimum & Maximum \\
\hline $\mathrm{Si} / \mathrm{Al}$ & 8.4 & 7.8 & 3.9 & 9.0 & 10.6 \\
\hline $\mathrm{Na} / \mathrm{Al}$ & 1.6 & 1.0 & 0.7 & 0.7 & 1.9 \\
\hline $\mathrm{Na} / \mathrm{Si}$ & 0.2 & 0.2 & 0.2 & 0.1 & 0.2 \\
\hline $\mathrm{Ca} / \mathrm{Si}$ & 0.4 & 0.5 & 0.0 & 0.4 & 0.6 \\
\hline
\end{tabular}

Table 5.11. Microanalysis of dark and light phases found in 100HA, which measured 2nd in order of maximum compressive strength at 179 days. 2 spots each of the darker and lighter phase were analyzed.

\begin{tabular}{|l|c|c|c|c|}
\hline & \multicolumn{2}{|c|}{ Darker phase } & \multicolumn{2}{c|}{ Lighter phase } \\
\hline $\mathrm{Si} / \mathrm{Al}$ & 8.8 & 7.8 & 11.3 & 9.5 \\
\hline $\mathrm{Na} / \mathrm{Al}$ & 5.1 & 3.3 & 4.2 & 3.3 \\
\hline $\mathrm{Na} / \mathrm{Si}$ & 0.6 & 0.4 & 0.4 & 0.4 \\
\hline $\mathrm{Ca} / \mathrm{Si}$ & 0.4 & 0.3 & 0.8 & 0.5 \\
\hline
\end{tabular}

Table 5.12. Microanalysis of dark phase found in 75HA25MK, which measured 1 st in order of maximum compressive strength at 179 days. The results are based on 6 analyses.

\begin{tabular}{|c|c|c|c|c|c|}
\hline & Bulk & Average & Standard deviation & Minimum & Maximum \\
\hline $\mathrm{Si} / \mathrm{Al}$ & 5.0 & 3.9 & 2.0 & 3.6 & 5.8 \\
\hline $\mathrm{Na} / \mathrm{Al}$ & 1.0 & 0.8 & 0.5 & 0.8 & 1.4 \\
\hline $\mathrm{Na} / \mathrm{Si}$ & 0.2 & 0.2 & 0.1 & 0.1 & 0.3 \\
\hline $\mathrm{Ca} / \mathrm{Si}$ & 0.3 & 0.4 & 0.3 & 0.2 & 0.9 \\
\hline
\end{tabular}


Table 5.13. Microanalysis of dark phase found in 75HA25MK, which measured 1 st in order of maximum compressive strength at 179 days. 2 spots each were analyzed of the darker and lighter phases.

\begin{tabular}{|c|c|c|c|c|}
\hline & \multicolumn{2}{|c|}{ Darker phase } & \multicolumn{2}{c|}{ Lighter phase } \\
\hline $\mathrm{Si} / \mathrm{Al}$ & 4.0 & 5.6 & 4.3 & 5.1 \\
\hline $\mathrm{Na} / \mathrm{Al}$ & 1.6 & 1.9 & 2.7 & 2.9 \\
\hline $\mathrm{Na} / \mathrm{Si}$ & 0.4 & 0.3 & 0.6 & 0.6 \\
\hline $\mathrm{Ca} / \mathrm{Si}$ & 0.2 & 0.3 & 0.4 & 0.7 \\
\hline
\end{tabular}

Table 5.14. Microanalysis of dark phase found in 50HA50MK, which measured 5 th in order of maximum compressive strength at 179 days. 2 spots of unreacted metakaolin were confirmed with EDS.

\begin{tabular}{|c|c|c|c|}
\hline & Bulk & \multicolumn{2}{|c|}{ Unreacted metakaolin } \\
\hline $\mathrm{Si} / \mathrm{Al}$ & 3.5 & 2.2 & 2.3 \\
\hline $\mathrm{Na} / \mathrm{Al}$ & 0.7 & 1.6 & 1.3 \\
\hline $\mathrm{Na} / \mathrm{Si}$ & 0.2 & 0.7 & 0.6 \\
\hline $\mathrm{Ca} / \mathrm{Si}$ & 0.2 & 0.0 & 0.0 \\
\hline
\end{tabular}

Table 5.15. Microanalysis of dark phase found in 75HA25FA, which measured 3rd in order of maximum compressive strength at 179 days. The results are based on 6 analyses.

\begin{tabular}{|c|c|c|c|c|c|}
\hline & Bulk & Average & Standard deviation & Minimum & Maximum \\
\hline $\mathrm{Si} / \mathrm{Al}$ & 6.6 & 7.1 & 3.3 & 8.4 & 10.1 \\
\hline $\mathrm{Na} / \mathrm{Al}$ & 1.5 & 1.5 & 1.0 & 0.9 & 2.8 \\
\hline $\mathrm{Na} / \mathrm{Si}$ & 0.2 & 0.3 & 0.2 & 0.1 & 0.3 \\
\hline $\mathrm{Ca} / \mathrm{Si}$ & 0.4 & 0.6 & 0.3 & 0.4 & 1.1 \\
\hline
\end{tabular}


Table 5.16. EDS analysis of dark phase found in 50HA50FA, which measured 4th in order of maximum compressive strength at 179 days. The results are based on 6 analyses.

\begin{tabular}{|c|c|c|c|c|c|}
\hline & Bulk & Average & Standard deviation & Minimum & Maximum \\
\hline $\mathrm{Si} / \mathrm{Al}$ & 5.2 & 5.3 & 2.9 & 3.7 & 8.7 \\
\hline $\mathrm{Na} / \mathrm{Al}$ & 1.5 & 1.9 & 1.0 & 1.5 & 2.8 \\
\hline $\mathrm{Na} / \mathrm{Si}$ & 0.3 & 0.6 & 0.5 & 0.3 & 0.5 \\
\hline $\mathrm{Ca} / \mathrm{Si}$ & 0.4 & 0.7 & 0.4 & 0.4 & 1.4 \\
\hline
\end{tabular}





\section{Appendix C}

\section{C.1 Microanalysis results for Phase III}

Table 5.17. Microanalysis of phases found in $100 \mathrm{LA}$ cured at $60^{\circ} \mathrm{C}$. The results are based on 6 analyses.

\begin{tabular}{|c|c|c|c|c|c|}
\hline & Bulk & Average & Standard deviation & Minimum & Maximum \\
\hline $\mathrm{Si} / \mathrm{Al}$ & 244.5 & 193.6 & 92.8 & 163.0 & 319.3 \\
\hline $\mathrm{Na} / \mathrm{Al}$ & 85.2 & 49.6 & 33.6 & 46.9 & 88.0 \\
\hline $\mathrm{Na} / \mathrm{Si}$ & 0.4 & 0.3 & 0.1 & 0.3 & 0.3 \\
\hline $\mathrm{Ca} / \mathrm{Si}$ & 0.2 & 0.2 & 0.0 & 0.1 & 0.2 \\
\hline
\end{tabular}

Table 5.18. Microanalysis of phases found in $62 \mathrm{LA} 38 \mathrm{MK}$ cured at $60^{\circ} \mathrm{C}$. The results are based on 6 analyses.

\begin{tabular}{|c|c|c|c|c|c|}
\hline & Bulk & Average & Standard deviation & Minimum & Maximum \\
\hline $\mathrm{Si} / \mathrm{Al}$ & 6.52 & - & - & - & - \\
\hline $\mathrm{Na} / \mathrm{Al}$ & 1.98 & - & - & - & - \\
\hline $\mathrm{Na} / \mathrm{Si}$ & 0.30 & - & - & - & - \\
\hline $\mathrm{Ca} / \mathrm{Si}$ & 0.10 & - & - & - & - \\
\hline
\end{tabular}

Table 5.19. Microanalysis of phases found in $37 \mathrm{LA} 63 \mathrm{MK}$ cured at $60^{\circ} \mathrm{C}$. The results are based on 6 analyses.

\begin{tabular}{|c|c|c|c|c|c|}
\hline & Bulk & Average & Standard deviation & Minimum & Maximum \\
\hline $\mathrm{Si} / \mathrm{Al}$ & 3.70 & - & - & - & - \\
\hline $\mathrm{Na} / \mathrm{Al}$ & 0.99 & - & - & - & - \\
\hline $\mathrm{Na} / \mathrm{Si}$ & 0.27 & - & - & - & - \\
\hline $\mathrm{Ca} / \mathrm{Si}$ & 0.07 & - & - & - & - \\
\hline
\end{tabular}


Table 5.20. Microanalysis of phases found in 100HA. The results are based on 6 analyses.

\begin{tabular}{|c|c|c|c|c|c|}
\hline & Bulk & Average & Standard deviation & Minimum & Maximum \\
\hline $\mathrm{Si} / \mathrm{Al}$ & 8.4 & 9.4 & 4.1 & 9.7 & 12.8 \\
\hline $\mathrm{Na} / \mathrm{Al}$ & 1.6 & 2.6 & 1.5 & 2.9 & 4.1 \\
\hline $\mathrm{Na} / \mathrm{Si}$ & 0.2 & 0.3 & 0.1 & 0.3 & 0.3 \\
\hline $\mathrm{Ca} / \mathrm{Si}$ & 0.4 & 0.4 & 0.0 & 0.4 & 0.4 \\
\hline
\end{tabular}

Table 5.21. Microanalysis of phases found in 75HA25MK. The results are based on 6 analyses.

\begin{tabular}{|c|c|c|c|c|c|}
\hline & Bulk & Average & Standard deviation & Minimum & Maximum \\
\hline $\mathrm{Si} / \mathrm{Al}$ & 5.0 & 3.6 & 1.8 & 1.7 & 6.4 \\
\hline $\mathrm{Na} / \mathrm{Al}$ & 1.0 & 1.2 & 0.7 & 0.7 & 2.0 \\
\hline $\mathrm{Na} / \mathrm{Si}$ & 0.2 & 0.3 & 0.1 & 0.3 & 0.4 \\
\hline $\mathrm{Ca} / \mathrm{Si}$ & 0.3 & 0.2 & 0.1 & 0.2 & 0.3 \\
\hline
\end{tabular}

Table 5.22. Microanalysis of phases found in 100MK. The results are based on 6 analyses.

\begin{tabular}{|c|c|c|c|c|c|}
\hline & Bulk & Average & Standard deviation & Minimum & Maximum \\
\hline $\mathrm{Si} / \mathrm{Al}$ & 2.08 & - & - & - & - \\
\hline $\mathrm{Na} / \mathrm{Al}$ & 0.43 & - & - & - & - \\
\hline $\mathrm{Na} / \mathrm{Si}$ & 0.20 & - & - & - & - \\
\hline $\mathrm{Ca} / \mathrm{Si}$ & 0.00 & - & - & - & - \\
\hline
\end{tabular}




\section{C.2 Microanalysis results for mortars cured at $80^{\circ} \mathrm{C}$}

Table 5.23. Microanalysis of phases found in $100 \mathrm{LA}$ cured at $80^{\circ} \mathrm{C}$. The results are based on 6 analyses.

\begin{tabular}{|c|c|c|c|c|c|}
\hline & Bulk & Average & Standard deviation & Minimum & Maximum \\
\hline $\mathrm{Si} / \mathrm{Al}$ & 244.5 & 151.2 & 64.5 & 129.0 & 241.5 \\
\hline $\mathrm{Na} / \mathrm{Al}$ & 85.2 & 40.2 & 26.5 & 41.7 & 68.0 \\
\hline $\mathrm{Na} / \mathrm{Si}$ & 0.4 & 0.3 & 0.1 & 0.3 & 0.3 \\
\hline $\mathrm{Ca} / \mathrm{Si}$ & 0.2 & 0.1 & 0.0 & 0.1 & 0.2 \\
\hline
\end{tabular}

Table 5.24. Microanalysis of phases found in $62 \mathrm{LA} 38 \mathrm{MK}$ cured at $80^{\circ} \mathrm{C}$. The results are based on 6 analyses.

\begin{tabular}{|c|c|c|c|c|c|}
\hline & Bulk & Average & Standard deviation & Minimum & Maximum \\
\hline $\mathrm{Si} / \mathrm{Al}$ & 6.5 & 3.8 & 2.1 & 2.5 & 7.2 \\
\hline $\mathrm{Na} / \mathrm{Al}$ & 2.0 & 1.1 & 0.7 & 0.9 & 2.2 \\
\hline $\mathrm{Na} / \mathrm{Si}$ & 0.3 & 0.3 & 0.1 & 0.2 & 0.4 \\
\hline $\mathrm{Ca} / \mathrm{Si}$ & 0.1 & 0.1 & 0.0 & 0.0 & 0.1 \\
\hline
\end{tabular}

Table 5.25. Microanalysis of phases found in $37 \mathrm{LA} 63 \mathrm{MK}$ cured at $80^{\circ} \mathrm{C}$. The results are based on 6 analyses.

\begin{tabular}{|c|c|c|c|c|c|}
\hline & Bulk & Average & Standard deviation & Minimum & Maximum \\
\hline $\mathrm{Si} / \mathrm{Al}$ & 3.70 & - & - & - & - \\
\hline $\mathrm{Na} / \mathrm{Al}$ & 0.99 & - & - & - & - \\
\hline $\mathrm{Na} / \mathrm{Si}$ & 0.27 & - & - & - & - \\
\hline $\mathrm{Ca} / \mathrm{Si}$ & 0.07 & - & - & - & - \\
\hline
\end{tabular}




\section{C.3 Microanalysis results for ternary mixtures}

Table 5.26. Microanalysis of phases found in LA-FA-MK. The results are based on 6 analyses.

\begin{tabular}{|c|c|c|c|c|c|}
\hline & Bulk & Average & Standard deviation & Minimum & Maximum \\
\hline $\mathrm{Si} / \mathrm{Al}$ & 6.2 & 4.4 & 1.6 & 4.5 & 6.0 \\
\hline $\mathrm{Na} / \mathrm{Al}$ & 2.0 & 1.3 & 0.7 & 1.4 & 2.1 \\
\hline $\mathrm{Na} / \mathrm{Si}$ & 0.3 & 0.3 & 0.1 & 0.3 & 0.4 \\
\hline $\mathrm{Ca} / \mathrm{Si}$ & 0.2 & 0.1 & 0.0 & 0.1 & 0.1 \\
\hline
\end{tabular}

Table 5.27. Microanalysis of phases found in HA-FA-MK. The results are based on 6 analyses.

\begin{tabular}{|c|c|c|c|c|c|}
\hline & Bulk & Average & Standard deviation & Minimum & Maximum \\
\hline $\mathrm{Si} / \mathrm{Al}$ & 4.1 & 3.6 & 1.3 & 3.3 & 5.0 \\
\hline $\mathrm{Na} / \mathrm{Al}$ & 1.0 & 1.3 & 0.8 & 1.2 & 2.8 \\
\hline $\mathrm{Na} / \mathrm{Si}$ & 0.2 & 0.4 & 0.1 & 0.3 & 0.6 \\
\hline $\mathrm{Ca} / \mathrm{Si}$ & 0.3 & 0.2 & 0.0 & 0.2 & 0.3 \\
\hline
\end{tabular}




\section{Appendix D}

\section{D.1 Copyright release for Figures 2.2, 2.4, 2.7, 2.9, 2.10, 2.11, 2.14}

Copyright Release Form for Art

Faye L. Christiansen grants Mary U. Christiansen permission to reproduce the following artwork for use in her dissertation and any subsequent publications.

Figure'2.2

Figure 2.4

Figure 2.7

Figure 2.9

Figure 2.10

Figure 2.11

Figure 2.14

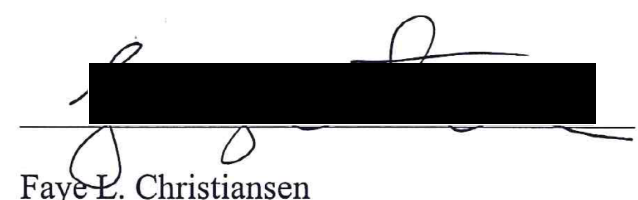

Faye 4 . Christiansen

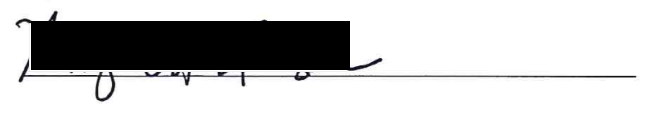

Mary U. Christiansen

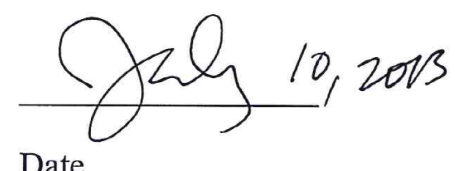

Date

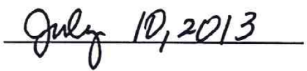

Date 


\section{D.2 License agreement for Figure 2.3}

\section{ELSEVIER LICENSE TERMS AND CONDITIONS}

Aug 08, 2013

This is a License Agreement between Mary U Christiansen ("You") and Elsevier ("Elsevier") provided by Copyright Clearance Center ("CCC"). The license consists of your order details, the terms and conditions provided by Elsevier, and the payment terms and conditions.

Supplier

Registered Company Number

Customer name

Customer address

License number

License date

Licensed content publisher

Licensed content publication

Licensed content title

Licensed content author

Licensed content date

Licensed content volume number

Licensed content issue number

Number of pages

Start Page

End Page

Type of Use

Portion

Number of figures/tables/illustrations

Format

Are you the author of this Elsevier article?
Elsevier Limited

The Boulevard, Langford Lane

Kidlington,Oxford,OX5 1GB,UK

1982084

Mary U Christiansen

47169 N Hwy 41 Apt B

HOUGHTON, MI 49931

3192701219155

Jul 19, 2013

Elsevier

Cement and Concrete Research

New cements for the 21st century: The pursuit of an alternative to Portland cement

Caijun Shi,A. Fernández Jiménez,Angel Palomo

July 2011

41

14

750

763

reuse in a thesis/dissertation

figures/tables/illustrations

both print and electronic

No 
Will you be translating?

Order reference number

Title of your thesis/dissertation

Expected completion date

Estimated size (number of pages)

Elsevier VAT number

Permissions price

VAT/Local Sales Tax

Total

Terms and Conditions
No

AN INVESTIGATION OF WASTE GLASS-BASED GEOPOLYMERS SUPPLEMENTED WITH ALUMINA

Aug 2013

GB 494627212

0.00 USD

0.0 USD / 0.0 GBP

0.00 USD

\section{INTRODUCTION}

1. The publisher for this copyrighted material is Elsevier. By clicking "accept" in connection with completing this licensing transaction, you agree that the following terms and conditions apply to this transaction (along with the Billing and Payment terms and conditions established by Copyright Clearance Center, Inc. ("CCC"), at the time that you opened your Rightslink account and that are available at any time at http://myaccount.copyright.com).

\section{GENERAL TERMS}

2. Elsevier hereby grants you permission to reproduce the aforementioned material subject to the terms and conditions indicated.

3. Acknowledgement: If any part of the material to be used (for example, figures) has appeared in our publication with credit or acknowledgement to another source, permission must also be sought from that source. If such permission is not obtained then that material may not be included in your publication/copies. Suitable acknowledgement to the source must be made, either as a footnote or in a reference list at the end of your publication, as follows: 
"Reprinted from Publication title, Vol /edition number, Author(s), Title of article / title of chapter, Pages No., Copyright (Year), with permission from Elsevier [OR APPLICABLE SOCIETY COPYRIGHT OWNER]." Also Lancet special credit - "Reprinted from The Lancet, Vol. number, Author(s), Title of article, Pages No., Copyright (Year), with permission from Elsevier."

4. Reproduction of this material is confined to the purpose and/or media for which permission is hereby given.

5. Altering/Modifying Material: Not Permitted. However figures and illustrations may be altered/adapted minimally to serve your work. Any other abbreviations, additions, deletions and/or any other alterations shall be made only with prior written authorization of Elsevier Ltd. (Please contact Elsevier at permissions@elsevier.com)

6. If the permission fee for the requested use of our material is waived in this instance, please be advised that your future requests for Elsevier materials may attract a fee.

7. Reservation of Rights: Publisher reserves all rights not specifically granted in the combination of (i) the license details provided by you and accepted in the course of this licensing transaction, (ii) these terms and conditions and (iii) $\mathrm{CCC}^{\prime}$ 's Billing and Payment terms and conditions.

8. License Contingent Upon Payment: While you may exercise the rights licensed immediately upon issuance of the license at the end of the licensing process for the transaction, provided that you have disclosed complete and accurate details of your proposed use, no license is finally effective unless and until full payment is received from you (either by publisher or by CCC) as provided in CCC's Billing and Payment terms and conditions. If full payment is not received on a timely basis, then any license preliminarily granted shall be deemed automatically revoked and shall be void as if never granted. Further, in the event that you breach any of these terms and conditions or any of CCC's Billing and Payment terms and conditions, the license is automatically revoked and shall be void as if never granted. Use of materials as described in a revoked license, as well as any use of the materials beyond the scope of an unrevoked license, may constitute copyright infringement and publisher reserves the right to take any and all action to protect its copyright in the materials.

9. Warranties: Publisher makes no representations or warranties with respect to the licensed material.

10. Indemnity: You hereby indemnify and agree to hold harmless publisher and CCC, and their respective officers, directors, employees and agents, from and against any and all claims arising out of your use of the licensed material other than as specifically authorized pursuant to this license. 
11. No Transfer of License: This license is personal to you and may not be sublicensed, assigned, or transferred by you to any other person without publisher's written permission.

12. No Amendment Except in Writing: This license may not be amended except in a writing signed by both parties (or, in the case of publisher, by CCC on publisher's behalf).

13. Objection to Contrary Terms: Publisher hereby objects to any terms contained in any purchase order, acknowledgment, check endorsement or other writing prepared by you, which terms are inconsistent with these terms and conditions or CCC's Billing and Payment terms and conditions. These terms and conditions, together with CCC's Billing and Payment terms and conditions (which are incorporated herein), comprise the entire agreement between you and publisher (and CCC) concerning this licensing transaction. In the event of any conflict between your obligations established by these terms and conditions and those established by CCC's Billing and Payment terms and conditions, these terms and conditions shall control.

14. Revocation: Elsevier or Copyright Clearance Center may deny the permissions described in this License at their sole discretion, for any reason or no reason, with a full refund payable to you. Notice of such denial will be made using the contact information provided by you. Failure to receive such notice will not alter or invalidate the denial. In no event will Elsevier or Copyright Clearance Center be responsible or liable for any costs, expenses or damage incurred by you as a result of a denial of your permission request, other than a refund of the amount(s) paid by you to Elsevier and/or Copyright Clearance Center for denied permissions.

\section{LIMITED LICENSE}

The following terms and conditions apply only to specific license types:

15. Translation: This permission is granted for non-exclusive world English rights only unless your license was granted for translation rights. If you licensed translation rights you may only translate this content into the languages you requested. A professional translator must perform all translations and reproduce the content word for word preserving the integrity of the article. If this license is to re-use 1 or 2 figures then permission is granted for non-exclusive world rights in all languages.

16. Website: The following terms and conditions apply to electronic reserve and author websites:

Electronic reserve: If licensed material is to be posted to website, the web site is to be password-protected and made available only to bona fide students registered on a relevant course if:

This license was made in connection with a course, This permission is granted for 1 year only. You may obtain a license for future website posting, 
All content posted to the web site must maintain the copyright information line on the bottom of each image,

A hyper-text must be included to the Homepage of the journal from which you are licensing athttp://www.sciencedirect.com/science/journal/xxxxx or the Elsevier homepage for books athttp://www.elsevier.com , and

Central Storage: This license does not include permission for a scanned version of the material to be stored in a central repository such as that provided by Heron/XanEdu.

17. Author website for journals with the following additional clauses:

All content posted to the web site must maintain the copyright information line on the bottom of each image, and the permission granted is limited to the personal version of your paper. You are not allowed to download and post the published electronic version of your article (whether PDF or HTML, proof or final version), nor may you scan the printed edition to create an electronic version. A hyper-text must be included to the Homepage of the journal from which you are licensing athttp://www.sciencedirect.com/science/journal/xxxxx . As part of our normal production process, you will receive an e-mail notice when your article appears on Elsevier's online service ScienceDirect (www.sciencedirect.com). That e-mail will include the article's Digital Object Identifier (DOI). This number provides the electronic link to the published article and should be included in the posting of your personal version. We ask that you wait until you receive this e-mail and have the DOI to do any posting.

Central Storage: This license does not include permission for a scanned version of the material to be stored in a central repository such as that provided by Heron/XanEdu.

18. Author website for books with the following additional clauses:

Authors are permitted to place a brief summary of their work online only.

A hyper-text must be included to the Elsevier homepage at http://www.elsevier.com . All content posted to the web site must maintain the copyright information line on the bottom of each image. You are not allowed to download and post the published electronic version of your chapter, nor may you scan the printed edition to create an electronic version.

Central Storage: This license does not include permission for a scanned version of the material to be stored in a central repository such as that provided by Heron/XanEdu.

19. Website (regular and for author): A hyper-text must be included to the Homepage of the journal from which you are licensing at http://www.sciencedirect.com/science/journal/xxxxx. or for books to the Elsevier homepage at http://www.elsevier.com

20. Thesis/Dissertation: If your license is for use in a thesis/dissertation your thesis may be submitted to your institution in either print or electronic form. Should your thesis be published commercially, please reapply for permission. These requirements include 
permission for the Library and Archives of Canada to supply single copies, on demand, of the complete thesis and include permission for UMI to supply single copies, on demand, of the complete thesis. Should your thesis be published commercially, please reapply for permission. 


\section{D.3 License agreement for Figure 2.5}

JOHN WILEY AND SONS LICENSE

TERMS AND CONDITIONS

Aug 08, 2013

This is a License Agreement between Mary U Christiansen ("You") and John Wiley and Sons ("John Wiley and Sons") provided by Copyright Clearance Center ("CCC"). The license consists of your order details, the terms and conditions provided by John Wiley and Sons, and the payment terms and conditions.

$\begin{array}{ll}\text { License Number } & 3192730369733 \\ \text { License date } & \text { Jul } 19,2013 \\ \text { Licensed content publisher } & \text { John Wiley and Sons } \\ \text { Licensed content publication } & \text { Wiley Books } \\ \text { Licensed content title } & \text { The Chemistry of Silica: Solubility, Polymerization, Colloid and Surface } \\ & \text { Properties and Biochemistry of Silica } \\ \text { Book title } & \text { The Chemistry of Silica: Solubility, Polymerization, Colloid and Surface } \\ & \text { Properties and Biochemistry of Silica } \\ \text { Licensed copyright line } & \text { Copyright } @ \text { (1979, John Wiley and Sons } \\ \text { Licensed content author } & \text { Ralph K. Iler } \\ \text { Licensed content date } & \text { Jun } 1,1979 \\ \text { Type of use } & \text { Dissertation/Thesis } \\ \text { Requestor type } & \text { University/Academic } \\ \text { Format } & \text { Print and electronic } \\ \text { Portion } & \text { Figure/table } \\ \text { Number of figures/tables } & 1 \\ \text { Original Wiley figure/table number(s) } & \text { Figure 1.6 } \\ \text { Will you be translating? } & \text { No } \\ \text { Total } & 0.00 \text { USD } \\ \end{array}$

Terms and Conditions

\section{TERMS AND CONDITIONS}

This copyrighted material is owned by or exclusively licensed to John Wiley \& Sons, Inc. or one of its group companies (each a "Wiley Company") or a society for whom a Wiley Company has exclusive publishing rights in relation to a particular journal (collectively "WILEY"). By clicking "accept" in connection with completing this licensing transaction, you agree that the following terms and conditions apply to this transaction (along with the billing and payment terms and conditions established by the Copyright Clearance Center 
Inc., ("CCC's Billing and Payment terms and conditions"), at the time that you opened your RightsLink account (these are available at any time athttp://myaccount.copyright.com).

\section{Terms and Conditions}

1. The materials you have requested permission to reproduce (the "Materials") are protected by copyright.

2.You are hereby granted a personal, non-exclusive, non-sublicensable, non-transferable, worldwide, limited license to reproduce the Materials for the purpose specified in the licensing process. This license is for a one-time use only with a maximum distribution equal to the number that you identified in the licensing process. Any form of republication granted by this license must be completed within two years of the date of the grant of this license (although copies prepared before may be distributed thereafter). The Materials shall not be used in any other manner or for any other purpose. Permission is granted subject to an appropriate acknowledgement given to the author, title of the material/book/journal and the publisher. You shall also duplicate the copyright notice that appears in the Wiley publication in your use of the Material. Permission is also granted on the understanding that nowhere in the text is a previously published source acknowledged for all or part of this Material. Any third party material is expressly excluded from this permission.

3. With respect to the Materials, all rights are reserved. Except as expressly granted by the terms of the license, no part of the Materials may be copied, modified, adapted (except for minor reformatting required by the new Publication), translated, reproduced, transferred or distributed, in any form or by any means, and no derivative works may be made based on the Materials without the prior permission of the respective copyright owner. You may not alter, remove or suppress in any manner any copyright, trademark or other notices displayed by the Materials. You may not license, rent, sell, loan, lease, pledge, offer as security, transfer or assign the Materials, or any of the rights granted to you hereunder to any other person.

4. The Materials and all of the intellectual property rights therein shall at all times remain the exclusive property of John Wiley \& Sons Inc or one of its related companies (WILEY) or their respective licensors, and your interest therein is only that of having possession of and the right to reproduce the Materials pursuant to Section 2 herein during the continuance of this Agreement. You agree that you own no right, title or interest in or to the Materials or any of the intellectual property rights therein. You shall have no rights hereunder other than the license as provided for above in Section 2. No right, license or interest to any trademark, trade name, service mark or other branding ("Marks") of WILEY or its licensors is granted hereunder, and you agree that you shall not assert any such right, license or interest with respect thereto.

\section{NEITHER WILEY NOR ITS LICENSORS MAKES ANY WARRANTY OR REPRESENTATION OF ANY KIND TO YOU OR ANY THIRD PARTY, EXPRESS,}


IMPLIED OR STATUTORY, WITH RESPECT TO THE MATERIALS OR THE ACCURACY OF ANY INFORMATION CONTAINED IN THE MATERIALS, INCLUDING, WITHOUT LIMITATION, ANY IMPLIED WARRANTY OF MERCHANTABILITY, ACCURACY, SATISFACTORY QUALITY, FITNESS FOR A PARTICULAR PURPOSE, USABILITY, INTEGRATION OR NON-INFRINGEMENT AND ALL SUCH WARRANTIES ARE HEREBY EXCLUDED BY WILEY AND ITS LICENSORS AND WAIVED BY YOU.

6. WILEY shall have the right to terminate this Agreement immediately upon breach of this Agreement by you.

7. You shall indemnify, defend and hold harmless WILEY, its Licensors and their respective directors, officers, agents and employees, from and against any actual or threatened claims, demands, causes of action or proceedings arising from any breach of this Agreement by you.

8. IN NO EVENT SHALL WILEY OR ITS LICENSORS BE LIABLE TO YOU OR ANY OTHER PARTY OR ANY OTHER PERSON OR ENTITY FOR ANY SPECIAL, CONSEQUENTIAL, INCIDENTAL, INDIRECT, EXEMPLARY OR PUNITIVE DAMAGES, HOWEVER CAUSED, ARISING OUT OF OR IN CONNECTION WITH THE DOWNLOADING, PROVISIONING, VIEWING OR USE OF THE MATERIALS REGARDLESS OF THE FORM OF ACTION, WHETHER FOR BREACH OF CONTRACT, BREACH OF WARRANTY, TORT, NEGLIGENCE, INFRINGEMENT OR OTHERWISE (INCLUDING, WITHOUT LIMITATION, DAMAGES BASED ON LOSS OF PROFITS, DATA, FILES, USE, BUSINESS OPPORTUNITY OR CLAIMS OF THIRD PARTIES), AND WHETHER OR NOT THE PARTY HAS BEEN ADVISED OF THE POSSIBILITY OF SUCH DAMAGES. THIS LIMITATION SHALL APPLY NOTWITHSTANDING ANY FAILURE OF ESSENTIAL PURPOSE OF ANY LIMITED REMEDY PROVIDED HEREIN.

9. Should any provision of this Agreement be held by a court of competent jurisdiction to be illegal, invalid, or unenforceable, that provision shall be deemed amended to achieve as nearly as possible the same economic effect as the original provision, and the legality, validity and enforceability of the remaining provisions of this Agreement shall not be affected or impaired thereby.

10. The failure of either party to enforce any term or condition of this Agreement shall not constitute a waiver of either party's right to enforce each and every term and condition of this Agreement. No breach under this agreement shall be deemed waived or excused by either party unless such waiver or consent is in writing signed by the party granting such waiver or consent. The waiver by or consent of a party to a breach of any provision of this Agreement shall not operate or be construed as a waiver of or consent to any other or subsequent breach by such other party. 
11. This Agreement may not be assigned (including by operation of law or otherwise) by you without WILEY's prior written consent.

12. Any fee required for this permission shall be non-refundable after thirty (30) days from receipt

13. These terms and conditions together with CCC's Billing and Payment terms and conditions (which are incorporated herein) form the entire agreement between you and WILEY concerning this licensing transaction and (in the absence of fraud) supersedes all prior agreements and representations of the parties, oral or written. This Agreement may not be amended except in writing signed by both parties. This Agreement shall be binding upon and inure to the benefit of the parties' successors, legal representatives, and authorized assigns.

14. In the event of any conflict between your obligations established by these terms and conditions and those established by CCC's Billing and Payment terms and conditions, these terms and conditions shall prevail.

15. WILEY expressly reserves all rights not specifically granted in the combination of (i) the license details provided by you and accepted in the course of this licensing transaction, (ii) these terms and conditions and (iii) CCC's Billing and Payment terms and conditions.

16. This Agreement will be void if the Type of Use, Format, Circulation, or Requestor Type was misrepresented during the licensing process.

17. This Agreement shall be governed by and construed in accordance with the laws of the State of New York, USA, without regards to such state's conflict of law rules. Any legal action, suit or proceeding arising out of or relating to these Terms and Conditions or the breach thereof shall be instituted in a court of competent jurisdiction in New York County in the State of New York in the United States of America and each party hereby consents and submits to the personal jurisdiction of such court, waives any objection to venue in such court and consents to service of process by registered or certified mail, return receipt requested, at the last known address of such party.

\section{Wiley Open Access Terms and Conditions}

Wiley publishes Open Access articles in both its Wiley Open Access Journals program [http://www.wileyopenaccess.com/view/index.html] and as Online Open articles in its subscription journals. The majority of Wiley Open Access Journals have adopted the Creative Commons Attribution License (CC BY) which permits the unrestricted use, distribution, reproduction, adaptation and commercial exploitation of the article in any medium. No permission is required to use the article in this way provided that the article is properly cited and other license terms are observed. A small number of Wiley Open Access journals have retained the Creative Commons Attribution Non Commercial License (CC 
BY-NC), which permits use, distribution and reproduction in any medium, provided the original work is properly cited and is not used for commercial purposes.

Online Open articles - Authors selecting Online Open are, unless particular exceptions apply, offered a choice of Creative Commons licenses. They may therefore select from the $\mathrm{CC}$ BY, the CC BY-NC and the Attribution-NoDerivatives (CC BY-NC-ND). The CC BY$\mathrm{NC}-\mathrm{ND}$ is more restrictive than the $\mathrm{CC} \mathrm{BY}-\mathrm{NC}$ as it does not permit adaptations or modifications without rights holder consent.

Wiley Open Access articles are protected by copyright and are posted to repositories and websites in accordance with the terms of the applicable Creative Commons license referenced on the article. At the time of deposit, Wiley Open Access articles include all changes made during peer review, copyediting, and publishing. Repositories and websites that host the article are responsible for incorporating any publisher-supplied amendments or retractions issued subsequently.

Wiley Open Access articles are also available without charge on Wiley's publishing platform,Wiley Online Library or any successor sites.

Conditions applicable to all Wiley Open Access articles:

- The authors' moral rights must not be compromised. These rights include the right of "paternity" (also known as "attribution" - the right for the author to be identified as such) and "integrity" (the right for the author not to have the work altered in such a way that the author's reputation or integrity may be damaged).

- Where content in the article is identified as belonging to a third party, it is the obligation of the user to ensure that any reuse complies with the copyright policies of the owner of that content.

- If article content is copied, downloaded or otherwise reused for research and other purposes as permitted, a link to the appropriate bibliographic citation (authors, journal, article title, volume, issue, page numbers, DOI and the link to the definitive published version on Wiley Online Library) should be maintained. Copyright notices and disclaimers must not be deleted.

- Creative Commons licenses are copyright licenses and do not confer any other rights, including but not limited to trademark or patent rights.

- Any translations, for which a prior translation agreement with Wiley has not been agreed, must prominently display the statement: "This is an unofficial translation of an article that appeared in a Wiley publication. The publisher has not endorsed this translation." 


\section{Conditions applicable to non-commercial licenses (CC BY-NC and CC BY- NC-ND)}

For non-commercial and non-promotional purposes individual non-commercial users may access, download, copy, display and redistribute to colleagues Wiley Open Access articles. In addition, articles adopting the CC BY-NC may be adapted, translated, and text- and data-mined subject to the conditions above.

Other Terms and Conditions:

BY CLICKING ON THE "I AGREE..." BOX, YOU ACKNOWLEDGE THAT YOU HAVE READ AND FULLY UNDERSTAND EACH OF THE SECTIONS OF AND PROVISIONS SET FORTH IN THIS AGREEMENT AND THAT YOU ARE IN AGREEMENT WITH AND ARE WILLING TO ACCEPT ALL OF YOUR OBLIGATIONS AS SET FORTH IN THIS AGREEMENT. 
clicking "accept" in connection with completing this licensing transaction, you agree that the following terms and conditions apply to this transaction (along with the Billing and Payment terms and conditions established by Copyright Clearance Center, Inc. ("CCC"), at the time that you opened your Rightslink account and that are available at any time at http://myaccount.copyright.com).

Limited License

With reference to your request to reprint in your thesis material on which Springer Science and Business Media control the copyright, permission is granted, free of charge, for the use indicated in your enquiry.

Licenses are for one-time use only with a maximum distribution equal to the number that you identified in the licensing process.

This License includes use in an electronic form, provided its password protected or on the university's intranet or repository, including UMI (according to the definition at the Sherpa website: http://www.sherpa.ac.uk/romeo/). For any other electronic use, please contact Springer at (permissions.dordrecht@springer.com or permissions.heidelberg@springer.com).

The material can only be used for the purpose of defending your thesis, and with a maximum of 100 extra copies in paper.

Although Springer holds copyright to the material and is entitled to negotiate on rights, this license is only valid, subject to a courtesy information to the author (address is given with the article/chapter) and provided it concerns original material which does not carry references to other sources (if material in question appears with credit to another source, authorization from that source is required as well).

Permission free of charge on this occasion does not prejudice any rights we might have to charge for reproduction of our copyrighted material in the future.

Altering/Modifying Material: Not Permitted

You may not alter or modify the material in any manner. Abbreviations, additions, deletions and/or any other alterations shall be made only with prior written authorization of the author(s) and/or Springer Science + Business Media. (Please contact Springer at (permissions.dordrecht@springer.com or permissions.heidelberg@springer.com)

Reservation of Rights

Springer Science + Business Media reserves all rights not specifically granted in the combination of (i) the license details provided by you and accepted in the course of this licensing transaction, (ii) these terms and conditions and (iii) CCC's Billing and Payment terms and conditions. 
Copyright Notice:Disclaimer

You must include the following copyright and permission notice in connection with any reproduction of the licensed material: "Springer and the original publisher /journal title, volume, year of publication, page, chapter/article title, name(s) of author(s), figure number(s), original copyright notice) is given to the publication in which the material was originally published, by adding; with kind permission from Springer Science and Business Media"

\section{Warranties: None}

Example 1: Springer Science + Business Media makes no representations or warranties with respect to the licensed material.

Example 2: Springer Science + Business Media makes no representations or warranties with respect to the licensed material and adopts on its own behalf the limitations and disclaimers established by CCC on its behalf in its Billing and Payment terms and conditions for this licensing transaction.

Indemnity

You hereby indemnify and agree to hold harmless Springer Science + Business Media and $\mathrm{CCC}$, and their respective officers, directors, employees and agents, from and against any and all claims arising out of your use of the licensed material other than as specifically authorized pursuant to this license.

\section{No Transfer of License}

This license is personal to you and may not be sublicensed, assigned, or transferred by you to any other person without Springer Science + Business Media's written permission.

No Amendment Except in Writing

This license may not be amended except in a writing signed by both parties (or, in the case of Springer Science + Business Media, by CCC on Springer Science + Business Media's behalf).

Objection to Contrary Terms

Springer Science + Business Media hereby objects to any terms contained in any purchase order, acknowledgment, check endorsement or other writing prepared by you, which terms are inconsistent with these terms and conditions or CCC's Billing and Payment terms and conditions. These terms and conditions, together with CCC's Billing and Payment terms and conditions (which are incorporated herein), comprise the entire agreement between you and Springer Science + Business Media (and CCC) concerning this licensing transaction. In the event of any conflict between your obligations established by these terms and conditions and those established by CCC's Billing and Payment terms and conditions, these terms and conditions shall control. 
Jurisdiction

All disputes that may arise in connection with this present License, or the breach thereof, shall be settled exclusively by arbitration, to be held in The Netherlands, in accordance with Dutch law, and to be conducted under the Rules of the 'Netherlands Arbitrage Instituut' (Netherlands Institute of Arbitration).OR:

All disputes that may arise in connection with this present License, or the breach thereof, shall be settled exclusively by arbitration, to be held in the Federal Republic of Germany, in accordance with German law. 


\section{D.5 License agreement for Figure 2.8}

\section{ELSEVIER LICENSE TERMS AND CONDITIONS}

Aug 08, 2013

This is a License Agreement between Mary U Christiansen ("You") and Elsevier ("Elsevier") provided by Copyright Clearance Center ("CCC"). The license consists of your order details, the terms and conditions provided by Elsevier, and the payment terms and conditions.

\section{Supplier}

Registered Company Number

Customer name

Customer address

License number

License date

Licensed content publisher

Licensed content publication

Licensed content title

Licensed content author

Licensed content date

Licensed content volume number

Licensed content issue number

Number of pages

Start Page

End Page

Type of Use

Intended publisher of new work

Portion

Number of figures/tables/illustrations

Format
Elsevier Limited

The Boulevard, Langford Lane

Kidlington, Oxford, OX5 1GB,UK

1982084

Mary U Christiansen

47169 N Hwy 41 Apt B

HOUGHTON, MI 49931

3192711460025

Jul 19, 2013

Elsevier

Fuel and Energy Abstracts

98/04131 Thermochemistry of aqueous silicate solution precursors to ceramics

September 1998

39

5

1

385

0

reuse in a thesis/dissertation

other

figures/tables/illustrations

1

both print and electronic 
Are you the author of this Elsevier article?

Will you be translating?

Order reference number

Title of your thesis/dissertation

Expected completion date

Estimated size (number of pages)

Elsevier VAT number

Permissions price

VAT/Local Sales Tax

Total
No

No

AN INVESTIGATION OF WASTE GLASS-BASED GEOPOLYMERS SUPPLEMENTED WITH ALUMINA

Aug 2013

GB 494627212

0.00 USD

0.0 USD / 0.0 GBP

0.00 USD

Please see D.2 for Introduction, General Terms and Limited License information for Elsevier. 


\section{D.6 License agreement for Figure 2.13}

Geopolymer Institute [http://www.geopolymer.org/about/legal-terms]

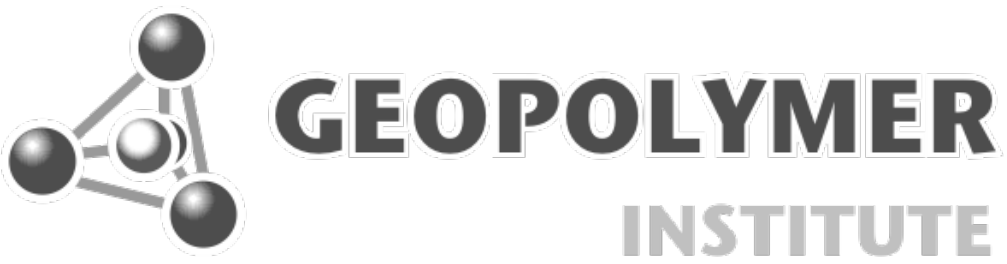

Legal terms

\section{Licence to use this web site}

We authorize:

The reproduction and representation as a private copy or for educational and research purposes (scientific papers) without any lucrative use.

This, provided you always give credit to the Geopolymer Institute. The source must be clearly indicated in the same way as in your document (i.e. in the caption of a figure or image, a quotation reference for text).

The scientific terminology must be used properly, for example: geopolymeric materials, geopolymeric binders, geopolymeric cements, poly(sialate), instead of the general terms such as inorganic, mineral polymer, alkali-activated, or any non standard new acronyms.

Establishing of a hyper-link, without frame, to the home page or a category page (not a single page because its reference may change).

We forbid:

Any other reproduction and representation of any part of this website without our written approval, even for non commercial purpose.

You may not alter, transform, or build upon any part of this website.

Any of these conditions can be waived if you get written permission from the Geopolymer Institute.

If some people, institutions, companies or other groups are breaching this licence, infringing this website content, we will publish their names here in addition to a possible prosecution.

\section{Trademarks}

Joseph Davidovits put the word GEOPOLYMER (its english spelling) in the Public Domain. It means that everybody can freely use this word in scientific papers, for commercial or non-commercial purpose without any authorization. However, no-one can register this word alone in any country.

The radical GEOPOLY ${ }^{\circledR}$ is a registered trademark filed on 21 august 1979 at INPI, Paris, France, ref. \# 1700 by Joseph Davidovits. Only valid in France. Record number: 1105 493, classification: 1 and 19.

The trademark Géopolymère ${ }^{\circledR}$ (the French spelling) is an international trademark registered on 15 march 1990 OMPI/WIPO, ref. \# 548387 by Joseph Davidovits, classification: 1, 17, 19, and 21. Origin France, 5 november 1986, 822 $376 / 1378923$.

\section{Publication service}


All the website content are provided by the Geopolymer Institute for information only. They do not create any commitment on behalf of the Geopolymer Institute. The information contained on the Geopolymer Institute web server are not contractual. They can be modified at any time and the Geopolymer Institute will not be liable for that.

The publication director is:

Institut Géopolymère

Pr. Joseph Davidovits

16 , rue Galilée - 02100 Saint-Quentin - France

Fax: +33/ (0)959977711

E-mail - Web: www.geopolymer.org

Non-profit organization registered in France

SIRET: 50275164700020 — APE: 8559A — Euro Tax ID: FR13502751647

The Web site host is:

SAS OVH

140 quay of Sartel

59100 Roubaix, France

Tel.: $0899701761-\underline{w w w . o v h . c o m}$

\section{Registered data}

Web site declared at the CNIL (French National Comission Computer and Liberty, Paris) under the ref. 560320 on 21 january 1998, and updated on 3 february 2005 under the ref. 1071569.

You can apply your right to access information concerning you by asking the registered office.

The Geopolymer Institute is a not for profit association dedicated to the promotion of the geopolymer science, registered at Saint-Quentin, in France on 7 may 1979, under this reference: Journal Officiel, N 121, 26 mai 1979, page 4444.

\section{Privacy statement}

We consider all messages received as confidential because they may contain information that is privileged and exempt from disclosure. We will not transmit to third parties your e-mail address. According to the French law (art. 34 of the law "Informatique et Libertés" ( Computer and Liberty ) 6-jan-1978), you have the right to access, edit, modify and delete all data concerning you. To apply this right, please write us.

\section{Cookies}

The Geopolymer Institute web site may use some cookies for regular readers.

It may use cookies if you visit the Geopolymer Shop in order to keep your session open and keep the content of your cart for two days maximum. You are free to delete this cookie.

It may use cookies if you are a registered user or you place a comment after an article (thus providing an username, and a valid e-mail). The cookie stored has a validity of 3 months. You are free to delete these cookies.

Our web host is using two cookies for a one hour session for performance purposes. You are free to delete these cookies.

We use the web service Google Analytics to compute anonymous statistics and web audience. They may use a cookie for that, but we do not control it. Please, check Google Analytics privacy statement to know more.

You are free to refuse and delete these cookies. 


\section{D.7 License agreement for Figures 2.16 and 2.17}

SPRINGER LICENSE

TERMS AND CONDITIONS

Aug 08, 2013

This is a License Agreement between Mary U Christiansen ("You") and Springer ("Springer") provided by Copyright Clearance Center ("CCC"). The license consists of your order details, the terms and conditions provided by Springer, and the payment terms and conditions.

License Number
License date
Licensed content publisher
Licensed content publication
Licensed content title
Licensed content author
Licensed content date
Volume number
Issue number
Type of Use
Portion
Author of this Springer article
Order reference number
Total

License Number

3192720485719

Jul 19, 2013

Springer

Journal of Materials Science (full set)

Relationships between composition, structure and strength of inorganic polymers

M. Steveson

Jan 1,2005

40

16

Thesis/Dissertation

Figures

No

Please see D.4 for terms and conditions of Springer license agreement not reprinted here to save paper. 


\section{D.8 License agreement for Figure 2.18}

SPRINGER LICENSE

TERMS AND CONDITIONS

Aug 08, 2013

This is a License Agreement between Mary U Christiansen ("You") and Springer

("Springer") provided by Copyright Clearance Center ("CCC"). The license consists of your order details, the terms and conditions provided by Springer, and the payment terms and conditions.

License Number
License date
Licensed content publisher
Licensed content publication
Licensed content title
Licensed content author
Licensed content date
Volume number
Issue number
Type of Use

Portion

Author of this Springer article

Order reference number

Title of your thesis / dissertation

Expected completion date

Estimated size(pages)

Total

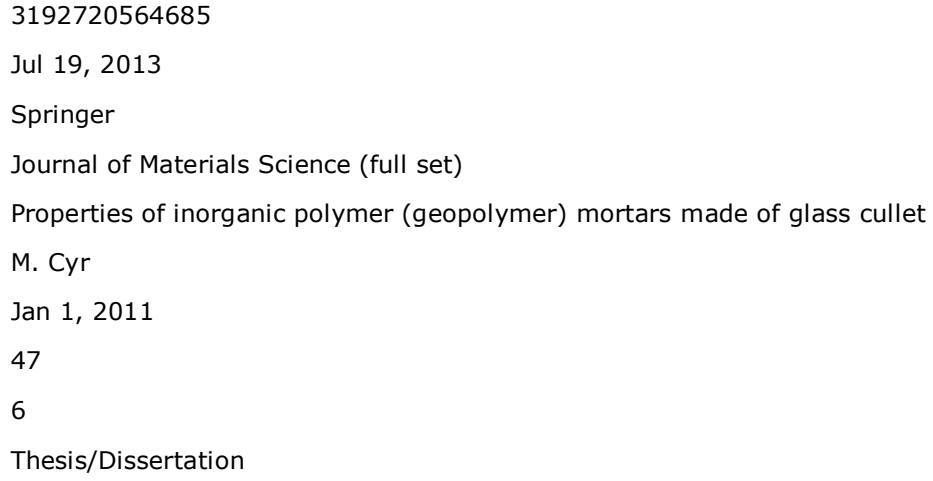

Figures

No

AN INVESTIGATION OF WASTE GLASS-BASED GEOPOLYMERS SUPPLEMENTED WITH ALUMINA

Aug 2013

300

0.00 USD

Please see D.4 for terms and conditions of Springer license agreement not reprinted here to save paper. 


\section{D.9 License agreement for Figures 2.21 and 2.22}

\section{ELSEVIER LICENSE TERMS AND CONDITIONS}

Aug 08, 2013

This is a License Agreement between Mary U Christiansen ("You") and Elsevier ("Elsevier") provided by Copyright Clearance Center ("CCC"). The license consists of your order details, the terms and conditions provided by Elsevier, and the payment terms and conditions.

Supplier
Registered Company Number
Customer name
Customer address
License number
License date
Licensed content publisher
Licensed content publication
Licensed content title
Licensed content author
Licensed content date
Licensed content volume number
Licensed content issue number
Number of pages
Start Page
End Page
Type of Use

Intended publisher of new work

Portion

Number of figures/tables/illustrations

Format

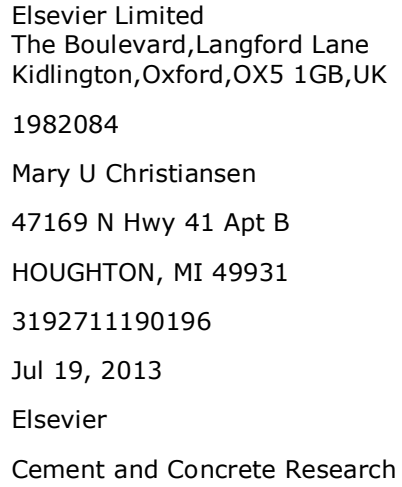

1982084

Mary U Christiansen

47169 N Hwy 41 Apt B

HOUGHTON, MI 49931

3192711190196

Jul 19, 2013

Elsevier

Cement and Concrete Research

An XRD study of the effect of the $\mathrm{SiO} 2 / \mathrm{Na} 2 \mathrm{O}$ ratio on the alkali activation of fly ash

M. Criado,A. Fernández-Jiménez,A.G. de la Torre,M.A.G. Aranda,A. Palomo

May 2007

37

5

9

671

679

reuse in a thesis/dissertation

other

figures/tables/illustrations

2

both print and electronic 
Are you the author of this Elsevier article?

Order reference number

Title of your thesis/dissertation

Expected completion date

Estimated size (number of pages)

Elsevier VAT number

Permissions price

VAT/Local Sales Tax

Total
AN INVESTIGATION OF WASTE GLASS-BASED GEOPOLYMERS SUPPLEMENTED WITH ALUMINA

Aug 2013

GB 494627212

0.00 USD

0.0 USD / 0.0 GBP

0.00 USD

Please see D.2 for Introduction, General Terms and Limited License information for Elsevier. 


\section{D.10 License agreement for Figure 2.23}

\section{ELSEVIER LICENSE TERMS AND CONDITIONS}

Aug 08, 2013

This is a License Agreement between Mary U Christiansen ("You") and Elsevier ("Elsevier") provided by Copyright Clearance Center ("CCC"). The license consists of your order details, the terms and conditions provided by Elsevier, and the payment terms and conditions.

\section{Supplier}

Registered Company Number

Customer name

Customer address

License number

License date

Licensed content publisher

Licensed content publication

Licensed content title

Licensed content author

Licensed content date

Licensed content volume number

Licensed content issue number
Elsevier Limited

The Boulevard, Langford Lane

Kidlington, Oxford, OX5 1GB,UK

1982084

Mary U Christiansen

47169 N Hwy 41 Apt B

HOUGHTON, MI 49931

3192720062084

Jul 19, 2013

Elsevier

Thermochimica Acta

Quantitative kinetic and structural analysis of geopolymers. Part 1 . The activation of metakaolin with sodium hydroxide

Zuhua Zhang,Hao Wang,John L. Provis,Frank Bullen,Andrew Reid,Yingcan Zhu 10 July 2012

539

\section{1}

23

33

reuse in a thesis/dissertation

other

figures/tables/illustrations

1

both print and electronic 
Are you the author of this Elsevier article?

Will you be translating?

No

Order reference number

Title of your thesis/dissertation

AN INVESTIGATION OF WASTE GLASS-BASED GEOPOLYMERS SUPPLEMENTED WITH ALUMINA

Expected completion date

Aug 2013

Estimated size (number of pages)

Elsevier VAT number

GB 494627212

Permissions price

0.00 USD

Please see D.2 for Introduction, General Terms and Limited License information for Elsevier. 


\section{D.11 License agreement for Figure 2.25}

\section{ELSEVIER LICENSE TERMS AND CONDITIONS}

Aug 08, 2013

This is a License Agreement between Mary U Christiansen ("You") and Elsevier ("Elsevier") provided by Copyright Clearance Center ("CCC"). The license consists of your order details, the terms and conditions provided by Elsevier, and the payment terms and conditions.

Supplier
Registered Company Number
Customer name
Customer address
License number
License date
Licensed content publisher
Licensed content publication
Licensed content title
Licensed content author
Licensed content date
Licensed content volume number
Licensed content issue number
Number of pages
Start Page
End Page
Type of Use

Intended publisher of new work

Portion

Number of figures/tables/illustrations

Format

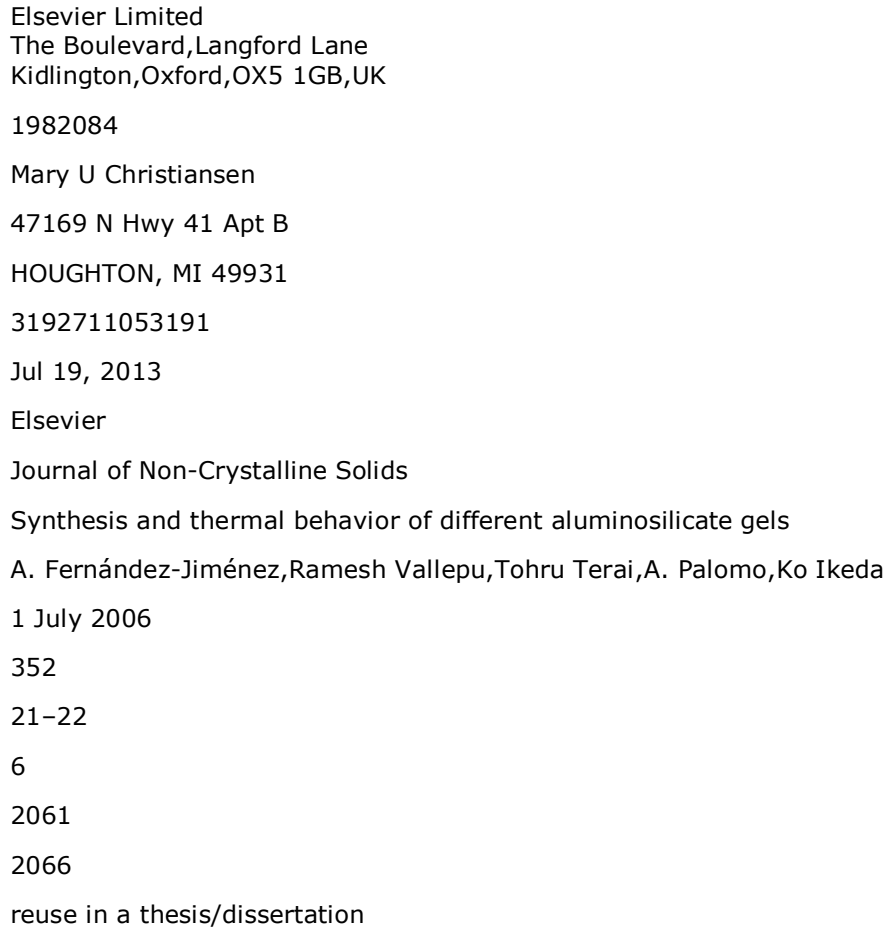

reuse in a thesis/dissertation

other

figures/tables/illustrations

1

both print and electronic 
Are you the author of this Elsevier article? No

Will you be translating?

Order reference number

Title of your thesis/dissertation

AN INVESTIGATION OF WASTE GLASS-BASED GEOPOLYMERS SUPPLEMENTED WITH ALUMINA

Expected completion date

Aug 2013

Estimated size (number of pages)

Elsevier VAT number

GB 494627212

Permissions price

0.00 USD

VAT/Local Sales Tax

0.0 USD / 0.0 GBP

Total

0.00 USD

Please see D.2 for Introduction, General Terms and Limited License information for Elsevier. 


\section{D.12 License agreement for Figure 4.9}

\section{ELSEVIER LICENSE TERMS AND CONDITIONS}

Aug 08, 2013

This is a License Agreement between Mary U Christiansen ("You") and Elsevier ("Elsevier") provided by Copyright Clearance Center ("CCC"). The license consists of your order details, the terms and conditions provided by Elsevier, and the payment terms and conditions.

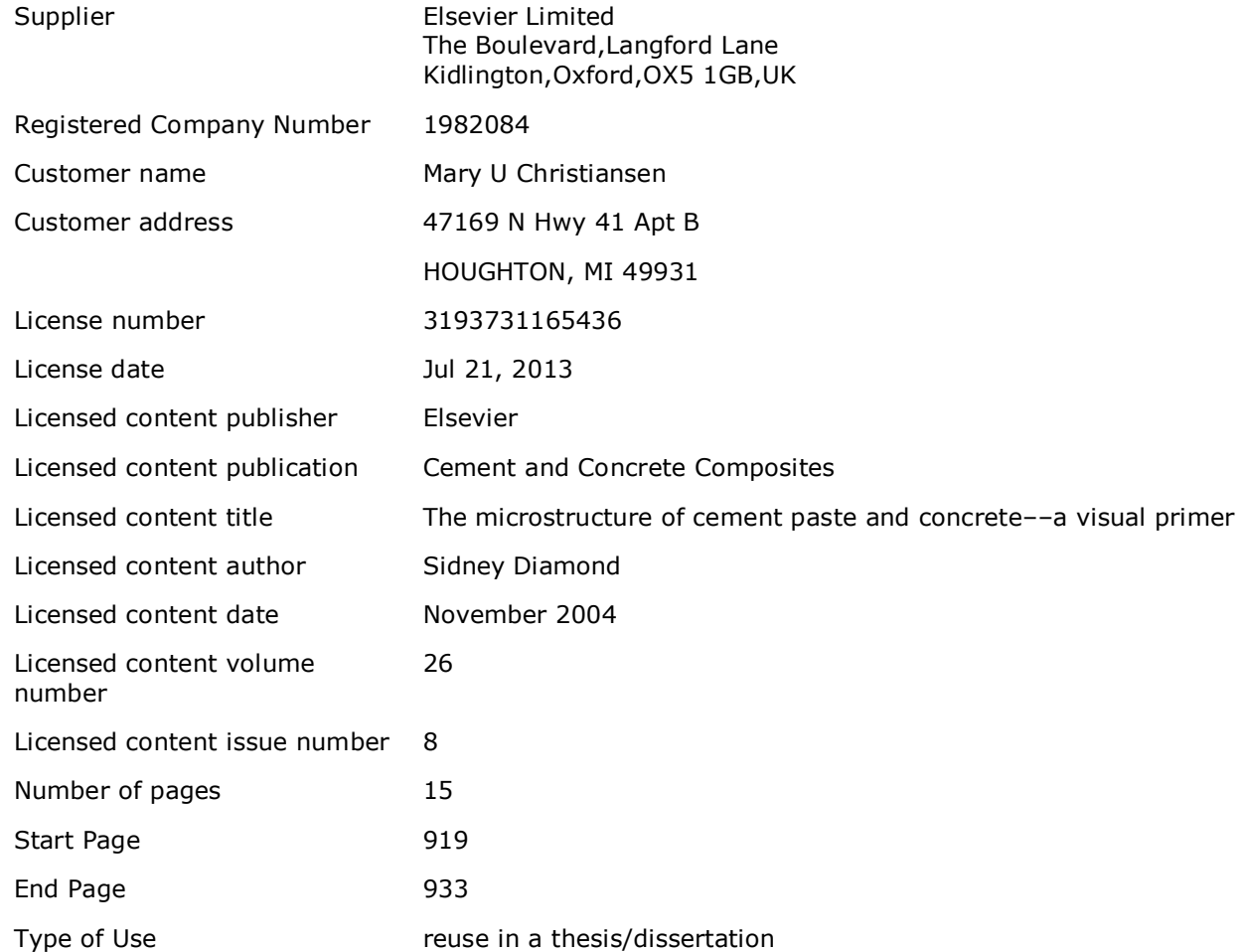


Are you the author of this
Elsevier article?
Will you be translating?

Order reference number

Title of your thesis/dissertation ALUMINA

Estimated size (number of pages)

Elsevier VAT number

Permissions price

VAT/Local Sales Tax

Total

0.0 USD / 0.0 GBP

0.00 USD

Please see D.2 for Introduction, General Terms and Limited License information for Elsevier. 